\title{
NON-MĀORI TEACHERS TEACHING MĀORI LANGUAGE IN ENGLISH-MEDIUM PRIMARY SCHOOLS: \\ WE ARE ALL IN THIS TOGETHER - HE WAKA EKE NOA
}

BY

Alice Elizabeth Patrick

A thesis submitted to the Victoria University of Wellington in fulfilment of the requirements for the degree of Doctor of Philosophy

Victoria University of Wellington 2020 



\section{ACKNOWLEDGEMENTS ${ }^{1}$ | HE MIHI}

Ko te mea nui i tēnei ao, he tangata. Tuia i te herenga tangata-ahakoa nō hea, nō hea.

Ngā mate o tēnā iwi, o tēnā iwi, ka mihia, ka tangihia.

Tènā koutou e te hunga ora.

He uri nō Koterana tēnei e mihi nei.

Ko Benechie te maunga. Ko Dee te awa. Ko North te moana.

He Māori āku tamariki, nō Ngāti Awa.

Ko Wiremu te mātāmua; ko Hone te pōtiki.

Tokoono āku mokopuna - ko Iraia rātou ko Raef, ko Taimana, ko Arahia, ko Taniora, ko Te Atawhai.

Aku taura here ki te kaupapa o te reo Māori me te mātauranga Māori ko rātou katoa.

I te tuatahi me mihi atu au ki ngā kaiako rangahau. I want to firstly acknowledge the primary school teachers who agreed to participate in this research. It would not have been easy having someone observe you teaching a subject where your knowledge is still growing. Yet you took on the challenge and allowed me access to your classroom to see what it was like at the chalk face (i.e. trying to integrate te reo Māori ${ }^{2}$ in a natural way albeit with limited proficiency). He taonga koutou. I wish each of you well as you advance through your teaching careers. I know you will remain committed to sustaining the Māori language - professionally and personally.

Tuarua, ka tuku mihi ki te whānau Laison nō Taranaki. Ko koutou te paparahi māku. Nā koutou ahau i atawhai i tōku whanaketanga - hei momo whāngai, ahakoa te kiritea. I want to acknowledge the Laison whānau ${ }^{3}$ who treated me like one of the family in my formative years as a young, shy and impressionable wee Scottish lass. My learning from you was informal, by osmosis. I learnt about everyday cultural practices that I have retained and instilled in my sons (e.g. washing tea-towels separately from personal clothing or towels, to maintain the 'tapu' nature of the body; feeding children and elderly first, to honour those two very important generations; allocating the best food to guests and ensuring there is $\mathrm{kai}^{4}$ left over when hosting, to demonstrate manaakitanga ${ }^{5}$ ). You

\footnotetext{
${ }^{1}$ When a Māori word appears for the first time, it is footnoted in English and added to the glossary (Appendix 1)

${ }^{2}$ The Māori language

${ }^{3}$ Family

${ }^{4}$ Food

${ }^{5}$ Hospitality
} 
laid the groundwork in my early years, albeit unknowingly, and I am indebted to you for that. My life has been so enriched because of those early foundations.

Kei te mihi hoki ki te whānau Takotohiwi o Ngāti Awa, Ngāti Awa te toki tē tangatanga i te rā, mō tā koutou manaaki i ahau i te ao Māori - kia ako ai. I also want to mihi to my ex-husband's Takotohiwi whānau in Whakatāne, from whom I learnt so much about te reo Māori me ōna tikanga ${ }^{6}$. My driver was the desire to be able to speak Māori to our (then unborn) children. You were gracious in accepting me and acculturating me to your ways. I learnt by watching and listening (and being a ringawera ${ }^{7}$ in the kitchen). I was entranced by the Māori language that flowed from the old people during tangihanga ${ }^{8}$, whānau hui ${ }^{9}$, wānanga ${ }^{10}$, and the singing of waiata tawhito ${ }^{11}$ - even though I struggled to understand. My resolve was to speak only te reo ${ }^{12}$ Māori to our tamariki ${ }^{13}$, which we did.

In the mid-70s, as a young adult, and as a result of my contact with these two whānau, I pored over the grammar-based textbook series Te Rangatahi and taught myself te reo Māori through to School Certificate level - complemented by adult night classes. This independent study provided a basic grounding, which I formalised by going on to study the language at university, while teaching full-time. This was a period when very few universities were offering te reo Māori - and Māori student participation rates were low. Incongruously, however, my Māori language classes at Victoria University comprised mainly Māori secondary school teachers, most of whom were already proficient in te reo Māori but were seeking a formal qualification. Some were native speakers. It was humbling to be in the minority, grappling with constantly new and difficult language.

Kei te mihi ki ōku kaiwhakaako Māori i te Whare Wānanga o Wikitoria i ngā rā o mua arā, ko Tā Hirini Mead rātou ko Tamati Kruger, ko Wiremu Parker, ko Ruka Broughton (nāna i tohi āku tamariki i te awa). He waimarie ahau nō te mea he pūkenga rātou ki te reo rangatira me onna tikanga hoki. It was a privilege to be taught by these lecturers - even though the content was not easy for me to digest, due to the complexity of the Māori

\footnotetext{
${ }^{6}$ Māori language and culture

${ }^{7}$ Helper/worker

${ }^{8}$ Funerals

${ }^{9}$ Family gatherings

${ }^{10}$ Discussions

${ }^{11}$ Old songs

12 The language

${ }^{13}$ Children
} 
language and the diverse topics therein (e.g. Te Paipera Tapu ${ }^{14}$, and Te Rangikaheke whose writings discussed tribal history, legends, Māori customs, politics of the day, whakapapa ${ }^{15}$, religion, proverbs and songs). Such texts were chosen because they were written in 'classical' Māori - to be appreciated by the Māori students, to elevate further their Māori language knowledge.

Kei te mihi hoki ki ōku kaiārahi - ko Keri Kaa (ahakoa te paku kohete i a au ki te Whānau o Ako Pai); ko Mary Boyce (nō te mea nā runga i tōna whakahauhau me ōna kōrero āwhina i tīmata ahau i tēnei momo rangahau); ko Fran Hunia hoki (he wahine hūmārie, hei tauira tikanga rua mōku).

Ki ētahi o rātou kua whetūrangitia, moe mai i te moenga roa. Kāre e warewaretia $\overline{0}$ koutou mahi e maha ki te akiaki i ahau nei.

My privileged access to te ao Māori seems to have been carefully mapped out - with our immigration from Scotland to New Zealand (NZ); having such a generous-spirited Māori family as close neighbours; being exposed to mātauranga Māori ${ }^{16}$ through my exhusband's whānau; and having very knowledgeable Māori language tutors and mentors. This connection to Māoridom has happened gradually over a period of 57 years, through sustained contact with Māori. Perhaps it has also been aided by the fact that the Māori and Scottish cultures have so much in common (e.g importance of whānau; loss of land and language; hospitality; love of storytelling through song and poetry). This natural affinity between the two cultures was certainly evident when my Scots family travelled to NZ for my son's wedding on the marae.

From my family's humble beginnings in Aotearoa NZ, I have been privileged as a Pākehā ${ }^{17}$ to be given access to te ao Māori ${ }^{18}$ - through the generosity of spirit demonstrated by key Māori people in my life. I've also been privileged to have a university education (the first in my extended family to do so), which has enhanced my learning of te reo Māori me ōna tikanga.

\footnotetext{
14 The Holy Bible

${ }^{15}$ Genealogy

${ }^{16}$ Māori knowledge

${ }^{17}$ Person of European descent

18 The Māori world
} 
Hopefully, my ability to 'cross over' to both cultures provides encouragement to other Pākehā (like my research participants and the teachers with whom I work in an advisory capacity). I am passionate about the maintenance of te reo Māori. And I feel a sense of responsibility and agency in this area (e.g. influencing and enabling non-Māori teachers to integrate te reo across the curriculum). I want to be a catalyst for social change instead of being immobilised and paralysed by the wrongdoings of my colonist ancestors.

Finally, on a practical level, in terms of bringing this $\mathrm{PhD}$ together, I want to thank Disability Services at Victoria University for the invaluable help with transcription services - as well as Sydney Kingstone for doing the final edits, and Anna Thomson for doing the formatting with such care and attention.

I owe much to my primary supervisor, Dr Corinne Seals. She sustained her interest, oversight and positivity about my kaupapa ${ }^{19}$ for the duration of my study - always available to provide constructive feedback and creative problem-solving. Without her, the process would have been arduous. Mutunga kore aku mihi ki a koe e te mātanga. I am also grateful to Karena Kelly, my secondary supervisor, for rightfully challenging me to carefully reflect on my positioning as a non-Māori researcher working in a Māori space.

Hei whakamutunga, e hiahia ana ahau ki te mihi ki āku tama me āku mokopuna. Ko koutou he ranga wairua ki ahau nei, kia whakatūturutia te reo Māori ki te kāinga, ki te kura hoki. Nō reira poipoia te reo rangatira, ā, kōrerotia - kia rere ai. He taonga i tuku iho.

19 Topic 


\section{ABSTRACT | HE WHAKARĀPOPOTOTANGA}

This thesis reports the findings of original research examining the role that non-Māori teachers can play teaching te reo Māori in English-medium ${ }^{20}$ primary schools, as per the expectation in the New Zealand Curriculum (Ministry of Education, 2007).

I undertook this research for personal and professional reasons, due to my personal exposure to te ao Māori and Māori education over 57 years. Although non-Māori, I have been fortunate to learn te reo Māori from very generous Māori whānau, language tutors and personal mentors. Professionally, I embarked on the study because of my longstanding work in Māori language education as a teacher, lecturer and adviser in schools ${ }^{21}$.

My research investigates non-Māori teachers' beliefs and practices, while uncovering some of the factors that can influence the teaching of te reo Māori in English-medium primary schools. I also explore what Māori language materials the teachers use (or need) to help them implement their Māori language programmes - and their notions of what constitute ‘quality' Māori language resources.

There are three empirical data sources - an online questionnaire $(n=40)$, classroom observations $(n=4)$, and teacher interviews $(n=4)$. Because of my topic being important to Māori, and worthy of research, I chose to be guided by kaupapa Māori ${ }^{22}$ values as an ethical base for my research.

The findings show some consistency across four case study teachers - in terms of their stated beliefs and their classroom practices (e.g. ensuring the learning of te reo is enjoyable, incorporating aspects of tikanga ${ }^{23}$, demonstrating good pronunciation and positivity about te reo). However, there are also inconsistencies in terms of the teachers not following through on their beliefs about: the importance of facilitating group work/practice opportunities, using Māori language materials, and drawing on students' prior knowledge/experiences. It is evident that there are contributing factors that influence

\footnotetext{
${ }^{20}$ Instruction in these schools is delivered in English

${ }^{21}$ The word 'school(s)' henceforth refers to English-medium educational settings, whereas the word 'kura' is reserved for Māori-medium settings

22 Pertaining to Māori knowledge, skills, attitudes

${ }^{23}$ Culture/customs
} 
teachers' practice (e.g. lack of quality resources and associated professional development (PD), lack of support from school leaders and parents, and lack of time).

The teachers' views on what constitute quality Māori language resources for Englishmedium primary schools (as indicated by the 40 online questionnaire participants) show that their top three priorities are real-life contexts, user-friendliness, and inclusion of tikanga - followed by audio support, English translations/glossaries, visual appeal, multimedia, teachers' notes, and alignment to the Māori language curriculum guidelines.

In the future, teachers would like to see resources developed that incorporate information technology (e.g. Māori language games/multimedia), help them to use Māori language in the classroom, provide pronunciation support, facilitate shared reading experiences (e.g. big bilingual books), and provide information about their local area.

This research contributes to the literature, as few studies have examined the teaching and learning of Māori language in English-medium primary schools. Furthermore, it contributes to the wider kaupapa of Māori language revitalisation by validating whānau aspirations/expectations around their tamariki/ mokopuna ${ }^{24}$ receiving reo Māori tuition, supported by quality Māori language materials. In addition, the research highlights a relationship between Māori language provision and Māori student achievement. The study also provides an evidence base for the Ministry of Education (and resource developers) regarding the creation of resources for English-medium primary schools and the need for teachers to receive quality PD.

There are theoretical implications, in that there is scope for other researchers to contribute to the discourse by undertaking culturally responsive studies associated with Māori language education and/or teacher cognition. There is also scope for research that provides empirical data about the relationship between Māori students having access to te reo Māori in their English-medium schooling and them achieving educational success.

There are practical implications for Te Mātāwai, the Māori Language Commission and the Ministry of Education as they implement initiatives that will contribute to government's goal of making Māori language universally available in schools, with one million New Zealanders speaking basic reo by 2040 . There are also implications for the practice of

\footnotetext{
${ }^{24}$ Children/grandchildren
} 
teachers, school leaders, and PD facilitators in English-medium primary school settings as well as resource developers who work in this space. Likewise, there are implications for NZ primary school students - in terms of recognising the benefits that ensue from learning te reo. In particular, there is a focus on the benefits for Māori students in having their language and culture validated - so they can stand strong and be successful in both te ao Māori and te ao Pākehā. Ko tērā te moemoeā mō āku mokopuna hoki. 


\section{TABLE OF CONTENTS | RĀRANGI UPOKO}

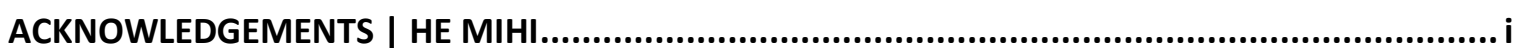

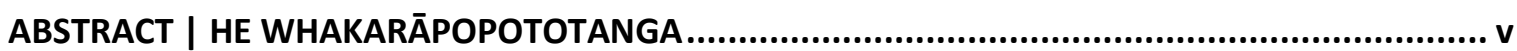

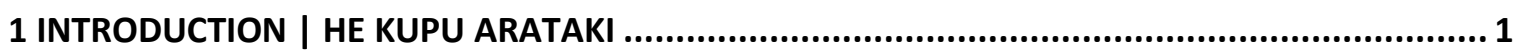

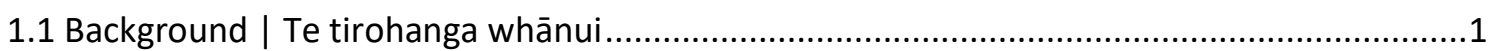

1.1.1 The demise and renaissance of Māori language ...............................................................

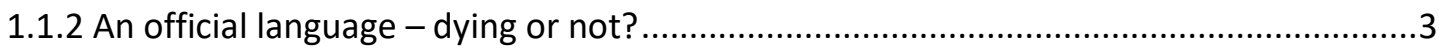

1.1.3 Community-based responses to Māori language demise................................................4

1.1.4 Government responses to Māori language demise .....................................................

1.1.5 Societal responses to Mãori language demise.............................................................

1.1.6 Efficacy of Māori language revitalisation ...................................................................11

1.2 Locating myself as a researcher | Ko wai tēnei kairangahau? ...............................................12

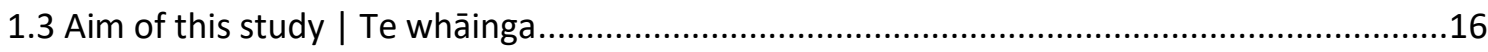

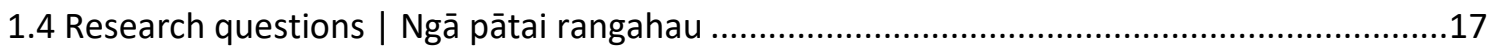

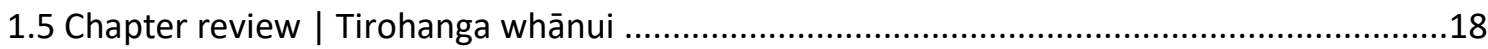

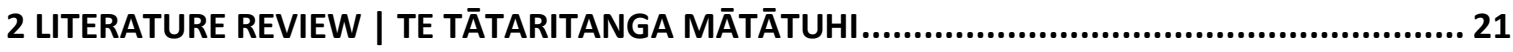

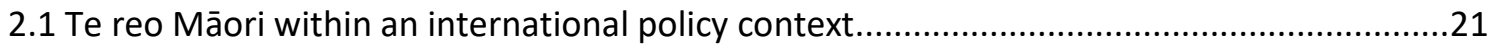

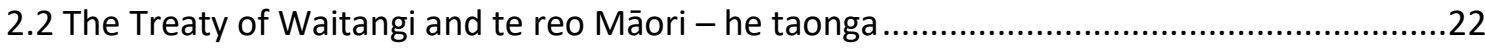

2.3 Relative status of English and Māori languages in Aotearoa NZ ..........................................22

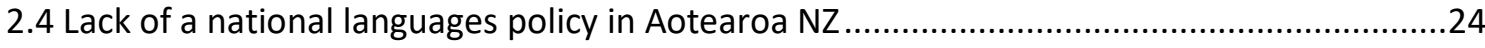

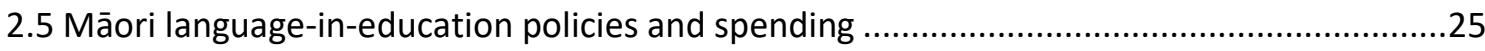

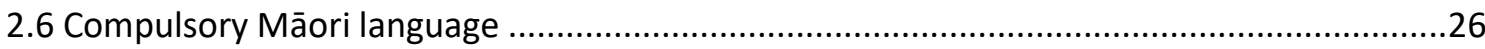

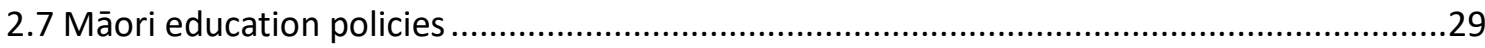

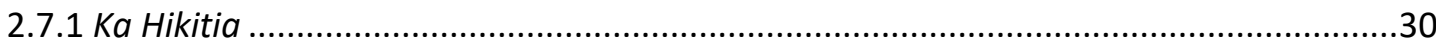

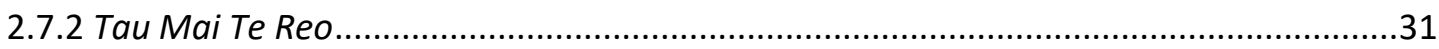

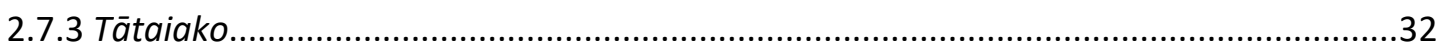

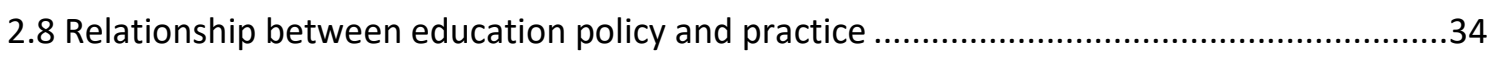

2.9 Factors that influence the teaching and learning of te reo Māori .........................................35

2.9.1 Lack of quality reo Māori resources.............................................................................36

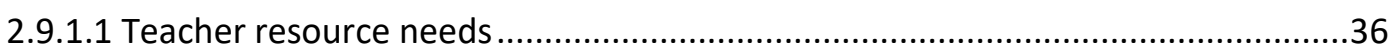

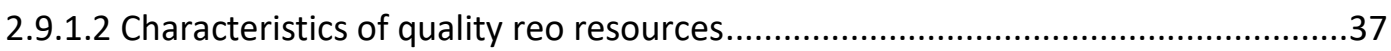

2.9.1.3 Resources to stimulate student interaction...........................................................40

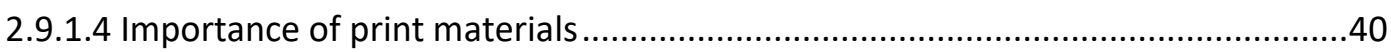

2.9.2 Little consultation with teachers regarding resource development.............................41 
2.9.3 Lack of second language instructional design in resource development. .42

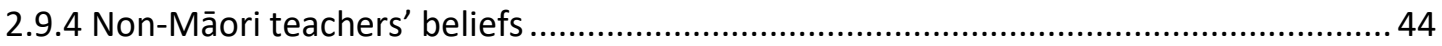

2.9.5 Insufficient and inferior professional development opportunities ............................... 46

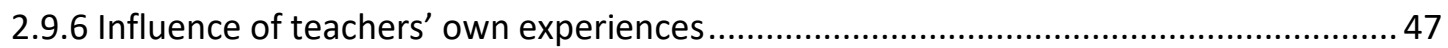

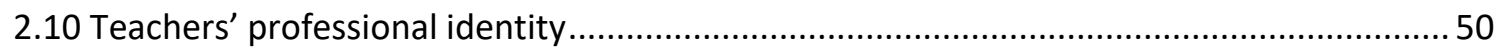

2.10.1 Changes in teaching and learning - evolving professional identity ........................... 51

2.10.2 Communities of learning - contributing to teachers' professional identity ................52

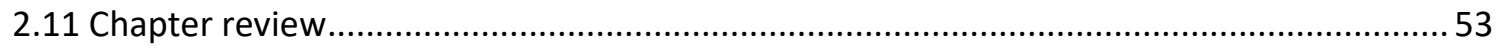

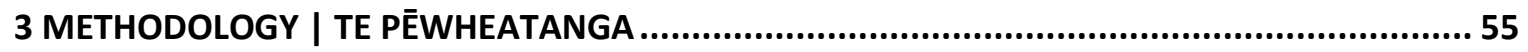

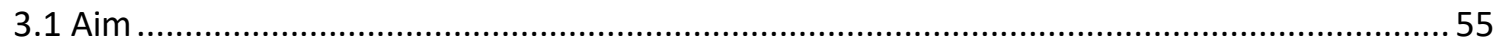

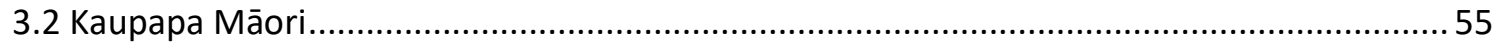

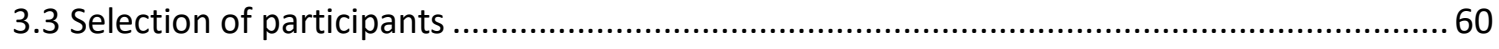

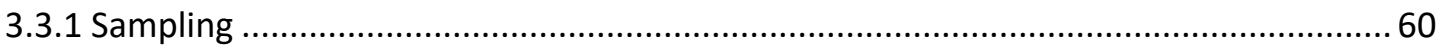

3.3.2 School deciles and Māori student population .............................................................. 62

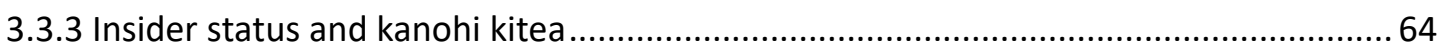

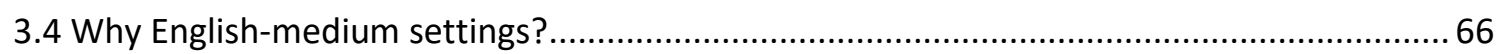

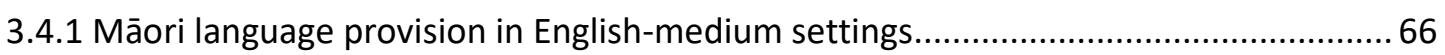

3.4.2 Priority learners in English-medium schools - differential achievement......................67

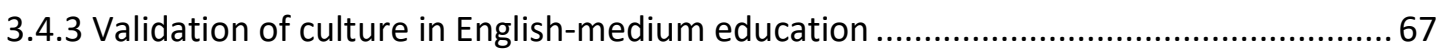

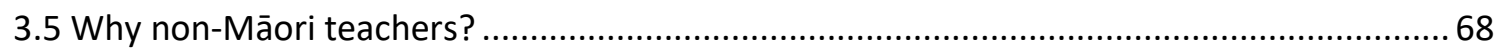

3.5.1 Te reo Māori and tikanga for non-Māori - pros and cons.............................................. 68

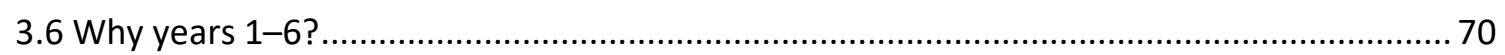

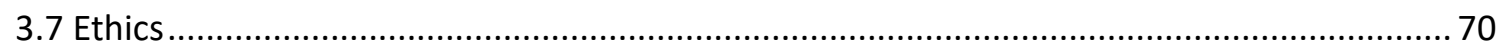

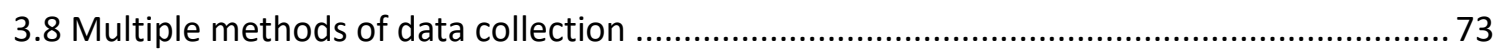

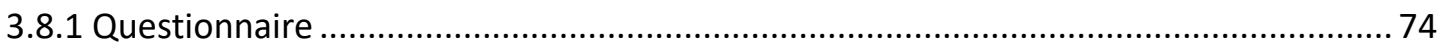

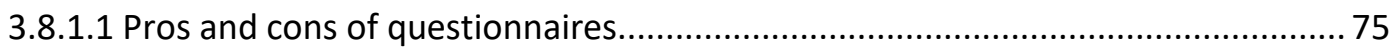

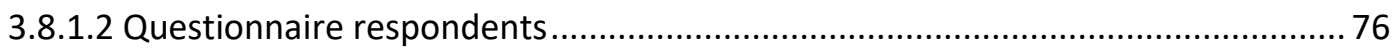

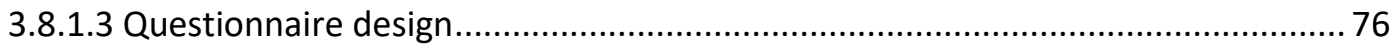

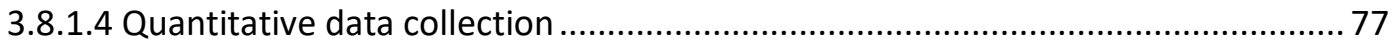

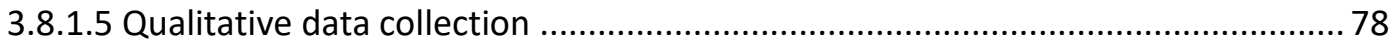

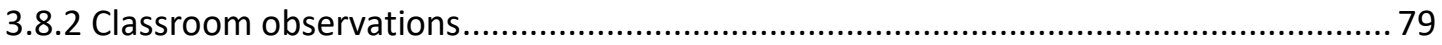

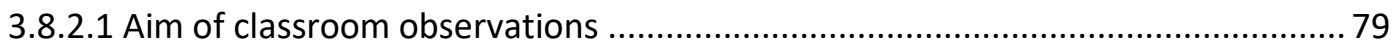

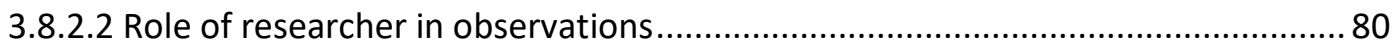

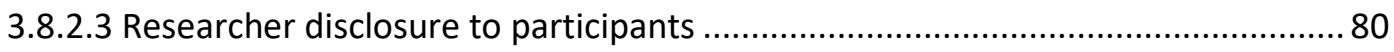

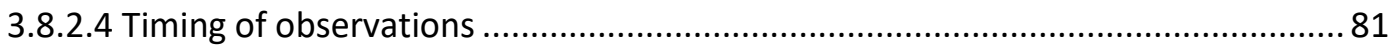

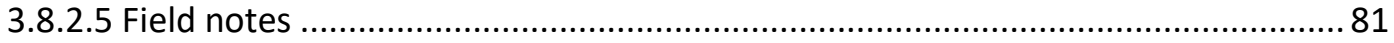


3.8.3 Interviews .83

3.8.3.1 Importance of teacher voice - an insider perspective .83

3.8.3.2 Challenges in interviews..................................................................... 84

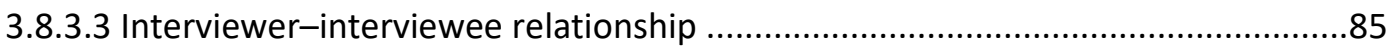

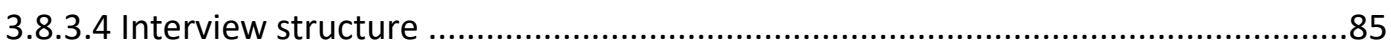

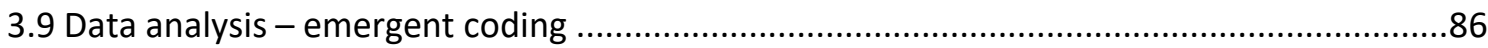

3.9.1 Coding key terms and sorting into categories ................................................87

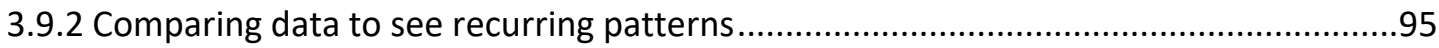

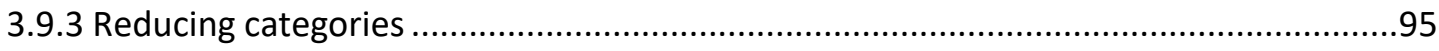

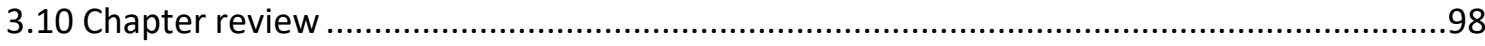

4 FINDINGS AND DISCUSSION, Part 1: Questionnaire | NGĀ KITENGA ME TE KŌRERO, Wāhanga 1: He rārangi pātai .......................................... 99

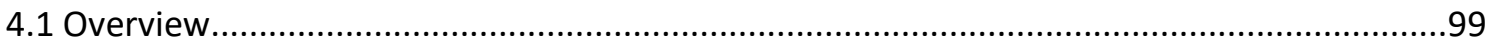

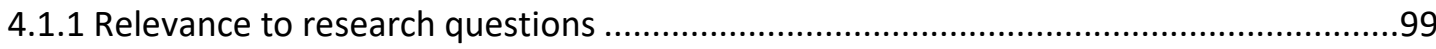

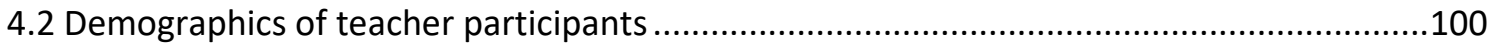

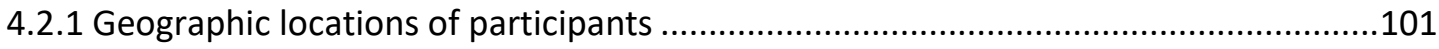

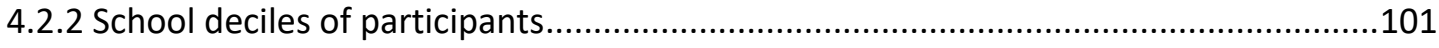

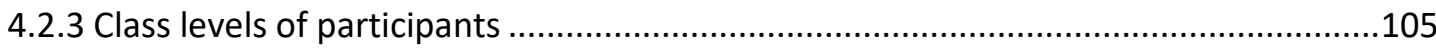

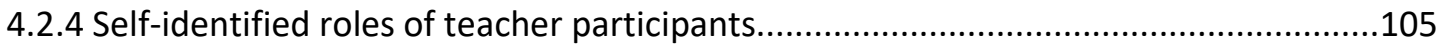

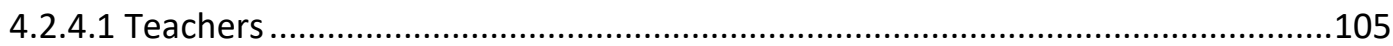

4.2.4.2 Lead teachers of Māori language..........................................................106

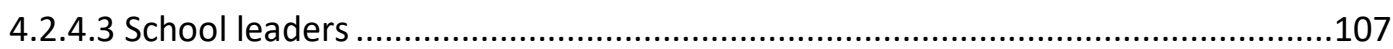

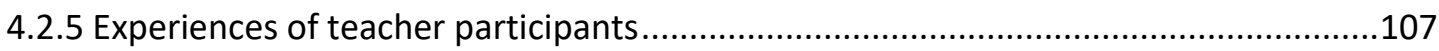

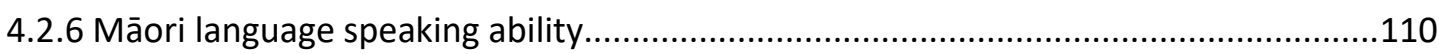

4.2.7 Age range of teacher participants............................................................... 111

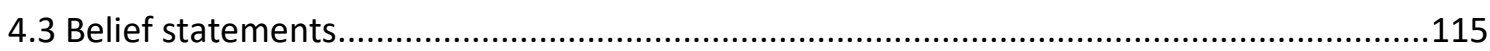

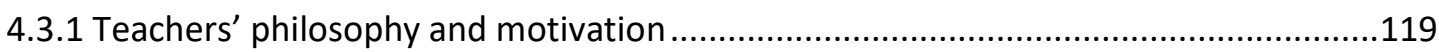

4.3.1.1 Belief statement 27 - Importance of te reo for NZ primary students ................119

4.3.1.2 Belief statement 21 - Compulsory reo Māori.................................................119

4.3.1.3 Belief statement 26 - Motivation for teaching te reo Māori.............................120

4.3.1.4 Belief statements 23 and 20 - Motivation for teachers to learn te reo ..............121

4.3.1.5 Belief statements 19 and 22 - Pronunciation and native speaker fluency..........124

4.3.2 Language, culture, and identity................................................................ 128

4.3.2.1 Belief statement $10-$ Integration of tikanga ............................................128

4.3.2.2 Belief statement 15 - Drawing on students' backgrounds and cultures .............132 
4.3.2.3 Belief statement 17 - Impact of te reo learning on Māori student achievement

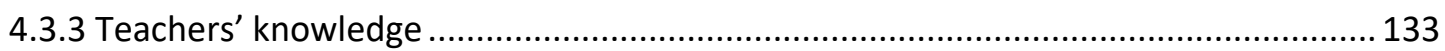

4.3.3.1 Belief statement 18 - Use of basic level of Māori in the classroom ................... 134

4.3.3.2 Belief statement 25 - Influence of previous experiences learning te reo .......... 134

4.3.3.3 Belief statement 5 - Second language acquisition ....................................... 136

4.3.3.4 Belief statement 3 - Ability to be flexible .................................................. 138

4.3.4 Teachers' classroom practices ...................................................................... 139

4.3.4.1 Belief statement 24 - Cross-curriculum integration of Māori .......................... 139

4.3.4.2 Belief statement 9 - Embedding Māori words/phrases in English .................... 140

4.3.4.3 Belief statement 8 - Emphasis on listening and speaking............................... 143

4.3.4.4 Belief statements 6 and 2 - Balancing student practice opportunities with teacher

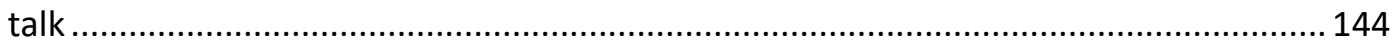

4.3.4.5 Belief statement 7 - The structuring of classroom learning .......................... 144

4.3.4.6 Belief statement 12 - Fun element in learning te reo................................. 146

4.3.4.7 Belief statements 13 and 14 - Using and adapting a range of materials........... 146

4.3.4.8 Belief statement 16 - Real-life contextualisation ...................................... 147

4.3.4.9 Belief statement 4- Inclusion of te reo Māori in curriculum planning............... 148

4.3.4.10 Belief statement 1 - External factors ................................................... 149

4.3.4.10.1 Lack of quality resources (as in belief statement 11) ........................... 150

4.3.4.10.2 Physical, user-friendly resources.............................................. 151

4.3.4.10.3 Resources for language progression ............................................. 152

4.3.4.10.4 Human resources ..................................................................... 154

4.3.4.10.5 Lack of support from school leaders .............................................. 154

4.3.4.10.6 Mismatch in cultural backgrounds ................................................. 155

4.3.4.10.7 Whānau support in schools......................................................... 156

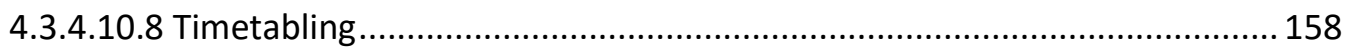

4.4 Prior learning of te reo Māori .............................................................................. 159

4.4.1 Comfort level teaching te reo Māori ...................................................................... 160

4.5 Top three characteristics of quality Māori language materials ...................................... 161

4.5.1 Qualitative comments about quality Māori language materials............................... 164

4.6 Frequency of use of existing Ministry materials ........................................................ 168

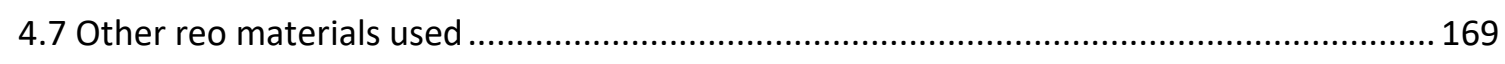

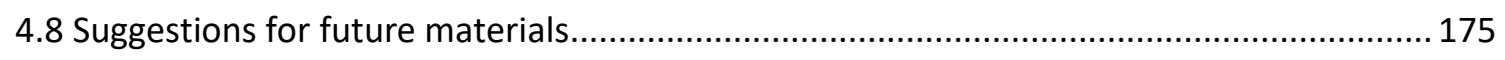

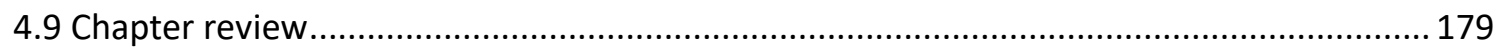




\section{FINDINGS AND DISCUSSION, Part 2: Observations |} NGĀ KITENGA ME TE KŌRERO, Wāhanga 2: He mātaki.

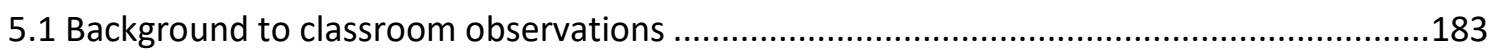

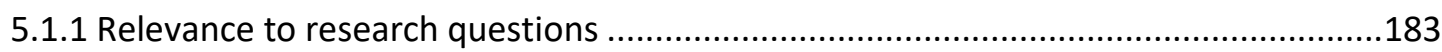

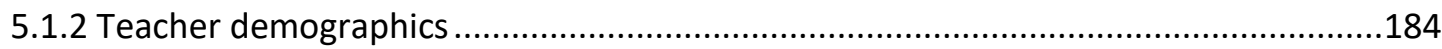

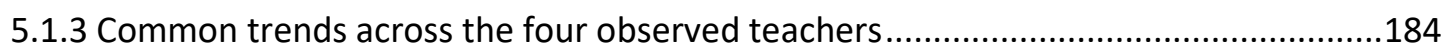

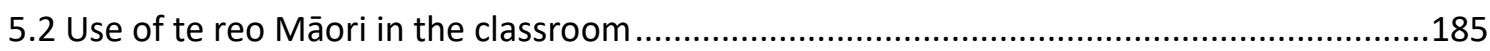

5.3 Scope for further opportunities for teachers to use Māori .................................................191

5.4 Teachers' attitudes towards Māori language and culture .....................................................194

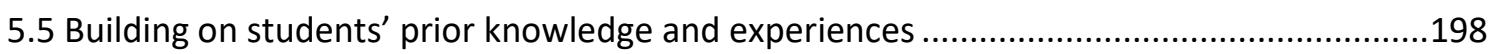

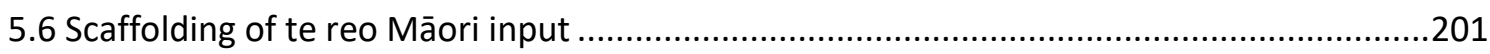

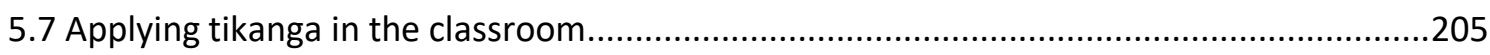

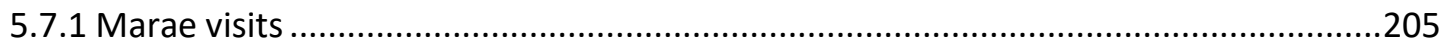

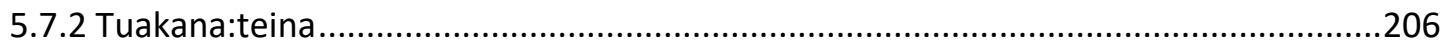

5.7.3 Valuing Māori language - a taonga for all ..............................................................207

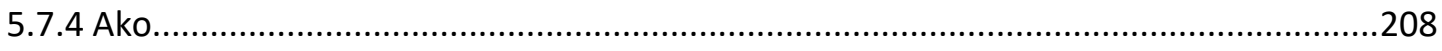

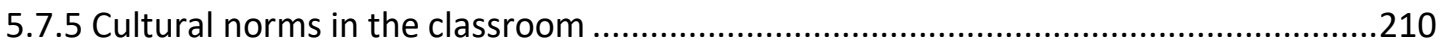

5.8 Te reo Māori in the linguistic landscape of the classroom and school ...............................211

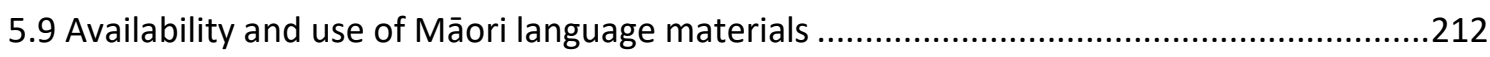

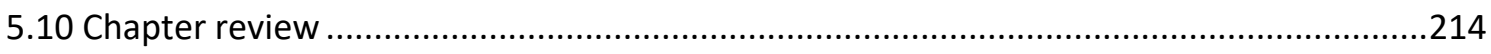

6 FINDINGS AND DISCUSSION, Part 3: Interviews |

NGĀ KITENGA ME TE KŌRERO, Wāhanga 3: He uiuitanga ................................................ 217

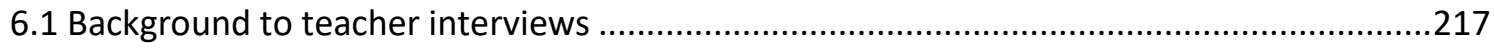

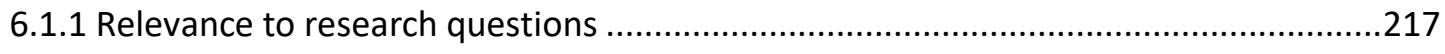

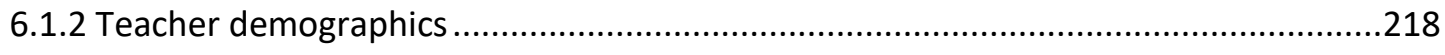

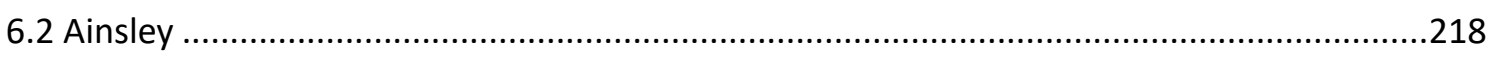

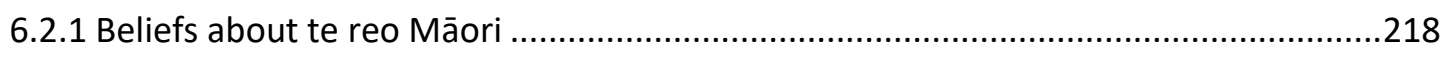

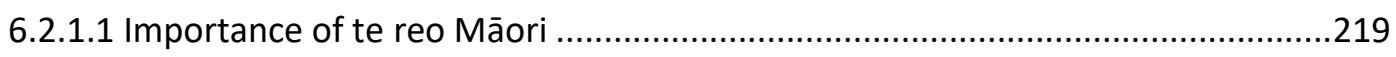

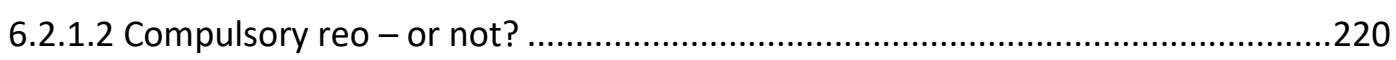

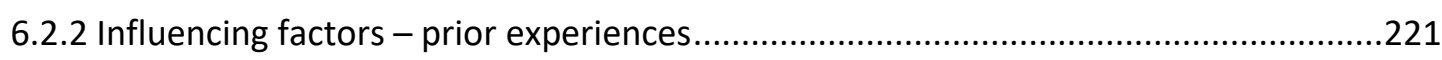

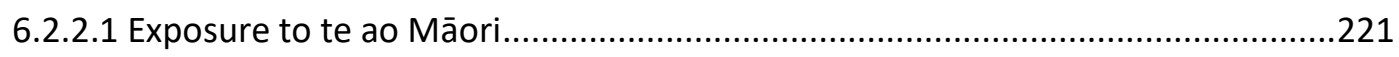

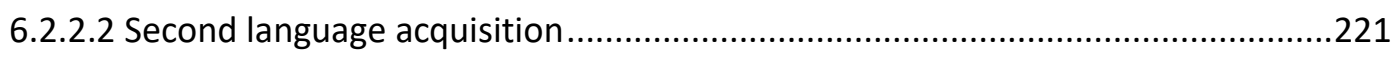

6.2.3 Influencing factors - professional and personal identities .........................................222

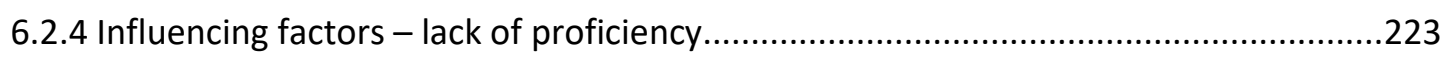

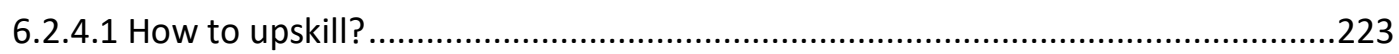

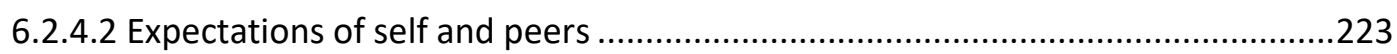




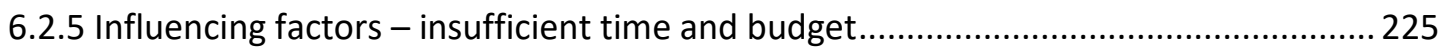

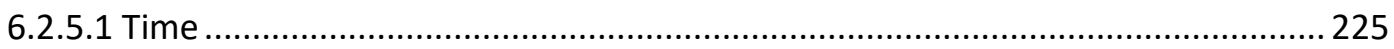

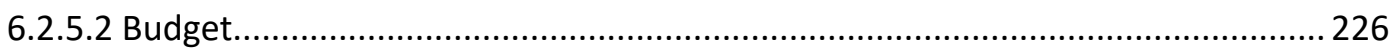

6.2.6 Influencing factors - support (or not) from parents ................................................ 227

6.2.6.1 Professional development - whole school........................................................ 227

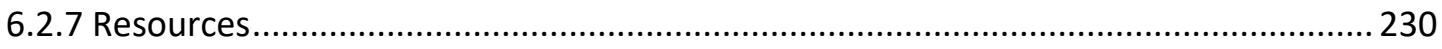

6.2.7.1 Te Aho Arataki Marau mō te Ako i te Reo Māori - Kura Auraki (2009) and He Reo

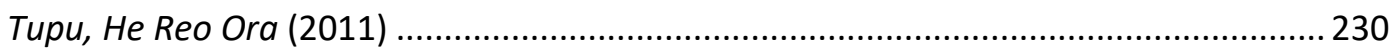

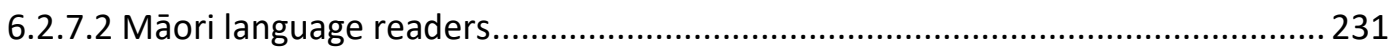

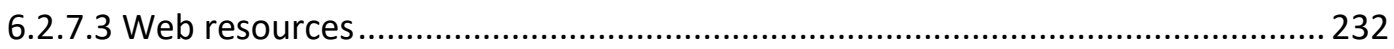

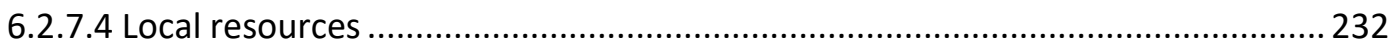

6.2.7.5 What constitutes a quality Māori language resource? ...................................... 233

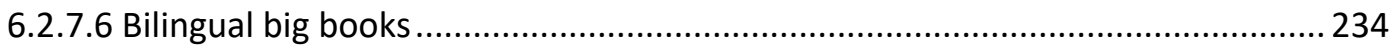

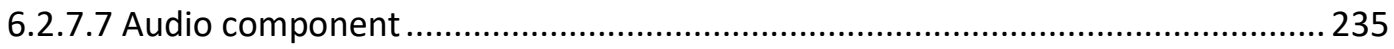

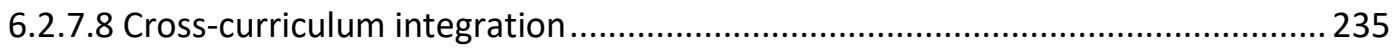

6.2.8 Correlation between te reo in the classroom and Māori student achievement..........236

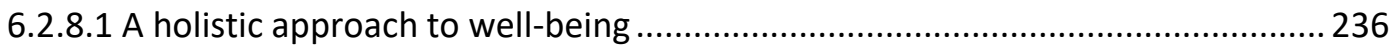

6.2.8.2 Relationship-building through validation of culture ....................................... 237

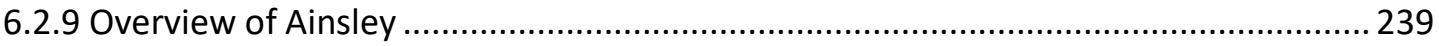

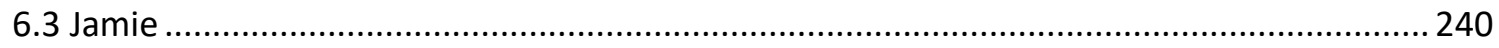

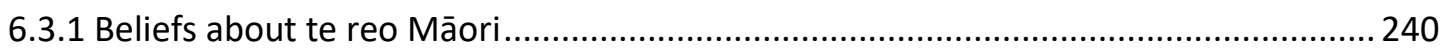

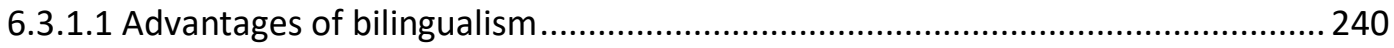

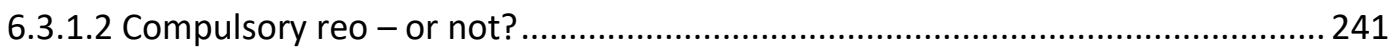

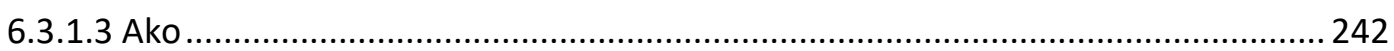

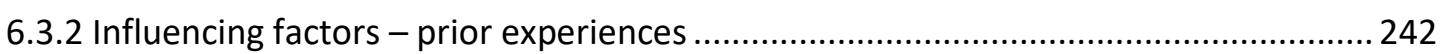

6.3.3 Influencing factors - lack of proficiency (and appropriate PD) .................................. 244

6.3.4 Influencing factors - support (or not) from school leaders....................................... 244

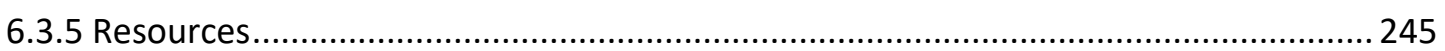

6.3.5.1 What constitutes a quality Māori language resource? ........................................ 245

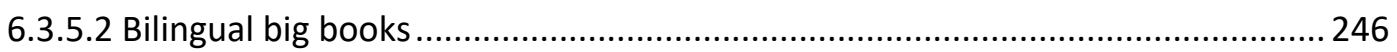

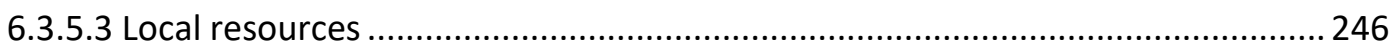

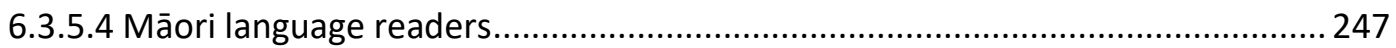

6.3.6 Influencing factors - insufficient time and budget................................................... 248

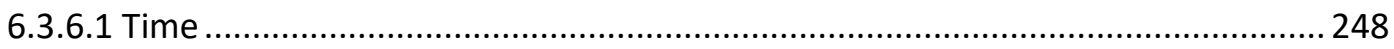

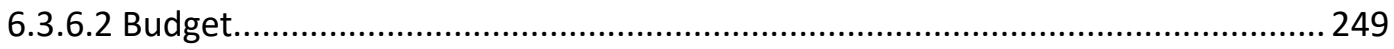

6.3.7 Correlation between te reo in the classroom and Māori student achievement......... 250 


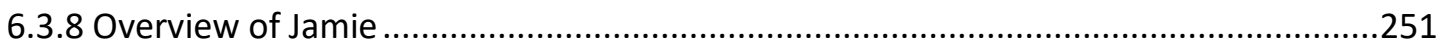

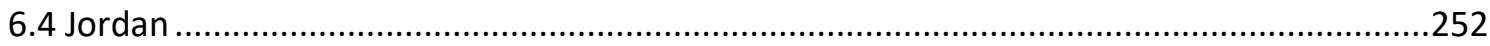

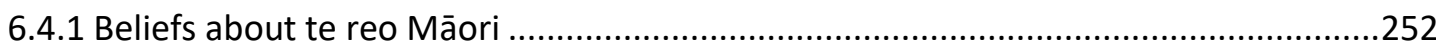

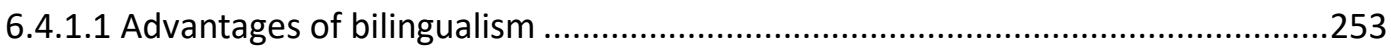

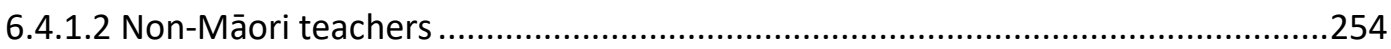

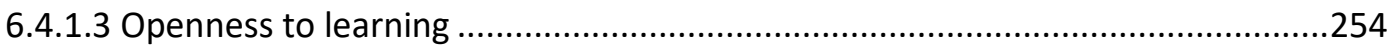

6.4.1.4 New Zealand identity - and redress of wrongs ..............................................25

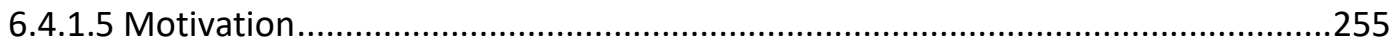

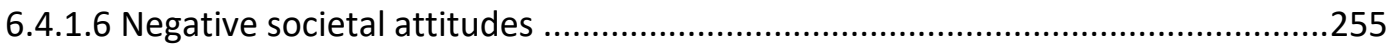

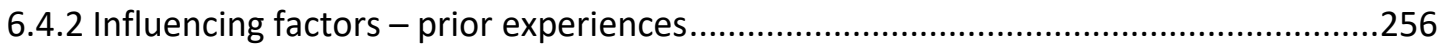

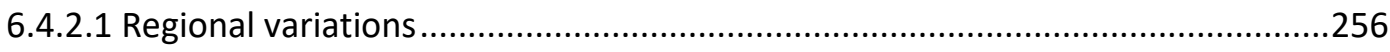

6.4.2.2 Learning te reo Māori in adolescence.................................................................25

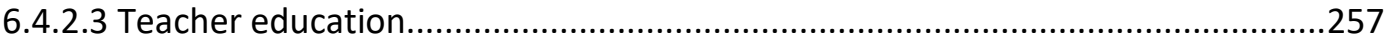

6.4.2.4 Influence of prior learning on current Māori language teaching..........................258

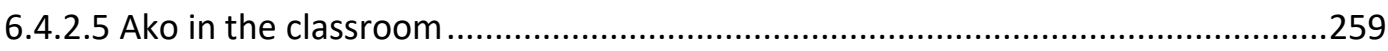

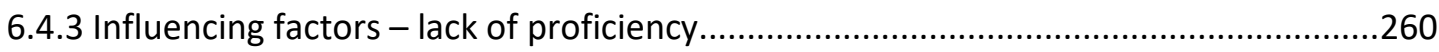

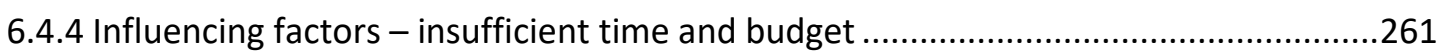

6.4 .5 Influencing factors - support (or not) from parents ...............................................262

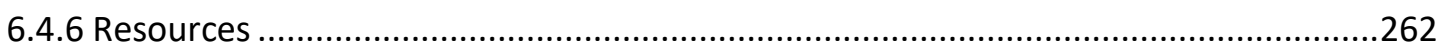

6.4.6.1 What constitutes a quality Māori language resource? ......................................262

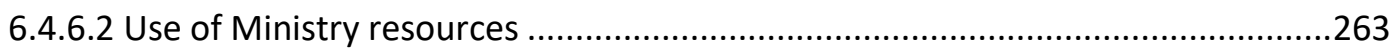

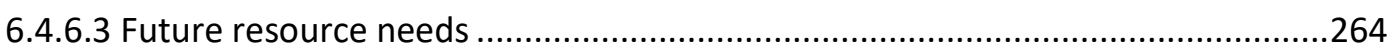

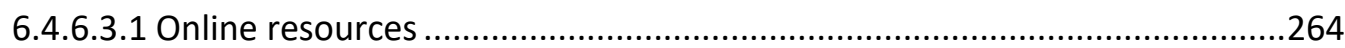

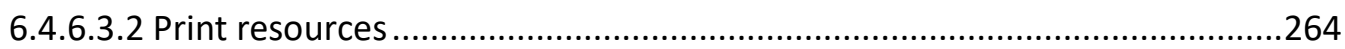

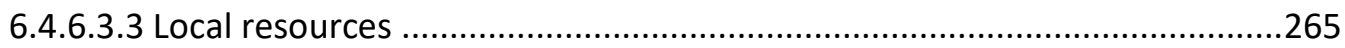

6.4.7 Correlation between te reo in the classroom and Māori student achievement ..........266

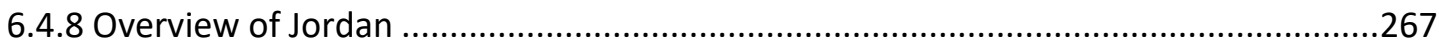

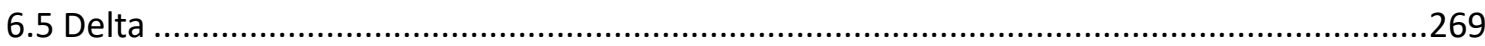

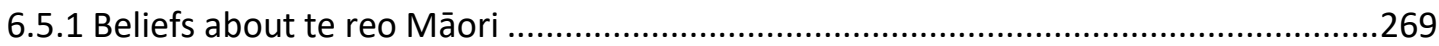

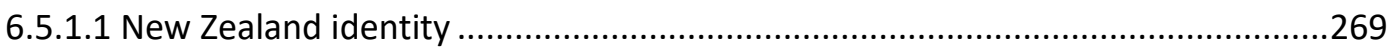

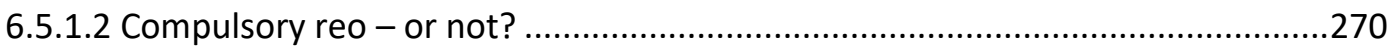

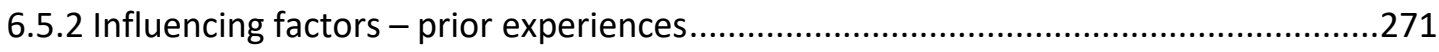

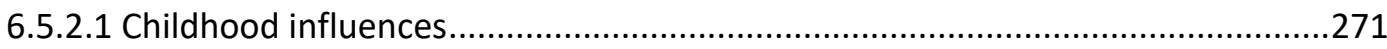

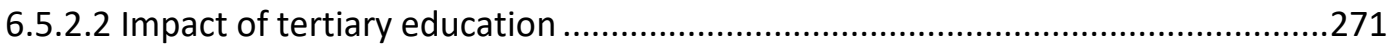

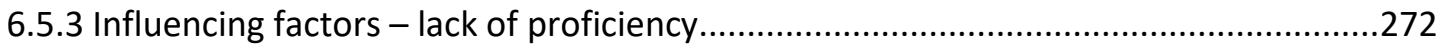

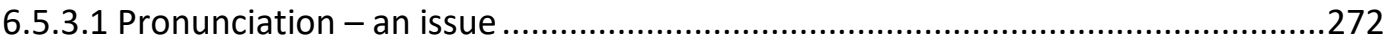




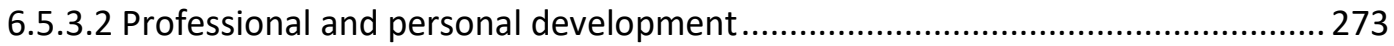

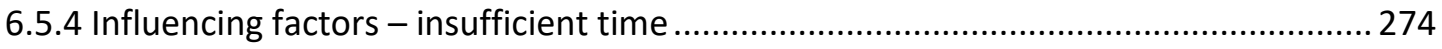

6.5.5 Influencing factors - support (or not) from parents .............................................. 275

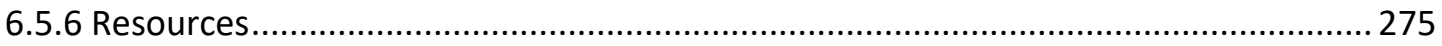

6.5.6.1 What constitutes a quality Māori language resource? ....................................... 275

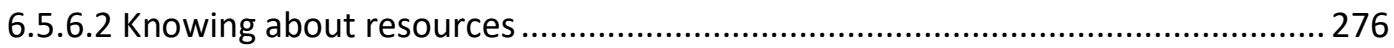

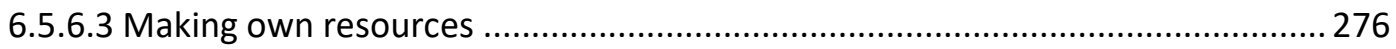

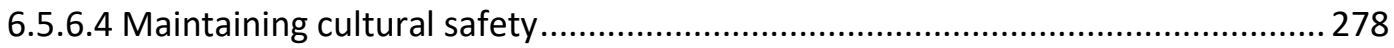

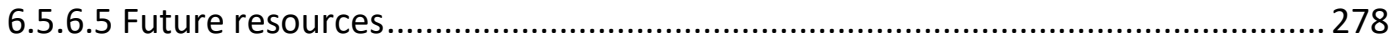

6.5.6.5.1 Future resources aligning to the curriculum ............................................ 278

6.5.6.5.2 Future resources featuring role models ..................................................... 279

6.5.6.5.3 Future resources in the form of posters ................................................ 280

6.5.6.5.4 Future resources for kapa haka............................................................. 280

6.5.7 Correlation between te reo in the classroom and Māori student achievement......... 280

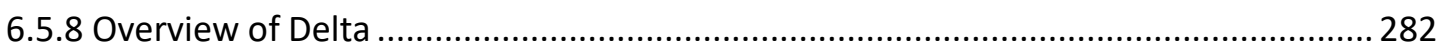

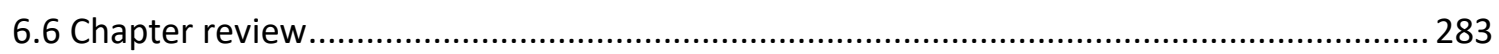

7 IMPLICATIONS AND RECOMMENDATIONS | NGĀ HĪRAUNGA ME NGĀ TAUNAKITANGA ... 288

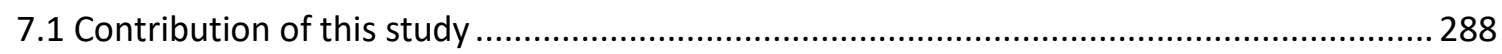

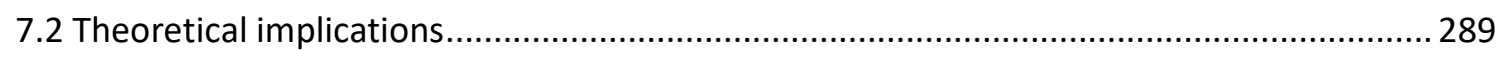

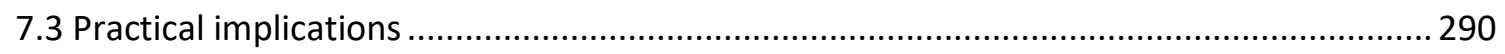

7.3.1 Māori Language Commission and Te Mātāwai.......................................................... 290

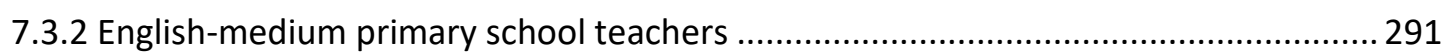

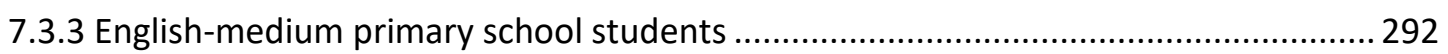

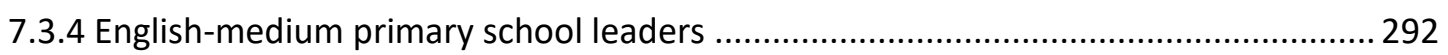

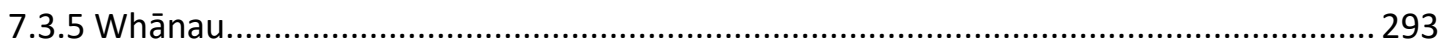

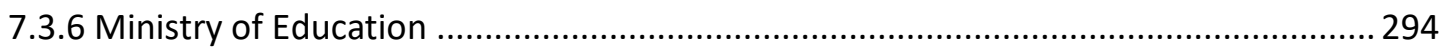

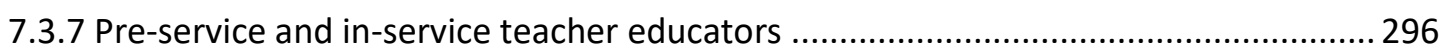

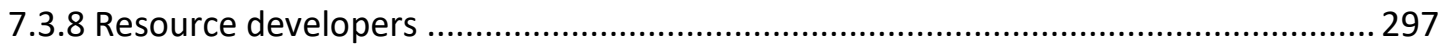

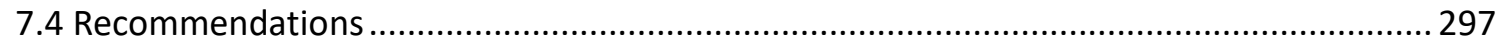

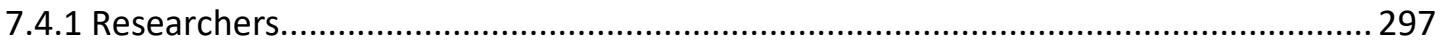

7.4.2 Māori Language Commission and Te Mātāwai................................................................. 297

7.4.3 English-medium primary school teachers ................................................................ 298

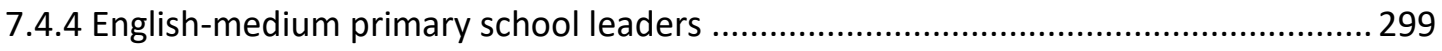

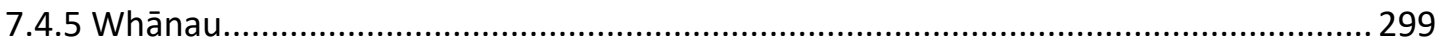

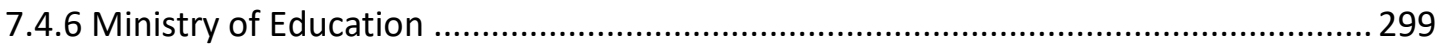

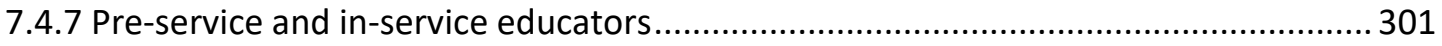




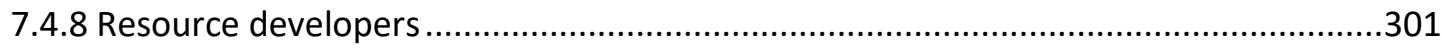

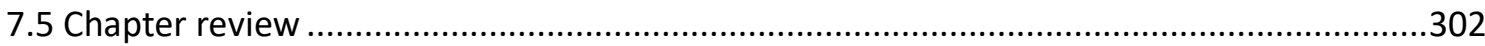

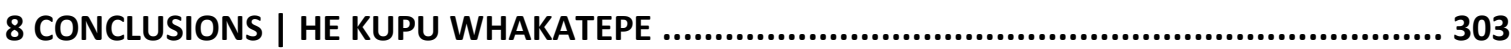

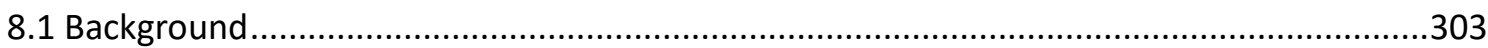

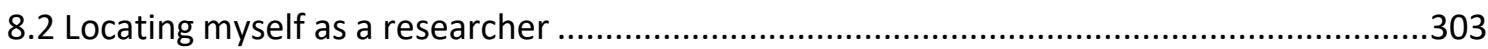

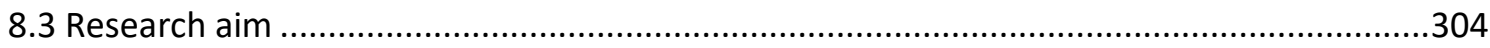

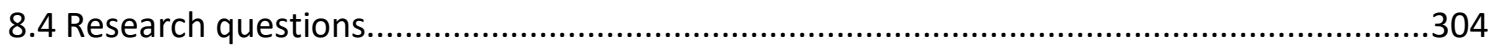

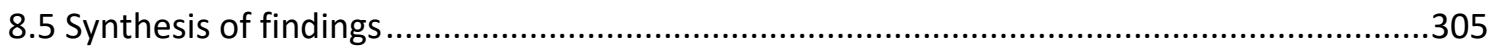

8.5.1 Beliefs of four case study teachers - consistencies and differences ............................305

8.5.2 Classroom practices of four case study teachers - consistencies..................................306

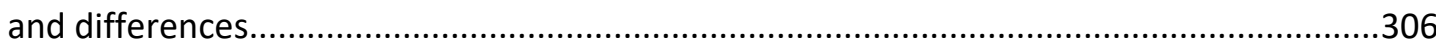

8.5.3 Congruence between beliefs and practices ..................................................................

8.5.4 Factors influencing the teaching of Māori ...................................................................308

8.5.5 Teachers' views on Māori language resources ..........................................................309

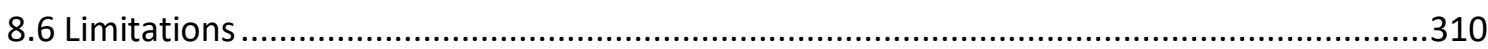

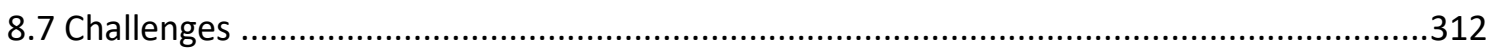

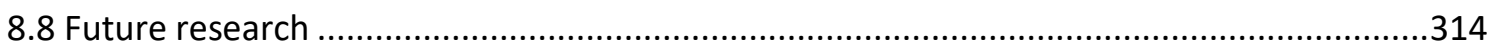

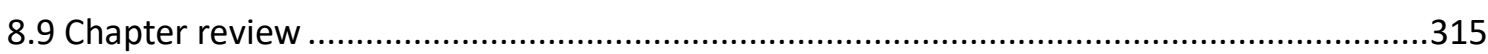

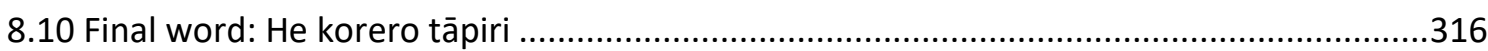

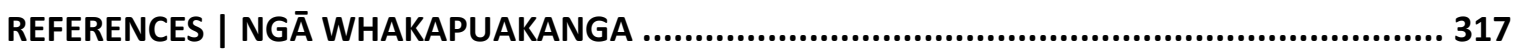

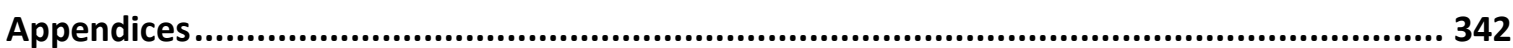

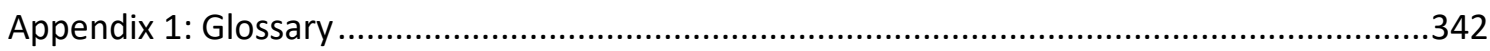

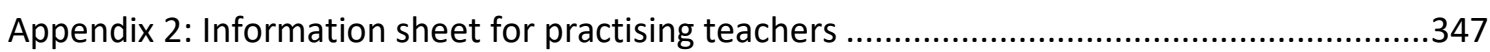

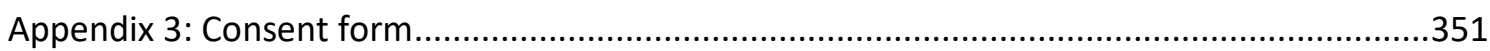

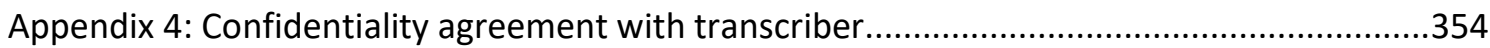

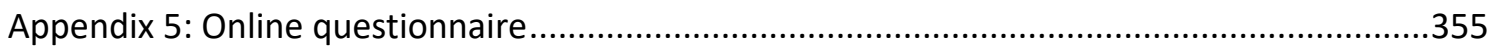

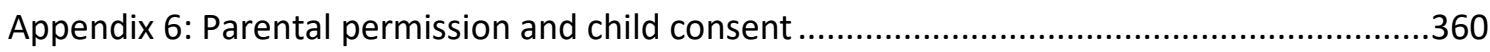

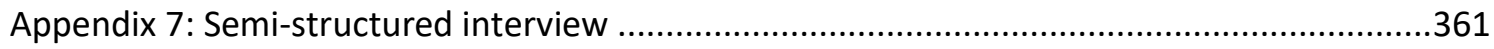

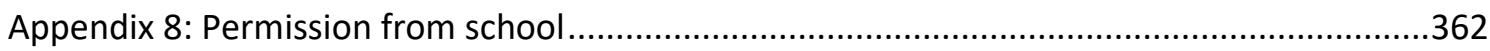

Appendix 9: Participant demographics ( $n=40$, including four men) .......................................363

Appendix 10: Teachers' frequency of use of different Ministry resources ................................366 


\section{INTRODUCTION | HE KUPU ARATAKI}

Few studies have investigated the beliefs and practices of English-medium primary school teachers in NZ endeavouring to teach te reo Māori ${ }^{25}$ (an official language), in order to fulfil the expectation of the Ministry of Education's (the Ministry's) national curriculum, The New Zealand Curriculum. This curriculum states that all students will “... have the opportunity to acquire knowledge of te reo Māori me ōna tikanga" (Ministry of Education, 2007b, p. 9). Moreover, it emphasises (p. 14) the benefits thereof (e.g. national identity; cross-cultural understanding; cognitive 'stretch'; and workforce options).

The aim of this thesis is to address the aforementioned gap by initially canvassing the beliefs of 40 non-Māori teachers, working in English-medium primary schools, about Māori language teaching and learning - then focussing in more depth on four of them as case studies (through observations and interviews), to explore:

- the relationship between their beliefs and their classroom practices,

- $\quad$ their views on Māori language resources ${ }^{26}$, and

- $\quad$ the different factors that can influence their use of Māori in the classroom.

\subsection{Background | Te tirohanga whānui}

Titiro whakamuri, hoki whakamua.

We need to reflect on the past, to clear the way for the future.

Alarmingly, Krauss (1992, pp. 4-10) predicted that, by the end of the 20th century, $40 \%$ of the 6800 languages that existed in the world would be 'threatened' or 'endangered', and another 20\%-50\% would be extinct. Another researcher (Harrison, 2007, pp. 3-7) has since claimed that languages are more threatened than birds, mammals and plants. He predicts that, in the future, we are likely to lose a language (and its associated forms of knowledge) about every ten days. This is a decline unprecedented in history. In a presentation to the Royal Society of NZ, Lo Bianco (2017) painted a worse secenario than that predicted by Krauss. He stated that $70 \%$ of the world's current languages are in fact endangered. The common theme across all these endangered languages is that they represent minority groups who have become dispossessed and disempowered (Crawford, 1995). Māori is one such

\footnotetext{
${ }^{25}$ The following words are used interchangeably: te reo Māori; te reo; and Māori language

${ }^{26}$ The words 'materials' and 'resources' are used interchangeably, in a non-technical way, to mean tangible items that help teachers to prepare and implement lessons
} 
language, because it was disenfranchised by the English language - as acknowledged by economists Grin and Villaincourt (1998, p. 188).

\subsubsection{The demise and renaissance of Māori language}

It was a different situation in the early 19th century, when te reo Māori was a vital, thriving language; indeed, it was the primary language spoken in Aotearoa NZ. But the prevailing situation of Māori language having primacy did not last. In fact, the language was nearly annihilated after European settlement ${ }^{27}$.

In response to the decline of Māori language, revitalisation efforts were stimulated by a petition to the NZ Parliament on September 14, 1972, demanding equal status for Māori language and English through the provision of broadcasting and educational opportunities for te reo Māori ${ }^{28}$. Many of those who presented the petition were products of the urban drift, such that there was no Māori language in their whānau. This was their call to action, to address the language loss and reclaim te reo Māori as part of their identity.

The petition, supported by 33,000 people, was successful - with te reo Māori becoming an option in primary and secondary schools, and a one-year training course being established for native speakers (to address the dearth of qualified teachers). In the following year, 1973, the September 14 date was commemorated in the form of the first Māori Language Day. The inaugural Māori Language Week was then held in 1975, in the week closest to September 14. The timing of this annual event has remained consistent over the years.

Spearheading the Māori language renaissance movement was a group of staunch advocates, Ngā Kaiwhakapūmau i te Reo. In 1984, they took a claim (Wai 11) to the Waitangi Tribunal, asserting that the Crown had a responsibility to protect, and indeed promote, Māori language because of it being acknowledged under the Treaty of Waitangi (the

\footnotetext{
${ }^{27}$ More information on the negative effects of assimilationist educational policies in the 1860s/70s and the urban drift in the 1960s/70s can be found in Biggs (1968); Benton (1981, 1983, 1991, 2001a); Davies and Nicholl (1993); Fishman (2001); Grin and Villaincourt (1998); Harlow (2003); Hinton (2001); Ka'ai-Mahuta (2011); Moon (2013); Soler and Smith (2000); Te Puni Kōkiri (1998, 2003, 2008); Waitangi Tribunal (1986); and Waite (1992) ${ }^{28}$ https://www.wgtn.ac.nz/news/2017/09/the-petition-that-sparked-te-reo-maori-revitalisation and
$\underline{\text { https://nzhistory.govt.nz/culture/maori-language-week/history-of-the-maori-language }}$
} 
Treaty) as a taonga ${ }^{29}$. The claimants called for Māori to be made an official language of Aotearoa NZ.

The Tribunal agreed that the Crown had not actively lived up to the promise laid out in the Treaty to guarantee the protection of te reo Māori. Furthermore, the Tribunal pointed to the cumulative adverse effects of ill-conceived educational policies on Māori children's learning (Waitangi Tribunal, 1986). For example, by this stage, only 2\% of Māori new entrant children spoke Māori as a heritage language ${ }^{30}$ - and there was little expectation that te reo Māori would survive (Ka'ai-Mahuta, 2011). Therefore, the Tribunal recommended that te reo should be taught in schools from an early age. Shortly after, the Māori Language Act was passed in Parliament in 1987, declaring te reo Māori an official language. The Act also saw the establishment of Te Taura Whiri i Te Reo Māori (The Māori Language Commission).

\subsubsection{An official language - dying or not?}

Nearly two decades later, UNESCO's framework (2003) for determining the vitality of a language described te reo Māori as being between 'definitely endangered' and 'severely endangered' (Lewis and Simons, 2009). Similarly, Bauer (2008) showed cause for alarm. She interrogated the data from the 2001 and 2006 censuses, concluding that the Māori language was struggling - and could even be losing ground. Moreover, she expressed concern that, due to what she regarded as the glowing interpretation of the data by Te Puni Kōkiri $^{31}$ (TPK), complacency could set in (p. 67). That is, Māori language advocates could be lulled into a false sense of security and feel satisfied about the progress being made to revitalise te reo.

Notwithstanding Bauer's assertion that Māori language was in crisis, her research exposed the unreliability of different data sets, in terms of the way the census data were collected (Bauer, 2008). She also raised issues associated with self-reporting one's ability in te reo; specifcally, the lack of clarity around descriptors - which was not conducive to a shared understanding across census respondents. In 2011, a significant judgement was handed down by the Waitangi Tribunal (Wai 262, 2011), confirming that the health of te reo Māori

\footnotetext{
29 Treasure

${ }^{30}$ A heritage language is defined here as one that has familial or ancestral ties (Hornberger \& Wang, 2008,

p. 6) - although not necessarily one's mother tongue

${ }^{31}$ Ministry of Māori Development
} 
was approaching crisis point, and it urgently needed saving from 'imminent death'. Furthermore, in 2011, a review of the Māori language sector, Te Reo Mauriora, confirmed the fragility of the language (TPK, 2014). The review revealed that 21.3\% of Māori people could hold a conversation about everyday things in te reo Māori - a 4.8\% decrease from the previous census in 2006.

The use of different sampling methods by Statistics NZ has confounded the picture. For example, the 2013 National Census data ${ }^{32}$ showed there were 125,532 Māori language speakers in $\mathrm{NZ}^{33}$. However, another national survey conducted by Statistics NZ in the same year, using the same questions but different sampling methods, showed 257,500 speakers of te reo Māori (Statistics NZ, 2013). There is no consensus regarding which result is correct. Such discrepancies make it difficult to make comparisons and arrive at a conclusion about the health of te reo Māori, based on numbers alone - hence Statistics NZ publishing a comprehensive paper cautioning about the unreliability of its data (Statistics NZ, 2014).

There are researchers who present a counter argument to te reo Māori being in crisis (OlsenReeder, 2018; Higgins and Rewi, 2014). Their positioning is that 'language death' arguments are potentially limiting - and may in fact be having a negative effect. They argue that te reo Māori is indeed already revitalised, with the next step being to increase the use of the language.

\subsubsection{Community-based responses to Māori language demise}

Over the years, Māori have responded to the demise of the Māori language by instigating several 'flax roots' ${ }^{34}$ movements.

One example of a community-based initiative to revitalise the language (primarily among adults) is Ataarangi - using coloured cuisenaire rods to develop Māori language skills (Mataira, 1980). Derived from Caleb Gattegno’s ‘Silent Way' method of language learning, this initiative was instigated by Māori communities in 1979, in response to the perilous state of te reo Māori (Benton, 1985). At that time, only 5\% of all Māori children could speak te reo (Waitangi Tribunal, 2011). It was important for inter-generational transmission that adults learnt the language. The Ataarangi method still survives today. Its mantra is: "It

\footnotetext{
32 There has been a delay in the publication of the latest census, conducted in 2018; hence my referencing Census 2013 http://archive.stats.govt.nz/Census/2013-census.asp

${ }^{33}$ Data extracted 1/11/2019 using NZ Stat builder

34 This term is used by many Māori in lieu of 'grass roots' - due to the importance of flax in Māori culture
} 
takes only one generation to lose a language - and at least three generations to restore that language."

In 1982, Māori language pre-school 'nests' (kōhanga reo) were established by the then Department of Māori Affairs, to promote te reo Māori in the early years. Like Ataarangi, this initiative was driven by the Māori community, out of concern for the loss of the language and culture. The community subsequently established Māori-medium primary schools (kura kaupapa), in 1985, to accommodate Māori children graduating from kōhanga reo. This was followed by the establishment of secondary schools (wharekura) in 1993, to cater to the Māori-speaking graduates from kura kaupapa (Smith, 2003, pp. 6-7).

These kura $^{35}$ reflected the educational aspirations of many Māori for their tamariki, "restoring the balance after years of subtractive bilingualism" (Bishop and Barr, 1999, p. 189), when English was the dominant language. Importantly, these kura created a pathway for a seamless Māori-medium transition in the compulsory education sector - with the aim of providing a future pool of expert speakers.

\subsubsection{Government responses to Māori language demise}

By way of responding to the demise of te reo Māori, the Māori Language Act 2016 was passed in Parliament, replacing the Māori Language Act 1987. The new Act acknowledged that previous Crown policies and practices had contributed to the loss of the language, intergenerationally - and there now needed to be a partnership between the Crown and iwi Māori ${ }^{36}$ to protect the language, as a taonga, for future generations.

The Act acknowledges that, historically, Māori have been denied the right to use te reo Māori. It seeks to lift the status of the language. The intent is significant; namely, to hand back control of the language to Māori as kaitiaki ${ }^{37}$ - albeit with continued support from the Crown, which includes the education sector. As such, the Ministry of Education has a responsibility to provide suitable access to te reo Māori in schools - including English-medium primary schools, the focus of my research.

Under the Act, legislative status has been given to the development of two separate but related Māori language strategies. The two strategies (Maihi Māori and Maihi Karauna) are complementary, in partnership with each other. Together, they ensure collective impact on Māori

\footnotetext{
${ }^{35}$ Māori-medium schools

${ }^{36}$ Māori people/tribes

${ }^{37}$ Guardians/ care-takers
} 
language revitalisation. The rationale for having a two-pronged strategic approach is to better define, and strengthen, respective roles within the Māori: Crown partnership - such that both partners share an overarching vision for Māori language revitalisation; namely, 'kia mauriora te reo', where Māori is a living language. This partnership is represented by the image of a whare ${ }^{38}$ with its two facing barge boards. (See Figure 1.1 below).

Figure 1.1: Mãori Language Strategy (TPK, 2019) - Mãori and Crown in partnership ${ }^{39}$

\section{Kia Mauriora te Reo \\ Kia rere, kia tika, kia māori}

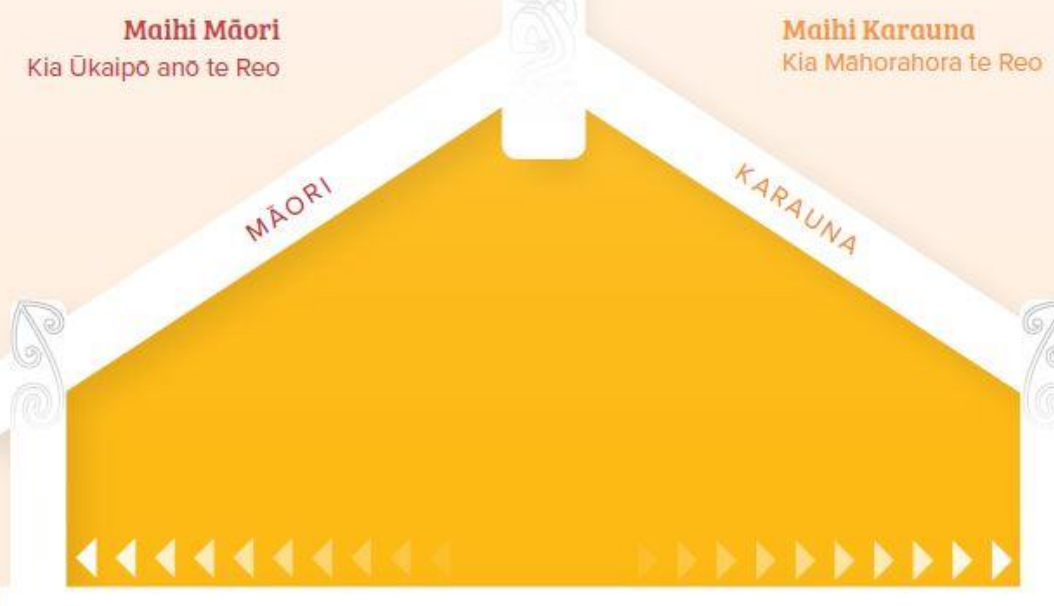

An independent statutory entity, Te Mātāwai, has been established under the Act. It comprises 13 members who have a leadership role in the Māori language revitalisation landscape (Bills Digest No 2326, NZ Parliamentary Library 2016). There are seven representatives from regional clusters of iwi, and four representatives from Māori language stakeholder groups. These 11 representatives are knowledgeable in te reo me ngā tikanga Māori. Moreover, they are deemed to be 'he kanohi kitea' ${ }^{40}$ amongst Māori i.e. people whose presence is visible in the Māori world.

\footnotetext{
${ }^{38}$ House

${ }^{39} \mathrm{https}$ ://thestandard.org.nz/ko-te-reo-te-mauri-o-te-mana-Māori/ Retrieved 17.2.18

${ }^{40}$ People who are visible at Māori hui/ gatherings/ fora
} 
Te Mātāwai also has two Crown appointees, to honour the government's Treaty obligation associated with te reo Māori being a taonga.

Te Mātāwai is responsible for Māori language planning at the micro level (e.g. local marae, community, hapū, iwi) through a Māori Language Strategy that gives effect to Māori aspirations, and focusses on kaupapa that matter to iwi and the community (Maihi Māori) - thus ensuring that, as proprietary owners of the language, they retain tino rangatiratanga ${ }^{41}$.

The creation of Te Mātāwai does not mean that the government can abrogate its responsibility. The Crown has had a significant hand in the historical marginalisation and decline of the language - especially in the area of education policy ${ }^{42}$. For that reason, the government's Māori Language Strategy (Maihi Karauna) will ensure that its responsibility is met in terms of national-level issues associated with te reo Māori (e.g. the teaching of Māori language in schools) and Māori language planning at a macro level (e.g. public sector).

The goal of government is for one million New Zealanders to be speaking basic reo by 2040 . Māori Language Commission CEO, Ngahiwi Apanui, believes the goal is achievable if there is more resourcing. Communication with the Ministry reveals that, at the time the new Māori Language Act 2016 was passed, the government spent \$19.164M on Māori language education in compulsory settings (English-medium and Māori-medium). Of this, $\$ 3.35 \mathrm{M}$ was spent on te reo Māori in primary schools ${ }^{43}$. (Personal communication with Matthew Gibbons, Ministry of Education, 6 April, 2017). This included approximately $\$ 2.78 \mathrm{M}$ specifically for schools where there were some students in Māori-medium units (i.e specially designated classes physically located in English-medium schools, but conducting their teaching and learning in te reo Māori). This left approximately $\$ 0.57 \mathrm{M}$ for Māori language programmes in English-medium primary schools (the target audience of my study) where there were no Māori-medium units - and, often, very little (or no) in-school Māori language expertise.

As of July 2016, despite the low level of funding for te reo Māori in English-medium primary schools, there were 45,103 students in Years 1-6 participating in Māori language learning in English-medium primary schools. (Personal communication with Matthew Gibbons, Ministry of Education, 6 April, 2017). These students were learning te reo Māori at levels 3-5 of the Ministry's Māori Language Resourcing

\footnotetext{
${ }^{41}$ Autonomy

${ }^{42}$ https://thestandard.org.nz/ko-te-reo-te-mauri-o-te-mana-Māori/ Retrieved 17.2.18

${ }^{43}$ All references to primary schools in this thesis refer to years 1-6 unless otherwise specified
} 
(MLR) funding framework as shown in Table 1.1 below. This is a framework used to verify whether the level of funding claimed by schools for their Māori language programmes corresponds with the actual number of hours per week that their curriculum is taught in Māori. For example, to qualify for Level 3 funding, teaching time in Māori would need to constitute $31 \%-50 \%$ of the classroom programme (i.e. 7.5-12.5 hours weekly). Similarly, Level 4 funding would be allocated to schools where $12 \%-30 \%$ of the classroom programme was in te reo Māori (i.e. 3-7.5 hours weekly). Realistically, based on my experience as a Māori language adviser, most primary schools are operating at Level 5 - which is less than 3 hours weekly. My target audience is this Level 5 cohort.

Table 1.1: Māori language resourcing levels 3-5

\begin{tabular}{|c|c|c|}
\hline $\begin{array}{l}\text { Māori Language } \\
\text { Resourcing Level }\end{array}$ & $\begin{array}{c}\text { Percentage of teaching } \\
\text { time in te reo Mãori }\end{array}$ & $\begin{array}{c}\text { Equivalent hours of } \\
\text { teaching time in te reo } \\
\text { Māori }\end{array}$ \\
\hline Level 3 & $31 \%-50 \%$ & $7.5-12.5 \mathrm{hrs}$ \\
\hline Level 4 & $12 \%-30 \%$ & $3-7.5 \mathrm{hrs}$ \\
\hline Level 5 & Less than 12\% & Less than 3 hrs \\
\hline
\end{tabular}

The Education (Update) Amendment Act 2017 acknowledges the unique position of te reo Māori as NZ's Indigenous language ${ }^{44}$, and an official language regarded under the Treaty as a taonga to be protected. Section 16 of the Act addresses cultural diversity, the Treaty, tikanga Māori, and te reo Māori. Hence the expectation in the New Zealand Curriculum (2007) that all students will be given the opportunity to acquire knowledge of te reo and tikanga Māori. In this curriculum, Māori language is located with other languages in the 'Learning Languages' area - because, for most students in English-medium schools, te reo Māori is a 'second or additional language', being taught as a subject (Ministry of Education, 2009, p. 17).

To manage its expectation, the Ministry developed Māori language curriculum guidelines, Te Aho Arataki Marau mō te Ako i te Reo Māori-Kura Auraki (Te Aho Arataki Marau), for primary and secondary schools, published in 2009. While the availability of the guidelines gives some recognition to the value of the language, the scope of its delivery in primary schools is invariably limited - time-wise and content-

\footnotetext{
${ }^{44}$ The use of a capital letter in the word 'Indigenous' is consistent throughout this document - in recognition of the status and rangatiratanga of Indigenous people (Seals \& Shah, 2018). The capital letter denotes native peoples who have been colonised.
} 
wise (Liddicoat, 2007, p. 3). Much depends on the goodwill, and capability, of teachers - and the demand (or not) from the school community. For example, some parents may deem other languages as having more status than Māori.

Principals can influence Māori language teaching and learning. The findings from NZ's National Monitoring Study of Student Achievement (NMSSA) programme ${ }^{45}$, on the learning of languages in Years 4 and 8, indicated that $11 \%$ of Year 4 principals and $6 \%$ of Year 8 principals made no provision for te reo Māori- even though most believed it was 'important' or 'very important' for students to learn Māori at school. Moreover, when making new staff appointments, half those principals reported that they took no account of applicants' ability to teach te reo Māori (Ministry of Education, 2018, pp. 78-79).

\subsubsection{Societal responses to Māori language demise}

A good sign for the teaching of Māori language in English-medium schools, and for the wider vision of Māori language revitalisation, is the fact that, over time, non-Māori attitudes have become more positive (TPK, 2008). However, this attitudinal shift in society is not necessarily translated into people's behaviour. That is, there can be a mismatch between attitudes and practices (TPK, 2010). This is pertinent to my research, part of which seeks to determine the consistencies (or lack of) between non-Māori primary school teachers' beliefs and their classroom practices i.e. what they reportedly believe (based on their responses in the online questionnaire) as opposed to what they actually do in the classroom (as evidenced in my observations).

Beyond teaching, there are instances where different Pākehā organisations/institutions have contributed to Māori language revitalisation. For example, since March 2019, the Treasury has adopted a Māori name, Te Tai Ōhanga ${ }^{46}$. Likewise, to encourage Māori language use in everyday situations, Westpac bank has begun its roll-out of an iwi language option on its ATMs in the Waikato-Tainui area - with more regional variations to follow. A Māori

\footnotetext{
45 The NMSSA programme investigated the teaching and learning of te reo in Years 4 and 8 - through a survey of teachers, students and principals at 100 English-medium schools. It also explored the students' knowledge of, confidence in, and attitudes towards, te reo Māori at Curriculum Level 1. There were 2300 English-medium students in the survey

${ }^{46}$ Ōhanga relates to the economy, financial matters, prosperity - while Te Tai is the term for the tide
} 
language adviser for that iwi, Pania Papa, has praised the innovation for its normalisation of the language, bringing it into everyday life and thereby lifting its prestige/mana.

During Māori Language Week in 2017, a range of organisations showed support for te reo Māori. For example, the Dominion Post newspaper proudly introduced macrons on Māori words $^{47}$ in their print and online publications. In its opinion piece (page A6 on 11 September 2017), the newspaper acknowledged that, as one of NZ's official languages, Māori deserves equal status to English: "A basic first step toward that deserved level of mana $^{48}$ is using the language correctly". In their efforts to normalise macronisation, to aid New Zealanders' pronunciation of te reo, the paper accepted that there would inevitably be resistance from some of their audience - in particular, those wedded to the form of the word that they were accustomed to, even if incorrect. Notwithstanding, the paper believed that most Kiwis ${ }^{49}$ were mature enough to accept the need to use te reo Māori correctly.

The Dominion Post newspaper continued to enhance the visibility of te reo Māori during Matariki celebrations ${ }^{50}$ in 2018, when they re-worked their masthead from Dominion Post to Te Upoko o te $\mathrm{Kk}^{51}$, acknowledging the Māori legend associated with Wellington, NZ's capital city. The change to the masthead also coincided with Wellington City Council's launch of its Māori language policy and plan, Te Tauihu ${ }^{52}$. The council's vision is that, by 2040 (200 years after the signing of the Treaty of Waitangi), Wellington will be a city where te reo Māori is a core feature. To that end, landmarks around Wellington have been given Māori names e.g. Whairepo Lagoon (Frank Kitts Lagoon), Ara Moana (the waterfront walkway), and Te Ngākau (Civic Square). Furthermore, nation-wide, Māori names for places/landmarks are increasingly being restored - replacing (or appearing with) their Anglicised forms e.g. Aotearoa (NZ); Tāmaki Makaurau (Auckland); Aoraki (Mt Cook); Taranaki (Mt Egmont); Ōwairaka (Mt Albert). With the enhanced visibility of te reo, Māori are better able to see themselves reflected in NZ society.

\footnotetext{
${ }^{47}$ A macron is an orthographic convention that places a horizontal line above a vowel, to indicate the lengthening of that sound

${ }^{48}$ Prestige

${ }^{49}$ New Zealanders

${ }^{50}$ Matariki is the Māori name for the cluster of stars known as Pleiades, rising in mid-winter - a time for remembering the dead, celebrating new life and planning for the new year

${ }^{51}$ The head of the fish

${ }^{52}$ Named after the front part of a Māori canoe/waka that pushes through the water - as an analogy for the Council's commitment to the 2040 goal of te reo being a core feature of Wellington.

https://wellington.govt.nz/your-council/plans-policies-and-bylaws/policies/te-tauihu-te-reo-maori
} 
Māori Language Week 2018 heralded other innovations. There were live screens outside some Westpac banks showing Māori words and phrases to learn. The telecommunications company Spark launched an application called $\mathrm{Kupu}^{53}$ - enabling people to find out the Māori word for an object by taking a photo of it on their cell phone. In addition, there were signs at some bus stops showing the Māori language for directions. At the same time, the national airline, Air NZ, provided an on-board Māori language quiz.

Furthermore, the non-Māori Prime Minister of NZ, Jacinda Ardern, raised the visibility of Māori language and culture in a personal way by choosing a Māori name for her baby's middle name (i.e. Te Aroha, meaning 'love'). And, just prior to the birth, she chose to wear a kahu huruhuru (Māori feather cloak) when she attended a formal dinner to meet the British queen at Buckingham Palace.

This year (2019), Wellington's university also added more visibility and prestige to te reo Māori by renaming the institution Te Herenga Waka - after the name of its marae (meaning the mooring place of canoes).

The aforementioned actions are deliberate responses in society signifying, to the world, the special nature of Māori language and the richness of NZ's Indigenous culture.

\subsubsection{Efficacy of Māori language revitalisation}

Unfortunately, despite many initiatives instigated by Māori, the government and wider society to maintain and promote the language, its decline has not been arrested. This is despite a global shift in recent decades, among different Western societies, towards recognising minority languages (Norrby and Hajek, 2011). The Deputy Vice Chancellor (Māori) at Victoria University, Professor Rawinia Higgins, reiterated in her inaugural lecture (7 July 2015) that, despite many Māori language initiatives over the years, the language is still not thriving; in fact, it may even be regressing. Hence her emphasis on the need for Māori language planning to give due consideration to the two generations ahead, those who are not yet even born, to ensure the sustainability of Māori language revitalisation efforts.

The lack of accelerated progress towards revitalisation is evident in my own work as a Māori language adviser in English medium primary schools, where teachers' delivery of

\footnotetext{
${ }^{53}$ Meaning 'Word'
} 
Māori language programmes continues to be hampered by a lack of quality materials and suitable professional development (PD) opportunities. These issues are not new. As far back as 1981, attention was drawn to the dearth of adequate resources for the teaching and learning of Māori language (Benton, 1981). Benton believed that, compared with teachers of other languages, Māori language teachers had to be more resourceful - due to comparably fewer materials, and fewer opportunities for associated PD.

\subsection{Locating myself as a researcher | Ko wai tēnei kairangahau?}

This $\mathrm{PhD}$ goes beyond intellectual curiosity. I have chosen to explore a kaupapa that is driven by my own experiences (as explained in the Acknowledgements section). I therefore acknowledge that my values are inevitably imbued in the research - and I cannot be totally dispassionate. Nevertheless, the research has intrinsic worth with potentially beneficial implications. Moreover, social justice research suggests that we should indeed concern ourselves with this type of investigation.

I recognise that some people will be uncomfortable with my choice of topic. This mistrust arises from the fact that some of the colonists, whose behaviour impacted so adversely on Māori ways of being, were my ancestors, my tūpuna. Many of them would have lorded their sense of privilege and power over Māori, the colonised minority. This is a reality that brings shame, especially seeing that the British settlers promised that the Indigenous culture would be protected and the iwi would be treated as equals, through the Treaty of Waitangi.

Being Pākehā in NZ is associated with power, class, privilege, and superiority. Furthermore, the framework for our society is based on British society (e.g. the Westminster system of government and common law are geared to Pākehā cultural norms). Within this framework, Pākehā have been (and still are) afforded certain privileges (e.g. holding more positions of power in NZ companies and agencies; facing less discrimination in the workplace and in society at large; having majority representation on local councils and Boards of Trustees; being less welfare dependent; having fewer incarcerations; enjoying better housing, education and employment opportunities; having their language taught in schools without question; and being portrayed positively in the media). This is a reality in which many Pākehā people operate in our society. Too often they are unaware of the advantages afforded to them as the dominant group in Aotearoa NZ, because they have never had to think about it. 
Firstly, I acknowledge that this reality applies to many of my Pākehā contemporaries. Secondly, it is important for me to establish that my journey has been different to most Pākehā New Zealanders, in that I have chosen to gravitate towards te ao Māori - embracing the Māori language in particular. Due to my lived experiences, and in the spirit of whakaiti $^{54}$, I have become used to being with the minority (e.g. at Māori hui; in kapa haka; on the marae ${ }^{55}$; at Māori cultural events; as a mum at Kōhanga $\mathrm{Reo}^{56}$, and now $\mathrm{Kui}^{57}$ at Puna Reo ${ }^{58}$; and in tertiary institutions learning, or teaching, te reo and tikanga). These experiences have shaped my values, my worldview, and my heart. Although my identity remains Scottish, and I have a strong connection to my homeland, at the same time I feel connected to te ao Māori because, despite being Pākehā, some of my ways of thinking and being have become more Māori.

My entry into te ao Māori started in the early 1960s, as a ten-year old, when my family arrived here from Scotland on the Assisted Passage Migration Scheme for British citizens - a scheme designed to boost the population of Australia and NZ. We were part of the preferred migrant group contributing to the workforce here and we were known as the ' $£ 10$ poms' because that was the meagre cost of emigrating to $\mathrm{NZ}$ at that time. In the main, the families were working class poor.

As a 10-year old, I vividly recall my mother's heartache when we boarded the train in Aberdeen, Scotland - headed for Tilbury docks in London, bound for NZ, by boat, a fiveweek trip. She had to leave behind a married daughter and 10 siblings (including a twin sister). She never recovered from this heartache; and, although we created our own nuclear family here, Scotland was always her tūrangawaewae ${ }^{59}$. My family was ignorant of the history of Aotearoa NZ, and we were unaware of the sociocultural situation here, where British immigrants like us were afforded more privileges than Māori, the tangata whenua ${ }^{60}$. Thanks to new urban Māori leaders who emerged at this time in the 1960s (after the Second World War, as a result of Māori people drifting to the city), a spotlight was shone on Māori issues like the loss of land, language and culture; and differential educational achievement.

\footnotetext{
${ }^{54}$ Humility

${ }^{55}$ Space in front of a Māori meeting house, used for social or ceremonial gatherings

${ }^{56}$ Māori language pre-school

${ }^{57}$ Grandmother

${ }^{58}$ Māori language early childhood centre

${ }^{59}$ Place of belonging

${ }^{60}$ Local people/hosts; Indigenous people (of the land)
} 
We immigrated to NZ because of the hope of a better lifestyle. The government had promised improved prospects of employment. My father moved from being a chimney sweep in Scotland to working as a telephonist for the NZ Post Office (using skills he learnt during the Second World War). We settled in Tauranga, in the decile 1 suburb of Merivale, where we were given a Housing Corporation house - much superior to the state housing we had come from in Scotland. As fate would have it, that was one of the most significant events in my life because next door to us was a Māori whānau, the Laisons (originally from Taranaki). They had a very strong influence on me. Through them, from the age of 10-17, I learnt to value Māori language and tikanga. This was not the norm for a Pākehā child in the 1960 s.

I was the only child left at home with elderly parents, so the Laison whānau took me everywhere with them. I became, if you like, their whāngai ${ }^{61}$, their eighth child. Every weekend we would visit their kuia, Nanny Nicholas, in Omokoroa. She was initially unused to having Pākehā in her whare. Consequently, even though I was only a child, she would bring out her one crockery cup for me (while the whānau drank from enamel mugs) and she would send the teenagers down the road to buy Madeira cake (because that is what she thought Pākehā ate with cups of tea).

The Laisons would also include me when they went to collect kaimoana ${ }^{62}$. I learnt, by watching, that there were rules associated with this practice (e.g. saying a karakia ${ }^{63}$ to Tangaroa ${ }^{64}$ before entering the water; not eating the kaimoana on the beach; throwing back undersized seafood; taking only enough for the whānau).

My love of waiata ${ }^{65}$ came from them too - through parties in their garage, where there were various musical instruments (e.g. saxophone, ukulele, guitar and spoons). As a result of this experience, I have sustained a passion for waiata to this day, as demonstrated with my involvement in kapa haka.

Even though the Laison whānau shared knowledge with me, I accept that, as a Pākehā, I would likely have been treated, and taught, differently to how they engaged with each other

\footnotetext{
61 'Adopted' child

${ }^{62}$ Seafood

${ }^{63}$ Prayer

64 The deity with oversight of the sea

65 Singing/songs
} 
- due to my being an outsider and being in a position of relative privilege. For example, I would not have been subjected to the same level of accountability in terms of doing things right, according to tikanga. And allowances would have been made for me in terms of cultural transgressions.

Looking back, every step of the way seems to have been chartered for me ${ }^{66}$. I am now able to see the world through a different lens, a different window. I am able to come to situations, problems or issues with two perspectives. The gift of Māori language and culture that I have received, over nearly six decades, is not something that I take for granted, or treat lightly. Rather, it is something that I treasure. For me, te reo Māori has been a real bonus, which is what I want for my mokopuna. I want them to be able to participate comfortably in te ao Māori and te ao Pākehā, so that they can enjoy the benefits of both worlds and become proficient in both languages - which is a privileged position.

I come to this research with an extensive professional background in Māori language teaching (primary, secondary and tertiary), Māori curriculum development, Māori research, and Māori resource development. As a non-Māori learner (and teacher) of Māori language for over 50 years, I can identify with non-Māori teachers endeavouring to teach te reo in primary schools (i.e. my research participants).

In addition to working in various educational settings, I have worked in government departments. While at TPK, I learnt to better understand social issues affecting Māori, and the impact of policy decisions. I subsequently worked at the Ministry of Education, as a senior adviser, where my area of responsibility was the teaching and learning of Māori language in English-medium schools (Years 1-13) - in particular: the development of Māori language curriculum guidelines, the provision of Māori language advisors in schools (equipped with PD around second language acquisition), and the creation of Māori language support materials. My goal was (and still is) to encourage non-Māori teachers (like me) to embrace the teaching of te reo in English-medium classes - as a way of enriching all NZ children's learning and development.

I want to ensure that Pākehā privilege does not perpetuate into future generations. Instead, I hope that the next generation of Māori mokopuna will have their language, culture and

\footnotetext{
${ }^{66}$ More information is provided in the Acknowledgements at the beginning of this document - including the impact of marrying into a Māori whānau, and the influence of certain lecturers and mentors along the way.
} 
identity validated at school - to give effect to the vision of the Māori Education Strategy, Ka Hikitia (Ministry of Education, 2007a, 2013b); namely, that Māori students will enjoy and achieve education success as Māori.

Despite the call for non-Māori to contribute to Māori language revitalisation, as in the Crown's Māori Language Strategy, I am mindful of the delicate balance (for non-Māori like me) between wanting to play a role in that process and, at the same time, not crossing the line in terms of what is appropriate and acceptable action for non-Māori. As I am not of the Māori world, it is not for me to justify the position of Pākehā engagement in this space. I have no proprietary rights. Te reo belongs to Māori. However, I would like to contribute to Māori-led efforts (i.e. working alongside Māori to make real change in this area).

I see myself as a conduit for non-Māori teachers wanting to engage in te ao Māori. I acknowledge, however, that there will be reservations. For example, there is the risk of non-Māori doing a poor job teaching the language in English-medium primary schools because they lack the necessary confidence, resources, proficiency and second language pedagogy. This is why, in my current role as a Māori language adviser in schools, I try to overcome these barriers by working with such teachers to build their confidence, upskill their Māori language proficiency, introduce relevant resources, and equip them with knowledge around second language acquisition.

\subsection{Aim of this study | Te whāinga}

The reality is that most Māori children are enrolled in English-medium education (Statistics NZ, 2008). There is a dearth of literature around the teaching and learning of their heritage language in English-medium educational settings. Most of the research relates to Māori language in immersion or bilingual situations (McComish, 2004).

My aim is to contribute to research that will help strengthen Māori language teaching and learning in primary schools. This will be done initially through an online questionnaire, exploring 40 teachers' stated beliefs about the teaching and learning of Māori language generally, and Māori language materials specifically. Following on from this, I will conduct observations in the classrooms of four of those teachers, to see what realistically happens in their real-life context, with real learners. Thereafter, those same four teachers will be 
interviewed by me, giving them the opportunity to articulate their beliefs, while reflecting on their Māori language teaching practice during my observations.

My research is important, because it will provide a lever for whānau, so that they can expect/request that their tamariki and mokopuna in English-medium primary schools be given Māori language tuition, supported by quality Māori language materials (Chapters 2, 4). In addition, the research creates an evidence base for a strategic approach to the development of Māori language materials suitable for English-medium primary school classrooms (Chapters 4, 6, 7). Moreover, the research provides teacher participants with an opportunity to reflect on, and refine, their practice in terms of enacting their beliefs and using materials to enhance the teaching and learning of Māori language (Chapters 4, 5). And, importantly, the research has the potential to increase public support for non-Māori teachers, and the issues they face, when expected to teach Māori language in primary schools (Chapter 6).

\subsection{Research questions | Ngā pātai rangahau}

There are four research questions guiding this thesis:

1. What do non-Māori teachers working in English-medium primary schools believe about Māori language teaching and learning?

2. How are their beliefs enacted (or not) in the classroom (i.e. the consistency, or not, between their stated beliefs and actual practice?)

3. What are some of the factors that can influence primary teachers' attempts to teach te reo Māori?

4. What are the teachers' views about Māori language resources in Englishmedium primary schools - specifically:

a) existing Ministry resources,

b) future Māori language resource needs, and

c) the characteristics of quality Māori language resources.

The first research question explores the beliefs of 40 non-Māori primary school teachers working in English-medium settings, in respect of the teaching and learning of te reo Māori in those settings. The tool for gathering this data is an online questionnaire through Facebook. The second question examines how four of the 40 questionnaire respondents implement te reo Māori in their classrooms, with a view to determining the extent to which their stated beliefs are congruent with their actual practice. To achieve this, I conducted 
classroom observations (four per teacher). The aim of the third question is to ascertain some of the factors that can influence the teaching of te reo Māori. Although initially included as an optional response in the online questionnaire, this aspect was further investigated during 1:1 interviews with the four teachers - following my observations of them in the classroom. Finally, the fourth question focuses on Māori language resources (existing, future, and quality characteristics thereof). Initially explored in the online questionnaire, these aspects were further investigated during the 1:1 interviews with the four questionnaire respondents whom I observed.

\subsection{Chapter review | Tirohanga whānui}

In this chapter, I have outlined the historical facts leading to te reo Māori being adjudged by UNESCO as an endangered language - even though it is an official language of Aotearoa NZ, a taonga, and there have been many initiatives (community, government, and societal) to revitalise it. I have also introduced a counter argument associated with the 'language death' narrative.

The chapter set out the aim of the study - and the four research questions, which focus on:

- The beliefs of non-Māori teachers about te reo Māori in English-medium primary schools;

- Their classroom practices in relation to the teaching of te reo (noting the consistency, or not, between their beliefs and practices);

- Factors that can influence reo Māori teaching in English-medium primary schools; and

- $\quad$ Teachers' views about Māori language materials (existing and future) and about what constitutes quality.

I have also taken the opportunity in this introductory chapter to explain my personal motivation, as a non-Māori, for exploring the teaching and learning of te reo in Englishmedium primary schools.

Chapter 2 provides a review of relevant literature - specifically around the Māori language policy context; factors that can influence te reo Māori teaching; the complex relationship between experiences, beliefs and practices; and the formation of teachers' professional identity. 
Chapter 3 focuses on methodology. It begins with information on the aim of the research, the Māori values that underpin it, and an outline of demographic and ethical considerations that informed my sampling. The three methods used for data collection are discussed; namely, an online questionnaire, classroom observations, and teacher interviews. There is also information on my approach to data analysis.

Chapter 4 discusses the findings that emerged from the online questionnaire - and the insights gained from the beliefs expressed by 40 teacher respondents about the teaching and learning of te reo Māori in English-medium schools. This includes their qualitative comments on the external factors that can influence their teaching of te reo Māori. The chapter also provides demographic information, including the teachers' prior learning of Māori, their self-rated proficiency, and their comfort levels teaching the language. Attention is given to the characteristics of 'quality' in Māori language resources. The chapter finishes with respondents' views on their use of Ministry (and other) resources, and their suggestions about future reo resources.

Chapter 5 discusses the emergent findings from my classroom observations in respect of four case study teachers' current Māori language use in the classroom; opportunities for further use; teacher attitudes; students' prior knowledge; scaffolding; inclusion of tikanga; visibility of te reo in the classroom; and availability (and use) of materials. There is discussion around some of the observed consistencies and differences associated with transferring beliefs into classroom practice.

In Chapter 6, the findings that emerged from the interviews with the four case study teachers are discussed in relation to: their beliefs about te reo Māori; their views on the factors that can influence their teaching of the language; their use of Māori language resources; and their perspective on Māori student achievement.

Chapter 7 begins with a discussion on the potential contribution of my study. It then goes on to outline the theoretical and practical implications of my research, with associated recommendations.

In Chapter 8, I draw conclusions. The chapter starts by revisiting my position as a nonMāori researcher; the aim of the study; and the research questions. It is followed by a synthesis of the emergent findings, relevant to the beliefs and practices of the four case 
study teachers. The challenges and limitations of the study are acknowledged - and suggestions are made about future research possibilities. 


\section{LITERATURE REVIEW | TE TĀTARITANGA MĀTĀTUHI}

The purpose of this literature review is to set the scene and provide a context for the kaupapa of my research. The review also draws on relevant research to inform that kaupapa, identifying any gaps worthy of follow-up.

The chapter begins by setting the scene; that is, providing a background to the policy context (international, Aotearoa NZ-wide, and education-specific) that relates to the teaching and learning of Māori language in NZ schools. Within this policy context, there is discussion about the absence of a national languages policy - and the push, by many, for compulsory Māori language education in primary schools. Literature is cited that points to different factors that can impact successful reo Māori teaching. At the end of the chapter, there is a discussion on the relationship between teachers' experiences, beliefs and practices - and their professional identity.

\subsection{Te reo Māori within an international policy context}

Since 1966, the United Nations (UN) has emphasised that there should be social and institutional tolerance of individuals/groups choosing to use a language. This attitude of tolerance was extended by the UN in 1992 to accommodate the active provision and promotion of languages. In part, this shift was due to the ever-increasing rate of languages becoming extinct (Austin and Sallabank, 2011). It also reflected the acknowledgement that there are valid social and cultural reasons for people to maintain their languages, including personal identity and inter-generational transmission (both of which are relevant to Māori).

Article 13 in the Declaration on the Rights of Indigenous Peoples (United Nations, 2008, p. 7) states that "indigenous peoples have the right to revitalise, use ... and transmit to future generations their... languages." In addition, Article 13 puts the onus on the state to act accordingly to ensure that this right is protected. When applied to NZ, Articles 13-15 of the Declaration reinforce that it is the Indigenous right of every Māori child to live as Māori - as expressed through tino rangatiratanga ${ }^{67}$ in the Treaty, founded in NZ law in 1840. A similar sentiment is expressed in the NZ Bill of Rights Act 1990, Part 2, Section 20, which states that, "A person who belongs to an ethnic, religious or linguistic minority in New Zealand shall not be denied the right, in community with other members of that

${ }^{67}$ Autonomy/self-determination 
minority, ... to use the language of that minority" (Ministry of Justice, 2013). The provision of Māori language in schools is one way of preserving the Indigenous language of Aotearoa - in the interests of social justice.

\subsection{The Treaty of Waitangi and te reo Māori - he taonga \\ ... te Tiriti, he taonga tuku iho ... he whakapai i ngā nawetanga \\ ... the Treaty, a treasure handed down ... to right the many wrongs \\ (Ministry of Education, 2006)}

The importance of the Treaty for teachers and leaders is reinforced in the cultural competencies in Tãtaiako (Ministry of Education, 2011, p. 8) - under 'Manaakitanga'. This resource sets out the expectation that a registered teacher will be able to describe how the Treaty influences their practice in the classroom. An obvious acknowledgement, and enactment, of the Treaty is the inclusion of te reo Māori in the classroom, in recognition of it being a taonga under the Treaty. As suggested by a former Associate Minister of Education, the Hon. Dr. Pita Sharples, in his foreword to Tātaiako, we should see Māori language being validated and integrated across the curriculum.

In 2011, the Education Review Office (ERO) reported that the Treaty was poorly enacted in schools. As one solution, ERO suggested that schools should provide students with regular and planned opportunities to learn Māori language. Furthermore, in line with the aforementioned views of Dr. Sharples, ERO (2011) ${ }^{68}$ suggested the following as characteristics of a school where the Treaty principles are evident:

- Te reo Māori and tikanga are valued and promoted.

- Students are given the opportunity to learn Māori.

- There are established relationships with whānau.

\subsection{Relative status of English and Māori languages in Aotearoa NZ}

In 1984, the Māori Language Board took a pan-tribal claim (WAI 11) to the Waitangi Tribunal $^{69}$, to gain official status for the Māori language. The Tribunal recommended that te reo Māori be recognised as a taonga under Article 2 of the Treaty - to be protected by

\footnotetext{
${ }^{68}$ https://nzcurriculum.tki.org.nz/Curriculum-resources/NZC-Updates/Issue-16-January-2012

${ }^{69}$ A commission of inquiry charged with investigating claims brought by Māori pertaining to breaches of promises made in the Treaty of Waitangi. The Tribunal's recommendations and findings are not binding on the Crown, however
} 
government. As a result, the government acknowledged its neglect of te reo Māori. In its 1986 finding, the Tribunal emphasised that the health of te reo Māori was a matter of national concern, not simply a Māori issue - and it was government's responsibility to ensure that Māori were able to access the language (in line with the Treaty principle of (protection'). The government responded with redressive action, by passing the Māori Language Act 1987 (TPK and Te Taura Whiri, 2003). This meant that Māori became an official language of Aotearoa NZ, 'de jure'70 (in law) - although some would argue that this status is barely evident in practice.

Interestingly, English is not a legislated official language in Aotearoa NZ, but is attributed this status de facto, because of its predominance. It is the language of power (social, economic, and political). In contrast, te reo Māori, an Indigenous minority language, has been positioned as subordinate - as a result of Māori people having been subjected to political control (Liddicoat, 2007). According to Liddicoat, the Māori Language Act 1987 did not give te reo Māori equal status with English. Rather, the Act mainly focused on the use of Māori language in legal proceedings and in the delivery of selected government services - based on the assumption that Māori was not going to be the normal language for official use, and that English would continue to be used in most contexts.

Liddicoat (2007, p. 11) contends that only when minority language speakers have political autonomy will there be “... equality of provision, use or support”. Furthermore, he believes that the availability of a minority language within the school curriculum does not, on its own, mean that the language will be used beyond that context in the wider society. In fact, he suggests that it is possible for the prestige of the language to be further diminished if learners see no valued contexts for the use thereof beyond their schooling. This has implications for the teaching of te reo Māori, and the need for teachers to facilitate real-life learning contexts. It also has implications for schools, in that they need to emphasise the benefits of te reo Māori. Liddicoat claims that it is the positioning of the Indigenous group, in terms of the ability to exercise political control, that will have an effect on the relationship between the learning of a minority language at school and its subsequent application and value thereafter (Liddicoat, 2007, pp. 10-12).

${ }^{70}$ NZ Sign Language subsequently became an official language too, in 2006. 
Historically, Māori have had little influence politically - such that they have not always been invited to contribute actively to decision-making around the future of their language. Too often, decisions have been made on their behalf by government (Spolsky, 2003). This runs counter to the spirit of the Treaty principle regarding 'participation'. Liddicoat's summation $(2007$, p. 9) is that the “...recognition of Māori as an official language does not specifically give the language a role in education ..." - due to the elevated prestige and status of English relative to te reo Māori.

Some Members of Parliament (MPs) are attempting to rectify this imbalance by speaking Māori as much as they can inside the NZ House of Parliament (the House), thus raising its visibility and its status in the political arena - as verified in Hansard transcripts. One MP who does this often is Hon. Peeni Henare. In so doing, he reinforces the Governor General's 'speech from the throne' which states: "One of the interests of this government is to our Māori language" (Hansard, 2017). Henare questions how the House can possibly exemplify this ideal if most of its MPs are reluctant to speak te reo.

\subsection{Lack of a national languages policy in Aotearoa NZ}

Ka ngaro te reo, ka ngaro tāua, pērā i te ngaro o te moa.

If the language is lost, you and I will be lost, as lost as the moa.

(A quote from the Treaty of Waitangi and te reo Māori claim, Wai 11, 1985-1987)

In 1992, Jeffrey Waite created a landmark discussion document as a step towards an official national languages policy for NZ (Holmes, 1997; Spence, 2004; East, Shackleford, and Spence, 2007). The aim was to help raise the profile of languages in this country. Waite's report, Aoteareo: Speaking for Ourselves, acknowledged the diversity in NZ's 160+ languages. His top priority was Māori language revitalisation. However, Waite's proposed policy gained little political traction (Kaplan, 1993; Benton, 1995; Harvey, 2013). His call for a national languages policy was revived in 2005 at the NZ Diversity Forum, then in 2010 by the NZ Human Rights Commission, and again in 2013 by the Royal Society of NZ. These successive attempts acknowledged that there had been no progress towards a cohesive macro-level languages policy for Aotearoa NZ, despite the country becoming increasingly diverse. 


\subsection{Māori language-in-education policies and spending}

Language-in-education policies are important because they act as a lever to support language revitalisation efforts - especially in the case of minority or marginalised languages like Māori (Liddicoat, 2013). Such policies specifically aim to instil systematic language practices in educational settings (Shohamy, 2006) - with the responsibility falling on the classroom teacher to implement the policies.

Fishman (2001) highlighted that schooling has become 'the central thrust' in international efforts to reverse language shift. Hence the importance of quality Māori language teaching and learning in NZ schools. Indeed, Ministry of Education policies (discussed later in this chapter) acknowledge that schools have a significant role to play in arresting the decline of Māori language. Furthermore, due to the impact over time of government's social and economic policies that have adversely affected the ability of whānau, hapu and iwi ${ }^{71}$ to transmit their language inter-generationally (Waitangi Tribunal, 2011; Winitana, 2011), many whānau look to schools to support their children's Māori language development (Bright, Broughton and Hutchings, 2017). However, Spolsky (2007), a NZ-born linguist and educator, points out that the school is a complex domain. Teachers and students bring with them a range of beliefs and practices. Moreover, there is flexibility within each school on how to prioritise spending and what to include in the curriculum.

The Education Act 1989, (61 (3) (a) (ii)), requires each school to have a school charter, with a section providing assurance that all reasonable steps will be taken to make te reo Māori programmes available to full-time students whose parents ask for it. This is an attempt to recognise the unique position of Māori as NZ's Indigenous language, and an official language. However, the requirement is somewhat weakened by the fact that access to te reo is not necessarily a given; it is often precipitated by parental requests. Moreover, because schools have the flexibility to decide on their own priorities and spending, they can choose (or not) to use their operational funding in this area by, for example, buying Māori language resources and employing facilitators for reo Māori PD. The reality is that, across NZ primary schools, there are varying degrees of commitment to te reo - and many schools have insufficient funding to dedicate to the language, with spending priorities generally being directed to core subjects like literacy and numeracy.

\footnotetext{
${ }^{71}$ Families, sub-tribes, tribes
} 
It is acknowledged that the target audience for the provision of Māori language materials thus far has been the Māori-medium sector - which makes sense, in terms of favouring educational settings where te reo Māori is prioritised as the first language. Nevertheless, there is also a need for language planning that will create quality Māori language materials (print and multimedia) to support second language acquisition in English-medium schools - where most of our Māori students are being educated (and where too many are underachieving). A cautionary statement from the Waitangi Tribunal (2011, p. 167) is worth noting here; namely that, while giving priority to Māori interests, “... this must not mean the Crown reducing its focus on more "mainstream, 72 te reo resourcing. There is no future in an 'either/or' approach to funding if the language is to be protected." $M \bar{a}$ te huruhuru, te manu ka rere. (Birds can fly only with feathers.)

Budget 2018 recognised the need for more Māori language funding to upskill teachers. In a press release (17.5.18), Hon. Kelvin Davis MP announced that there would be an injection of $\$ 1.1 \mathrm{M}$ in $2017 / 2018$, plus $\$ 11.4 \mathrm{M}$ over the following three years, to lift teacher capability across the school system in terms of delivering quality Māori language education. This was clearly a response to the government's vision to increase the use of Māori language in early childhood centres and schools by 2025. Nearly a year later (April 2019), Davis launched a pilot programme, in four regions, to help implement that policy; namely, Te Ahu o te Reo Māori. The focus of the pilot is on interactive Māori lessons for 700 teachers (early childhood through to secondary) - to raise their comfort levels using Māori phrases with students. The intention is that, in each region, the programme will be co-designed by local iwi and the Ministry. At the launch, Minister Davis emphasised that the initiative contributed to nation-building - because of Māori language and culture being such a part of who we are as New Zealanders (Williams, 2019).

\subsection{Compulsory Māori language}

To recognise the historical suppression of the Māori language, the New Zealand Curriculum (Ministry of Education, 2007, p. 9) states that all students will have "... the opportunity to acquire knowledge of te reo Māori and tikanga Māori." However, despite being an official language of Aotearoa NZ, Māori is not compulsory in English-medium schools. The reluctance of successive governments to make the language compulsory could

\footnotetext{
${ }^{72}$ English-medium sector (where the majority of NZ students are educated)
} 
be attributed to many factors - including a lack of teacher confidence and proficiency, too few PD opportunities, a dearth of resources, the objections of some New Zealanders, and/or the Ministry's lack of a long-term plan.

For example, a long-term plan for compulsory reo Māori in primary schools would need to clarify expectations around:

- $\quad$ Frequency of tuition (e.g. Would there be a quantifiable number of minimum hours? Would the language be compartmentalised into a certain time slot on the timetable - or, ideally, integrated across the curriculum?)

- $\quad$ Teacher capacity and capability (e.g. Would the teaching of te reo be the role of specialists - or would all teachers upskill sufficiently through appropriate PD provided by the Ministry?)

- Monitoring (e.g. How would the quality of reo Māori teaching be monitored? By whom? And to what extent?)

In the absence of a national languages policy, there is ongoing debate about Māori language being compulsory in primary schools. There are proponents and opponents at both ends of the political spectrum, and indeed across society. Included in the public calls for compulsory Māori language in primary schools is the primary school teachers' union, the NZ Educational Institute (NZEI, 2018). In its policy working document, clause 17.1.6 (p. 37), the union recognises that te reo Māori is the responsibility of all teachers in all schools. Moreover, clause 17.5 .4 (p. 38) asserts that te reo Māori should be part of the core curriculum, with curriculum level 1 being a component in all schools, as a minimum. At the same time, in clause 17.6.1 (p. 38), the union emphasises the need for an investment of time and resources if this is to become a reality.

When NZ's new coalition government was formed on 27 October 2017, comprising three political parties (Labour, NZ First and the Greens), it announced its policy around the 'universal availability' of te reo in schools as a first step. The government's vision is that, by 2025 , the fundamentals of the language will be integrated into early childhood, primary, and intermediate school education (Hansard, 2018a). The reason for the protracted period is to allow for teacher upskilling in te reo Māori. Interestingly, the government avoids the use of the word 'compulsory'. In the House of Parliament, the Associate Minister of Education (Māori Education), Hon. Kelvin Davis MP, has provided assurance that teachers will be supported to increase their understanding of, and ability to speak, Māori - and also 
their ability to teach it. This assertion indicates that government recognises its important role in protecting and promoting te reo Māori (Hansard, 2018b). The NZ Principals' Federation president, Whetu Cormick, acknowledges that the government's plans are a step in the right direction towards a bilingual country - although he admits that the eventual goal is for te reo to be compulsory in each school (Walters, 2017).

Optimistically, Andrew Robb (a non-Māori journalist, former adviser to the Māori Party, and fluent Māori language speaker) suggests that it is feasible to expect a generation of Pākehā children who can speak Māori, having been brought up with the language (Robb, 2017). Robb believes that, if indeed Māori language is going to be taught in all schools, it should be taught by Māori - as a way of exercising tino rangatiratanga over te reo rangatira o tēnei whenua (i.e ensuring ownership and control of the chiefly language of this country). He therefore asserts that people like him, and me (and most of my research participants), who call for the teaching of Māori to be compulsory in primary schools, need to consider what Māori people themselves deem to be priorities for the revitalisation of their language.

Robb provides us with a salutary reminder of the potential tension between non-Māori supporters of the cause and Māori exercising autonomy - and the resultant implications for resourcing. He cautions that the well-intentioned desire for non-Māori tamariki to be taught Māori must not undermine Māori priorities for resourcing - lest we inadvertently threaten the right of Māori to make decisions about how to protect their language.

Notwithstanding the issue of resourcing, in the High Court recently there was an interesting judgement in the case of two parents who were separating. They disagreed over what type of school their daughter should attend (Parahi, 2018). The non-Māori father wanted her to go to an English-medium school, whereas her Māori mother wanted her to be educated in a Māori-medium setting. Judge Hinton used the Māori Language Act 2016 to guide her decision, ruling that the child should attend a school where there is instruction in both English and te reo Māori. At the same time, the judge indicated her stance on compulsory Māori language in schools by highlighting her consternation that, even in 2017, te reo Māori is not taught as a compulsory subject in primary schools. Such a bold statement from a member of the judiciary, from the highest court in the land, suggests that there may be a societal shift in attitude towards making te reo Māori compulsory in Aotearoa NZ. 


\subsection{Māori education policies}

In 2001, a Māori Education Framework was proposed by Professor Mason Durie at a Hui Taumata Mātauranga ${ }^{73}$. This framework (Durie, 2001) was adopted by the Ministry. It had three goals aimed at ensuring Māori educational advancement - the first of which had the most impact; namely, enabling Māori to "live as Māori (p.3)." The two underlined words were critical, hence their prominence in subsequent Ministry documents. Durie (2003) later elaborated that being able to live as Māori meant having access to the Māori world - and if, at the end of their schooling, a Māori youth was ill-prepared to participate in that world, their education would have been incomplete, regardless of other learning.

Durie recognised the inextricable relationship between tikanga Māori and te reo Māori, with Māori language being a conduit to the Māori world. Furthermore, he emphasised that the key to keeping young Māori engaged as learners was for their language and culture to be validated - thus providing a strong sense of identity.

Following on from Durie's work, the Ministry re-ignited its commitment to the teaching and learning of Māori language in English-medium settings, by developing a four-year strategy (2003-2007) to improve the quality of te reo Māori in English-medium schools (Years 1-13). The strategy focused on the development of the (draft) Māori language curriculum guidelines, the precursor to Te Aho Arataki Marau - with the addition of online support materials (Te Whakaipurangi Rauemi) and the employment of Māori language advisers in schools.

Thereafter, the Ministry introduced three main policies to acknowledge the importance of Māori language in education. The policies still exist. They are:

- $\quad$ Ka Hikitia (Ministry of Education, 2007a, 2013), the Māori Education Strategy, which includes the provision of quality Māori language programmes in schools (supported by a range of associated materials).

- Tau Mai Te Reo (Ministry of Education, 2013), the Māori Language in Education Strategy, which ensures that te reo Māori is prioritised in educational settings, including English-medium (with funds allocated for the development of materials).

\footnotetext{
${ }^{73}$ Māori Education Summit
} 
- Tātaiako (Ministry of Education, 2011), a set of cultural competencies that teachers need in order to help Māori students achieve.

These three policies are discussed below.

\subsubsection{Ka Hikitia}

The title of the Ministry's Māori Education Strategy, Ka Hikitia, means to step up, lift up or lengthen one's stride. Congruent with Durie's thinking, the vision of the strategy is that Māori students will enjoy, and achieve, education success - as Māori. My research contributes to Goal 6 of Ka Hikitia in terms of strengthening Māori language education research.

The education system has historically underserved too many Māori children. This is evidenced in OECD data (OECD, 2013), which describes large performance gaps between students - with Māori (and Pasifika) students being less likely to have positive outcomes. Hence the moral imperative to improve the situation. The broad aim of the Māori Education Strategy, therefore, is to transform the education sector and improve Māori student outcomes.

Figure 2.1: Two iterations of Ka Hikitia

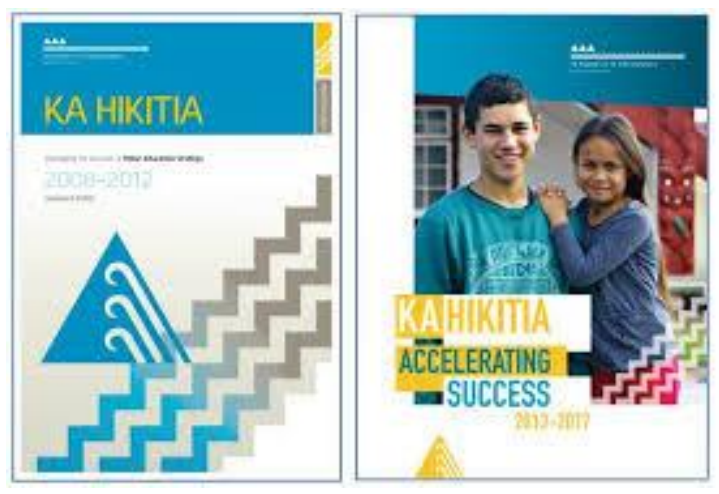

So far, there have been two iterations of Ka Hikitia (2008-12; 2013-17) ${ }^{74}$ - as depicted in Figure 2.1 above. Both iterations acknowledge the fragile position of te reo Māori and emphasise the importance of the language in the education system, such that all learners (Māori and non-Māori) should have access to high-quality Māori language teaching (and associated resources). The first iteration was aimed at enabling Māori students to reach

\footnotetext{
${ }^{74}$ During my study, the third iteration of Ka Hikitia was in development, but overdue
} 
their potential and enjoy education success as Māori. Being Māori was promoted as an advantage - not a deficit. The focus was on ensuring that Māori students received quality reo Māori teaching, had access to knowledge of tikanga Māori, and could improve their proficiency. Included in this focus was the need for a range of Māori language teaching and learning resources. In the second iteration of the strategy, the pace for bringing about change was accelerated - with four ways identified to achieve that. Three of these are particularly relevant to my research, namely:

1. prioritising the provision of Māori language resources, so they are targeted in areas most needed,

2. seeking ways to understand what is happening 'on the ground' (in my role as researcher, with access to teachers and classrooms), and

3. maintaining motivation by sharing examples of progress (in the dissemination of my findings).

\subsubsection{Tau Mai Te Reo}

Aligned with the above Māori Education Strategy, Ka Hikitia, is the Ministry's Māori Language in Education Strategy, Tau Mai Te Reo, 2013-2017 - as depicted in Figure 2.2 below.

Figure 2.2: Cover of Tau Mai Te Reo

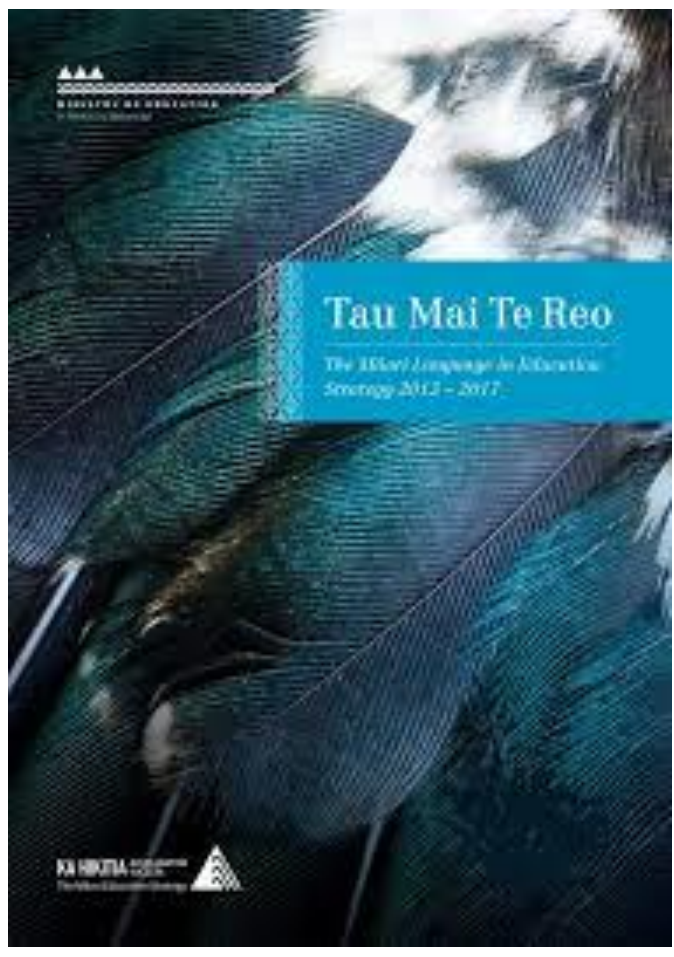


This strategy is also relevant to my study. It acknowledges that more research needs to be done in respect of Māori language in the English-medium sector - including what kind of support teachers need. One of the Ministry's priority actions is to “... develop and strengthen quality resource ... support for Māori language..." in that sector - so that “...learners are engaged in a range of language learning resources... geared to their particular needs and interests" (Ministry of Education, 2013, p. 37).

The aim of Tau Mai Te Reo is to ensure that te reo Māori is valued, properly considered, and prioritised in education - to contribute to Māori language use in homes and communities. Importantly, the strategy brings Māori-medium and English-medium schools under one language policy. This sends a message that the provision of Māori language in education is not solely the responsibility of the Māori-medium sector. Indeed, one of the four focus areas in Tau Mai Te Reo is to support Māori language in the English-medium sector - the target sector in my research.

A whakatauk $\overline{1}^{75}$ that appears in the strategy (p. 42) is particularly relevant in this context: "Kua takoto te mānuka. The leaves of the mānuka tree have been laid down." This proverb is a form of wero $^{76}$, a challenge emanating from a ritual performed on the marae, when visitors respond to a warrior's challenge by picking up leaves that have been laid on the ground - to indicate that they have come in peace. The analogy is that all teachers (including non-Māori primary teachers in English-medium settings) are being challenged to pick up the mānuka and do more to ensure the effective provision of Māori language for generations to come.

\subsubsection{Tātaiako}

Tãtaiako (Ministry of Education, 2011) sets out five cultural competencies that teachers need to develop, to help Māori learners achieve educationally, as shown below in Figure 2.3.

These competencies are aligned with the Standards for the Teaching Profession ${ }^{77}$ (Education Council, 2017), which have been implemented fully since January 2018. The

\footnotetext{
${ }^{75}$ Proverb

${ }^{76}$ Challenge

77 Previously known as Practising Teacher Criteria (2015) and, before that, Registered Teacher Criteria (2010), these standards set out the ethical behaviour expected of every teacher, describing the expectations of effective teaching practice (i.e. what it means to be a teacher in Aotearoa NZ)
} 
alignment is purposeful, to encourage reflection (and action) in respect of what constitutes a culturally competent teacher. The first of the six Standards, about Te Tiriti o Waitangi partnership, is particularly relevant to my research. It describes teachers' ability to practise and develop their use of te reo and tikanga Māori.

Figure 2.3: Cultural competencies for teachers, in Tātaiako ${ }^{78}$

\section{TĀTAIAKO COMPETENCIES}

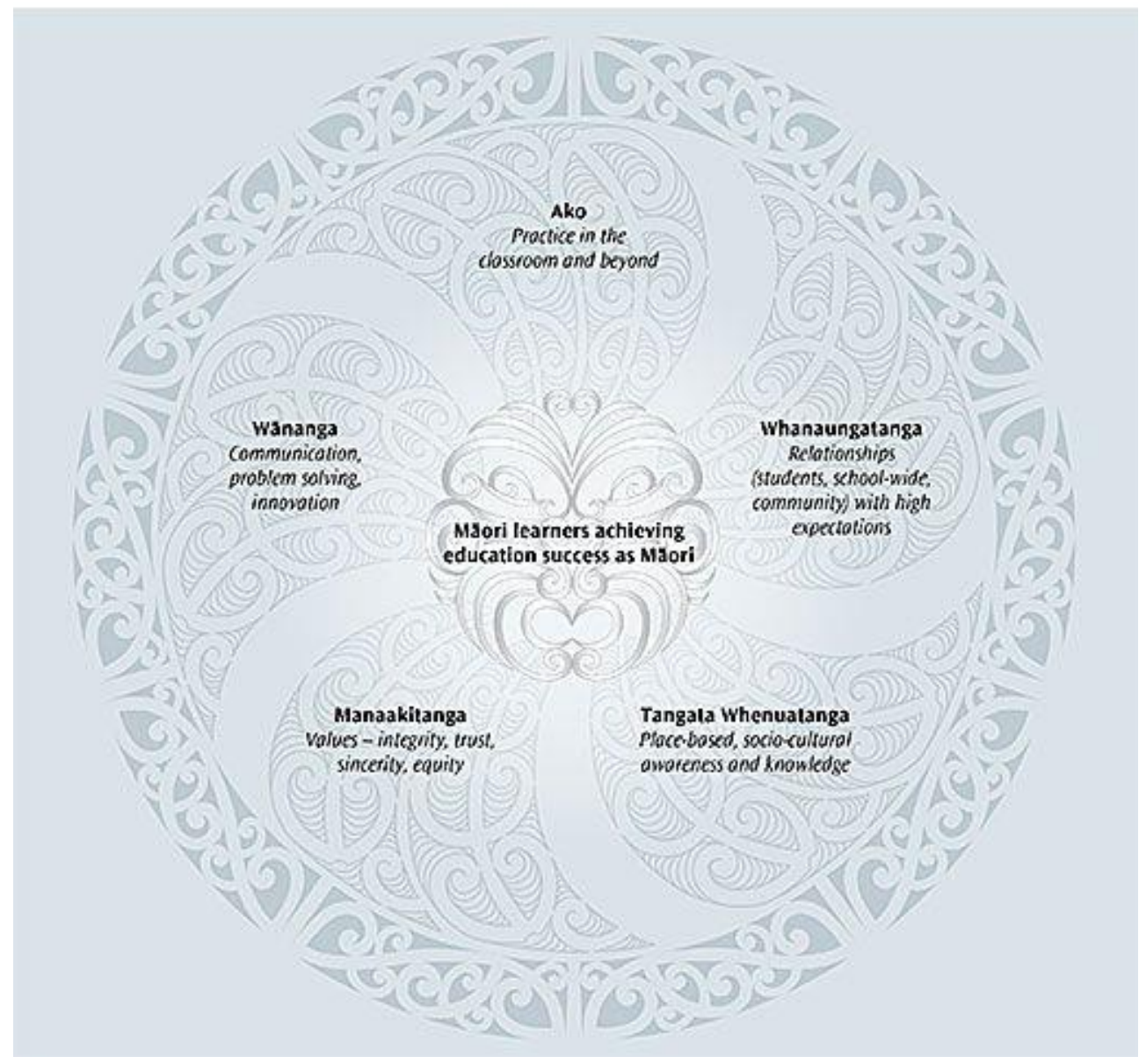

In Tãtaiako (Ministry of Education, 2011, pp. 8, 10) the use of Māori language in the classroom is specifically reflected in two of the competencies; namely:

- 'Manaakitanga' (showing respect for Māori beliefs, language and culture); and

\footnotetext{
${ }^{78} \mathrm{https}: / /$ teachingcouncil.nz/required/Tataiako.pdf
} 
- 'Tangata Whenuatanga' (providing contexts for learning - where the language, identity and culture of Māori learners and their whānau are affirmed).

My research informs teachers' progress towards these two competencies.

What is clear in the three policy documents described above (i.e. Ka Hikitia, Tau Mai Te Reo, and Tãtaiako) is the expectation that all English-medium primary school teachers will support their students to learn Māori language, as part of their delivery of the New Zealand Curriculum (Ministry of Education, 2007). This is highlighted in a proverb quoted in Tau Mai Te Reo (Ministry of Education, 2013, p. 6); namely: "He waka eke noa. A canoe that we are all in, with no exception." The vision is that, through exposure to quality Māori language in primary school, all students will value te reo Māori and enjoy the benefits associated with the learning thereof e.g: national identity; enhanced linguistic ability; knowledge of another culture; cognitive challenge; socialisation in different contexts; and career opportunities (Ministry of Education, 2009, pp. 13-14).

\subsection{Relationship between education policy and practice}

Curriculum documents set out the learning that needs to be achieved. Teachers in Aotearoa NZ are expected to put into practice what the Ministry sets out in its national curriculum, the New Zealand Curriculum (Ministry of Education, 2007). However, across different teachers, there may not be a consistent interpretation of the curriculum, due to the influence of teachers' underlying beliefs (Woods, 1996). It is possible that curriculum implementation could fail if those who mandate it do not give due consideration to what teachers believe and know (Barnard and Burns, 2012). Indeed, Schiffman (1996) contends that, too often, language planners focus on legislation, while ignoring associated cultural values and ideas that can influence teachers' implementation of the curriculum.

In the case of my research, the teaching and learning of Māori language in English-medium primary schools is influenced by teachers' beliefs and knowledge about curriculum-related matters such as: second language teaching methods; Māori language resources; assessment; implementation of the Māori language curriculum guidelines; place of grammar; and vocabulary-building. Progress in teaching te reo depends on teachers' openness to Māori knowledge and expertise. 
In research by Barr and Seals (2018), respondents report being unsure of how to implement Māori language in their English-medium classes. Although many acknowledge that it is their professional obligation, the teaching of te reo Māori takes them out of their comfort zone. They feel uncomfortable using the language. It is not their heritage language and, historically, there has been little regard for NZ's Indigenous language. Furthermore, because they do not identify as Māori, some of these teachers feel they do not have a right to it (Barr and Seals, 2018). The researchers therefore question the likely success of Māori language teaching when many teachers may be conflicted by having to construct (and model) an identity that is prescribed - in the face of their own personal beliefs, experiences and knowledge.

Despite the expectation in Aotearoa NZ to incorporate Māori language into the curriculum, framed in well-intentioned government policies (as outlined earlier), the reality that I have observed (as a Māori language adviser in schools) is that, while most teachers in Englishmedium primary school classrooms are open to learning, and are doing their best to incorporate Māori language into the school curriculum, they are faced with factors that get in the way of implementing an effective Māori language programme that will engage students and enhance their success in learning te reo Māori.

\subsection{Factors that influence the teaching and learning of te reo Māori}

In a survey of the literature on the teaching and learning of te reo Māori as a school subject, McComish (2004, p. 27) stated that “...there is no international body of research and materials development to draw on."

There is, however, some evidence from Aotearoa NZ highlighting factors that influence the teaching of te reo Māori. These include:

- $\quad$ the lack of quality reo resources, especially for Year 5 and beyond, and curriculum level 5 upwards (e.g. Ministry of Education, 2017);

- $\quad$ too little consultation with teachers on what Māori language resources are needed (e.g. TPK, 2001);

- the absence of second language instructional design in the development of reo Māori resources (e.g. ERO, 2007);

- $\quad$ non-Māori teachers' beliefs about Māori language teaching and learning (e.g. Barr and Seals, 2018); and 
- $\quad$ insufficient and inferior Māori language PD opportunities for teachers (e.g. Ministry of Education, 2018).

These factors are discussed below - as is the influence of teachers' own experiences.

\subsubsection{Lack of quality reo Māori resources}

The lack of quality resources can be disempowering for both teachers and learners. Indeed, it could be unhelpful (and perhaps even counter-productive) to introduce Māori language learning in primary schools if implementation is not supported by high-quality materials.

\subsubsection{Teacher resource needs}

In Aotearoa NZ, the policy position of the primary school teachers' union, NZEI, is that teachers and schools offering te reo Māori should be appropriately resourced, with special provision nationally (NZEI, 2018). If this was given high priority, it would be easier for teachers to integrate te reo into their classroom curriculum, thus promoting NZ's Indigenous language.

Research by Barr and Seals (2018) shows that some non-Māori teachers attempting to teach te reo in primary schools feel there is very little direct 'ground-up' support for them in the classroom (e.g. resources). Furthermore, an unpublished thesis by Jackman (2013) illustrates there is potential for student disengagement when there is a paucity of suitable Māori language materials (e.g. students complaining of having to do the same worksheets each year during Māori Language Week).

Similar concerns about the lack of Māori language resources were communicated by ERO in its 1993/4 annual report (Education Review Office, 1994c). Additionally, during the launch of Māori Language Year in 1995, the Chief Executive of TPK specifically bemoaned the lack of Māori language resources, which he believed was an area requiring special attention (Benton, 1995). Likewise, in a discussion document presented at a Hui Taumata $^{79}$ in Wellington, the linguist Dr. Mary Boyce (1995) pointed to the fact that the good intentions of Māori language learners were being undermined by a dearth of materials.

Similarly, Christensen (2001), in his PhD dissertation on Māori language revitalisation, referred to other researchers who had highlighted the paucity of Māori language resources.

${ }^{79}$ Māori Summit 
They included Spolsky (1989), Hirsch (1990), Fairhall and Shuker (1994), and Hohepa \& Smith (1996) - all of whom were critical of the Ministry's slow response to the demand for Māori language resources. The then Secretary for Education, Dr. Maris O'Rourke, acknowledged the need for the Ministry to increase its production of Māori language materials, to promote the expansion of the language (Benton, 1995). Such a dearth reflected a lack of institutional investment, where insufficient recognition had been given to the mana ${ }^{80}$ associated with te reo Māori.

\subsubsection{Characteristics of quality reo resources}

Research by McKinley, Christensen, Black, and Richardson (1996), and Christensen (2001), is especially relevant to my fourth research question - about the characteristics of quality Māori language resources. Both studies recommended that Māori language resources needed to be simple enough for teachers (and their students) to make meaning, while at the same time interesting enough to capture students' attention.

ERO (2007), in its review of materials to support the teaching and learning of Māori language, agreed with these researchers. The ERO report emphasised that teachers' practice (and, by association, student achievement in te reo) was limited by the dearth of Māori language resources in schools. Furthermore, ERO flagged two areas outside the scope of their investigation but nevertheless in need of further research; namely, canvassing teachers' views on what reo materials they need/want in the future, and seeking their opinions on what they regard as quality Māori language materials. These two gaps in ERO's investigation are therefore explored in my study - in Research Question 4.

The NZ researchers, McKinley et al. (1996), reviewed Ministry of Education and commercial resources designed to facilitate the teaching and learning of te reo Māori. They found that too many of them were inferior due to inaccurate grammatical structures, errors in macronisation, sub-standard translations, and inappropriate images. In addition, there was poor content (and curriculum) coverage. In response, the researchers set down a list of criteria for Māori language print materials - to ensure they were of a comparably high standard to English resources. These quality criteria (which I have elaborated on below, in parentheses) are still relevant today. Moreover, most of them can easily be applied to other media. They are:

${ }^{80}$ Status 
- Inclusion of real-life contexts relevant to students (described in TPK's 2001 audit as being suitable for 'te rangatahi a tēnei ao hurihuri' i.e. the youth of today),

- Accuracy of Māori language structures (to expose learners to good language exemplars),

- Use of correct Māori orthography e.g. macrons, spelling (to preserve the form of the language and help pronunciation),

- Appropriateness of visuals (to capture attention, support the text, convey mood, and avoid stereotypical representations of Māori people),

- Inclusion of Māori tikanga/values/beliefs/perspectives (to reinforce Māori knowledge),

- $\quad$ Alignment to the curriculum (to make links to the achievement objectives in the Ministry’s Māori curriculum guidelines),

- Appropriateness of language, in terms of level of difficulty and different age groups (to engage students),

- Availability of user-friendly teachers' notes (to guide teachers on how to maximise the resources in a range of ways), and

- Accuracy of English translations (to help those teachers, and whānau, for whom Māori is a second language).

Conversely, in the Ministry's unpublished review (2008) ${ }^{81}$ of a levelling framework for basic Māori language readers (Ngā Kete Kōrero series), Māori-medium teachers described undesirable characteristics as being resources:

- $\quad$ lacking a storyline,

- $\quad$ containing grammatically incorrect language,

- using non-Māori turns of phrase,

- $\quad$ having a high vocabulary load,

- $\quad$ using English concepts as a basis,

- $\quad$ focussing on grammar structures, and

- $\quad$ having poor illustrations.

\footnotetext{
${ }^{81}$ Although unpublished, this review is known to me because I was involved in writing the report to the Ministry, contracted by Huia Publishers
} 
In 2016, the views of some English-medium teachers were surveyed at a NZ Literacy Association (NZLA) conference in Waitangi, September 25-28, 2016. A publisher of Māori language resources, Sharon Holt, conducted a written survey of 55 primary school teachers (mainly non-Māori) about their needs regarding reo Māori print publications for Englishmedium primary classrooms. The findings showed that these teachers wanted print materials that:

- were user-friendly, in terms of the language being commensurate with their basic level of reo Māori proficiency,

- had an audio component (as an aid to pronunciation), to complement the written,

- contained child-centred stories, to engage students,

- $\quad$ provided ideas for follow-up language activities/games, suitable for differentiated learning, and

- $\quad$ explained simple sentence structures.

A year later, the Ministry of Education (2017) summarised teachers' views on what constitutes a good Māori language resource - in terms of stimulating student interest and facilitating teacher use; namely:

- Relevance and appropriateness,

- Visual appeal,

- Durability,

- Currency (including real-life contexts),

- Accuracy of te reo,

- Inclusion of a glossary,

- $\quad$ Potential for multiple uses, and

- Inclusion of support materials (e.g resource sheets; teachers' notes).

And in the same year, 2017, CORE Education (Core) ${ }^{82}$ produced an evaluative summary paper on effective Māori resources. Although aimed at Māori-medium settings, some of the findings are applicable to the English-medium sector. For example, the need for materials to:

\footnotetext{
${ }^{82}$ Specialists in developing innovative e-learning environments. Henceforth, described as Core
} 
- $\quad$ reflect tikanga Māori i.e. 'strongly founded upon whakaaro Māori'83 (p.4),

- $\quad$ align with the curriculum, and

- $\quad$ include ideas about how to use the resource in multiple ways, to maximise a range of learning opportunities.

As is evident across the aforementioned pieces of research, there are generic criteria of quality Māori language resources (e.g visual appeal; real-life contexts; inclusion of tikanga; audio support; curriculum alignment; user-friendliness; teachers' notes; English translation/glossary; multimedia). I therefore used these generic criteria (albeit modified) as a basis for my online questionnaire, when asking teachers to rank characteristics of quality in order of importance (Question 28, Appendix 5). From that data, I derived the top three criteria of quality across all questionnaire respondents $(n=40)-$ and across the case study teachers selected from that pool, whom I subsequently observed and interviewed $(\mathrm{n}=4)$. This is further discussed in Chapter 3.

\subsubsection{Resources to stimulate student interaction}

McKinley et al. (1996) emphasised that quality Māori language resources should provide a stimulus for students' interaction in, and practice of, te reo Māori. This is necessary in taskbased language teaching (TBLT), a learner-centred approach promoted in the Ministry's Māori language curriculum guidelines, Te Aho Arataki Marau (Ministry of Education, 2009). Adopting this approach, teachers create opportunities for their students to practise communicating in the target language, by doing interactive tasks (Willis and Willis, 2007). Tomlinson (2011) supports the need for resource developers to provide learners with such authentic, contextualised language input - to help facilitate student output.

\subsubsection{Importance of print materials}

Interestingly, Core (2017) found that teachers wanted to retain traditional media, to complement IT. They recognised that a blended approach (i.e. using both digital and physical media) would allow more flexibility in accommodating students' different learning needs and teachers' varied teaching methods. Similarly, Ministry-commissioned research on Māori language resources in schools (Ministry of Education, 2017) reported that teachers were not keen to limit resources to digital platforms; they wanted complementary print and digital resources. This concurred with the research findings of

\footnotetext{
${ }^{83}$ Māori thinking/thoughts
} 
McKenzie (2014), where teachers voiced the need for more print material to be developed for Māori language teaching and learning, in addition to digital formats.

Holliday (1994) emphasised the importance of printed books as a source of language input - because they enable the learner to interact with text and then make useful deductions about how the target language works. Likewise, Elley's research (1991), where second language learners were exposed to 'book floods', highlighted the effectiveness of intense exposure to printed texts - such that learners showed gains in literacy (twice the normal rate), vocabulary, grammar knowledge, reading and writing.

The importance of printed resources in the target language (including graded instructional readers) has also been emphasised by Professor Rod Ellis - as a way of providing extensive second language input (Ellis, 2005a). Furthermore, a Massey University study, Te Hoe Nuku Roa (Durie, 1995), reported that one of the barriers to the increased use of Māori language was access to Māori language reading material. Adult respondents in the study were disappointed at the lack of reo Māori reading resources. Indications were that, if a range of reading materials was provided at various levels of complexity (including preschool and primary school readers at the emergent level), adults would indeed read more Māori. Similarly, research by Core (2018) indicated that teachers wanted resources that would develop the Māori language capability and cultural knowledge of the whole whānau, thus enhancing home:school relationships and supporting the inter-generational transmission of te reo. This would have obvious benefits for whānau:child reading experiences at home.

In the face of the above research advocating print materials, it is perhaps incongruous that only $10 \%$ of the Ministry's Māori language resources for the English-medium sector are in print, with $87 \%$ being in digital form (Ministry of Education, 2017).

\subsubsection{Little consultation with teachers regarding resource development}

As well as a lack of quality Māori language materials, there is a second obstacle in the teaching and learning of te reo; namely, the failure of many resource developers to consult with teachers, the end-users. McKinley et al. (1996) recommended the trialling of new Māori language resources in the classroom, prior to their publication, to ensure that resources were fit for purpose and audience. Additionally, TPK's audit in 2001 (precipitated by concerns from ERO, and teachers, about the inadequacy of materials to 
support the teaching and learning of Māori language in schools) found that there was limited curriculum coverage in the materials that had been produced. The audit recommended that there should be comprehensive consultation between resource developers and teachers, so that end-users could suggest ideas for new materials and provide feedback on materials they received. This need for teachers to evaluate materials is supported by Parr, Aikman, Irving, and Glasswell (2004) and Ellis (2005a) - but, as acknowledged by Tomlinson (2011), there is scant research in this area.

In TPK's audit above (2001), very few of the participant teachers reported having been involved in the development of Māori language resources. Due to this lack of consultation, they felt that the Ministry of Education's development of resources was 'hit and miss'. The audit found that there was a mismatch between materials being produced and teachers' needs/students' interests (p. 3 in Cabinet Minute SEQ (01) 111). Some teachers lobbied for the Ministry to produce a strategic long-term publication plan that accommodated the Māori language needs of schools. Moreover, many were reportedly producing their own materials - and sharing them with peers. The TPK audit concluded that value for money would only be achieved if Māori language resources were well-matched to teachers' (and students') needs.

To that end, in my study, the opinions of non-Māori primary school teachers in Englishmedium settings were sought - in terms of the types of resources they needed.

\subsubsection{Lack of second language instructional design in resource development}

In addition to the lack of quality Māori language materials, and little consultation about the development thereof, there is a third obstacle; namely, the failure of many resource developers to integrate second language instructional design into their resources. Tomlinson's view (2011) is that, to create pedagogically sound materials, developers should consult second language acquisition researchers about how language learning occurs. Although critical of resource developers for not doing so, he is also critical of second language researchers. He believes they have too often focused on theories, while failing to research the development of resources to support those theories. Research by Prowse (2011) and Tomlinson (2003) suggests that second language resource development can be ad hoc (as highlighted in TPK's audit in 2001 in respect of te reo Māori) and/or largely guided by developers' intuitions, with no evidence base. 
Similarly, ERO (2007), in its review of curriculum materials supporting Māori language, agreed that current second language theories should inform the future development of reo Māori resources. This is important in the NZ school context because the reality is that there are far more second language learners of Māori than native speakers ${ }^{84}$ (Christensen, 2001). Both Ratima and May (2011) and TPK (2001) acknowledge that there is some way to go in resource development, to accommodate the bulk of primary school students and teachers for whom Māori is a second language.

Most teachers have little (or no) knowledge of theories and practices associated with second language teaching and learning. This issue was raised more than fifteen years ago by lecturers at Waikato University (Crombie and Johnson, 2001), in their analysis of the then Māori syllabus for primary schools, Tihē Mauri Ora (1990). Similar views were outlined in the Ministry's Māori Education Strategy, Ka Hikitia 2008-2012, which recognised the need for knowledge of second language teaching to enhance teachers' ability to teach te reo Māori as a second language. One of the priorities for action in that strategy was to "... consolidate and build evidence around second language teaching, to enhance the effectiveness of PD programmes and lift the quality of teaching te reo Māori as a second language" (Ministry of Education, 2007a, p. 34).

There is a problem, however, in that there is no single agreed theory of second language acquisition - and no consensus among researchers regarding the main pre-requisites of successful second language learning (Ellis, 2005b). This is because second language acquisition is a relatively new field (having started in the late 1960s), and it is a complex phenomenon. Nevertheless, Tomlinson (2011) believes there are enough commonalities across researchers to arrive at a set of general second language acquisition principles relevant to the development of resources. I have taken the liberty of adapting these principles, as follows.

\footnotetext{
${ }^{84}$ While a misnomer (as there is no single native speaker 'gold standard' in actual social language use i.e. there is variation), I have used this term because it is the common way that people tend to talk about language. The term is also included in my Belief Statements (Appendix 5), which were constructed using language that would resonate with teachers
} 
Learners need to be exposed to resources that:

- $\quad$ engage them affectively (to stimulate their curiosity, interest, attention and wairua ${ }^{85}$ ) and cognitively (to encourage deep processing and longlasting learning);

- $\quad$ lead them to implicitly 'notice' salient features about the target language (rather than the teacher continually providing explicit information about the form of the language);

- $\quad$ stimulate opportunities for them to 'output' the target language in authentic contexts (to enhance their ability to communicate appropriately, fluently and accurately); and

- contain sufficient examples of authentic, contextualised language that enable them to extract meaning (described in 1985 by Krashen as 'comprehensible input') i.e. where the learner can understand most of the content, despite the purposeful inclusion of some features slightly beyond their existing proficiency - which the teacher can 'scaffold' (with the aid of teachers' notes if necessary).

According to Krashen, the main goal of language learning resources is to make second language activities in the classroom as meaningful as possible, by providing a real-life context to help learners understand and acquire the target language (Krashen and Terrell, 1983). Such resources could include: simple readers, games, realia, pictures, timetables, menus, recipes, cartoons, newspapers, brochures, advertisements/notices/pānui, maps, letters, family trees, dialogues, interviews, surveys, role play/ drama, games and songs/waiata.

Tomlinson (2011) reminds us that second language learners need to be able to use resources without too much difficulty. Moreover, they must enjoy using the resources (notwithstanding that enjoyment is not in itself suffice), and they need to see themselves reflected in the resources.

\subsubsection{Non-Māori teachers' beliefs}

Aside from there being a lack of Māori language materials, poor consultation about the development thereof, and little consideration of second language instructional design, there

${ }^{85}$ Spiritual side 
is another potential obstacle; namely, teachers' personal beliefs, which can influence their teaching practices. For example, as exemplified in my online questionnaire, many nonMāori teachers feel uncomfortable teaching Māori language. And in earlier research by Renwick and Vize (1992), interviews with 300 teacher trainees prior to graduation showed that Māori language was one of three areas that the graduands were least looking forward to teaching - and felt the least prepared for.

As already stated, there is a gap in the research in terms of exploring non-Māori teachers' beliefs and practices in relation to the teaching and learning of Māori language in primary school classrooms generally - and the use of suitable Māori language materials specifically. This is a sector where $93 \%$ of teachers are non-Māori. (Personal communication with Matthew Gibbons, Ministry of Education, 6 April 2017). They are expected to integrate Māori language into their classroom programme - so that it becomes visible and regularised. Such regularisation in schools is supported by Higgins (2015), a board member of Te Mātāwai (the independent statutory entity charged with revitalising Māori language), because of the resultant contribution to wider Māori language revitalisation efforts. Indeed, the regular use of a minority language like Māori promotes its prestige and value, which is described by Bourdieu (1986) as its 'symbolic capital'. Moreover, regularisation helps to compensate for the historic dominance of the English language (Heller, 1995).

However, most English-medium primary school teachers have insufficient confidence, proficiency and resources to fulfil the expectation set down in the elaboration of the first Standard for the Teaching Profession, in terms of practising and developing their use of te reo and tikanga Māori (Education Council, 2017). There is therefore a gap between expectation and implementation; between policy and practice - as evidenced in my firsthand experience working as a Māori language adviser in schools.

Faced with the expectation of having to use Māori, their lack of proficiency can make English-medium teachers feel uncomfortable, embarrassed, or anxious. They are aware of their often-poor pronunciation and are concerned that their efforts may be deemed a token gesture only. They feel awkward about their meagre attempts to use Māori. Moreover, as already mentioned, some feel inhibited by the fact that they are not the legitimate owners of the language (Barr and Seals, 2018). Beliefs about lack of ownership can impact adversely not only on a teacher's motivation to integrate Māori language (and culture) into their classroom programme but on Māori language revitalisation efforts generally. 
The research of Barr and Seals (2018) revealed that one reason for the mismatch between teachers' beliefs about the need to teach Māori language and their subsequent classroom practice was poor access to Māori language teaching materials. This was exacerbated by the proficiency level required to tackle existing Māori language materials distributed by the Ministry to schools, which the English-medium teachers found daunting because they were designed for the Māori-medium sector.

The reality is that English-medium teachers in primary schools are being challenged to do more, as part of their professional skill set, to ensure the effective provision of Māori language in those settings. Stewart (2014) argues that high-quality materials are imperative to support teachers in this challenge - and that such materials need to be accessible and manageable for English-medium teachers and students.

\subsubsection{Insufficient and inferior professional development opportunities}

In addition to the obstacles already mentioned (i.e. the dearth of suitable quality materials, little consultation with teachers, lack of instructional design, and teacher beliefs) is the challenge faced by English-medium teachers due to their low level of Māori language proficiency. Inevitably this impacts (negatively) on their students' proficiency, as evidenced in my own observations as a Māori language adviser in schools. There are too few quality PD opportunities to help teachers upskill their ability and access the available materials. This is borne out in the NMSSA programme (Ministry of Education, 2018, p.78) where English-medium teachers (Years 4 and 8) were asked to provide overall ratings of the in-school professional support they had received to teach Māori language. On a fourpoint scale from 'very poor' to 'excellent', only $28 \%$ of Year 8 teachers and $44 \%$ of Year 4 teachers rated their professional support as 'good' or 'excellent'. This is not a resounding vote of confidence in reo Māori PD provision.

The lack of timely and relevant PD to help teachers use the Ministry's Māori language resources was criticised by TPK in its audit (2001), which highlighted insufficient support for teachers around using the resources. To that end, TPK recommended that the Ministry should align its PD programmes more closely with the release of new resources. A few years later, ERO (2007) suggested there was still a likely correlation between teachers' ineffective use of Māori language resources and the lack of associated PD. Similarly, the Ministry of Education (2017) exposed the need for PD to be factored into the release of new materials in the English-medium sector. 
Materials, and associated PD, are particularly needed to support the implementation of two core Ministry resources for the teaching and learning of Māori language in primary schools (the publication of which has undoubtedly increased the demand for support materials). These two core materials are the Māori language curriculum guidelines for Years 1-13, Te Aho Arataki Marau (Ministry of Education, 2009) and the multimedia resource for Years 1-6, He Reo Tuри He Reo Ora ${ }^{86}$ (Ministry of Education, 2011).

The former document is particularly relevant to my third research question about factors that can influence classroom practice in the teaching of te reo. These curriculum guidelines provide the foundation for all teaching and learning of Māori language in English-medium schools in Aotearoa NZ. They help teachers to plan and implement effective Māori language programmes, across eight levels of achievement. In addition, they provide some evidence-based information on the teaching of second languages per se. The latter document, He Reo Tupu, supports the Māori language curriculum guidelines. In research by Core (2018, p. 8), He Reo Tupu was described as 'a model resource' - because it was practical, easy to use, and was available online with multimedia aspects (including video examples of te reo Māori being used). Moreover, the resource could be easily adapted to the various needs and reo abilities of both students and teachers. As such, it was one of the Ministry resources most commonly used by the English-medium teacher respondents in Core's research.

\subsubsection{Influence of teachers' own experiences}

The beliefs held by teachers are partly a product of their socialisation in the education system i.e. firstly as school students, then in their pre-service and in-service teacher education (Pajares, 1992; Sercu and St. John, 2007; Holt-Reynolds, 1992; Mockler, 2011; Palmer, 1998; Johnson, 1994). These researchers concluded that teachers' own language learning experiences influenced their beliefs - and that their beliefs about the 'right' way of teaching were based on their past life experiences. That is, "We teach the way we were taught" (Barnard and Burns, 2012, p. 106). In the words of Borg (2006, p. 35), teachers' beliefs are "... defined and refined on the basis of educational and professional experiences throughout teachers' lives." Johnson (2006) adds that, by understanding the influence of teachers' earlier (good or bad) experiences as learners, we can provide better PD support.

\footnotetext{
${ }^{86}$ Referred to hereafter as He Reo Tupu
} 
Lortie (1975) describes personal experiences of learning as an apprenticeship of observation, which initially occurs during schooling. Included in this apprenticeship are notions about what constitutes an effective teacher and how students should behave. Freeman (1992) claims that the experiences and memories of one's own schooling become de facto guides for teachers when they are making decisions about what to do in the classroom. This is potentially why many of the teachers in research conducted by the Ministry of Education (2017) were reportedly still using resources that they themselves had encountered as students of te reo Māori (e.g. Te Rangatahi textbooks) - because they felt more comfortable and confident doing so, especially in the absence of quality PD.

In Richardson's review (1996) of a collection of teacher cognition studies, focussing her attention on the role of beliefs in pre-service teacher education, she claimed there were three aspects that influenced the development of a person's beliefs and knowledge about teaching. Two of these are particularly relevant to my study; namely:

- a person's experiences of life (including those experiences outside teaching), and

- a person's experiences of learning (e.g. being a student or teacher trainee), which aligns with Lortie's views (1975) on the apprenticeship of observation.

Similarly, in another teacher cognition study of pre-service education, Johnson (1994) found that the decisions made by teacher trainees during their teaching practicum were influenced by their own experiences as second language learners - in terms of (for example) the materials they used, the activities they facilitated, and their general classroom organisation. She described how her most compelling finding was the "... apparent power that images from prior experiences within formal language classrooms had on these teachers' images of themselves as teachers and their perceptions of their own instructional decisions" (Johnson 1994, p. 449). She reported (pp. 445-456) that teacher trainees “... judged the appropriateness of ... materials in terms of their own first-hand experiences as second language learners."

Likewise, in research by Numrich (1996), the diaries of 26 pre-service teachers revealed that their decisions about whether to take up, or avoid, certain teaching strategies were based on their own experiences (positive or negative) of those strategies when they were learners. For example, they were generally positive about integrating cultural aspects into 
their teaching but not so the teaching of grammar, due to their respective favourable and unfavourable learning experiences of those two dimensions.

Based on the literature, the teaching of Māori language in NZ primary schools may well be influenced by how teachers themselves were taught Māori (e.g. at school, during teacher training, or through in-service PD). This view encapsulates the concept of $a k o^{87}$, with its associated implication of there being a reciprocal relationship between teaching and learning in the classroom (i.e. between teacher and students). The Ministry is increasingly recognising the mutual benefit of an environment where the thinking and behaviour of one party (e.g. teacher) affects the other (e.g. students), and vice versa (Pennington, 1992). For example, NZ teachers are encouraged by the Ministry to recognise, validate and learn from the knowledge and cultural capital that their students bring to the classroom, in the spirit of ako.

In my study, I have extended the notion of ako to include the importance of teachers' experiences both as learners and as teachers - as suggested by Borg (2003, 2006). As learners, their prior experiences (in whānau, early childhood, schooling, pre-and in-service teacher education) would have influenced their beliefs. Equally, their subsequent experiences as teachers would have impacted on their beliefs.

In seminal work, Clark and Peterson (1986) claimed that beliefs influence behaviours, while at the same time being influenced by behaviours. Their model acknowledged a mutually informing interaction (Beach, 1994; Woods, 1996; Borg, 2006; Tabachnick and Zeichner, 1986). That is, the relationship between teachers' beliefs and their practices is two-way, with one informing the other, such that teachers' beliefs will influence their behaviour in the classroom; and, conversely, their classroom practice will further shape their beliefs (i.e. another form of $a k o$ ).

Hence my investigation of both teachers' beliefs (in the online questionnaire) and their actions (during classroom observations) - due to the inter-relationship.

\footnotetext{
${ }^{87}$ A concept that describes the notion of reciprocity in a teaching and learning relationship (including the teacher as a learner)
} 


\subsection{Teachers' professional identity}

The notion of identity is relevant to my study in that research shows a relationship between a teacher's beliefs/practices and their identity - in terms of how they perceive themselves professionally. Pennington (1999) reminds us that a teacher is not only a teacher; they have multiple identities (e.g. colleague, parent, partner, friend etc). Their different experiences in those roles shape their beliefs and classroom practices. That is, identity is not fixed; it is influenced by one's experiences. Supporting this social constructionist approach to identity, Richards (2017) emphasises the role played by social processes (i.e. interaction with others) in shaping a teacher's professional identity.

Like Woods (1996), Richards claims that each person has two different identities - based on a set of values and beliefs. The first is an 'aspirational' (or ideal) identity (i.e. a goal for behaviour). This is the idealised image of how we feel we should be or how we would like to be. In the context of my research, this could describe teacher participants who express the belief that they value te reo Māori. The second identity described by Richards is 'performed' (or actual) identity (i.e. demonstrable behaviour). This could be associated with how things actually are in the participants' classrooms, in respect of observable acts of Māori language teaching. For example, a teacher may have an idealised notion that a 'good teacher' is one who is a facilitator and motivator of student-centred Māori language learning. But, when observed, their actual behaviour is more 'top-down' and procedural, such that te reo is used mainly in the context of classroom management (e.g. commands, greetings, farewells).

The reality of the classroom means that teachers may not behave according to their aspirations and ideals. Negative factors can intervene (e.g. fear of mispronouncing Māori, tiredness, competing curriculum priorities, lack of confidence, poor self-efficacy, parental objections). When such circumstances prevail, teachers can often revert to past behaviour (e.g. repeating the same Māori content each year and not extending themselves or their students), even though it conflicts with their aspirational identity. Richards (2017) claims that, conversely, when conditions are favourable (with few barriers and constraints), teachers are more likely to behave consistently with their aspirational identity. Furthermore, he identifies that conflict between both types of identity can cause teachers stress - when, for example, they are unable to answer students' questions, or they try to cover up for their lack of knowledge and proficiency. This is especially the case in teacher-directed learning. 


\subsubsection{Changes in teaching and learning - evolving professional identity}

Traditionally, teaching practice operated from a 'top-down' basis, where the emphasis was on transmitting content. Power resided with the teacher and, in this 'transmission' model, there was little student autonomy (Rowland, 2006). In this approach, students were passive recipients of knowledge. The teacher's role was to deliver content in a clear structured way, show students how to problem solve, and teach facts that would build up students' background knowledge.

In contrast is the current approach to teaching, which focuses on students being active participants in the learning process. OECD (2009) suggests that the teacher's role is to facilitate student inquiry, encourage students to independently develop solutions to problems, and allow them to play an active role in the teaching and learning process. In this approach, students become more autonomous. The focus is on their thinking and reasoning processes - more so than their acquisition of specific knowledge (Staub and Stern, 2002). These changes from a traditional 'transmission' model to student-centred practice impact on teachers' professional identity.

The NZ education system has adopted a student-centred ethos - to better prepare learners for society, as outlined in the New Zealand Curriculum (Ministry of Education, 2007). Evidence-based research around pedagogical theory and best practice, together with teacher self-reflection, has brought about changes in our pedagogical approach - such that 'teaching as inquiry' is currently recommended by the Ministry. This focus on inquiry in NZ schools provides opportunities for students to exercise agency and be actively engaged in the learning process. They are encouraged to be critical thinkers and questioners. The teacher's role is no longer solely to transmit knowledge, as the expert, in a 'top-down' way. The focus is on enabling learning and facilitating interactive experiential opportunities (as in the task-based approach to Māori language learning and teaching mentioned earlier, TBLT), to create autonomous learners.

In addition to the changes in pedagogy mentioned above, teaching practice has evolved because of our digitally connected world. Knowledge transmission by educators is now less important than students 'learning how to learn' for life. By having a say in their own learning, students are likely to become more engaged. This has implications for the teaching and learning of Māori language and culture, in that students can use IT to access other 
relevant input beyond the teacher (whose limited proficiency may be a barrier to student learning).

A model for an inquiry approach to te reo Māori is found in the Ministry's Māori language curriculum guidelines, Te Aho Arataki Marau (Ministry of Education, 2009, p. 20). See visual excerpt in Figure 2.4 below. This cycle is student-centred - based on students' prior knowledge, goals, strengths and needs in relation to reo Māori learning. Teachers are encouraged to make sound pedagogical choices about how to teach, in order to enhance students' Māori language outcomes. They are also encouraged to reflect on their practice and plan the next steps to facilitate learning.

Figure 2.4: Inquiry cycle for teaching te reo Māori (Ministry of Education, 2009, p.20)

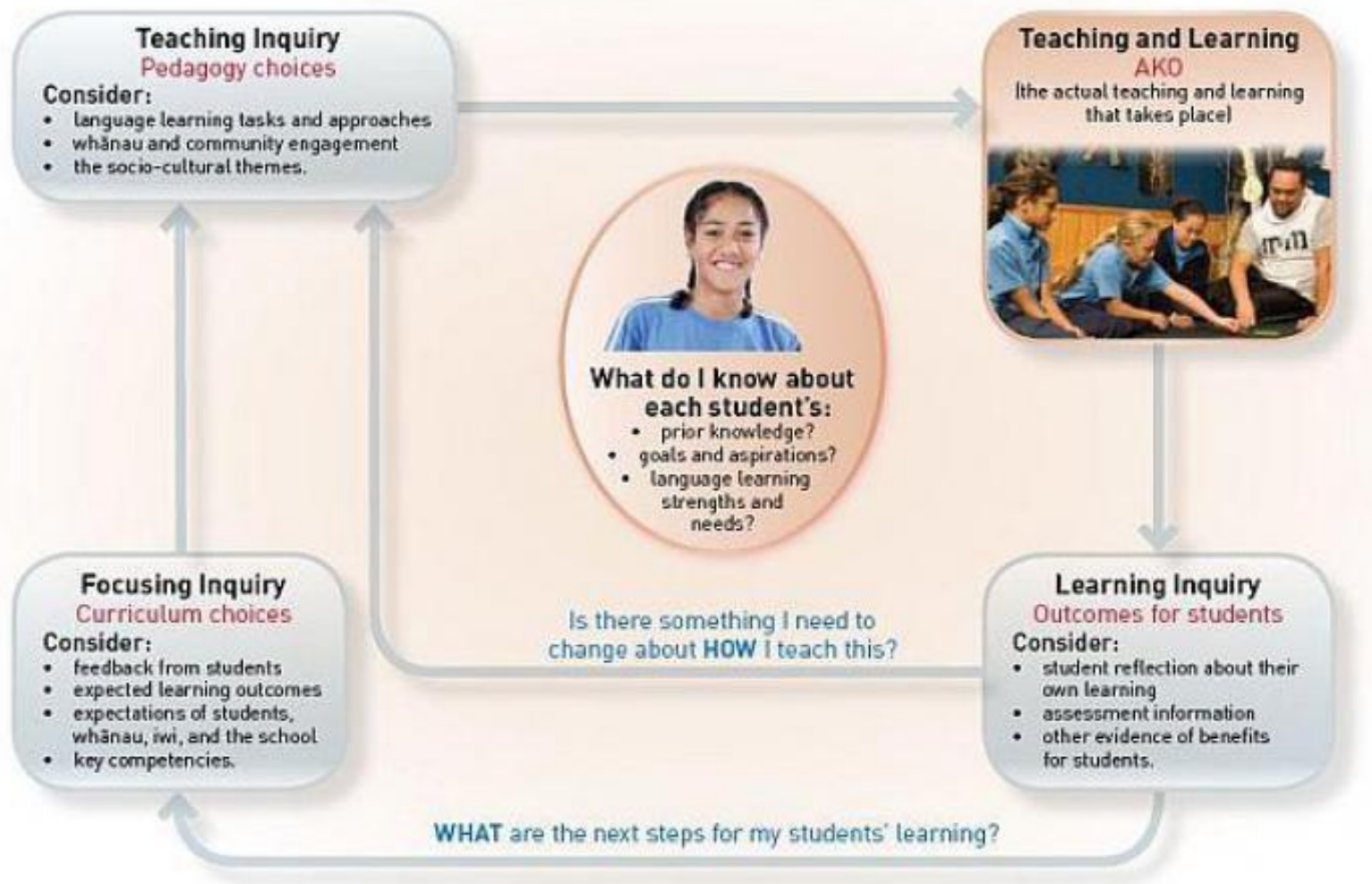

\subsubsection{Communities of learning - contributing to teachers' professional}

\section{identity}

Beijaard et al. (2004) suggest that professional identity is formed through interactions with others in a work context - and that this process can be aided by Communities of Learning (Cunningham, 1999; Gee, 2000). In an educational context, these are groups of people with similar beliefs, attitudes and opinions who work together collaboratively and share their expertise - with a view to solving common problems in their practice (e.g. how to integrate 
Māori language into the classroom curriculum). Such communities could comprise teachers within the same school, teachers across a local cluster of schools, teachers across Aotearoa NZ (or the world), or other educational professionals. Communities of Learning help teachers to develop their professional identity, through collaboration with others. Timperley, Wilson, Barrar, and Fung (2007), in NZ's Best Evidence Synthesis (BES) research, promote the value of our teachers participating in such a professional community with colleagues, because of the opportunities it affords to process new information - and the positive impact it has on students.

In the Education (Update) Amendment Act 2017, the Ministry implemented a policy around Communities of Learning (Kāhui Ako) - as part of the government's Investing in Educational Success (IES) initiative. The Ministry was inspired by other countries (e.g. Finland, Singapore and Hong Kong) who had been successful in improving the quality of teaching and the level of student achievement by adopting a similar approach. The policy aim of Communities of Learning is to help learners achieve valued outcomes and reach their potential, using an inquiry approach. Educators from all educational settings are funded to work together (alongside whānau/hapori/hapū/iwi ${ }^{88}$ ) to determine shared goals, or achievement challenges, that will address the needs of learners.

It is envisaged that, through collaboration across a bigger pool of teachers, with their respective skills and knowledge, the education system will be improved - especially for the Ministry's priority learners ${ }^{89}$, which includes many Māori students. The aim is to enhance the quality of teaching across NZ schools and reduce the variability between teachers. This variability is an issue in the teaching of te reo Māori, as highlighted in research by NZCER (Bright et al., 2017), which looked at whānau decisions about Māori language pathways for their tamariki. One of the participants crystallised the situation by likening the delivery of Māori language in English-medium schools to a game of snakes and ladders; that is, there are some good years, then nothing - depending on the teacher.

\subsection{Chapter review}

This chapter recounted the policy initiatives introduced by government to address the decline of the Māori language. The contentious issue of whether te reo should be

\footnotetext{
${ }^{88}$ Families, communities, sub-tribes, tribes

${ }^{89}$ Students who have not historically experienced success in the NZ education system
} 
compulsory in primary schools was also discussed - along with factors that can influence the teaching of the language (e.g. issues associated with resources and PD). The literature acknowledged the complex and dynamic nature of teaching, due to teachers having to deal with diverse students, in a variety of contexts, covering different content, using varied approaches.

The chapter also discussed teachers' professional identity - and the influence of a teacher's experiences on their beliefs and practices. The literature highlighted a two-way relationship between beliefs and practices (i.e. one informing the other - as in the concept of ako).

The next chapter will focus on methodology - specifically, the three methods used for data collection; namely, an online questionnaire, classroom observations, and teacher interviews. There is also information in that chapter on my approach to data analysis. 


\section{METHODOLOGY | TE PËWHEATANGA}

This chapter provides information on the research aim and the Māori values that underpin my study. Also discussed is the rationale for selecting non-Māori teacher participants from English-medium primary school settings. Demographic considerations are outlined, as are the associated ethics, and the three methods of data collection (i.e. online questionnaire, classroom observations, and teacher interviews). The chapter closes with information on my approach to the analysis of the data.

\subsection{Aim}

The aim of this research is to describe the beliefs and experiences of non-Māori teachers (Year 1-6) who are endeavouring to fulfil Ministry expectations in the national curriculum (Ministry of Education, 2007, p. 9) by teaching te reo Māori in English-medium primary schools (where most children in NZ are being educated). It is envisaged that the findings will also highlight some of the factors that influence the teaching and learning of Māori language in such schools.

\subsection{Kaupapa Māori}

Ko te reo te kākahu o te whakaaro.

Ko te reo te mauri o te mana Māori.

Language clothes one's thoughts.

The language is the essence of Māori identity.

(Statement attributed to Sir James Henare, used in 1986 Waitangi Tribunal report, p. 1).

Underpinning the research are some key 'kaupapa Māori' 90 values. Professor Graham Smith (1992, p. 1) describes kaupapa Māori as “... the philosophy and practice of being Māori" - which Pihama (2010) insists must be defined and controlled by Māori. It is a legitimate Indigenous approach to research that accommodates Māori ways of knowing and being (Irwin, 1994). It reflects Māori philosophies of the world, Māori beliefs/values, and Māori ways of operating (Pihama, 2010). According to Jackson (2013), a kaupapa Māori approach allows for an element of fluidity that enables researchers to pursue a particular aspect wherever it takes them - as long as it is morally the right thing to do.

\footnotetext{
${ }^{90}$ Knowledge, skills, attitudes, and values of Māori society
} 
Although I am non-Māori, as are my participants, the topic is Māori - and it is worthy of researching, because it is important to Māori people. To honour that, I chose to privilege some of the Indigenous values integral to kaupapa Māori research - as an ethical base that would improve my practice. Notwithstanding, I acknowledge that the proprietary interest in te reo Māori belongs to Māori and, as outlined in the previous paragraph, kaupapa Māori research is (in the main) the reserve of Māori researchers. Nevertheless, in the interests of social justice, which Indigenous researcher Dr Linda Smith (2012) suggests should underpin all research, I felt compelled to embark on this study. I was encouraged by Smith's suggestion that non-Māori are not precluded from using kaupapa Māori in their research. Also encouraging was the generous validation from Mead (1996, p. 207) of non-Māori researchers “... attempting to work ... on topics of importance to Māori”. Similarly, I was motivated by support from Higgins (2015) for non-Māori contributing to Māori language revitalisation (including the regularisation of te reo Māori in schools).

My research presents the views of non-Māori primary school teachers endeavouring to engage in aspects of the Māori world - although not situated in that world. The findings will hopefully act as a conduit between te ao Māori and the Pākehā-dominated world of most English-medium primary school classrooms - a space where Māori language, Māori tikanga and Māori teachers are not yet highly visible.

Table 3.1 below sets out the kaupapa Māori values that I incorporated into my research. There is a definition of each value, with examples of how this was demonstrated in my $\operatorname{research}^{91}$. These values are italicised in the main text.

Table 3.1: Kaupapa Māori values imbued in this research

\begin{tabular}{|l|l|l|}
\hline Kaupapa Māori value & Definition & Examples in my research \\
\hline Ako & $\begin{array}{l}\text { An exchange of ideas, } \\
\text { with one informing the } \\
\text { other in a reciprocal way }\end{array}$ & $\begin{array}{l}\text { Being open to the ideas } \\
\text { expressed by the teachers, } \\
\text { incorporating these into the } \\
\text { writing up of the research }- \text { for } \\
\text { a wider audience to learn from } \\
\text { (including me) }\end{array}$ \\
\hline
\end{tabular}

\footnotetext{
${ }^{91}$ I have arrived at these definitions based on my 50+ years experience (both personal and professional) through Māori whānau, kapa haka, and Māori language teaching/advising
} 


\begin{tabular}{|c|c|c|}
\hline Kaupapa Māori value & Definition & Examples in my research \\
\hline Manaakitanga & $\begin{array}{l}\text { Respecting and looking } \\
\text { after people }\end{array}$ & $\begin{array}{l}\text { Keeping the mana of research } \\
\text { participants intact, by creating } \\
\text { an atmosphere of trust, and } \\
\text { acknowledging their lack of } \\
\text { confidence in using te reo }\end{array}$ \\
\hline Kanohi ki te kanohi & Face-to-face & $\begin{array}{l}\text { Making personal visits to each } \\
\text { school prior to data collection, } \\
\text { to establish relationships, } \\
\text { clarify any questions from the } \\
\text { teachers or their principals, and } \\
\text { familiarise the students with } \\
\text { my physical presence and the } \\
\text { need for audio-recording } \\
\text { equipment. } \\
\text { Conducting face to face } \\
\text { observations and interviews }\end{array}$ \\
\hline Tauutuutu & Giving back/reciprocity & $\begin{array}{l}\text { Ensuring there was something } \\
\text { in this research for participants. } \\
\text { For example: insights into their } \\
\text { teaching of Māori, via my } \\
\text { individual interview notes } \\
\text { (shared with them); } \\
\text { information about the research } \\
\text { findings, via a copy of the } \\
\text { abstract; and a stimulus for } \\
\text { teaching te reo, via my koha }{ }^{92} \\
\text { comprising a package of } \\
\text { commercial bilingual readers } \\
\text { (Arahia Books) published in } \\
2017\end{array}$ \\
\hline
\end{tabular}

${ }^{92} \mathrm{Gift}$ 


\begin{tabular}{|c|c|c|}
\hline Kaupapa Māori value & Definition & Examples in my research \\
\hline Kotahitanga & $\begin{array}{l}\text { Unity (i.e. coming together } \\
\text { for the common purpose of } \\
\text { having te reo as a thriving, } \\
\text { living language in } \\
\text { Aotearoa) }\end{array}$ & $\begin{array}{l}\text { Engaging non-Māori in a } \\
\text { Māori kaupapa (te reo rangatira } \\
\text { o tēnei whenua) - thus } \\
\text { contributing to Māori language } \\
\text { revitalisation, and Māori } \\
\text { student success }\end{array}$ \\
\hline Mana tangata & Accrued status & $\begin{array}{l}\text { Acknowledging teachers' } \\
\text { efforts to incorporate te reo } \\
\text { Māori while balancing the } \\
\text { everyday demands of the } \\
\text { classroom. } \\
\text { Affirming participants for } \\
\text { 'taking risks' in their teaching } \\
\text { of te reo (e.g. being observed } \\
\text { and using reo Māori materials). } \\
\text { Valuing participants' } \\
\text { contribution to Māori language } \\
\text { teaching and learning in } \\
\text { primary schools }\end{array}$ \\
\hline Rangatiratanga & $\begin{array}{l}\text { Autonomy/the right to } \\
\text { exercise authority }\end{array}$ & $\begin{array}{l}\text { Respecting participants' } \\
\text { perspectives as classroom } \\
\text { teachers, recognising their } \\
\text { contribution to the health and } \\
\text { survival of te reo Māori. } \\
\text { Using verbatims to convey the } \\
\text { voice and experiences of the } \\
\text { participants }\end{array}$ \\
\hline
\end{tabular}




\begin{tabular}{|c|c|c|}
\hline Kaupapa Māori value & Definition & Examples in my research \\
\hline Wānanga & Meeting and discussing & $\begin{array}{l}\text { Facilitating participant input in } \\
\text { post-observation } \\
\text { kōrero/interview }\end{array}$ \\
\hline Whakawhanaungatanga & Relationship-building & $\begin{array}{l}\text { Valuing the importance of a } \\
\text { sustained relationship between } \\
\text { researcher and participants }\end{array}$ \\
\hline Whakaiti & Humility & $\begin{array}{l}\text { Being mindful of the privilege } \\
\text { of being able to observe in real } \\
\text { classroom settings. } \\
\text { Retaining humility in terms of } \\
\text { conducting research on the } \\
\text { teaching and learning of a } \\
\text { language that is not my } \\
\text { heritage, but which has } \\
\text { significantly shaped me (and } \\
\text { my tamariki/mokopuna) for the } \\
\text { better }\end{array}$ \\
\hline Pono & Being honest & $\begin{array}{l}\text { Being truthful with } \\
\text { participants, so that they are } \\
\text { well-informed about the } \\
\text { research process and the } \\
\text { intended benefits/outcomes }\end{array}$ \\
\hline Tika & Being accurate & $\begin{array}{l}\text { Conducting the research in an } \\
\text { appropriate and ethical way } \\
\text { that is appropriate for the } \\
\text { context and the participants }\end{array}$ \\
\hline
\end{tabular}




\subsection{Selection of participants}

I wanted to gain an in-depth understanding of the beliefs and practices of non-Māori primary school teachers in English-medium settings - in relation to Māori language teaching and learning generally, and Māori language materials specifically. My intention was to capture the richness of these teachers' experiences, while acknowledging the likely impact on them of being involved in my study (Menard-Warwick, 2005; Norton, 2013). The rationale for focussing on non-Māori teachers is explained below in section 3.5.

Initially, I conducted an online questionnaire with 40 non-Māori teachers working in English medium primary classrooms across different regions of Aotearoa NZ. I posted the questionnaire on the primary school teachers' Facebook page, to capture multiple teachers' views. They could decide whether or not to participate - based on their interest and the criteria for participation (i.e. non-Māori primary teachers working in English-medium settings). I provided an incentive to participation, where each respondent would be eligible to receive one of four Māori language resource packages (Arahia Books) - based on a random draw from their 40 names.

The questionnaire was followed by classroom observations and interviews with four of the respondents who were teaching in the Wellington region.

\subsubsection{Sampling}

Having used a participant self-selection approach to sampling in the questionnaire, in the interests of convenience, I took a different approach in the subsequent observation and interview phases of the research; namely, purposive sampling. This was made possible through whakawhanaungatanga ${ }^{93}$; namely, the previous professional relationship that I had established and sustained (as a reo Māori PD adviser) with four of the Wellington teachers who completed the questionnaire. I personally solicited these teachers, who gave me permission to observe and interview them - as case studies. Random members of the teaching profession, unknown to me, may not have been as committed to the research (Tremblay, 1957).

The small number of case study participants in my sampling is acknowledged as a limitation in terms of generalisability (Mackey and Gass, 2012, p. 82). However, I had no

\footnotetext{
${ }^{93}$ Relationship-building
} 
intention of generalising the findings; this was a start only i.e. a stake in the ground. My interpretation of the qualitative data was therefore restricted to four, for reasons of practicality e.g. geographic proximity and ease of accessibility. I sought respondent validation - by going back to participants to verify that I had represented their views truthfully and correctly in the write-up of my interview notes (tika and pono). I accepted that, if there were dissenting views, this would be an opportunity for me to better understand their perspective. (There were in fact no contradictions. The checking process verified the trustworthiness of the interview findings).

Having worked with the four case study teachers before, I had some pre-conceived views about their ability to effectively integrate te reo Māori into their classroom programmes and utilise resources. This could have affected the research process and conclusions, raising questions of validity. However, I needed to select participants whom I knew would be willing to discuss challenges in their teaching of Māori language.

The four participants whom I selected to be observed and interviewed were given pseudonyms. They were:

- non-Māori teachers in English-medium primary schools (three women and one $\left.\operatorname{man}^{94}\right)$;

- drawn from four state schools in Wellington, with variations in decile ratings (deciles 1-10), roll sizes (210-373 students), Māori student population $(12 \%-43 \%)$, and class levels (i.e. at both ends of the primary school); and

- $\quad$ aged 25-64 years old, with teaching experience that spanned 6-16+ years.

Three of them (Ainsley, Jordan and Jamie) self-rated their proficiency as 'basic'95 - while the other (Delta) regarded her proficiency as "limited"96. Table 3.2 below summarises the demographic considerations in my selection of the four teachers - woven alongside my main criteria of being non-Māori, English-medium primary school teachers.

\footnotetext{
${ }^{94}$ This reflected the teacher demographic among English-medium primary teachers (as ascertained in personal communication on 13 April 2016 with Megan Chamberlain, Research, Ministry of Education; and on 14 February 2017 with Jessica Forkert, Indicators and Reporting, Ministry of Education - based on Education Counts data) i.e. $85 \%$ women and $15 \%$ men

${ }^{95}$ Being able to use basic rote phrases and sentences, in highly familiar contexts

${ }^{96}$ Being able to communicate in words only, not sentences
} 
Table 3.2: Demographic considerations in selection of four interviewees

\begin{tabular}{|l|l|l|l|l|l|l|}
\hline Pseudonym & Gender & $\begin{array}{l}\text { Class } \\
\text { level }\end{array}$ & $\begin{array}{l}\text { School } \\
\text { decile } \\
\text { range }\end{array}$ & $\begin{array}{l}\text { School } \\
\text { roll }\end{array}$ & $\begin{array}{l}\text { \% of Māori } \\
\text { students on } \\
\text { roll }\end{array}$ & $\begin{array}{l}\text { School } \\
\text { district }\end{array}$ \\
\hline Ainsley & F & Y $1-2$ & $8-10$ & 210 & $13 \%$ & Wellington \\
\hline Jordan & M & Y 5-6 & $8-10$ & 373 & $12 \%$ & Wellington \\
\hline Delta & F & Y 5-6 & $4-7$ & 239 & $23 \%$ & Wellington \\
\hline Jamie & F & Y 5-6 & $1-3$ & 311 & $43 \%$ & Wellington \\
\hline
\end{tabular}

It was important to me that these four case study teachers benefited from the study (tauutuutu). Therefore, I encouraged them to regard the observation and interview phases as a type of PD that could refine their thinking and practice around Māori language teaching and learning. Furthermore, I pointed out that their participation would be useful evidence for their teaching portfolios ${ }^{97}$ - especially the first Standard for the Teaching Profession (Education Council, 2017), which specifically sets out the expectation that teachers will use te reo and tikanga Māori.

\subsubsection{School deciles and Māori student population}

Two of the criteria in the selection of the four teachers to be observed and interviewed were of special interest - because of the association between the two; namely, the number of Māori students on the roll and school decile ratings.

The school decile system in Aotearoa NZ originated in 1989 as a way of allocating resourcing. Decile ratings are based on five socio-economic factors derived from census data. They indicate the extent to which students are drawn from low socio-economic communities. For example, a decile 1 rating is assigned to $10 \%$ of NZ schools because they have the highest proportion of students from low socio-economic communities. The next $10 \%$ of schools are considered decile 2 schools etc. At the other end of the continuum, a decile 10 rating is assigned to $10 \%$ of NZ schools who draw the lowest proportion of their students from low socio-economic areas. The funding allocation is differential. For example, low decile schools receive more assistance as they are seen to have greater needs.

\footnotetext{
${ }^{97}$ A collection of evidence in relation to the Standards for the Teaching Profession in NZ
} 
I purposely chose to observe Māori language being taught in a range of school deciles and school sizes, with varying degrees of Māori student representation - because, in each school context, there are different limitations and opportunities (Hanson, 1980). Moreover, there is a correlation between schools with high numbers of Māori students and low decile ratings (Fiske and Ladd, 2000). For example, in the (low) decile 1-3 school where I observed, Tāwhiri (a pseudonym), 43\% of the students were Māori. Due to the higher proportion of Māori students in such schools, it is even more important for teachers to be teaching te reo as part of the classroom programme - to validate their Māori students' heritage language. In the (middle) decile 4-7 school, Myer Rd (a pseudonym), 23\% of the students were Māori - compared with $12 \%$ and $13 \%$ respectively in the two (high) decile 8-10 schools, Eastside and Redfield (pseudonyms), as shown in Table 3.3 below. These two schools closely represent the percentage of Māori in the NZ population (which is approximately 15\%).

Table 3.3: Decile ratings and percentages of Māori students in the four interviewees' schools

\begin{tabular}{|l|l|l|l|}
\hline School pseudonym & Decile & \% of Mãori students & School size \\
\hline Tãwhiri School & $1-3$ (low) & $43 \%$ & 311 \\
\hline Myer Rd School & $4-7$ (middle) & $23 \%$ & 239 \\
\hline Redfield School & $8-10$ (high) & $13 \%$ & 210 \\
\hline Eastside School & $8-10$ (high) & $12 \%$ & 373 \\
\hline
\end{tabular}

According to the Ministry, Wellington has a greater percentage of high decile Englishmedium primary schools than the national average i.e. $38.5 \%$ and $32.1 \%$ respectively. (Personal communication with Bea Wooding, Advisor, Information Requests, Ministry of Education, 28 November 2017). Conversely, there are fewer low decile English-medium primary schools in Wellington than the national average (24.4\% and 29.2\% respectively). And the percentage of middle decile English-medium primary schools in Wellington is reasonably comparable to the national average (37.2\% and $38.4 \%$ respectively). See Table 3.4 below. 
Table 3.4: Percentage of English-medium year 1-6 schools in Wellington, by decile, against national average

\begin{tabular}{|l|l|l|}
\hline & Wellington & National average \\
\hline \% of Year 1- 6 low decile schools (i.e. decile 1-3) & $\begin{array}{l}24.4 \% \\
\text { i.e. } 41 \text { schools }\end{array}$ & $29.2 \%$ \\
\hline \% of Year 1- 6 middle decile schools (i.e. decile 4-7) & $\begin{array}{l}37.2 \% \\
\text { i.e. } 35 \text { schools }\end{array}$ & $38.4 \%$ \\
\hline \% of Year 1- 6 high decile schools (i.e. decile 8-10) & $\begin{array}{l}38.5 \% \\
\text { i.e. } 60 \text { schools }\end{array}$ & $32.1 \%$ \\
\hline
\end{tabular}

\subsubsection{Insider status and kanohi kitea ${ }^{98}$}

Researchers can be intrusive to the operations of a school, and to teachers' programmes and timetables. So, in terms of accessing schools and teachers, it was important for me to have willing participants - not teachers who felt obliged to participate. I relied on my status as an 'insider' within the teaching profession, due to my longstanding teaching background and my PD work in schools around Māori language. These credentials helped me to gain access to classrooms, reinforce my professional credibility, and sustain already-established relationships (whakawhanaungatanga). Smyth and Holian (1999, p. 2) assert that being a researcher who is an 'insider' ensures that we “... ground our work in everyday issues as those involved experience them." This was important to me in terms of accurately adjudging the factors that can influence the teaching of te reo Māori in English-medium primary schools.

Being an insider can make the research process easier - as was the case for Canh (2012) researching Vietnamese secondary teachers' beliefs and practices about grammar. He emphasised how being an insider facilitated the research process because he knew how the education system worked from the inside and gained permission from former students (who had subsequently become teachers) to participate. These two conditions are in common with my situation (i.e. my having a thorough knowledge of the sector and being granted permission from previous teacher advisees).

Notwithstanding, while it can be viewed as advantageous (as above), being an insider brings with it associated responsibility - in terms of being honest (pono). For example, in my study, there may have been an expectation from the participant teachers that my

${ }^{98}$ Someone who is visible at Māori gatherings/events 
research findings and recommendations would thereafter lead to direct and swift improvements in the teaching and resourcing of Māori language in English-medium primary school classrooms. However, I could not realistically provide such assurance knowing that the accountability for implementing any recommendations lay with others (especially the Ministry).

Barnard and Burns (2012, p. 104) point to other negative aspects associated with researchers having insider status. They may fail to notice contextual peculiarities, due to their being so much a part of the setting. In addition, they may be perceived as a threat to teachers' 'professional face' - particularly during observations (e.g. teachers being fearful of not living up to the observer's expectations, or having their limitations and weaknesses exposed). Therefore, I needed to remain open to the information provided by the four interviewees and convey a genuine non-judgemental stance (mana tangata).

The notion of being an insider fits well with the Māori concept of 'he kanohi kitea', a term that literally describes being seen in the flesh (e.g. at Māori events). This 'seen face' makes it easier to build and maintain a trust relationship between researcher and participants (Bishop, 1996). In te ao Māori, the seen face is valued as it indicates membership to a community and it enhances credibility (Smith, 1997). This notion is interpreted by Kana and Tamatea (2006) as a way for researchers to validate their acceptance by research participants and stakeholders. In the case of my research, I have no Māori whakapapa. However, for decades, I have been open to learning in te ao Māori alongside Māori whānau, colleagues and mentors. I have learnt by watching, listening and attending Māori hui - he kanohi kitea.

Rewi (2014) associates he kanohi kitea with the principles of $p o n o^{99}$ and $t i k a^{100}$. The former requires the researcher to be honest, so that participants feel comfortable with, and are wellinformed about, the research process - including the ensuing benefits and desired outcomes of the research (for themselves and their community). The latter acts as a guide for carrying out the research in the correct manner, in a way that is the most suitable for the context and the participants. Hence my being guided by kaupapa Māori values (described in section 3.2). I was keenly aware of the need to represent the teachers' views honestly. Like them, I was a stakeholder - being both a learner and teacher of te reo Māori, and a Māori language

\footnotetext{
${ }^{99}$ Being true, valid, honest, genuine, sincere

${ }^{100}$ Being correct, accurate, appropriate
} 
adviser in schools. I also had a stake as a grandmother of Māori mokopuna, for whom I have aspirations in terms of their learning Māori language in the home and at school.

\subsection{Why English-medium settings?}

The NZ classroom is a platform where Māori teachers and the Māori language are underrepresented. Most Māori students, and indeed most students, are being educated in Englishmedium settings. The Ministry's descriptor 'Māori language in English-medium' refers to students learning te reo Māori as a subject - or being taught the curriculum through the medium of te reo Māori for up to $50 \%$ of the time. Some students may have transitioned from Māori-medium kura, but most will have little or no knowledge of things Māori. This presents a challenge for teachers and resource developers. Feedback from English-medium teachers suggests a solution - that Māori language resources could be developed to simultaneously accommodate two levels of student proficiency; namely, a basic level of reo for beginners and a more advanced level for those students with more proficiency (Ministry of Education, 2017).

\subsubsection{Māori language provision in English-medium settings}

As at 1 July 2016, there were 1,074 schools providing Māori language in English-medium settings - with 161,381 students learning te reo (i.e. $20.5 \%$ of the total school population in primary and secondary schools). Just over a third of these students identified as Māori. Moreover, within English-medium primary schools, the target group in this research, approximately a fifth of the students identified as Māori. (Personal communication with Matthew Gibbons, Ministry of Education, 6 April 2017). Because the majority of Māori students are in English-medium schooling, exposure to their heritage language is important to support their identity.

The Office of the Auditor General (2013) provides a salutary reminder of the importance of the future education system for Māori - in that, by 2030, approximately a third of all students will be Māori, which has implications for our future workforce. The Office emphasises (p. 7) that, “... for our country's prosperity, the education system must perform well for Māori." Hence the reason for my research focussing on English-medium teachers - because, by becoming more culturally responsive, they can play a role in revitalising te reo rangatira o Aotearoa ${ }^{101}$, a taonga of national significance (kotahitanga). This view was

101 The chiefly language of NZ 
supported by TPK (2003) in the development of its previous Māori language strategy, the foundation of subsequent government policy, which emphasised the need for wider NZ society to value te reo Māori and for educational opportunities to learn Māori to be expanded.

\subsubsection{Priority learners in English-medium schools - differential achievement}

An additional reason for my focussing on English-medium classrooms is the fact that a disproportionate number of Māori students in these settings are considered by the Ministry to be 'priority learners'. These are students who have not historically experienced success in the education system (OECD, 2010; NZ Human Rights Commission, 2012). The OECD data shows that there is a wide range of educational achievement in Aotearoa NZ, as evidenced in international tests. Moreover, the NZ Treasury, in providing advice around lifting student achievement, confirms that Māori (as well as students from Pasifika and low social economic backgrounds) are more at risk of underachievement than other students (NZ Treasury, 2012).

In the words of the Human Rights Commission (2012, p. 28), it is “... the system failing Māori students; not ... Māori students ... failing the system. ” The Secretary for Education, Iona Holsted, in her appearance before Parliament's Education and Workforce Select Committee (on 14.2.18), acknowledged that the solution lay in teachers' responsiveness to Māori students' identity, language and culture. Part of this cultural responsiveness is Māori language education - as highlighted in the NMSSA study (Ministry of Education, 2018), where greater proportions of Māori students (than non-Māori) in English-medium schools deemed the learning of Māori to be very important. This finding makes sense in view of the association between te reo Māori and cultural heritage and identity.

\subsubsection{Validation of culture in English-medium education}

The former Education Minister, Hon. Hekia Parata MP, pointed to the benefits of an education where Māori culture and identity are integral to learning (Biddle, 2017). The Minister emphasised how important it was for young Māori to leave school not only with good qualifications but with strong cultural capacity, including Māori language. Similarly, both ERO (2010) and the then Education Council (2011) suggested that the validation of Māori students' language, culture and identity in English-medium primary schools could go a long way to addressing the issue of differential achievement. 
Similar claims had been made previously, during an evaluation of Māori language PD programmes for English-medium primary school teachers. The evaluators (Murrow, Hammond, Kalafatelis, Fryer, and Edwards, 2006) found that Māori students benefited from their teachers having participated in Māori language PD - specifically in terms of the following outcomes:

- a heightened sense of belonging,

- $\quad$ increased pride in being Māori,

- $\quad$ higher levels of confidence,

- $\quad$ improved behaviour, and

- $\quad$ enhanced relationships with their teachers.

The evaluation also highlighted that a key barrier to the successful implementation of Māori language in English-medium primary schools, as identified by the participant teachers, was the lack of suitable resources. My research is therefore important, especially seeing that most Māori students are being educated in English-medium settings.

\subsection{Why non-Māori teachers?}

All my research participants were non-Māori, the numerically dominant group in NZ - and in the teaching profession. According to April 2016 statistics from the Ministry, 93\% of teachers in English-medium primary classes are non-Māori. (Personal communication with Matthew Gibbons, Analyst, Ministry of Education, on 6 April 2017). Most are second language learners of Māori. Penetito (2010) reminds us that, while Māori people are expected to become totally familiar with the Pākehā world, the converse is not true. Too few non-Māori are comfortable in the Māori world. And non-Māori teachers have little access to the actual use of te reo Māori. This means there is likely to be a gap between the background/culture of most teachers and the Māori children whom they teach. Hence my focus on non-Māori teachers - because their learning and teaching of te reo could help bridge that gap.

\subsubsection{Te reo Māori and tikanga for non-Māori - pros and cons}

The Waitangi Tribunal (2011) highlighted the fact that non-Māori New Zealanders were increasingly embracing Māori language and culture. Nevertheless, some people argue that Māori language resourcing should mainly, or even exclusively, be directed towards Māori 
(Benton, 2001) - due to there being only a finite amount of resourcing to support Māori language revitalisation. (This viewpoint was discussed in Chapter 2, in the section on Compulsory Māori Language). Such an approach could potentially disadvantage and disincentivise non-Māori people (including teachers) from learning, or using, te reo Māori.

The contrasting view is that non-Māori have a role to play in the maintenance and promotion of te reo Māori (Higgins, 2015; Boyce, 1995; and Te Huia, 2016). Indeed, these researchers assert that, even when Māori language proficiency is limited (as is the case for most primary school teachers), the positive attitudes of non-Māori can contribute to Māori language revitalisation. In the House of Parliament (Hansard, 2018b), Hon. Rino Tirikatene MP emphasised the need for non-Māori support in reviving the language. He publicly expressed his view that Māori need non-Māori help to revive the language - which is why he disapproves of disparaging remarks made by Māori towards those non-Māori who are demonstrating their support for te reo Māori.

This is also the view of the NZ primary school teachers' union, NZEI. The union has long believed that all teachers need to upskill in terms of things Māori - as ratified at its Annual Meeting in 1992. The contribution by non-Māori teachers alleviates the cultural burden placed on the shoulders of the small pool of Māori teachers in English-medium primary schools. In the past, the latter would have been expected, by dint of being Māori, to take on the responsibility of te reo Māori. There is now an understanding that non-Māori can be catalysts for change.

Non-Māori who are open to learning (and teaching) the language, like my research participants, can contribute to:

- The government's goal that, by 2025, Māori language will be progressively integrated into early childhood, primary, and intermediate school education - and that, by 2040 , one million New Zealanders will be able to speak basic reo (Hansard, 2018c).

- The Ministry's Māori education strategy, Ka Hikitia 2008-2012 (Ministry of Education, 2007a), which aims to specifically increase:

- “... the effective teaching and learning of ... te reo Māori” (Goal 2), by enhancing the effectiveness of PD and improving the quality of teaching te reo as a second language. 
- "... the number of quality... teachers proficient in te reo Māori" (Goal 3), by strengthening the opportunities for teachers to engage in high quality $\mathrm{PD}$, to improve their proficiency in Māori.

- $\quad$ “... the visibility of te reo Māori in ... schools, to promote the currency and relevance of te reo Māori” (Goal 5), by supporting them to increase the visibility of te reo Māori.

- The Māori Language Commission’s Mission Statement to “... promote te reo Māori as an ordinary means of communication and a living language ...", thus helping to bring about their vision that “... all NZ will resonate with our indigenous language."

\subsection{Why years $1-6 ?$}

I selected teachers in Years 1-6 as a focus for this study because, according to the Māori Language Commission (the Commission), in its Statement of Intent (Māori Language Commission, 2017), less than a third of primary schools provide programmes for the teaching of te reo Māori as a second language. It is important for students to start learning Māori in the early years, to lay the foundations for future learning and to accelerate proficiency - as outlined in a survey on the health of the Māori language (Statistics NZ, 2001). That survey revealed a correlation between being exposed to te reo Māori in the early years and gaining higher oral proficiency. A subsequent survey, Te Kupenga (Statistics NZ, 2013), was conducted on Māori well-being (including cultural well-being). It found that the number of young people with a high level of Māori language proficiency was increasing - no doubt attributable to a good foundation in the early years.

\subsection{Ethics}

There are potential benefits for the teacher participants in my study, in that the experience of being involved provides an opportunity to reflect on their existing beliefs about the teaching and learning of te reo Māori - and perhaps re-evaluate their position. Antonek, McCormick, and Donato (1997); Beijaard, Meijer, and Verloop (2004); and Mockler (2011) highlight the importance of reflection in the development of a teacher's professional identity - where teachers are encouraged to continually review their classroom practice (shaped by their own experiences of learning), to find ways of improving their craft. This reflection not only contributes to their sense of identity as teachers, but also to their beliefs about teaching and learning - and their subsequent practice. 
Notwithstanding, due to my having 'insider' knowledge of the participants, there was the potential for researcher bias. I was conscious of the need to be stringent in following three main ethical principles: beneficence, justice, and respect ${ }^{102}$ - as follows:

- $\quad$ Beneficence: I kept the well-being of the participants at the front of my mind, taking all necessary steps to show manaakitanga (e.g. not overburdening teacher participants with research-associated meetings that would take them away from their students or extracurricular commitments; providing kai and koha in interviews).

- Justice: I was motivated by the benefits of Māori language teaching and learning, upholding the right for all NZ children to access the Indigenous language of Aotearoa (kotahitanga).

- $\quad$ Respect: I aimed to do the right thing (tika) by demonstrating genuine respect for:

- $\quad$ the teachers' efforts at integrating te reo Māori in the classroom;

- $\quad$ the teachers' right to be well-informed about the research;

- $\quad$ the teachers' right to make decisions free from any controlling influence; and

- kaupapa Māori values (set out earlier in this chapter), which provided a clear steer for the right way to conduct the research.

In addition, I made every attempt to imbue the Treaty principles of partnership and protection, by:

- contributing to the work of Māori researchers focussed on Māori language education (Partnership) i.e. kotahitanga; and

- acknowledging that te reo Māori is the cultural and intellectual property of Māori (Protection) i.e. rangatiratanga.

Furthermore, where appropriate, I used Māori language during the research (e.g. information sheet and interviews), to enhance the visibility and mana of the language.

I understand the potential criticism associated with my having to manage a dual relationship - trying to maintain the objectivity of the research at the same time as having had a professional relationship with the interviewees in the past. However, I prefer to view the

102 Principles promoted by the Education Faculty at Victoria University of Wellington, NZ 
situation positively in that my knowledge of the four interviewees allowed me to choose teacher participants who were demonstrably committed to integrating Māori language in the classroom. Furthermore, because I knew them, there were no issues associated with establishing rapport during the interviews (Bishop, 1997). Also, due to my being a nonMāori member of the sub-culture of teachers, and a second language speaker of te reo Māori, I was well-placed to understand the issues faced by these teachers.

I acknowledge, however, that the participants' right of veto may have been difficult if they perceived a power imbalance, emanating from our previous adviser: advisee relationship. The fact that I was no longer their Māori language adviser in schools, and they were not dependent on me in any way, helped to address perceived power imbalances (Talmy, 2010). I gave them the opportunity to freely consent to (or decline) participation, without coercion. The guidance of my research supervisors, acting as kaitiaki ${ }^{103}$ to keep the research 'safe' in terms of ethics, also provided a mechanism for limiting researcher bias (to avoid compromising validity).

Each participant was provided with an electronic copy of the information sheet (Appendix 2), before completing the online questionnaire. This sheet honoured the principles of pono and tika by providing background information on the research and outlining the research protocols, including:

- $\quad$ ethics approval,

- $\quad$ the research (and the researcher),

- $\quad$ expectations of the participants,

- $\quad$ contact details for me and my primary supervisor,

- what would happen to the data once collected, and

- my commitment to sharing a summary of the findings with the participants at the end of the research.

The questionnaire respondents were asked to give their informed consent (Appendix 3), as a record of their agreement to participate under the conditions outlined, and about which they were fully informed. The consent form mirrored what was on the information sheet, in terms of setting out what was expected of participants. It assured confidentiality and provided participants with the ability to refuse to respond to specific questions and 'opt

${ }^{103}$ Guardians 
out' of the research (up until the end of data collection i.e. end of Term 3, 2017). I sought the four case study teachers' agreement to audio-record during observations (one hour per day, over four days) and interviews (one hour). These audio-recordings were subsequently transcribed.

One final consideration was the ethical implication of students' presence during classroom observations. This risk was mitigated by using consent forms. Permission was sought from the school principal (Appendix 8) and the parents of the affected students (Appendix 6) prior to any site visits for data collection (tika). If a parent refused permission for audiorecording, the teacher moved that child away from the recording devices. In this way, the student was still able to participate in the normal classroom programme - without any detrimental effect on their learning. During class observations, in consultation with the respective teachers, every effort was made to minimise disruption to the teaching and learning programme.

Participants (and their schools) were allocated pseudonyms, to protect their identity. Any identifying details were removed. Electronic data (i.e. audio recordings) were stored on my password-protected computer - backed up by an external drive. The only people with access to each data set were me and the transcribers (who signed a confidentiality agreement, as in Appendix 4). All information will be destroyed four years after the completion of the research (i.e. 2023).

To ensure the well-being of the four case study interviewees, I provided kai. This helped to restore equilibrium after a busy day in the classroom. (It was not seen as an inducement, but as a recognised and valued part of manaakitanga). In addition, a koha was given to them - as a practical way of my giving back (i.e. tauutuut ${ }^{104}$ ). The koha was a bilingual package of commercial Māori language resources, Arahia Books, targeted at Englishmedium primary schools.

\subsection{Multiple methods of data collection}

The methodologies most widely used by teacher cognition researchers are self-report instruments, unstructured observations, and semi-structured interviews (Borg, 2006). These tools were combined in my study - as a way of discerning the relationship between stated

${ }^{104}$ Reciprocity 
beliefs vis-a-vis ideal teaching practices (i.e. how things should be) and classroom reality (i.e. how things actually are). The online questionnaire and semi-structured face-to-face interviews drew out the former, while the classroom observations elucidated the latter. Having multiple sources of data allowed me to see associations across the data and crosscheck how reliable and trustworthy my findings were.

Geertz (1973) advocated such a multi-method approach when exploring teachers' beliefs and practices - to enable the comparison and triangulation of data. The aim of the crossvalidation process in my research was to help determine the degree of consistency (or not) between what teachers believed about the teaching and learning of te reo Māori, and what they did in the classroom (Barnard and Burns, 2012). I was also interested in exploring what factors influenced their teaching of te reo Māori.

Barnard and Burns (2012) report that, in Borg's review of 25 language teacher cognition studies, the interview was the most common data collection tool (specifically 24 of the 25 studies) - followed by questionnaires (11 studies), then observations (9 studies). My combination of these methods allowed for useful insights into the teacher participants' reallife classroom experiences. Such a multi-layered approach also helped to strengthen the findings and conclusions - and ensure reliability of interpretation. A teacher's beliefs can manifest themselves in different ways across different forms of elicitation. One single method of data collection would have been inadequate. For example, using a questionnaire on its own would have provided only a partial view of the reality of non-Māori teachers trying to teach Māori language and use appropriate materials in their English-medium primary school classrooms.

Due to my ongoing work in such schools as a Māori language adviser, I was aware of needing to be flexible and adaptable during the data-gathering phase - especially in terms of: accessing four teachers who were willing to be observed; getting each school principal's agreement for one of their teachers to participate; working around the schedule of busy teachers faced with an already-crowded curriculum; and gaining parental consent for children to be audio-recorded.

\subsubsection{Questionnaire}

The first step in my study was the online questionnaire (Appendix 5), using Qualtrics. The aim of the questionnaire was to gather (mainly) quantitative data on non-Māori teachers' 
beliefs about the teaching and learning of Māori language generally, and Māori language materials specifically. The questionnaires were completed online by 40 teachers between late December 2016 and mid-March 2017.

\subsubsection{Pros and cons of questionnaires}

Questionnaires allow for a large amount of data to be gathered and analysed relatively efficiently. They have been used widely in teacher cognition research, to:

- $\quad$ gauge foreign teachers', and students', perceptions of grammar and error connection (Schulz, 1996, 2001);

- $\quad$ explore teachers' beliefs about grammar (Burgess and Etherington, 2002);

- determine teachers' beliefs about foreign language learning (Allen, 2002); and

- $\quad$ establish teachers' beliefs about literacy (Westwood, Knight and Redden, 1997).

As already acknowledged, although useful in canvassing multiple teachers' views, my online questionnaire could not, on its own, point to a direct relationship between teachers' beliefs and practices. Some factors that lack genuineness could potentially be at play in teachers' responses - including social desirability and political correctness. That is, a questionnaire is limited in terms of unpacking the complexities of teachers' thought processes - as highlighted by Kagan (1990), who raised reservations about using 'shortanswer' or 'self-report' scales when investigating teacher cognition. He believed (p.47) that standardised statements could “... mask or mis-represent a particular teacher's highly personalised perceptions and definitions." Hence the need to include other measuring instruments in my research; namely observations and interviews (kanohi ki te kanohi).

Because self-report instruments generally depend on a high response rate if they are to be credible (Barnard and Burns, 2012), my questionnaire was distributed using social media, specifically the NZ primary school teachers' Facebook page. The Facebook platform was convenient, providing quick and easy accessibility to potential voluntary respondents, at no cost. Participants self-selected according to my inclusion criteria. My aim was to source a group of non-Māori teachers working in English-medium primary schools who were willing to voluntarily communicate their beliefs about Māori language teaching and their 
views on reo Māori resources. I was dependent on their goodwill and their available time to complete the online questionnaire.

(Further information on the disadvantages of self-selection can be found under Limitations, in Chapter 8).

\subsubsection{Questionnaire respondents}

There were 40 questionnaire respondents. Four of them self-identified as men. None of the respondents dropped out after their initial agreement to participate. It is possible that I may have been able to recruit more participants if I had been able to administer the questionnaire face-to-face (as recommended by Iwai, Kondo, Limm, Ray, Shimizu and Brown, 1999) either with individual teachers, or with a cluster of teachers in one place. This would also have given me the opportunity to personally explain what was involved and answer any questions. Additionally, it may have provided encouragement to teachers to write more comprehensive statements in the open-ended questions. However, for reasons of practicability, face-to-face recruitment for the questionnaire was not possible.

\subsubsection{Questionnaire design}

In the design of the questionnaire, I was mindful of the need to be careful about wording and layout. By justifying my choice of items, I was better able to validate the questionnaire - to determine if it measured what it purported to measure, especially in relation to answering my research questions. I also had to consider the target audience - in this case, busy practising teachers working in a demanding complex environment, with very little time or space to give full attention to a questionnaire.

The online questionnaire was piloted by a teacher who is similar to the participants. She is a non-Māori teacher who, at the time, was teaching in an English-medium primary school (decile 4) in the Wellington region. She is enthusiastic about the teaching and learning of Māori in schools - and the creation/ use/adaptation of appropriate reo Māori materials that will facilitate positive outcomes for her students. The piloting process allowed me to verify the clarity of my instructions, the wording and relevance of my questions, and the suitability of the response choices. In addition, I was keen to problem-solve any technical issues in terms of functionality. To that end, she trialled the questionnaire on both her laptop and her iPhone - to ensure there was consistency across the two media. 


\subsubsection{Quantitative data collection}

At the beginning of the online questionnaire, teacher participants were asked to respond to 27 different 'belief' statements (by highlighting 'Yes', 'No' or 'Unsure'). I was mindful that I was providing limited choices only. That is, the statements (and responses) may not have accommodated all their views. However, in the design and piloting of the questionnaire, my main consideration was my target audience and their teaching context (i.e. busy classroom teachers). Having three balanced points, with an equal distance between categories, meant that it was easy and quick for them to respond to. Moreover, I provided space in the questionnaire for qualitative comments (see Questions 29, 36, 37, 41, 46 in Appendix 5).

The 27 randomised belief statements focused on: the teaching and learning of Māori language generally; participant teachers' own teaching (and learning) of the language; and the use of te reo Māori materials.

In the second part of my questionnaire (Question 28, Appendix 5), I used a 'forced choice' approach where respondents were 'forced' to rank items in a pre-specified list; namely, nine characteristics associated with quality Māori language materials in schools (derived from my review of the literature). The teachers were asked to nominate the top three out of the following nine characteristics, in terms of importance:

- $\quad$ Multimedia

- User-friendly

- Visually appealing

- $\quad$ Audio component (as an aid to pronunciation)

- $\quad$ Teachers' notes

- Curriculum alignment

- Inclusion of Māori tikanga, values, concepts

- $\quad$ Real-life contexts (age-appropriate)

- $\quad$ English translation (or glossary).

They were also asked (in Questions 30-35) about six types of free Ministry-provided Māori language materials. Five of these are available in print and /or online, and the other is a DVD on task-based second language teaching. Images of these resources were added to the 
online questionnaire as a memory jogger for respondents. (Appendix 10 provides descriptors and images of these resources).

Stocktake data compiled by Huia Publishers on behalf of the Ministry (Ministry of Education, 2017) revealed that the English-medium sector is almost totally dependent on the Ministry for producing resources to support the teaching and learning of te reo Māori. In fact, only $1 \%$ of Māori language resources used in that sector are reportedly produced by commercial publishers. The Ministry's support in this area is described as 'critical' hence my desire to seek information from the teachers about the frequency of use of these six common resources (i.e. used always, most of the time, about half the time, sometimes, or never).

Demographic information was also collected in the questionnaire (about respondents' ages, number of years teaching, previous learning of Māori, class level, current role in the school, and their self-rated speaking ability in Māori). These questions were included as a way of describing the participants in depth - so that readers could decide for themselves if this research had application to their contexts.

\subsubsection{Qualitative data collection}

As stated earlier, alongside the quantitative data, I created space in the questionnaire for teachers to add qualitative, open-ended comments. This decision was influenced by researchers like Schunk (1991), Brookhart and Freeman (1992), and Munby (1982, 1984) who advocated for the inclusion of qualitative research methodology when studying beliefs - as a way of gaining additional insights. The opportunity to include such questions in questionnaires is also legitimised by Brown (2009), in instances where there are small samples.

Regarding the placement of these open-ended questions, Dornyei and Taguchi (2010) suggest that they be located at the end of the questionnaire, due to the extra cognitive effort required to answer such questions - which, if placed at the beginning, could lead to respondents losing interest (Barnard and Burns, 2012). I gave this suggestion due consideration but, for reasons of logical sequencing and continuity, I decided against the placement of the open-ended questions at the very end of the questionnaire. They were instead integrated throughout the questionnaire, as an optional adjunct to certain quantitative questions that focussed on: the characteristics of quality Māori language 
materials; the resources that teachers use (not necesssarily provided by the Ministry); and the types of Māori language resources they would like to see developed in the future for their English-medium settings.

At the end of the questionnaire, respondents were invited to write any final qualitative comments about Māori language teaching in schools generally, or Māori language materials specifically. (See Appendix 5 for a full list of questions, including belief statements).

\subsubsection{Classroom observations}

The second phase of the research consisted of observations, which allowed for data to be collected as evidence of teachers' practices during their normal classroom programme.

The teacher cognition research landscape increasingly emphasises the importance of what actually happens in classrooms. For example, although Borg (2003c) believes that the analysis of teachers' thinking is a useful form of research, he suggests that, for reasons of authenticity, we need to capture what teachers actually do in their natural classroom environment as they go about their regular day-to-day business. Hence the inclusion of an observation component in my study. Borg believes that too many teacher cognition researchers in the past have studied the 'reported' beliefs of teachers, and their relationship to teacher practice, without including a component of actual classroom practice. Such researchers have chosen to use other measures, or combinations thereof (e.g. questionnaires, interviews, written reflections, documentary analysis).

Based on the assumption that students' acquisition of te reo in the classroom largely depends on their teachers' language practices, I was keen to identify what opportunities teachers took to use Māori language - as a way of validating Māori students' identity and contributing to a sense of national identity among all students.

\subsubsection{Aim of classroom observations}

Agreement was gained from four of the 40 questionnaire respondents for me to observe them in their classroom settings - as case studies. My aim was to witness, first-hand, Māori language teaching and learning in English-medium primary school classrooms - to compare those four non-Māori teachers' actual practices with their previously espoused beliefs in the online questionnaire. Initially, I had envisaged that the observations would be 
video recorded. But, on reflection, I considered this to be too intrusive in terms of heightening the awareness of my presence. Instead, the observation process involved:

- $\quad$ observing the teacher participants in action (equipped with Lavalier lapel microphones - for subsequent transcription),

- audio-recording the classroom interactions (for transcription), using two audio-recording devices in different parts of the room (with permission from the teachers, schools, students/parents), and

- $\quad$ writing (and analysing) field notes that I discretely wrote while observing from the back of each classroom.

\subsubsection{Role of researcher in observations}

Using a classroom ethnographic approach, my role was that of a semi-participant observer. In the interests of maintaining objectivity, I did not intend to interact with the teacher and students, but, rather, to sit unobtrusively in the room making extensive notes. However, on occasions where a teacher or student asked for help, or invited me to participate in the classroom programme, I responded accordingly (albeit keeping my engagement to a minimum e.g. by providing a brief answer only, then carrying on with my observation field notes). Even though I knew this could potentially affect the data collection process, I adopted this stance because it would have been ethically wrong for me to do otherwise (Borg, 2006) e.g. refusing to help students when requested, or ignoring a teacher's Māori language query.

In the interests of non-interference, I resisted correcting Māori language errors made by the teacher (and students) - as this would have undermined their efforts and affected their confidence. Moreover, I was manuhiri ${ }^{105}$ in their classroom - there to observe, not teach. My interference could have affected my trust relationship with the teachers, resulting in an unwillingness on their part to continue in the study. Positioning myself in this way required me to take a neutral stance and minimise any disturbances that my presence might cause (whakaiti), albeit being willing to help if called upon

\subsubsection{Researcher disclosure to participants}

In the interests of pono and tika, I was overt about the focus and rationale for the observations, as disclosed to the teacher participants in the comprehensive information

105 A visitor 
sheet (Appendix 2). I negotiated for observations to be undertaken in one complete week with each teacher suggesting specific times convenient to them. As stated in the literature (Borg, 2006), there is no 'right' number of observations. My goal was to have four hours of recorded observation data, per teacher, collected on four sequential days.

Before the start of data collection, I facilitated a pre-observation kōrero ${ }^{106}$ with each teacher, kanohi ki te kanohi ${ }^{107}$, as recommended by Johnson (1992a). I began by acknowledging their willingness to participate in the research. I also checked to ensure that they had indeed understood everything on the information sheet (Appendix 2), which had been made available to them before commencing the online questionnaire. During this one to one time with each participant, they were encouraged to ask any questions and suggest suitable times for me to observe them (to mitigate disruption to their classroom programme).

\subsubsection{Timing of observations}

I observed each teacher once daily, over five consecutive days, one hour each day (i.e. five hours per teacher). However, on the first day there was no data collection (as suggested by Duff, 2008). The aim on that day was to familiarise the students and teacher with my presence in the room, as well as the audio-recording devices.

On the subsequent four days, audio-recordings were made - for ease of data collection and analysis. This provided a total of 16 hours of observational data across the four teachers. The aim was to get a sense of the day to day reality in English-medium primary school classrooms, in the context of Māori language teaching and learning, and the use of Māori language materials. This approach helped me to build up a picture over time, as opposed to my doing 'one off' observations that would have reflected a mere snapshot of the situation at a point in time.

\subsubsection{Field notes}

As well as getting permission from the teachers and parents to audio-record my observation sessions, I explained that I would be making manual field-notes - to aid the subsequent coding and analysis. Writing field notes helped me to keep focussed, while remaining open to new and/or interesting information. In the field notes, I highlighted key aspects of the

\footnotetext{
106 Talk

${ }^{107}$ Face to face
} 
observations that I wanted to revisit in the follow-up interviews (e.g. because of their salience or special interest).

As suggested in Barnard and Burns (2012), I used different coloured pens for writing the field notes into a large notebook. I organised the data on double pages. On the right-hand pages, I used a black pen to record facts and descriptions of behaviour and interactions with the time being recorded alongside (e.g. use of materials; pair or group work; studentinitiated kōrero in te reo Māori; tikanga). I also used a highlighter pen to indicate Māori words, phrases and sentences used in the classroom (by teacher and students). The lefthand pages remained blank during my observations - reserved for my subsequent reflective remarks, which I wrote in blue pen (e.g. emerging concepts like ako and tuakana:teina ${ }^{108}$, which are Ministry focii in terms of effective teaching and learning in NZ classrooms). During my post-observation interviews, I used a red pen to make annotations on my field notes (e.g. when teachers elaborated on, or provided reasons for, their teaching decisions and actions). I later wrote up the field notes in the form of a narrative - to be analysed qualitatively and sorted into categories during the coding process.

Initially, I had designed a framework to guide the observations - with pre-set headings (i.e. things to look for in teachers' and students' behaviours that would illuminate Māori language teaching and learning), but I subsequently realised that such an approach might pre-empt my observations and data analysis. I therefore opted for open, unstructured observations with no pre-conceived notions of what would be worthy of observing and recording (Everson and Green, 1986); that is, anything and everything was possible.

This 'blank slate' approach allowed me to write down classroom events inductively, as they occurred, before subsequently looking for patterns of behaviour occurring naturally across the four teachers in their real classroom settings. Furthermore, the non-interventionist approach enhanced validity (Mackey and Gass, 2012). According to Whyte (1984), such an approach is more conducive to serendipitous exploration and discovery. Indeed, in teacher cognition research nowadays, unstructured observations are more common than structured observations, because the latter can limit a researcher from being open to seeing

\footnotetext{
${ }^{108}$ Literally a relationship between an older and younger sibling of the same gender, which has evolved in schools as a buddy-system model
} 
any unanticipated (or anomalous) behaviours relevant to the focus of their study (Borg, 2006).

\subsubsection{Interviews}

Individual semi-structured interviews (Appendix 7) were conducted in the final phase of the data collection. These kanohi ki te kanohi interviews acknowledged the importance of privileging teacher voice and providing an opportunity for teachers to reflect on their practice (wānanga), which is often difficult when faced with the demands of a busy classroom.

Interviews have been a well-used tool in teacher cognition research. They are especially useful when combined with other forms of data (Mackey and Gass, 2012) - as a way of corroborating teachers' beliefs about what happens in the classroom and providing them with the opportunity to outline their reasons for the teaching decisions they make. Johnson (2006) claims that teachers can be better supported professionally if they are given the opportunity to reflect on, and interprete, their own practices. This provides insight into their lived classroom experiences, through their eyes, while enabling their actions in the classroom to be understood by others in similar conteaxts - thus enhancing credibility.

The audio-recorded interviews were conducted with the same four teachers whom I observed. I approached the interviews sensitively, being mindful of some anxiety the participants could experience during my observations in their respective classrooms due to my having been their previous Māori language adviser. The opportunity for a postobservation interview mitigated the risk of my making untriangulated decisions about what was important in the data collection. Participants were able to confirm (or reject) suppositions emanating from my observations (Agar, 1996).

With participants' agreement, the interviews were transcribed - as Word documents. The reason for transcribing was to allow me to revisit the content many times, along with my interview notes, during coding in the analysis phase.

\subsubsection{Importance of teacher voice - an insider perspective}

Vasquez and Reppen (2007), who investigated post-observation meetings (between 'novice' ${ }^{109}$ ESL teachers and their mentors), found that teacher discourse often focused on

\footnotetext{
${ }^{109}$ A teacher with less than 6 years' experience
} 
challenging interactions with specific students (or classes). Similarly, Richards (1999), in analysing the narratives of ESL teachers, discovered that the most common kaupapa to emerge were stories of problems with students. These researchers highlighted the importance of listening to teachers' stories - to really appreciate the issues facing them in their professional world.

In my study, the teachers' retrospective verbal reports in the interviews provided an insider perspective. Each of the four case study teachers was able to reflect on, and rationalise, their teaching behaviour associated with Māori language in the classroom, and their use of relevant materials. They were able to express their own points of view. This meant they were active participants, interpreting their own experiences - as opposed to being passive research subjects (Holstein and Gubrium, 1997). Their voices were paramount - as highlighted by Mangubhai, Marland, Dashwood, and Son (2004, p. 294), who stressed the importance of "... creating a climate conducive to teacher reflection ..." facilitated by interviewers who are “... empathic, supportive and non-evaluative, asking open-ended questions, seeking clarification ... of the teacher's remarks and using the language of the teachers where possible."

\subsubsection{Challenges in interviews}

The purpose of interviewing the teachers was to give them freedom to articulate their views. I was mindful, however, of the limitation of using the interview tool on its own, knowing that it would not provide insights about what teachers did - only what they said they did. Hence the multi-pronged approach (i.e. questionnaires, observations, interviews). The advantage of the kanohi ki te kanohi interviews over the questionnaires was that I could ask for clarification along the way. The interviews also allowed me to elicit information about behaviours I had observed in the classroom - and beliefs that teachers had expressed in the questionnaire.

I was aware of a potential challenge if teachers had difficulty articulating their beliefs. This problem was highlighted by Kagan (1992b, p. 66) who stated that, because “...teachers are often unaware of their own beliefs, they do not always possess language with which to describe and label their beliefs, and they may be reluctant to espouse them publicly." There were other possible challenges too that I knew could affect my data collection and analysis. These included: teacher participant withdrawals; interruptions during interviews; and difficulties emanating from any (perceived or real) power relationships due to my having 
worked in a professional capacity with these interviewees in the past. For example, I could have been perceived as a type of assessor (like ERO) - there to scrutinise and judge performance. If so, this could have engendered feelings of anxiety and a fear of criticism.

\subsubsection{Interviewer-interviewee relationship}

Talmy (2010) emphasises that interviews are not contextually neutral - and that the interviewer's relationship with participants, in their respective roles, will have a bearing on the data that emerges.

While acknowledging participants' possible anxieties about the classroom observations that preceded my interviews, I was confident there would be few (if any) barriers associated with my interviewing the four selected interviewees. These were teachers who were personally approached by me. Having worked with me in a professional capacity in the past, they recognised that this was meaningful research, worthy of their involvement. They also appreciated that their opinions mattered (ako). Moreover, we had a longstanding professional relationship.

Each interviewee was interviewed once, kanohi ki te kanohi, for up to one hour. The timings and locations of the interviews were of the teachers' choosing. To show manaakitanga, I provided kai during the interviews. And, as already mentioned under Ethics, by way of reciprocation (tauutuutu), I provided a koha to the teachers in the form of a commercial package of bilingual readers designed for the English-medium classroom; namely, Arahia Books.

\subsubsection{Interview structure}

Because of the small number of interview participants $(n=4)$, I was able to opt for a semistructured approach, akin to an unfolding conversation where I could take different, and perhaps unpredictable, directions (Borg, 2006) - rather than having a pre-set list of questions delivered in the same standardised way. To avoid surprises, and retain participant comfort levels, interviewees were given advance written notification about the themes/kaupapa that would be discussed in the interview. My focus was on listening, and responding thoughtfully, to the interviewees' statements. The interview questions had been piloted by the same teacher who piloted the questionnaire. She ensured that the interview lines of inquiry were clear and appropriate in terms of addressing the research questions. 
The piloting also allowed me to practise asking the questions at an appropriate pace, to allow time for respondents to answer.

The semi-structured interview provided me with the flexibility to seek clarification/elaboration, and to probe other issues, in response to interviewees' comments (Cohen, Manion and Morrison, 2000). It was also an opportunity for me to re-establish rapport with each interviewee (whakawhanaungatanga), an aspect that is deemed by Fontana and Frey (1994) to be fundamental in ensuring a quality interview. Moreover, the informal conversation-style of the interview was conducive to the validation of the concept $a k o$, with its notion of reciprocity (in this case researcher:participant), which sat well with the kaupapa Māori values that informed my study (as outlined earlier in this chapter).

Although I was particularly interested in the teachers' views on Māori language materials, I used an approach recommended by Tsui (2003), where I started the interview exploring more general themes/kaupapa (e.g teachers' motivation; and prior influences that shaped their own teaching of te reo Māori). The placement of such general kaupapa at the beginning of the interview helped to ease teachers into talking, before moving on to more specific kaupapa by me prompting, or probing issues not already mentioned (e.g the possible relationship between Māori students learning their heritage language and achieving at school).

After writing up my interview field notes, I sent each of the four participants a copy of my narrative - for their feedback and validation (as recommended by Miles and Huberman, 1994). This was a practical way of demonstrating the kaupapa Māori principle of tauutuutu, giving back to research participants. It allowed for a shared understanding about their statements and my interpretation thereof. The resultant qualitative data helped me to see inter-connections between the teachers, develop themes, and collect verbatims so that their reality could be represented (Kvale, 1996). As emphasised by Jackson (2013), it is behoven on those who conduct kaupapa Māori research to transform, for the better, the reality of those who are researched. (See Appendix 7 for the interview questions).

\subsection{Data analysis - emergent coding}

The quantitative data emerging from the closed items in the Qualtrics questionnaire were straightforward to analyse - due to the Qualtrics format. (See Chapter 4). 
In addition, the computer-assisted data analysis software NVivo 10, used for qualitative content analysis, helped me to classify, sort and arrange the qualitative information that emerged from the transcribed audio-recordings of the classroom observations and interviews (as well as the qualitative questions in the online questionnaire). With NVivo, I was able to group similar responses together and highlight possible themes/patterns/issues emerging from the transcribed data. NVivo also allowed me to look for inter-relationships across the data sources.

My personal notes from the observations and interviews added to my data analysis process, which was iterative. I took time to re-version the initial coding and arrange the data in new ways, to see possible relationships (e.g. across the data sources; within each teacher's questionnaire responses/ practice/verbalisations; and across teachers). The emphasis was on keeping an open mind in order to speculate on what the data implied.

\subsubsection{Coding key terms and sorting into categories}

In the initial coding, I systematically went through a subset of transcript data, line by line (Johnson and Christensen, 2012), to become familiar with the content whilst looking for any key words/phrases/sentences, ideas, issues and comments that were relevant to the research questions and the literature - or were of pertinent interest to me (e.g. the impact of te reo Māori in the classroom on Māori student achievement). I acknowledge that my coding judgements could have been influenced by my personal interest in the research topic - and that another researcher may have coded differently.

I re-read the information several times and incrementally organised the raw qualitative data into themes and initial categories that were relevant to my research questions (van Lier, 1988) - and to the real world of the classroom, in respect of Māori language teaching and learning. To enhance trustworthiness, I used illustrative verbatim extracts (pono). These verbatims provided insight into the participants' viewpoints and classroom lives, in the interests of rangatiratanga, thus adding to the validity of my research processes. (See my initial coding scheme below, in Table 3.5). 
Table 3.5: Initial coding - before reduction

\begin{tabular}{|c|c|c|c|}
\hline Initial macro categories & Description & Sub-coding themes & Sample data excerpts \\
\hline $\begin{array}{l}\text { Teacher philosophy and } \\
\text { motivation }\end{array}$ & $\begin{array}{l}\text { Teacher beliefs re } \\
\text { importance of } \\
\text { Māori - and the } \\
\text { motivation to learn } \\
\text { (and teach) the } \\
\text { language }\end{array}$ & $\begin{array}{l}\text { - Importance of learner enjoyment } \\
\text { - Intrinsic motivation to learn and teach (i.e. personal } \\
\text { interest) } \\
\text { - Extrinsic motivation to learn and teach (e.g. } \\
\text { performance appraisal) } \\
\text { - Reo ownership considerations } \\
\text { - Importance as a taonga (Treaty) } \\
\text { - Proposition of 'compulsory' reo } \\
\text { - Planning for te reo }\end{array}$ & $\begin{array}{l}\text { "It should be taught; ... it's just a } \\
\text { part of who we are. It's an } \\
\text { acknowledgement that we are } \\
\text { New Zealanders" }\end{array}$ \\
\hline Teacher attitudes & $\begin{array}{l}\text { Framing te reo and } \\
\text { tikanga in a } \\
\text { positive light }\end{array}$ & $\begin{array}{l}\text { - He taonga } \\
\text { - Excitement re marae trip }\end{array}$ & $\begin{array}{l}\text { "I think it's a massive part of who } \\
\text { we are as a country. It's an } \\
\text { acceptance that it's part of NZ" }\end{array}$ \\
\hline Missed opportunities & $\begin{array}{l}\text { Openings for } \\
\text { teachers to } \\
\text { consolidate or } \\
\text { extend students' } \\
\text { knowledge of reo } \\
\text { Māori and tikanga }\end{array}$ & $\begin{array}{l}\text { - Transferring reo from one context to another (e.g } \\
\text { across curriculum learning areas) } \\
\text { - Exploring word derivations e.g. 'pencil' (pene- } \\
\text { rākau), and 'whiteboard pen' (pene-papamā) } \\
\text { - Not capitalising on students' knowledge of te ao } \\
\text { Māori (e.g. overlooking Māori student's knowledge of }\end{array}$ & $\begin{array}{l}\text { NB In this case, there are no data } \\
\text { excerpts from teachers, as these } \\
\text { are the researcher's views (during } \\
\text { observations) on what teachers } \\
\underline{\text { could have potentially done to }}\end{array}$ \\
\hline
\end{tabular}

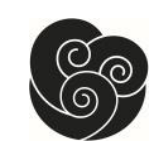




\begin{tabular}{|c|c|c|c|}
\hline & & $\begin{array}{l}\text { Rūaumoko, kaitiaki of earthquakes, during study of } \\
\text { natural disasters) }\end{array}$ & $\begin{array}{l}\text { maximise students' Māori } \\
\text { language learning opportunities. }\end{array}$ \\
\hline Teacher input & $\begin{array}{l}\text { Teachers' use of te } \\
\text { reo Māori }\end{array}$ & $\begin{array}{l}\text { - Classroom management } \\
\text { - Praise } \\
\text { - Greetings } \\
\text { - Translanguaging } \\
\text { - Elicitation (e.g. asking Qs) } \\
\text { - Correction of students } \\
\text { - Scaffolding } \\
\text { - Pre-teaching of vocab } \\
\text { - Language complexity } \\
\text { - Making errors in te reo } \\
\text { - Modelling (e.g. pepeha }{ }^{110} ; \text { pronunciation) }\end{array}$ & $\begin{array}{l}\text { "I think it's really hard as non- } \\
\text { Māori, with limited easy-to-use } \\
\text { resources, to be able to fully use it } \\
\text { in the classroom - other than } \\
\text { commands and phrases" }\end{array}$ \\
\hline Tikanga & $\begin{array}{l}\text { Discussion, or } \\
\text { enactment, of } \\
\text { Māori culture }\end{array}$ & $\begin{array}{l}\text { - Tikanga integration into classroom routines (e.g. no } \\
\text { sitting on tables; daily karakia) } \\
\text { - Marae visit (e.g. preparing pepeha; practising } \\
\text { hongi }^{111} \text { ) } \\
\text { - Misconception (i.e. confusion between marae and } \\
\text { wharenui) }\end{array}$ & $\begin{array}{l}\text { "When you are reciting your } \\
\text { whakapapa, it's like who your } \\
\text { family is, your line of descent, } \\
\text { where you've come from. It's who } \\
\text { your genes are - your people, your } \\
\text { whānau" }\end{array}$ \\
\hline
\end{tabular}

${ }^{110}$ Introduction of oneself in the context of place/land

${ }^{111}$ Pressing of noses 


\begin{tabular}{|c|c|c|c|}
\hline Māori achievement & $\begin{array}{l}\text { Relationship } \\
\text { between Māori } \\
\text { students learning te } \\
\text { reo and their wider } \\
\text { achievement at } \\
\text { school }\end{array}$ & - Affirmation of language, culture and identity & $\begin{array}{l}\text { "By valuing who they are as a } \\
\text { human, and what they bring in, } \\
\text { it's going to lead to achievement } \\
\text {... They come in with a range of } \\
\text { skills, ... and we have to work out } \\
\text { what they've got - and use that to } \\
\text { engage and support them" }\end{array}$ \\
\hline Students' cultural capital & $\begin{array}{l}\text { Validating, and } \\
\text { drawing on, } \\
\text { students' prior } \\
\text { knowledge/ } \\
\text { experiences }\end{array}$ & $\begin{array}{l}\text { - Students' experience with te ao Māori (beyond the } \\
\text { classroom) }\end{array}$ & $\begin{array}{l}\text { "I'm going to share something } \\
\text { with you about my whānau, my } \\
\text { family - who I am and where I am } \\
\text { from. It's close to my heart, so I } \\
\text { really need you to show respect } \\
\text { for that. And that's the same when } \\
\text { we are each doing our mihi }{ }^{112} \text {, } \\
\text { because it's part of you, where } \\
\text { you are anchored, and where } \\
\text { you're from" }\end{array}$ \\
\hline $\begin{array}{l}\text { Teachers' second language } \\
\text { acquisition knowledge }\end{array}$ & $\begin{array}{l}\text { Understanding of } \\
\text { second language }\end{array}$ & $\begin{array}{l}\text { - TBLT within a communicative approach } \\
\text { - Content in He Reo Tupu and Te Aho Arataki Marau }\end{array}$ & $\begin{array}{l}\text { "Have you tried putting it into the } \\
\text { dictionary? Have you looked it up }\end{array}$ \\
\hline
\end{tabular}

${ }^{112}$ A term sometimes used instead of 'pepeha'. It conveys a wider sense of greetings 


\begin{tabular}{|c|c|c|c|}
\hline & $\begin{array}{l}\text { teaching and } \\
\text { learning theory }\end{array}$ & - Learner strategies & $\begin{array}{l}\text { in the Māori: English dictionary? } \\
\text { That might be your first step" }\end{array}$ \\
\hline Linguistic landscape & $\begin{array}{l}\text { Reo Māori } \\
\text { visibility in } \\
\text { classroom }\end{array}$ & $\begin{array}{l}\text { - Signage } \\
\text { - Wall displays (e.g. posters and student work) }\end{array}$ & $\begin{array}{l}\text { "[We need] more visuals for the } \\
\text { classroom, because I think most } \\
\text { teachers get their posters from the } \\
\$ 2 \text { shop. Imagine if we got a } \\
\text { whole pack; that would be } \\
\text { awesome" }\end{array}$ \\
\hline $\begin{array}{l}\text { 'Noticing' i.e. singling out } \\
\text { an item for closer attention }\end{array}$ & $\begin{array}{l}\text { Student attention } \\
\text { drawn to the form } \\
\text { or meaning of a } \\
\text { word }\end{array}$ & $\begin{array}{l}\text { - Spelling and pronunciation } \\
\text { - Word meanings (incl derivations) } \\
\text { - Influence of context and tone (e.g. "Haere mai") }\end{array}$ & $\begin{array}{l}\text { "It starts with 'kai' - you know, } \\
\text { like the food you eat - and then } \\
\text { 'tuna', eel. So just break it down; } \\
\text { Kaituna" }\end{array}$ \\
\hline
\end{tabular}




\begin{tabular}{|c|c|c|c|}
\hline $\begin{array}{l}\text { Tuakana: teina (peer } \\
\text { teaching) }\end{array}$ & $\begin{array}{l}\text { Students learning } \\
\text { from each other }\end{array}$ & $\begin{array}{l}\text { - Arranged } \\
\text { - Involuntary }\end{array}$ & $\begin{array}{l}\text { "Help your buddy. You need to } \\
\text { encourage him" }\end{array}$ \\
\hline $\begin{array}{l}\text { Ako (reciprocity of } \\
\text { teaching and learning) }\end{array}$ & $\begin{array}{l}\text { Teacher being open } \\
\text { to learning from } \\
\text { students (i.e. } \\
\text { teacher as a } \\
\text { learner) }\end{array}$ & $\begin{array}{l}\text { - Pronunciation } \\
\text { - Te ao Māori }\end{array}$ & $\begin{array}{l}\text { "We don't know how to do this } \\
\text { yet. We don't know how to } \\
\text { pronounce the words the best yet. } \\
\text { We're on that first step of our } \\
\text { learning, but we're going to give it } \\
\text { our best go. We are just trying to } \\
\text { do the best we can; we are all in } \\
\text { the learning stage." }\end{array}$ \\
\hline Teaching strategies & $\begin{array}{l}\text { Approaches to } \\
\text { support student } \\
\text { learning }\end{array}$ & $\begin{array}{l}\text { - Opportunities for practice (e.g. whole class, groups, } \\
\text { pairs, individuals) } \\
\text { - Emphasis on listening and speaking }\end{array}$ & $\begin{array}{l}\text { "If you follow along as well, it's } \\
\text { like your buddy is teaching you". }\end{array}$ \\
\hline Teacher identity & $\begin{array}{l}\text { Teachers' self- } \\
\text { positioning }\end{array}$ & $\begin{array}{l}\text { - Personal vs professional } \\
\text { - Ideal vs actual }\end{array}$ & $\begin{array}{l}\text { "Professionally I am connected } \\
\text { because that's where my career }\end{array}$ \\
\hline
\end{tabular}




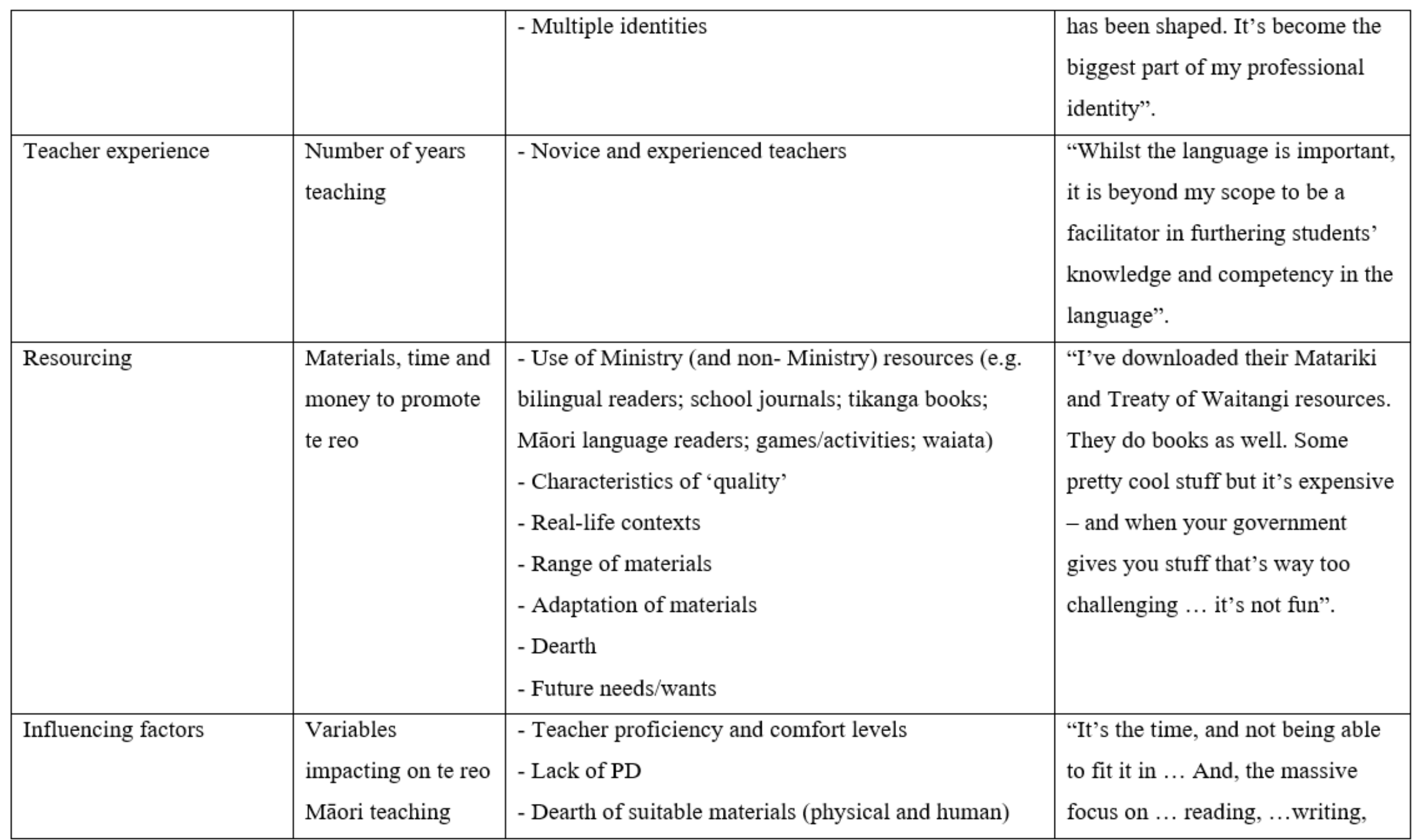

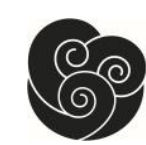




\begin{tabular}{|l|l|l|l|}
\hline & & $\begin{array}{l}\text { - Lack of support from parents and senior management } \\
\text { - Timetabling }\end{array}$ & $\begin{array}{l}\text { and ...maths ... deemed to be } \\
\ldots \text { the more important things to } \\
\text { focus on. The programme is tight, } \\
\text { and. ... we're really struggling to } \\
\text { fit everything in". }\end{array}$ \\
\hline Student output & $\begin{array}{l}\text { Students' use of } \\
\text { te reo }\end{array}$ & $\begin{array}{l}\text { - Responses (e.g. to question/greetings/roll call) } \\
\text { - Initiation } \\
\text { - Questions } \\
\text { - Metadata discourse }\end{array}$ & $\begin{array}{l}\text { "Is that a word for saying } \\
\text { 'beautiful' in Māori?" }\end{array}$ \\
\hline
\end{tabular}




\subsubsection{Comparing data to see recurring patterns}

In the second phase of coding, after categorising the data into themes, I looked for recurring patterns that became evident through the coding process. I sought to establish connections within and across categories - constantly making comparisons in terms of similarities and differences. The aim was to look for relationships and recurring themes across the data sets (Braun and Clarke, 2006) - to facilitate analysis and draw some conclusions in relation to my research questions. I was mindful that my interpretation of the data would potentially affect validity. My intention was not simply to identify the beliefs of the 40 teachers who responded to the online questionnaire, but to determine relationships across the beliefs (and, ultimately, the practices) of the four case study teachers.

\subsubsection{Reducing categories}

Thirdly, having compared the data, I refined down the information by merging items (Mackey and Gass, 2012) - to create seven macro categories. (See final, reduced coding scheme in Table 3.6 below). This reduction process was challenging. It required consistency and thoroughness. I had to constantly revisit the data, to clarify the interrelationships across the initial sub-coding themes set out in Table 3.5 above.

Thereafter, the final coding categories that emerged from the initial subset of transcript data were applied to the rest of the data set (i.e. qualitative questions in the online questionnaire, observation field notes, interview notes, and audio-recordings of the observations and interviews).

Table 3.6: Final, reduced coding scheme

\begin{tabular}{|l|l|l|}
\hline Final macro categories & Description & Coding themes \\
\hline Teacher philosophy and & Teacher beliefs and & - Taonga (Treaty) \\
attitudes re te reo Māori - & - Intrinsic motivation \\
and motivation to & - Extrinsic motivation \\
& learn/teach it & - Ownership considerations \\
& & - Compulsory reo \\
& & - Attitudes \\
\hline
\end{tabular}




\begin{tabular}{|c|c|c|}
\hline Teacher output & $\begin{array}{l}\text { Teachers' use of te reo } \\
\text { Māori-commensurate } \\
\text { with proficiency }\end{array}$ & $\begin{array}{l}\text { - Classroom management } \\
\text { - Praise } \\
\text { - Greetings } \\
\text { - Translanguaging } \\
\text { - Elicitation (e.g. asking Qs) } \\
\text { - Scaffolding } \\
\text { - Pre-teaching vocab } \\
\text { - Language complexity } \\
\text { - Modelling, with occasional } \\
\text { errors } \\
\text { - Missed opportunities } \\
\text { (across contexts) } \\
\text { - Teacher proficiency and } \\
\text { comfort }\end{array}$ \\
\hline $\begin{array}{l}\text { Tikanga - and students' } \\
\text { cultural capital }\end{array}$ & $\begin{array}{l}\text { Validation/ discussion/ } \\
\text { enactment of Māori culture }\end{array}$ & $\begin{array}{l}\text { - Tikanga integration } \\
\text { - Misconception } \\
\text { - Students' prior knowledge } \\
\text { /experiences } \\
\text { - Impact of language, } \\
\text { culture and identity on } \\
\text { Māori achievement }\end{array}$ \\
\hline $\begin{array}{l}\text { Knowledge re L2 acquisition } \\
\text { and strategies }\end{array}$ & $\begin{array}{l}\text { Approaches to support } \\
\text { student learning }\end{array}$ & $\begin{array}{l}\text { - Planning for te reo } \\
\text { - TBLT } \\
\text { - 'Noticing' (form and } \\
\text { meaning) } \\
\text { - Cross-curriculum } \\
\text { integration } \\
\text { - Tuakana: teina (peer } \\
\text { teaching i.e. arranged and } \\
\text { involuntary) } \\
\text { - Ako (teacher being open to } \\
\text { learning from students e.g. }\end{array}$ \\
\hline
\end{tabular}




\begin{tabular}{|c|c|c|}
\hline & & $\begin{array}{l}\text { pronunciation and te ao } \\
\text { Māori) } \\
\text { - Linguistic landscape / } \\
\text { visibility (signage and } \\
\text { walls) }\end{array}$ \\
\hline Teachers' prior experiences & $\begin{array}{l}\text { Influence of teaching } \\
\text { experience and prior reo } \\
\text { Māori learning on identity } \\
\text { and current reo teaching }\end{array}$ & $\begin{array}{l}\text { - Formal schooling } \\
\text { - Teacher training } \\
\text { - In-service PD } \\
\text { - Whānau } \\
\text { - Community } \\
\text { - Novice and experienced } \\
\text { teachers } \\
\text { - Identity }\end{array}$ \\
\hline Influencing factors & $\begin{array}{l}\text { Variables impacting on te } \\
\text { reo Māori teaching }\end{array}$ & $\begin{array}{l}\text { - Lack of PD } \\
\text { - Little support (parents, } \\
\text { school management) } \\
\text { - Timetabling } \\
\text { - Resources to promote te } \\
\text { reo: } \\
\text { - Ministry (and } \\
\text { - commercial) } \\
\text { - Lack } \\
\text { - Ranality } \\
\text { - Adaptation } \\
\text { - Future needs/wants }\end{array}$ \\
\hline Student output & Students' use of te reo & $\begin{array}{l}\text { - Practice opportunities } \\
\text { - Responses } \\
\text { - Initiation } \\
\text { - Questions } \\
\text { - Metadata discourse }\end{array}$ \\
\hline
\end{tabular}


This was a worthwhile exercise in that I used the emergent codes to guide my analysis, reporting, and discussion of the findings in Chapters 4-7.

\subsection{Chapter review}

Different methods of data collection have been used in teacher cognition research - each with their own merits. My research combined the three most popular methods: a self-report tool (questionnaire); unstructured observations; and semi-structured interviews. This combination enabled me to discern the difference between the perceived 'ideal' teaching and learning of Māori language (via the questionnaire and interviews) and the 'actual' classroom reality (via the observations). The three methods also allowed me to see associations across the different sources of data and cross-check the findings for reliability.

After my analysis of the quantitative data derived from the Qualtrics questionnaire, and the qualitative data using the NVivo software, I was able to design a coding scheme to help sort the information into categories, based on the most recurring, underlying themes associated with:

- teachers' beliefs about te reo,

- teachers' use of te reo in the classroom,

- teachers' incorporation of Māori culture,

- teachers' knowledge of second language acquisition,

- the impact of teachers' own experiences learning te reo,

- the factors that can influence the teaching of te reo in English-medium primary schools, and

- $\quad$ students' use of te reo.

The next chapter will discuss the findings from the online questionnaire - and the insights gained from the beliefs expressed by the 40 teacher respondents about the teaching and learning of te reo Māori in English-medium primary schools. The chapter also focuses on the characteristics of quality in Māori language resources - and respondents' views on their use of Ministry (and other) resources, as well as their suggestions about future reo resources. 


\section{FINDINGS AND DISCUSSION, Part 1: Questionnaire |}

\section{NGĀ KITENGA ME TE KŌRERO, Wāhanga 1: He rārangi pātai}

Ko te reo te manawapou o te iwi.

Māori language is the life-source of Māori people.

(Ministry of Education, 2009, p. 81)

\subsection{Overview}

This is the first of three chapters dedicated to the research findings and discussion thereof. The three chapters align with the three methods used in undertaking the research; namely the online questionnaire (Chapter 4), classroom observations (Chapter 5), and teacher interviews (Chapter 6). I chose to write up the emergent findings in this way, to show a progression. Research questions were cross-referenced accordingly.

This chapter deals with the online questionnaire. In addition to demographic information, it provides insights into teachers' stated beliefs about the teaching and learning of Māori language in English-medium primary schools. The discussion around their beliefs makes reference to other relevant research that provides more context for, or substantiates, my findings - thus situating the results within a wider field of research.

The chapter also discusses the influence of the teachers' prior learning of Māori language, their self-rated reo Māori proficiency, and their comfort levels teaching the language. In addition, the teacher respondents evaluate characteristics of 'quality' in Māori language resources. Furthermore, they indicate what Ministry (and other) resources they use providing suggestions on the future development of reo Māori resources needed in Englishmedium primary schools.

There is also discussion, based on the teachers' qualitative responses in the questionnaire, about external factors that can influence the teaching of te reo Māori in English-medium primary schools (e.g. lack of resources, time, PD, and encouragement from school leaders/whānau).

\subsubsection{Relevance to research questions}

The online Qualtrics questionnaire answered the first of my research questions; namely: What do non-Māori teachers working in English-medium primary schools believe about 
Māori language teaching and learning? The questionnaire was accessed voluntarily by 40 English-medium primary school teachers through social media (Facebook page for primary school teachers). Respondents needed to fit the criteria of being non-Māori teachers, working with Years 1-6 in English-medium primary schools in NZ.

The questionnaire also provided some insight into my fourth research question; namely: What are these teachers' views about Māori language teaching and learning resources in English-medium primary schools - specifically:

- $\quad$ existing Ministry resources;

- $\quad$ future Māori language resource needs; and

- $\quad$ the characteristics of quality Māori language resources.

As well as being explored in the online questionnaire, this fourth research question was further investigated during 1:1 interviews with four of the 40 questionnaire respondents as discussed in more detail in Chapter 6.

The questionnaire provided information (albeit to a lesser extent) in relation to my third research question too; namely: What are some of the factors that can influence teachers' attempts to teach te reo Mãori? Responses to this question were optional in the online questionnaire but were explored further during my 1:1 interviews.

The information that follows is a description, and analysis, of the quantitative and qualitative data obtained from the questionnaire.

\subsection{Demographics of teacher participants}

There were 40 non-Māori teachers, working in English-medium primary schools, who responded to the online questionnaire on Facebook. In Appendix 9, there is an overview of their relevant demographics. The information, in table form, illustrates the teachers' geographic locations, school deciles, class levels, roles, teaching experience, Māori language ability, and age range. Each of these aspects is elaborated on below - giving the reader necessary contextual information prior to the subsequent discussion on the actual findings.

In view of their voluntary participation, and in the context of NZ's small primary school teaching population (approximately 20,000), this sample of 40 teachers was adequate for my purpose. Each respondent taught Year 1-6 students (aged approximately 5-11) in 
English-medium classrooms. Four men completed the questionnaire, representing $10 \%$ of the participant cohort - which is less than the percentage of male teachers in the primary school teaching population (i.e. 15\%). Thirty-nine of the 40 questionnaire respondents taught in state-funded schools, owned and administered by the Ministry. Consequently, there was an expectation on them to provide all their students with the opportunity to acquire Māori language (and culture) - as outlined in the New Zealand Curriculum (Ministry of Education, 2007, p. 9).

One respondent was teaching in an independent school (i.e. a privately-owned school where all students pay tuition fees). Although these types of schools do not have to adhere to the New Zealand Curriculum, they are expected to follow a programme of comparable quality. However, it is difficult to ascertain the extent to which the Ministry's expectation (that English-medium primary school teachers will facilitate opportunities for te reo Māori learning) is carried over to the private school system.

\subsubsection{Geographic locations of participants}

The 40 questionnaire respondents came from 11 different regions of Aotearoa NZ. Despite Auckland's larger population, only eight came from that region, while more than a third $(n=15)$ came from the Wellington region. There were also respondents from the Waikato area $(n=5)$; Bay of Plenty $(n=3)$; Hawke's Bay/Gisborne $(n=2)$; and Canterbury $(n=2)$. One teacher came from Dunedin, Taranaki, Northland, Manawatū and Nelson.

Looking at regional trends was outside the scope of this research. For the purpose of my study, teachers' geographic location was irrelevant - as they were all using the New Zealand Curriculum (except perhaps the teacher working in the independent school).

\subsubsection{School deciles of participants}

As explained in Chapter 3, deciles are used when allocating resourcing to schools. They indicate the extent to which students are drawn from different socio-economic communities. That is, the higher the socio-economic environment, the higher the decile. Parents often use deciles as indicators of quality. Professor John Hattie's research in the Ministry's asTTle ${ }^{113}$ project highlighted that school deciles were being used by many as a predictor of academic success - thus associating the socio-economic status of students with

\footnotetext{
${ }^{113}$ Assessment Tool for Teaching and Learning, designed to assess students' achievement in reading, writing and maths at curriculum levels 2-6 (divided into sub-levels i.e. Advanced, Proficient and Basic)
} 
achievement (Hattie, 2002). The Minister of Education, Hon. Chris Hipkins, acknowledges that, currently, the decile system contributes to inequality - hence the government's plans to replace it with an equity index.

There was a range of school deciles represented across my 40 questionnare respondents, with more than half the teachers $(n=24$, i.e. $61.5 \%)$ coming from decile $8-10$ schools. These high decile schools tend to be well-resourced and have fewer Māori students on the roll in contrast to low decile schools where there is a concentration of minority group students. Māori journalist, Joel Maxwell, highlights the disparity and the resultant social and racial divisions generated by school deciles (Maxwell, 2018). Researchers attribute this divide to non-Māori parents fleeing from such schools in favour of a “... high decile, low Māori school" (Fiske and Ladd, 2000, p. 197) - because of their expectations of a quality education in those schools. This leads to reduced diversity in schools and the stigmatisation of low decile schools.

Given this situation, there are implications for high decile schools with low numbers of Māori students, in that they may not feel the pressing need to teach te reo when most of their students, and indeed their community members, are non-Māori. Furthermore, the parents may not recognise the benefits of learning NZ's Indigenous language. They may in fact have expectations that their children will learn a foreign language that currently has high economic impact (e.g. Mandarin).

Regardless, the fact remains that there is an expectation from the Ministry that Mâori language will be an important part of the curriculum. And, irrespective of the number of Māori students on school rolls, te reo has a part to play in engendering our national identity as Kiwis. Indeed, the Māori Language Commission's current Statement of Intent, 2017/182020/21, highlights increasing interest in, and support for, Māori language in wider NZ society - due to it being a marker of national identity (Māori Language Commission, 2017). As evidence, the Commission uses the example of English-medium schools who choose to offer Māori language, despite often having small numbers of Māori students on the roll.

Eight questionnaire respondents in my study (20.5\%) were teaching in decile 4-7 schools (i.e. medium decile schools), while seven (18\%) taught in decile 1-3 schools (i.e. low decile schools). It is perhaps surprising that there were so few teacher respondents from the latter group of schools, seeing these are the schools with higher Māori student populations. One 
possible reason for the poor engagement of low decile teachers with my online questionnaire, and its kaupapa, could be that their time and resourcing is split across a range of priority learners (not just Māori, but Pasifika students too). Consequently, they may have little time (and energy) to peruse the primary school teachers' Facebook page, where the invitation to complete the questionnaire was posted.

It should be noted that one teacher, Lexi, was a reliever in many schools, covering a range of deciles. Consequently, she has been omitted from Table 4.1 below, which shows the specific school deciles of research participants.

Table 4.1: School deciles of participants, highest to lowest (indicated by colour bands)

\begin{tabular}{|l|l|l|l|l|l|l|l|}
\hline Pseudonym & Age & $\begin{array}{l}\text { Years' } \\
\text { experience }\end{array}$ & Decile & $\begin{array}{l}\text { Class } \\
\text { level }\end{array}$ & Role & Region & $\begin{array}{l}\text { Reo } \\
\text { ability }\end{array}$ \\
\hline Laurel & $45-54$ & $1-2$ & 10 & Y5-6 & Teacher & Auckland & Limited \\
\hline Janet & $25-34$ & $6-10$ & 10 & Y1-2 & Teacher & Auckland & Limited \\
\hline Riina & $45-54$ & $6-10$ & 10 & Y1-2 & Teacher & Wellington & Limited \\
\hline Jessie & $45-54$ & $11-15$ & 10 & Y1-2 & Teacher & Auckland & Limited \\
\hline Nate & $35-44$ & $1-2$ & 10 & Y5-6 & Teacher & Manawatū & Limited \\
\hline Natania & $25-34$ & $3-5$ & 10 & Y3-4 & Teacher & Wellington & Basic \\
\hline Sheena & $25-34$ & $6-10$ & 10 & Y5-6 & Teacher & Auckland & Basic \\
\hline Shevon & $35-44$ & $16+$ & 10 & Y5-6 & $\begin{array}{l}\text { Senior } \\
\text { teacher }\end{array}$ & Waikato & Basic \\
\hline Tatiana & $35-44$ & $16+$ & 10 & Y1-2 & Teacher & Dunedin & Basic \\
\hline Chad & $35-44$ & $16+$ & 10 & Y5-6 & $\begin{array}{l}\text { Lead } \\
\text { teacher } \\
\text { Māori }\end{array}$ & Wellington & Basic \\
\hline Jordan & $35-44$ & $6-10$ & 9 & Y5-6 & Teacher & Wellington & Basic \\
\hline Jane & $45-54$ & $6-10$ & 9 & Y5-6 & Teacher & Nelson & Basic \\
\hline Jolene & $55-64$ & $11-15$ & 9 & Y5-6 & $\begin{array}{l}\text { Senior } \\
\text { teacher }\end{array}$ & Wellington & Basic \\
\hline Gwen & $35-44$ & $6-10$ & 10 & Y5-6 & Teacher & Wellington & Basic \\
\hline Catriona & $35-44$ & $11-15$ & 10 & Y1-2 & Teacher & Wellington & Basic \\
\hline Kerry & $25-34$ & $6-10$ & 9 & Y3-4 & $\begin{array}{l}\text { Senior } \\
\text { teacher }\end{array}$ & Auckland & Basic \\
\hline Ainsley & $25-34$ & $6-10$ & 9 & Y1-2 & $\begin{array}{l}\text { Lead } \\
\text { teacher } \\
\text { Māori }\end{array}$ & Wellington & Basic \\
\hline
\end{tabular}




\begin{tabular}{|c|c|c|c|c|c|c|c|}
\hline Marg & $35-44$ & $11-15$ & 9 & Y5-6 & Teacher & $\begin{array}{l}\text { Bay of } \\
\text { Plenty }\end{array}$ & Limited \\
\hline Summer & $55-64$ & $11-15$ & 8 & Y1-2 & Teacher & Wellington & Limited \\
\hline Rikki & $25-34$ & $3-5$ & 8 & $Y 3-4$ & $\begin{array}{l}\text { Lead } \\
\text { teacher } \\
\text { Māori }\end{array}$ & Waikato & Basic \\
\hline Ellen & $45-54$ & $3-5$ & 8 & Y1-2 & Teacher & Wellington & Basic \\
\hline Jamesina & $45-54$ & $16+$ & 8 & Y1-2 & Teacher & Gisborne & Basic \\
\hline Bentley & $25-34$ & $3-5$ & 8 & Y5-6 & Teacher & Northland & Good \\
\hline Bex & $35-44$ & $1-2$ & 8 & Y5-6 & Teacher & Wellington & Basic \\
\hline Hannah & $35-44$ & $16+$ & 7 & $\mathrm{Y} 3-4$ & Teacher & Taranaki & Basic \\
\hline Roberta & $45-54$ & $16+$ & 7 & Y3-4 & $\mathrm{DP} / \mathrm{AP}^{\mathrm{a}}$ & Wellington & Basic \\
\hline Trina & $25-34$ & $11-15$ & 7 & Y1-2 & Teacher & Waikato & Limited \\
\hline Goldie & $35-44$ & $11-15$ & 7 & Y3-4 & Teacher & Christchurch & Basic \\
\hline Sasha & $35-44$ & $6-10$ & 6 & $Y 5-6$ & Teacher & Auckland & Basic \\
\hline Gemma & $25-34$ & $6-10$ & 5 & Y1-2 & Teacher & $\begin{array}{l}\text { Bay of } \\
\text { Plenty }\end{array}$ & Limited \\
\hline Dee & $45-54$ & $6-10$ & 5 & $Y 5-6$ & $\begin{array}{l}\text { Senior } \\
\text { teacher }\end{array}$ & $\begin{array}{l}\text { Bay of } \\
\text { Plenty }\end{array}$ & Limited \\
\hline Delta & $55-64$ & $16+$ & 5 & Y5-6 & Teacher & Wellington & Limited \\
\hline Maria & $35-44$ & $1-2$ & 3 & Y1-2 & $\begin{array}{l}\text { Beginning } \\
\text { teacher }\end{array}$ & Auckland & Basic \\
\hline Heather & $55-64$ & $6-10$ & 2 & $Y 3-4$ & Teacher & Auckland & Basic \\
\hline Dreena & $35-44$ & $16+$ & 1 & $\mathrm{Y} 1-2$ & Teacher & Christchurch & Good \\
\hline Zoe & $35-44$ & $6-10$ & 1 & Y5-6 & Teacher & Waikato & Basic \\
\hline Jamie & $35-44$ & $16+$ & 1 & Y5-6 & Teacher & Wellington & Basic \\
\hline Shari & $35-44$ & $1-2$ & 1 & Y1-2 & Teacher & Waikato & Basic \\
\hline Grace & $25-34$ & $11-15$ & 1 & $Y 3-4$ & $\begin{array}{l}\text { Senior } \\
\text { teacher }\end{array}$ & Hawkes Bay & Basic \\
\hline
\end{tabular}

${ }^{a}$ Deputy principal/assistant principal 


\subsubsection{Class levels of participants}

Teachers' responses to Question 45, about their class levels, indicated that a slightly greater number of respondents $(n=17)$ worked in the senior classes of the primary school (i.e. Year 5-6 classes, aged approximately 9-11). Nine respondents were working in the middle classes of the primary school (i.e. Year 3-4 classes, aged approximately 7-9) - and 14 were teaching in the junior school (i.e. Year 1-2 classes, aged approximately 5-7).

Junior classes are important for laying good foundations and instilling enjoyment in learning Māori language, before students progress to more complex language further up the school. There is more scope for teachers in senior classes to go beyond aural-oral activities and facilitate simple Māori language tasks that require some reading and writing. There is also the potential for these teachers to build on students' prior learning in the lower levels of the school, to establish a language progression. This aspect was discussed in a research report associated with the NMSSA programme (Ministry of Education, 2018). In the findings, the researchers emphasised how important it was for English-medium primary teachers to lift the level of te reo Māori in their schools - a task made harder due to the bulk of Ministry-produced resources being targeted at the early levels of the curriculum (Ministry of Education, 2017).

\subsubsection{Self-identified roles of teacher participants}

The online questionnaire respondents were asked, in Question 44, to self-identify their role in the school - from a choice of categories: teacher, lead teacher of Māori language, senior teacher, Deputy Principal/Assistant Principal, principal, and 'other'.

In their quintessential paper on identity, Bucholtz and Hall (2005, p. 586) suggest that identity is “... the social positioning of self and other”. My participants' self-positioning allowed me to see how they perceived their identity relative to others in the wider educational landscape - in terms of, for example, sameness/difference; authority/disempowerment; and mana/lack of status.

\subsubsection{Teachers}

Most of the respondents ( $\mathrm{n}=30$ ) self-identified as 'teacher'; as in Figure 4.1 below. Based on this, it is likely that the teaching of te reo Māori in English-medium Year 1-6 classes falls mainly to classroom teachers like them (as opposed to lead teachers of Māori, senior management or other people). 
These teachers will be aware of the expectations set down in Tátaiako (Ministry of Education, 2011, p. 2) regarding the 'cultural locatedness' that a teacher needs in order to help Māori students achieve educationally; namely: knowing how to validate and affirm Māori (and iwi-specific) culture; and applying that knowledge.

\section{Figure 4.1: Roles of research participants}

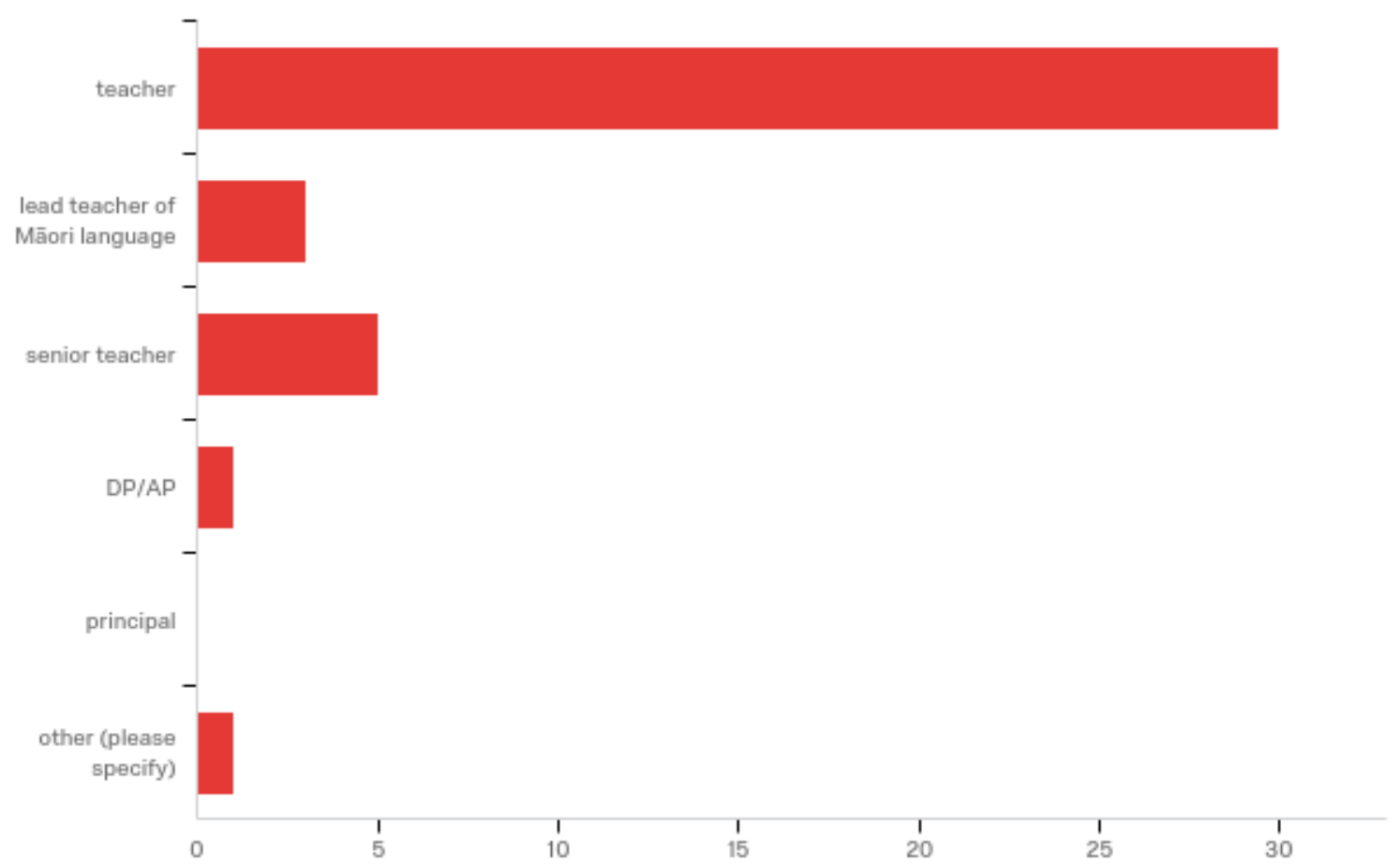

\subsubsection{Lead teachers of Māori language}

Of the other questionnaire respondents (see Figure 4.1 above), three described themselves as 'lead teachers of Māori'. These positions are likely to be associated with extra remuneration, allocated as 'units'. Such units help to develop leadership capacity and career pathways. Schools are required to give due consideration to the allocation of these units across the different curriculum areas. The intent is to distribute leadership and responsibility, aligned to a school's strategic direction. The fact that only three lead teachers of Māori responded to the questionnaire may indicate that very few of the participants' schools have made the teaching and learning of Māori language a strategic priority by appointing a lead teacher in this area.

There is an expectation from the colleagues of reo Māori lead teachers, as set out in job descriptions, that lead teachers will take on additional responsibility for the school-wide planning and implementation of te reo Māori. It is worth noting that these lead teachers are not necessarily Māori themselves, nor do they need any in-depth knowledge of the language 
beyond the basics. However, based on my experience in primary schools, these are teachers with an open disposition towards Māori language - and an appreciation of its value.

\subsubsection{School leaders}

School leaders (including principals) will be aware of the expectations set down in Tãtaiako (Ministry of Education, 2011, p. 2) regarding the 'cultural locatedness' that is required to help Māori students achieve educationally; namely, “ ... being able to lead and engage others in validating and affirming Māori and iwi culture."

Five of the questionnaire respondents described themselves as 'senior teachers'; and one as a 'deputy/assistant principal'. (See Figure 4.1 above). These are important roles in the school, in terms of supporting teachers to implement the curriculum, including Māori language. As discussed later in section 4.3.4.10.5, Ministry research (BES) conducted by Timperley et al (2007) emphasised how important it was for school leaders and senior management to be actively involved in PD (i.e. setting an example from the top). Otherwise teachers can become demotivated and unenthusiastic about the prospect of new learning, including te reo Māori. Similarly, recent research conducted by Haemata (2019), looking at the teaching of te reo Māori in English-medium settings, pointed to the value of having school leaders who appreciate te reo Māori and understand the importance of the language in $\mathrm{NZ} \mathrm{-} \mathrm{so} \mathrm{that} \mathrm{a} \mathrm{strong} \mathrm{reo} \mathrm{programme} \mathrm{can} \mathrm{be} \mathrm{created} \mathrm{and} \mathrm{sustained} \mathrm{in} \mathrm{the} \mathrm{school.}$

The fact that no principals completed the questionnaire may be because respondents were invited to participate via the Facebook page for primary school teachers. Perhaps there are few principals who access this avenue - or they may have regarded their participation as inappropriate, because of the target audience being classroom teachers. Alternatively, they may not have prioritised the opportunity to impart their views on te reo Māori - in the face of other pressing priorities associated with running a school (e.g. managing staff; prioritising budgets; reporting to whānau and the Ministry).

\subsubsection{Experiences of teacher participants}

The Ministry was unable to advise on the average years' teaching experience among Year 1-6 English-medium primary teachers. (Personal communication with Bea Wooding, Advisor, Information Requests, Ministry of Education, 28 November 2017). It is therefore impossible to state whether most of the teachers in this study are representative of Year 16 teachers nationwide - in terms of longevity in the profession. As can be seen in Figure 
4.2 below, responses to Question 43 indicated that the biggest number of teacher participants $(n=13)$ had been teaching for 6-10 years.

The smallest number of respondents $(n=4)$ were teachers with 3-5 years' experience, having recently become fully registered teachers (within the past 1-3 years). In addition, there were six beginning teachers, still required to do two years' service before becoming fully registered. There is much for new teachers to learn e.g. what to teach, how to teach, and how to relate to (and manage) students. Some will adhere to a more formal approach, feeling constrained by their low Māori language proficiency - which may inhibit good teacher:learner relationships (Richards, 2017).

There are implications for Māori language in English-medium primary schools, where most of the teachers (like my research participants) are not very experienced in teaching te reo regardless of their years of service. Being expected by the Ministry to integrate the language into their classroom (often with the added constraints of poor resourcing and no PD), they seek to find the right balance between adopting a formal teacher persona (where Māori language lessons are necessarily structured, due to their own low proficiency) or a more personable self (where relationships are the precursor to effective Māori language learning i.e. whakawhanaungatanga).

Figure 4.2: Teacher participants' years of experience

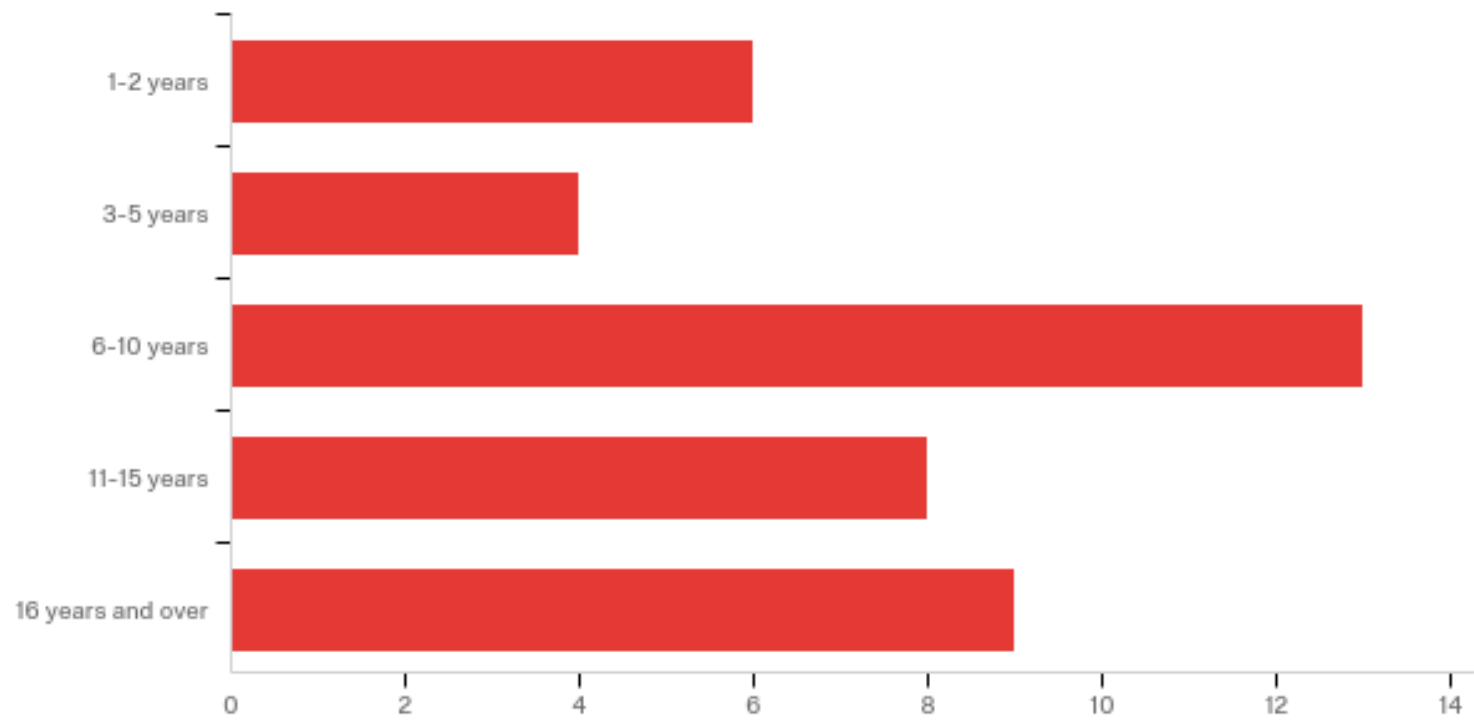

Fairly evenly distributed were the long-standing teachers with over 16 years' experience $(n=9)$, and teachers with 11-15 years' experience $(n=8)$ - as shown in Figure 4.2 above. When these two groups are combined with the questionnaire respondents who had 6-10 
years experience $(n=13)$, it forms a large group comprising 30 experienced teachers. This contrasts with the relatively small group of 'novice' teacher respondents $(n=10)$ with less than six years' experience i.e. either beginning teachers $(n=6)$ or recently registered teachers $(n=4)$. That is, in this study, experienced teachers outnumbered novice teachers 3:1, compared with the national ratio of nearly 4:1 - based on Ministry data, which indicates that there are 10,383 experienced teachers (with 6+ years experience) in English-medium primary settings and 2,783 novice teachers (with less than 6 years' experience). (Personal communication with Bea Wooding, Advisor, Information Requests, Ministry of Education, 28 November 2017).

The greater number of experienced teacher participants is probably attributable to the fact that they represent a bigger pool of the teaching profession in English-medium primary schools. However, it may also be because of their responsiveness to a shift, over time, where Māori language has gained a higher profile in such schools. Figure 4.3 below (Haemata, 2019, p. 27) shows the upward trend in the number of primary school students learning te reo Māori in English-medium settings in the past decade, 2008-2018. The steady growth is especially noticeable in the last five years, 2014-2018, where there has been an increase of almost 27,000 students - which is nearly four times the increase in the previous five years, 2008- 2013.

This data suggests that primary school teachers and students in English-medium settings are increasingly recognising the need to embrace te reo Māori. 
Figure 4.3: Number of primary students learning Māori in English-medium, 2008-2018 (extracted from Haemata 2019, p. 27, Figure 3)

Number of primary students learning Māori in English-medium (2008-2018)

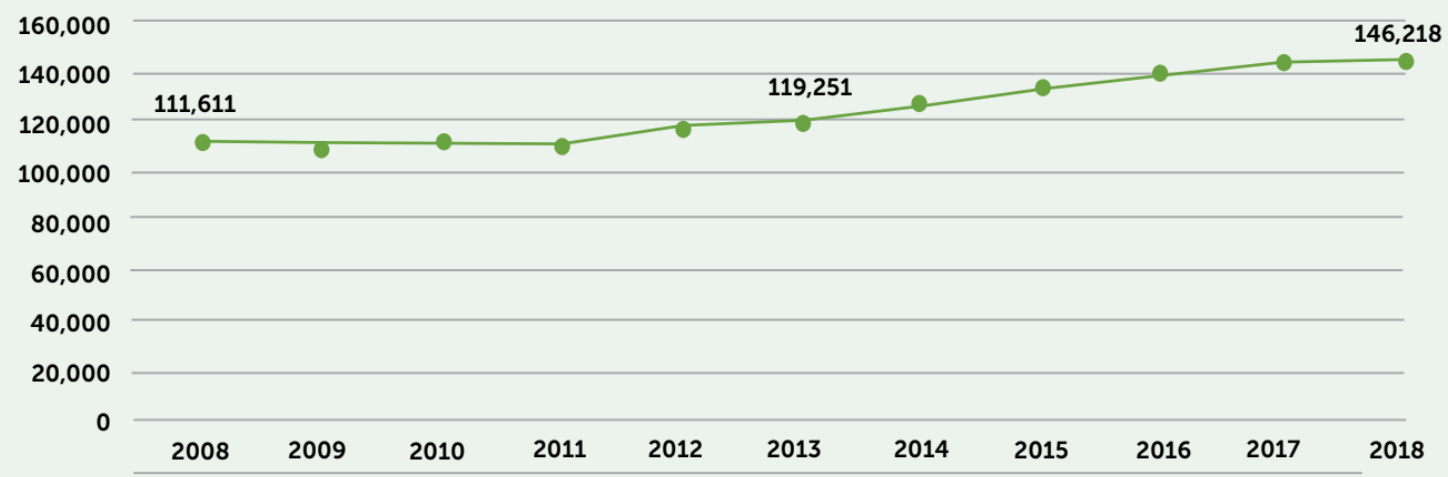

Figure 3: Number of primary students learning Māori in English-medium settings (2008-2018)

\subsubsection{Māori language speaking ability}

One of the primary school principals in case study research by Barr and Seals (2018) recognised that students' exposure to Māori language was very much dependent on the proficiency of their teacher. In my questionnaire (Question 40), eleven teachers rated their speaking ability at the lowest level of the self-rating scale; namely, 'limited'. The largest number of respondents $(\mathrm{n}=27)$ rated their speaking ability one step up, as 'basic'. Above that, only two teachers described their speaking ability as 'good' 114 and none of them rated their proficiency as being 'very good'115.

Based on these findings, it is likely that Māori language proficiency is an issue for most English-medium primary teachers, which will naturally impact on their use of te reo. This lack of proficiency was borne out in recent evaluative research by Haemata (2019), in its investigation of te reo Māori in English-medium compulsory education. The findings showed that the low level of proficiency among English-medium primary teachers inhibited their ability to deliver a quality reo Māori programme. Too often, cultural aspects (e.g. waiata and kapa haka) were prioritised over the language. Similarly, in a national survery of primary and intermediate schools, Bright and Wylie (2017) found that, in their efforts to

\footnotetext{
${ }^{114}$ Able to communicate meaningfully, in familiar contexts, using common words and simple grammatical structures

${ }^{115}$ Able to communicate with ease, in a variety of contexts, using a wide range of vocabulary and language structures
} 
address differential achievement, schools were foussing more on tikanga than te reo. This 'avoidance' of Māori language is likely due to teachers' lack of confidence and competence in the language.

As stated later, regarding Belief Statement 18, the Ministry does not collect data on the proficiency of these teachers. (Personal communication with Bea Wooding, Advisor, Information Requests, Ministry of Education, 28 November 2017). But it is inevitable that teacher proficiency is a factor that affects student learning.

\subsubsection{Age range of teacher participants}

Ministry data shows that the average age for an experienced teacher (6+ years experience) in English-medium primary schools is 48 years - while the average age for novice teachers (with less than 6 years' experience) is 32 years. (Personal communication with Bea Wooding, Advisor, Information Requests, Ministry of Education, 28 November 2017).

Responses to Question 42 (Appendix 5), about teachers' ages, indicated that the biggest number of teachers in this study $(n=18)$ were in the middle age range (i.e. $35-44$ years old). The greater response to my questionnaire from this cohort may have been due to their familiarity and comfortability with Facebook (where my invitation to participate first appeared) - moreso than the eight teachers in the older range (45-54 years) and the four teachers aged 55 - 64 years. (See Figure 4.4 below). There was no teacher at the extreme ends of the scale - aged 65 or older, or in the youngest age group (18-24 years). There were, however, ten respondents aged 25-34 years. 
Figure 4.4: Teacher participants' age range

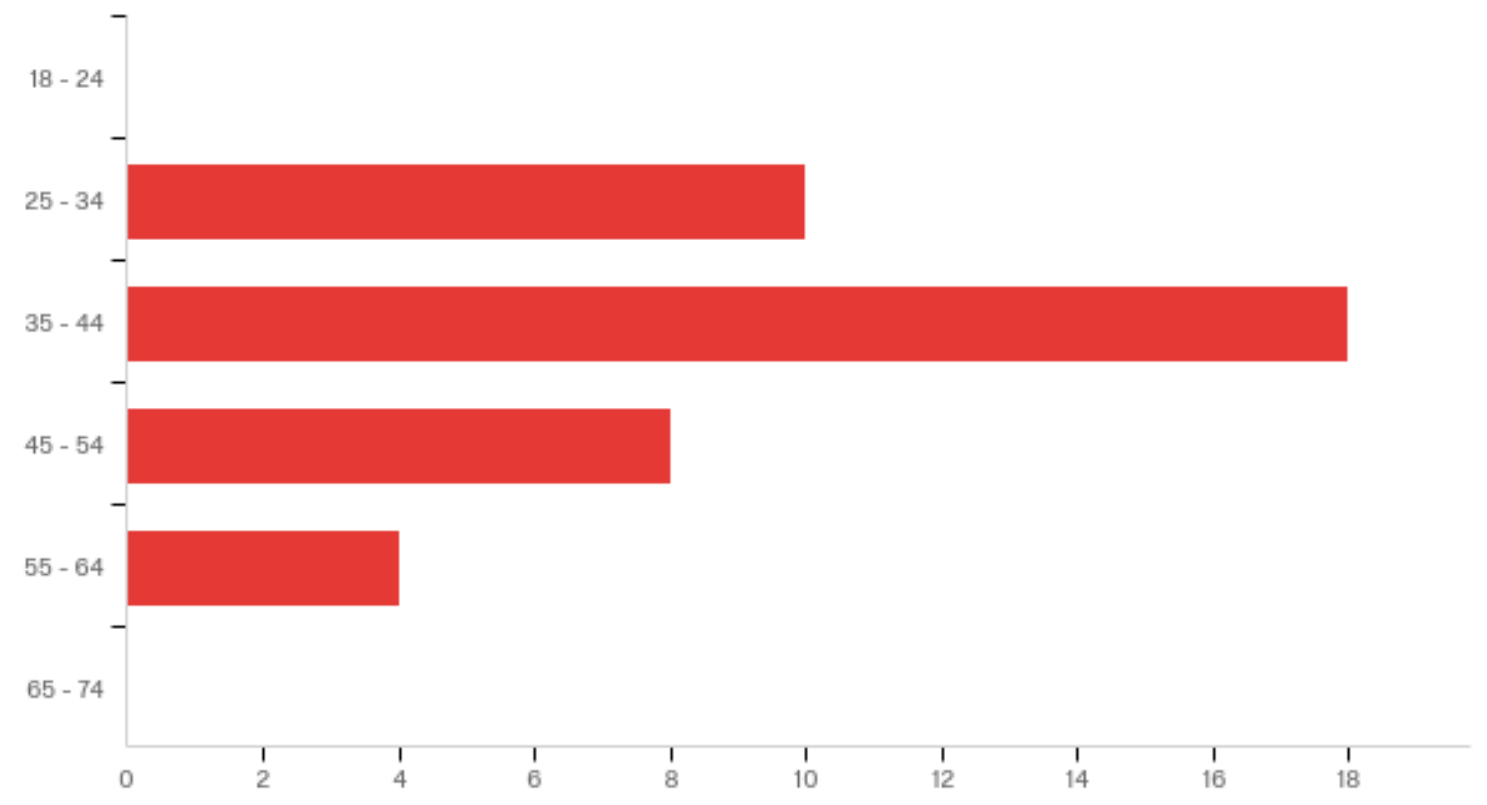

It is interesting to note that, as shown in Table 4.2 below, the six respondents with less than two years' experience did not come from the younger age brackets (18-24 and 25-34). Five of them were aged 35-44, and one was in an even older age bracket (45-54). This may indicate that people are deferring their choice to pursue teaching until later in life - after having done other things. That is, they are not leaving school and heading straight to teacher training. This suggests that their decision to go teaching is well considered and purposeful. 
Table 4.2: Teacher participants' years of experience in ranked order (most to least experienced)

\begin{tabular}{|c|c|c|c|c|c|c|c|}
\hline Pseudonym & Age & $\begin{array}{l}\text { Years' } \\
\text { experience }\end{array}$ & Decile & $\begin{array}{l}\text { Class } \\
\text { level }\end{array}$ & Role & Region & $\begin{array}{l}\text { Reo } \\
\text { ability }\end{array}$ \\
\hline Dreena & $35-44$ & $16+$ & 1 & Y1-2 & Teacher & Christchurch & Good \\
\hline Jamesina & $45-54$ & $16+$ & 8 & Y1-2 & Teacher & Gisborne & Basic \\
\hline Shevon & $35-44$ & $16+$ & 10 & Y5-6 & $\begin{array}{l}\text { Senior } \\
\text { teacher }\end{array}$ & Waikato & Basic \\
\hline Hannah & $35-44$ & $16+$ & 7 & Y3-4 & Teacher & Taranaki & Basic \\
\hline Roberta & $45-54$ & $16+$ & 7 & Y3-4 & $\mathrm{DP} / \mathrm{AP}^{\mathrm{a}}$ & Wellington & Basic \\
\hline Tatiana & $35-44$ & $16+$ & 10 & Y1-2 & Teacher & Dunedin & Basic \\
\hline Chad & $35-44$ & $16+$ & 10 & Y5-6 & $\begin{array}{l}\text { Lead } \\
\text { teacher } \\
\text { Māori }\end{array}$ & Wellington & Basic \\
\hline Jamie & $35-44$ & $16+$ & 1 & Y5-6 & Teacher & Wellington & Basic \\
\hline Delta & $55-64$ & $16+$ & 5 & Y5-6 & Teacher & Wellington & Limited \\
\hline Jolene & $55-64$ & $11-15$ & 9 & Y5-6 & $\begin{array}{l}\text { Senior } \\
\text { teacher }\end{array}$ & Wellington & Basic \\
\hline Goldie & $35-44$ & $11-15$ & 7 & Y3-4 & Teacher & Christchurch & Basic \\
\hline Grace & $25-34$ & $11-15$ & 1 & Y3-4 & $\begin{array}{l}\text { Senior } \\
\text { teacher }\end{array}$ & Hawkes Bay & Basic \\
\hline Jessie & $45-54$ & $11-15$ & 10 & Y1-2 & Teacher & Auckland & Limited \\
\hline Trina & $25-34$ & $11-15$ & 7 & Y1-2 & Teacher & Waikato & Limited \\
\hline Catriona & $35-44$ & $11-15$ & 10 & Y1-2 & Teacher & Wellington & Basic \\
\hline Summer & $55-64$ & $11-15$ & 8 & Y1-2 & Teacher & Wellington & Limited \\
\hline Marg & $35-44$ & $11-15$ & 9 & Y5-6 & Teacher & $\begin{array}{l}\text { Bay of } \\
\text { Plenty }\end{array}$ & Limited \\
\hline Dee & $45-54$ & $6-10$ & 5 & Y5-6 & $\begin{array}{l}\text { Senior } \\
\text { teacher }\end{array}$ & $\begin{array}{l}\text { Bay of } \\
\text { Plenty }\end{array}$ & Limited \\
\hline Sheena & $25-34$ & $6-10$ & 10 & Y5-6 & Teacher & Auckland & Basic \\
\hline Gemma & $25-34$ & $6-10$ & 5 & Y1-2 & Teacher & $\begin{array}{l}\text { Bay of } \\
\text { Plenty }\end{array}$ & Limited \\
\hline Gwen & $35-44$ & $6-10$ & 10 & Y5-6 & Teacher & Wellington & Basic \\
\hline Zoe & $35-44$ & $6-10$ & 1 & Y5-6 & Teacher & Waikato & Basic \\
\hline Ainsley & $25-34$ & $6-10$ & 9 & Y1-2 & $\begin{array}{l}\text { Lead } \\
\text { teacher } \\
\text { Māori }\end{array}$ & Wellington & Basic \\
\hline Jordan & $35-44$ & $6-10$ & 9 & Y5-6 & Teacher & Wellington & Basic \\
\hline
\end{tabular}




\begin{tabular}{|c|c|c|c|c|c|c|c|}
\hline Jane & $45-54$ & $6-10$ & 9 & Y5-6 & Teacher & Nelson & Basic \\
\hline Janet & $25-34$ & $6-10$ & 10 & Y1-2 & Teacher & Auckland & Limited \\
\hline Heather & 55-64 & $6-10$ & 2 & Y3-4 & Teacher & Auckland & Basic \\
\hline Sasha & $35-44$ & $6-10$ & 6 & Y5-6 & Teacher & Auckland & Basic \\
\hline Kerry & $25-34$ & $6-10$ & 9 & Y3-4 & $\begin{array}{l}\text { Senior } \\
\text { teacher }\end{array}$ & Auckland & Basic \\
\hline Riina & $45-54$ & $6-10$ & 10 & Y1-2 & Teacher & Wellington & Limited \\
\hline Ellen & $45-54$ & $3-5$ & 8 & Y1-2 & Teacher & Wellington & Basic \\
\hline Rikki & $25-34$ & $3-5$ & 8 & Y3-4 & $\begin{array}{l}\text { Lead } \\
\text { teacher } \\
\text { Māori }\end{array}$ & Waikato & Basic \\
\hline Bentley & $25-34$ & $3-5$ & 8 & Y5-6 & Teacher & Northland & Good \\
\hline Natania & $25-34$ & $3-5$ & 10 & Y3-4 & Teacher & Wellington & Basic \\
\hline Nate & $35-44$ & $1-2$ & 10 & Y5-6 & Teacher & Manawatū & Limited \\
\hline Lexi & $35-44$ & $1-2$ & $1-10$ & Y3-4 & $\begin{array}{l}\text { Relief } \\
\text { teacher }\end{array}$ & Wellington & Basic \\
\hline Laurel & $45-54$ & $1-2$ & 10 & Y5-6 & Teacher & Auckland & Limited \\
\hline Shari & $35-44$ & $1-2$ & 1 & Y1-2 & Teacher & Waikato & Basic \\
\hline Maria & $35-44$ & $1-2$ & 3 & Y1-2 & $\begin{array}{l}\text { Beginning } \\
\text { teacher }\end{array}$ & Auckland & Basic \\
\hline Bex & $35-44$ & $1-2$ & 8 & Y5-6 & Teacher & Wellington & Basic \\
\hline
\end{tabular}

a Deputy principal/assistant principal

${ }^{b}$ Because Lexi is a relief teacher in many schools, she teaches across a range of deciles 


\subsection{Belief statements}

Teachers who voluntarily accessed the online questionnaire (Appendix 5) on social media (Facebook) were asked, in Questions 1-27, to respond to a range of belief statements about Māori language teaching and learning - by selecting YES or NO or UNSURE (whichever of the three options best reflected their beliefs).

Beliefs in teacher cognition research have been variously described as: 'culture of teaching' (Richards, Tung and Ng, 1992), 'conceptions of practice' (Freeman, 1993), 'theories of practice' (Burns, 1996), 'routines' (Crookes and Arakaki, 1999), 'personal pedagogical systems' (Borg, 1998c), 'pedagogical knowledge' (Gatbonton, 1999), 'pedagogical principles' (Breen, Hird, Milton, Oliver and Thwaite, 2001), and 'specific pedagogical knowledge' (Spada and Massey, 1992). My preferred definition of 'beliefs' is simple. It is taken from Meijer, Verloop and Beijaard (2001, p. 446); namely, one's 'personal values, attitudes and philosophies.'

I crafted the belief statements in the questionnaire after gaining insights from the successful use of this method by different researchers. For example (as outlined in Chapter 3), Lightbown and Spada (2013) created a list of agree/ disagree statements about language learning; Poulson, Avramidis, Fox, Medwell, and Wray (2010) created 28 belief statements associated with three reading approaches; Kinzer (1988) developed 15 statements about reading orientation, requiring participants to choose 5 of them; Wilson, Konopak, and Readence (1992) elicited teachers' beliefs by asking them to rate hypothetical teaching scenarios around lesson planning; Konopak and Williams (1994) asked participants to select four statements (out of twelve) that matched their beliefs about vocabulary learning; and Johnson (1992b) asked students to select one of three lesson plans that best reflected their beliefs. These approaches to eliciting teachers' beliefs informed my writing of the belief statements in this study, as did my experience as a teacher of te reo Māori and a Māori language adviser in schools. I also received suggestions from my $\mathrm{PhD}$ supervisors.

My quantitative summary of the 40 teacher respondents' stated beliefs is depicted below in Table 4.3, in the randomised order that the belief statements were presented in the questionnaire. 
Following the visual summary in Table 4.3, teacher responses to each individual Belief Statement are discussed - clustered under the following sub-headings:

- $\quad$ Teachers' philosophy and motivation (Belief Statements 27, 21, 26, 23, $20,19,22)$

- $\quad$ Language, culture and identity (Belief Statements 10, 15, 17)

- $\quad$ Teachers' knowledge (Belief Statements 18, 25, 5, 3)

- $\quad$ Teachers' classroom practices (Belief Statements 24, 9, 8, 6, 2, 7, 12, 13, $14,16,4)$

- $\quad$ External factors (Belief Statements 1, 11). 
Table 4.3: Quantitative summary of teacher participants' responses to belief statements ${ }^{a}$

\begin{tabular}{|c|c|c|c|c|}
\hline Question & Corresponding belief statement & Yes & No & Unsure \\
\hline 1 & $\begin{array}{l}\text { I believe that my teaching of te reo Māori } \\
\text { can be affected by external factors, over } \\
\text { which I have no control }\end{array}$ & $\mathrm{n}=\mathbf{2 6}$ & $\mathrm{n}=7$ & $\mathrm{n}=7$ \\
\hline 2 & $\begin{array}{l}\text { I believe that teachers should balance their } \\
\text { own speaking of Māori with practice } \\
\text { opportunities for students }\end{array}$ & $\mathbf{n}=\mathbf{3 8}$ & $\mathrm{n}=2$ & $\mathrm{n}=0$ \\
\hline 3 & $\begin{array}{l}\text { I believe I have the necessary Māori } \\
\text { language ability to depart from a planned } \\
\text { Māori lesson and make 'on the spot' } \\
\text { changes }\end{array}$ & $\mathrm{n}=10$ & $\mathrm{n}=6$ & $\mathbf{n}=\mathbf{2 4}$ \\
\hline 4 & $\begin{array}{l}\text { I believe that teachers need to consciously } \\
\text { include Māori language in their wider } \\
\text { curriculum planning }\end{array}$ & $\mathbf{n}=\mathbf{3 0}$ & $\mathrm{n}=9$ & $\mathrm{n}=1$ \\
\hline 5 & $\begin{array}{l}\text { I believe that primary teachers should know } \\
\text { a bit about the theory of second language } \\
\text { acquisition (SLA), to help them implement } \\
\text { interactive lessons that have real- life } \\
\text { application }\end{array}$ & $\mathbf{n}=\mathbf{3 0}$ & $\mathrm{n}=8$ & $\mathrm{n}=2$ \\
\hline 6 & $\begin{array}{l}\text { I believe that teachers need to provide many } \\
\text { different opportunities for students to } \\
\text { practise Māori language }\end{array}$ & $\mathbf{n}=\mathbf{3 7}$ & $\mathrm{n}=3$ & $\mathrm{n}=0$ \\
\hline 7 & $\begin{array}{l}\text { I believe students should participate in } \\
\text { individual, pair, group and whole class } \\
\text { activities when learning Māori }\end{array}$ & $\mathbf{n}=\mathbf{3 8}$ & $\mathrm{n}=2$ & $\mathrm{n}=0$ \\
\hline 8 & $\begin{array}{l}\text { I believe the emphasis should be on } \\
\text { listening and speaking when primary } \\
\text { school students are learning Māori }\end{array}$ & $\mathrm{n}=\mathbf{2 6}$ & $\mathrm{n}=10$ & $\mathrm{n}=4$ \\
\hline 9 & $\begin{array}{l}\text { I believe it's OK for teachers to use Māori } \\
\text { words or phrases in an English sentence, } \\
\text { if they can't say it all in Māori }\end{array}$ & $\mathbf{n}=\mathbf{3 5}$ & $\mathrm{n}=5$ & $\mathrm{n}=0$ \\
\hline
\end{tabular}




\begin{tabular}{|c|c|c|c|c|}
\hline 10 & $\begin{array}{l}\text { I believe it's important to try and integrate } \\
\text { tikanga Māori (cultural components) into } \\
\text { my teaching }\end{array}$ & $\mathrm{n}=\mathbf{3 9}$ & $\mathrm{n}=1$ & $\mathrm{n}=0$ \\
\hline 11 & $\begin{array}{l}\text { I believe there is a lack of quality Māori } \\
\text { resources, which hinders my ability to } \\
\text { incorporate te reo Māori into my teaching }\end{array}$ & $\mathrm{n}=19$ & $\mathrm{n}=11$ & $\mathrm{n}=10$ \\
\hline 12 & $\begin{array}{l}\text { I believe that teachers should include games, } \\
\text { activities and songs to make it fun to learn } \\
\text { Māori }\end{array}$ & $\mathrm{n}=\mathbf{4 0}$ & $\mathrm{n}=0$ & $\mathrm{n}=0$ \\
\hline 13 & $\begin{array}{l}\text { I believe that teachers should use a range of } \\
\text { Māori language materials to build } \\
\text { students' proficiency }\end{array}$ & $\mathrm{n}=\mathbf{3 8}$ & $\mathrm{n}=2$ & $\mathrm{n}=0$ \\
\hline 14 & $\begin{array}{l}\text { I believe it's important to adapt Māori } \\
\text { language materials to suit the diverse needs } \\
\text { of my students, so that they can achieve } \\
\text { some success learning Māori }\end{array}$ & $\mathbf{n}=\mathbf{3 8}$ & $\mathrm{n}=2$ & $\mathrm{n}=0$ \\
\hline 15 & $\begin{array}{l}\text { I believe that teachers should draw on } \\
\text { students' backgrounds/cultural } \\
\text { experiences to explain Māori words and } \\
\text { concepts e.g. pepeha }\end{array}$ & $\mathrm{n}=\mathbf{3 8}$ & $\mathrm{n}=2$ & $\mathrm{n}=0$ \\
\hline 16 & $\begin{array}{l}\text { I believe that students learn Māori language } \\
\text { better if there is a real-life context e.g. kai; } \\
\text { whānau }\end{array}$ & $\mathrm{n}=\mathbf{3 9}$ & $\mathrm{n}=1$ & $\mathrm{n}=0$ \\
\hline 17 & $\begin{array}{l}\text { I believe that teachers' use of Māori } \\
\text { language can enhance Māori student } \\
\text { achievement }\end{array}$ & $\mathbf{n}=\mathbf{3 7}$ & $\mathrm{n}=3$ & $\mathrm{n}=0$ \\
\hline 18 & $\begin{array}{l}\text { I believe that primary teachers should know } \\
\text { enough Māori language to use it at a basic } \\
\text { level in the classroom }\end{array}$ & $n=34$ & $\mathrm{n}=6$ & $\mathrm{n}=0$ \\
\hline 19 & $\begin{array}{l}\text { I believe that teachers should try to model } \\
\text { correct pronunciation of Māori }\end{array}$ & $\mathrm{n}=\mathbf{4 0}$ & $\mathrm{n}=0$ & $\mathrm{n}=0$ \\
\hline 20 & $\begin{array}{l}\text { I am motivated to learn Māori to help my } \\
\text { performance appraisal }\end{array}$ & $\mathrm{n}=\mathbf{2 6}$ & $\mathrm{n}=4$ & $\mathrm{n}=10$ \\
\hline 21 & $\begin{array}{l}\text { I believe that learning Māori should be } \\
\text { compulsory in NZ primary schools }\end{array}$ & $\mathrm{n}=\mathbf{3 6}$ & $\mathrm{n}=4$ & $\mathrm{n}=0$ \\
\hline 22 & $\begin{array}{l}\text { I believe that I don't have to be a native } \\
\text { Māori speaker to incorporate te reo into my } \\
\text { teaching }\end{array}$ & $n=40$ & $\mathrm{n}=0$ & $\mathrm{n}=0$ \\
\hline 23 & $\begin{array}{l}\text { I am motivated to learn Māori out of } \\
\text { personal interest }\end{array}$ & $\mathrm{n}=\mathbf{3 5}$ & $\mathrm{n}=4$ & $\mathrm{n}=1$ \\
\hline 24 & $\begin{array}{l}\text { I believe that primary teachers should be } \\
\text { able to integrate Māori language across the } \\
\text { curriculum }\end{array}$ & $\mathrm{n}=\mathbf{3 4}$ & $\mathrm{n}=3$ & $\mathrm{n}=3$ \\
\hline
\end{tabular}




\begin{tabular}{|l|l|l|l|l|}
\hline 25 & $\begin{array}{l}\text { I believe that the way I include te reo Māori } \\
\text { in my teaching is influenced by the way I } \\
\text { was taught Māori }\end{array}$ & $\mathbf{n}=\mathbf{1 8}$ & $\mathrm{n}=5$ & $\mathrm{n}=17$ \\
\hline 26 & $\begin{array}{l}\text { I am motivated to include Māori language } \\
\text { in my teaching }\end{array}$ & $\mathbf{n}=\mathbf{3 8}$ & $\mathrm{n}=1$ & $\mathrm{n}=1$ \\
\hline 27 & $\begin{array}{l}\text { I believe it's important for all NZ primary } \\
\text { school students to learn Māori }\end{array}$ & $\mathbf{n}=\mathbf{3 9}$ & $\mathrm{n}=0$ & $\mathrm{n}=1$ \\
\hline
\end{tabular}

aThe bolded numerical values indicate the teachers' majority beliefs; the bolded text draws the reader's attention to the essence of each Belief Statement. No bolding was used in the formatting of the questionnaire presented to respondents.

\subsubsection{Teachers' philosophy and motivation}

Overwhelmingly, the teachers saw value in the teaching and learning of Māori language in NZ schools, such that most believed it should be compulsory. Consequently, they were motivated to teach the language in their classrooms. They deemed it was important to model correct pronunciation - but not to have native speaker fluency. These aspects are discussed in more detail below.

\subsubsection{Belief statement 27 - Importance of te reo for NZ primary students}

All but one of the teachers agreed that learning te reo Māori was important for all NZ primary school students. Similarly, case study research by Barr and Seals (2018) found that teacher (and principal) participants were all positive about te reo Māori in primary school settings. Furthermore, in research conducted as part of the NMSSA programme (Ministry of Education, 2018), most of the participating teachers believed it was important that students learnt Māori - because of its status as an official language and a valued aspect of NZ society. Those teachers, like my research participants, believed that the language had a role to play in shaping the culture and identity of Aotearoa NZ.

\subsubsection{Belief statement 21 - Compulsory reo Māori}

In line with the respondents' beliefs about the importance of te reo Māori were their beliefs about the language being compulsory. There was very strong agreement (90\%) that te reo Māori should be compulsory in primary schools $(n=36)$. This is a firm stance, considering that most primary school teachers would need to invest much time and energy in PD to upskill in this area. Moreover, they would have to manage the consequences of Māori language being added to an already crowded curriculum - which is perhaps why four teacher participants remained unsure. Nevertheless, the overwhelming belief that Māori language should be compulsory in their sector suggests that these respondents feel te reo is 
important enough to accommodate into their busy classroom programmes. This positivity is consistent with TPK's (2010) survey of New Zealanders' attitudes, values and beliefs about te reo Māori, where $64 \%$ of non-Māori respondents agreed that the language should be compulsory in schools.

The high number of positive responses in my study could of course be due to 'face-saving' behaviour. That is, some teacher participants may have been fearful to appear anything other than supportive and affirmative - due to the increased visibility nowadays of Māori language and culture in teaching (and in wider Aotearoa NZ). For those who may have lacked the confidence to show their disagreement, the inclusion of the 'unsure' option provided an 'out' $(n=4)$ - with reassurance that they would not be adversely judged.

As mentioned earlier in the literature review, the question of whether Māori language should be compulsory in schools is a contentious issue. It is worth noting that current government policy avoids using the term 'compulsory', possibly due to the negative connotations (for many people) of the word 'compulsory'; that is, some people feel resentful at being made to do something. The Chief Executive of the Māori Language Commission, Ngahiwi Apanui, chooses to avoid the word 'compulsory'. Instead, he recommends making the language a 'core' component of the curriculum in primary and secondary school settings (Māori Language Commission, 2017).

To achieve this goal, a staggered approach is suggested - over 17 years. The proposed plan would begin with Year 1 students in 2020, rolling out in each successive school year until all Year 1-13 students were accommodated. There would likely be support from students themselves - as evidenced in a national online survey conducted by the NZ School Trustees Association (NZSTA) together with the Office of the Children's Commissioner (OCC) in 2018. The primary and secondary school student respondents $(n=1500)$ were keen to see compulsory reo Māori classes introduced into the education system.

\subsubsection{Belief statement 26 - Motivation for teaching te reo Māori}

Aligned with the teacher respondents' beliefs about the importance of te reo Māori in primary schools, and making it compulsory in that sector, was their motivation. Almost all of them ( $n=38)$ were motivated to include Māori language in their classroom programme. Additionally, in the NMSSA study (Ministry of Education, 2018), most of the participating teachers indicated that they enjoyed teaching te reo Māori. 
These findings reinforce the genuine positivity amongst the teacher respondents about the special place that te reo Māori has in Aotearoa NZ. They recognise that, as the Indigenous language, it has a part to play in terms of what it means to be a NZ citizen - even as a nonMāori. Interestingly though, when lodging applications for NZ citizenship, applicants are not given basic instruction in, nor are they expected to know about, te reo Māori - despite Māori language and cultural components being incorporated into the citizenship process, such as the application forms and citizenship ceremony. (Personal communication with Anna Morgan, Advisor, Department of Internal affairs, 30 November 2017).

An alternative explanation for my questionnaire respondents' strong motivation to teach Māori could be their sheer acceptance and resignation that this is the status quo in NZ classrooms, due to Ministry expectations set out in the national curriculum. That is, they feel they have no choice. Research conducted by the Ministry of Education (2017) found that such expectations presented a challenge for English-medium teachers. They felt undue pressure to have the requisite local knowledge and tikanga knowledge - with very little support in the form of resources or PD. Because of their limited knowledge, they had to work out for themselves what was appropriate and realistic to teach.

\subsubsection{Belief statements 23 and 20 - Motivation for teachers to learn te reo}

It is often assumed that someone who is unsuccessful in learning a second language must be lacking the desire to learn. However, Norton-Peirce (1995) highlights that the situation is in fact more complex. She asserts that successful language learning can be influenced by the power relationship between learners and speakers of the target language. An example in Aotearoa NZ would be a non-Māori teacher being so mindful of not having proprietary rights to te reo that it becomes a barrier to their use of the language in the classroom.

Most of my respondents $(n=35)$ reported that they were intrinsically motivated to learn te reo Māori - out of personal interest, for personal satisfaction, or for a sense of achievement (see Figure 4.6 below). These positive responses affirm a recognition of the inherent value of the Māori language, and its contribution to our identity as New Zealanders (i.e. a symbol of nationhood). 
Figure 4.6: Teachers' motivation to learn te reo Māori out of personal interest

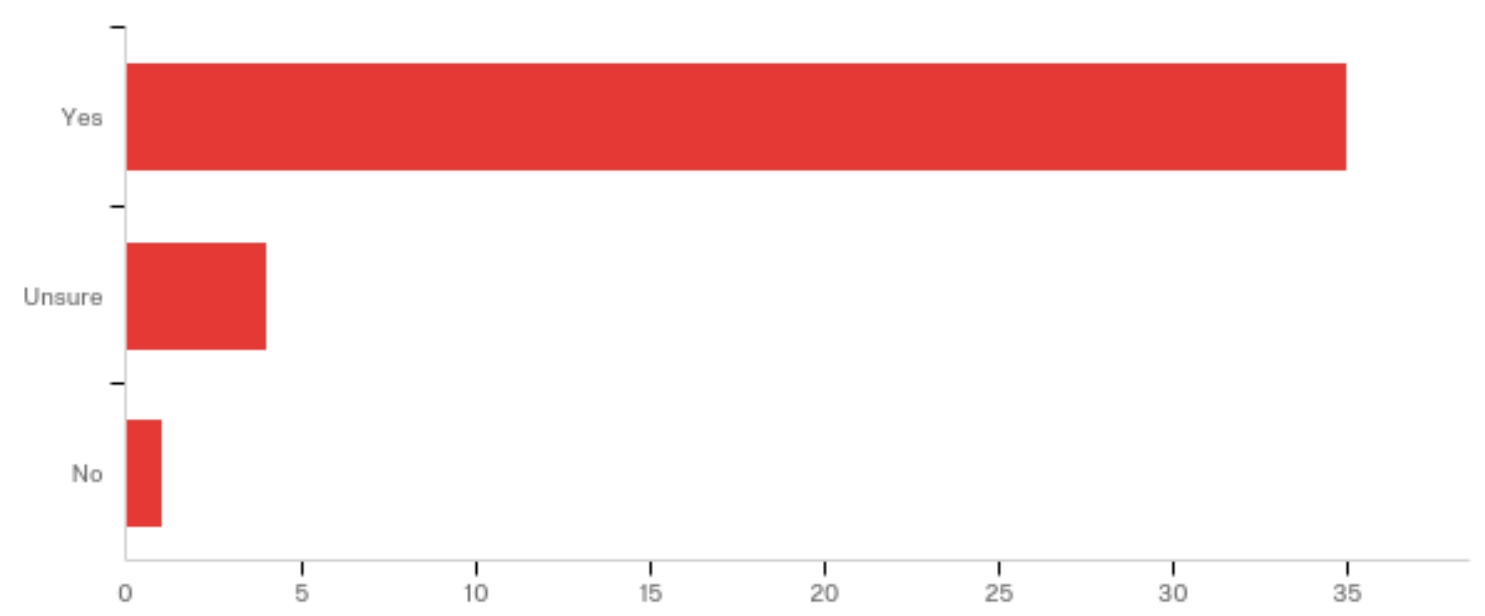

Interestingly, while investigating NZ teacher trainees' attitudes and motivations towards learning Māori language, Pine (2018) ${ }^{116}$ found a mismatch in that, despite holding positive attitudes towards learning te reo, the trainees did not intend to continue their study of te reo Māori beyond their pre-service education. His participants also reported that accessing Māori-speaking communities required much time and effort. As highlighted by Nation (2014), when too much effort is required to seek out practice opportunities, it is more likely that a learner will give up.

In my study, over half the teachers $(n=26)$ expressed a belief that performance appraisal provided motivation for them to learn Māori, due to knowledge of the language being advantageous in their teaching careers. Ten other participants disagreed - and four were reportedly unsure. (See Figure 4.7 below). By selecting the 'unsure' option, they were able to avoid a response that could be perceived as being socially unacceptable in terms of leaving the impression that they were motivated to teach te reo Māori because of extrinsic rewards or affirmations. Their stated uncertainty could be because of their desire to:

- $\quad$ maintain a degree of political correctness; and /or

- $\quad$ retain the 'halo' effect (Mackey and Gass, 2015), in terms of aiming to impress (or not wanting to offend) the researcher.

\footnotetext{
${ }^{116}$ http://journal.mai.ac.nz/content/teacher-trainees\%E2\%80\%99-attitudes-and-motivations-towardslearning-te-reo-m\%C4\%81ori. MAI Journal, Volume 7, Issue 2 (2018).
} 
Figure 4.7: Teachers' motivation to learn te reo Māori to enhance performance appraisal

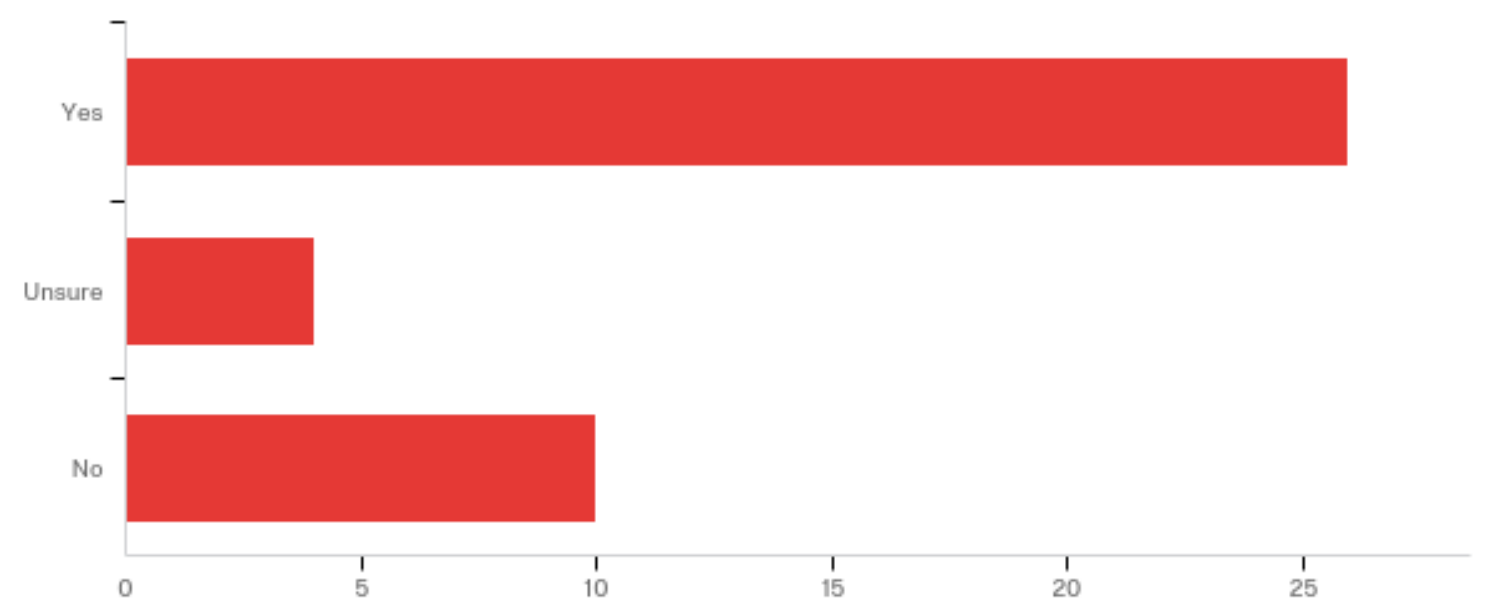

Extrinsically motivated teachers could be primarily driven by the Ministry's expectation in the national curriculum to deliver te reo Māori to all students. Another lever coud be the increasing emphasis in schools on the cultural competencies outlined in Tãtaiako (Ministry of Education, 2011). These competencies contribute to the six Standards for the Teaching Profession (Education Council, 2017), which set out what it means to be a teacher in Aotearoa NZ. The standards are used in teachers' performance appraisals. To that end, many teachers would be motivated to include Māori language in their teaching programme - to demonstrate the first standard about commitment to the Treaty of Waitangi, which includes practising and developing the use of te reo and tikanga Māori. This in turn could enhance their career prospects or, at the very least, provide a way to avoid negative consequences.

There are examples beyond the teaching realm where people can be extrinsically motivated to learn and use Māori (e.g. in the media and in job applications). Many NZ broadcasters are now speaking Māori on-air (e.g. daily greetings and common phrases). However, this is not always met with approval (Radio NZ, 2017). A former leader of the National Party in Aotearoa NZ, Dr. Don Brash, caused a public furore by describing such efforts as 'virtue signalling' - implying that people who are learning and using te reo are motivated by the fact that others will then think better of them. Another example of extrinsic motivation, relating to job interviews, can be found at Victoria University of Wellington. Graduates applying for jobs (including teaching) can opt for extra tuition on how to respond to Treatyrelated questions in interviews - to increase their chance of being successful. 
These examples show the current regard given to te reo Māori and the Treaty - particularly in our changing public sector where there is increasing opportunity, and demand, for organisations to operate bilingually.

\subsubsection{Belief statements 19 and 22 - Pronunciation and native speaker fluency}

Congruent with their positive beliefs about the importance of Māori language, and their motivation to teach and learn the language themselves, the respondents were unanimous that teachers should model correct Māori language pronunciation. The fact that all of them agreed on this suggests a very high degree of awareness and sensitivity, in terms of their respect for te reo Māori and their desire to exercise a duty of care (i.e. manaakitanga and kaitiakitanga ${ }^{117}$ ) to maintain the language's integrity. They presumably believe this is something that is realistically achievable and worthy of effort, hence their positive response to Belief Statement 19 about pronunciation.

Alternatively, their positivity could emanate from their 'aspirational' identity (i.e. their idealised image of what constitutes a good teacher). As mentioned earlier in the literature review, in the discussion about problems defining teacher identity, Richards (2017) claims that a teacher's aspirational identity, with its associated insights and obligations, can conflict with their actual identity. He describes this phenomenon as identity stress, a state where teachers may perhaps find themselves covering up (e.g. for their poor pronunciation). One such example in case study research by Barr and Seals (2018) is the primary school teacher, Caroline. She was particularly aware of her inadequacies in pronunciation especially when trying to use the language in front of Māori students. She expressed how uncomfortable she became, because it felt artificial. Her aspiration to use te reo correctly in the classroom, to be deemed a good teacher, clearly caused stress. Indeed, Barr and Seals (2018) found that poor pronunciation of te reo Māori caused all three of their case study teacher participants to feel like outsiders.

In Core's exploratory research, nearly $69 \%$ of the English-medium teacher respondents highlighted that pronunciation was an area of weakness (CORE Education, 2018, p. 6). This is despite te reo being a language with a close phoneme:grapheme ${ }^{118}$ relationship and only 5 vowels, 8 consonants and 2 digraphs. Core's research found it was difficult to 'unlearn' poor pronunciation that had become entrenched over time. Moreover, teachers

\footnotetext{
117 Guardianship/stewardship

${ }^{118}$ Sound: Written form of a sound
} 
became nervous in case their attempts were criticised. One teacher acknowledged: "Pronunciation is a real problem for most staff" and another commented: "Pronunciation is ...a school focus (p. 6)."

Evidence from research by Macalister (2006) shows that Māori words are increasingly being used in NZ English (e.g. whānau/family; maunga/mountain). However, he found that these loan words were often mispronounced - not necessarily on purpose, but perhaps through a lack of awareness or effort. This situation exemplifies the phenomenon of 'microaggression', a term initially coined by psychiatrist Chester M. Pierce in the 1970s - in the context of racial bias. It refers to statements or actions that convey (intentionally or unintentionally) negative slights towards a marginalised group. One example that received nation-wide coverage in NZ in 2018, as reported in the Otago Daily Times newspaper (28.4.18), was that of a voice artist, Dave Ward, being specifically asked by an advertiser to deliberately mispronounce a NZ placename (Waimate) 'the white way'. He refused.

Another example of micro-aggression is that of teachers who mispronounce Māori students' names and downplay their error. Children's names are significant because they carry meaning and can evoke stories. Much consideration has gone into the choice of a child's name. And, for many minority groups, the name has ancestral and historical significance. For example, in the case of my own two sons and two of their children, the name of their ancestor, Takotohiwi, is handed down inter-generationally as their middle name. This is a way of honouring the past.

Sports commentators are a prime example of mispronunciation - and Māori players' names are often modified for ease (e.g. 'Triple T' for All Black, Te Toiroa Tahuriorangi). In response, NZ Rugby has introduced an initiative called 'Say my Name' - which provides video-recorded guidance on how to correctly pronounce players' names, as a mark of respect.

When a teacher fails to (try to) honour the correct pronunciation of a child's name, they are as it were dishonouring the whānau and their culture. Moreover, the integrity of the language suffers. Research by Kohli and Solorzano (2012) reveals an association between the mispronunciation of students' names and poor academic performance. They claim that mispronunciation has the effect of negating a student's identity, causing anxiety and resentment, and creating in them a negative emotional state that hampers them 
academically. The researchers acknowledge that, in the main, teachers are not being deliberately disrespectful. It is more a case of them feeling out of their monocultural/monolingual comfort zone when faced with unfamiliar names. Nevertheless, due to the adverse impact on learning, the researchers describe this situation as a form of micro-aggression, which can easily be overlooked or go unaddressed - as if not worth the trouble of confronting or rectifying.

Kohli and Solorzano suggest that name mispronunciation can cause a student embarrassment, or even shame - leading them to be less favourably disposed to their own language and culture. I have a personal example of such a situation. When my younger son, Hone, started secondary school, he had a relieving form teacher for six weeks. Every morning, when the roll was called, that teacher pronounced his name as 'Horny'. This was particularly embarrassing in front of his adolescent peers (because of its association in slang) - so much so that, in trying to be the same as the majority, he asked if he could be called the English equivalent of Hone; namely, John. At the same time, he requested that I remove the Māori message on our home answerphone - due to him feeling embarrassed and whakama $\bar{a}^{119}$ about te reo. Fortunately, my son's negative response to such incidents of micro-aggression did not have a long-term adverse effect. But it could have. The cumulative effect of exposure to such micro-aggression can be damaging. Indeed, mispronunciation of te reo Māori is so ingrained in many New Zealanders that it is doing damage to the health of the language - albeit unwittingly.

Interestingly, despite believing (without exception) that correct pronunciation was important, the teacher respondents in my study also unanimously believed that native speaker fluency was not necessary for English-medium teachers trying to integrate Māori language into their primary school teaching. This stance may be surprising to those outside the profession, who look at teachers and assume that native speaker fluency is imperative for teaching te reo. However, the collective response of the teachers in my research suggests that, in contrast to the manageable goal of correct pronunciation, the goal of native speaker fluency is likely to be unachievable, too daunting or unduly time-consuming. Having such a goal could in fact lead to immobilisation and inertia. So, instead, they have learnt to acknowledge their limitations in terms of native speaker fluency and embrace the concept of ako - being open to learning from, or alongside, students and whānau. Furthermore, it

${ }^{119}$ Ashamed 
could be said that, due to their lack of native speaker fluency, they may in fact be in a better position to empathise with, and help, their students. That is, as second language learners themselves, they can recognise the pitfalls in learning te reo Māori and are therefore wellplaced to suggest useful second language learning strategies to facilitate their students' learning.

For non-Māori teachers who feel inadequate or lack confidence in reo Māori pronunciation, there is assurance from Māori academic Professor Rawinia Higgins, Victoria University of Wellington. She legitimises the use of te reo Māori by non-Māori. As discussed earlier, Higgins (2015) acknowledges that, despite many efforts, te reo Māori is still not thriving and, in fact, may be regressing. She emphasises that, to survive, te reo Māori needs to be normalised across a range of domains, and that non-Māori can contribute to strengthening the vitality of the language by increasing their understanding and use. Hence her support for the regularisation of te reo Māori in schools, as a way of contributing to Māori language revitalisation.

Her stance is supported by NZ researchers Boyce (1995) and Te Huia (2016) who believe that, despite low levels of Māori language proficiency among most non-Māori, positive attitudes can contribute to revitalisation. That is, non-Māori can be change agents in their community - and beyond. Two well-known examples are NZ broadcasters Guyon Espiner and Jack Tame. They are Pākehā champions of te reo Māori endeavouring to normalise its use, which reflects a societal shift. The Hon. Nanaia Mahuta MP has communicated the government's perspective on normalising te reo, saying that the emphasis should not be on fluent speakers but on those who want to speak at a conversational level (Walters, 2018).

To facilitate the desired outcome of Māori language normalisation, Higgins (2015) suggests that we focus on Article 3 of the Treaty (about participation, citizenship and identity). Her view is that, in doing so, the language will become more relevant to all NZ citizens, thus increasing its status. This is particularly pertinent in view of NZ's changing demographics and the increasing number of people with Māori whakapapa. The plea from Higgins is simply to use the language. That is, none of us needs to be a native speaker to communicate in te reo.

To support this goal, the Ministry has invested in, and promotes, a communicative approach to language teaching - where the focus is on exposing students to Māori language that 
relates to authentic, real life contexts. This is discussed in a Ministry-commissioned literature review by Professor Rod Ellis (2005b). He describes the need for students to encounter language in genuine meaningful situations, in preparation for real life communication beyond the classroom. While the goal of Māori language use by teachers is laudable, there remains a gap between the ideal and the reality - in that too few primary teachers have had the necessary PD equipping them to implement a communicative approach.

\subsubsection{Language, culture, and identity}

Just as English-medium primary teachers have a role to play in teaching Māori language, they have a part to play in upholding Māori culture. During school hours they are the main conduits for such knowledge. All except one of the 40 questionnaire respondents in my research regarded the inclusion of a cultural component to be an important complement to the teaching and learning of Māori language - thus ensuring that language learning is more than lexicon and grammar. Moreover, they saw value in drawing on students' backgrounds and cultures, to affirm their identity and enhance their learning. A cultural component helps students to compare their beliefs and cultural practices with those of the target language such that they start to appreciate the Māori world. These aspects are discussed in more detail below.

\subsubsection{Belief statement 10 - Integration of tikanga}

As stated by Bennett, Bennett, and Allen (2003, p. 237): "The person who learns a language without learning a culture risks becoming a fluent fool." Culture is embedded in the use of language in society (Ramirez, 2017). The collocation 'te reo me onna tikanga' (language and culture) is common in Māori. It suggests an inextricable inter-connectedness beween the two dimensions. The same relationship is communicated in the Ministry publications discussed earlier in Chapter 2 (Ka Hikitia, Tãtaiako, and Tau Mai te Reo), where language and culture (and identity) are dominant recurring themes. As emphasised by leading Māori academic, Professor Mason Durie (2003), these are the logical conduits to hauora ${ }^{120}$ for Māori students.

Seeing the world through a different lens makes teachers better placed to relate to Māori students while, at the same time, helping non-Māori students to gain an appreciation of

${ }^{120}$ Health and well-being 
cultural difference. Bishop and Glynn (1999) make a strong argument for the role that culture plays in education - a point that is largely ignored, in their view, by many people working in this field. The researchers highlight (p.78) that “... many educators remain ignorant of the fact that they bring to educational interactions their own traditions of meaning-making that are themselves culturally generated. This... perpetuates the domination of the... majority culture...; it is important for educators to critically evaluate how one set of cultural traditions (their own) can impinge on another (their students)." That is, too many teachers view the world through one lens only. They are therefore unable to see other valuable perspectives that their students bring, which makes it more difficult for them to relate to a diverse range of learners.

Kennedy (2016) emphasises the importance of students exploring the target culture at the same time as learning the target language, to cement their connection and sustain their interest in progressing beyond the basics of the language. Since the New Zealand Curriculum learning area Learning Languages was introduced in 2007, there has been an acknowledgement about the importance of teaching cultural aspects alongside target languages. This is made clear in the way that the learning area is structured, with the complementary strands of Language Knowledge and Cultural Knowledge contributing to the core strand of Communication (Ministry of Education, 2007). The curriculum acknowledges that culture is a conduit for understanding others' belief systems and world views - and, consequently, understanding more about oneself. In the literature, Kramsch (1993, 2009a) describes the latter as learners arriving at a 'third place' - a place created by the intersection of the target culture and the learner's own culture. She suggests that, in reflecting on their experiences, the learners arrive at a position where they can see themselves both from the inside and from the outside. The premise is that, as we develop an understanding of other cultures, we are at the same time developing a greater understanding of our own.

Little research has been done in Aotearoa NZ in terms of the role of culture in language learning in schools. However, research conducted for the NMSSA programme indicated that $88 \%$ of the English-medium teacher respondents ${ }^{121}$ promoted Māori cultural values in their classes (Ministry of Education, 2018, p.74). But Basturkmen (2012) found that, while teachers acknowledged the value of integrating culture into their teaching of a second

${ }^{121}$ Year 4 and Year 8 teachers 
language, this could be at odds with their actual classroom practice. For example, the few studies (done in secondary schools) indicate that, although NZ teachers believe in the benefits of culture in languages education, they are unsure how to integrate this aspect into their teaching practice (Ramirez, 2017; Oranje, 2013; East and Scott, 2011; Richards, Conway, Roskvist and Harvey, 2010). According to Ramirez (2017), even specialist language teachers in secondary schools seem ill-prepared in terms of knowing about, and applying, the ICLT (intercultural communicative language teaching) principles developed for NZ's Ministry of Education by Newton, Yates, Shearn and Nowitski (2010) - despite these principles being central to the integration of culture in the second language learning classroom.

In theory, Māori culture is the easiest for NZ teachers and students to access (compared with other languages in our schools) because it belongs to, and is visible in, this country. Furthermore, learners of Māori can more readily enhance their knowledge of tikanga by researching local history, listening to local stories, visiting places of cultural significance, and accessing native speakers (Oranje, 2016) - thus enabling a stronger connection between te reo Māori and tikanga Māori.

Case study research by Kennedy (2016), conducted in a NZ secondary school, emphasised that the development of intercultural competence ${ }^{122}$ should be a goal for both primary and secondary school students (Byram and Parmenter, 2012; Sercu, 2010). This is especially so in today's society, where our students are being prepared to be global citizens and live in a multicultural, multilingual, digitally connected world. Kennedy recommended that teachers could improve students' intercultural competence by facilitating regular opportunities in the classroom for learners to explicitly compare, reflect on, and make associations between cultures - as espoused in Newton et al.'s third ICLT principle about encouraging and developing an exploratory reflective approach to culture and culture-inlanguage (Newton et al., 2010).

There are pockets of optimism around teachers' familiarity with the principles of ICLT. Research findings (Sercu, 2005; Conway and Richards, 2014) suggest that NZ teachers of languages are gradually becoming aware of, and favourably disposed to, ICLT practices.

\footnotetext{
${ }^{122}$ The ability to interact and communicate effectively across cultural boundaries - and reflect on one's own culture (Byram, 1997)
} 
Oranje's PhD research (2016) is equally optimistic, albeit with the caveat that there is a need for PD and supplementary resources to support ICLT.

In my online questionnaire, while one teacher was 'unsure' in their response to Question 10 about the importance of tikanga, the other 39 teacher respondents overwhelmingly recognised it was indeed important to integrate tikanga into their teaching of te reo. This finding aligned with their subsequent responses to Question 28, pertaining to the top three characteristics of quality Māori language resources in English-medium primary schools. In response to this question, 23 of the 40 teacher respondents ranked the inclusion of Māori tikanga in the top three rankings. Their overall rankings were: real life contexts $\left(1^{\text {st }}\right)$; and the inclusion of tikanga, as well as user-friendliness (both $2^{\text {nd }}$ equal) - to be elaborated on later in Section 4.4.

However, there was perhaps some inconsistency regarding tikanga in the teachers' subsequent qualitative comments in the questionnaire, when asked in Question 37 to provide suggestions about future Māori resources that should be developed. Only three of the 40 respondents suggested there was a need for tikanga resources. (See Figure 4.24 later in this document, extracted from NVivo, about teachers' suggestions on future resources). The low need for cultural knowledge seemed incongruous in view of the teachers' emphasis on tikanga in the two previous sections of the online questionnaire (i.e. Belief Statement 10 about the integration of tikanga and Question 28 about the top three rankings of quality). It was also surprising to me in the context of my own work as a Māori language adviser in schools - where teachers are, generally, very tentative about things associated with tikanga. I would have anticipated a higher demand across the 40 questionnaire respondents for future resources to include some information on cultural aspects - to complement the teaching and learning of te reo.

Notwithstanding, I acknowledge that, when completing the online questionnaire, each teacher respondent made a conscious decision about what Māori language resources should be developed in the future, based on their immediate needs. From the result, it is evident that these teachers have more pressing needs around language than tikanga. That is, they need practical 'hands-on' resources they can use in the classroom on a day-to-day basis. The following is a summary of what the 40 questionnaire respondents suggested in respect of future Māori language resources (in order of popularity - with tikanga being ranked towards the bottom): 
- $\quad$ games and multimedia;

- $\quad$ resources using classroom language;

- $\quad$ pronunciation support;

- $\quad$ resources showing cross-curriculum integration;

- $\quad$ resources to build up students' Māori language knowledge, beyond vocabulary;

- exemplification of curriculum-specific vocabulary;

- $\quad$ bilingual texts and Māori readers;

- $\quad$ resources highlighting tikanga;

- $\quad$ resources re waiata, and Māori myths and legends.

\subsubsection{Belief statement 15 - Drawing on students' backgrounds and cultures}

In the NMSSA study (Ministry of Education, 2018, p. 74), more than 80\% of the Englishmedium teachers said they were able to draw on some of their students' background experiences to support the teaching and learning of te reo in the classroom. Similarly, in my questionnaire (Question 15), most of the teachers $(n=38)$ recognised that, to help explain Māori concepts and vocabulary items, there was value in drawing on students' prior knowledge.

Research by Bourdieu (1977b) is relevant here. He coined the term 'cultural capital' in the 1960s, while attempting to explain students' differential achievement in France's education system - a situation that the NZ education system is facing, in terms of Māori and Pasifika underachievement. The term refers to cultural knowledge, skills and dispositions, accumulated over time as a result of life experiences, which are then given status. The equivalent of this notion, regarding Māori learners specifically, is described by Patara (2012) as 'mana motuhake'123 - the cultural experiences that Māori students bring to the classroom, as part of their identity, which should (ideally) inform teaching and learning. As indicated below in association with Belief Statement 17, research by Menard-Warwick (2009) confirms that a teacher's affirmation of a student's identity is likely to lead to improved learning outcomes for that student.

${ }^{123}$ Self-determination and control over one's destiny 


\subsubsection{Belief statement 17 - Impact of te reo learning on Māori student achievement}

In response to Question 17, all but three of the 40 questionnaire respondents believed there was an association between teachers' inclusion of te reo Māori in the classroom and Māori student achievement. This unified belief suggests that these teachers can see the positive outcomes that emerge from the teaching and learning of te reo Māori-especially for Māori students, too many of whom fall within the Ministry's category of 'priority learners'. These are students whose experience at school does not lead to positive education outcomes, which contributes to disengagement. It is likely that, if their identity was affirmed through the use of Māori language at school, there would be a positive flow-on effect to other curriculum areas. This notion was suggested by Menard-Warwick (2009), who (as stated above in respect of Belief Statement 15) found that learners were more invested in learning if their identities were reflected and celebrated, making the classroom a relatable space for them. Conversely, they were more likely to become disengaged and resistant to learning if their identities were disregarded.

The same point is made by Seals and Peyton (2017) who stress that there is a relationship between the validation of a student's language/culture and their success at school in different subjects. Similarly, the findings of the NMSSA research in English-medium schools (Ministry of Education, 2018) showed statistically significant positive correlations between students' Māori language achievement and their attitudes to, and confidence in, te reo Māori.

Research by Haemata (2019) investigated the teaching of te reo Māori in English-medium settings. The findings suggested that one of the main unifying drivers for schools providing a Māori language programme was the contribution that such a programme could make to wider education success for Māori students. As is evident in its Māori education strategy, Ka Hikitia (Ministry of Education, 2013), Māori student achievement is an important priority for the Ministry. Hence my exploring it further - in the follow-up interviews with the four teachers whom I observed teaching. (See sections 6.2.8, 6.3.7, 6.4.7 and 6.5.7).

\subsubsection{Teachers' knowledge}

In the online questionnaire, my research participants expressed a belief that NZ primary teachers should know some basic Māori language for use in the classroom. Interestingly, only half of them saw a link between how they were taught te reo Māori and how they were now teaching it. There are some factors that could contribute to the lack of unanimity 
around this belief (e.g. how and where they learnt Māori; the extent and quality of their learning; and their reflections on their reo Māori journey). Regardless, 75\% of them acknowledged the importance of knowing about second language acquisition, to enhance their practice (and student outcomes). But only $25 \%$ of them believed they had the ability and proficiency to be flexible in their Māori language teaching. These aspects are discussed in more detail below.

\subsubsection{Belief statement 18 - Use of basic level of Māori in the classroom}

As stated earlier in section 4.2.6, the Ministry's response to an inquiry from me about the reo Māori proficiency of English-medium primary teachers indicated that their average proficiency level is unknown. (Personal communication with Bea Wooding, Advisor, Information Requests, Ministry of Education, 28 November 2017). However, in response to Question 18, most of my research respondents $(n=34)$ believed that primary school teachers should know enough reo to use it at a basic level. Six teachers were unsure though (as shown in Figure 4.8 below). Their uncertaintly may have been due to the fact that there was not necessarily a shared understanding of what a 'basic' level of Māori language looks like - since my definition thereof did not appear until later in the questionnaire (in Question $40)$ i.e. the ability to use simple rote phrases and sentences, in highly familiar contexts.

Figure 4.8 Beliefs about primary teachers needing to know enough Māori language to use it at a basic level in the classroom

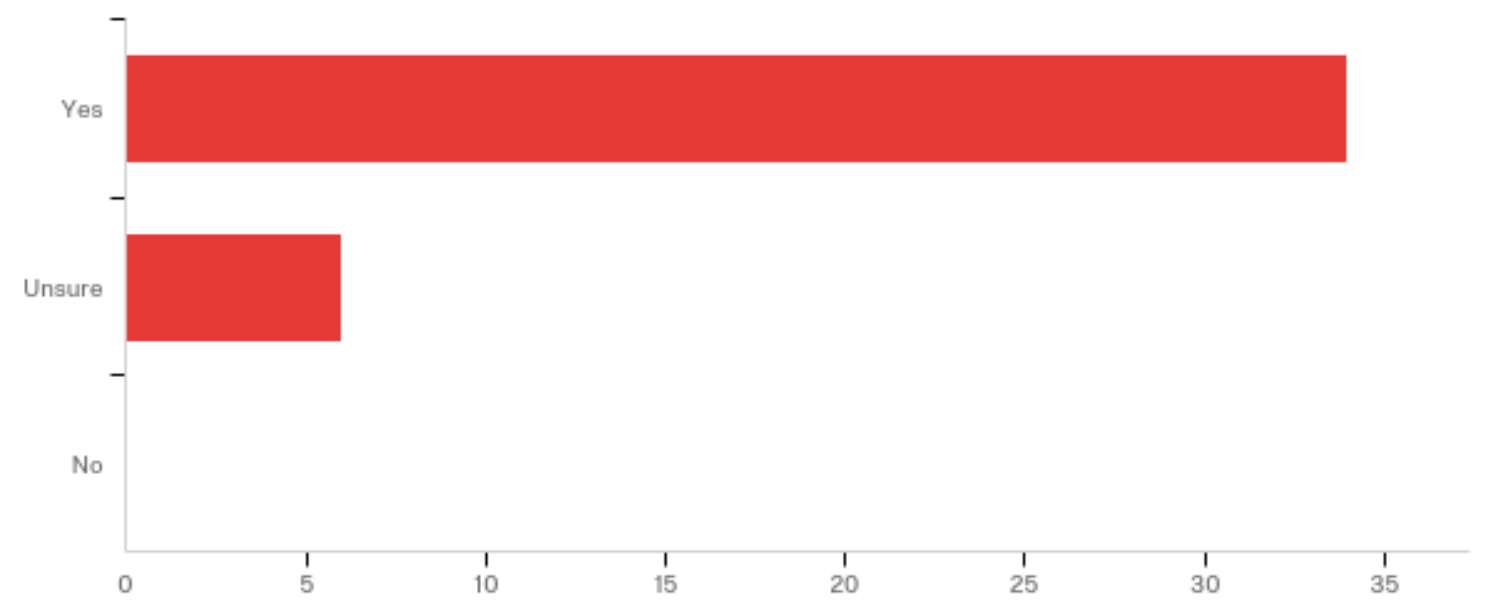

\subsubsection{Belief statement 25 - Influence of previous experiences learning te reo}

Van den Branden (2009) found that teachers often replicate the way they were taught and are resistant to doing things differently or being open to the unfamiliar. In deciding whether their own prior experiences learning te reo had an influence on the way they currently teach the language, my teacher participants were divided in their response to Question 25 
- with $45 \%(\mathrm{n}=18)$ believing there was indeed an association (i.e. an aspect of ako). However, approximately the same number of teachers $(n=17)$ disagreed that there was any relationship; and five respondents were unsure (see Figure 4.9 below).

Figure 4.9: Teacher beliefs about the influence of how they were taught te reo Māori on the way they teach it

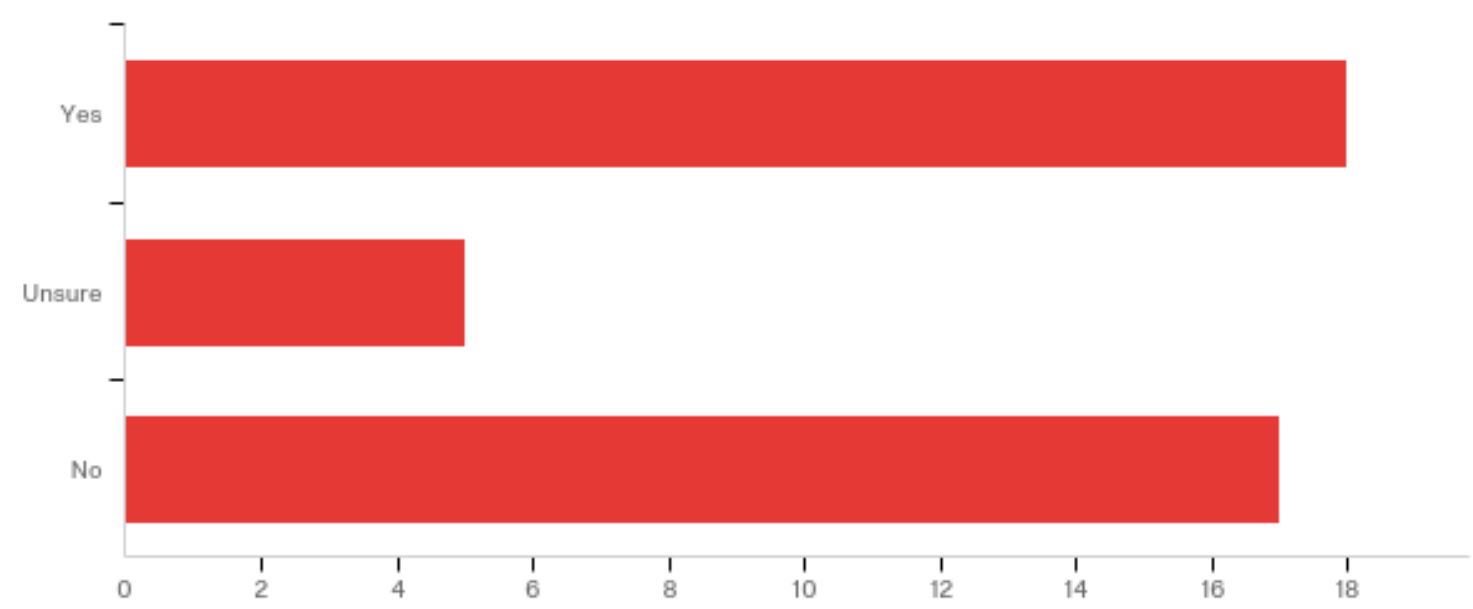

This lack of consensus could be attributable to:

- the range of ways the teachers had acquired their knowledge of te reo, which could make comparisons difficult (e.g. whānau; early childhood, primary, secondary and tertiary education; pre-and in-service; and community opportunities),

- $\quad$ the extent of reo knowledge gained (or not) from those experiences (i.e. various degrees of acquisition achieved),

- the variability in the quality of reo Māori teaching that they received,

- $\quad$ the respondents' ability (or not) to reflect on their experiences as learners of te reo Māori, in terms of what to emulate or reject when teaching the language, and /or

- $\quad$ the lack of appropriate PD (pre-service and in-service).

For example, in case study research, Barr and Seals (2018) suggested that the sometimesnegative attitude of one of their teacher participants, Caroline, towards Māori language in the classroom, could have emanated from her experience learning te reo in a tertiary teacher education setting. She had been forced to study Māori, rather than it being an elective. In addition, as a teacher now, she faces situational constraints that impact on her teaching of te reo, from one year to the next, in terms of having to deal with different school priorities, different children's needs, and different levels of resourcing. 
It should be noted that, later in my questionnaire, two of the 40 teacher respondents stated that they had no prior learning of te reo to draw on; that is, they were a blank canvas. One explained that they were currently learning 'on the job', having come from a different country. This shows how integral the teaching and learning of te reo Māori is in NZ classrooms - such that a teacher from overseas feels compelled to quickly get up to speed with this aspect of the curriculum, which is accepted as part of how NZ primary school teachers operate.

\subsubsection{Belief statement 5 - Second language acquisition}

In response to Question 5, about theoretical knowledge, $75 \%$ of the teachers $(n=30)$ believed that knowledge of second language acquisition was useful for underpinning their practice. However, eight of them were unsure and two negated its importance (see Figure 4.10 below).

Figure 4.10: Beliefs about primary teachers needing to know something about the theory of second language acquisition (SLA), to help them implement interactive lessons that have real-life application

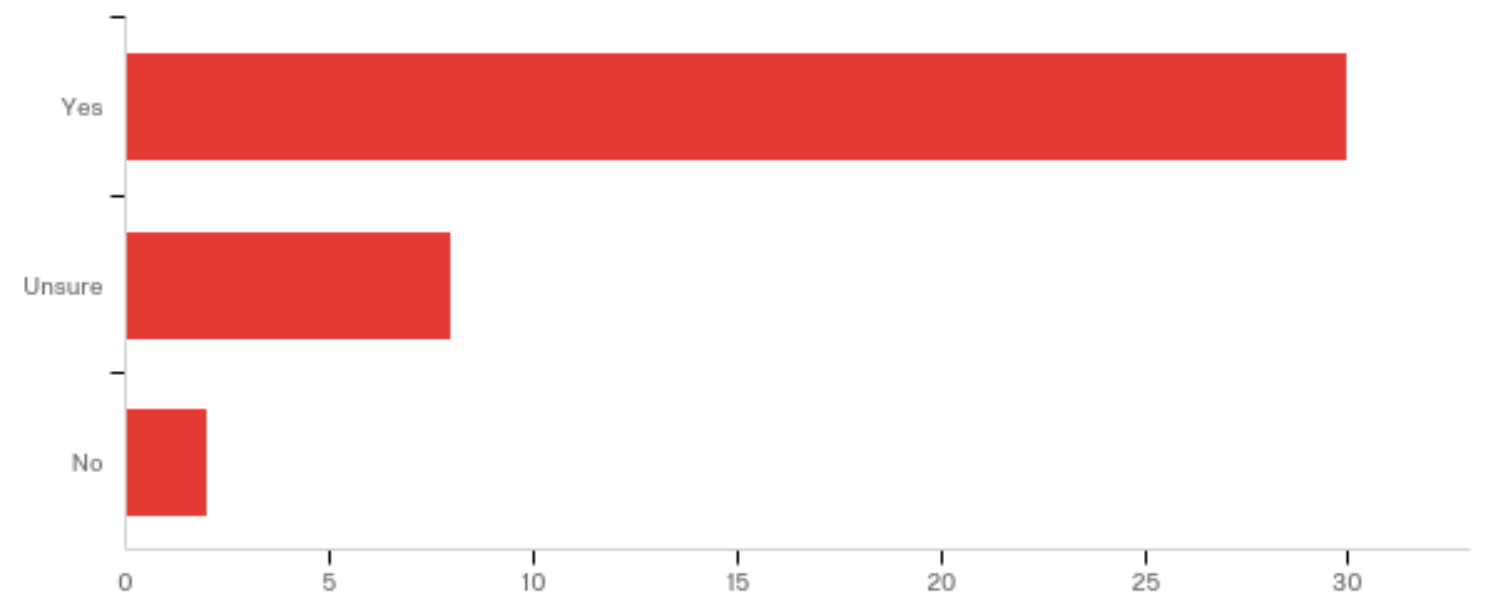

Research by Haemata (2019) indicated that English-medium primary teachers' lack of knowledge around second language pedagogy inhibited their ability to provide quality reo Māori programmes. It is therefore encouraging that many of the questionnaire respondents $(n=30)$ in my study recognised the importance of second language acquisition knowledge. Their favourable response suggests that, although they are generalist practitioners in English-medium primary schools, expected to teach all subjects, they are also starting to develop some specific knowledge about the teaching and learning of an additional language (hitherto the domain of specialist teachers of languages in secondary schools). As such, they are becoming familiar with the theory of second language learning, as communicated 
in the Ministry's resource First Class (Ministry of Education, 2010), which featured in my questionnaire. This is a DVD that shows task-based second-language teaching approaches known to be effective with diverse students in Years 5-9.

Teachers are becoming better at applying the theory to their practice. For example, they recognise the importance of engaging students in meaningful real-life tasks that are related to their experiences (as emphasised by Rangimārie Rose Pere in her seminal work in NZ, 1994, about ako and the mutual relationship between learner and teacher). They are also more cognisant of the need to provide students with ample opportunity to revisit previous learning and practise new learning through interaction with others - to improve their confidence, fluency and accuracy (as emphasised in the Ministry's multimedia reo Māori resource for primary schools, He Reo Tupu, published in 2011). And they have a deeper appreciation of the complementary relationship between language and culture (as highlighted in the Ministry's Māori language curriculum guidelines, Te Aho Arataki Marau, published in 2009).

The increased awareness of second language acquisition among primary school teachers may be attributable to Ministry-sponsored research, disseminated widely, and freely available - specifically:

- the work done by Ellis (2005a) on the principles of instructed second language acquisition and task-based language teaching;

- the paper written by Crabbe (2005) on the 'essence' of second language learning in NZ schools; and

- $\quad$ the evidence-based framework developed by Newton et al. (2010) setting out principles associated with ICLT.

However, Oranje's study $(2016)^{124}$ suggests that, despite the worthy investment in the above resources, which are both practical and scholarly, the Ministry may not be maximising the opportunity to provide teachers with PD where they can absorb this knowledge and apply it to the classroom. She argues that this oversight is particularly significant for the teaching of te reo Māori. The responses provided by the Māori language teachers in her research (p. 321) suggested that secondary school teachers of te reo were “... among the least qualified in teaching and language acquisition; least likely to be

${ }^{124} \mathrm{n}=76 \mathrm{NZ}$ secondary school teachers of languages 
members of professional associations; and least likely to demonstrate cognitions and practices representative of ICLT." This indicates that, alongside the need for the Ministry to provide PD to practising teachers around second language acquisition (theory and practice), there is also a need for pre-service teacher educators (primary and secondary) to include second language acquisition in their programmes. This is especially relevant in view of the ever-increasing profile of Māori language in primary schools, stimulated by Ministry expectations around te reo in that sector - prior to students arriving at secondary school.

\subsubsection{Belief statement 3 - Ability to be flexible}

In response to Question 3, only a quarter of the teachers $(n=10)$ believed they had enough Māori language knowledge to depart from their planned lesson to make 'on the spot' changes. A much higher number $(n=24)$ believed they did not have the ability to be flexible and agile when teaching te reo. Six respondents were unsure (see Figure 4.11 below). It is likely that most of the respondents are dependent on their lesson plans due to their low levels of confidence and proficiency. This limitation could explain why many teachers retain 'tried-and-true' content each year (e.g. commands, colours, greetings, numbers and songs). Although undoubtedly easier for the teacher (than planning new work), such restricted input means that students are unlikely to be cognitively challenged. They are only learning formulaic language - not the grammatical knowledge needed for productive language use. They may consequently become disengaged and develop negative attitudes towards learning te reo. Such attitudes could influence their subsequent subject choices at secondary school.

Figure 4.11: Teachers' beliefs about having the necessary Māori language ability to depart from a planned Mäori lesson and make 'on the spot' changes

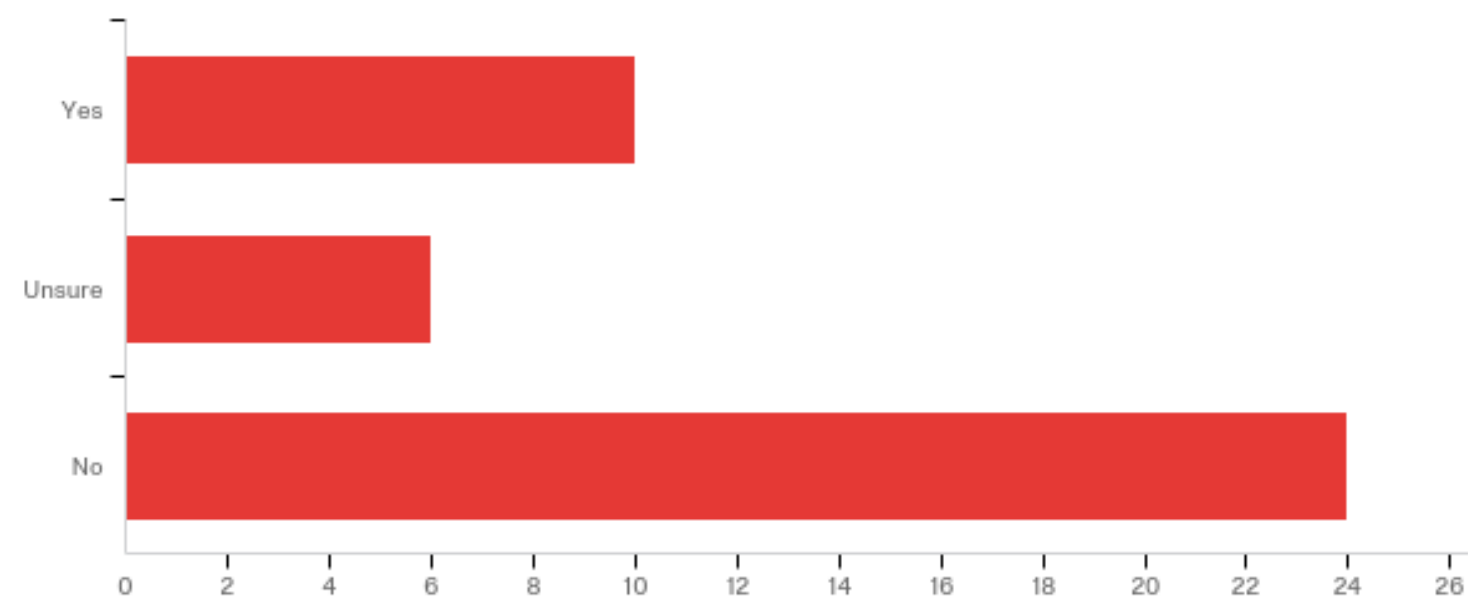




\subsubsection{Teachers' classroom practices}

Most of the teacher respondents believed it was important to plan and integrate Māori language across the curriculum. To do that, they were open to embedding English words and phrases into Māori sentences - in order to sustain communication. In addition, most of them agreed that the emphasis in primary school should be on listening and speaking - at curriculum levels 1 and 2. They also believed in balancing teacher talk time with student practice time (be that individual, paired, small group or whole class), to make it enjoyable and applicable to real life contexts. In addition, they recognised the importance of using, and adapting, a range of materials to enrich students' learning and keep them engaged. These aspects are discussed in more detail below.

\subsubsection{Belief statement 24 - Cross-curriculum integration of Māori}

The ability of teachers to integrate te reo Māori across a range of curriculum areas would contribute to the normalisation of the language, because students would be able see that the language is appropriate in a range of learning contexts - not just as a stand-alone subject. Most of the respondents $(n=34)$ believed that English-medium primary school teachers should be able to integrate Māori language across the curriculum - although three of them disagreed. Another three were 'unsure', which could be a face-saving response, in that the belief statement may have called into question their ability to incorporate te reo across the curriculum (see Figure 4.12 below).

Figure 4.12: Belief that primary teachers should be able to integrate Māori language across the curriculum

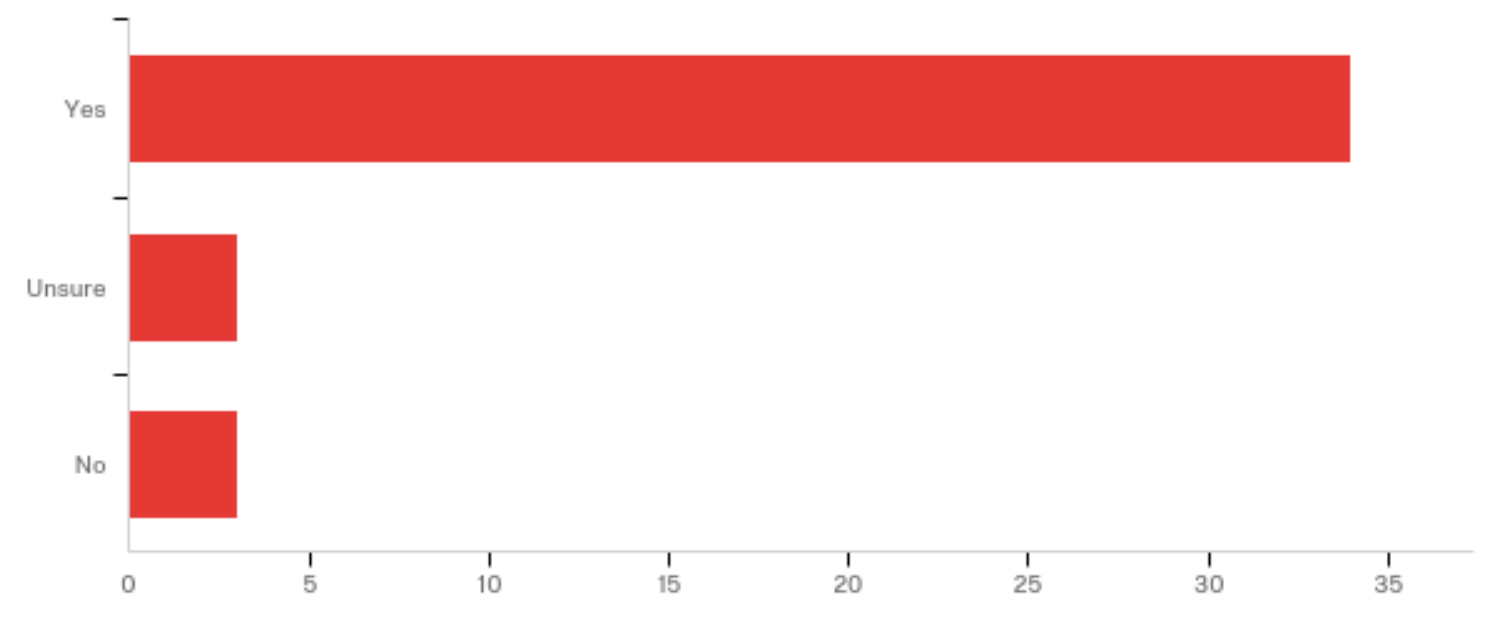


The primary school teachers' union, NZEI, recommends that teachers' Māori language programmes should span all areas of the curriculum ${ }^{125}$. This is the ideal situation, where the language is used throughout the day in normal curriculum activities. However, based on my experience as a Māori language adviser in English-medium primary schools, the reality is that te reo Māori is often compartmentalised within the classroom programme, being allocated a specific (and usually short) time slot. Invariably, it is neglected outside that time.

It is evident that Māori language is rarely being assessed in English-medium primary school settings (Ministry of Education, 2017). This situation prevails even though the Māori language curriculum guidelines, Te Aho Arataki Marau (Ministry of Education, 2009), set down achievement objectives and descriptions of skills that cover six language modes (listening, reading, viewing, speaking, writing, presenting). These are designed to guide the assessment of te reo Māori at all curriculum levels. In addition, within He Reo Tupu (Ministry of Education, 2011), there are assessment rubrics already pre-prepared for teachers to use easily and quickly. Moreover, these are matched to the achievement objectives of the aforementioned Māori language curriculum guidelines.

The gap in monitoring Māori language progress can send a message that te reo is of little value and a low priority, in contrast to other formally assessed curriculum subjects especially the core subject areas, which are deemed to have more status; namely: English, mathematics, and science. Furthermore, te reo Māori must sometimes compete with other languages being taught as a subject and timetabled at the same time as Māori. This results in students being forced to make a choice between Māori and another second language.

\subsubsection{Belief statement 9 - Embedding Māori words/phrases in English}

One way that teachers with limited proficiency can integrate Māori language across the curriculum is to embed Māori words or phrases in English sentences, paying attention of course to pronunciation. This is a useful second language learning strategy. Crystal (2003) described such words as borrowings or loan words. A NZ researcher, Macalister (2006), conducted research to investigate senior secondary students' familiarity with Māori words. They had a range of 70-80 loan words at that stage of their life. However, Macalister predicted (p. 21) that this number would likely increase with age and through exposure to

\footnotetext{
${ }^{125}$ Clause 17.5.5 ratified at its Annual Meeting 1992 and reconfirmed by its National Executive in Minute
} $07 / 277$ 
other Māori words encountered in adult life. The increasing number of loan words being transferred from Māori (an endangered, minority language, indigenous to this country) to English (the dominant language) is interesting and suggests that te reo Māori is gradually being accepted as part of NZ's identity.

Most of the questionnaire respondents $(n=35)$ in my study believed that it was acceptable to use Māori words and phrases in an English sentence (see Figure 4.13 below). Their responses suggest a level of comfort using this strategy, as a form of 'scaffolding' - to overcome their own inability to speak Māori in whole sentences, to facilitate students' understanding, and to model for students how to avoid communication breakdowns in reallife contexts. In doing so, the teachers are legitimising the use of te reo Māori, increasing its visibility, and effecting changes to NZ English that better reflect our shared history and our real use of languages in this country.

One situation where primary teachers are used to having Māori words embedded in English texts is in their reading of children's books - especially instructional readers produced by the Ministry. Macalister (1999) found that there had been a shift over three decades in respect of Māori borrowings in these readers. In the 1960s, Māori loan words in the readers were mainly related to history and artefacts - whereas those in the 1990 s were more associated with community and social interaction. Macalister attributed the shift to a growing acknowledgement of Māori as a living culture, as opposed to a historical culture.

Figure 4.13: Beliefs about it being OK for teachers to use Māori words or phrases in an English sentence, if they cannot say it all in Māori

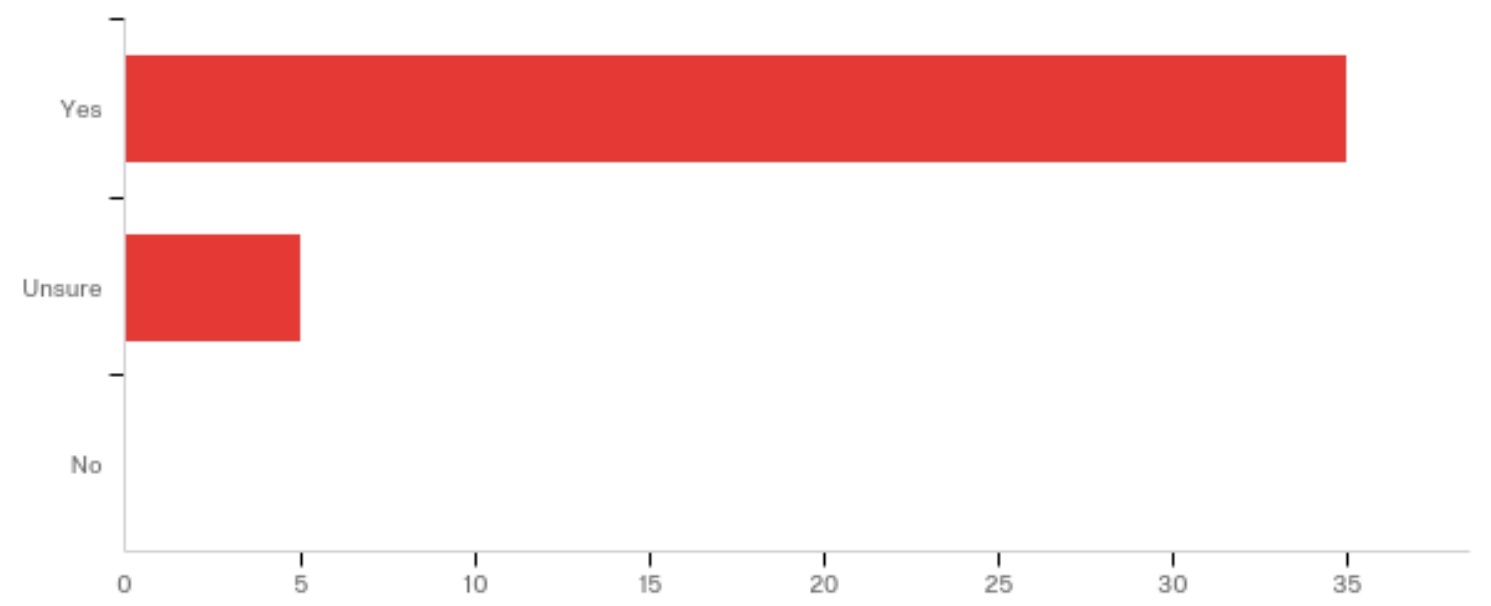

The inclusion of Māori loan words in children's books is beneficial in that it contributes to the receptive and productive ability of both the children and teachers (or parents) who are 
reading the stories (Daly, 2007). In this way, Kiwi children can be exposed, in a natural way, to Māori vocabulary. Additionally, Māori children particularly benefit from seeing themselves in the books relating to te ao Māori - through the inclusion of Māori vocabulary items. Māori language research by NZCER (2017) highlights the call for more bilingual resources - to accommodate second language learner needs (i.e. teachers and students).

People's ability to 'go across' two (or more) languages, fluidly and naturally, is described as translanguaging - where each of the respective languages in a person's repertoire comes together to form an integrated language system (Williams, 2002), thus building a linguistic repertoire across languages. In relation to my study, there are benefits (in terms of comprehension) for English-medium primary school students who are able (and indeed encouraged by the teacher) to translanguage (i.e. move between their heritage language and te reo Māori) - as a way of overcoming potential communication breakdowns.

Primary school teachers in Aotearoa NZ can use this strategy by reading bilingual texts and displaying bilingual visuals, thus facilitating the opportunity for their students to experience both languages together. A Māori researcher at Auckland University, in her work on TransAcquisition Pedagogy (Tāmati, 2016), recommended that students should be provided with opportunities to express and negotiate meaning in both languages. Although her theory arose from a study of Māori-medium students learning English, it is not unreasonable to suggest that the same benefits (including having a better grasp of both Māori and English) could be accrued by English-medium students learning Māori - if they used both Māori and English inter-dependently, in mutually supportive ways. Indeed, research by Treffers-Daller, Hofweber, and Marinis (2018) claims that translanguaging can help students to develop the weaker of their two languages - and may reduce their anxiety around using it.

Translanguaging is the focus of research in Victoria University of Wellington's Translanguaging Aotearoa project. The researchers, Seals and Olsen-Reeder (2017), are exploring how tamariki become socialised into te reo Māori. They have audio-recorded the actual language used by two- to four-year-old children attending a Puna Reo ${ }^{126}$. The outcome is a hybrid children's book that contains Māori language embedded in English, and the converse, on a 50:50 basis. The intention is that the translanguaging in the book

${ }^{126}$ A Māori early childhood centre, run by registered teachers 
will help to balance the power relationship between the two languages (Canagarajah, 2011) - where (normally) English is the language of the majority, and te reo Māori is a minority language $^{127}$.

However, notwithstanding the obvious benefits of translanguaging for building vocabulary, if not done appropriately such embedding could have adverse effects for second language learners of te reo in terms of grasping syntax e.g. different word order in Māori (verb, subject, object) and English (subject, verb, object); and different placement of adjectives (after and before nouns respectively). Seals and Olsen-Reeder (2017) avert this possibility by using translanguaging in places where the syntax of both languages matches up.

\subsubsection{Belief statement 8 - Emphasis on listening and speaking}

The Ministry's multimedia resource for English-medium primary schools, He Reo Tupu, recommends that teachers "... keep the focus initially on listening and speaking competence ...", at levels 1 and 2 of the curriculum, “... as with our first language", because "... speech is the main means of communication at this stage" (Ministry of Education, 2011, pp. 12, 19, 179).

Most of the teachers in my study $(n=26)$ believed that listening to, and speaking, te reo were the priorities in primary schools. However, 10 teachers disagreed (see Figure 4.14 below). The latter provided no further information to clarify their stance. Their disagreement could perhaps be due to their lack of theoretical knowledge about the importance of these two language modes in the early stages of learning a second language - or they may believe that all four skills should be equal (i.e. listening, speaking reading, writing).

\footnotetext{
${ }^{127}$ As reported by Oranje (2016), the 2013 census revealed that, approximately, only $3.7 \%$ of New Zealanders could hold a conversation in Māori about everyday things - as opposed to $90 \%$ of the population speaking English
} 
Figure 4.14: Beliefs about the emphasis being on listening and speaking when primary school students are learning Māori

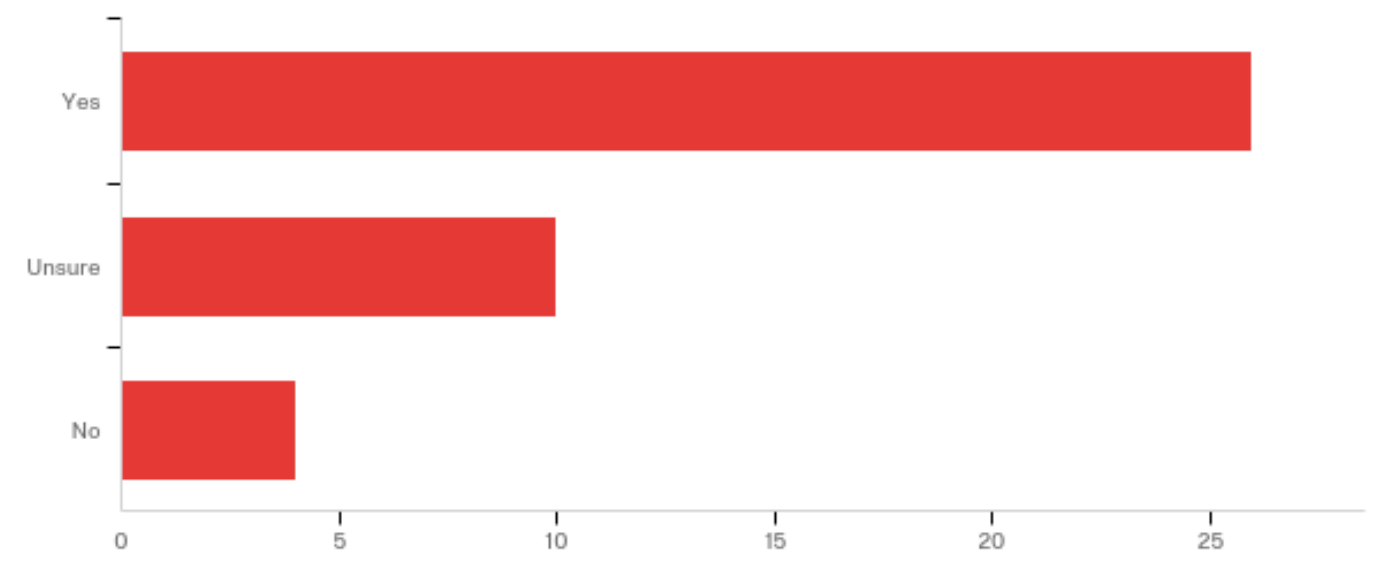

\subsubsection{Belief statements 6 and 2 - Balancing student practice opportunities with teacher talk}

In their response to Question 6, three teachers were 'unsure' about the need for student practice. However, most $(n=37)$ stated the belief that students need opportunities to practise their Māori language skills in the classroom - to improve their fluency.

There was convergence with the teachers' responses to Question 2, about teacher talk-time, where almost all the teachers $(n=38)$ recognised the need to balance their own speaking with practice time for students to experiment with their new learning.

These findings suggest that teachers are mindful of the need to apportion time for student output alongside teacher input, in line with a task-based approach to second language teaching and learning. It is likely that the three teachers who were unsure about providing opportunities for student practice had little knowledge about TBLT - despite it being espoused in the Ministry's Māori language curriculum guidelines Te Aho Arataki Marau (2009) and its supplementary multimedia resource He Reo Tuри (2011). This is important theoretical knowledge that needs to be better communicated to teachers, so that they can facilitate opportunities for students to practise their new learning by performing real-life, meaningful tasks.

\subsubsection{Belief statement 7 - The structuring of classroom learning}

Creating opportunities for students to practise their new learning is conducive to student engagement. It encourages students to interact and communicate effectively, at their respective levels of ability, so that they become a community of learners. In facilitating 
such opportunities, the teacher needs to acknowledge that learners are different - and they learn differently (Ministry of Education, 2009). This is probably why most of the respondents $(n=38)$ believed that students should learn Māori in a range of ways: individually, in pairs, in groups, and in whole class activities. Research conducted for the Ministry of Education (2017) confirmed that English-medium teachers want reo Māori resources that they can use in multiple ways - for individual, paired and group activities.

Paired and group activities are recommended in the Ministry's Māori language curriculum guidelines (Ministry of Education, 2009), in terms of a task-based approach to help students practise the language and develop fluency. While learning from each other (ako), students are also improving their own individual proficiency. Moreover, as they interact, learning becomes a social activity. Task-based pair work is particularly useful for encouraging students to listen to their partner, thus reflecting real life one-to-one dialogue. It also creates a non-threatening environment, where students can practise the target language with a classmate, without being under the direct scrutiny of the teacher - or multiple peers.

Group work also has its place. It gives students the opportunity to work things out together, as a diverse grouping, by sharing their knowledge and explaining/justifying decisions to their peers - as opposed to being told directly by the teacher. Interestingly, in research by Phipps and Borg (2009), teachers stated the belief that group work was valuable for students. However, in practice, they reverted to whole class interactions - which was easier than facilitating groups. Research conducted by Core, investigating Māori language resources, indicated that $47 \%$ of teachers highlighted a need for more group-oriented learning resources (CORE Education, 2018, p.7). This has implications for the Ministry in terms of future resource development for te reo Māori.

In group work, students are motivated by the power of the peer group to help fellow members achieve a common goal in a task - so that the group performs well as a whole (Good and Brophy, 1987). This is conducive to tuakana:teina practices, where more able learners can support those less able. Furthermore, while students are participating in group work, the teacher is freed up to monitor students' oral production of te reo and provide guidance/encouragement.

Having practised with their peers in the more intimate paired and group environments, students are more likely to build up the confidence needed for whole class activities using 
Māori language. Such activities maximise the diversity of students within the classroom, which means there is a broader range of experiences and ideas contributing to the learning.

Notwithstanding the benefits of working in pairs, small groups, and as a whole class, there is also a place in the classroom for students to work individually. For example, some students may be fast learners of Māori language, needing to tackle more demanding tasks in a self-directed way. In doing so, they are building their sense of autonomy. Conversely, some students may need to work individually because they require more time to grasp new reo Māori learning. In both scenarios, the students can work individually at their own pace.

\subsubsection{Belief statement 12 - Fun element in learning te reo}

Practice opportunities need to be enjoyable. This is recognised by the teacher respondents $(n=40)$, all of whom stated the belief that the learning of te reo Māori should be fun - by using activities, games and songs. Such variety contributes to a non-threatening learning environment and helps to sustain students' motivation to keep learning Māori. In research by Core, over $71 \%$ of teacher respondents highlighted how students are more likely to be engaged and motivated to learn if exposed to interactive activities such as games, for both individuals and groups (CORE Education, 2018, p.7).

However, it is possible for a hitherto motivated learner to become uninvested during the learning process if the learning context is inconsistent with their expectations (Norton, 2013). For example, if students expect learning to be fun, poor teaching can remove any enjoyment factor, resulting in the learner becoming disengaged. In such situations, the learner may even be labelled a poor learner (Norton and Toohey, 2001). Norton's research reminds us that teachers need to ensure that the fun elements of their teaching sustain students' motivation and, at the same time, keep them invested in Māori language learning.

\subsubsection{Belief statements 13 and 14 - Using and adapting a range of materials}

One way of keeping students motivated and invested is by exposing them to a range of materials (i.e. extensive second language input), so that their learning will be enriched. This provides a springboard for them to practise (i.e. output). In response to Question 13, most of the teachers $(n=38)$ believed that it was indeed important to use a range of materials. Two were unsure, however.

To help teachers provide a range of materials, there are several ideas presented in the Ministry’s Māori language curriculum guidelines, Te Aho Arataki Marau (2009, pp. 42-43, 
46-47, 50-51, 54-55). These guidelines suggest a variety of possible 'text types', using different media, across the eight different curriculum levels - to help build students' proficiency and prevent boredom. Examples include: readers, photos, posters, menus, advertisements, maps, timetables, notices, cartoons, pamphlets; audio- and video-recorded components, interactive learning programmes online; waiata, proverbs, riddles, and poems. The aim is to expose students to a range of materials containing language that mirrors what they can expect in the outside world.

Notwithstanding, the provision of Māori language materials is insufficient on its own. This is partly because English-medium primary teachers lack the necessary confidence and proficiency in relation to Māori language. Consequently, they need support (ideally PD) to help them maximise the use of materials - and, in the spirit of a student-centred curriculum, show them how to adapt materials to accommodate their students' needs. The importance of adapting Māori language materials was evident in teachers' responses to Question 14. Most of the respondents $(n=38)$ recognised the benefits of adaptation, to ensure there were good Māori language exemplars for students to emulate - with suitable learning contexts and manageable Māori language content relative to their own (and their students') invariably limited Māori language proficiency.

In terms of the free Māori language readers created by the Ministry for Māori-medium settings, English-medium teachers would need PD to learn how to adapt and simplify them in a variety of ways (e.g. embedding English words in Māori text; using only high frequency Māori words; keeping Māori sentences short; and providing a glossary of words or a translation). Once they discovered that many of the basic Māori-medium readers were indeed manageable (after adaptation), teachers' confidence would likely increase in respect of teaching te reo - which would encourage them to do more. They would be better placed to make decisions about adaptation - based on their learners (e.g. prior Māori language knowledge, interests, strengths, and age) and the linguistic features they believe are important to focus on (e.g tense; placement of adjectives; prepositions).

\subsubsection{Belief statement 16 - Real-life contextualisation}

It is good practice to select materials that are relevant to children's real-life contexts (Ministry of Education, 2017). The 'teaching as inquiry' approach advocated in the New Zealand Curriculum (Ministry of Education, 2007, p. 35) and in Te Aho Arataki Marau (Ministry of Education, 2009, p. 20) stresses the need for teachers to capitalise on the real 
lives of their students, including their culture, to optimise learning. There is alignment between these Ministry ideals and the teachers' responses to Question 16, in that all except one of the 40 teachers agreed it was beneficial for students if their learning of Māori was contextualised in real-life. Such an approach ensures that learning is meaningful. When students are exposed to authentic language, they are prepared for real-life communication beyond the classroom.

\subsubsection{Belief statement 4 - Inclusion of te reo Māori in curriculum planning}

The majority $(75 \%)$ of respondents $(n=30)$ agreed it was important to consciously include te reo Māori in their curriculum planning. One teacher disagreed, however, while nine were unsure (see Figure 4.15 below). This could mean that some of the teacher respondents were unfamiliar with the Ministry's reo Māori curriculum guidelines, Te Aho Arataki Marau (2009), in which there is specific discussion around planning (p. 31). The reality is that, due to te reo Māori not being a core curriculum subject, the language could easily be lost in the delivery of a teacher's busy classroom programme; hence the need for its deliberate and planned inclusion.

Figure 4.15: Belief that teachers need to consciously include Māori language in their wider curriculum planning

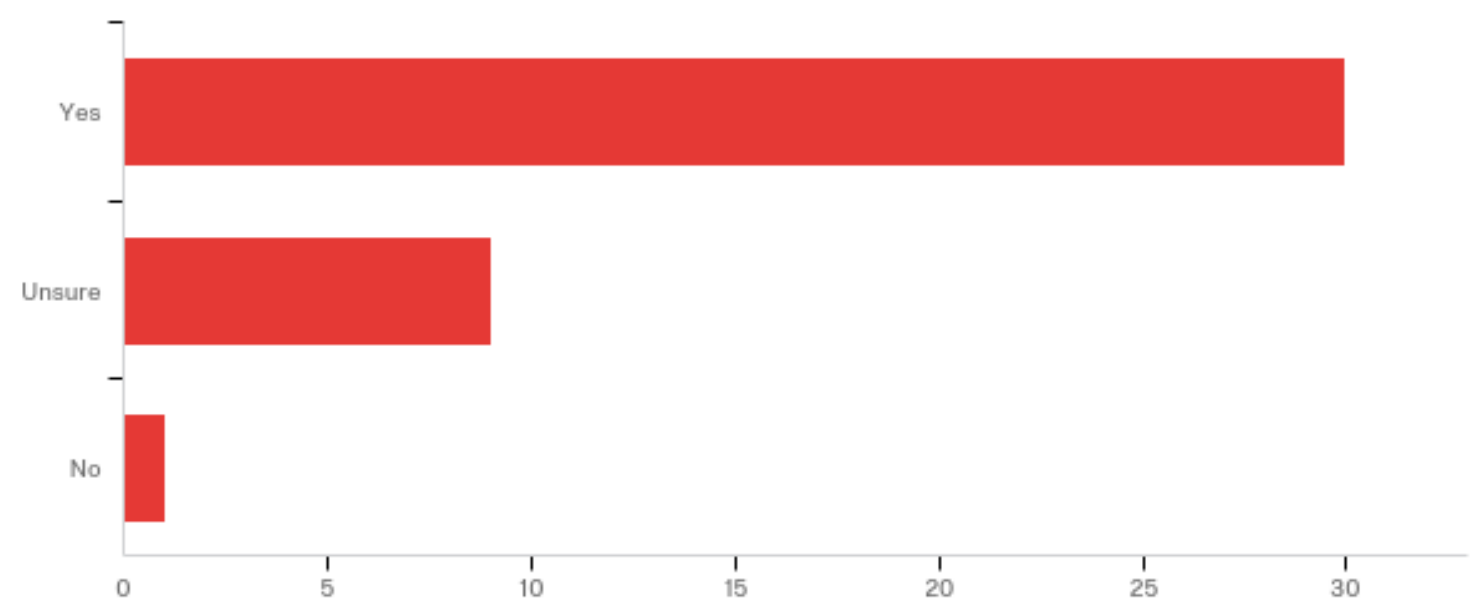

By integrating Māori language into their curriculum planning, teachers are demonstrating their commitment to the Treaty. By association, they are also acknowledging, and attempting to improve, the historic underachievement of Māori students in English-medium schools. Moreover, the planned inclusion of Māori language in the school curriculum is one way of addressing the insidious racism highlighted by students (unprompted) in research published by NZSTA and OCC (2018). 


\subsubsection{Belief statement 1 - External factors}

More than half the respondents $(n=26)$ indicated there were external factors influencing their teaching of Māori language. However, seven teachers disagreed. These may have been teachers with a sense of autonomy and self-efficacy in their personal teaching of te reo, such that (for them) there were no identifiable obstacles or enablers. Another seven teachers were unsure if indeed there were external factors influencing their Māori language teaching. Within a busy classroom, their uncertainty may be attributable to feelings of powerlessness and resignation about the status quo - or simply a lack of time to reflect on the things that may impede or facilitate the delivery of a quality Māori language programme (see Figure 4.16 below).

Figure 4.16: Teachers' beliefs about their reo Māori teaching being affected by external factors, over which they have no control

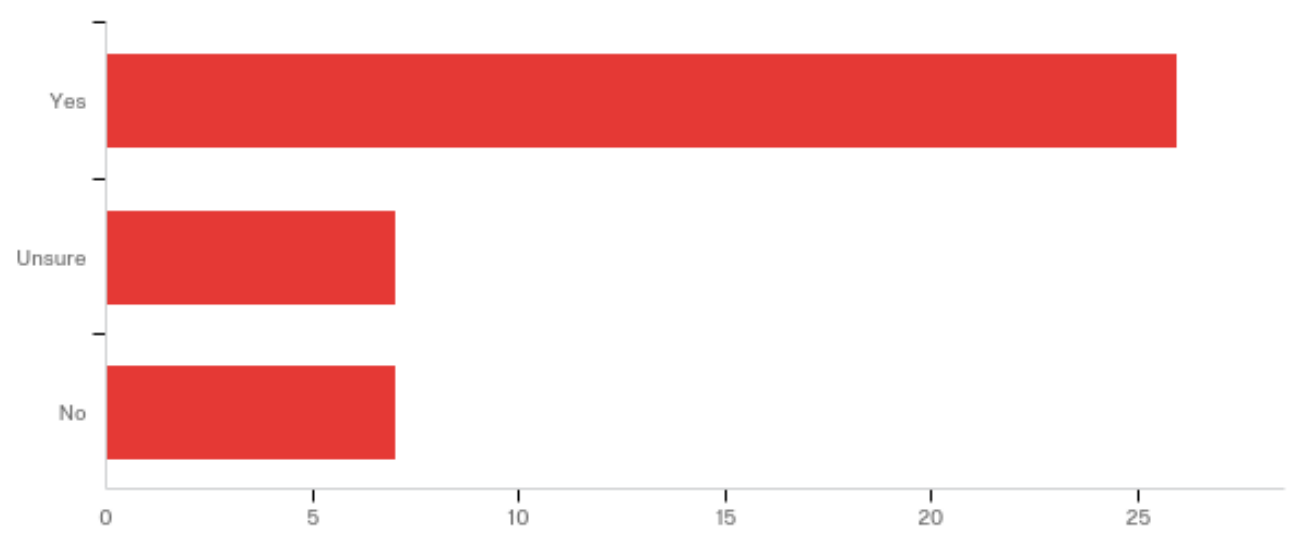

In their additional qualitative written comments on the online questionnaire, five teachers elaborated on four specific external factors (beyond their control) that influenced their teaching of te reo; namely, the lack of quality resources, lack of leadership, lack of parental support, and school timetabling. (See Figure 4.17 below, extracted from NVivo, where each teacher is demarcated by a different colour). Due to the extra time required for these five participants to voluntarily type such comments into the questionnaire, we can assume that the four factors must have been specific issues of interest for them. It is important to note that their comments are largely focused on elements that are lacking in their Māori language programmes. This could suggest that the teachers are unused to dealing with such obstacles in other areas of the curriculum. The 'lacks' associated with Māori language teaching and learning may mean this is a subject that is treated differently, perhaps regarded by schools as being of lesser importance. 
Figure 4.17: External factors that can influence the teaching of te reo

What are some of the influencing factors

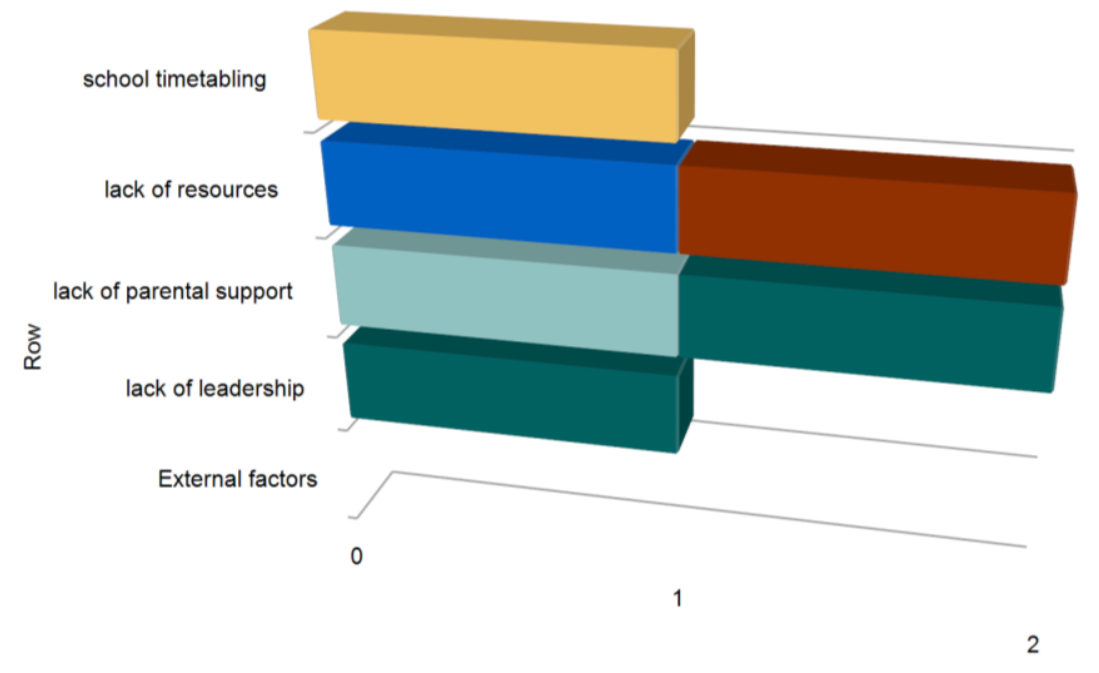

\begin{tabular}{|ll|}
\hline$\square$ Ainsley & $\square$ Kerry \\
$\square$ Bentley & $\square$ Laurel \\
$\square$ Bex & $\square$ Lexi \\
$\square$ Catriona & $\square$ Marg \\
$\square$ Chad & $\square$ Maria \\
$\square$ Dee & $\square$ Natania \\
$\square$ Delta & $\square$ Nate \\
$\square$ Dreena & $\square$ Riina \\
$\square$ Ellen & $\square$ Rikki \\
$\square$ Gemma & $\square$ Roberta \\
$\square$ Goldie & $\square$ Sasha \\
$\square$ Grace & $\square$ Shari \\
$\square$ Gwen & $\square$ Sheena \\
$\square$ Hannah & $\square$ Shevon \\
$\square$ Heather & $\square$ Summer \\
$\square$ Jamesina & $\square$ Tatiana \\
$\square$ Jamie & $\square$ Tessie \\
$\square$ Jane & $\square$ Trina \\
$\square$ Janet & $\square$ Zoe \\
$\square$ Jolene & \\
$\square$ Jordan & \\
& \\
\hline
\end{tabular}

Coding references count

Each of the four aforementioned external factors is discussed below - based on information derived from across all 40 teachers' responses to the belief statements in the online questionnaire (i.e. not just the five teachers who provided written global comments).

\subsection{Lack of quality resources (as in belief statement 11)}

In this research, the notion of a quality resource was based on the list of nine possible characteristics of 'quality' in the online questionnaire, from which respondents ranked the top three (see Question 28). The respondents' aggregated rankings of quality are discussed in section 4.5.

Nearly half $(47.5 \%)$ of the 40 teachers (i.e. $n=19)$ who completed the online questionnaire believed that one of the external factors inhibiting their teaching of te reo Māori was the lack of quality resources. However, eleven of them (27.5\%) were unsure if the lack of quality reo resources was an issue; and ten of them (25\%) discounted it as being a factor (see Figure 4.18 below). 
Figure 4.18: Beliefs about the lack of quality resources hindering teachers' ability to incorporate te reo Māori into their teaching

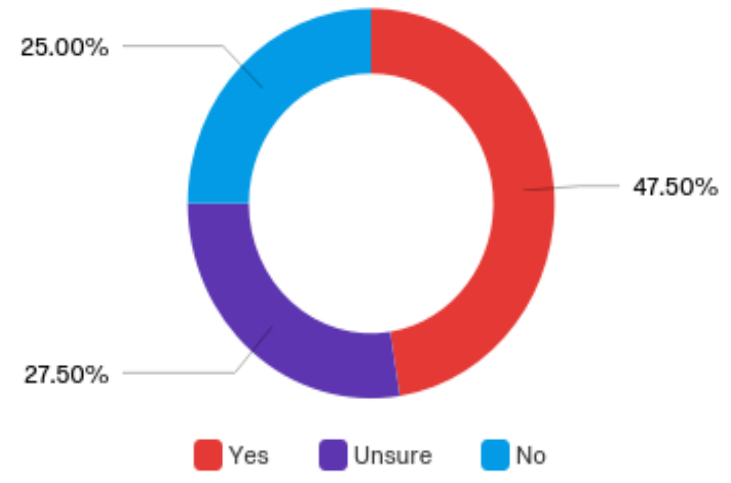

Based on my work in English-medium schools as a Māori language adviser, I would have anticipated a higher number of teachers confirming Belief Statement 11 about the lack of quality reo Māori resources being a barrier. The primary teachers with whom I work are frustrated at not being able to find quality Māori language resources that are engaging, simple to use and aligned to the curriculum. In the same vein, Barr and Seals (2018) emphasised that, to enact government policy around the teaching and learning of te reo, teachers need to be provided with appropriate resources. Otherwise, implementation can be adversely affected.

It is possible that the teacher respondents in my study who were unsure about, or discounted, the negative effect of a lack of quality reo Māori resources may have managed to successfully adapt Māori-medium materials published by the Ministry, to make them suitable for English-medium settings. Or they may have acquired the necessary school funds to purchase commercial reo Māori resources designed for English-medium settings. Alternatively, it could be that some of them are happy (and indeed prefer) to recycle the same resources each year. But there is a risk doing this, in that students will tire of the same input year after year - and they will not progress their learning.

\subsection{Physical, user-friendly resources}

The teachers who added supplementary written comments in the questionnaire about the lack of quality resources focused mainly on physical resources. For example, Jolene made a plea for user-friendly resources that could be used in genuine contexts:

"I would love to have easy-to-use resources that supported me in teaching, using Māori authentically." 
Moreover, Shari commented about having very few user-friendly resources to take her students beyond basic commands and formulaic language. (The latter type of language is described by Ellis, 2002, as rote-learned chunks of language, especially in early language acquisition, that are stored and retrieved as and when required - to aid fluency). Shari said:

"I think it's really hard as non-Māori, with limited easy-to-use resources, to be able to fully use it [te reo] in the classroom - other than commands and phrases."

Shari's remark about not being Māori suggests that she may feel inadequate and unauthentic in trying to meet the Ministry's expectations to deliver a quality programme in a language that is not hers (cf. Barr and Seals, 2018). Furthermore, she recognises the inevitable limitations created by the dearth of suitable Māori language resources - such that teachers default to 'tried and true' language. This scenario is limiting in terms of progressing students' reo Māori ability beyond the basics, so that they can generate meaningful communication.

\subsection{Resources for language progression}

Like Shari, the dearth of resources to progress students' learning was emphasised by Sheena:

"Most teachers see the value in teaching it [te reo] but lack the resources to implement a meaningful programme in their classroom that extends beyond colours and numbers."

Another teacher, Summer, specifically commented on the need for Māori language learning progressions - to overcome the possibility of teachers repeating the same topics each year, irrespective of year level or student ability:

"There needs to be more resources (time and money) allocated to this. In the past I have not seen schools develop sequential learning programmes and have been a bit frustrated at the repetition of teaching very basic language across levels (e.g. colours, days of the week etc). This has devalued the language as a living treasure."

The comments by Sheena and Summer highlight the need for resources that will help them facilitate students' incremental growth in the acquisition of te reo Māori. Otherwise (as 
already stated), teachers will naturally default to the safety of tried and true basics, which they have used for many years (e.g. colours, numbers, days of the week, commands, songs). Teachers who are satisfied with such a restricted and rote repertoire may be unaware of how limiting this input is for children's Māori language progression. Moreover, such basic items do not represent authentic communication.

It is interesting to note that, in Summer's comment above about te reo being a living treasure, she has clearly taken on board, and developed an understanding of, the concept of Māori language being a 'taonga' - something that is used, valued, and recognised in the Treaty. As such, she acknowledges the obligation on her as a teacher (as conveyed in Ministry expectations) to contribute to Māori language revitalisation by developing a quality reo Māori programme where students can progress from one level to another. To achieve this end, she emphasises that teachers need adequate resourcing.

Sheena and Summer, like Jolene and Shari, are keen to have resources that go beyond standard rote items - so that they can facilitate a Māori language programme that is meaningful and has application to real life. Their comments about physical resources indicate a desire for user-friendly materials that will support sequential learning and authentic communication in the classroom. The quotes from Sheena and Summer illustrate that teachers are cognisant of the inherent value of Māori language, hence their desire to do it justice within their classroom curriculum (progressing beyond the repetitive basics).

A Māori language progression in primary schools is hampered by teachers' low proficiency. Research for the NMSSA project (Ministry of Education, 2018) shows that, realistically, many English-medium students are studying te reo Māori at the lower end of curriculum level 1, irrespective of their class level or age - due to starting off their Māori language learning in different years of their schooling. As such, it is entirely feasible for a Year 1 student (aged approximately five) to be learning te reo at level 1 while older students higher up the same school are doing likewise. This is acknowledged in the Māori language curriculum guidelines, Te Aho Arataki Marau (2009, p. 32), which states that the curriculum levels described therein "...do not coincide with traditional year levels or with students' years of schooling." Such a situation exists because of the various starting points for learning te reo in NZ schools. It could be overcome if all students started te reo Māori at the age of five and were gradually exposed to increasingly complex language during their years at primary school. This would create a language progression across the different 
curriculum levels - especially levels $1-2$, which is the current focus in primary schools. However, this would require signicantly enhanced teacher proficiency.

\subsection{Human resources}

Some of the comments about the lack of resources went beyond physical resources - to include human resources. For example, Jordan made the following comment about the difficulty his school experienced finding specialist help: "We have struggled to find a kapa haka teacher or a specialised language teacher." Furthermore, Goldie specifically commented on her colleagues' lack of proficiency: "Both teachers I teach with have no Māori knowledge." These are external factors over which the teacher respondents have no control. Such scenarios can cause frustration and lead to teacher inertia - even for those teachers who are highly motivated to embed te reo Māori in their classroom programme.

As stated earlier in 4.3.1.4, research by education theorist Norton-Peirce (1995) is relevant - specifically her construct of 'investment', which provides an additional perspective on motivation. She draws a relationship between someone's desire to learn a target language (with its perceived benefits), and the context in which they are learning. Her findings recognise that each learner has agency. They can choose to either invest in learning, or challenge (and even resist) the language practices and ways of thinking that they are exposed to. Therefore, it is possible for a learner to maintain high levels of motivation, in terms of their sustained desire to learn the target language, while at the same time having little investment in their specific learning situation - due to inconsistencies between their expectations and the learning context they find themselves in. So, while Jordan and Goldie continue to be motivated about instilling Māori language in their school, their current investment is dwindling due to external factors beyond their control; namely, the lack of specialised help and the lack of reo proficiency among their colleagues.

\subsection{Lack of support from school leaders}

Research findings by Timperley et al. (2007) emphasise the importance of leaders being active participants in PD, if it is to be effective. Top-down support from school leaders is important for embedding Māori language in schools. Leaders could add mana to the teaching of te reo by including knowledge of the language in teachers' performance appraisal, with a focus on the cultural competencies set out in Tãtaiako (Ministry of Education, 2011, p. 2), where school leaders are expected to “...lead and engage others in validating and affirming Māori and iwi culture.” Haemata (2019) goes as far as saying that 
the success, and growth, of a school's Māori language programme is largely dependent on school leadership showing their support and providing adequate resourcing. Conversely, lack of demonstrable support from senior management can affect the degree to which teachers personally invest in the teaching and learning of te reo Māori, despite being motivated in this area.

\subsection{Mismatch in cultural backgrounds}

A contributing factor to the reported lack of support from school leaders could be demographics. In her presentation at U-learn ${ }^{128}$ (2017), Dr Ann Milne claimed that $80 \%$ of school leaders in Aotearoa NZ were non-Māori. She suggested that, for the majority, there was little exposure to Māori language and culture in their own education. As such, many of these leaders are likely to replicate the environment where they enjoyed educational success - an environment where, historically, there was little acknowledgement and appreciation of the benefits of Māori language in schools. The significance of te reo Māori in the current education system may not therefore resonate with such leaders.

One of my research participants, Roberta, highlighted this point. She wrote in the questionnaire about being particularly unsupported by her leaders, despite being part of the senior management team herself. She said:

"I believe valuing the Māori language in a school needs to come from the leadership team. Without...your Principal and BOT [Board of Trustees], the journey is far more difficult."

Roberta's comments were specifically directed at her BOT (responsible for establishing school policies) and her principal (responsible for managing the school in line with Board policies). She felt disappointed in their failure to demonstrate that they value te reo Māori (e.g. by, for example, taking action to develop a Māori language policy; making Māori language a strategic priority; ensuring that Māori language is built into teachers' planning; using te reo at school assemblies; and integrating Māori language into teachers' performance appraisal). A lack of demonstrable support from the top makes the efforts of

\footnotetext{
${ }^{128}$ An annual professional learning conference for teachers, facilitators and school leaders, from early childhood through to tertiary https://www.youtube.com/watch?v=5cTvi5qxqp4
} 
classroom teachers more difficult, as they endeavour to incorporate te reo Māori into the school curriculum on a regular basis and in a meaningful way.

\subsection{Whānau support in schools}

Roberta also took time to write a comment about there being a lack of support from parents in her school to progress the teaching and learning of te reo. Her comment highlights the challenge facing teachers in terms of doing the right thing (as per the Ministry expectation to teach the language) in the face of parent disinterest or negativity.

The Ministry recognises the importance of engaging whānau in the education of their children, acknowledging that they have much to contribute in a school:whānau partnership that exemplifies ako (see principle 5 in Ka Hikitia, 2013-2017). Moreover, Māori whānau engagement contributes to the 'partnership' principle associated with the Treaty (e.g. schools having a genuine relationship with Māori). Furthermore, the Ministry emphasises that whānau engagement is a significant contributor to student learning (Ministry of Education, 2007a, 2007, 2009). Similarly, the cultural competency 'Whanaungatanga' in Tātaiako (Ministry of Education, 2011) prioritises relationships with whānau and the community. Also, in terms of parental support for the learning of Māori, NZEI recommends that teachers' Māori language programmes should be developed in cooperation with parents and community ${ }^{129}$. Such a network would facilitate collective action (e.g. parents collectively supporting, and lobbying for, te reo Māori in their children's school). It would also enhance the 'social capital' of the community in respect of the gains to be accrued from having a network of social relationships (Bourdieu, 1986).

A collective stance from parents is sometimes threatened when non-Māori parents demonstrate their lack of support by voting with their feet and removing their child from a school (Gordon, 2015). This is not unique to Aotearoa NZ. Indeed, researchers Seals and Peyton (2017) highlight that there are parents all around the world who still question the value of learning any language other than English - because of the perception that English is a powerful language, with more status. This creates a situation where monolingual native speakers of English are attributed more prestige than bilingual or multi-lingual speakers (Cummins, 2005).

${ }^{129}$ NZEI Annual Meeting, 1992 
In the questionnaire, Roberta commented on her experience with some parents who demonstrated their dissatisfaction about the amount of reo Māori being introduced in her school. They protested by 'walking', as she describes:

"We have had parents remove their children from our school as they feel we are implementing too much Te Reo into our curriculum - and [yet] what we have implemented is minor. Luckily, ... those that are not on board have left the school."

This quote shows that the teaching of Māori language is a potentially divisive issue in schools (as indeed it is in wider NZ society). The actions of parents who 'walk' go beyond subtle forms of micro-aggression, like failing to correctly pronounce te reo or mocking others who endeavour to pronounce the language properly.

There may be varied reasons for parents deciding to re-locate their children to another school. They could be unaware of, or unconvinced by, the benefits that will accrue from their children learning te reo Māori; namely: national identity, enhanced linguistic ability, knowledge of another culture, cognitive challenge, socialisation in different contexts, and career opportunities (Ministry of Education, 2009, pp. 13-14). Or they may prefer their children to pursue a language perceived to have more status than Māori (e.g. Mandarin). Alternatively, they could be seeking upward social mobility. Regardless, they are making a discriminatory statement against Māori, the minority group. The result is a clear division in Aotearoa NZ between rich and poor schools (high and low deciles), and this divide is associated with ethnicity - as evidenced by Gordon (2015).

One solution to 'white flight' would be for schools to do a better job of communicating to parents the value to be gained from their children learning te reo Māori - and the advantages of preparing their offspring for real life, socialising as Kiwis in NZ's increasingly diverse society. The NMSSA initiative in English-medium schools (Ministry of Education, 2018) found a positive relationship between the amount of te reo spoken at home and achievement in the language. However, their evidence showed that there were very few of the participating students' homes where te reo Māori was 'always' or 'often' spoken. One possible drawcard to engage whānau with te reo Māori would be their having access to the school's Māori language resources (e.g. a ‘take-home' mini-version of a Māori reader being used in class - as provided with the commercial readers produced by Arahia Books). This would then build a home: school partnership where te reo is reinforced in both domains. 
Such an idea was suggested in Core's research (CORE Education, 2018), as a vehicle for engaging whānau.

\subsection{Timetabling}

In addition to the aforementioned external factors identified by the questionnaire respondents as affecting their teaching of Māori language (i.e. the the dearth of suitable quality resources, the absence of a Māori language progression, and the lack of support from leaders and parents), school timetabling was a potential obstacle. As mentioned previously, Māori language is too often having to compete with other subjects. These may well be subjects that are very important for social or academic reasons, but they do not necessarily enhance Māori language, culture and identity. This is evident in the following comment by Summer:

"The competing time allocations for each curriculum area, and the inclusions of more social programmes, has made it difficult to allow enough time for genuine language learning."

Summer highlights the busy nature of primary classrooms in Aotearoa NZ, where teachers are expected to be generalist practitioners covering all aspects of the curriculum, and more - as in her comment about social programmes.

The flexibility associated with the New Zealand Curriculum means that primary schools across the country can determine their own schedules around the timing of different learning areas - and the content to be focused on. As such, schools (ideally in consultation with their school community) make choices about their curriculum priorities. Invariably, core curriculum areas (like English, Maths, and Science) take precedence over te reo Māori, a subject that is not compulsory. A solution to this dilemma of competing priorities, which relegates te reo, would be for teachers to be sufficiently proficient in te reo Māori to integrate the language across several curriculum areas - instead of trying to compartmentalise Māori into a small time-finite slot during the day/week. That is, an increase in teachers' proficiency would enable te reo Māori to become a central part of our national curriculum. 


\subsection{Prior learning of te reo Māori}

Responses to Question 38, regarding the teachers' previous learning of Māori language, showed that the most common pathway $(n=23)$ was pre-service teacher education. In addition, a smaller number of respondents $(n=16)$ had been exposed to te reo Māori PD during their in-service careers. And some $(n=16)$ had pursued their learning of Māori language on a personal level. For example, eight of them had done some learning at university, while another eight had availed themselves of opportunities through wānanga $^{130}$. Others $(n=15)$ had received some Māori language input at primary school. Only two of the respondents stated that they had learnt Māori at secondary school, and four of them had accessed community learning opportunities - with one of those being through Ataarangi (discussed in Chapter 1). There were two respondents who described themselves as having no previous learning of te reo Māori at all (see Figure 4.19 below).

Figure 4.19: Teachers' prior knowledge of te reo Māori

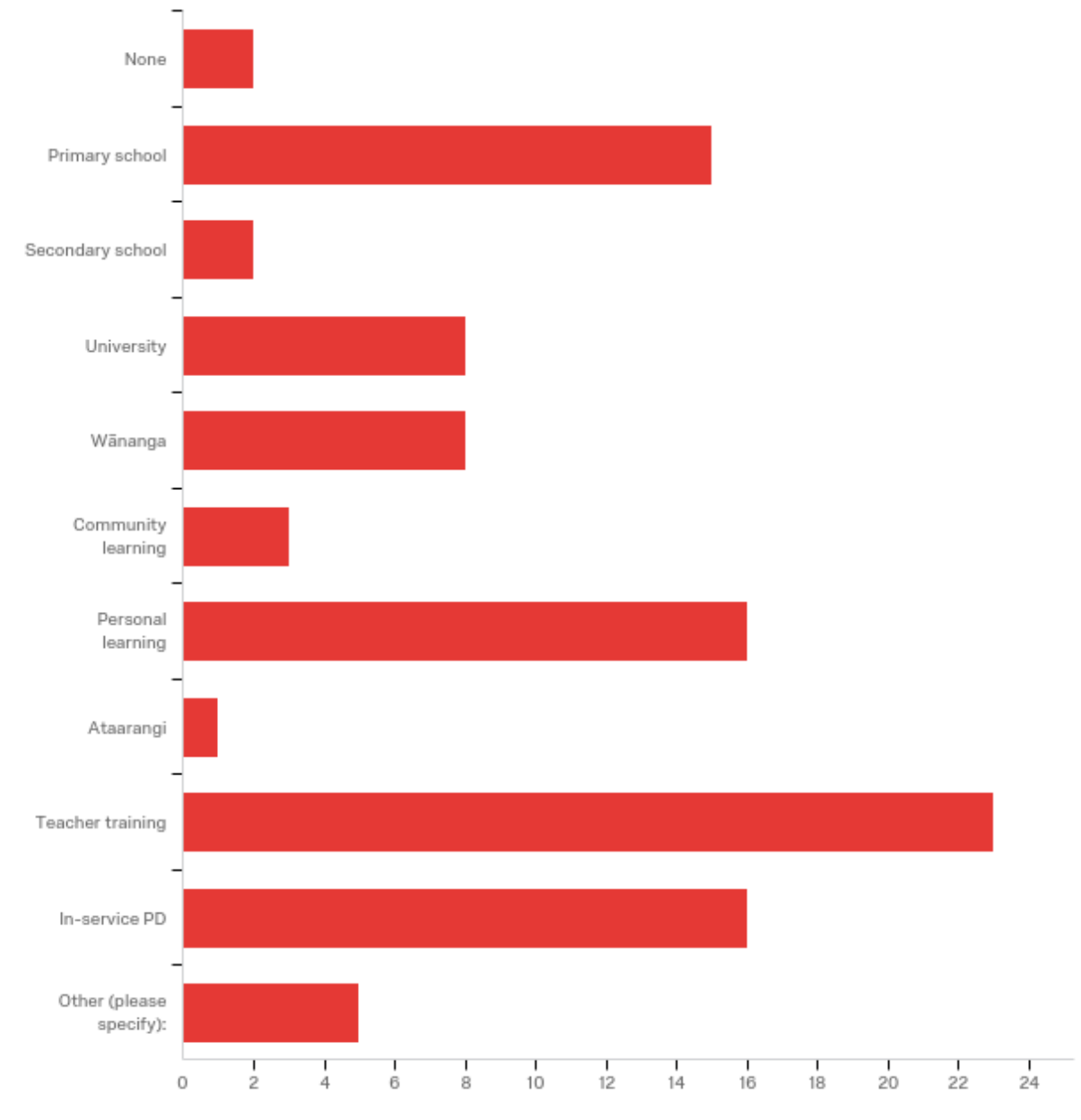

${ }^{130}$ Places of higher learning, guided by Māori philosophies 
Four teachers chose to elaborate on additional sources of prior learning. Roberta was currently learning 'on the job', having come from a different country. Nate had experienced some input as a member of the Army kapa haka, while Sasha had learnt some Māori language through Correspondence School. Janet's exposure was due to having a fluent speaker in her classroom for half an hour fortnightly, over two terms, which enabled her to increase proficiency. No information was provided about whether that fluent speaker was a peer, a community member, or a student. Nevertheless, such a situation is conducive to ako (i.e. the opportunity for reciprocal learning).

\subsubsection{Comfort level teaching te reo Māori}

When rating their level of comfort teaching Māori language, in Question 39, a little over half of the respondents $(n=21)$ deemed that they were 'somewhat comfortable', while more than a quarter of them $(n=11)$ took a neutral stance - being 'neither comfortable nor uncomfortable'. Of the remaining teachers, five felt 'somewhat uncomfortable' about teaching te reo Māori; two considered themselves to be 'extremely comfortable'; and one was at the other end of the continuum, feeling 'extremely uncomfortable' (see Figure 4.20 below). This finding suggests that there is still some way to go to build up teachers' level of comfort - to enable them to implement a quality Māori language programme as part of their classroom curriculum.

Figure 4.20: Teacher participants' comfort levels teaching te reo

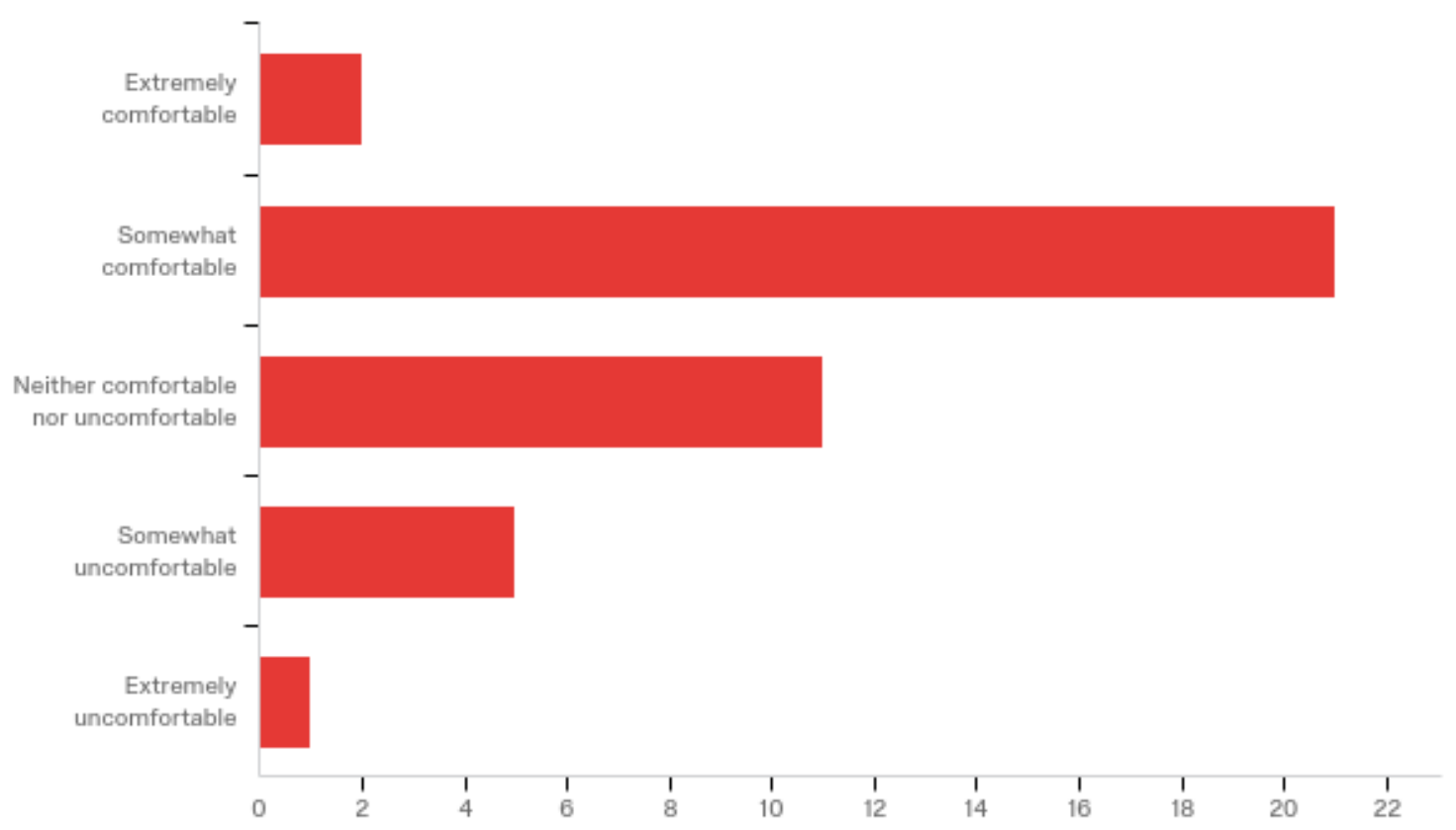




\subsection{Top three characteristics of quality Māori language materials}

In Question 28, participants were asked to choose three of nine characteristics that contribute to quality Māori language materials. The teachers' rankings are shown in Table 4.4 below.

Table 4.4: Teacher respondents' ranking of quality in reo resources (in order of importance)

\begin{tabular}{|l|l|}
\hline \multicolumn{1}{|c|}{ Ranking } & Characteristic of 'quality' \\
\hline $1^{\text {st }}$ & depiction of real-life contexts \\
\hline $2^{\text {nd }}$ & ease of use \\
\hline $2^{\text {nd= }}$ & integration of Māori tikanga, values, concepts \\
\hline $4^{\text {th }}$ & availability of an audio component \\
\hline $5^{\text {th }}$ & inclusion of an English translation/glossary \\
\hline $6^{\text {th }}$ & visual appeal \\
\hline $6^{\text {th }}$ & inclusion of multimedia \\
\hline $8^{\text {th }}$ & incorporation of teachers' notes \\
\hline $9^{\text {th }}$ & alignment to the curriculum \\
\hline
\end{tabular}

Figure 4.21 below shows that, when the findings were aggregated, more than half of the respondents $(n=26$ i.e. $65 \%)$ ranked real-life contexts at the top of the nine characteristics of quality. As already indicated in the discussion around Belief Statement 16, materials with real life contexts help teachers to promote learning that can be applied to everyday life (including the classroom). This notion sits well with the task-based theory of second language teaching and learning - as espoused in the Māori language curriculum guidelines, Te Aho Arataki Marau (Ministry of Education, 2009, pp. 21-23). Such an approach highlights the importance of students communicating and interacting in teacher-facilitated tasks that focus on meaning and are authentic in terms of having a relationship to real life (Ellis, 2005a) - in contrast to a more traditional, grammar-based approach where the focus is on the teacher explaining rules and the students doing exercises associated with those rules. 
Figure 4.21: Top three characteristics of quality in reo Māori materials

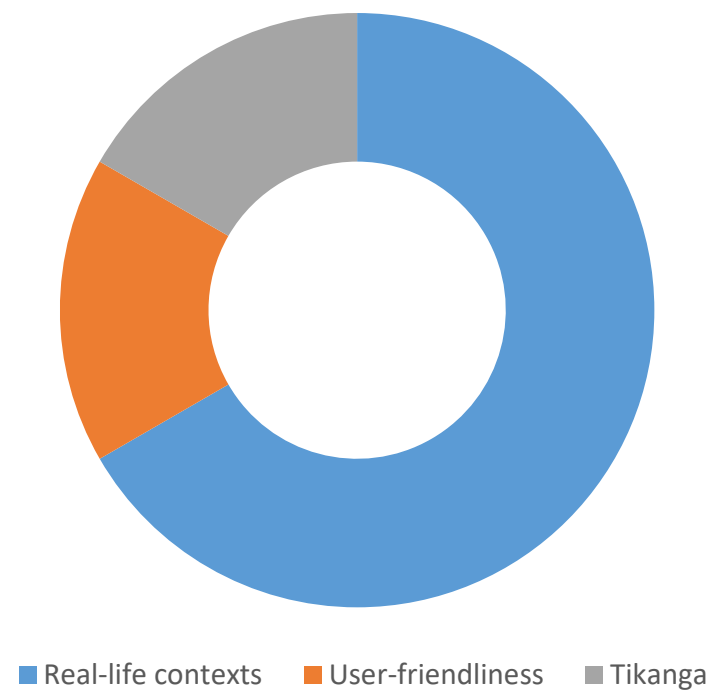

The second (equally) highest consistent rankings of quality were that materials should include aspects of tikanga and be user-friendly (as shown in Figure 4.21 above). Each of these two aspects was nominated in the 'top three' by $17.5 \%$ of respondents i.e. $n=7$ respectively.

The high ranking given by the participants to a tikanga component is congruent with an online survey ${ }^{131}$ completed in 2017 by primary school teachers $(n=17)$ to evaluate the success of the commercial bilingual publications, Arahia Books. Those teachers were required to rate the various aspects of the publications - out of a maximum of five points. Tikanga rated very highly in that the average rating for the inclusion of background information around tikanga was 4.5 points.

It was therefore surprising in my research that the teacher participants' high ranking of tikanga in the top three characteristics of quality was not mirrored in their subsequent suggestions about future Māori language resources (as explained in relation to Question 37 of the online questionnaire).

In terms of the other characteristic in the top three rankings of quality, I interpreted the term 'user-friendly' from a teacher's perspective, with reference to the classroom, where there is a need for materials to be easily understood and used - due to the busy and complex nature of teaching. One teacher, Jordan, specifically commented in the questionnaire that he wanted resources that required little or no copying and cutting up. He believed that these

${ }^{131}$ This survey was conducted by Sharon Holt, former publisher of Arahia Books 
manual tasks were a disincentive to using materials; he wanted resources that were 'readymade'. This view was reiterated in research by the Ministry of Education (2017), where teacher respondents called for materials that did not require assembly - due to their being time-poor. They believed that such manual tasks eroded their time with students.

The availability of an audio component was the fourth most common characteristic of 'quality' ranked by teachers. This is unsurprising in that such a component provides a pronunciation aid for teachers whose use of a resource may otherwise be limited by their poor pronunciation and feelings of inadequacy in this area.

The fifth most common characteristic of 'quality' ranked by the teachers was the inclusion of an English translation/glossary. This is also unsurprising in that the vocabulary bank of most non-Māori teachers in English-medium primary school settings is limited to basic items, hence their need for Māori words in a text to be translated. Furthermore, this facility enables students to make bi-literacy associations. That is, they can make connections between the English language (which is familiar to most of them) and te reo Māori (which is much less familiar).

Ranked equally, in the sixth position, were visual appeal and multimedia. There is no doubt that an illustrator can make a text come alive, to engage the audience. This is especially important in children's resources. Likewise, in today's world of technological advancement, with children's exposure to a range of media early in life, it is important to provide multiple platforms for accessing educational resources.

Initially, I found it surprising that the teachers gave a low ranking to the inclusion of teachers' notes, in terms of adding quality to Māori language materials. Only two of the 40 teachers ranked this aspect in the top three criteria - one of them ranking it as the second most important feature of quality, with the other ranking it third. The other 38 teachers' low ranking of teachers' notes seemed inconsistent with some of their qualitative responses elsewhere in the questionnaire - where they called for support to help them use Māori language materials. Indeed, from my experience in schools, I regard teachers' notes as being imperative, especially in the absence of PD, to help teachers maximise their use of materials and enhance their students' learning of Māori as a second language.

On reflection though, my initial surprise at the low overall ranking given to teachers' notes has since been tempered. I now interprete the finding in the context of participants being 
required to make a choice (from a prescribed list) about what they consider to be the top three characteristics of quality in Māori language materials. As such, their choices do not necessarily mean that they believe teachers' notes to be unimportant - but rather there are other quality characteristics that they deem to be more important at the present time.

I have applied the same rationale to the finding that alignment to the curriculum received the lowest ranking overall, in terms of the teacher participants' top three characteristics of quality materials. Initially, I jumped to the conclusion that this would likely be a disappointment for the Ministry, having invested in the development of the Māori language curriculum guidelines, Te Aho Arataki Marau (Ministry of Education, 2009). However, it may be more realistic to interprete this finding as being attributable to the fact that, when asked to make choices about what constitutes quality reo materials, teachers have more pressing priorities in relation to student engagement and the day-to-day life of the classroom. This does not necessarily mean an undervaluing of the curriculum guidelines, which are important for helping teachers plan and deliver quality Māori language programmes at eight levels of achievement - as well as providing information about the teaching of second languages.

\subsubsection{Qualitative comments about quality Māori language materials}

Having ranked their top three characteristics of quality, based on options that I provided in the online questionnaire (Question 28), teachers were invited to write additional comments about the characteristics of 'quality' Māori language materials (see Figure 4.22 below, extracted from NVivo). 
Figure 4.22: Comments about characteristics of quality Māori language resources

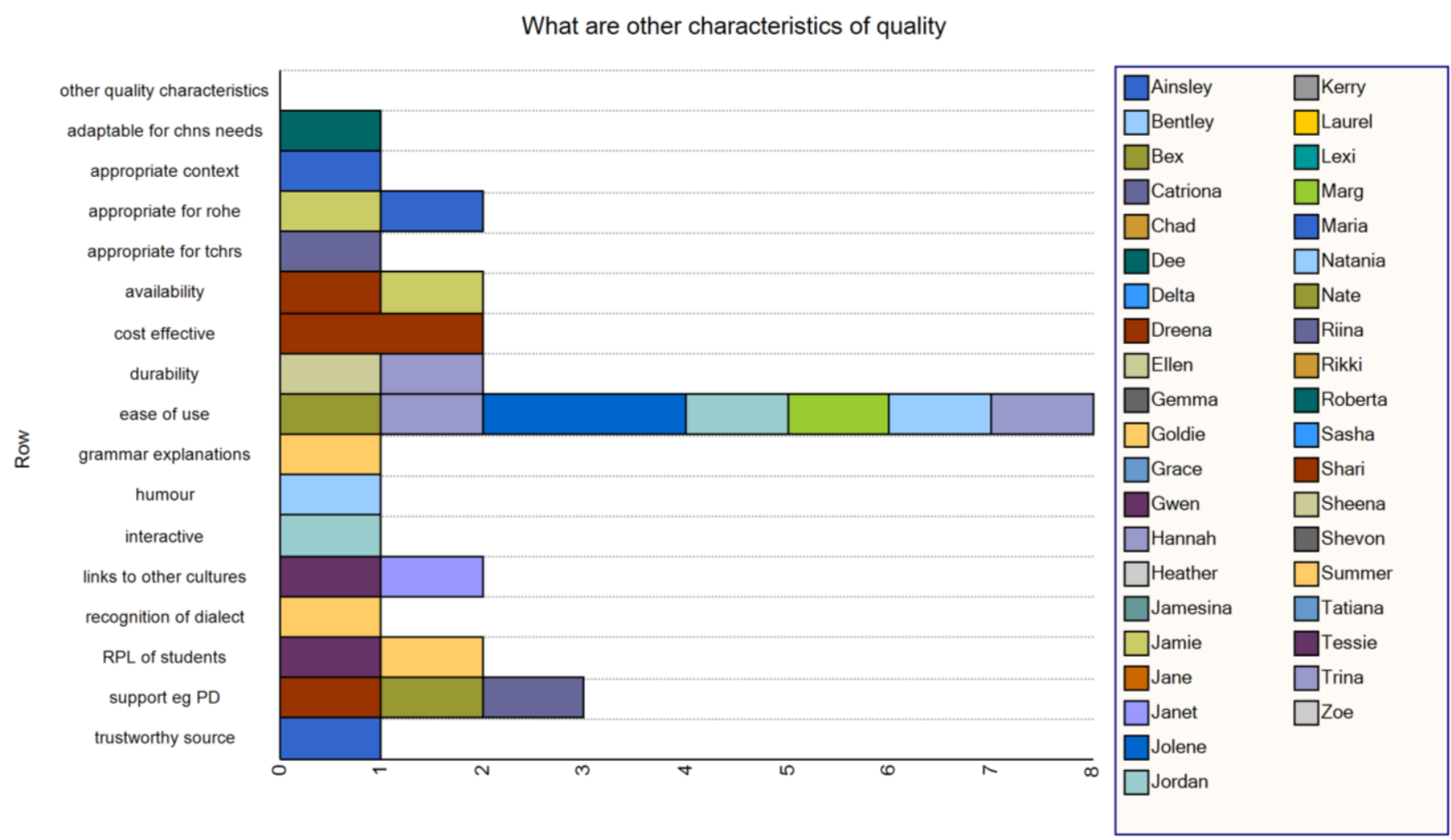

Coding references count

The most recurring comments $(n=7)$ about quality characteristics were around ease of use (e.g. little or no cutting up and photo copying; able to be edited to suit the needs of the children; easy to integrate into the class for everyday use).

The prevalence of respondents' written comments in the questionnaire about userfriendliness is consistent with the high ranking given to user-friendliness in their rankings of the top three characteristics of quality resources (as discussed earlier in relation to Question 28). One teacher, Natania, specifically commented on the ease of using the animations in the Ministry's multimedia resource for English-medium primary schools, $\mathrm{He}$ Reo Tири (Ministry of Education, 2011), which featured in my questionnaire (see Question 31 in Appendix 5, and also Appendix 10). She said their user-friendliness contributed to her successful implementation of Māori language in the classroom. Moreover, they appealed to children (i.e. funny, with relatable life experiences, and easy to follow).

Three teachers (Dreena, Nate and Riina) linked the notion of quality with the provision of $\mathrm{PD}$, to ensure maximum use of the resources. Nate emphasised the importance of PD for clarifying things that were not explicit in the resources, saying: 
"The teacher must feel supported with the package they are using; having PD and/or someone to go to, to confirm issues not covered in the bare materials."

Riina highlighted the role of PD support in building teacher confidence. She wanted “...support...for the teacher who is not as knowledgeable, so they can be confident to give it a go". Additionally, Dreena commented on teachers needing to know how to maximise Māori language resources. She therefore expressed a desire for PD that would provide teachers with "... support to know how to use them most effectively". Such comments about the need for support illustrate how important it is for the introduction of new materials to be accompanied by appropriate PD. This would, ideally, be face-to-face with a skilled facilitator. However, there are also possibilities through e-learning.

Other determinants of quality Māori language materials, as specified in the teachers' qualitative comments, included:

- $\quad$ availability $(n=2)$

- durability $(\mathrm{n}=2)$

- $\quad$ recognition of students' prior learning and cultural knowledge $(\mathrm{n}=2)$

- $\quad$ links to other cultures $(n=2)$

- $\quad$ appropriateness for teachers' (cultural) backgrounds $(\mathrm{n}=1)$

- $\quad \operatorname{cost}(n=1)$

- $\quad$ inclusion of dialect-specific content $(n=1)$

- $\quad$ explanations of grammar $(\mathrm{n}=1)$

- $\operatorname{humour}(\mathrm{n}=1)$

- $\quad$ interactivity $(\mathrm{n}=1)$

- $\quad$ trustworthiness of source $(n=1)$.

Four different teachers raised the important consideration of culture. One of them, Gwen, commented twice - on two related aspects; namely, the importance of recognising the prior cultural knowledge that students bring to the classroom, and the need to create opportunities in the classroom for students to make cross-cultural associations. Gwen emphasised the need for resources that make connections between Māori and other cultures:

"To include/share other cultures in the classroom that are similar to Māori beliefs or legends. Making the connections between cultures can help put wider Māori beliefs into context." 
These insights suggest that Gwen is particularly aware of how important it is for teachers to be open to seeing other world views, so that they can be culturally responsive in their practice (i.e embracing diversity by respecting and validating others' languages, cultures and prior experiences).

Janet showed similar insights to Gwen. She specifically recognised the rich cultural background that Māori children bring to the classroom. Janet believed that their stories were invaluable as a resource:

"The most powerful resources are Māori students, using their stories - been to a tangi, where are they from etc. Using their stories as a springboard for all students to share about themselves, making it meaningful and connecting them to one another."

This is an important reflection because, as espoused by Bourdieu (1986) in his work on different forms of 'capital', the acknowledgement and validation of a student's cultural background is associated with positive educational outcomes - as emphasised in the Ministry's Māori education strategy, Ka Hikitia (Ministry of Education, 2013). Materials that include a cultural component can contribute to these outcomes, while at the same time equipping non-Māori teachers with aspects of Māori cultural knowledge.

The heightened awareness of other people's cultures does not only apply to students. Teachers can also become more interculturally competent through exposure to professional reading aimed at helping them to:

- $\quad$ personalise their students' learning, by capitalising on the students' prior knowledge/experience,

- $\quad$ embed the concept of ako, by fostering a classroom environment where the teacher is open to learning from the students, and

- $\quad$ engage whānau as genuine partners, to help maximise student potential.

The extent of teachers' professional reading has been found to have a significant positive relationship with their awareness of the need to teach in a way that encourages students to make comparisons and connections between languages and cultures - in order to celebrate the uniqueness of each (Oranje, 2016). Professional reading provides evidence-based research and helps to maintain currency, which is an important aspect of being a professional teacher in Aotearoa NZ. Becoming more informed helps teachers to gain a 
better understanding of Māori values, so that classroom interactions are more culturally responsive. Additionally, it helps them navigate their way around the all-too-common reality of there being a demographic mismatch between themselves and many of their students - as highlighted by Māori educationalist Dr Wally Penetito (NZCER, 2011, p. 42):

"Most teachers know very little about what it means to be Māori, and yet most of our kids are in mainstream."

This mismatch influences the delivery of the New Zealand Curriculum.

\subsection{Frequency of use of existing Ministry materials}

Questions 30-35 in the online questionnaire explored how frequently the respondents used six free Ministry-provided resources (i.e. always use/use most of the time/use about half the time/use sometimes/never use). These resources are designed to support the teaching and learning of te reo Māori in English-medium primary schools. Respondents were provided with images of each resource in the online form of the questionnaire - as memory joggers. Five of these resources are available in print and /or online. The sixth resource is a DVD. (Appendix 10 provides an overview of the frequency of use. It also shows images of the resources).

These existing Ministry resources are under-utilised. However, it cannot be assumed that their under-utilisation means that the resources are inferior. It could be because they are unknown to the respondents - or that there has been little/ no PD to show teachers how to maximise the resources. The Ministry stocktake (2017), discussed in Chapter 3, highlights a need to develop new ways of facilitating PD, to ensure the effective use of materials.

To summarise, teachers' responses to Questions 30-35 indicated that the Māori language curriculum guidelines for Years 1 - 13, Te Aho Arataki Marau, were rarely used - perhaps because they are unfamiliar. The supplementary multimedia resource for Years 1-6, He Reo Tири, was used more frequently because of its practical hands-on content. Incongruously, the multimedia waiata resource, Hei Waiata Hei Whakakoakoa, was under-utilised despite respondents indicating they were having to search for waiata resources online. Similarly, the plethora of Māori language readers produced by the Ministry ${ }^{132}$ were not

${ }^{132}$ See Down the Back of the Chair, the Ministry's online catalogue of teaching and learning resources for schools, kura and ECE http://www.thechair.co.nzl 
being maximised in English-medium primary schools - due to most of them being too difficult for those settings, having been designed specifically for Māori-medium students. Furthermore, the useful suite of online Māori language resources designed to support the professional development of teachers, Te Whakaipurangi Rauemi, was also underutilised probably because teachers are unaware of its existence. Finally, the DVD, First Class, aimed at increasing teachers' knowledge about second language teaching and learning in Years 5-9, was especially under-utilised. This could be due to outdated technology, or simply because teachers are unaware of its existence and its purpose.

\subsection{Other reo materials used}

In addition to the teachers stating in the questionnaire what Ministry-provided resources they used in the classroom to facilitate te reo Māori, they were invited to write down other Māori resources they used (Question 36). As can be seen in Figure 4.23 below (extracted from NVivo), the most common response $(n=6)$ was that teachers often resort to making their own materials - due to a lack of resources appropriate for their needs in teaching te reo in English-medium primary school classrooms.

Figure 4.23: Other Māori resources used by teachers, in addition to Ministry resources

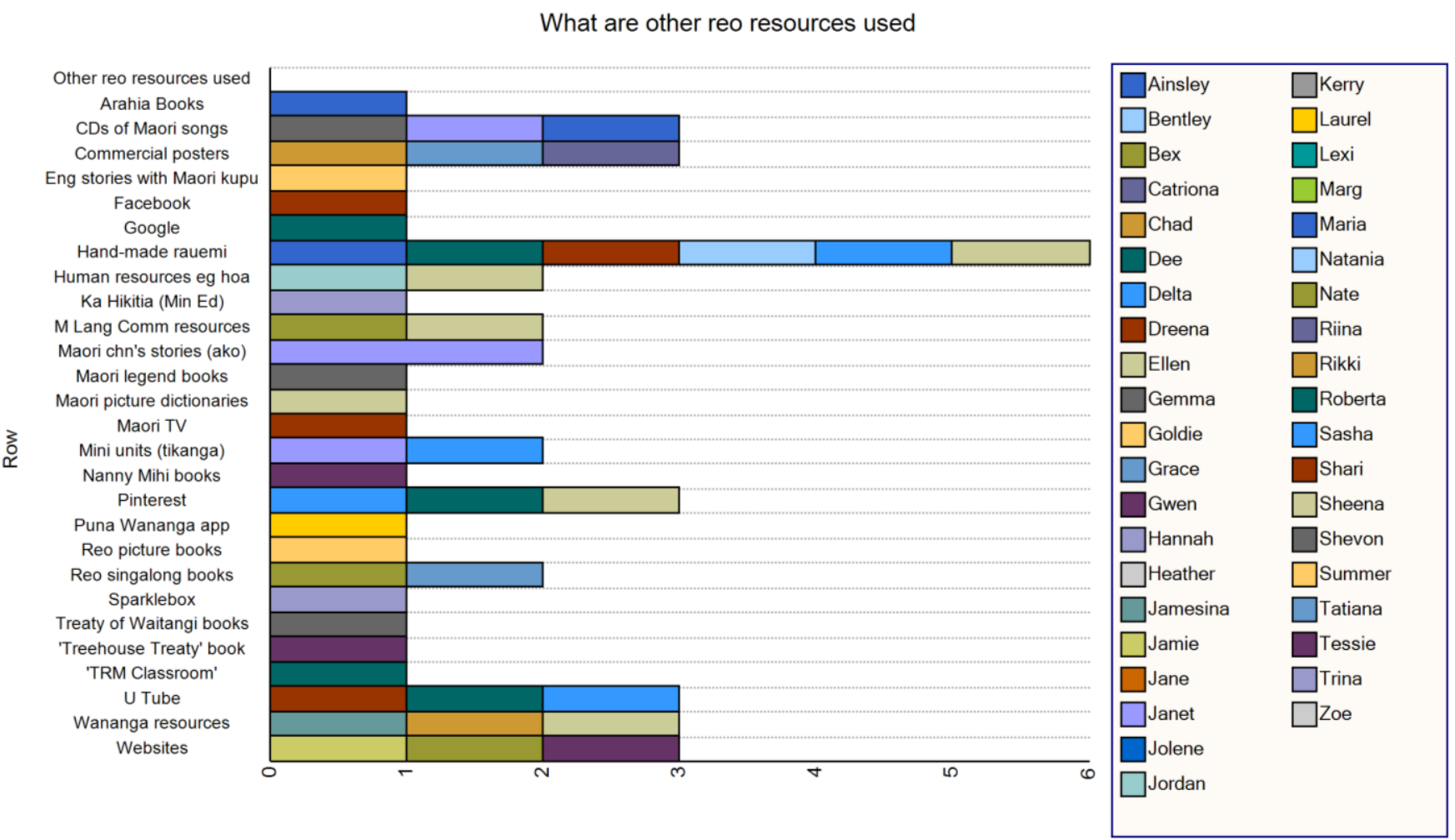


Delta, Roberta, and Sheena found Pinterest useful for making Māori resources, while Ainsley stated that she makes whatever she needs - to suit the learning of the children (e.g. pepeha booklets and posters). In doing so, she said she experienced another form of ako; namely, learning while making the resources. That is, she found resource-making helped her to consolidate her own learning, before having to teach the content to students. Moreover, her making of resources was a way of providing students with resources that matched their needs. Similarly, Dreena and her colleagues tailored their Māori language resource-making to their students. They favoured “... resources we have made ourselves, so they are appropriate and relevant." Relevance to student needs was also the motivation for Sheena making Māori language resources; in particular, “... teacher-made materials posters, worksheets, pair games/ activities that are relevant to the class I am teaching." It is evident that these research participants are conscientious about delivering a student-centred curriculum.

Prior to discovering the Ministry's multimedia package, He Reo Tupu (2011), Natania also resorted to making her own resources. These included “...some flashcards I ... made myself, other charts about days, weather, months, and other vocabulary I made myself, simply to get to the point of what I was teaching - before I knew about He Reo Tupu." Natania developed the hand-made resources to enhance her teaching and her students' learning. Another teacher, Sasha, did the same - to add value to her teaching of numeration in Māori:

"I use a Māori snakes and ladders game I created to teach numbers to 100 in te reo."

In this case, her Māori language resource added value to the children's grasp of the mathematical concept associated with expanded numerals - which is easier to understand when using Māori numeration.

The Ministry of Education (2017) found that English-medium teachers resort to creating their own Māori language resources (including posters, flashcards, assessment rubrics, and CDs/audio files) due to a lack of suitable resources available to them. Furthermore, they reportedly frequent $\$ 2$ shops to purchase requisite materials. At the same time as making their own, teachers maximise other Māori language resources (beyond those that are Ministry-funded). An overview is provided in Table 4.5 below, using data extrapolated from Figure 4.23 above. 
Table 4.5: Overview of other types of Māori language resources used by teachers

\begin{tabular}{|c|c|c|c|c|}
\hline Waiata resources & $\begin{array}{l}\text { Resources from } \\
\text { organisations }\end{array}$ & Print resources & Multimedia resources & Miscellaneous resources \\
\hline $\begin{array}{l}\text { - Waiata CDs }(n=3) \\
\text { - YouTube songs }(n=3) \\
\text { pronunciation }(n=3) \\
\text { - Reo Singalong books } \\
(n=2)\end{array}$ & $\begin{array}{l}\text { - Wānanga resources } \\
(\mathrm{n}=3)\end{array}$ & $\begin{array}{l}\text { - Treaty books, e.g. } \\
\text { Treehouse Treaty }(\mathrm{n}=2) \\
\text { - Arahia Books ( } \mathrm{n}=1) \\
\text { - Books on Māori legends } \\
(\mathrm{n}=1) \\
\text { - Picture books ( } \mathrm{n}=1) \\
\text { - Nanny Mihi books, by } \\
\text { Melanie Drewery }(\mathrm{n}=1) \\
\text { - Māori picture } \\
\text { dictionaries ( } \mathrm{n}=1) \\
\text { - English readers with } \\
\text { Māori language } \\
\text { embedded (n=1) }\end{array}$ & $\begin{array}{l}\text { - Sparklebox }(\mathrm{n}=1) \\
\text { - Te Reo Māori in the } \\
\text { Classroom website } \\
(\mathrm{n}=1) \\
\text { - Facebook }(\mathrm{n}=1) \\
\text { - Google }(\mathrm{n}=1) \\
\text { - Puna Wānanga app } \\
(\mathrm{n}=1) \\
\text { - Māori TV }(\mathrm{n}=1)\end{array}$ & $\begin{array}{l}\text { - Commercial posters } \\
(\mathrm{n}=3) \\
\text { - Mini-units on tikanga } \\
(\mathrm{n}=2) \\
\text { - Human resources }(\mathrm{n}=2) \\
\text { - Children's own stories } \\
\text { (mentioned twice by } \\
\text { Janet) }\end{array}$ \\
\hline
\end{tabular}


It was evident from the teachers' comments in the questionnaire that sourcing Māori songs was important for Māori language programmes in English-medium primary school settings (despite the infrequent use of the Ministry's free resource, Hei Waiata Hei Whakakoakoa - as featured in the questionnaire and reported earlier). The NMSSA findings (Ministry of Education, 2018, p. 76) confirmed that singing waiata and participating in kapa haka were two of the three most popular ways (in addition to karakia) for English-medium teachers to expose Year 4 and Year 8 students to Māori language at school. Research by Haemata (2019) also found that English-medium teachers deemed waiata and kapa haka to be important aspects contributing to students' Māori language outcomes.

Teachers view waiata and kapa haka as a valid way of providing Māori language input. Yet, realistically, students can (and, in many instances, do) learn waiata, kapa haka items and karakia by rote - without necessarily understanding the meaning associated with the words. Furthermore, the teaching of waiata is not as onerous or demanding for the teacher as the facilitation of real-life second language tasks using te reo, which requires more preparation and more language proficiency.

Nevertheless, singing is a legitimate vehicle for students to learn te reo Māori. In my experience, waiata are useful for practising pronunciation and phrasing in a group situation, in a non-threatening atmosphere of whanaungatanga - compared with being put 'on the spot' individually, or in pairs, having to communicate orally. Māori songs can also potentially help to consolidate, and indeed expand, learners' vocabulary banks. And, for most of us, waiata provide enjoyment. Moreover, the singing of waiata provides an opportunity to exemplify ako (reciprocal teaching and learning) and tuakana:teina practices, in that the more confident singers can lead those who are less confident.

Furthermore, many waiata represent 'he taonga tuku iho' (i.e. something handed down inter-generationally - to be valued and treasured). They are a way of helping teachers and students appreciate te reo Māori me ōna tikanga. They also provide a conduit for students to develop an appreciation of Māori values imbued in the lyrics - $\underline{\text { if }}$ the students are provided with the necessary background knowledge and translation.

Master's research by Rubie (1999), exploring the effect of kapa haka on Māori students, found that there were many benefits; namely: improved confidence and self esteem, enhanced motivation for learning (including reading, writing and visual 
language through action songs and haka), more positive feelings about school, and improved results in standardised tests.

Likewise, in Whitinui's (2007) research about the educational benefits for Māori students participating in kapa haka, he pointed to a positive effect on school participation and achievement. He concluded that this was because kapa haka validated Māori culture, boosted confidence, nurtured identity, and instilled pride in being Māori. Similar findings emerged in research commissioned by the Ministry for Culture and Heritage, looking at the benefits of kapa haka (Pihama, Tipene and Skipper, 2014). The findings show a link between students' participation in kapa haka and improved learning outcomes at school.

As well as using waiata to provide Māori language input in the classroom, some of the teachers indicated that they sought out resources from organisations. For example, as well as the Ministry of Education publication Ka Hikitia (the Māori education strategy), these teachers were using resources produced by the Māori Language Commission (e.g. Māori Language Week resources), Ako Aotearoa (e.g. practical, evidence-based resources to support good teaching and learning), and various Wānanga (e.g. attractive, and mostly free, resources designed for adults studying Māori at tertiary level - but able to be adapted for the primary school classroom). Teachers' access to Wānanga resources suggests that they have opted to invest their personal time in studying te reo Māori - for their own development (personal and/or professional), to add value to their students' learning. This is substantiated in research by the Ministry of Education (2017) - where some Englishmedium teachers were found to be enrolled in Wānanga courses (albeit with very little support from their schools).

Interestingly, despite the high use of IT in most NZ classrooms, many of the teachers clearly prefer to use books to provide input on Māori language and culture. It would seem likely, based on the range of print resources specified in Table 4.5 above, that teachers are having to pay for commercially produced books (e.g. readers, legends, dictionaries, Treaty books and picture books). This is possibly due to the dearth of Ministry-produced Māori language readers suitable for English-medium primary schools. However, although school budgets for Māori language are limited, only one questionnaire respondent, Dreena, raised cost as a factor for consideration. (That was in response to Question 29 of the online questionnaire - about the characteristics of a quality reo resource). This suggests that, regardless of what they have to pay for quality resources, teachers are prepared to do so because of the value 
they place on the teaching and learning of Māori language in their English-medium primary classrooms.

Multimedia resources provide a range of Māori language content that teachers can adapt to suit their needs (e.g. Sparklebox, 'Te Reo Māori in the Classroom' site, Facebook, Google, applications, and Māori TV). Research has shown that English-medium teachers use various media to locate Māori language content e.g. Māori TV, YouTube, Pinterest, Google Classrooms, vlogs, Instagram, Snapchat, and applications (Ministry of Education, 2017). While acknowledging the wide range of online Māori resources available to support student learning, the teachers in that study were aware that some of the resources were not high quality. Hence the need identified in that research for a user-friendly, online data base that teachers could search via topic, theme, author, date, iwi/region, or curriculum level - with accessible links to quality Māori language content online.

In summary, despite there being few suitable Māori language resources available in English-medium primary schools, the teacher respondents in my study demonstrate agency and self-efficacy. Instead of feeling disempowered, they are being proactive by, for example, finding suitable content through a range of multimedia, making their own resources, purchasing commercially produced materials, or acquiring resources from other organisations (beyond the Ministry). This indicates a level of enthusiasm, engagement and investment in the teaching of Māori language.

Finally, it should be noted that there were other miscellaneous resources used by my 40 questionnaire respondents:

- commercial posters (e.g. featuring visuals of generic topics such as number, weather, greetings);

- $\quad$ mini unit plans on the various aspects of Māori culture (e.g. pōwhiri ${ }^{133}$; parts of a meeting house); and

- $\quad$ students' personal stories about their experiences in te ao Māori (e.g. going to hui; collecting kaimoana; visiting Nanny).

${ }^{133}$ Formal welcome on marae 


\subsection{Suggestions for future materials}

TPK's audit in 2001 (mentioned in Chapter 2) recommended the need for a more strategic approach to Māori language resource development in schools. A subsequent report by ERO (2007), reviewing curriculum materials that promote the teaching and learning of Māori language, supported TPK by recommending that future resources should:

- $\quad$ reflect current second language teaching and learning theories;

- $\quad$ support the range of English-medium students' proficiency levels; and

- $\quad$ be informed by the Māori language curriculum guidelines.

Recent research found that English-medium teachers wanted simple Māori language teaching and learning resources, with lots of repetition, tailored to English-medium contexts (Ministry of Education, 2017). The teachers also requested English translations of the Māori texts - as a scaffold, to compensate for their own lack of proficiency in te reo. Moreover, they requested that the English translations be located on the same page as the Māori text - which they found more useful for developing biliteracy skills than having the Māori text in one place and the English translation in another.

In my teacher respondents' suggestions about future Māori language resources, in Question 37 , the most popular ideas $(n=21)$ were around the development of games and multimedia (as illustrated in Figure 4.24 below, extracted from NVivo). A survey of English-medium teachers by Core (2018) also revealed a desire for game-based and online resources because of their potential to engage students through interactive activities (individually and in groups). This reflects the appeal that all forms of multimedia have for the current (and future) generation(s) of digital natives. There are implications for the Ministry and resource developers in that they need to keep abreast of technological advancements in this fastevolving digital world.

Figure 4.24 below shows the teachers' ideas about future resources. In addition to the games and multimedia already mentioned, the next most popular suggestions were for resources that:

- $\quad$ exemplified everyday classroom language $(n=6)$;

- $\quad$ provided pronunciation support $(\mathrm{n}=5)$; and

- $\quad$ presented Māori language in the form of readers ( $n=5)$ and/or bilingual texts $(n=5)$. 
Figure 4.24: Teachers' suggestions re future resources

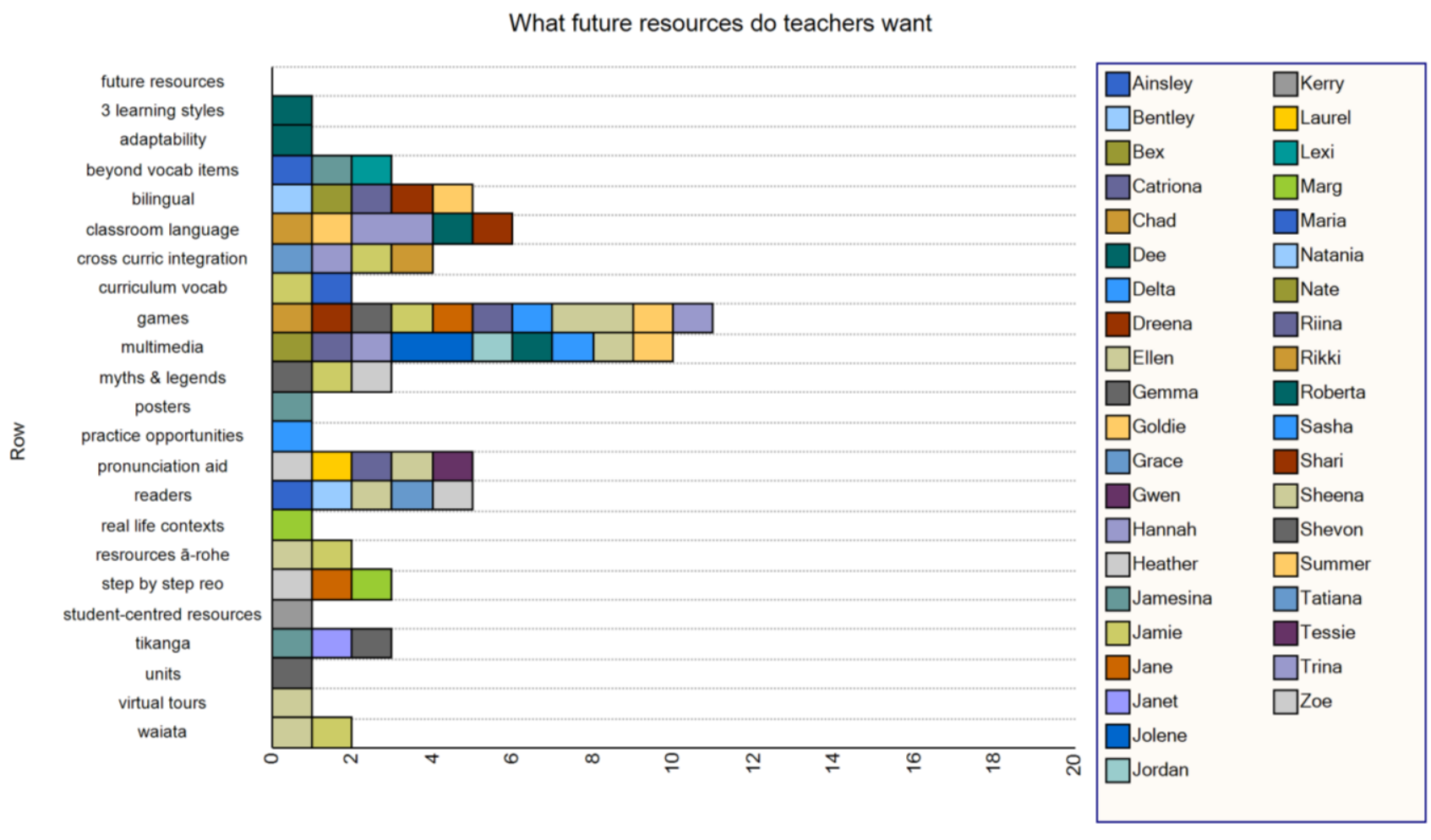

Coding references count

The suggestion about future resources needing to show everyday classroom language aligns with teachers' rankings of nine characteristics of a 'quality' resource (see Question 28 in the questionnaire) - where the top ranking was for real-life contexts. Furthermore, responses to Question 16 of the questionnaire (about real-life contextualisation) confirm that teachers believe it is beneficial for students if their learning of Māori is contextualised in real-life. Likewise, teachers' suggestions about future resources needing to support pronunciation are closely linked to their responses earlier in the questionnaire (Question 19), where they were unanimous about needing to model good Māori language pronunciation.

It is worth noting too that, despite games and multimedia resources being their priority, some teachers $(n=10)$ are still keen to see the development of print materials - in the form of bilingual texts and readers at their level. This aligns with teachers' responses in section 4.7 (about other reo materials used), where books are reportedly still desirable despite the prevalence of multimedia. It is also congruent with research done by the Ministry of Education (2017), Core (2017), McKenzie (2014), Ellis (2005a), and Holliday (1994) - all of whom recognise the value of print materials for providing language input, albeit blended with other media. 
Only three of the teachers suggested a future need for tikanga. This small number surprised me, in view of the teachers' earlier rankings (in Question 28) of the quality characteristics of Māori language resources where Māori tikanga/values/concepts were ranked in the top three attributes (of nine) by 23 of the 40 teachers. A possible explanation for the inconsistency across questions is that, although the teachers believe that tikanga is an important characteristic of quality reo materials, they have more immediate pressing needs; namely, to get basic help around Māori pronunciation, vocabulary development and grammar - with specific application to the classroom. Alternatively, teachers may believe that there are enough physical and online resources available to fill their knowledge gaps around tikanga.

Of the three teachers who requested the future development of tikanga-related resources, two (Janet and Ainsley) commented on the need to respect Māori people and Māori culture. Janet saw this as her bottom line:

"My passion is about building a respect for Māori and the tikanga. Whilst the language is important, it is beyond my scope to be a facilitator in furthering students' knowledge and competency in the language."

Another teacher, Jamesina, recognised the limitations associated with a lack of cultural knowledge. She readily admitted:

"I only know what I look into and would love to know I'm doing things respectfully."

Like Janet, she was mindful of needing to respect the Māori culture. Hence her recommendation for resources that would confirm the 'right' way of doing things ${ }^{134}$ - lest she unwittingly cause offence. She accepted that she has a responsibility, as a non-Māori teacher, to contribute to efforts aimed at raising the status of Māori language and culture, by using it in the classroom.

Similarly, in case study research by Barr and Seals (2018, p. 14), a primary school teacher participant, James, saw his role as a facilitator of te reo for his students - which in turn was a conduit to Māori culture. He believed that Māori language gave Māori students a sense

\footnotetext{
134 The word 'tikanga' (culture) is derived from 'tika' (right) - hence the association with the right way of doing things (i. e. correct cultural practices)
} 
of being accepted. He said, “...if what your culture speaks isn't valued, then how can you value yourself? Or feel as an equal party"?

Penetito (2010) goes further saying that, when Māori language is not valued, it is a form of institutional racism - perpetuated inter-generationally. He states that this creates an unequal power relationship, where the dominant group in society are the key decision-makers who promote certain values - at the expense of another group's values. (See section 1.2 for a discussion about 'white privilege').

To show that it values te reo Māori, the Ministry has allocated \$7.6M (over four years, 2017-2020) to be invested in supporting Māori language in schools/kura. The money is to be specifically spent on the design and delivery of localised curriculum resources across Aotearoa (e.g. local people/places/events/stories; and regional and national events like the land wars and the commemoration of the Treaty of Waitangi). These resources will play an important part in better defining our landscape and, indeed, our identity as a country - from a Māori world view. The fact that only two of my respondents viewed the development of local resources as a future priority for resource development may indicate the need for the Ministry to better communicate the value of place-based education, in the context of 'our place' and our relationship with it (Penetito, 2009).

Encouragingly, in a survey conducted by Core (2018), some English-medium teachers expressed a need for these types of resources - specifically, resources that acknowledge mana whenua ${ }^{135}$ and contribute to an understanding of local Māori (e.g. through important land features, stories and historical events). One teacher (p. 6) explained it as follows: "We share our knowledge of understanding of place, where we come from .... Knowledge of how to say mihi, for example, is integral to this." For them, it is clearly important that future resources have authentic contexts, to enrich the teaching of pepeha/mihimihi in the classroom.

Finally, in analysing my teacher respondents' suggestions about future resource development, it became apparent that some teachers may be unaware of what resources are available, free, from the Ministry. An example is a request from Ellen for “... songs that are translated ... with integrated follow-up activities." This type of resource already exists in

\footnotetext{
135 Authority and power over tribal land - occupied inter-generationally and imbued with the tribe's history and legends
} 
the form of Hei Waiata Hei Whakoakoa (2008) - mentioned earlier and explored in my online questionnaire (Question 33). It is provided free to schools by the Ministry. Moreover, not only does it have English translations and suggested activities for the waiata, it also has music notation, and is available in print and online.

This lack of awareness by teachers, regarding what is available in the way of Māori language resources, is noteworthy in relation to my third research question (about possible factors that can influence teachers' attempts to teach te reo Māori). It is possible that, where teachers indicate that a dearth of resources is inhibiting their reo teaching, they may simply be unaware of existing resources.

\subsection{Chapter review}

The online Qualtrics questionnaire allowed me to answer the first of my research questions about the beliefs of 40 non-Māori teachers, in English-medium primary schools (deciles 110), in respect of Māori language teaching and learning. The questionnaire also provided some insight into my fourth research question about teachers' views on Māori language resources in English-medium primary schools (i.e. existing use; future suggestions; and the characteristics of quality). Additionally, the questionnaire informed my third research question about factors that can influence teachers' attempts to use te reo Māori.

Across the teachers there was a range of reo Māori ability and comfort levels teaching the language, but it was clear that teacher proficiency is an issue. For example, only $25 \%$ of the respondents believed that their proficiency was adequate enough for them to be flexible and make 'on the run' adaptations when implementing lesson plans.

Fewer than half of the teachers believed that their prior experiences learning Māori influenced their current teaching of the language. These views would likely have been influenced by the various ways they learnt, the quality of teaching they received, and the extent of their learning. This finding suggests that more than half of the teachers may be open to doing things differently (e.g. improving pedagogy; using reo Māori materials). They themselves may have been recipients of poor teaching, and are now looking to remedy the situation for their students.

The teacher participants believed Māori was important for all NZ primary school students, thus validating its status as a taonga. Most were intrinsically motivated to include the 
language in their teaching, which confirms that they value te reo. Moreover, they thought that the language should be compulsory, despite there being no moves from the Ministry to instigate such a policy.

The respondents believed categorically that teachers should model good pronunciation of te reo Māori. This aligns with one of the cultural competencies in Tãtaiako (Ministry of Education, 2011); namely, manaakitanga (i.e. demonstrating respect towards Māori beliefs, language and culture). Most of them expressed a belief that English-medium primary school teachers should know, and use, basic Māori language in the classroom - but they were unanimous about not needing to have native speaker fluency, as they recognised that would be unrealistic.

The teachers indicated which Ministry (and other) resources they use, and what they would like to see developed in the future (e.g. games/multimedia; classroom language; and pronunciation support). It was evident that the current Ministry resources are being underutilised - not necessarily because they are inferior but perhaps because they are unknown or there has been little/ no associated PD to facilitate their uptake. In terms of what constitutes a quality reo Māori resource, the top three criteria among the 40 questionnaire respondents were real-life contexts, user-friendliness, and inclusion of tikanga.

Added to teachers' (generally) low levels of proficiency and comfort teaching Māori, there were certain external factors evident in teachers' written qualitative responses that clearly influenced their attempts to teach Māori language. They cited factors that were all impediments; namely, a lack of support from school leaders and parents; poor allocation of time for Māori language compared with core subjects and social programmes; and a lack of user-friendly resources. The fact that some of the questionnaire respondents took the time to add written comments about these factors suggests that these may not be issues they have to contend with in other learning areas, which enjoy elevated status in the curriculum.

Having school leaders who are unsupportive of Māori language teaching and learning can have a negative effect on teachers, in terms of sustaining their reo Māori efforts in the classroom. The absence of support may be due to the leaders' own lack of exposure to, or knowledge of, te reo Māori - or their juggling of competing priorities while running the school. Furthermore, whānau support is important. It demonstrates that a school and its parent community are in a genuine partnership. As such, parents can contribute to their 
children's learning of te reo Māori by conveying a positive attitude and seeing the value therein.

Having insufficient time to do justice to Māori language teaching is an issue in primary school, with its already crowded curriculum. Teachers feel pressure to prioritise core subjects that are formally assessed, which means that te reo can easily be overlooked. Upskilling teachers' proficiency would help to address this issue, as they would then be able to integrate te reo Māori across different curriculum areas - thus increasing its visibility.

In the case of resources, it is possible that those teachers who disagreed with (or were unsure about) there being a lack of quality resources may in fact be content with their own restricted 'go to' resources that they recycle each year, with each new class. In doing so, there will be an element of security for the teachers - especially those who are anxious, lacking in confidence, and loathe to move out of their comfort zone and try new resources. However, this narrow approach limits the potential for students to grow their Māori language ability.

In terms of the theoretical knowledge associated with second language acquisition, $75 \%$ of the teachers believe that this is important for underpinning their practice. However, there are few PD opportunities in pre-service and in-service education to show them how to apply this knowledge in the classroom. Nevertheless, some of the affirmative responses to the belief statements in the questionnaire suggest that a few of the teachers do in fact use second language teaching strategies; namely:

- $\quad$ Embedding Māori language words and phrases into English sentences,

- $\quad$ Placing an emphasis on listening and speaking,

- $\quad$ Facilitating enjoyable practice opportunities for students (individual, pair, small group or whole class),

- Using a range of materials (adapted if necessary), and

- Capitalising on students' real-life experiences (including their culture).

This finding is important because such strategies will enhance student learning outcomes.

The teachers' responses in the questionnaire indicated that the integration of tikanga into their Māori language teaching was important for students' appreciation of the Māori world, 
and what it means to be Māori. Similarly, the teachers believed it was important to draw on students' backgrounds and cultures, to affirm their identity and enhance their learning. This finding is worthy of note because of the inextricable relationship between te reo me ona tikanga (language and culture) - as emphasised in Ka Hikitia (Ministry of Education, 2013).

In conclusion, teachers could be better supported by having user-friendly Māori language resources suitable for English-medium primary school settings, with accompanying PD to: familiarise them with relevant resources, upskill their Māori language proficiency, enhance their understanding of tikanga, and increase their knowledge about second language acquisition. Furthermore, they could be supported by having more time within the busy classroom curriculum to accommodate te reo Māori teaching and learning - and more encouragement from school leaders and whānau.

The questionnaire provided important quantitative baseline information (and some qualitative data) prior to undertaking the next research phase (i.e. observations), which aimed to determine the extent to which four case study teachers' beliefs were enacted in the classroom. The next chapter discusses the findings from these classroom observations in respect of: the four teachers' current Māori language use in the classroom; opportunities for future use; teacher attitudes; students' prior knowledge; scaffolding; inclusion of tikanga; visibility of te reo in the classroom; and availability (and use) of materials. 


\section{FINDINGS AND DISCUSSION, Part 2: Observations |}

\section{NGĀ KITENGA ME TE KŌRERO, Wāhanga 2: He mātaki}

\subsection{Background to classroom observations}

This chapter provides information on my observations in four classrooms - including the relevance of the observations to my research questions; the demographics of the four teachers who were observed; and the common trends across the four observed teachers in terms of: the use of Māori language in their classrooms; opportunities for future use; their attitudes; students' prior knowledge; scaffolding; inclusion of tikanga; visibility of te reo in the classroom; and availability (and use) of materials.

\subsubsection{Relevance to research questions}

The classroom observations helped to answer my second research question: How are their beliefs enacted (or not) in the classroom i.e. the consistency (or not) between their stated beliefs and actual practice? This question explored how four of the initial 40 questionnaire respondents implemented te reo Māori in their respective classrooms - and to what extent there was congruence between their stated beliefs and their actual practice during my observations.

For each of the four case studies, I spent one hour daily on four consecutive days collecting data during observations (see Table 5.1 below) - plus an initial familiarisation day prior, checking the optimum positioning for the audio equipment and familiarising the students with my physical presence in the room.

Table 5.1: Dates of observations

\begin{tabular}{|c|c|c|c|c|}
\hline $\begin{array}{c}\text { Teacher } \\
\text { (Classroom) }\end{array}$ & $\begin{array}{c}\text { Observation 1 } \\
\text { (one hour) }\end{array}$ & $\begin{array}{c}\text { Observation 2 } \\
\text { (one hour) }\end{array}$ & $\begin{array}{c}\text { Observation 3 } \\
\text { (one hour) }\end{array}$ & $\begin{array}{c}\text { Observation 4 } \\
\text { (one hour) }\end{array}$ \\
\hline $\begin{array}{c}\text { Ainsley } \\
\text { (Classroom 1) }\end{array}$ & 9 May 2017 & 10 May 2017 & 11 May 2017 & 12 May 2017 \\
\hline $\begin{array}{c}\text { Jordan } \\
\text { (Classroom 2) }\end{array}$ & 30 May 2017 & 31 May 2017 & 1 June 2017 & 2 June 2017 \\
\hline $\begin{array}{c}\text { Delta } \\
\text { (Classroom 3) }\end{array}$ & 20 June 2017 & 21 June 2017 & 22 June 2017 & 23 June 2017 \\
\hline $\begin{array}{c}\text { Jamie } \\
\text { (Classroom 4) }\end{array}$ & 23 May 2017 & 24 May 2017 & 25 May 2017 & 26 May 2017 \\
\hline
\end{tabular}




\subsubsection{Teacher demographics}

The teachers whom I observed were known to me, in a professional capacity. Although they did not share the same Māori language proficiency, they were recognised in their schools as being committed to te reo. They taught at different class levels in Wellington schools (covering a range of deciles and roll sizes), and they had varied years of teaching experience. (See Table 5.2 below). A Year 3-4 teacher had also agreed to be observed and interviewed, but she had to withdraw from the study at the last minute due to illness, which resulted in her being absent from school for two terms. Notwithstanding, it was more important for me to have a variety of decile ratings than a range of class levels, because of the relationship between deciles and Māori student rolls ${ }^{136}$ (as discussed in Chapter 4).

Table 5.2 - Demographics of teachers who were observed and interviewed

\begin{tabular}{|l|l|l|l|l|l|l|}
\hline Pseudonym & $\begin{array}{l}\text { Teacher } \\
\text { age } \\
\text { range }\end{array}$ & $\begin{array}{l}\text { Years of } \\
\text { teaching } \\
\text { experience }\end{array}$ & Gender & $\begin{array}{l}\text { Class } \\
\text { level }\end{array}$ & $\begin{array}{l}\text { School } \\
\text { decile } \\
\text { range }\end{array}$ & $\begin{array}{l}\text { School } \\
\text { roll (at } \\
\text { March } \\
\text { 2018) }\end{array}$ \\
\hline $\begin{array}{l}\text { Ainsley } \\
(\text { Classroom 1) }\end{array}$ & $25-34$ & $6-10$ & F & Y 1-2 & $8-10$ & 210 \\
\hline $\begin{array}{l}\text { Jordan } \\
(\text { Classroom 2) }\end{array}$ & $35-44$ & $6-10$ & M & Y 5-6 & $8-10$ & 373 \\
\hline $\begin{array}{l}\text { Delta } \\
(\text { Classroom 3) }\end{array}$ & $55-64$ & $16+$ & F & Y 5-6 & $4-7$ & 239 \\
\hline $\begin{array}{l}\text { Jamie } \\
(\text { Classroom 4) }\end{array}$ & $35-44$ & $16+$ & F & Y 5-6 & $1-3$ & 311 \\
\hline
\end{tabular}

\subsubsection{Common trends across the four observed teachers}

This chapter is organised under eight general trends that were common across all four teachers whom I observed:

- Use of te reo Māori in the classroom,

- Scope for teachers to use more te reo in the classroom,

- Teachers' attitudes towards Māori language and culture,

- $\quad$ Building on students' prior knowledge and experiences,

136 Typically, there are more Māori students in low decile schools - and fewer in high decile schools 
- Scaffolding of te reo Māori input,

- Applying tikanga in the classroom,

- Te reo Māori in the linguistic landscape of the English-medium classroom/school, and

- $\quad$ Availability, and use of, Māori language materials.

The reason for organising the chapter around trends (as opposed to teacher-specific observations) was to minimise the likelihood of the four case study participants being identified in my descriptions of classroom behaviour. I wanted to keep their mana intact commending them for their genuine attempts to integrate te reo Māori into their busy classroom schedules and, in the spirit of whakaiti, acknowledging my indebtedness for being able to observe in their classrooms. Without identifying the four teachers specifically, I was able to make suggestions (based on my observations) about future opportunities where they could build on their use of basic Māori language in the classroom - which may help other teachers who read this research.

\subsection{Use of te reo Māori in the classroom}

Based on my observations, and my professional judgement from being a Māori language teacher and adviser in schools ${ }^{137}$, the pronunciation of the four case study teachers was good in that they fulfilled the requirements of the Māori language curriculum guidelines, at curriculum level 1 (Ministry of Education, 2009, p. 42); namely, to "imitate the pronunciation ... of Māori words, phrases, and sentences." One of the teachers (in preparing her class for a marae trip) made sure that, when she introduced a new Māori word, the students were given ample opportunity to practise its pronunciation. She also ensured there was time for them to work with classmates to verbalise their pepeha (which was modelled using a scaffolded cloze template ${ }^{138}$ ) and practise doing a hongi. These practical 'hands on' activities successfully engaged the students - as evidenced in their enthusiastic attitudes when they stood up to practise with each other and with the teacher.

\footnotetext{
${ }^{137}$ In the past, I taught te reo Māori in English-medium settings (primary, secondary and tertiary) for nearly 50 years. Currently I provide private Māori language tuition and I also work as a PD facilitator in schools upskilling English-medium teachers' proficiency. Moreover, my Master's degree in Applied Linguistics examined the teaching and learning of Māori language in pre-service teacher education, using a communicative approach

${ }^{138}$ Tēnā koutou. Ko Mea tōku ingoa. Nō reira, tēnā koutou, tēnā koutou, tēnā tātou katoa. (Greetings to you. My name is So-and-so. Therefore greetings to you, greetings to you, greetings to us all)
} 
They were learning from each other (student:student and student:teacher) - as reflected in the teacher's words, while facilitating paired practice:

"If you follow along as well, it's like your buddy is teaching you."

This comment demonstrated the teacher's understanding of ako (which conveys a sense of reciprocity between teaching and learning), and tuakana:teina (which emphasises the importance of peer teaching).

Māori language use in the classrooms was, in the main, instructional and formulaic - for the purpose of classroom management (which suggests it was difficult for the teachers to use te reo in a flexible and agile way). Examples included:

- "Haere mai." (Come over here) (Classroom 2, Recording 3)

- "E noho." (Sit down) (Classroom 3, Recording 3)

- "Whakarongo mai. Titiro mai." (Listen and look this way) (Classroom 3, Recording 1)

- “Tahi, rua, toru, whā." (One, two, three, four). "Pūkana!" (Eyes dilated!) (Classroom 3, Recording 1)

- "Tahi, rua, toru, whā, rima, ono, whitu, waru, iwa, tekau." (One, two, three, four, five, six, seven, eight, nine, ten) (Classroom 1, Recording 3).

The first three examples above are common classroom commands for managing children's behaviour (i.e. asking them to come, sit, listen and look). The other two examples above involve the use of Māori numbers, in ascending order, to provide students with a finite time to complete a task (e.g. tidying up; coming together on the mat; focussing their attention on the teacher; being quiet). In one classroom, the teacher would call out the first two numbers 'tahi, rua' to which the students would respond with the next two numbers in the series, 'toru, whā', while stopping to look and listen. The use of Māori numbers as a classroom management strategy was popular with all four teachers.

Occasionally, there were instances where the teachers used Māori to praise or encourage students' efforts. For example:

- "Homai te pakipaki." (Give a clap) (Classroom 3, Recording 1)

- "Kia kaha." (Be brave. Give it a go) (Classroom 3, Recording 3)

- “Ka pai." (Well done) (Classroom 4, Recording 1). 
These words of affirmation and encouragement made a pleasant change from the perfunctory commands to sit/stand, look/listen. The verbal affirmations were sometimes reinforced visually, with teachers using a 'thumbs up' gesture to show their approval.

Teachers maximised the two words "Ka pai." As well as being used in the context of teacher praise (as above), these words were sometimes used by the teacher in the form of a question (with raised intonation), to determine students' understanding i.e. "Ka pai?" (OK?), as in Classroom 1, Recording 3. The students would respond using the same two words "Ka pai" (but with different 'flatter' intonation) as a statement, to confirm their understanding. This is important knowledge being developed implicitly by the students, in terms of knowing the effect of different intonation on meaning.

On a few occasions, Māori was used to greet students (e.g. "Ahiahi mārie"139) - as in the calling of the roll (Classroom 3, Recording 4). There were also times when teachers successfully embedded a Māori word or phrase into an English sentence - while providing the English equivalent alongside. Such self-translations are a type of translanguaging, where the use of two languages, side-by-side, assists learning and comprehension (as discussed in a paper and seminar associated with Victoria University of Wellington's Translanguaging Aotearoa project (Seals, 2018a, 2018b)).

Some examples of self-translations that I heard in the classrooms are listed below:

- “Sit down. E noho” (Classroom 3, Recording 1).

- “Listening please, whakarongo" (Classroom 4, Recording 1).

- $\quad$ “Awesome, ka pai” (Classroom 3, Recording 4).

- "Then the people of the marae, the tangata whenua ${ }^{140}$, will sing a song" (Classroom 1, Recording 1).

- "We're the manuhiri, the visitors" (Classroom 1, Recording 1).

These examples show that self-translations were used to reinforce te reo Māori in a range of contexts; namely, giving instructions; commending students; and introducing new vocabulary associated with tikanga Māori. Over time, teachers exercised their judgement and appropriately removed self-translation scaffolding - when they believed that a specific word, phrase or sentence was firmly embedded. Examples included:

\footnotetext{
${ }^{139}$ Good afternoon

${ }^{140}$ Local people/hosts
} 
- " "Please start with a picture of you and your Māmā ${ }^{141}$." (This reinforced the word for 'mother' that had appeared in the students' reader on Mother's Day). (Classroom 1, Recording 4).

- "Write a letter to a friend or whānau member about Matariki ${ }^{142}$." (In this instance, the teacher adjudged that the Māori words for 'family' and 'Māori New Year' were well-established in her classroom - and, indeed, in the NZ vernacular). (Classroom 3, Recording 1).

- " "Have a good kanikani ${ }^{143}$." (The teacher used the Māori word for 'dance', with no need for an English translation, due to the context i.e. playing some music for children to dance to). (Classroom 1, Recording 4).

- "Wow, look at this! Âtaahua! ${ }^{144}$." (The tone and body language of the teacher, in her use of a Māori adjective to praise a child's artwork, conveyed the teacher's positive reaction without the need for translation). (Classroom 1, Recording 2).

- "If you're ready for a story, haere ki te whāriki ${ }^{145}$." (Here, an English translation would have been redundant, due to the teacher's daily use of this formulaic instruction as part of her classroom management getting children to the mat). (Classroom 1, Recording 2).

One teacher demonstrated some sociolinguistic understanding, explaining to the students that meaning can often be affected by context. The example used was "Haere mai" (in Classroom 1, Recording 1). She explained to the students that it can mean "Welcome" (as heard on the marae, for example) or "Come over here" (as used in the classroom, for example). She also explained that, in the case of the latter, there are nuances of understanding that are affected by the speaker's tone of voice. To exemplify, she uttered the words "Haere mai" in an angry tone to show that, in this instance, she would likely be summonsing a child because of a misdemeanour - in contrast to her using a gentler tone to simply beckon a child.

\footnotetext{
${ }^{141}$ Mum

142 Māori New Year

${ }^{143}$ Dance

144 Beautiful

${ }^{145}$ Go to the mat
} 
The teacher followed up this class discussion on the use of "Haere mai" by facilitating a game that required a physical response from students. They had to modify their body movements, to differentiate between "Haere mai" (Come over here) and "Haere atu" (Go away $)^{146}$. The teacher extended the learning by substituting another verb 'huri', meaning 'to turn' - as in "Huri mai" (Turn towards me) and "Huri atu" (Turn away from me). The students were clearly engaged in this fun activity, with some remarking, "I love this game." This shows the importance of using the language in meaningful (and fun) ways to engage students, while at the same time developing their understanding of how language use can vary depending on the context.

The same teacher (Classroom 1, Recording 2), when introducing the Māori word for a geometric 'square' (tapawhā rite), explained the derivation of the word to the students as follows: "Tapa is side, whā is four, rite means the same. So it's a shape that has four sides that are the ...?" (to which students responded in unison with the appropriate word 'same'). By breaking down the new word into its constituent parts, the teacher added meaning for the students - with a view to promoting retention.

Student initiation of te reo Māori was rare. The four examples that I observed (across 16 observations) are described in the following paragraphs, with some information on the contexts.

During a lesson on creating colourful cards for Mother's Day (Classroom 1, Recording 4), one student volunteered information on the Māori names for two colours (tawa/purple and kākāriki/green) - as an extension of the teacher's questioning about what colours the students were using for their cards. The conversation went as follows (with the student's initiation of extra information in bold):

TEACHER: What colours have you used?

STUDENT: Pink.

TEACHER: Māwhero. Mā is white. What's whero?

STUDENT: Red. And tawa is purple.

TEACHER: Tawa is purple; you're right.

STUDENT: And kākāriki is green

TEACHER: Did you use kākāriki? You've got some kākāriki going on. You're doing well.

\footnotetext{
146 'Mai' is a particle indicating direction towards the speaker, while 'atu' is a particle indicating direction away from the speaker
} 
The aforementioned exchange reflects the teacher's efforts to sustain communication by eliciting student responses and modelling how to embed the Māori names for the colours into English sentences - in a real-life, authentic classroom context. The safe and affirming learning environment that the teacher created was conducive to this student voluntarily sharing her prior knowledge of te reo Māori.

In a different classroom (Classroom 2, Recording 1), the teacher was preparing a student (pseudonym Ngaio) for her reading assessment, and needed to record her birth date. The exchange triggered a question from Ngaio (emboldened below) about an equivalent word in Māori, as follows:

TEACHER: Haere mai Ngaio, we are going to do a reading assessment. NGAIO: OK.

TEACHER: Ngaio, when is your birthday?

NGAIO: April 4. Whā - is that four?

TEACHER: Yeah, $4^{\text {th }}$ yeah.

NGAIO: I don't know what April is though.

TEACHER: Ah, it's written up on the wall there.

NGAIO: The fourth of the fourth of seven - 2007.

TEACHER: OK. Whenever you're ready Ngaio.

(After this exchange, the reading assessment began).

Clearly curious, and keen to learn more Māori, Ngaio created an opening for the teacher to supply further information; namely, the Māori name for April. However, he did not provide this - instead referring the student to a wall chart of Māori months (perhaps trying to promote learner autonomy). The likely effect of the teacher not capitalising on student interest in te reo is that the use of the language in the classroom is not being reinforced, which is not conducive to increased use by the students. Teacher responses to students' needs are more likely to sustain students' motivation and increase their investment in learning a language, as already discussed (in Chapter 4) in relation to research by Norton (2013).

The third instance of students initiating te reo followed a kapa haka session with an external tutor. Some of the male students initiated an extra practice of the performance item they had learnt earlier that day; namely, 'Paopao' (a type of rotarota/rhythmic verse using hand 
actions and literary devices like alliteration). The item was difficult to recall in terms of the actions and associated words. Nevertheless, the students seemed to revel in the cognitive challenge - such that I overheard one student saying, "I love it" (Classroom 2, Recording 1). There is scope for teachers to maximise such spontaneous use of te reo by students, and to consolidate their learning from other input - in this case, kapa haka (which clearly engaged the students).

The final example of students initiating Māori language was after a game of bingo based on classroom objects, when one student attempted to embed a Māori word from the bingo into a question; namely: "What is the time on the karaka ${ }^{147}$ ?"And another asked the question: "Where is my pepa ${ }^{148}$ ?" (Classroom 2, Recording 2). These students were attempting to use te reo by straddling both languages in a meaningful and fluid way. This would be a useful teaching technique for teachers to model and encourage, so that their students experience te reo Māori and English together - in genuine communication.

\subsection{Scope for further opportunities for teachers to use Māori}

At times, there were opportunities where teachers could have increased their input in te reo but they were seemingly unable to do so. This could have been due to them lacking the necessary proficiency in the language. (As previously stated, three of the four teachers whom I observed rated their spoken proficiency as basic, while the fourth teacher believed that her speaking ability was limited).

Alternatively, the teachers may have felt uncomfortable teaching te reo. (In their questionnaire responses about their comfort levels teaching te reo Māori, two of the four teachers selected a neutral response, while a third stated that they were 'somewhat uncomfortable', and the other believed they were 'somewhat comfortable').

Another possible reason for teachers not increasing their reo Māori input was their apparent difficulty in transferring the Māori language that they knew in familiar contexts to a less familiar context. (In their belief statements, none of the four teachers believed that they had the necessary Māori language ability to depart from a planned Māori lesson and make 'on the spot' changes). I observed examples of this lack of flexibility, as follows:

${ }^{147}$ Clock
${ }^{148}$ Paper 
- Knowing the Māori words for 'my name' (taku ingoa), in the context of teaching students how to communicate their name in a pepeha, but not transferring that to Art when reminding students that the first thing they needed to write on their paper was their name (Classroom 1, Recording 4)

- Knowing the Māori words for the colours, when reading a Māori poem, but invariably using the English colour words during Art - and, similarly, opting to use the English word 'green' while waiting for the computer light to go on (Classroom 1, Recording 2)

- Knowing the main parts of the body, in the context of the song 'Upoko, pakihiwi, turi, waewae, taringa, whatu, ihu, waha' (Head, shoulders, knees, feet, ears, eyes, nose, mouth), but not reinforcing the Māori word for 'nose' (ihu) during a lesson on blowing noses (Classroom 1, Recording 3)

- Knowing the Māori words for basic classroom objects, in the context of multichoice Kahoot quizzes and classroom picture bingo, but not transferring that to real life communication in the classroom when discussing with a student her lost pencil (pene-rākau); directing a student to a specific chair (tūru); and asking students to move the tables (tēpu) (Classroom 2, Recording 1)

- Knowing the Māori words for Earth (Papatūānuku), moon (marama) and stars (whetū), in the context of Matariki (the Māori New Year), but not integrating these when later discussing galaxies (Classroom 2, Recording 3)

- Knowing the word for 'eyes' (whatu), in the context of a simple Māori language reader about Mother's Day (Te Rāo Māmāa), but not reinforcing that when referring to an English literacy strategy called 'Eagle Eyes', practised by the students in their reading (Classroom 1, Recording 4).

In the case of the latter example, there was scope for the teacher to provide scaffolding through role-play - to complement students' reading in te reo Māori. For example, students could have enacted certain commands that appeared in the Māori language reader about Mother's Day, specifically: 'Katia ō whatu' (Close your eyes); and 'Huakina ō whatu' (Open your eyes). Such enactments would have sustained the students' engagement in meaningful contexts and helped to consolidate their learning. 
Another potential opportunity for more reo input occurred while the teacher in Classroom 2 was teaching the Māori words for classroom objects. There was an opening for the teacher to draw students' attention to word order in Māori (with adjectives following nouns e.g papa-mā, meaning 'white-board'), and the derivation of the compound words for pēkekura, pene-rākau, and pene-papama $\bar{a}^{149}$. The associated meanings would have aided students' retention.

There is scope for teachers to maximise opportunities to model te reo Māori, so that students encounter the language in different contexts - thus consolidating their knowledge. Notwithstanding, I acknowledge the reality of life in the busy primary school classroom where, when teaching te reo at the same time as managing approximately 30 students and accommodating a variety of curriculum areas, it is easier to spontaneously revert to English than scramble for the Māori equivalent.

During my observations, there were other opportunities worthy of follow-up - specifically around encouraging Māori students to share their knowledge about something particularly relevant to their culture (and, moreover, likely to be of interest to others i.e. teacher and students). Examples are cited below:

- A teacher did not follow up on a Māori student's comment about her and her mother regularly doing hongi. The child volunteered this information in the middle of a class discussion that was preparing students for the cultural practice of 'hongi' when being greeted and formally welcomed on the marae. But the child's personal experience of this practice was not maximised. Similarly, the same teacher, while discussing the many purposes of a marae, created very little space for that student to expand on the experience of her grandmother's tangihanga on the marae. These two instances may have left the Māori student feeling that her unique knowledge of te ao Māori (relative to her peers) is not worthy of sharing. She may therefore be disinclined to do so again (Classroom 1, Recording $1)$.

- Another teacher, during literacy learning, overlooked a Māori student's choice of a book about the marae (Classroom 4, Recording 1). There was

\footnotetext{
${ }^{149}$ School bag $($ pēke = bag, kura = school); pencil $($ pene = pen, rākau = wood $)$, whiteboard pen $($ papa = board, mā $=$ white)
} 
an opening for the teacher to invite the student to elaborate on his choice of reading material and tap into his interest in the Māori world. The same teacher, during a class study on natural disasters, did not capitalise on a Māori student's knowledge of the Māori guardian of earthquakes, Rūaumoko - preferring instead to proceed with her planned lesson. (Classroom 4, Recording 2).

In the examples above, there were opportunities for the teacher to validate Mâori knowledge and draw out Māori students' prior learning. However, in the busy classroom, with competing priorities and diverse student needs, such opportunities can easily be overlooked. Nevertheless, further exploration by the teacher would have tapped into the world of these Māori students and validated their cultural knowledge - while enriching non-Māori peers and providing a springboard for further inquiry.

\subsection{Teachers' attitudes towards Māori language and culture}

Two of the four teachers whom I observed were particularly good at framing Māori language and culture in a very positive light by, for example:

- $\quad$ expressing enthusiasm about an imminent class trip to the marae e.g. "I'm pretty excited" (Classroom 1, Recording 1)

- $\quad$ emphasising the mana of the marae, describing it as 'a special place' where 'cool things happen' like the 'special ceremony called a pōwhiri' (Classroom 1, Recording 1)

- $\quad$ emphasising the mana of those who have a speaking role on the marae e.g. "A very important man will say a speech" (Classroom 1, Recording 1)

- describing the ritual of the hongi as a 'really nice thing' to do, 'a way of saying hello... like a kiss' (Classroom 1, Recording 1)

- heightening students' anticipation, pre-reading, by saying they were about to read a special book - special because it was in te reo Māori (Classroom 1, Recording 4)

- $\quad$ reinforcing the need to respect others, by not laughing, when listening to each other's pepeha (lest laughter be construed as a 'put-down') (Classroom 3, Recording 1) 
- valuing the students' pepeha, by planning to publish them on the computer, with graphics (Classroom 3, Recording 1)

- $\quad$ highlighting the significance of pepeha, such that each child was videorecorded doing theirs, as a way of showcasing their knowledge and monitoring their incremental progress on subsequent attempts (Classroom 1, Recording 1).

One teacher was particularly effective in conveying the aspect of emotion that can be associated with delivering one's pepeha. She provided a model - prior to students working on theirs, and said:

“I'm going to share something with you about my whānau, my family - who I am and where I am from. It's close to my heart, so I really need you to show respect for that. And that's the same when we are each doing our mihi, because it's part of you, where you are anchored, and where you're from. This is from my precious book. It's got my grandparents in it. They're all dead" (Classroom 3 , Recording 1).

The teacher gave an emotional sigh then proceeded to read her pepeha and whakapapa, straight after which she commented:

"Got there without crying! [At that point, the students clapped to show their appreciation for the teacher having shared her personal story]. So that's how close to my heart all of that is, because it's my whānau and where I'm from. And Crafty Rascal ${ }^{150}$ was our boat ..., so that's our waka ${ }^{151}$ " (Classroom 3, Recording 1).

The teacher's personalised modelling of her pepeha signified to the students that certain emotions can be stirred up when people talk about their tūrangawaewae and whānau. Furthermore, the image of being anchored may have helped to convey to students the notion of stability associated with those dimensions.

\footnotetext{
${ }^{150}$ A pseudonym has been used in place of the real name of the family boat

${ }^{151}$ Boat/canoe
} 
After delivering her own pepeha, the teacher continued to instil respect for this aspect of Māori culture by encouraging one of the Māori students to share their pepeha, as a way of providing a good exemplar for other students. She said to them:

"I need you to really listen hard and notice if you can see anything different from his [pepeha] to yours. He's being very brave, and we need to show whakaute $^{152}$, and listen - because he's sharing what's very close to his heart. We have to show respect because this is ... the essence of where they are from" (Classroom 3, Recording 1).

By saying this, the teacher acknowledged the fear element associated with orally communicating something of a personal nature to a public audience, and the need for others to respond respectfully.

The student subsequently delivered his pepeha with pride, communicating about the significant people in his world. The teacher asked him to do it a second time, encouraging his classmates to actively listen to what he was sharing, to 'notice' any points of difference from their own pepeha. For example, the child in question was being raised by his grandfather. Consequently, he used the word 'koro' ${ }^{153}$ in his pepeha. This would have been a new word for some of his peers - most of whom only referred to their mother and/or father in their respective pepeha, based on the standard template they had been provided. It was clear that the teacher was sufficiently flexible to vary that framework to accommodate changes necessitated by individual students' family circumstances and personalised learning needs.

The teacher was effective in building inter-cultural bridges, across language and culture. By encouraging her students to critically listen to each other's pepeha, she was facilitating the opportunity for them to shed new light on the content and delivery of their own pepeha - thus building their understandng of inter-cultural connectedness. Moreover, prior to delivering her own pepeha and whakapapa, she wove te reo Māori into her English introduction - in context. This type of translanguaging provided a useful model that her students could emulate.

\footnotetext{
${ }^{152}$ Respect - which is one of the school's values, hence the word being known to the teacher and children ${ }^{153}$ Grandfather
} 
Another student in the same class related how she had done her pepeha (and whakapapa) in a different class the previous year - and she had retained the paper version of it. This illustrates the value she placed on her pepeha, as a way of representing the place where she belongs (and communicating the significant people in her family). The teacher emphasised this value by saying:

"When you are reciting your whakapapa, it's like who your family is, your line of descent, where you've come from. It's who your genes are - your people, your whānau" (Classroom 3, Recording 1).

The validation from the teacher, and the continued use of te reo embedded in her English kōrero, reinforced for students the significance of knowing who they are, who they belong to, and where they come from - as a way of establishing identity.

One of the unintended consequences of studying pepeha was the engagement of whānau. Students were required to do some homework, researching their tūrangawaewae and whakapapa, which necessitated assistance from family members. One teacher encouraged and commended her students by saying:

"I'm really proud of those people that checked with their whānau and got more information" (Classroom 3, Recording 1).

A Māori student was particularly proud to report that, in the holidays, she had gone back to her Nan to do some research on her pepeha - such that she could now stand tall, firm in her identity, and deliver her pepeha without reference to notes.

This kind of situation exemplifies the benefits of a genuine home-school partnership where each partner has a valid contribution to make to student learning. The teacher had taken positive steps to engender a meaningful relationship with whānau, by organising an afternoon session (with kai provided) where the tamariki displayed their Māori knowledge to parents and caregivers. These kinds of personal connections are key as students progress through the education system - hence the Ministry's emphasis on whānau engagement in its Māori education strategy, Ka Hikitia (Ministry of Education, 2013).

Another consequence of students learning their pepeha is that it emphasises the importance of local knowledge and knowing 'our place'. This aspect is especially significant for Māori, 
who have a spiritual and intimate connection to Papatūānuku (Earth Mother) - due to intergenerational stories of the land, and ancestors being buried there (Mikaere, 2004). Such a focus sits well with current Ministry priorities around creating local resources across Aotearoa, through its initiative Te Aho Ngārahu (which is discussed further in the next chapter, in the context of interviewee comments about resources).

Based on my observations, students in all four classes were enthusiastic and engaged when learning Māori - except one child whose extremely negative comments were captured in the audio-recording. He said:

“I love Māori - not! I hate Māori. F*** you Māori” (Classroom 2, Recording 4).

Although his utterances were out of the teacher's hearing, it seems likely that he wanted his strong views to be recorded - which is why he no doubt positioned himself close to the recording device and laboured the point. The context was inane; namely pack-up time at the end of the school day. Furthermore, there was nothing discernible in the audiorecording, nor in the contemporaneous events of the classroom, that would have precipitated such negativity. While it is important for teachers to affirm students' positive responses to learning Māori language, and capitalise on that, it is also important for them to address any issues (as presented in this case) - to determine underlying reasons for student negativity. In such instances, it would be advisable if there was dialogue between teacher and students - to reframe any negative responses and reinforce positive feelings about te reo amongst the other students, thus taking the sting out of the negativity.

\subsection{Building on students' prior knowledge and experiences}

As is good teaching practice, there was some evidence of teachers maximising students' prior learning in respect of Māori language and culture. For example, one teacher made real-life contextual links for a student who was compiling his pepeha, by relating the Māori place name for the geographic area where he belongs (Awakairangi) to the signage of the local park with the same name, where he plays soccer - as follows (Classroom 3, Recording $1)$. 
STUDENT (prior to practising their pepeha): I don't have my river.

TEACHER: Okay, it's called Awakairangi in Māori, our river. Have you been to

Awakairangi Park, to play soccer?

STUDENT: Yes. How do I say it again?

TEACHER: Awa-kai-rangi.

(Student then recites their pepeha).

TEACHER: Well done.

The semiotic association provided by the teacher helped the student to make a meaningful connection. This made it easier for him to embed the proper noun that he needed when naming the relevant river in his pepeha. Similarly, the teacher capitalised on a Māori student having recently visited her tūrangawaewae, by asking:

"In the holidays did you go back to the marae, and see the river?" (Classroom 3, Recording 2).

This conversation helped the student to relate the Māori names for the land features being referenced in her pepeha to the actual landforms back home. There was therefore a connection between classroom learning and real-life experiences (Bourdieu, 1977b).

In the same classroom, a Māori student exhibited confidence in, and knowledge about, her own culture. The teacher asked whether any of the students had included a hapu ${ }^{154}$ in their pepeha. For most of her classmates, this was an unknown word, so the Māori student explained it in her own words, as follows:

"It's a family grouping. That means a group of families. But an iwi is...extended" (Classroom 3, Recording 2).

Her explanation showed that she clearly understood the notion of whānau, hapū and iwi in the Māori world. When the teacher validated the girl for her knowledge of things Māori, she confidently replied:

"Every day when we do a [Māori] task, I zip through. Besides, I've been in Māori kōhanga for two years" (Classroom 3, Recording 2).

\footnotetext{
${ }^{154}$ Sub-tribe
} 
The student had brought her cultural capital into the classroom, based on her Māorimedium pre-school education experience. From my observations on four separate occasions, this was clearly a child who thrived when given the opportunity to share her Māori knowledge and have that knowledge validated by others (including the teacher). Her self-esteem was positive, as was her attitude to learning, largely due to the environment created by the teacher - where Māori knowledge was valued and authenticated.

Prior to a marae visit, one of the teachers asked the students if they had been to a marae before. Their experience was limited. One student had been to a museum marae. And one of them (a Māori student) had experienced the marae environment in real life. The teacher encouraged the other students to listen (albeit briefly) to that child's real-life experience of going to the marae when her grandmother died. As mentioned earlier, more depth could have been gained from the child's sharing of that personal experience, had she been given more time and space to do so. Notwithstanding, the teacher praised the child by saying:

"You've got lots of awesome knowledge there. It's pretty cool that you can be one of our experts" (Classroom 1, Recording 1).

When the same teacher was explaining about the call (karanga) that welcomes visitors onto the marae, including the words "Haere mai", one of the students promptly interjected saying:

"I know what 'haere mai' means. It means something like 'come closer" (Classroom 1, Recording 1).

That student had activated his prior learning by making the connection between a classroom activity (described earlier in 5.2) that required a physical response to the words "Haere mai", and the use of the same words in the context of a welcome call onto the marae.

Likewise, during an Art lesson, a student spontaneously broke out into a song about the Māori words for the colours, which was appropriate in the context of their using different coloured crayons. Others joined in. Additionally, on another occasion, while students were learning to wash their hands after a lesson on blowing noses, some boys (in Classroom 1, Recording 3) made an association between the word 'ringaringa' in the command, "Horoia $\bar{o}$ ringaringa" (Wash your hands) and its inclusion in the haka instructions, "Ringaringa pakia" (Slap hands). This led to their spontaneous, uninhibited rendition of the well-known 
haka 'Ka Mate'. The students were thus developing the ability to apply te reo Māori across different real-life contexts.

\subsection{Scaffolding of te reo Māori input}

One teacher acknowledged to her students that they (including herself) were all beginners in learning about pepeha. She said:

"We don't know how to do this yet. We don't know how to pronounce the words the best yet. We're on that first step of our learning, but we're going to give it our best go. We are just trying to do the best we can; we are all in the learning stage" (Classroom 3, Recording 3).

By including herself as a learner, she gave permission for the students to be learners too (in the spirit of ako) - such that it was acceptable to make mistakes during the process. She recognised that the learning would be incremental, which would require scaffolding and lots of encouragement.

The teacher took care to model the pronunciation of potentially difficult words in the pepeha, especially those with diphthongs, which students repeated e.g. '... tōku kāinga ināianei' (my home now). This modelling of pronunciation, followed by student repetition, increased the learners' confidence to verbalise their pepeha. Moreover, being a second language learner of Māori, the teacher was able to provide the students with helpful word attack strategies. For example, when a student was having difficulty pronouncing his river, Kaituna, the teacher was able to break it down for him into two meaningful chunks, by saying:

“It starts with 'kai' - you know, like the food you eat - and then 'tuna', eel. So just break it down, Kaituna" (Classroom 3, Recording 1).

In deconstructing the word, the teacher was instilling good practice for the student to attack other Māori words, bit by bit - as an aid to pronunciation and comprehension. Similarly, when discussing bird-shaped kites (manu aute) common during Matariki, the same teacher suggested a strategy for remembering the Māori word for 'bird' i.e. 'manu'. She used an association technique, as follows:

"It's in the name of the Samoan rugby team. Yes, Manu Samoa." 
In this way, the teacher demonstrated that the use of mnemonics can be a useful strategy for embedding vocabulary.

Prior to a class marae trip, one teacher dedicated time to preparing students for what to expect during a pōwhiri, introducing key words relevant to the visit e.g. pōwhiri (formal welcome), karanga (call of welcome), tangata whenua (hosts), manuhiri (visitors), whaikōrero (speech-making), waiata (song/s), pepeha (introduction of self, in context of land features), hongi (pressing of noses), and wharenui (meeting house). Visual cues were used to set the scene - specifically the sequential steps of a pōwhiri sourced in the Ministry's multimedia resource He Reo Tири (Resource Sheet 8.3). This was a resource that featured in my online questionnaire. (See Chapter 4). Students were encouraged to make predictions about what was happening in the pictures - and what the respective roles of the different people might be during a pōwhiri.

The images were a useful way of introducing new vocabulary and stimulating discussion around protocol relevant to the marae (e.g. students needing to wait at the entrance for the hosts' karanga before moving on to the marae; boys being seated at the front, with girls behind; hosts beginning the speech-making by way of welcome; visitors responding with a formal speech; each speech being followed with a song; hosts and visitors lining up to hongi at the end of the pōwhiri process). The use of these Ministry-produced images in $\mathrm{He}$ Reo Tири was relevant in the context of my fourth research question about the use of Māori language resources in the classroom. It also related to my third research question about factors that can influence teachers' attempts to teach te reo Māori, one of which is the availability, or not, of suitable resources (as discussed in Chapter 6).

The teacher who was preparing students for the marae trip contextualised the learning further, by weaving in a Māori greeting and response - something students were likely to hear at the marae; namely: "Kei te pēhea koe?" (How are you?) and "Kei te pai." (Good). One of the students picked up on this and volunteered information about there being a book with the title Kei te pēhea koe, and a song too - both of which the student had been exposed to during her early childhood education. The teacher was flexible enough to facilitate student learning 'in the moment'. She responded deftly, encouraging those children who knew the Māori song to sing it together. She also undertook to follow up, by locating the book and researching the song online. 
As part of the scaffolding to prepare for the marae visit, the teacher made sure that she monitored new learning along the way by encouraging student reflection. For example: "Can you tell someone next to you something new you've learned" (Classroom 1, Recording 1). She also reviewed the learning at the end of each lesson: "What were some of the important things that we know now?" Additionally, in a shared Māori language reading experience (about Mother's Day), she scaffolded the students into working out the English meaning, by using picture clues in the reader - supported by cues from her (Classroom 1, Recording 4). For example:

TEACHER (reading text): Māmā, e ara. That means "Get ...

STUDENTS (in chorus): ... up.”

TEACHER (reading text): Māmā, katia ō whatu. Close your ...

STUDENTS (in chorus): ... eyes.

TEACHER (reading text): Māmā, kuhu mai. Come ...

STUDENTS (in chorus): ... here.

TEACHER: Come in.

The teacher was guiding the children to create meaning by making an intelligent guess. This is a frequently used learning strategy (Schmitt, 2008). In the last sentence, when they were not quite correct (albeit nearly), she sensitively corrected them, by re-casting. Such was the students' engagement with this simple Māori language reader that some of the students could still be heard reciting "Māmā, Māmā”" during post-reading tasks. Moreover, one child (non-Māori) chose to write 'Māmā' when creating her Mother's Day card successfully transferring her new knowledge to another appropriate real-life context.

The same teacher scaffolded students' learning of the Māori names for the colours by using a meaningful context; namely, the colours on the clothes they were wearing. The visual cues and personalised context reinforced the teacher's oral input.

I observed total student engagement in another class (Classroom 3, Recording 3) when students completed a worksheet on the topic of Matariki, the Māori New Year. This was because the worksheet had a range of activities that accommodated different student interests and strengths. For example, there was a matching word exercise (English to Māori); a Māori word find; a true/false task in English (re: three facts about Matariki); a drawing task; a cloze exercise (with missing words provided); and a templated mini pepeha 
book $^{155}$ for students to fill in. In addition, the teacher had taught a Māori song about the Matariki stars - as a platform for their study. The students were extremely quick to grasp the words and tune of this new waiata. So the teacher maximised the opportunity provided by the song for literacy learning - by asking the students to point to the names of each of the seven stars (on the printed song sheet) while singing. Their enjoyment of the waiata was such that they asked if they could perform it at school assembly.

Additionally, while the teacher roved around the classroom, monitoring the students' work on Matariki, the following dialogue unfolded (Classroom 3, Recording 3):

TEACHER: Are you guys going okay?

STUDENT: Trying to work out what this is.

TEACHER: Have you tried putting it into the dictionary ${ }^{156}$ ? Have you looked it up in the Māori: English dictionary? That might be your first step.

The teacher was attempting to make the students less teacher-dependent, so that they could exercise more responsibility over their own learning - thus embedding the philosophy of inquiry learning promoted by the Ministry of Education (2007), as mentioned in Chapter 2. Such an approach aligns with tikanga Māori in terms of ako (as discussed later in this chapter), where there is the potential for mutual learning (in this case, student:student).

The students in Classroom 3 were learning to be more self-reliant and autonomous, by adopting an important language learning strategy; namely, using a dictionary to work out word meanings for themselves. Some students went beyond the task at hand, using the online Māori dictionary to successfully discover the meaning of unfamiliar words and phrases in the song about the Matariki stars e.g. 'pīataata' (shining); 'rangi' (sky); 'ēnei ngā tamariki' (these are the children).

Access to the online dictionary, encouraged by the teacher, contributed to these students' insatiable desire to know more about Māori language and customs. For example, one student entered the words 'Ngāti Porou waka', to find out the name of the canoe on which her ancestors came to Aotearoa - for inclusion in her pepeha. The online Māori dictionary also helped with the pronunciation of new words, by using the audio facility (e.g

\footnotetext{
${ }^{155}$ The framework for the pepeha was as follows: Ko .... tōku maunga/awa/waka/marae/whaea/matua/ingoa. (My mountain/river/canoe/ marae/mother/father/name is ...)

${ }^{156}$ Referring to the online Māori dictionary https://Māoridictionary.co.nz
} 
whakapapa/genealogy). Furthermore, the success of these students in finding out the necessary information, through inquiry, stimulated their classmates to follow suit. This again demonstrates the power of ako and tuakana:teina practices in the classroom.

\subsection{Applying tikanga in the classroom}

Kennedy (2016) highlights the fact that, in most cases, the teacher is the main conduit for cultural input in students' language learning experiences - and that the approach a teacher takes can influence students positively or negatively. That is, the way that a teacher explains cultural aspects of a target language can affect how students engage with that language. Hence the importance of teachers being open to, and becoming familiar with, a Māori cultural perspective - doing their best to pass on aspects of tikanga in a way that sustains their students' investment in learning te reo.

The following sub-sections discuss the incorporation of tikanga in the participant schools in terms of: the organisation of visits to marae; the fostering of tuakana:teina relationships; the special value accorded to te reo; the demonstrable practice of ako; and the integration of Māori concepts in the classroom.

\subsubsection{Marae visits}

The NMSSA initiative (Ministry of Education, 2018, p.76) revealed that $26 \%$ of Year 8 teachers and $19 \%$ of Year 4 teachers organised a marae visit for their English-medium students - to facilitate a cultural perspective.

One teacher whom I observed was preparing students for a marae trip. She equipped them with cultural knowledge and culture-specific vocabulary, to ensure there were no 'surprises' for them on the day of the visit. Interestingly, there was initially some confusion among the students about what constituted a marae. Some of them thought, erroneously, that the marae was the physical structure of the meeting house (when in fact the marae is the open courtyard). However, the teacher was able to clarify this by showing them a picture of a meeting house (on the marae), which she correctly described as a wharenui.

During my observations in that class, the teacher scaffolded, and reviewed, new learning (Classroom 1, Recording 1). This involved each child becoming familiar with: 
- the sequential steps to a pōwhiri, and people's respective roles (e.g. kaikaranga $^{157}$, kaikōrero $^{158}$, ringawera);

- $\quad$ seating arrangements at the marae (i.e. boys in the front, girls behind);

- two Māori songs (appropriate for visitors to a marae, to support the school's speakers);

- $\quad$ removing their shoes on entry to the wharenui;

- $\quad$ delivering their pepeha orally; and

- exchanging a hongi (based on the teacher's demonstration and the students' subsequent practice with their peers).

In organising the marae trip, the teacher was putting the children's learning of te reo Māori and tikanga into a real-life context. The only aspects of tikanga that were not discussed (in relation to the imminent marae visit) were the giving of a koha (from the school to the marae), and the partaking of kai (by everyone) at the completion of the pōwhiri. Given the comprehensive nature of activities that I observed during my four days in the class, it is likely that these aspects were indeed covered outside of my observation visits.

\subsubsection{Tuakana:teina}

In two of the four classrooms, there was evidence of tuakana:teina relationships - where, for example, older students extended manaakitanga to new students. Or, alternatively, students who were more accomplished assisted those who were less able. Supporting others, working together, and showing manaakitanga were intrinsic traits demonstrated by tuākana in these classrooms - facilitated by the teachers.

This was evident in students' preparation for the marae trip, where the teacher encouraged the students to practise their pepeha and hongi with different buddies - each learning from the other, a reciprocity that is conveyed in the following Māori proverb: 'Mā te tuakana ka tōtika te teina; mā te teina ka tōtika te tuakana' (From the older sibling the younger one learns how to do something; from the younger sibling the older one learns how to be tolerant). She reinforced the value of this practice, with comments like: "Help your buddy" and "You need to encourage him" (Classroom 1, Recording 1). Such an approach brings mutual benefits. The younger or less knowledgeable child gains new knowledge, while the

${ }^{157}$ Person who sends out a call of welcome

158 Speaker/s 
older or more knowledgeable child can consolidate their own learning by teaching others. The tuakana:teina approach is useful for organising students into groups according to mastery - instead of age.

Another teacher used a tuakana:teina approach to organise buddy reading, in pairs, where the students in that class read their pepeha in Māori to the younger new entrant students in the school. This helped to model the place-based aspects of the pepeha. In another case, a non-Māori student forgot the Māori word for 'mother' while delivering his pepeha, so one of his classmates inconspicuously took on the role of tuakana and quietly provided the requisite word "whaea' 159 , so that he could continue his delivery. I observed the same tuakana independently helping another classmate to track the words in their pepeha, using finger-pointing. On another occasion, when a student felt tentative about the imminent delivery of her pepeha, I observed the teacher asking a Māori student to sit next to her because she did not know all the words.

There was a sense of satisfaction in students when, over time, with encouragement and practice, they accomplished the oral delivery of their pepeha. I heard one proud student saying:

"I remembered and got all of the words by myself" (Classroom 3, Recording 4).

This is relevant in terms of teachers' stated belief statements (in the questionnaire) about students needing to practise their new learning, to consolidate. Boosted by their sense of pride, some students whom I observed were even practising their pepeha informally with a range of classmates - uninstigated by their teacher.

\subsubsection{Valuing Māori language - a taonga for all}

In one of the four classrooms, there was a student with special needs. He was included in the learning of te reo. His classmates helped him create his mini pepeha book from the template provided. This exemplified the aforementioned tuakana:teina approach being practised in a natural, spontaneous and responsive way - without any cajoling from the teacher. In the safe, inclusive classroom environment there was respect for the special needs student and for what he had to communicate. This was further evidenced by the teacher reading out that child's pepeha (Classroom 3, Recording 2), while his peers listened

${ }^{159}$ A synonym for māmā/mum 
intently. She then carefully placed it into his school bag to take home, saying: "I'll put this in here, so it's safe. Precious." The teacher was emphasising the intrinsic value of the child's pepeha, to be shared with whānau, reinforcing the notion of Māori language being a taonga - as in the Treaty.

It was pleasing to observe such inclusivity, where learning te reo as a second language was not restricted to certain students but, instead, was available to all so that they could experience success at their level. I observed immigrant children (for whom English was a second language) also enjoying success in learning Māori and appreciating its value. One recent immigrant from Afghanistan spontaneously broke out into a Māori song from the school's kapa haka, 'Utaina mai ngā waka', while working on an unrelated task. She had clearly embraced the learning of te reo Māori in her new adopted country - as evidenced subsequently in the effortless delivery of her pepeha.

\subsubsection{Ako}

In the spirit of ako, one of the teachers was open to receiving a student's help with the pronunciation of the river Whangaehu. The student broke the word down into four syllables to help the teacher (i.e. Wha-nga-e-hu). The teacher repeated the student's pronunciation correctly, saying:

“Thumbs up, that made me feel so good. So it's said in three separate syllables, four actually ..."(Classroom 4, Recording 2).

This affirmation is likely to have made the student feel pleased about sharing his knowledge with the teacher, who was in turn open to being a learner.

In the same vein, another teacher admitted to the students that (like most of them) she had never been to a marae before - and that she was learning alongside them (Classroom 1, Recording 1). The teacher also acknowledged that the Māori language was relatively new to her, which is why she looked up words in the dictionary before facilitating the shared reading of a Māori book:

"I didn't know what all of the words meant, so I got my laptop and googled for some help" (Classroom 1, Recording 4). 
She encouraged them as learners (like herself) by saying, "I'm starting to really practise using te reo Māori." She also admitted to being very much a learner in attending the school's kapa haka practices - learning alongside, and from, her students (ako).

Another teacher took a similar approach. For example, she was comfortable admitting to a student that her pronunciation of a specific place name was inferior - so she highlighted the word and encouraged the student to seek advice at home on its pronunciation. She showed respect for other languages too, by asking a student to confirm with their father how to properly pronounce his Samoan name. On another occasion, the same teacher admitted that she had forgotten the Māori word for 'star' (during their study of Matariki, the Pleiades constellation). The dialogue (Classroom 3, Recording 1) went as follows:

TEACHER: Who remembers the Māori word for stars, because I don't?

STUDENT: I think whetu.

TEACHER: It was, wasn't it? I used to teach a boy called Whetū. I didn't know

it meant 'star'.

In this way, the teacher reassured the students that she too was learning - and that she had to revisit things many times before they made sense and became embedded. For example, she said:

“That's how many times I have to say something, like a new word, to learn it. Even for my times tables. Just even in my head" (Classroom 3, Recording 1).

This reassurance would likely contribute to students' perseverance and confidence in tackling te reo Māori, and indeed other learning areas, rather than giving up.

The non-threatening atmosphere created in the four classrooms made it possible for students to correct teachers' Māori language errors. I observed this during the activity "Haere mai. Haere atu" (described earlier in 5.2). When the teacher inadvertently used the wrong verb for "Huri mai. Huri atu" (Turn towards me. Turn away from me), a student supplied the correct word so that the activity could continue. Similarly, in another classroom, some students corrected their teacher's pronunciation of Aotearoa. They felt comfortable to do so because of the positive atmosphere created in the classroom in respect of learning Māori. 
Such openness to new learning, along with a willingness to take risks and make mistakes (and be corrected by students and whānau, if necessary), contributes to the disposition described in the elaboration of the second Standard for the Teaching Profession, about Professional Learning (Education Council, 2017). This elaboration describes teachers' ability to critically examine how their assumptions and beliefs (including cultural beliefs) impact on practice (and ultimately the achievement of a diverse group of students in their classroom). The four teachers whom I observed were prepared to put aside the traditional belief of the teacher knowing all. They showed that, like their students, they were learners of te reo Māori, open to being supported by others - thus demonstrating the concept of ako.

\subsubsection{Cultural norms in the classroom}

In one teacher's classroom, there was an awareness of not sitting on food tables - out of respect for tikanga Māori. The teacher reminded the children by saying:

"Bottoms off the table. We don't put our bottoms where we put food. Our bodies don't go on top of the table." (Classroom 1, Recording 1).

She was trying to inculcate the Māori concepts of 'noa' (ordinary/profane) and 'tapu' (sacred/set apart) - where food is deemed to be 'noa', and the body is 'tapu', such that the two are kept apart.

Another teacher promoted the advantages of 'mahi tahi' (cooperation), as follows: "It's time to pack up. If we do it quick enough and if we work together as a team, you can go out for a game" (Classroom 3, Recording 3). The teacher was laying the foundations for teamwork and collaboration in the classroom, which is something that is highly valued in the Māori world - as in the following proverb: "Mā whero, mā pango ka oti ai te mahi." (By red and black the work will be done).

A further aspect of tikanga occurred when one teacher was talking to the students about my presence in the room and used a very familiar form of address. She referred to me as Whaea Alice - which has connotations of a mother-like or aunt-like figure. This is a common, and polite, term used to address women teachers in Māori-medium settings, for example.

The inculcation of such cultural norms in the classroom helps to expose students to Māori values and Māori ways of doing things. 


\subsection{Te reo Māori in the linguistic landscape of the classroom and}

\section{school}

The visibility of Māori on classroom walls and in school signage provides a source of Māori language input (beyond the teacher), for students to 'notice' and respond to - thus enhancing their linguistic awareness and literacy practices (cf. Dagenais, Moore, Sabatier, Lamarre and Armand, 2009; Clemente, Andrade and Martins, 2012). However, the reality in most English-medium primary classrooms is that English is overwhelmingly the predominant language - which reflects the relative status of te reo Māori in Aotearoa NZ, despite it being an official language. Indeed, research highlights that minority languages often struggle to be seen (Gorter, Marten and Van Mensel, 2012).

On the four teachers' classroom walls, there were a few Māori wall charts (e.g. numbers 110; an image of a wharenui; and some Māori myths and legends). The latter were relevant to the topics being studied at the time; namely, a legend about Wellington Harbour (in relation to the place-based study of local land features, associated with the children's pepeha), and a legend about Matariki (relevant to the study of Māori New Year celebrations). In one classroom, there were two free posters published by the Māori Language Commission - about family and the kitchen. (They seemed to be unrelated to the learning contexts in that classroom). On a white-board there was a saying in Māori; namely, "Kia ū; ka haere tonu" (Stay calm and carry on) - a play on the very popular British slogan Keep calm and carry on. Presumably this was a mantra for desired classroom behaviour.

In terms of signage, one school enhanced the visibility of te reo by naming its classrooms in Māori e.g. Rūma Tahi, Rūma Rua (Room One, Room Two), and class groupings were organised using the Māori names for native birds. In addition, one teacher had labelled parts of the classroom in Māori e.g. matapihi (window); kūaha (door); tēpu (table); te tēpu marama (the moon-shaped table). By using Māori signage, teachers are assigning value and status to te reo Māori. It is important for students to see Māori language being used in everyday contexts, so that it becomes normalised and has comparable status to English.

Another form of linguistic landscaping that I observed was the showcasing of students' Māori work on the walls. In doing so, teachers were sending important messages to their students that the work they had done was valued, the classroom belonged to them, and there were opportunities to learn from each other (ako). Moreover, because of students' 
investment and ownership in their work, they were likely to look at it again - thus providing an opportunity for consolidation.

In one teacher's classroom there was a selection of children's guided writing on the wall, based on the topic 'Tūrangawaewae - This is where I stand'. Although their writing was in English, this was a place-based kaupapa conducive to a Māori world view, in terms of students gaining a sense of place and a sense of belonging. In another classroom, there was a display entitled 'Family'. There was a missed opportunity here for the title to be written in Māori (due to the word 'whānau' being in the NZ vernacular), or in both Māori and English (e.g. 'Whānau/Family') - to increase the visibility of te reo. Elsewhere, there were children's stories from a previous topic of inquiry, about the Māori demi-god Māui and his attempts to slow down the sun. Additionally, in another classroom, there were visual displays of the children's self-portraits. Under each one, there were the same three Māori phrases denoting the three school values:

- Kia takohanga (translated by the school as 'Be responsible')

- $\quad$ Kia whakaute (translated by the school as 'Be respectful')

- $\quad$ Kia tūpato (translated by the school as 'Be safe').

Based on my observations, the four teachers attempted to visually present Māori language in the classroom space, as a daily stimulus for students. However, there was potential for the visibility of the language to be increased to ensure that students were exposed to Māori language-rich environments - thus enhancing the status of te reo Māori and broadening all students' linguistic repertoires.

\subsection{Availability and use of Māori language materials}

Māori language learning materials were scarce in all four classrooms; and there were few books written in English about Māori topics. I found one such book only. It was called At the Marae (by Mario Rego) and was suitable for an imminent marae visit - to complement the teacher's use of a visual resource sheet about the pōwhiri process, from the Ministry's multimedia resource He Reo Tuри (2011).

Another teacher used the same multimedia resource, for a different topic; namely the classroom. He laminated the associated Bingo game (Resource sheet 2.2 in He Reo Tupu), so that students could reinforce the Māori names for the classroom objects. The fact that the teacher found the time (and money) to colour photocopy, size and laminate the Bingo 
cards sent a subliminal message to the students that he valued te reo Māori - and wanted them to do so too. There was genuine enthusiasm, engagement and excitement amongst the students while playing 'classroom bingo' in Māori. In fact, they pleaded for a second game, which the teacher agreed to, despite competing curriculum priorities. This time, he delegated the role of 'caller' to a student - who was provided with scaffolding in the form of the Māori words (backed with matching pictures) being printed on a set of palm-sized cards. This made the student caller's task easily achievable.

On completion of the two bingo games, the teacher encouraged the students to integrate these words into their everyday classroom language. He modelled two sentences to illustrate how this might be done (Classroom 2, Recording 2):

"I'll go and get my pēke-kura. Have you seen my pene-rākau?"

However, as already indicated, I witnessed only two instances where his students successfully transferred their new learning of te reo to real life. One student embedded the Māori word for clock (karaka) in an English question, asking about the time on the clock; and another inquired in English about the whereabouts of some pepa (paper). Teachers could facilitate more use of te reo Māori by further modelling (i.e. embedding Māori words into English sentences in a natural way, for students to emulate).

Another effective Ministry resource used in one of the four classrooms was a publication for schools, Junior Journal 53 (2016). The journal helped students to understand the concept of pepeha from a child's perspective. This provided the necessary context for the students, and was a springboard for their future learning. The teacher designed a matching task based on the text in this junior journal, as a way of consolidating the content. And she made available an audio-recording of the text - for a small group of students to independently listen to on their Chromebook laptops (using earphones), while reading the printed version. She also used a free online resource called Green Grubs, to provide each student with a template of a mini pepeha book http://greengrubsgardenclub.blogspot.com (see Figure 5.1 below). 
Figure 5.1: Template of mini pepeha book, sourced on Green Grubs site (http://greengrubsgardenclub.blogspot.com)

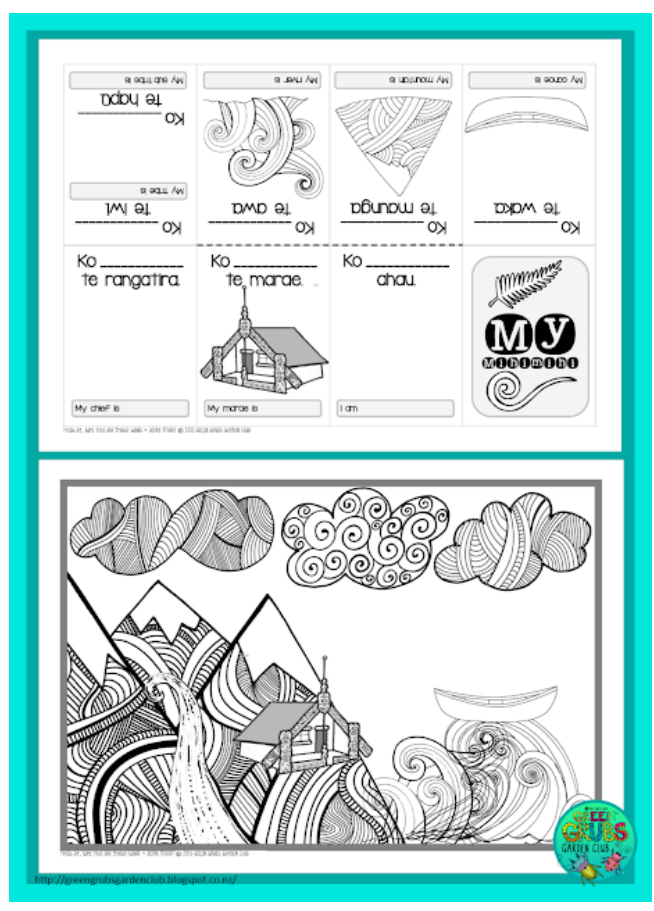

\subsection{Chapter review}

In this chapter, I provided information on my observations in four teachers' classrooms, where my focus was on the use of te reo Māori - and supporting materials. This information was relevant to my second research question; namely: How are their beliefs enacted (or not) in the classroom i.e. consistency (or not) between stated beliefs and actual practice?

Common trends emerged regarding the classroom practice of the four observed teachers. They all used some Māori language in the classroom (although there were opportunities to use more); and their attitudes were positive. Moreover, they provided students with some scaffolding to progress their learning of Māori. A few aspects of tikanga were included in their classrooms, to complement the teaching of Māori language, and some Māori language was visible in the linguistic landscape of their rooms. However, there was little evidence of Māori language resources being used.

There were some consistencies between the beliefs and classroom practices of the four case study teachers; in particular: ensuring that learning te reo was enjoyable for students; valuing Māori language; modelling good pronunciation; integrating some tikanga; being restricted by poor proficiency; and being hampered by a lack of resources. 
There was, however, one observable inconsistency between the four teachers' beliefs and their classroom practice. Although some of the teachers tried to build on students' prior learning (as outlined in section 5.3), there were four occasions when they could have capitalised more on Māori students' cultural knowledge. These occasions related to cultural aspects associated with hongi, tangihanga, marae, and Rūaumoko. The teachers' practices were inconsistent with their responses to Belief Statement 15, where all four agreed on the importance of recognising students' prior knowledge.

The aforementioned findings from my classroom observations indicate that, generally, teachers demonstrably value the Indigenous language of Aotearoa NZ. Furthermore, the teachers model good pronunciation and they endeavour to integrate aspects of tikanga. This is a good platform going forward, in terms of government plans to increase the teaching and learning of te reo Māori in schools.

Notwithstanding, there is still the huge unresolved issue of low levels of reo Māori proficiency amongst English-medium primary teachers. In good faith, and with positive attitudes, they use what they know (and what they feel confident to use); but, too often, this is a restricted repertoire revisited each year - irrespective of the class level that they are teaching. The situation is exacerbated by the teachers' lack of knowledge about, or use of, the few suitable Māori resources that are available. They need a broader range of materials designed specifically for English-medium primary school settings. They also need PD support (to upskill their reo, learn how to use resources, and become familiar with second language acquisition).

There is scope for teachers to recognise, and capitalise on, students' prior knowledge. This aspect was stated as an important belief in the teacher questionnaire, but not consistently enacted in the classroom - especially when it involved creating a space for Māori students to share their knowledge of the Māori world. Teachers' inconsistency in this area (between their beliefs and their classroom practice) is likely due to the demographic mismatch between most English-medium primary teachers and their Māori students. As such, they may be unaware of the added value and richness that a Māori student's perspective could add to the learning of all (students and teacher i.e. ako). The consequence of their not recognising prior knowledge may be that Māori students are left feeling unvalidated and, therefore, reluctant to share their experiences in the future. 
The next chapter will discuss the findings of interviews with the four case study teachers, in relation to: their verbalised beliefs about te reo Māori; their views on the factors that can influence their teaching of the language; their use of Māori language resources; and their perspective on Māori student achievement. 


\section{FINDINGS AND DISCUSSION, Part 3: Interviews |}

\section{NGĀ KITENGA ME TE KŌRERO, Wāhanga 3: He uiuitanga}

\subsection{Background to teacher interviews}

This chapter discusses the findings of my interviews, kanohi ki te kanohi, with the four case study teachers (who initially completed the online questionnaire and whom I subsequently observed in the classroom - as described in the previous two chapters). The chapter begins by showing the relevance of the interviews to the research questions. Thereafter, each of the four teachers is discussed in relation to: their beliefs about te reo Māori; factors that influence their teaching; Māori language resources; and Māori student achievement. The chapter review at the end synthesises the critical factors that inhibit te reo Māori teaching - as well as those that enable.

\subsubsection{Relevance to research questions}

The interview phase of the study allowed me to explore my third research question; namely: What are some of the factors that can influence teachers' attempts to teach te reo Māori? The intention of this question was to uncover aspects that can influence the teaching of te reo Māori, in terms of making it easier or harder. This question was explored earlier in the online questionnaire, but only as an optional response. My aim during the interviews was to probe further and wānanga/discuss the four teachers' views on the factors that they believe influence their teaching of te reo Māori.

The interviews also allowed me to explore my fourth research question about Māori language resources; namely: What are these teachers' views about Māori language teaching and learning resources in English-medium primary schools - specifically:

- $\quad$ existing Ministry resources;

- $\quad$ future Māori language resource needs; and

- $\quad$ the characteristics of quality Māori language resources.

Although initially explored in the online questionnaire, the 1:1 kanohi ki te kanohi interview situation allowed scope for further elaboration on these aspects. 


\subsubsection{Teacher demographics}

As already indicated, there were four interviewees; namely, Ainsley, Jamie, Delta and Jordan (pseudonyms) - three women and one man. Each of them is discussed below - and their demographics are shown earlier in Table 5.2.

\subsection{Ainsley}

Ainsley is a lead teacher of Māori language in a Wellington school (decile 8-10, with a roll of just over 200 students, $13 \%$ of whom are Māori). She was given this responsibility due to her interest in te reo Māori and her background in second language learning; namely, French. Ainsley started off her teaching career in an early childhood setting - but is currently teaching Year 1-2 children (approximately 5-7 years old). Her age falls within the 25-34 years range and she has 6-10 years' teaching experience.

At the time of my observations, Ainsley was in a team-teaching situation with two other colleagues, working across 61 students. She was responsible for the reo Māori input - on a rotational basis. That is, she would deliver the content to one group (comprising approximately 20 students), then immediately repeat it with two subsequent groups. There was a range of ethnicities; namely: 34 Pākehā; 10 Māori; 5 Samoan; and 12 additional minority ethnicities.

\subsubsection{Beliefs about te reo Māori}

Consistent with her response in the online questionnaire (Question 20, Appendix 5), Ainsley confirmed in her interview that performance appraisal was not her motivation for wanting to teach Māori. Rather, she says:

"I do it because I want to. What comes out of my appraisal is irrelevant."

Her comments make it clear that she is genuinely committed to the teaching and learning of te reo Māori in her classroom - irrespective of any potential extrinsic rewards. Moreover, she sustains her motivation and remains personally invested in this kaupapa, in the face of any personal and situational constraints (as discussed by Norton-Peirce, 1995). Such constraints are over-ridden by her feelings of self-efficacy and her desire to do what is right. However, while emphasising the importance of te reo Māori, Ainsley has reservations about making it compulsory - due to teachers' lack of proficiency. These aspects are discussed in more detail below. 


\subsubsection{Importance of te reo Māori}

When asked about the importance (or not) of te reo Māori in schools, Ainsley communicated that it was important in terms of providing another world view. Because of her personal beliefs and values, she is motivated to use Māori language in the classroom despite her lack of proficiency. In her words, its importance lies in:

“... finding out who we are as a nation and as a people. We've got to honour our history ... through increasing the knowledge ... of our young people. I have no Māori heritage but I'm a Kiwi - and NZ is my home and always will be. So, I want to know about it, why things happened and why they are important to certain people. When you have only been exposed to the Pākehā view, it's very hard to understand the other side .... Because our history is told from a Pākehā perspective, it's harder to see why Māori feel excluded - because you don't have that cultural understanding."

In expressing this viewpoint, Ainsley highlights the value of Māori language and culture as a key contributor to our sense of nationhood, and our understanding of NZ history from all perspectives. Ainsley's view is consistent with, and strengthened by, that of Professor Rawinia Higgins (2015), deputy Vice Chancellor (Māori) at Victoria University of Wellington. As a member of the Waitangi Tribunal and Te Mātāwai, as well as Chairperson of the Māori Language Commission, she promotes the relevance of te reo for all NZ citizens. (See Chapter 4).

Ainsley uses the words 'our history', which implies that all people in Aotearoa NZ have a shared history. However, she then immediately exposes a caution, due to that history being told from the dominant colonial perspective (i.e. Pākehā), which ignores the other half of the story (i.e. Māori perspective) - as highlighted by former NZ primary teacher, Tamsin Hanly, who has developed an alternative history curriculum from both Māori and Pākehā perspectives (Radio NZ, 2016). Ainsley's comments about the inter-relationship between nationhood, history, and the knowledge/awareness of our young people are significant, due to her being a teacher of young people. As such, she is a conduit for socialising students into recognising the importance of a known shared history. She and her colleagues are therefore in a powerful position to embed Māori language in schools. 


\subsubsection{Compulsory reo - or not?}

Despite her support for Māori language teaching in primary schools, Ainsley is wary of making it compulsory. Her inclination is to agree, because it's important, but she has reservations:

“I want to agree with it being compulsory, because it's important, but it makes you go, 'Ugh, I don't want to do that'. People don't like being told what to do. I know I am standing here saying we have to be a change, but if you turned around and said te reo was compulsory, I would panic - because I'm being told I have to do something that I don't know about... . But if they (teachers) were all competent, then let's make it compulsory; do it, but not now, when everyone's not confident - not until student teachers are coming in knowing something ... and the resources we have are useful to make our classes more bilingual."

Ainsley's view on compulsory reo is strongly influenced by the current reality of low teacher proficiency and a lack of suitable resources.

Just as speech is not uttered in a vacuum (Bakhtin, 1986), Ainsley's words are positioned within a specific context; namely, the professional community of teachers to which she belongs. Her views reflect lived experiences in the world of the classroom. Bakhtin (p. 88) claimed that "... the use of words in live speech communication is always ... contextual in nature" - and that our thoughts and verbalisations are relational. He asserted (p. 92) that, "Our thought itself ... is born and shaped in the process of interaction ... with others' thought; and this cannot but be reflected in the forms that verbally express our thought as well." As such, Ainsley's views are likely to have been shaped and informed by her ongoing professional dialogue with peers about the possibility of Māori language being compulsory in English medium primary school settings.

Many of Ainsley's colleagues will have ambivalent feelings regarding the potential to be catalysts for change, in terms of contributing to Māori language revitalisation. They may believe that compulsory Māori language tuition in primary school is the right thing to implement but, at the same time, they are fearful and anxious of this eventuality due to their lack of proficiency and the dearth of quality resources to support them. Moreover, they must contend with an already-crowded curriculum, where other subjects also demand time. 


\subsubsection{Influencing factors - prior experiences}

Māori language and culture are unfamiliar to Ainsley. However, her background in learning another language, and in teaching in an early childhood setting, make it easier for her to build her knowledge of te reo Māori. These aspects are discussed in more detail below.

\subsubsection{Exposure to te ao Māori}

Te reo Māori was not part of Ainsley's upbringing. She was exposed to no Māori language learning during her primary schooling in the mid-to-late 90s. Although kapa haka was introduced at the end of that period, according to Ainsley it was not a domain for nonMāori. Furthermore, she felt that participation in kapa would have brought consternation within her family - as it was not at all a part of their normal life, nor that of her friends. Ainsley's honesty about her lack of cultural knowledge, due to her prior experiences, was evident during my observation of her teaching, where she admitted to her students that the imminent class trip to the marae would be her first.

Notwithstanding, Ainsley's experience teaching in the early childhood sector, where there was an expectation that te reo Māori me ōna tikanga would be integrated, meant she was used to normalising the language and making it visible for students.

\subsubsection{Second language acquisition}

After her primary school education, Ainsley went on to learn French at secondary school. This provided a useful platform for her introduction to te reo Māori, after her decision to pursue teaching:

"Because I know languages, I can do it, but someone else might not be able to see the patterns that I see."

Her insight highlights the association between having knowledge of a second language and being able to confidently embrace a third. This is because bilinguals have experience in language learning, having already developed an ability in their first and second languages (Cenoz, 2013). According to Cenoz, a well-developed bilingual brain stands a learner in good stead for further language learning. Cenoz found that knowledge of two languages generally has a positive effect on the acquisition of a third - not just in terms of communicative ability, but also in terms of language learning strategies and metalinguistic awareness. 
Furthermore, as suggested in the New Zealand Curriculum's key competency 'Using language, symbols, and texts', second language learners can see patterns, make meaning of codes, and develop strategies that facilitate their learning.

\subsubsection{Influencing factors - professional and personal identities}

Although currently not part of her personal identity, te reo Māori has become part of Ainsley's professional identity. This aspect is discussed more fully below.

Despite being an experienced primary school teacher who supports the teaching and learning of te reo Māori, Ainsley acknowledges that there is a degree of compartmentalisation between her teaching world and her personal world - which she needs to navigate. She discloses:

"There is no opening personally. I have no connection to te ao Māori personally, because that's not the way my life's path has gone."

This comment underscores the influence of Ainsley's background experiences in shaping her personal identity. The Māori world is foreign to her; it is not her norm. Nevertheless, she states that te reo Māori is very much a part of her professional identity - part of being a teacher in Aotearoa:

"Professionally I am connected because that's where my career has been shaped. It's become the biggest part of my professional identity."

Like the teachers in a study by Barr and Seals (2018), Ainsley cannot claim ownership of te reo Māori. However, like them, she knows she has an important role to play in nurturing and promoting the language in her classroom, providing access for her students. To do this successfully, she must negotiate between her personal and professional identities.

Despite her previous lack of exposure to things Māori, Ainsley made it clear in our interview that she would certainly be open to creating a personal connection with te ao Māori - if such an opportunity arose. It seems likely that her identity and her views on Māori language have been, and indeed continue to be, influenced by opportunities (and expectations) in her chosen teaching career, as well as interactions with colleagues - as suggested by Beijaard et al (2004). That is, Ainsley is continually having to reorganise her sense of who she is and how she relates to others in her personal world and the professional 
world of the classroom. While building up her 'cultural capital', she is constantly having to reassess her identity (Norton, 2013).

\subsubsection{Influencing factors - lack of proficiency}

In the online questionnaire (Question 40, Appendix 5), Ainsley self-rated her speaking ability as basic. In the interview, she elaborated on this, expressing frustration at the absence of pathways for teachers like herself to upskill. In addition, as the lead teacher of te reo in her school, she conveyed a sense of burden due to the weight of expectation from colleagues. These aspects are discussed more fully below.

\subsubsection{How to upskill?}

Ainsley's self-awareness is evident. She understands how important te reo Māori input is for her students - especially her Māori students, because of their heritage. Ainsley has therefore endeavoured to gain some basic proficiency in te reo Māori, to enhance her teaching. However, she reports how difficult it has been to access help (e.g. who and where to go to for upskilling):

"How do you know what you don't know, and how do you go about finding out what you don't know? I've never been exposed to it. Where do I go, where do I start?"

There is a sense of frustration in Ainsley's comments - wanting to do the right thing but not finding the correct avenues nor the appropriate people. Based on Ainsley's experiences, there would seem to be no clear pathways, institutionally, for teachers like her to follow in order to upskill in te reo Māori.

\subsubsection{Expectations of self and peers}

Ainsley's concern about her lack of proficiency is heightened by the expectation of her colleagues who, because of her position of responsibility as lead teacher of Māori, believe that she will provide them with support, advice, guidance and knowledge in this area. Ainsley takes this role seriously because of the potential benefits of having Māori language across the school. She says:

"I've got to be passionate about it because then things will happen for it." 
However, the expectation of others weighs heavily on her, and brings with it a degree of professional isolation:

"It's lonely because everyone on staff looks to me... and I don't know. When you are in the classroom, you want to be able to spontaneously bring it out."

Apart from the weight of expectation, Ainsley expresses a sense of frustration. She admits that her lack of proficiency limits the ability to be flexible in modelling te reo in the classroom.

Moreover, she recognises the significance of this 'lack' in the context of her potential contribution to the larger picture of Māori language revitalisation. Ainsley is aware that she is in a position where there are daily opportunities to model Māori language for her students, as an agent at the micro-level of the classroom (Liddicoat, 2014) - providing bottom-up opportunities that contribute to the government's macro-level planning around Māori language revitalisation. However, Ainsley cannot maximise these potential opportunities due to her limited proficiency.

She would like to advance her own ability in te reo Māori, and that of her students, through a focus on literacy:

"We (teachers and students) should be learning to read and write in te reo."

She empathises with her teaching colleagues in terms of how daunting it is to be expected to read a Māori language text with little or no knowledge of how to pronounce the words:

"When people aren't confident that they can read a text in te reo, they're not going to do it."

Ainsley's insight explains why many teachers are immobilised when it comes to tackling even a basic Māori reader with their students. She comments on the impact of being surrounded by such immobilisation:

"It's hard when the people around you aren't using it; ... you're not hearing them do it."

This leads her to express concerns about how to personally sustain a genuine commitment to learning and teaching te reo Māori. 
As illustrated in research by Norton (2013), a person can be motivated to learn a language but may become uninvested in the process when external factors (out of their control) are brought to bear. Based on Ainsley's comments, these factors would include the lack of reo Māori proficiency, the dearth of quality Māori language resources, and the lack of opportunities for effective Māori language PD. Nevertheless, despite these obvious constraints, Ainsley remains invested in wanting to upskill so that she can integrate the language into her normal teaching programme, in a natural way:

"When I'm forcing it, that's when it feels more like lip service. The more I know, the easier it is."

Based on my experience as a Māori language adviser in schools, many teachers are like Ainsley. They genuinely want to go beyond the formulaic basics of te reo Māori, so that they can integrate the language into other curriculum areas, but they are hampered by their lack of proficiency.

\subsubsection{Influencing factors - insufficient time and budget}

Competitive timetabling and poor financial resourcing can impinge on the teaching and learning of te reo Māori in schools. These two issues are further discussed below.

\subsubsection{Time}

Ainsley believes that a major barrier to teaching te reo Māori is time - due to competing priorities in the curriculum:

"Unless you can find a way to integrate it, it's hard to find time. We ... think it's important so we set aside time for a te reo lesson once a week, but it's not enough for the kids to become comfortable with the language or the ideas of Māori culture."

Her view is that, “... if every school put emphasis on it, we could see change.” Ainsley’s comments throw light on the dilemma of busy teachers coping with an already-crowded curriculum, such that Māori language is invariably ‘squeezed in' or compartmentalised into a finite timeslot - because of competition with other subjects or social programmes.

Barr and Seals (2018) acknowledged that time was the most significant resource contributing to teachers' Māori language use in the classroom. Furthermore, the NMSSA 
research (Ministry of Education, 2018, p.75) highlighted the wide range in hours that English-medium teachers (Years 4 and 8) allocated annually to the teaching of Māori language; namely, between 5 hours (or less) and 40 hours (or more).

The variability of time could be due to a range of factors, some of which are beyond teachers' control. As already mentioned, although they have a degree of flexibility within the New Zealand Curriculum to make judgements on what to prioritise, and how to teach a subject, teachers are faced with the pressing reality of a crowded curriculum. Core subjects (like maths, reading, and writing) tend to be prioritised, in response to pressure from parents and school leaders. Indeed, in the NMSSA study, the reason provided by English-medium teachers for not rating te reo Māori as being (very) important was because they believed there were other more pressing priorities in their students' learning (Ministry of Education, 2018).

Furthermore, up until the time that National Standards ${ }^{160}$ were abolished in January 2018, teachers were compelled to adhere to a strict regime of assessment and reporting to parents. Now that the standards no longer exist, it is feasible that teachers' time will be more freed up to accommodate other subjects, including te reo Māori. Much depends of course on teachers having the necessary confidence and competence to facilitate Māori language in the classroom - supported by quality resources and PD opportunities. If these conditions prevail, it is possible that teachers will dedicate more time to te reo.

\subsubsection{Budget}

As well as being time poor, Ainsley faces the practical issue of there being insufficient funds at her school (as in most schools) to purchase commercial Māori language resources - in the absence of suitable, user-friendly, free resources from the Ministry. For example, when discussing a commercial company that produces Māori language materials, Ainsley explained that she downloads their free resources but does not purchase their books, due to expense:

\footnotetext{
${ }^{160}$ This is the previous government's policy for primary schools, which set out a description of the learning required in reading, writing and mathematics to meet the demands of the New Zealand Curriculum. A student's performance was adjudged at four levels (i.e. above, at, below and well-below the required standard).
} 
“I've downloaded their Matariki and Treaty of Waitangi resources. They do books as well. Some pretty cool stuff but it's expensive - and when your government gives you stuff that's way too challenging ... it's not fun."

Ainsley's comments highlight the need for the Ministry to produce quality Māori language resources that are free to schools and appropriate for the English-medium primary school sector. In that way, teachers would feel better supported to facilitate a Māori language programme - thus meeting the Ministry's expectation in the national curriculum.

\subsubsection{Influencing factors - support (or not) from parents}

Because of the lack of reo Māori visibility in Ainsley's school over many years, the parents were consulted in 2015 about the prospect of raising the profile of the language in classrooms. The result was that the parents became the key driver in making te reo Māori PD happen for all staff, with an external facilitator, in 2016:

"We've had huis with the whānau, and they have said they want it. That was a big driver. That's why we got .... PD last year. That came through strongly, that they wanted things happening within the classroom and we realised that we weren't going to be able to do that without support, so there's definitely demand for it."

This shows the influence that parents can have as demanding consumers of education. Further information on the outcomes of the Māori language PD for Ainsley and her peers is outlined below.

\subsubsection{Professional development - whole school}

All staff at Ainsley's school (including the principal) worked with an external PD facilitator of Māori language for two terms (2-3 visits per term). Then, as a way of collecting evidence about the transfer of the new learning gained from the PD to the classroom, the facilitator conducted observations in each classroom. She used an observation guide (co-constructed with the school), which focused on generic principles of good practice in second language teaching and learning. She found that each teacher had stepped up, as called to do so in the Ministry's Māori education strategy Ka Hikitia (Ministry of Education, 2013).

The teachers' Māori language lessons were reportedly well-prepared and appropriately sequenced. At the beginning of each lesson, they reviewed the previous learning and 
communicated to students the learning intentions for that lesson. Moreover, a range of content was delivered across the classrooms - all of which had been introduced during PD sessions; namely:

- communicating how children travelled to school (e.g. I haere mai au mā runga VEHICLE);

- $\quad$ locating classroom objects, using prepositions (e.g. Kei hea tō OBJECT? Anei, kei PREPOSITION i te pouaka);

- $\quad$ expressing feelings (e.g. Kei te pēhea koe? Kei te STATE OF BEING);

- describing whakapapa/family relationships (e.g. Ko SOMEONE taku RELATION); and

- $\quad$ naming food items and giving choices (e.g. He FOOD, he FOOD rānei?).

In the notes for file written by the PD facilitator for the school, it was evident that the teachers' confidence had significantly increased since her initial work with them a few terms earlier. They had extended themselves beyond their own comfort zone - and, most importantly, beyond the basic rudimentary classroom instructions that are too often the norm in NZ classrooms. The lessons were interactive, with children moving around the room to practise te reo in twos and threes. The concept of tuakana:teina was exemplified in student interactions. Similarly, the concept of ako was clearly demonstrated, with children helping the teachers (and each other) with their reo, and teachers being open to that help which was testimony to the safe learning environment that had been created for the learning of Māori as a second language. Furthermore, the students with specific learning needs were able to experience success in learning te reo Māori.

The PD facilitator observed that various materials were used to facilitate a range of Māori language input by teachers and practice opportunities for students. These included flashcards, animations, PowerPoint slides, songs, and YouTube clips. The Ministry's multimedia resource $\mathrm{He}$ Reo Tupu (introduced by the external facilitator during PD) was the basis for each teacher's Māori language programme. They found it easy for planning and scaffolding students' learning because of its user-friendliness and comprehensive coverage (e.g. alignment to Māori language curriculum guidelines, with associated assessment rubrics; inclusion of everyday topics suitable for the classroom; information on communicative language teaching and task-based learning; design of resource sheets for second language tasks; inclusion of video clips about tikanga). Furthermore, the associated 
animations from that resource were used to extend the students' language awareness (e.g. looking for familiar words, while also attuning their ears to Māori language not yet introduced).

The PD facilitator reported that there was now an openness and willingness in the school to teach Māori language - spurred by the students' receptiveness and enjoyment thereof. There was also a genuine desire to normalise te reo Māori in the classroom - as opposed to compartmentalising the language into one isolated timeslot during the week. From the PD facilitator's observations, Māori language was on a sustainable path. Furthermore, some teachers reportedly commented on the positive effects of te reo Māori on their Māori students. They felt that the validation of Māori language and culture was a springboard to better relationships with the Māori students and their whānau, as well as enhancing Māori student achievement in other curriculum areas.

This progress across the whole school may not have been possible without the initial support and encouragement from parents. Based on Ainsley's experience working with those parents, she is of the view that most of them believe te reo Māori is important - as evident in whānau hui at the school:

“.. 80\%-90\% are totally supportive, but you get those random people who are culturally insensitive, or just don't know better, because they haven't been exposed to it and are not the sort of people who are open to different things. ... it's a societal community thing - and until ... everyone sees this as important ... there's only so much you can do.”

Ainsley's comments point to the fact that there still exists, in some segments of society, a level of insensitivity and ignorance that is ingrained. That is, there are New Zealanders who (unlike most of the parents in her school) do not value te reo Māori as the Indigenous language of this country - and there is little that can be done to alter their entrenched views. As an example, she cites a difference of opinion with one parent who urged her to teach French, a language with which Ainsley is familiar, instead of Māori. In response, Ainsley reminded the parent of the official status of Māori language in NZ, by saying:

"Te reo is one of the official languages of NZ; that is why it's part of our curriculum." 
In this way, Ainsley was able to provide evidence that Māori language deserved a privileged place in schools. In the future, she (and other teachers) could refer parents to the evidence in the Ministry's Māori language curriculum guidelines, Te Aho Arataki Marau (2009, pp. 13-14), which sets out sound rationale for a school's inclusion of te reo Māori especially the section about the benefits to be accrued by students learning te reo Māori.

\subsubsection{Resources}

Ainsley assigns primary agency to the Ministry to provide appropriate support for the teaching and learning of Māori language in schools. She regards it as their responsibility to help English-medium primary school teachers make the integration of te reo Māori easier - through the provision of quality resources in those settings.

"If they want us to be doing this, they have to support us with the right stuff."

This comment relates to the expectation that teachers should incorporate Māori language into their classroom programme (New Zealand Curriculum, 2007; Tătaiako, 2011; and the Education [Update] Amendment Act 2017). Ainsley's sentiment has been reiterated by other English-medium teachers with whom I have worked in the past. They challenge the notion of expecting non-fluent teachers to teach te reo Māori, a language they do not know, using resources that they do not understand.

Ainsley finds it easier to implement te reo when she knows about, and can access, appropriate resources to support the topic at hand. This was evidenced during my observations, when she read a very basic Māori language reader, Te Rā $o$ Māma $\bar{a}^{161}$, about Mother's Day - prior to her students making Mother's Day cards. Ainsley's further comments on specific Māori language resources are discussed below.

\subsubsection{Te Aho Arataki Marau mō te Ako i te Reo Māori - Kura Auraki (2009) and He Reo}

\section{Tupu, He Reo Ora (2011)}

Ainsley acknowledges that the Ministry's Māori language curriculum guidelines, Te Aho Arataki Marau (2009), are useful in a general way; for example, providing reasons why te reo is important (pp. 13-14). But her first 'go to' for teaching te reo in the classroom is the

\footnotetext{
${ }^{161}$ This story was one of three very simple readers originally written for Māori-medium students, with accompanying teachers' notes in Māori. The notes were subsequently adapted for English-medium teachers - to make them more accessible
} 
Ministry's multimedia resource for primary schools, He Reo Tupu (2011) - because of its 'hands-on' practicality and ease of planning:

"This one is my Bible ... the one I go to first, to develop unit plans for the school. It's the most accessible document; there's paper and online. It's broken down, it gives you the vocab you want, the tikanga. It has been the thing I find the easiest to use. I can use the resource sheets. It has achievement objectives."

It is important for busy generalist teachers like Ainsley to have 'hands-on', user-friendly resources for planning and implementing Māori language content that is aligned to the curriculum. She rates the Ministry's multimedia resource He Reo Tupu (2011) highly. It is her 'Bible' for the following reasons: availability in print and online; accessibility; alignment to the objectives in the curriculum; inclusion of resource sheets for second language tasks; cultural explanations; and ease of vocabulary building. These are aspects that Ainsley considers to be very important in Māori language resources. They would be worthwhile suggestions for resource developers to emulate.

\subsubsection{Māori language readers}

Regarding the Ministry's Māori readers, Ainsley finds almost all of them too challenging (which is unsurprising, as they were written for Māori-medium students):

"In the school, I've found boxes of Māori readers that would only have been relevant for people that could read fluently."

This situation suggests that government funding may be mis-spent distributing such Māori texts to English-medium schools - because they are too complex for these settings. However, it would be worthwhile for the Ministry to consider re-versioning some of these texts and providing associated teachers' notes - as they did with the basic reader mentioned earlier, Te Rā o Māmā. In this way, the readers could be better utilised in English-medium primary schools - thus reaching a wider audience.

In addition, some of the Ministry's older (now out of print) basic Māori readers could be revived or reversioned and made available online - because of their appropriateness for English-medium students (e.g. Ngā Kākahu o Airini - which covers days of the week, clothing items and modes of transport). However, it is acknowledged that there may be some issues associated with the intellectual property of the original authors. This would 
require the Ministry of Education to negotiate with those authors (or their families), in order to achieve a positive outcome for all - which may involve financial incentivisation. Aside from IP issues, the availability of today's technology would aid the 'revival/reversioning' process - in particular, the Ministry's new online hub, Kauwhata Reo (launched 4.9.19), a repository for all Māori language resources, designed to improve searchability.

\subsubsection{Web resources}

Because of the paucity of resources in English-medium settings, Ainsley resorts to downloading resources from the web (e.g. GoNoodle, USA-based educational technology focused on physical activity and interactive learning; and Teacher Talk, a NZ education hub for early childhood educators). She uses the latter particularly when searching for resources related to Matariki and the Treaty of Waitangi. Ainsley also uses YouTube, especially for Māori songs - to complement what the external kapa haka tutor does in the school. In addition, she has integrated into her reo Māori programme the 20 bilingual 'emotional faces' cards from the Ministry's initiative PB4L, Positive Behaviour for Learning. Ainsley finds these cards (as shown in examples below in Figure 6.1) to be a useful extension for progressing students beyond basic responses to how they are feeling.

\section{Figure 6.1: Examples of PB4L emotional faces cards ${ }^{162}$}

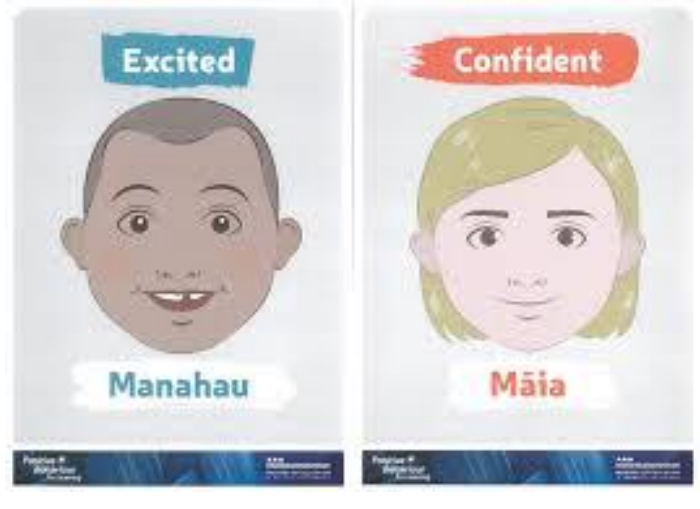

\subsubsection{Local resources}

Because of the new Māori language focus in Ainsley's school, the teachers are keen to incorporate local stories into their physical environment, so that the students learn about the cultural and historical significance of the whenua. Hence their employment of someone to do a carving for the school that reflects the history of the local area. The school's trip to the local marae is also a way of seeking out local knowledge. This place-based approach is

${ }^{162}$ Permission was given by Anne Tuffin at the Ministry of Education for the inclusion of these images 
one that is shown to have benefits for students (Penetito, 2009), in terms of creating a sense of 'belonging' to a community. It is also emphasised in one of the five cultural competencies in Tãtaiako (Ministry of Education, 2011, p.10); namely, 'Tangatawhenuatanga', where teachers are expected to provide learning contexts that affirm Māori identity, language, and culture.

Research by Core (2017) revealed a need for resources that reflected a place-based curriculum (including local stories handed down from tīpuna). Responding to teachers' needs, the Ministry has given priority to this approach, through the initiative Te Aho Ngārahu, with an investment of \$1.91M annually (over four years, 2017-2021) for the development of resources based on local stories. Such an approach is highly recommended by applied linguists and sociolinguists because it offers students a unique opportunity to see themselves as part of the school environment. In the case of learning te reo Māori, the students and the context in which they are learning the language are integrated. This enables them to see the relationship between their learning of te reo and the world in which they live.

Moreover, the feeling of connection to the community helps to establish their social identity and sustains their investment in the learning process. This is confirmed in research by Norton-Peirce (1995); Menard-Warwick (2009); Norton (2013); and Seals and Peyton (2017) - all of whom emphasise the relationship between teachers' affirmation of students' identity and students' subsequent academic achievement.

\subsubsection{What constitutes a quality Māori language resource?}

In the online questionnaire, teacher respondents were asked to rank the top three characteristics (out of nine suggestions sourced in the literature) associated with what constitutes a quality Māori language resource. (See Question 28 in Appendix 5). Ainsley’s top three characteristics were that resources needed to:

- $\quad$ be user-friendly (to facilitate uptake by teachers and students)

- $\quad$ have an audio component (to aid pronunciation)

- reflect real life (so that students can relate to the content).

In terms of Māori resources in her classroom, there were a few Māori visuals on the classroom walls. These depicted mainly formulaic phrases and aspects of Māori culture (including a picture of a marae, relevant to their imminent visit). There was also a 
commercial wall chart showing numbers 1-10; and two free Māori Language Commission posters (depicting a family tree and a kitchen). Te reo Māori was visible in other small ways. For example, the class was named after a native bird - and the room number was in Māori, as was the description of their crescent-shaped table. However, relative to the amount of English language on display, te reo Māori was scant - which reduced the opportunities available to students to enhance their linguistic awareness.

\subsubsection{Bilingual big books}

Regarding future resource development, Ainsley is particularly keen for the Ministry to develop bilingual 'big books' with illustrations - so that (after being introduced to the book by the teacher in a shared reading group) students can read cooperatively in a group, independent of the teacher, working out the meaning together and enjoying the social aspect of learning. As a teacher, she likes to see the English equivalent directly under the Māori text - to save her and the children continually having to go to the back of the book for a translation (which can interrupt the flow and affect children's engagement). In addition to the dual text, she would like to see a glossary of individual words, so that she and her students can match individual Māori words to their English equivalents. The development of such bilingual 'big books' would help to address Ainsley's previously mentioned difficulties associated with her proficiency being too limited to use existing Māori language readers produced by the Ministry.

Ainsley specifically requested that the Ministry produce a resource like that illustrated below in Figure 6.2. This is a commercial resource, produced by Janessa Docking, setting out 9 strategies for reading - using 'animal helpers'. Ainsley believes that such a resource in te reo Māori would be invaluable for Māori literacy - to remind students of the strategies they have been taught during English reading instruction. 
Figure 6.2: Images of 'animal helpers' used as mnemonics for reading strategies (https://www.teacherspayteachers.com/Product/Animal-Reading-Strategies-Eagle-Eye278724)

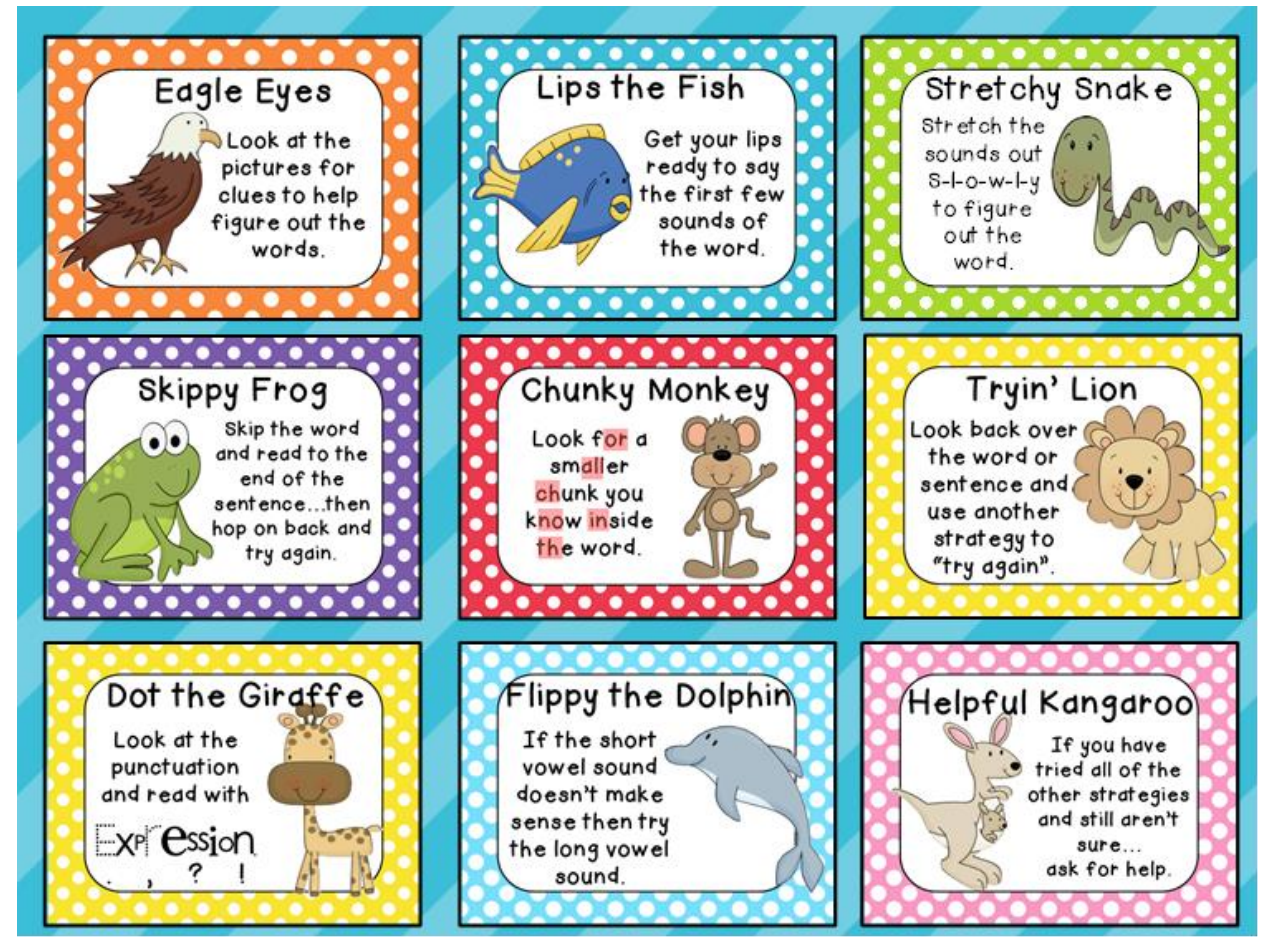

\subsubsection{Audio component}

To overcome any pronunciation problems, Ainsley is enthusiastic about the idea of adding an audio component to Māori language resources. The audio would need to go beyond individual vocabulary items to accommodate the pronunciation and intonation of sentences, as in the audio recordings of the Arahia Books given to the four interviewees as a koha for their participation in the research.

\subsubsection{Cross-curriculum integration}

Ainsley favours the development of resources that provide ideas for the cross-curriculum integration of Māori (i.e. showing teachers how to scaffold te reo into other learning areas) - especially kaupapa that are common in most English-medium primary classrooms (e.g. family; Matariki). During my observations of her teaching, Ainsley managed to integrate some Māori language into Art (exploring the style of Mondrian); Health (personal hygiene); and Social Studies (the celebration of Mother's Day). In applied linguistics, this is known as Content and Language Integrated Learning (CLIL). It refers to a situation where there is a dual focus, such that the target language is integrated into the broad curriculum and is used to teach all or part of another subject (Coyle, 2007). The intended 
outcome for students is twofold - they are learning content while simultaneously learning the target language (Marsh, 1994).

Realistically, in a typical English-medium primary classroom in NZ, this would involve the teacher using te reo Māori for a small percentage of the time (e.g. parts of a lesson or activity), while covering content in another area of the curriculum. Much of the content would inevitably be delivered in English, due to most teachers' low levels of Māori language proficiency. Nevertheless, having te reo Māori blended into different curriculum contexts would have benefits for students as their confidence and competence in that target language would inevitably be enhanced, through exposure (Cenoz, Genesee and Gorter, 2014).

\subsubsection{Correlation between te reo in the classroom and Māori student achievement}

In terms of an association between Māori students having their language, culture and identity validated at school, and enjoying educational success as Māori (which is the vision of the Ministry's Māori Education Strategy, Ka Hikitia), Ainsley believes that any student, Māori or otherwise, needs to feel valued:

"By valuing who they are as a human, and what they bring in, it's going to lead to achievement...but it might not be measured by National Standards. They come in with a range of skills, ... and we have to work out what they've got and use that to engage and support them."

The inference in Ainsley's comment is that, if teachers can capitalise on Māori students' prior experiences and the cultural capital they bring to the classroom (i.e. their Māori background), those students are more likely to achieve - because they feel valued and their identity is affirmed. This association is emphasised in the elaboration of one of the Standards for the Teaching Profession (Design for Learning), which states the expectation that teachers will "... harness the rich capital that learners bring..." (Education Council, 2017, p. 20).

\subsubsection{A holistic approach to well-being}

Ainsley directly calls out National Standards (since abolished in January 2018 by the new government). She challenges the capacity of these standards to go beyond the assessment 
of a student's cognitive ability, to measure the affective aspects of their development. That is, Ainsley's interpretation of achievement is not solely limited to academic outcomes. As an experienced teacher, she can see the value of students achieving in a range of other areas, using different benchmarks. This includes the ability to establish relationships, show empathy, work cooperatively, excel in physical/artistic/musical pursuits, and develop spiritual awareness.

Such a perspective is congruent with Professor Mason Durie's holistic model of hauora/well-being. In this holistic model (see 'te whare tapa whā' in Figure 6.3 below), Durie depicts four cornerstones that contribute to total well-being/hauora; namely, physical well-being (tinana), spiritual well-being (wairua), mental well-being (hinengaro), and social well-being (whānau). To portray this concept, Durie uses the image of a Māori meeting house (wharenui), where each wall represents a different dimension - with all four walls being necessary for the stability of the house (Durie, 1994, p. 70).

Figure 6.3: Dr Mason Durie's (1994) holistic model of hauora/well-being (https://www.ero.govt.nz/publications/wellbeing-for-success-a-resource-forschools/useful-wellbeing-resources/)

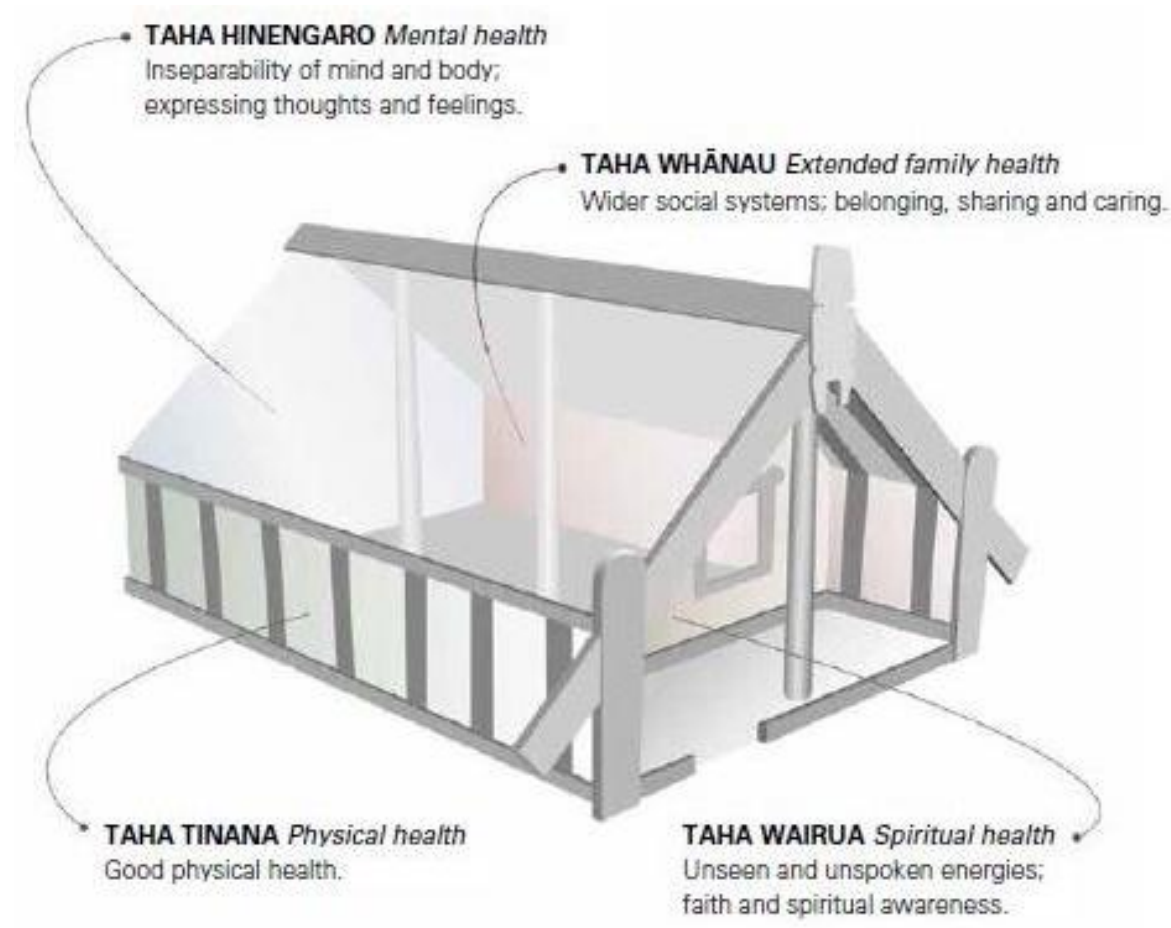

\subsubsection{Relationship-building through validation of culture}

Ainsley provides examples of how she tries to teach in a culturally responsive way by tapping into Māori students' prior knowledge, thus acknowledging the power of ako. She describes one student in her class who “... comes in with knowledge of a lot of things Māori 
and we can use that to engage her." Another Māori student in the school (although not in Ainsley's class) is a graduate of kōhanga reo and delights when Ainsley speaks to her in te reo:

"She shines, like in kapa haka. But the rest of the time ... the kids just don't see her shine."

These two examples highlight the potential for connecting with Māori students through their existing cultural knowledge (cf. Menard-Warwick, 2009). This is a powerful force for establishing relationships with Māori students - when they realise that their culture is being validated at school.

Ainsley describes a third Māori student with whom she has also developed a relationship even though she is not in her class.

“Everyone knows that if you've got a good relationship, you're going to be more successful ... you're doing the right thing for these children ... But I don't know how that is replayed in the classroom. Are they getting enough opportunity to be themselves outside of the Pākehā box that we squash them into?"

The first two words in the above quote suggest that the importance of whakawhanaungatanga is a popular notion among colleagues in their professional dialogue. Indeed, establishing relationships with students is likely to be the foundation for successful teaching and learning. Furthermore, Ainsley demonstrates a high level of critical awareness in her observations about the Pākehā-dominated educational landscape where, for too long, many Māori students have been forced to conform. Her views are so strong on this issue that she uses the verb 'squash', which conjures up the image of a negative force being applied to Māori students by Pākehā stakeholders (including teachers) who hold the power. Ainsley highlights the issue of Māori students not being encouraged to participate and achieve at school as Māori. Her stance is meaningful in that it reflects support for the Ministry's Māori education strategy Ka Hikitia, where the expectation is that Māori children will achieve comparably to their non-Māori peers, while at the same time retaining their Māoritanga ${ }^{163}$.

${ }^{163}$ Māori culture 


\subsubsection{Overview of Ainsley}

Ainsley believes that Māori language and culture are important, as key contributors to nationhood. She recognises that she is a conduit for helping students to understand NZ history from all perspectives. Consequently, she is committed to the teaching and learning of the language in her classroom. However, despite her commitment, Ainsley is honest about her lack of exposure (currently and in the past) to te ao Māori. As such, although Māori language is part of her professional identity as a NZ teacher, it is not part of her personal identity. Nevertheless, other prior experiences give her an advantage in teaching te reo; namely, having learnt a second language (thus being able to see 'patterns') and having taught in the early childhood sector (where there is a long-standing expectation in the curriculum, Te Whāriki, that Māori language and culture will be integrated into children's learning).

Ainsley is not motivated by potential extrinsic awards, but by her desire to do the right thing - despite constraints (e.g. dearth of quality resources suitable for English medium primary school settings; few opportunities for PD; her own, and colleagues', lack of proficiency; little time in an already crowded curriculum; and insufficient funding). Although she values the language, she has reservations about it being compulsory at this point in time, due to the aforementioned constraints. Despite having only basic reo proficiency, she is the lead teacher of Māori in her school, which brings with it a weight of expectation from her colleagues who seek her advice and guidance. She recognises that her lack of proficiency limits her ability to model Māori language in the classroom on a daily basis - as a way of contributing to Māori language revitalisation.

In terms of what constitutes quality Māori language resources, Ainsley believes they must be user-friendly, reflecting real life, with an audio component to aid pronunciation. She sees value in the creation of big bilingual books that are pitched at an appropriate level of Māori language for English medium teachers and students. She also recognises the importance of local resources, to help embed a place-based approach and create in students a sense of belonging to a community.

Ainsley supports the notion of there being a relationship between Māori language in the classroom and Māori student achievement. She does this by valuing Māori students' prior 
experiences and the cultural capital they bring to the classroom. Her premise is that they are more likely to achieve if they feel valued and their identity as Māori is affirmed.

\subsection{Jamie}

Jamie teaches Year 5-6 students (approximately 9-11 years old) in a school in the Wellington region (decile 1-3, with a roll of just over 300 students, $43 \%$ of whom are Māori). She sits within the 35-44 age range and has over 16 years' teaching experience. At the time of my observations, there were 21 students in her class. The majority $(n=9)$ were Samoan, two of whom were second language speakers of English. There were seven Māori students, one of whom attracted special funding under the Ministry's Ongoing Resourcing Scheme (ORS) ${ }^{164}$. The class also included two Syrian students (both of whom were secondlanguage speakers of English), one East Asian student, one Niuean student, and one Tokelauan student.

\subsubsection{Beliefs about te reo Māori}

Although Jamie emphasises the benefits of knowing two languages, she (like Ainsley) is reticent to advocate for compulsory Māori language in schools - due to concerns about teacher proficiency. In her words:

"Teachers should do it [te reo], definitely, but at their ability."

She believes it would be impractical and unfair to expect all teachers to have the same level of proficiency. Nevertheless, she is prepared to put herself in the vulnerable position of learning alongside her students - thus exemplifying the principle of ako. Further information on Jamie's beliefs is provided below.

\subsubsection{Advantages of bilingualism}

Jamie believes it is a strength to know two or more languages. She impresses this upon her students, many of whom are Pasifika and can speak the languages used in their homes (e.g. Samoan, Gagana Tokelau, and Vagahau Niue):

\footnotetext{
164 This is a fund for students with the highest level of need for special education. It enables them to join in and learn alongside other students
} 
"I've always said to them, you're so lucky because you know two languages; I know one."

She tries hard to be inclusive and to validate her students speaking other languages beyond English. By reinforcing their use of more than one language, Jamie is conveying the importance of their heritage languages and cultures - which she believes is a bonus, not a deficit:

"If I say to these kids I don't want you speaking Samoan and Māori, I only want you using English, then that says I really don't like their cultures."

In validating her students' ability to communicate in more than one language, Jamie is lifting the status of those languages and their respective cultures - such that English is not regarded as the superior, dominant language. Jamie's validation is further justified by the literature on the advantages of bilingualism; for example, the findings of Treffers-Daller et al (2018); Bialystok (2011); Lauchlan, Parisi and Fadda (2012); May (2008). These researchers point to bilinguals' superior mental dexterity, enhanced concentration, higher level thinking, heightened perceptual awareness, and greater ability to multi-task.

\subsubsection{Compulsory reo - or not?}

In the context of the ongoing debate in the public arena about compulsory Māori language in primary schools, Jamie expresses reservations about any expectation that teachers should be fluent in te reo Māori:

"That's not fair because you will get people like me who, no matter how hard they try, will never be fluent in any language except their first."

Jamie's opinion is influenced by her own difficulties learning other languages (including te reo Māori), which is a stance that may be typical of many of her colleagues, who struggle with second language learning per se. Jamie would prefer instead for each individual teacher to make a decision that aligns with their aptitude for language learning generally, and their ability in te reo Māori specifically:

"Each teacher should do it to whatever level they're capable of doing it."

She has personalised the issue of compulsory reo Māori, due to her level of anxiety at the prospect. There are undoubtedly many teachers who feel similarly because of the 
challenges associated with learning Māori as a second language - and teaching it in an already full curriculum.

\subsubsection{Ako}

In the spirit of ako, Jamie participates alongside her students whenever Māori language specialists are brought into the school:

"I participate as a student. Can't expect them to learn it if I'm not willing to do it too."

Her attitude is that teachers need to be role models in the learning process - demonstrating to students that teachers are also learners. She believes strongly that, when schools hire external Māori language tutors to work with the children, teachers need to be students too - learning alongside:

"Even if they only pick up the basics, at least they're there. The kids see them doing it and it becomes something that everyone's doing. I don't agree with teachers ... going off to do their own thing. The kids see ... that it's not valued."

In this way, Jamie seeks to be a good role model for her students, showing them that it is worthwhile learning te reo Māori - despite her own limited ability. She is prepared to be vulnerable in this second language learning situation. Even though she acknowledges it is daunting, she is invested in the learning process and is prepared to sustain her efforts learning with her students and being open to learning from them, thus demonstrating the concept of ako (i.e. the teacher as a learner).

\subsubsection{Influencing factors - prior experiences}

Jamie disclosed in her interview that, when she was a student at primary and intermediate school, she was not permitted to participate in the Māori cultural group - due to her being non-Māori. This experience tainted her view on things Māori for some time thereafter: "I guess that soured me towards it for a time." Such sentiments show how people's early life experiences can lead to negative attitudes that can be difficult to shift. Research by Seals (2018b) indicates that students' identity is affected by how they are positioned by others. In Jamie's case, she was positioned as being an outsider, by dint of not being Māori. This distanced her from engagement with the Māori world, a world where she did not feel valued, a world where she had been rejected. 
Added to her negative perspective, emanating from her exclusion from kapa haka as a child, was the environment in which she grew up:

"If you weren't white, you were frowned upon... and that just made it worse. You can't think like this anymore."

Jamie acknowledges that attitudes have changed somewhat since her upbringing, when racism was widespread and blatant in Aotearoa NZ. She discusses the impact of such negative attitudes within her own family, which influenced her early views about Māori people, and their associated language and culture. She also acknowledges that, although the situation has improved over time, there are still vestiges of racism that exist in the $21^{\text {st }}$ century:

"There's still a lot of prejudice and it's disgusting."

She cites an example of a family member who was critical of her efforts to pronounce Māori properly: "If I say Māori...he will turn around and say 'Mouldy'." Nevertheless, despite being a recipient of such instances of micro-aggression, being ridiculed for attempting to correctly pronounce te reo Māori, Jamie has shown enough resilience and self-efficacy in her teaching career to persevere with the correct pronunciation of Māori language. Moreover, due to having taught for many years in schools with high Māori rolls, she has overcome the negative feelings from childhood that were associated with kapa haka, te reo Māori and Māori people. She now embraces Māori language - and students' right to use it (even though she herself struggles).

Jamie talks with optimism about the next generation of parents and children, for whom the learning of te reo will be something that's more accessible:

“They're the lucky ones because they're being exposed and they're going to carry it on and make sure the next generation does it - their kids and their kids, and eventually it will be very strong."

There is a sense of optimism in Jamie's comments. She recognises and values the importance of inter-generational transmission as a major contributor to the revitalisation of te reo Māori. 


\subsubsection{Influencing factors - lack of proficiency (and appropriate PD)}

When asked about the most difficult aspect of teaching Māori, Jamie responded unhesitatingly with the comment, "I don't know enough." She acknowledges that the biggest obstacle is her own lack of proficiency - as evidenced in the online questionnaire, where she indicated that her reo Māori speaking ability was basic. She related how, during her teacher training, she struggled to pick up the language - even though she enjoyed participating in Māori events. Nevertheless, she was determined to grasp the basics (e.g. greetings and commands) prior to becoming a classroom teacher. She reports that her proficiency has gradually improved over the years, commensurate with her exposure to te reo Māori in schools. And, importantly, she has demonstrated an openness to learning more. As stated earlier, Jamie allows students to see her vulnerability as she struggles to make progress in her acquisition of Māori. In doing so, she is setting a good example for her students, who are also likely to encounter challenges during their learning.

Jamie reports that, in the past, she has participated in PD programmes aimed at addressing teachers' Māori language proficiency. These have been variable in terms of quality. The one that was the most successful was where an external PD facilitator helped the teachers to progress in small steps, acknowledging that not everyone would move at the same pace. This facilitator created a learning environment that mirrored the reality of students' differentiated learning in the classroom.

By contrast, Jamie had floundered in other Māori language PD programmes when expectations were too high and unrealistic. Such programmes ignored the fact that most English-medium teachers' ability in te reo is very basic - as confirmed in research associated with the NMSSA programme (Ministry of Education, 2018). There was a mismatch between PD delivery and teachers' needs. One such need was learning how to maximise the use of Māori language materials. English-medium teachers reported not knowing how to find, or effectively use, reo Māori resources - due to the lack of PD opportunities (Ministry of Education, 2017).

\subsubsection{Influencing factors - support (or not) from school leaders}

Jamie emphasised that school leaders needed to have a positive attitude towards Māori language, and regard it as important. Based on her experience in a few schools, she stated her belief that the success of a school's Māori language programme was largely dependent 
on support from school leaders. She saw a need for teachers' Māori language efforts in the classroom to be affirmed by the leadership team. All too often she has taught in schools where teachers were commended for their students' achievement in different areas of the curriculum, but not te reo Māori. That is, the status of te reo Māori was low, in relation to other subjects.

\subsubsection{Resources}

Like Ainsley, Jamie was keen to see the development of bilingual readers that engage students while exposing them to simple Māori language. She also emphasised the need for resources that develop children's local knowledge. The paragraphs below provide more information on Jamie's beliefs about Māori resources.

\subsubsection{What constitutes a quality Māori language resource?}

Jamie's top three characteristics of a quality Māori language resource (as ranked from a list of nine possibilities in the online questionnaire - see Question 28 in Appendix 5) are that they should:

- include multimedia components (to appeal to diverse learners and learning styles)

- $\quad$ be user-friendly (to encourage use by teachers and students)

- $\quad$ set out an English translation/glossary (to facilitate dual literacies).

In terms of visible Māori language resources in Jamie's classroom, there was one; namely, a set of commercially made magnetic Māori words for the days and months. These were used during a reading session. In our interview, Jamie referred to other rauemi ${ }^{165}$ she uses; namely, the Ministry's multimedia resource He Reo Tupu (2011), the online Māori dictionary and the website Twinkl.

Jamie (like Ainsley) relies on He Reo Tupu because of its ease of use e.g. Māori language examples with translations, learning outcomes aligned to the curriculum guidelines, bilingual flashcards with pictures, and explanations of grammar. In the case of the latter, teachers have identified a need for support around Māori language grammar and linguistics (Ministry of Education, 2017). Jamie likes the associated resource sheets in He Reo Tupu, which she prints off and laminates in preparation for second language activities.

${ }^{165}$ Resources 
Furthermore, her students particularly enjoy using the flashcards independent of her. The Ministry of Education (2017) found that teachers were keen to have flashcards because students could use them immediately - for a range of learning activities/games. In Jamie's words:

"Anything to do with games they absolutely love - played with all the time."

This comment echoes other teachers' responses in my online questionnaire (Appendix 5), when asked what future resources that need to be developed. Many of them $(n=21)$ recommended games and multimedia. Hence the popularity of $\mathrm{He}$ Reo Tupu, with its multimedia components, making it easier for teachers to teach te reo Māori and encourage students to exercise autonomy in the learning thereof.

In the case of the online Māori dictionary, Jamie would prefer an adaptation thereof; namely, the ability to type in a phrase (not just a word). She spoke very favourably about Twinkl because of the materials being designed by teachers, for teachers. She found this site particularly useful for planning and assessment materials that are appropriate for NZ classrooms. Moreover, she had confidence in these resources because they were teacherdriven.

\subsubsection{Bilingual big books}

Like Ainsley, Jamie sees a specific need for the creation of big books with dual text (Māori and English) and quality illustrations - “... especially...early readers, where I would guess most teachers would be." This would make the resources more accessible and user-friendly for teachers like her, especially those who are reticent and lacking in confidence to 'give te reo a go'.

Jamie also recognises a need for resources that go beyond a focus on nouns and verbs. She would particularly like to see rauemi that explore thoughts and feelings (as in Health-related topics) - which are harder to express and are likely to require more complicated language. There is a challenge therein for resource developers; namely, how to create resources using simple reo while, at the same time, maintaining student interest.

\subsubsection{Local resources}

Jamie, like Ainsley (discussed earlier) and Jordan (in the next section), recognises a need for resources that focus on local knowledge - including the history of the area (e.g. the 
Māori names for the maunga/mountain and awa/river, and the meaning behind those names). She recommends that each school be supported to create an introductory enrolment package containing such information - to facilitate place-based learning (as recommended by Penetito, 2009). In addition, she wants resources that will help teachers facilitate student learning about their pepeha and whakapapa - to strengthen their identity. As emphasised by Māori psychologist, Diana Kopua: "You can't know your identity if you don't know your whakapapa" (Kopua, 2018).

Although Jamie encourages her students to follow up a line of inquiry by asking whānau to provide the relevant information on such aspects of their heritage, it is common for them to draw a blank - hence her express need for local resources:

"These kids need to know where their family comes from. We are always asking them, 'What's your awa?' And they don't know. So, we're googling. Not knowing makes it so much harder."

Jamie's words convey a sense of frustration in respect of wanting to do the right thing by Māori students, but not being well-supported with appropriate resources that would increase the cultural knowledge (and therefore capital) of those students, and the teachers too. Her use of the personal pronoun 'we' suggests that she is aligning herself with others in her profession who experience the same struggles and can identify with her situation.

\subsubsection{Māori language readers}

Jamie, like Ainsley, highlighted the difficulty level of the Ministry's Māori language readers. Because the target audience for these readers is the Māori-medium sector, the language structures are too complicated for English-medium students and teachers. Fortunately, she has found something that is more manageable; namely, the Ministry's multimedia resource for Year 1-6, Не Reo Tири. She finds the material on the associated website much more enabling and easier to use than the Māori language readers:

"It's an excellent resource because it has it in Māori and in English, so you know what you're looking at. I love the resources because they're easy ... stepby-step, everything there - the pictures, translations, sentence structures, learning intentions. All I need to do is pick what I'm doing ... and deliver it. That's what resources need to be; otherwise teachers will go, 'I can't do that too hard'." 
Jamie's comments emphasise the need for user-friendly Māori language resources to facilitate the teaching and learning of te reo Māori in a busy classroom.

\title{
6.3.6 Influencing factors - insufficient time and budget
}

Jamie drew attention to the inordinate amount of time taken to prepare lessons using the Ministry's free Māori language readers - due to the difficult level of reo therein (as already mentioned). Added to this was the cost of purchasing commercial resources in te reo. Both these factors are discussed below.

\subsubsection{Time}

At a bilingual school where Jamie taught previously, there was an expectation that nonMāori teachers would try to use some of the Ministry's Māori language readers (designed for Māori-medium settings):

\begin{abstract}
"I was expected to ... take two hours' worth of literacy in Māori on a Friday, which was a huge jump from anything I'd ever done. We were expected to use the Māori readers ... translating the books into English, so we knew what the book was about, and then teaching the kids to read in Māori."
\end{abstract}

This is a huge task for most English-medium teachers, the majority of whom (like Jamie) have limited proficiency in Māori language. Nevertheless, she and other non-Māori colleagues at her previous school persevered tenaciously. They approached the challenge by planning together and sharing any associated resources that they found or made. They also sought help from a Māori colleague, to work out the meaning of the Māori texts because there was no English translation or glossary provided:

"It was difficult and time-consuming. The first lesson I planned with the Māori language teacher took three hours. I am all for it, but it shouldn't take me three hours."

The inordinate amount of time Jamie and her former peers spent on a two-hour Māori language teaching session each week would have impacted on the planning of other subjects. However, these non-Māori teachers demonstrated their commitment to te reo Māori by continuing to meet the school's expectation each week. Despite the inherent difficulties using the Ministry's Māori language readers, Jamie found that her confidence to use te reo in the classroom increased as a result of repeating this arduous exercise. This 
is congruent with the literature on second language learning which describes learning gains emanating from repeated exposure over time (Ellis, 2005b; Schmitt, 2008).

The advantage for Jamie and her former non-Māori colleagues using the Ministry's Māori language readers was that they were free of charge. However, the downside was the timeconsuming process to first translate them into English - then plan appropriate literacy instruction. This highlights the pressing need for bilingual resources that are suitable for non-Māori teachers to use in English-medium primary schools. Due to the lack thereof, such teachers turn to commercial reo Māori resources to fill the gap - if they have adequate budget.

\subsubsection{Budget}

In respect of commercial resources, there are sales representatives who go into schools. Jamie stated she would find it helpful if these people proactively promoted Māori language books - especially those that provide quality learning and value for money. Currently, Māori resources seem to be absent from their kete ${ }^{166}$.

In schools where there is no budget to buy commercial Māori language materials, teachers make their own. This point is borne out in research by Core (2018), where the findings of a teacher survey revealed that teacher-made resources were the most common of all reo Māori resources used in the classroom. Indeed, Jamie commented about having to personally make Māori language resources, due to the cost of buying commercial ones (and the lack of reo Māori books available through the sales representatives visiting schools).

Jamie also highlighted the lack of price relativity across resources in different curriculum areas, such that Māori language resources were reportedly dearer: "They're actually a lot more expensive to buy than English resources - not sure what that's about." The price differential could well be due to cost efficiencies. For example, it is cheaper for a publisher to do a large print run for an English resource, confident that there will be a demand from teachers, due to English being a core curriculum subject. In contrast, there is likely to be less demand for a Māori language resource - such that publishers are unable to benefit from any cost efficiencies associated with a large print run, so the cost price per unit rises commensurately.

${ }^{166}$ Basket 
Jamie raised another issue too; namely, the inequity between the availability of Māori language resources in Māori-medium settings compared with English-medium settings:

"Why aren't we getting stuff? We don't need to have readers at every level. But what we need to have is the big books. The inequality when it comes to the sharing of resources between the two [settings] is crazy. If they want me to teach Māori, I need to have the resources - it's as simple as that."

She makes a valid point in that most Māori students are being educated in English-medium schools - too many of whom are deemed to be priority learners, and all of whom deserve to have quality, affordable resources to access their heritage language.

\subsubsection{Correlation between te reo in the classroom and Māori student}

\section{achievement}

In terms of a possible relationship between Māori students' exposure to their language at school, and their resultant achievement, Jamie believes that:

“... if their language is nurtured, and is seen as important, it can only have positive repercussions. They will value themselves and therefore they will make a better effort, because they see they are being valued by someone else. If we do that ... it's going to make a better person because ... they were valued, they were believed in. If they have all of that, then they will pass that down to their children - and that's what we want. We want Māori to go from strength to strength."

Jamie's comments show that she acknowledges the relationship between a student feeling valued at school, and their resultant efforts leading to achievement. She also recognises the importance of inter-generational transmission, if te reo Māori is to be healthy and grow.

Teachers could help to bring positive changes in Māori student achievement by valuing the language, culture and identity of Māori students. This is one of the guiding principles in the Ministry's Māori education strategy, Ka Hikitia (Ministry of Education, 2013). The strategy stresses that Māori students are more likely to achieve if they can see themselves, their experiences and their knowledge reflected in the classroom. Similarly, as already stated, studies by the likes of Menard-Warwick (2009), Norton (2013), and Seals and Peyton (2016) highlight the correlation between a student's identity being affirmed and 
subsequent academic achievement. This point is emphasised by Professor Mason Durie in the following statement (Ministry of Education, 2007, p. 50):

"If education is going to be meaningful, people have got to be able to interprete it from their own worldviews. And that essentially means that culture is integral to learning. If you leave a cultural perspective out of the learning process, then it's cerebral learning, which doesn't touch the heart."

Hence the need for teachers to validate and nurture the cultural capital that Māori students bring to the classroom, so that they can enjoy academic success as Māori - as expressed in the vision of Ka Hikitia (Ministry of Education, 2013).

\subsubsection{Overview of Jamie}

Jamie's own schooling experience, and her family's attitudes, initially caused Jamie to view Māori language and culture in a negative light. At school she was denied entry to kapa haka, and at home she was exposed to racist comments about Māori. Over time, and because of her becoming a teacher, she has been able to cast aside this negativity. As such, she now embraces Māori language and culture - and students' right to access those dimensions. Although herself monolingual, Jamie validates students in her class who know two (or more) languages, and she acknowledges the benefits of being bilingual.

Jamie admits that the biggest obstacle in using Māori language in the classroom is her lack of proficiency. She is open to learning but finds it difficult. Moreover, only one PD course has been successful in accommmodating the needs of English medium teachers like her. Jamie is reluctant to support compulsory Māori language in schools, due to teachers' current low proficiency in te reo Māori. She believes it would be an unfair and impractical expectation. She is, however, prepared to be a learner of Māori language in her classroom, thus demonstrating ako. In this way she is an exemplar to students, communicating the message that learning Māori is worthwhile.

Jamie believes that school leaders need to do more to support, and praise, teachers' efforts in building their Māori language programme - such that the status of Māori language is comparable with other subjects. She questions the lack of time and money allocated to Māori language in schools. In the case of the latter, Jamie raises the anomaly of price relativity (i.e. Māori language resources reportedly being more expensive than resources 
in different curriculum areas). Furthermore, she perceives an inequity in the volume of Māori language resources produced for Māori-medium students as compared with English-medium students.

During my observations, there was only one Māori language resource visible in Jamie's classroom. She has been frustrated by the difficulty level of the Ministry's Māori language readers over the years. However, she has used the Ministry's multimedia resource for Year 1-6, He Reo Tupu, which she finds to be user-friendly. Jamie reported also using a teacher-driven site called Twinkl to source resources that are designed for teachers by teachers. She is keen to see the development of big bilingual readers with simple, manageable language and quality illustrations. She also sees a need for resources that develop students' local knowledge and strengthen their identity. She regards a quality Māori language resource as having multimedia components, being user-friendly, and including a translation or glossary.

\subsection{Jordan}

Jordan is a teacher of Year 5-6 students (approximately 9-11 years old) in a school in the Wellington region (decile 8-10, with a roll of nearly 400 students, $12 \%$ of whom are Māori). He sits within the 35-44 age range, and has 6-10 years' teaching experience. There were 27 students in his class at the time of my observations; namely, 11 NZ European, 11 Asian, 3 Māori and 2 Samoan.

Jordan appreciates the benefits of bilingualism, hence his enthusiasm about teaching te reo Māori. Furthermore, he has no inhibitions about his not being Māori and is open to seeking advice from others. Jordan is cognisant of the need to redress historical wrongs. And, like Ainsley, he sees te reo Māori as part of NZ culture and identity. There is further discussion of these aspects below.

\subsubsection{Beliefs about te reo Māori}

Jordan believes that Māori language is important; it is part of NZ identity. Although aware of negative societal attitudes towards the language, he is open to learning and teaching it. He does not view his being non-Māori as a barrier to using the language in the classroom. His beliefs are further fleshed out below. 


\subsubsection{Advantages of bilingualism}

When asked about the importance (or not) of the teaching and learning of te reo Māori, Jordan expressed a very positive view. Moreover, he communicated that he enjoys the cognitive challenge of learning te reo Māori: "It's good for the brains to have that extra sort of thing." This comment aligns with seminal research among French-speaking children in Montreal on the advantages of bilingualism - as evidenced in a battery of tests (Peal and Lambert, 1962). The researchers concluded that bilingual children were advantaged in terms of concept formation and mental flexibility (e.g. the ability to process information and adapt to ongoing changes). Subsequent research has confirmed that second language learning stimulates neural pathways, facilitates high-level thinking, increases mental dexterity, supports multi-tasking, and encourages sustained attention and perceptual awareness (Treffers-Daller et al., 2018; Bialystok and Majumder, 1998; Bialystok, 2011; May, Hill and Tiakiwai, 2004). These are all dispositions that contribute to academic success and sustained cognitive performance in life - which in turn is a predictor of longterm wellbeing/hauora. Such findings support the views espoused by Māori academic, Professor Mason Durie (2003), who highlighted the importance of te reo Māori as a contributor to hauora (as outlined earlier in this chapter, in relation to Ainsley) i.e. he momo rongoā te reo ${ }^{167}$.

Jordan uses te reo Māori in everyday life with his own children, supported by his wife, as evidenced in this comment about it being normal in their whānau:

"We do it all the time, little words - like we're on the bus and say 'kia ora'. My wife does it as well. She is like me in that way ... in our acceptance and trying to push the language."

It is evident from his reference to the 'little words' they use that Jordan is proactively qualifying his restricted use of te reo Māori in a public forum - to show that his whānau are making a visible contribution, albeit small. He and his wife are attempting to normalise the use of Māori language with their children, by applying it in everyday life. At the same time, however, it is likely that Jordan recognises he could do more to demonstrate his stated positivity about Māori language and its revitalisation.

${ }^{167}$ The language is a type of medicine 


\subsubsection{Non-Māori teachers}

While there are many non-Māori learners of te reo Māori who are constantly trying to ensure they are using te reo appropriately, and self-reflecting on that, Jordan has few concerns about the fact that he is a non-Māori teaching te reo in the classroom:

"I don't worry about that too much, because I think that's a big barrier to so many people. There was a teacher who used to get so panicky and flustered. I don't worry if I get it wrong; there's learning in that. I really want to get it right but, if I don't, I will go away and correct it."

Jordan's comment highlights how some teachers may be immobilised, in terms of using Māori language in the classroom, due to their not being Māori - and therefore having no feelings of ownership or entitlement (Barr and Seals, 2018). They can feel awkward, believing that their efforts are contrived and unnatural. Jordan is at the other end of the continuum. He feels comfortable taking the plunge, despite being non-Māori. His philosophy is to 'give it a go'. Notwithstanding, he states that he is open to learning from his mistakes, and to being helped/ corrected.

\subsubsection{Openness to learning}

Jordan particularly relies on a Māori friend (also a teacher, but in a different school) for advice on tikanga. He seeks guidance by asking questions like: 'What would I do in this situation? How would I follow protocol if this was happening?' This demonstrates Jordan's awareness of the gaps in his knowledge - and his openness to learning, in terms of finding out about correct procedures and processes associated with kaupapa Māori. It also highlights his recognition of the need to behave in the correct way (according to tikanga ${ }^{168}$ ) when in another cultural milieu; namely, te ao Māori. Jordan's Māori friend is a sounding board for what Jordan describes as “... bigger picture stuff, more than about the language." This suggests that he seeks out opportunities to engage in open conversations about issues facing Māori in NZ society, in order to enhance his understanding of another world view.

\subsubsection{New Zealand identity - and redress of wrongs}

Like Ainsley, Jordan is motivated to teach the language because it is part of New Zealand's culture, as evident in this statement:

\footnotetext{
168 The essence of the word 'tikanga' is derived from 'tika' meaning right/correct
} 
"I think it's a massive part of who we are as a country. It's an acceptance that it's part of NZ."

Jordan's appreciation of te reo as an integral aspect of NZ identity is accompanied by his awareness of historical grievances, and the need for us to take action to redress those ills. He expresses a vision:

"To try and fix it all up and say sorry ... and get a new generation to be more accepting."

In expressing this vision, Jordan demonstrates empathy for the cumulative unfairness that has contributed to the demise of the Māori language in Aotearoa NZ. Moreover, he is committed to making things better in the future - starting where he has some influence; namely, in his classroom and at home with whānau.

\subsubsection{Motivation}

Interestingly, in the interview, Jordan stated that performance appraisal was not a motivating factor in his learning of Māori language: "Not at all. I'm not showing off. I don't do it for that. It's something I need to improve on. It's about the kids in front of me." That is, his verbal comments indicated categorically that he saw no relationship between his pursuit of te reo and the positive implication thereof in terms of favourable feedback during staff appraisal. However, in his online questionnaire, Jordan stated the belief that performance appraisal was indeed a motivating factor in his learning of Māori. This inconsistency may be due to Jordan trying to save face in the kanohi ki te kanohi interview situation with me, having previously known me in my professional capacity as a Māori language adviser in schools.

\subsubsection{Negative societal attitudes}

Regardless, Jordan believes that the teaching of Māori language is not done well in NZ schools - and that most teachers are not doing enough in the classroom. He attributes this to some teachers (and parents) having difficulty accepting other cultures, while others are influenced by certain societal attitudes where things associated with Māori have low status. This is evidenced in Jordan's comment about there being “... a general societal barrier, looking down perhaps on Māoridom; and I think that can transfer through kids, and through mums and dads." 
This comment about the inter-generational transmission of negative attitudes towards things Māori reflects his awareness (like Jamie) of an element of racial intolerance prevalent in NZ society - which can make the teaching and learning of Māori language in English-medium primary classrooms more difficult to embed. Jordan confides that, even today among his friends and parents' associates, there are comments like 'bloody Māoris' in response to certain news items on the TV.

To illustrate this element of societal bias, Jordan refers to the current public debate about the use of Māori language in mainstream media - where some New Zealanders (like the former MP, Don Brash) have complained about simple greetings in Māori being used at the start of a programme (as is the practice of non-Māori broadcasters, Guyon Espiner and Jack Tame). As Jordan points out:

"Some people are resistant to learning te reo, and .... hearing 'kia ora' on the news."

This comment about negative societal attitudes draws attention to the uphill battle ahead for Māori language revitalisation, in terms of trying to promote the use of the language in wider society (including schools) - in the face of intolerance and resistance when even a smidgen of Māori is spoken.

\subsubsection{Influencing factors - prior experiences}

Jordan's responses suggest that his previous experiences learning te reo Māori have not markedly influenced his teaching of the language. The main influence for him is his passion for IT integration into all aspects of classroom learning. His views are further discussed below.

\subsubsection{Regional variations}

Jordan's potential influences, in terms of Māori language exposure, have been many. Initially he was introduced to te reo Māori (albeit mainly through waiata and haka) at a primary school in a NZ province with a high Māori population. Because of this upbringing, he is aware of, and sensitive to, regional variations of Māori language.

"There's different dialects, and that made me much more aware that there are those differences, and how they fit together, and how everyone's protocol fits together." 
Jordan's appreciation of iwi-specific characteristics (in terms of different pronunciation, spellings, word meanings, or tikanga) would be unfamiliar to most English-medium teachers with whom I have worked. They are unlikely to recognise how important these variations are to individual iwi in terms of denoting a point of difference that they want to maintain as part of their uniqueness. An awareness of such regional variations would be helpful to teachers in terms of building relationships with local iwi and trying to accommodate their unique linguistic and cultural differences in the classroom. This knowledge would also be helpful when teachers are using local resources.

\subsubsection{Learning te reo Māori in adolescence}

Interestingly, whilst Jordan was still at school, in Years 12 and 13, his non-Māori father decided to go to night school to learn Māori. Because of Jordan's intention to become a teacher, his father encouraged Jordan to accompany him - knowing it would be useful in teaching. The emphasis at night school was on oral communication - which Jordan (being a shy teenager) found difficult and embarrassing at the time. However, with practice, he improved orally. And it turned out to be a good foundation for his subsequent full year introductory course in te reo Māori at university. However, despite his learning gains, Jordan did not re-enrol for a second year of Māori. Since then, he feels that his use of the language has plateaued, and that he has not developed beyond the basics.

\subsubsection{Teacher education}

After university and time overseas (which included the learning of Korean as a second language), Jordan enrolled in a pre-service teacher education programme for graduates in NZ, to become a primary school teacher. Unfortunately, there was very little Māori language content during that one-year course. Consequently, his knowledge remained at a basic level. However, in his first few years of teaching, he was appointed to a school where staff received Māori language PD on an ongoing basis, sustained over three years. Jordan was very receptive to this $\mathrm{PD}$ - both personally and professionally:

"It was my passion .... so that I could teach the kids more than colours and numbers."

Jordan makes clear his desire to take children beyond the same content that they are typically exposed to each year in NZ classrooms; that is, the topics that teachers feel 'safe' delivering (irrespective of their class level). He reports that he is motivated to do more. 
He believes that the PD mentioned above, delivered by an external facilitator in his previous school, influenced all the teachers at that school - not just himself:

"When Liz [pseudonym] came in, it changed the way that our school saw te reo Māori. It completely changed it - our whole outlook on it. It made it visible, made it out there. The community was involved. We got the whānau group up and running. To have that accessible for everyone would be amazing."

In these comments, Jordan emphasises the importance of quality PD to create school-wide change - so that all teachers gain the necessary confidence, and reo Māori competence, to use the language in their classroom. Moreover, through such PD, they learn to appreciate the benefits of te reo Māori for Māori students specifically (as part of their Māori identity), and other students too (as part of their NZ identity). Importantly, in such an environment where PD is implemented successfully, and there is demonstrable classroom transfer, Māori whānau would more likely become engaged in the process - which is one of the Ministry's criteria for Māori student success. Because of this, Jordan is keen to establish a whānau group in his current school, based on his positive experiences at his former school.

\subsubsection{Influence of prior learning on current Māori language teaching}

Although positive about his prior experiences learning Māori, Jordan is unsure whether those experiences influence the way he now teaches the language. He says:

"I guess it does a little bit, but my teaching style is about figuring out what the kids need and their background, and what they've got - so I can adapt what I think is necessary. I don't recall whether I was taught like that."

This comment suggests that Jordan is more focused on student-centred learning of Māori than a specific method of teaching the language based on his own experiences as a learner of te reo.

In his student-centred approach, he tries to maximise the use of IT - even though he himself was not taught Māori that way. This aspect of his teaching is not only a personal interest and strength of Jordan's, but a focus of the school where he is currently teaching:

"Everyone's into their computers. That works well for me, and that's the kids' motivation; they love that sort of stuff." 
Jordan's teaching context (where IT is a specific area of focus), combined with his personal strength in IT, explains why he is keen to see the development of interactive Māori resources - the likes of which he has started to create, to build up his students' Māori vocabulary knowledge. To do this, he uses Kahoot - a free, fun, games-based learning platform where teachers and students can quickly create learning games to use on their devices. Jordan envisages that, in the future, students will be able to develop their own oral quizzes for te reo Māori - and programme them to test pronunciation:

"Having the kids being able to interact and listen. And make it more individual. I'd like to hear a sentence and have a child be able to answer that - and the computer hears it and checks it out."

Jordan's comments suggest a preference for resources that promote learner autonomy. This aligns with the 'inquiry' approach to teaching and learning in NZ primary schools, where students are self-motivated out of curiosity and take ownership of their learning (ERO, 2011; Ministry of Education, 2007; Sercu and St. John, 2007).

\subsubsection{Ako in the classroom}

Although Jordan feels there has been a 'drop off' in his use of te reo, due to the lack of Māori language PD in his current school, he tries to normalise the language in his classroom by introducing new words or phrases. All classes in his syndicate learn a 'Māori word of the week' - an initiative set up in fact by one of his Māori students. According to Jordan, this student is one of few Māori students who expresses an interest in te reo. Jordan tries to satisfy this student's curiosity about the language by seeking out knowledge from the web, which increases his own learning too. This is a good example of ako - where the teacher is open to being a learner.

Jordan favours student learning that goes beyond individual words or small phrases. Hence his desire for resources that provide students with sentence-based input. This is a worthwhile goal, as it would pave the way for more genuine communication in te reo Māori. At the same time though, it would be demanding for most English-medium primary teachers. Indeed, a survey by NZCER, for the Ministry's NMSSA project, found that although most of the primary teacher respondents claimed they were using Māori in the classroom, the level of reo was very basic - usually restricted to individual words and 
formulaic, rote-learnt phrases (Ministry of Education, 2018). Research by Haemata (2019) produced similar findings.

To facilitate authentic communication would require a level of Māori language that goes beyond the current proficiency level of most primary teachers. Quality Māori language resources, accompanied by PD that is designed specifically to upskill proficiency (and provide the theoretical knowledge associated with second language acquisition), would go a long way to remedy the situation.

\subsubsection{Influencing factors - lack of proficiency}

In the online questionnaire (Question 40, Appendix 5), Jordan self-rated his speaking ability in te reo Māori as basic. He admits that his lack of proficiency is a barrier to applying the language in the classroom but lauds the benefits of second language learning per se especially in terms of cognitive development and acceptance of difference. However, he acknowledges that learning a second language is difficult - based on his own experience learning Korean, which gave him an appreciation of the effort required to learn a second language.

His plea is for English-medium primary teachers to receive more PD input around te reo Māori, to increase their comfort level when using the language in the classroom. His reason for having self-rated his own comfort level as being 'neutral' (in the online questionnaire - Question 39, Appendix 5) was because of his awareness of the need to learn more. That is, like the students whom he teaches, he believes that he is a learner (which is congruent with the concept of ako). He confides that there are times when he feels like a fraud - when, because of his prior learning experiences, his colleagues have high expectations of his Māori language ability:

"I feel like a bit of a fake at times, when people say, 'You are this amazing te reo speaker', and I hardly know anything. I have a basic idea, but I don't know enough.”

Clearly the weight of other people's expectations can be problematic for Jordan, as they are for Ainsley. Both teachers seem unable to fully acknowledge their achievements in learning some Māori (albeit basic, but more than most of their peers). They remain anxious that they may be exposed for being phony, as described in research around the psychological phenomenon of the imposter syndrome (Vergauwe, Wille, Feys, de Fruyt 
and Anseel, 2015; Sakulku and Alexander, 2011). In Jordan's case, he is all too aware of the limitations of his Māori language proficiency and is perturbed when others have an over-inflated estimation thereof. His feelings of inadequacy and self-doubt are likely to be exacerbated by his own admission that he has regressed since changing schools, due to no longer being a recipient of quality Māori language PD.

\subsubsection{Influencing factors - insufficient time and budget}

Like Ainsley and Jamie, Jordan believes that the biggest barrier to using Māori language in the classroom is time - due to the focus, hitherto (pre-2018), on National Standards in reading, writing, and maths. Jordan highlights the dilemma that he and his colleagues face trying to fit te reo Māori into a very crowded curriculum:

"It's the time, and not being able to fit it in. And, that's everything. And, the massive focus on the National Standards. Your reading, your writing, and your maths. Those are the ones that are deemed to be, or seem to be, the more important things to focus on. So, our week is reading, writing, and maths. The programme is tight, and I struggle to get through my reading groups...We're really struggling to fit everything in.”

It is evident that Māori language is one of the things being squeezed in, due to competing priorities - especially with subjects like literacy and numeracy that neccesarily retain their status. Research has verified that teachers are time-poor, which effects their teaching of te reo Māori (Ministry of Education, 2017). Because of this, they want reources that are ready to use across different reo Māori abilities, without any need for 'assembly' (e.g. copying, printing, cutting, gluing, laminating, etc).

Jordan reports that a shortage of time and money has prevented Māori language PD in his current school. However, the school has managed to find a small budget to secure the specialist services of a kapa haka tutor. This avenue would seem to be the main conduit at Jordan's school for students to access Māori language. The NMSSA findings (Ministry of Education, 2018, p. 76) confirm the importance of kapa haka. Indeed, singing waiata and participating in kapa haka were two of the three most popular ways (in addition to karakia) for the English-medium teachers in that study to expose Year 4 and Year 8 students to te reo Māori. Furthermore, the teachers who were interviewed in research conducted by the Ministry of Education (2017) and Haemata (2019) confirmed that kapa haka was an 
important entry point for both students and teachers to engage with te reo Māori and develop positive attidudes towards the language. Research participants believed that kapa was enjoyable, helped with pronunciation, and built up confidence to use the language.

\subsubsection{Influencing factors - support (or not) from parents}

Jordan could provide no evidence of parents at the school being forthcoming with positive views about the inclusion of te reo Māori in their children's education. At the same time, however, there had been no 'push-back' from them in terms of Māori language teaching and learning. Jordan attributes this to the school being situated in a diverse community, which creates an environment where difference is accepted - or at least tolerated:

"I think they are receptive to it because of the community being quite diverse - at least on the surface."

His qualified phrase at the end of the above quote suggests that there may indeed be negative undertones among the parents. But they choose to keep these thoughts in check either to avoid confrontation or to maintain a degree of political correctness and social acceptability.

\subsubsection{Resources}

Jordan mainly uses one Ministry resource, Не Reo Tupu, but bemoans having to 'make up' some of its components. His main priority is to have Māori resources that integrate IT. Like Ainsley and Jamie, he is very keen for local resources to be developed - to add relevance for his students. These aspects are further discussed below.

\subsubsection{What constitutes a quality Māori language resource?}

Jordan's top three characteristics of quality Māori language resources (according to his rankings in the online questionnaire - see Question 28 in Appendix 5) are that they should:

- exemplify real-life contexts (to enable students to identify with the content)

- $\quad$ include an English translation or glossary (to ensure the correct meaning of te reo is communicated)

- $\quad$ be user-friendly (to allow for easy access e.g. no cutting or laminating). 
In terms of visible Māori language resources in Jordan's classroom, there was a set of small flashcards and accompanying Bingo cards from the Ministry resource He Reo Tupu, which he used to teach the Māori words for classroom objects. Also visible were examples of some students' guided writing (in English) based on a Māori place-based kaupapa i.e. 'Tūrangawaewae - This is where I stand' (as already discussed in Chapter 5).

\subsubsection{Use of Ministry resources}

Jordan acknowledged never having used most of the Ministry's free resources depicted in my online questionnaire - except for the aforementioned multimedia resource He Reo Tupu (which he used 'always)', and the waiata resource Hei Waiata Hei Whakakoakoa (which he used 'about half the time'). This was consistent with his responses in the online questionnaire (Questions 31 and 33 respectively, Appendix 5). Like Ainsley and Jamie, Jordan was especially enthusiastic about the child-friendly animations in He Reo Tupu, and the ease of assessment practices therein due to the inclusion of rubrics with learning intentions.

During PD at his former school, Jordan was introduced to the Māori language curriculum guidelines, Te Aho Arataki Marau (2009), and a video clip from the DVD First Class (showing task-based teaching and learning in NZ classrooms, Years 5-9). While he appreciates the background and underlying theory espoused in these two Ministry resources, especially the historical significance of the Māori language and the need for second language learning to be interactive, he prefers to use 'hands-on' resources like the multimedia and waiata resources mentioned above (i.e. He Reo Tupu and Hei Waiata Hei Whakakoakoa).

As for Māori language readers in his school, they reside in a cupboard, largely unused, because they do not match the needs or interests of the students. Jordan dismissed these Ministry readers as being too difficult, or uninteresting, for his students: "Content-wise, no one wants to read about it." This suggests that, in the main, there is a mismatch between the real lives and interests of his English-medium primary school students and the kaupapa featured in the Ministry's Māori language readers. Moreover, there is also a mismatch between the students' level of reo Māori and the language in the readers.

Jordan said he was keen to explore the new bilingual readers, Arahia Books, which I had presented as a koha for his participation in the research - in the interests of tauutuutu. He 
was open to using these readers because they are targetted at English-medium primary students and teachers, have accompanying teachers' notes written specifically for that audience, and are aligned to the Ministry's Māori language curriculum (Te Aho Arataki Marau) and its associated multimedia resource for Year 1-6 (He Reo Tupu), with which he is already familiar.

\subsubsection{Future resource needs}

Regarding the future development of resources for the teaching and learning of te reo Māori, Jordan believes there is a need for materials that accommodate a teacher's professional and personal needs, as outlined below.

\subsection{Online resources}

Jordan's priority is to see the development of more interactive online materials to improve students' vocabulary knowledge and pronunciation. This is no doubt partly due to his predisposition to, and comfort levels with, IT. It is also partly due to his students' ready uptake of technology, as digital natives. He envisages these types of materials being used by teachers on their interactive whiteboards or, alternatively, by students on their personal devices.

\subsection{Print resources}

In terms of print resources, his plea is “... make it easy for me.” That is, he wants Māori language games and activities, as found in the Ministry's multimedia resource He Reo Tupu (2011), to be pre-cut and laminated or magnetised - to save the teacher having to spend precious time doing this:

“He Reo Tuри He Reo Ora is fantastic, but it's so much work. We're time poor."

While he acknowledges the benefits of the different components in He Reo Tuри (e.g. second language tasks; resource sheets to support the tasks; assessment rubrics; tikanga; and animations), Jordan reiterates his opposition to having to personally make up the resources from templates. This is because it erodes his time for planning and face-to-face work with students. As mentioned earlier in Chapter 4, teacher participants in research conducted by the Ministry of Education (2017) were of the same opinion - that, due to time pressures, it was futile to provide them with resources that needed assembly. 


\subsection{Local resources}

Like Ainsley and Jamie, Jordan makes a plea for local resources to be developed - to align with most schools' inquiry at the beginning of each year around the theme of 'our place/our tūrangawaewae/our community'. He stresses the difficulty of imparting to students the concept of a pepeha if, in their local area, there are no visible land features to relate to nor a marae or known kaumātua ${ }^{169}$ to seek advice from:

"One of the problems for me ... is explaining concepts like ... your mountain and ... your water. Even I struggle with that a little bit. I don't have a connection to a piece of land. That's a really tricky one to get across, i.e. where I'm from, as a white person. Kids don't relate to having a mountain that you're living under the shadow of."

In this comment, Jordan no doubt echoes the sentiments of many non-Māori teachers who are faced with the expectation of communicating to students the concept of pepeha and tūrangawaewae, as a way of introducing themselves - usually at the beginning of each school year. It is difficult for them trying to convey another world view, without having had the relevant experience in te ao Māori, which would help them to contextualise another perspective - a perspective that lays much store on the importance of land.

Jordan specifies what would be particularly useful for his school; namely:

"A brief outline of the northern cluster's history; tribes that lived here, food, local pepeha, what this place was."

This kind of information would clearly be helpful to schools trying to acknowledge the tangata whenua in the area. The Ministry's current focus on producing local Māori stories in a variety of media, through its initiative Te Aho Ngārahu, will help teachers and students. It is anticipated that some of these resources will explore local landmarks that schools can incorporate into their respective pepeha. Others are likely to feature events, famous people, legends, and history associated with a specific area.

${ }^{169}$ Elder/s 


\subsubsection{Correlation between te reo in the classroom and Māori student}

\section{achievement}

Jordan believes that his use of te reo is a way of validating Māori students at the school, in terms of affirming their identity:

"I think whenever you are validated ... you're always going to feel more comforted or accepted. Because they're able to see me giving it a go, I think they would feel much more comfortable ... and would then try and succeed."

These comments suggest that Jordan acknowledges the impact on students' comfort levels when they feel that their language is valued (Menard-Warwick, 2009; Norton, 2013; Seals and Peyton, 2016) - as demonstrated by teachers' visible use of the language. He also highlights the value of the concept ako, which legitimises the teacher being a learner too. Jordan believes that this position of humility should have a spin-off to his students, encouraging them to give te reo Māori a go - like him. He reports, however, that the Māori students at his high decile school seem to have little awareness of taha Māori ${ }^{170}$ - due to their lack of exposure, apart from attendance at significant Māori events: "There may be the odd tangi or hui... but not a great deal of the language stuff ....". It would seem from this comment that Jordan, like the external kapa haka tutor at his school, is potentially a key conduit and Māori language exemplar for his students. As such, his level of proficiency has implications for their learning of te reo. That is, if his Māori language ability grows, he will be able to commensurately extend his students beyond the basics.

Jordan shared one example of how his use of te reo is helping him to connect with an able, but relatively disengaged, Māori student who is often late (or absent) and is underachieving. This student was what could be described as a tutū $\bar{u}^{171}$ (not dissimilar to Māui, the character in Māori mythology famous for his mischievous exploits). Jordan uses te reo to build a relationship with this student and help define acceptable levels of behaviour in the classroom. In the context of the student's swearing for example, he explains to the student:

"You've got your tikanga at home; and your tikanga at school."

\footnotetext{
${ }^{170}$ A Māori perspective

${ }^{171}$ Mischievous, disobedient
} 
Jordan's use of the Māori word 'tikanga' is apt - and more culturally relevant for the student. Jordan successfully communicates that there is a right and appropriate way of behaving in the classroom, which may be different to norms of behaviour at home. Jordan tackles the issue using a 'mana-enhancing' approach (Irwin, 2017), to keep the student's pride and self-worth intact. This augurs well for a sustained relationship. That is, the shared understanding of tikanga between Jordan and this student has contributed to a connection between the two, thus creating a good platform for learning.

Indeed, Jordan's relationship-building with this student is helping to address the issue of previous under-achievement:

"I am trying to get a bond with him to try and help. I am trying to make that connection with him, to try and encourage him to do the best he can ... to help him succeed. It's the relationship that is key."

Jordan's comments exemplify the spirit of the Ministry's Māori education strategy, $K a$ Hikitia, in terms of building a relationship with Māori students (whakawhanaungatanga) and acknowledging Māori students' inherent potential (te uri o māia), which is too often untapped.

Jordan is putting into practice the vision behind the Ministry's strategy; namely, that Māori students should enjoy and achieve educational success as Māori. As already discussed, the two underlined words are important because the vision goes beyond educational achievement; it stresses the importance of students retaining their Māori essence along the way (i.e. their culture, language and identity) - as emphasised by Durie (2003).

\subsubsection{Overview of Jordan}

Jordan believes that Māori language is important, because it is part of NZ identity. He is open to learning the language and teaching it - and doesn't believe that being non-Māori is a barrier to using the language in the classroom. Moreover, he enjoys the cognitive challenge of learning Māori as a second language and is open to learning from others. He seeks out people who can plug the gaps in his knowledge - especially cultural knowledge.

Jordan's previous experiences as a child and adolescent, growing up in a NZ province with a high Māori population, influenced his receptivity towards Māori language and 
culture. This was cemented during a full year introductory course in Māori at university, prior to his becoming a teacher. Another influential experience was his learning of Korean as a second language whilst overseas. Jordan acknowledges the benefits of second language learning, despite the associated difficulties.

He was also influenced by a three-year PD opportunity in his previous school. It built up his confidence and competence, motivating him to go beyond the basic, 'safe' content that is so prevalent in NZ primary schools (e.g. colours and numbers). Since the termination of that PD a few years ago though, Jordan feels that his Māori language ability has regressed.

However, he has maintained his positive attitude towards the language and culture. Notwithstanding, Jordan is very aware of the negative attitudes that persist, intergenerationally, in today's society - even amongst his own, and parents', friends. Being informed about historical grievances and the unfair treatment of Māori, Jordan is committed to making things better in the future, starting in the classroom where he has some influence.

Jordan admits to never having used most of the Ministry's free resources that were outlined in my questionnaire (Appendix 5). For example, Māori language readers sent by the Ministry to his school remain in a cupboard, largely unused, because they do not match the needs of English medium students and teachers. However, Jordan reportedly 'always' uses the Ministry's multimedia resource He Reo Tupu (although he resents having to spend time making up some of its components). During my observations, Jordan used flashcards and bingo cards from that resource. In addition, he uses the waiata resource Hei Waiata Hei Whakakoakoa 'about half the time'.

Jordan is keen to see the development of interactive Māori resources - similar to Kahoot. He regards a quality Māori language resource as being one that exemplifies real life contexts and is user-friendly, with an English translation or glossary. He sees a need for local resources to be developed around the theme of our place/ tūrangawaewae. Such resources would emphasise the importance of the land, while making it easier for nonMāori teachers to communicate the concept of pepeha. 
Jordan believes that the biggest barrier to his use of Māori language in the classroom is having the time to do so within the crowded curriculum. In addition to the lack of time, he highlights the poor resourcing for Māori language in his current school - such that kapa haka is the main conduit for te reo, by default. Jordan acknowledges that exposing Māori students to their heritage language at school is a way of building a genuine relationship, and validating their culture and identity - as well as contributing to their overall achievement.

\subsection{Delta}

Delta is a teacher of Year 5-6 students (approximately 9-11 years old) in a Wellington school (decile 4-7, with a roll of nearly 250 students, $23 \%$ of whom are Māori). She sits within the 55-64 age range and has more than 16 years' teaching experience. At the time of my observations, there were 23 students in her class: 2 Pasifika, 3 Asian, 9 Māori, and 9 Pākehā.

\subsubsection{Beliefs about te reo Māori}

As outlined below, Delta believes that te reo Māori is part of NZ identity - and should be compulsory.

\subsubsection{New Zealand identity}

Delta believes that Māori language should be taught in NZ schools because of its significance for this country:

“It should be taught; ... it's just a part of who we are. It's an acknowledgement that we are New Zealanders."

Delta's use of the pronoun 'we' indicates a belief that te reo Māori is important for all New Zealanders, irrespective of ethnicity. Her usage suggests an aspect of inclusivity, as in the Māori word 'tātou'172, a pronoun that creates a sense of oneness and unity. Delta's stated belief is similar to the sentiment expressed by two other interviewees, Ainsley and Jordan, in terms of te reo Māori being an integral part of NZ identity. The significance of such views is underscored in the Māori language curriculum guidelines, Te Aho Arataki Marau,

${ }^{172} \mathrm{We} / \mathrm{us}$ (inclusive of speaker/writer and audience) 
published by the Ministry (2009, p. 12), which acknowledges that te reo is " ... a primary source of our nation's self-knowledge and identity....".

\subsubsection{Compulsory reo - or not?}

Delta expressed surprise at recent discussions in the media about whether the language should be taught in schools - because, in her mind, this has been a long-standing expectation. That is, she believes that the teaching and learning of te reo Māori in schools is not a recent phenomenon:

"The expectation that it will be taught has been around for a long time. In the media they're talking about should it be taught or not - and actually it's been happening for decades. I think the media get a hold of things and try to rark it up."

It seems likely that, in her 16+ years of experience, Delta has worked in schools that have endeavoured to include Māori language in their curriculum - hence her (erroneous) assumption that this is happening nationally. Moreover, her belief about the importance of te reo is bound to have contributed to her making the assumption about it being mandatory.

In her online questionnaire response (Question 21, Appendix 5), Delta expressed a belief that Māori language should be compulsory in schools. She reiterated this in our interview. As already stated, she was under the misapprehension that it already was compulsory - like in Wales (where students must learn Welsh at school, up until the age of 15/16):

"I thought it already was [compulsory]. You can only teach in Wales if you speak Welsh. They're strict about it, and they brought the language back."

Delta's comments highlight the successful history of language revival in Wales over the past four decades - largely due to the government policy making 'Welsh as a second language' compulsory in schools. Although this is a shining example for Aotearoa NZ, it is problematic to make a direct comparison because, unlike Māori people in this country, Welsh people constitute the majority in their country ${ }^{173}$.

The reality in NZ is that many teachers in English-medium primary schools continue to perpetuate a limited repertoire of colours, numbers, greetings and songs (irrespective of

\footnotetext{
${ }^{173}$ For more information on Welsh language learning in schools, and associated issues similar to NZ (e.g. insufficient time allocation; prominence of core subjects; lack of continuous PD; teachers' lack of confidence and proficiency), see Jones (2016)
} 
class levels). This is a situation that could be rectified if the teaching and learning of Māori language was normalised across all schools. That is, positive change would come from increased exposure to te reo Māori, which in turn would lead to acceptance of its enhanced profile in our schools.

\subsubsection{Influencing factors - prior experiences}

Delta has been influenced by her childhood and her tertiary studies - as outlined below.

\subsubsection{Childhood influences}

As a child, Delta was exposed to the Italian language. It was spoken around her by older family members. She built up some receptive knowledge of the language, by exposure, but developed little proficiency:

"My aunties and uncles used to speak it when I was little, but not now. I didn't learn much; they used it when they didn't want us to hear."

The fact that her relations excluded Delta (and her peers) from their conversations in Italian would have contributed to her non-acquisition of her heritage language. Despite having little proficiency though, she takes pride in her Italian heritage. Moreover, her receptive exposure to Italian will have undoubtedly helped in her endeavours to learn te reo Māori me ona tikanga - because of the similar vowel sounds, for example, and the commonalities in the two respective cultures (e.g. a mutual love of whānau, tūrangawaewae, kai, and waiata). Indeed, it was these commonalities that shaped the mutual respect and warm relationship between Māori Battalion soldiers in Italy during the Second World War and the many Italian whānau who embraced them.

\subsubsection{Impact of tertiary education}

Delta believes that, unlike many of her friends, she is open-minded about embracing Māori language. She attributes her relative openness to having gone to university, as a mature student. Prior to that experience, she had what she describes as a 'Pākehā view of the world' - a notion that implies a monocultural and monolingual bias, with one perspective only. Her attendance at university enabled her to see beyond that limited, and limiting, world view:

"I think it's because I went to university. When I'm with my friends, they have that middle-class Pākehā view, and we have big discussions around that." 
Clearly Delta has been influenced by her tertiary education. It has opened up another world for her to consider, enabling her to explore what is valued by the Indigenous people of Aotearoa NZ - including the taonga of te reo Māori. In contrast, friends in her own social grouping, which comprises professionals and business people, may have a restricted view emanating from their monocultural perspective on the world. Delta's ability to see another world view stimulates what she, euphemistically, describes as 'big discussions'. It is likely that these discussions manifest as different forms of debate, of varying intensity, where (at times) views may be polarised.

She comments retrospectively on a specific Māori lecturer during her teacher training who helped non-Māori teacher trainees like herself to explore Māori culture and Māori history:

"She sort of opened up our eyes to the positivity of Māori culture. I think that was the whole purpose of the course because a lot of Māori knowledge was acknowledged. There was a lot of knowledge in the Māori culture before the Pākehā came. We learnt the history of NZ, which was interesting."

Through this tikanga-based experience in her pre-service teacher education, Delta was able to appreciate the wealth and depth of mātauranga Māori prior to colonisation. This gave Delta a positive view of Māori culture and Māori people. Moreover, the experience allowed her to capture a glimpse of NZ history from a Māori perspective - a perspective that was hitherto unknown to her, although articulated in the first Teaching Standard about demonstrating a commitment to the partnership associated with the Treaty. As a teacher in her 50s, she muses on whether the younger generation of teachers may have an advantage over her, having been introduced to Māori language and culture at school - which was not the case during Delta's schooling.

\subsubsection{Influencing factors - lack of proficiency}

Delta's most pressing issue is pronunciation. She has benefited from PD in the past. But this is no longer available - so she is pursuing independent learning. These aspects are discussed further below.

\subsubsection{Pronunciation - an issue}

In the online questionnaire (Question 40, Appendix 5), Delta self-rated her speaking ability in te reo Māori as being 'limited'. Consequently, she declared that she felt 'somewhat 
uncomfortable' teaching Māori language - even though she had been using te reo in the classroom for years, having mistakenly believed it was indeed mandatory. For her, the most difficult aspect of teaching the language is pronouncing the words correctly, due to the influence of English. This is despite her exposure, in her formative years, to Italian - with its similar vowel sounds to Māori. She reports that she needs to encounter a Māori word many times before being able to replicate the correct pronunciation. Hence her use of the online Māori dictionary - because of its audio facility:

"I use that interactive website a lot, and I have to hear it again and again and again, maybe 20 times."

As in the case of Jamie, Delta's comments underscore the importance of a learner having repetitive exposure to the target language, on multiple occasions over time, if their learning is to advance (Ellis, 2005b; Schmitt, 2008). In my observations in Delta's classroom, I noticed that her students were using the same online dictionary as she was, to help their pronunciation. Delta has clearly modelled this behaviour for her students, such that they can now independently use the online dictionary - not only for pronunciation, but also for word meanings. This brings added value to the students in terms of building learner autonomy, where they are taking some responsibility for what and how they learn. It also suggests that they, like their teacher, are invested in the learning of te reo.

\subsubsection{Professional and personal development}

In terms of participating in PD targeted at improving teachers' Māori language ability, Delta has only had one such opportunity in her 16+ years of teaching. This was three years prior to her participation in my research - at a previous school where she taught. The PD was delivered by an external facilitator. Delta was fortunate at the time to have a young Māori colleague in her school who was proficient in te reo Māori. He provided her with on-hand support, especially in the form of Māori language games, which supplemented the external facilitator's PD input. However, she has since moved schools, and that support and mentoring is no longer available. Consequently, she has made the decision to learn te reo Māori independently - using the commercial publication Q's course in Māori (Hita, 2005). This publication, comprising a book and a $\mathrm{CD}$, includes pronunciation: “[I'm] trying to learn how to pronounce - and stuff like that." The initiative that she demonstrates in tackling the learning of te reo Māori, on her own, shows her keenness to improve her 
pronunciation and general proficiency, so that she can be a good Māori language model for her students - albeit at a basic level.

\subsubsection{Influencing factors - insufficient time}

Delta believes that she and her colleagues need to dedicate more time to Māori language planning - as part of their wider collaborative planning across the curriculum. Currently, te reo is not a focus in the school - although there are pockets of visibility. For example, the recitation of karakia after lunch has become the norm in one area of the school:

"It [te reo] doesn't seem to be one of the main focuses, I would say. I think we should consider Māori more in our planning. It must be integrated."

Delta's comments suggest that, if there was more deliberate and purposeful inclusion of Māori language during teachers' planning of other curriculum areas, the students would be exposed to more reo Māori. Furthermore, the content of the language would be more diverse and enriching for students - because of the specific linkages across the different learning areas (as noted earlier in this chapter, in my reference to CLIL).

To overcome the lack of Māori language planning at her school, Delta proposes a solution that she has experienced in other schools; namely (in her words) Māori rotations. This approach requires each teacher to choose an aspect of Māori language (or culture) that they will plan and deliver to all classes, on a rotational basis (e.g. te reo; poi; Māori art; stick games). Delta says:

"In other schools, we had Māori rotations which has been really good, because each teacher chooses their strength. The kids move around and they're getting different types of Māori."

She is enthusiastic about this approach because it allows for greater coverage of Māori language and culture for students. At the same time, it is relatively non-threatening and face-saving for teachers, because the selection of topics is based on teachers' personal interests or strengths. This means they are more likely to be invested in the teaching thereof. 


\subsubsection{Influencing factors - support (or not) from parents}

Delta reports that she has only experienced one dissenting voice amongst parents in respect of Māori language teaching and learning. She attributes this not to racism but to their lack of understanding of the 'bigger picture':

"I don't think it's racism; it's just ignorance. Broadening your world view is extending your thinking."

This comment is congruent with Delta's previous acknowledgement that tertiary study opened up another world view for her to appreciate. This in turn made her value the respective cultural backgrounds of her students, and the range of knowledge and experiences that they bring to the classroom. She recognises that others' views may be more restrictive, due to their limited life experiences.

\subsubsection{Resources}

Delta's comments on Māori language resources reflect her views on the paucity thereof. She has resorted to using Pinterest or making her own resources. In the future, she would like to see the development of posters, and the provision of equipment/materials associated with kapa haka. She also sees a need for resources featuring role models. These aspects are further discussed below.

\subsubsection{What constitutes a quality Māori language resource?}

Delta's top three characteristics of quality Māori language resources (according to her rankings in the online questionnaire - see Question 28 in Appendix 5) are that they should:

- $\quad$ have an audio component (to aid pronunciation);

- $\quad$ include an English translation (or glossary); and

- $\quad$ be user-friendly.

In terms of the visibility of Māori language resources in her classroom, there were posters about kōwhaiwhai ${ }^{174}$; labels on different classroom objects; wall displays showing Māori myths and legends; and children's stories about Māui ${ }^{175}$, as recounted by Māori storytellers.

\footnotetext{
${ }^{174}$ Painted rafter patterns

${ }^{175}$ A well-known character in Polynesian narratives
} 


\subsubsection{Knowing about resources}

Knowing about the existence of relevant resources is an issue identified by Delta. For example, at the beginning of the year, she was looking for a resource on pepeha, not realising that the Ministry had very recently published an instructional reader with that focus. Now that she is familiar with that resource, she is finding it easier to teach the concept of pepeha (as was evident during my observations). She emphasised the added value of the reader: "This was really good; this helped me a lot." But, had she not come across that specific junior journal, serendipitously, her introduction of the pepeha concept may have been superficial and lacking in depth. This points to a need for the Ministry to disseminate information about new or topic-specific resources - especially around popular Māori topics taught in most NZ schools (e.g. pepeha; whānau; kai; kaute; marae; huarere $\left.{ }^{176}\right)$.

During my interview, I had on hand the Ministry resources specified in my online questionnaire (Questions 30-35, Appendix 5). Delta was underwhelmed by the Ministry's meagre provision of resources to support the teaching and learning of Māori language in English-medium primary schools, saying, "It's not much is it?" At the same time, she acknowledged that she had never seen the Ministry's Māori language curriculum guidelines, Te Aho Arataki Marau (2009). However, she had used, and liked, the Ministry's multimedia resource He Rео Тири (2011), as verified in her online questionnaire response (Question 31, Appendix 5). This resource was introduced to her by the external PD facilitator at her previous school, three years prior. She used it 'most of the time' especially the flashcards.

\subsubsection{Making own resources}

In response to the aforementioned ignorance, or paucity, of resources to suit the needs of her English-medium students, Delta resorts to making her own miscellaneous selection of materials. This approach is congruent with findings from Core (2018), which showed that teachers were accustomed to creating or adapting new Māori language resources, in order to accommodate the needs of their diverse students. Delta says:

\footnotetext{
${ }^{176}$ Introducing oneself in terms of the land; family; food; counting; marae; weather
} 
"I'm used to just hunting and making. I have gathered a little thing of resources along the way. They're just bits and pieces. I've collected little gems that I like about...harakeke ${ }^{177}$ weaving. I love doing rākau ${ }^{178}$ with the kids."

These are cultural activities that Delta clearly enjoys facilitating in the classroom.

While imparting such aspects of tikanga, she is providing a potential conduit for te reo because of the language that is associated with such cultural activities. The use of harakeke, in particular, provides scope for teachers like Delta to facilitate students' deeper inquiry into such aspects as the extensive use of flax in traditional times, its medicinal properties, its harvesting (guided by conservation), the importance of associated karakia, and the analogy with whakapapa and whānau. There is therefore a need for resources that show non-Māori teachers how to maximise such opportunities for further learning in related curriculum areas. This would enable them, for example, to go beyond the practical 'how to' of weaving flax (e.g. in Art), to explore the underlying beliefs and values associated with this plant. Such resources would help to facilitate CLIL (discussed earlier in this chapter), with te reo being integrated naturally alongside wider curriculum content - thus increasing students' competence in the language (Coyle, 2007; Marsh, 1994; Cenoz et al., 2014).

Delta often turns to Pinterest - a social network where educators can share images and other media content to help in the teaching and learning of Māori language in the classroom:

"It's the resources, finding resources that are fit for the kids. There's a lot more that are on Pinterest now. A lot of people share things from websites on there. Lots of teachers use it, so if you're searching for something on Matariki, pictures come up for each resource that's there."

The benefit of Pinterest was also discussed in research conducted by Huia Publishers for the Ministry of Education (2017). They found it was a popular source of Māori language content in English-medium schools. Clearly, this is a useful social network for teachers when seeking resources to fill their needs in the classroom. They like the immediacy of

\footnotetext{
${ }^{177}$ Flax

${ }^{178}$ A game using wooden sticks thrown between participants, in time to a song, to develop suppleness and hand: eye coordination. The proper name is tī rākau
} 
Pinterest; it enables them to find the right resources, at the right time, without needing to spend too much time researching at length.

\subsubsection{Maintaining cultural safety}

For non-Māori teachers like Delta who are keen to facilitate cultural activities in the classroom, it is extremely important that aspects of cultural safety are embedded into the Māori language resources they use - so that they know how to properly care for te reo Māori me ōna tikanga. Moreover, while recognising the importance of privileging a Māori perspective, non-Māori teachers need to know how to keep themselves safe from potential criticism (e.g. from Māori parents/caregivers, and Māori language/culture advocates). Such criticism could arise if they were to delve superficially into tikanga Māori, into a world that is not their own, without fully appreciating the underlying significance thereof. Non-Māori teachers need information therefore that shows them how to enter this 'other' world with care and sensitivity - so that they understand, respect and honour the beliefs and values that underpin Māori cultural norms. An understanding of the kaupapa Māori principles that guide my research would be a good starting point.

\subsubsection{Future resources}

Delta had definite ideas about resources that need to be developed in the future particularly posters, and resources that align with the curriculum and feature Māori role models. These are discussed further below.

\subsection{Future resources aligning to the curriculum}

In terms of future Māori language resource development, Delta is keen to have resources “... that kind of link into the school curriculum." While this makes sense, it also poses a problem for resource developers (which teachers may not altogether appreciate) - in that, under the New Zealand Curriculum, each school has the flexibility to decide its own school curriculum and learning contexts (in consultation with its local community). Because of this, and the Ministry's promotion of inquiry learning, there is no fixed list of topics that resource developers can focus on. This is why the writer of He Reo Tupu (Ministry of Education, 2011) consulted primary teachers and advisers in English-medium schools, to determine eight general kaupapa likely to be covered in most English-medium schools; namely, Self and Family; Food; Numeration; Marae; Health; Celebrations; Sport; and Weather. 
Regardless of how the preferred topics are determined, the main consideration for resource developers is to align their resources with the achievement objectives in the Ministry's Māori language curriculum guidelines, Te Aho Arataki Marau (2009). Furthermore, ongoing dialogue between resource developers, teachers and the Ministry would ensure the strategic development (and evaluation) of quality, user-friendly reo Māori resources.

\subsection{Future resources featuring role models}

Delta recommended that future resources should feature Māori role models, to inspire rangatahi ${ }^{179}$ :

"We definitely need more...young people...[that] kids can relate to - to try and develop mana and...pride."

Delta realises the benefit of having successful role models, across a range of fields, to lift young and impressionable students' aspirations. She cites an example of a young illustrator who visited her school and impressed her students as a positive role model:

"A young Samoan boy...was drawing for the school journals, and he came into class, and my boys were just like WOW!!”

She is keen to have resources developed that show Māori role models whom the students can see themselves reflected in. Furthermore, she believes that, by students asking certain questions of the role models, common experiences would be highlighted (both positive and negative) and key ingredients for success would emerge. She suggests questions like the following:

"What was school like for you? How come you've gone through this, and you've gone on to excel? What has been the thing that has sparked you to do that?"

Delta recognises that exposure to such role models could have a positive influence on tamariki in their formative years - especially in terms of goal setting, self-belief, and perseverance in the face of setbacks.

${ }^{179}$ Youth 


\subsection{Future resources in the form of posters}

Another recommendation from Delta, in terms of the future development of Māori language materials in English-medium settings, is the production of posters. A few Māori visuals were displayed on her classroom walls - depicting mainly formulaic phrases and aspects of Māori culture. She would like a more comprehensive set of posters distributed to each school, covering a range of kaupapa:

"[We need] more visuals for the classroom, because I think most teachers get their posters from the \$2 shop. Imagine if we got a whole pack; that would be awesome.”

Posters are indeed a good medium for enhancing the visibility of te reo Māori (me ōna tikanga) in the linguistic landscape of the classroom. They give relevance to the language, while influencing the status that students attach to it (Landry and Bourhis, 1997). Moreover, they also provide a source for students' autonomous learning.

\subsection{Future resources for kapa haka}

Delta recognises the importance of presenting students with quality, durable resources which they are more likely to use, and value, if they are aesthetically pleasing. As such, Delta would like to see each school given a set of well-made poi, for kapa haka:

"Imagine if each school had ... a set of poi. Good quality ones. Because schools make them and they break."

Delta's comments reinforce the value of kapa haka in most English-medium schools (Ministry of Education, 2018) - and the practical requirement for associated needs like poi, guitar, tutor and uniforms. These are expensive items for schools to fund from their operational funding, when there are so many other competing priorities. It would be helpful if there were dedicated funds from the Ministry, or private business donations, to support kapa in schools - since it is reportedly a major conduit for te reo Māori.

\subsubsection{Correlation between te reo in the classroom and Māori student}

\section{achievement}

Delta believes there is indeed a correlation between Māori language input in the classroom and Māori student success. However, she is dismayed by the fact that she has witnessed a 
lack of cultural pride in too many of her Māori students over the years. From her perspective, very few stand out as having such pride:

“A lot of Māori children don't have pride in their culture. It's hard for me to understand and it's sad."

This situation is no doubt difficult for Delta to rationalise, due to her own pride in having Italian heritage. She is saddened by the fact that so many of her Māori students do not share that same sense of pride in their Māori heritage. She believes they have missed out on having Māori language and culture validated at school - and gaining a sense of belonging that comes from the inter-generational transmission of culture and language.

Furthermore, Delta acknowledges the relationship between cultural alienation (emanating from colonisation and urbanisation) and the criminal justice system (Durie, 2003). Such a relationship is evident in NZ's crime statistics, which show a disproportionate number of Māori being incarcerated. Delta is keen to do what she can in the classroom to be a circuit breaker - by affirming Māori students' language, culture and identity:

"Anything that we can do to boost that pride in who you are ... your genealogy and ancestors standing behind you - that's awesome. I think that's amazing. Anything we can do to keep Māori out of the jails and make our society better, and have people achieving."

Despite being non-Māori herself, Delta appreciates the richness of Māori culture and the knowledge of illustrious ancestors whose descendants are the students whom she teaches. She is keen to do what she can to imbue a sense of cultural pride in her Māori students, as a platform for academic success. Otherwise, they may grow up to be young adults like those described by elder statesman, Sir Apirana Ngata MP, as an alienated people, “... ka haere manene noa iho i te mata o te whenua ..." ${ }^{180}$ (Kaa, 1996, p. 332).

Non-Māori teachers like Delta have a role to play in remedying this situation, so that Māori students grow up feeling that they belong in (and are equipped for) both the Pākehā world and the Māori world. They would then have a sense of agency and empowerment in the face of any oppression or subjugation from societal pressures, enabling them to realise their aspirations and goals. This would contribute to the vision of Ngata, who encouraged young

${ }^{180}$ Literally ' ... wandering the face of the earth ...' 
Māori people to embrace the skills and knowledge available in the Pākehā world, for their physical well-being, while at the same time holding on to their Māori culture, for their dignity - as follows: Ko tō ringa ki ngā rākau a te Pākehā, hei ara mō tō tinana. Ko tō ngākau ki ngā taonga a ò tīpuna Māori, hei tikitiki mō tō māhuna.

\subsubsection{Overview of Delta}

Delta believes that Māori language is significant as it contributes to NZ identity. Put simply, she describes it as a part of who we are. Interestingly, she was under the misapprehension that Māori was already compulsory in schools. She certainly thinks it should be. Delta's prior experiences have influenced her teaching of Māori language specifically the exposure to her family's heritage language, Italian, as a child. The similarities between Italian and Māori, especially the cultural aspects, have made it easier for Delta to embrace Māori language and culture. Another significant experience from her past was her going to university as a mature student. It opened up another world view, allowing her to see NZ history from a Māori perspective.

In terms of school parents' views, Delta has only encountered one dissenting voice about te reo Māori during her 16+ year teaching career. She attributes this to ignorance and that parent's limited life experiences.

Delta has participated in one course of Māori language PD, with an external facilitator. It was beneficial. She self-rates her speaking ability as being 'limited '. Furthermore, she struggles with pronunciation. To improve her Māori language skills she is learning independently, using a commercial publication. This shows her commitment to being a good Māori language role model for her students.

Because of the dearth of Māori language resources, Delta often resorts to making her own; or she saves time by using Pinterest. She recognises the need for new resources to align to the curriculum. In particular she would like to see the future development of posters and the provision of materials /equipment needed for kapa haka in schools. She also sees a need for resources that depict Māori role models, to lift Māori students' aspirations across a range of fields. 
Some Māori language resources were visible in Delta's classroom - in the form of Māori art posters, classroom labels, wall displays featuring myths/ legends, and children's stories about Maui. However, she highlighted an issue in regard to the mechanism whereby teachers can find out about, and access, relevant Māori language resources. This perhaps suggests a need for the Ministry to strengthen its communications in this area. Although Delta had never encountered the Ministry's Māori language curriculum guidelines, she liked using its companion document for Year 1-6 i.e. He Reo Tupu - a resource introduced to her by the external facilitator during PD. Delta's top three characteristics of what constitutes quality Māori language resources are the inclusion of an audio component (for pronunciation); the provision of an English translation or glossary; and user-friendliness.

She believes there are is a correlation between Māori students having access to their heritage language in the classroom and their subsequent success overall. However, she is concerned at having witnessed a lack of cultural pride in too many of her Māori students during her teaching career. She attributes this in part to them not having their language and culture validated at school. She highlights the pathway into the criminal justice system for too many Māori students. She therefore believes that teachers should purposefully plan for Māori language within their wider curriculum planning - to ensure that students are exposed to more reo, and Māori student identity is validated.

\subsection{Chapter review}

This chapter discussed the findings from my interviews with four of the 40 teachers who completed the initial online questionnaire (described in Chapter 4) and were subsequently observed (described in Chapter 5). The interviews were especially relevant to two of my research questions - about the factors that can influence teachers' attempts to teach te reo Māori; and teachers' views on Māori language resources (existing, future, and quality characteristics thereof) in English-medium primary schools.

Based on information from the four interviewees, the factors that most influenced their teaching of te reo Māori were: their prior experiences and beliefs; their limited Māori language skills; the lack of relevant resources and PD; and school structures. These factors are summarised below and also in Table 6.1 at the end of this chapter. 
All four interviewees discussed the influence of their prior experiences in terms of inhibiting or enabling their ability to teach Māori language. Ainsley, Jamie and Delta had no, or little, exposure to te ao Māori in their upbringing. This made it hard for them to embrace the teaching of Māori language in the classroom. In contrast, Jordan had been exposed to Māori language prior to becoming a teacher. Like Ainsley and Delta, he had also been exposed to some second language learning, which provided a basis of how languages work. This knowledge was then built on in their learning, and subsequent teaching, of Māori.

In expressing their beliefs, the four interviewees demonstrated a positive, open attitude towards Māori language. They believed in the benefits of bilingualism, and the contribution that Māori language makes to both Māori, and NZ, identity. They also believed there was a relationship between Māori students being exposed to their heritage language in the classroom and their resultant overall achievement.

The four teachers were not hampered by being non-Māori - instead embracing the concept of ako, where the teacher is a learner. The key issue for them, however, was their low proficiency. Their poor language skills hindered their ability to move students beyond the basics. It also meant that the same Māori language content was repeated each year, which was limiting for their students' progression in the language.

The four case study teachers found that a lack of resources suitable for English medium primary school settings inhibited their practice - as did the lack of financial resourcing dedicated to Māori language in their schools. Furthermore, their teaching of Māori was hampered by not knowing about, or not using, existing (potentially useful) Māori language resources published by the Ministry. The exception was the resource He Reo Tupu (Ministry of Education, 2011), which was utilised because of it being multimedia and userfriendly.

The four interviewees' ideas for future resources were varied. They want Māori readers to be developed at their level, including big bilingual books (for the purposes of dual literacy), with an audio component (to help pronunciation). They want local resources too (to reinforce a sense of place). In addition, they see a need for interactive, online materials 
and user-friendly Māori language games/activities (to facilitate the delivery of a varied and enjoyable programme). They also recommend that resources be aligned to the curriculum (to ensure consistency with the achievement objectives in the Ministry guidelines). Other ideas for future resource development included posters, poi for kapa haka, resources with ideas for cross-curriculum integration of te reo, and materials that feature Māori role models.

Across the four interviewees, the top three (out of nine) characteristics of quality Māori language resources for English-medium primary school settings were: user-friendliness, inclusion of an English translation/glossary, and depiction of real-life contexts. It is interesting to note that the integration of Māori tikanga, values and concepts (although regarded by the 40 questionnaire respondents as one of their top three characteristics of quality) did not feature in any of the interviewees' top three rankings. This shows a degree of variability in teachers' choices when considering their needs at a particular point in time.

It was evident from the four teachers' experiences that the quality of PD was varied.

However, each of them was fortunate enough to have had one positive PD experience (inservice), which was reportedly very enabling in terms of increasing their Māori language ability, as well as the use of Māori language resources and their understanding of second language acquisition.

The teachers reported that school structures could be potentially inhibiting for the teaching and learning of Māori - in particular, the time allocated within the school curriculum for Māori language, in the face of other curriculum priorities (especially core subjects). This lack of time was reportedly exacerbated when there was little or no support while they endeavoured to facilitate Māori language learning in their classroom. They called for support from senior leadership and whānau, in order to progress Māori language in their schools.

The next chapter will discuss the potential contribution of my study, outlining the theoretical and practical implications, with associated recommendations. 
Table 6.1: Inhibiting and enabling factors

\begin{tabular}{|c|c|c|}
\hline & Inhibiting factors & Enabling factors \\
\hline $\begin{array}{l}\text { Prior } \\
\text { experiences }\end{array}$ & $\begin{array}{l}\text { - Being unfamiliar with Māori language or a Māori world } \\
\text { view } \\
\text { - Having no understanding of, or experience in, the } \\
\text { acquisition of a second language }\end{array}$ & $\begin{array}{l}\text { - Having been exposed to te reo Māori specifically, and te ao } \\
\text { Māori generally } \\
\text { - Having theoretical and practical knowledge of second } \\
\text { language acquisition }\end{array}$ \\
\hline Beliefs & $\begin{array}{l}\text { - Being cautious about teaching te reo Māori, due to lack of } \\
\text { confidence and/or lack of proprietary rights }\end{array}$ & $\begin{array}{l}\text { - Being open and willing to teach Māori language, } \\
\text { recognising the advantages of bilingualism } \\
\text { - Having a positive attitude towards Māori language - and } \\
\text { its importance for Māori identity and NZ identity } \\
\text { - Appreciating the relationship between Māori language } \\
\text { learning and Māori student achievement } \\
\text { - Understanding the concept of ako, recognising that the } \\
\text { teacher is at times a learner who seeks others' help } \\
\text { (including students) }\end{array}$ \\
\hline Skills & $\begin{array}{l}\text { - Not having standard pronunciation, accompanied by a low } \\
\text { level of reo Māori proficiency }\end{array}$ & $\begin{array}{l}\text { - Having standard pronunciation of, and proficiency in, } \\
\text { Māori language }\end{array}$ \\
\hline Resources & $\begin{array}{l}\text { - Lacking access to quality bilingual resources, pitched at a } \\
\text { level suitable for English-medium settings } \\
\text { - Having insufficient budget to purchase commercial Māori } \\
\text { language resources } \\
\text { - Having no knowledge of, or familiarity with, the } \\
\text { Ministry's existing Māori language resources (print and } \\
\text { online) }\end{array}$ & $\begin{array}{l}\text { - Accessing quality bilingual resources (including local } \\
\text { resources), suitable for English-medium teachers and } \\
\text { students } \\
\text { - Having sufficient budget to buy commercial Māori } \\
\text { language resources } \\
\text { - Being familiar with, and using, the Ministry's existing } \\
\text { Māori language resources (print and online) }\end{array}$ \\
\hline
\end{tabular}

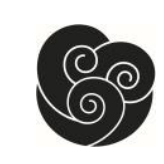




\begin{tabular}{|c|c|c|}
\hline & Inhibiting factors & Enabling factors \\
\hline $\begin{array}{l}\text { Professional } \\
\text { development }\end{array}$ & $\begin{array}{l}\text { - Having no PD opportunities to: } \\
\text { - } \quad \text { upskill in te reo Māori; } \\
\text { - } \quad \text { understand the principles of second language } \\
\text { - } \text { acquisition; or } \\
\text { - learn how to maximise Māori language resources }\end{array}$ & $\begin{array}{l}\text { - Having PD opportunities (pre- and in-service) to increase } \\
\text { knowledge of: } \\
\text { - } \quad \text { te reo Māori; } \\
\text { - } \quad \text { second language acquisition; and } \\
\text { - } \quad \text { the use of Māori language resources }\end{array}$ \\
\hline $\begin{array}{l}\text { School } \\
\text { structures }\end{array}$ & $\begin{array}{l}\text { - Having insufficient time to devote to Māori language } \\
\text { teaching, due to other curriculum priorities (especially core } \\
\text { subjects) } \\
\text { - Having little/no support from senior management and/or } \\
\text { parents to implement a quality Māori language programme. }\end{array}$ & $\begin{array}{l}\text { - Teaching in an environment where there is a generous } \\
\text { amount of time allocated to Māori language teaching and } \\
\text { learning in the school curriculum } \\
\text { - Receiving support from parents and/or senior management } \\
\text { to help drive the teaching and learning of Māori language }\end{array}$ \\
\hline
\end{tabular}




\section{IMPLICATIONS AND RECOMMENDATIONS |}

\section{NGĀ HITRAUNGA ME NGĀ TAUNAKITANGA}

This chapter discusses the contribution of my research, the theoretical and practical implications, and the associated recommendations relevant to different stakeholders.

\subsection{Contribution of this study}

I came to this study as a non-Māori who has worked in the Māori education field and participated in te ao Māori (through whānau and friends) for over 50 years. As such, I am keen to encourage non-Māori teachers in English-medium primary schools to embrace the teaching of te reo Māori - for the benefit of all NZ students (in terms of this country's national identity), and especially Māori students (in terms of validating their language, culture and identity).

This study is useful for anyone who recognises the value of Māori language to NZ society. It will enhance people's understanding of the teaching of te reo by non-Māori primary school teachers working in English-medium classrooms - specifically around: teachers' stated beliefs; their classroom practices; factors that influence their practices; their views on what constitute quality Māori language materials; and what materials they want developed for their settings.

My study contributes to the literature and to the wider kaupapa of Māori language revitalisation by:

- endorsing the value of whānau aspirations/ expectations around tamariki/mokopuna receiving reo Māori tuition in English-medium primary schools, supported by quality Māori language materials (Chapters 2,7);

- $\quad$ providing an evidence base for a strategic approach by the Ministry, the Māori Language Commission and resource developers, in terms of the creation of quality Māori language materials that will help Englishmedium primary teachers to incorporate te reo Māori (Chapters 2,4,8); 
- $\quad$ offering insight into the factors that can influence non-Māori primary school teachers in English-medium settings when attempting to teach te reo alongside other curriculum priorities (Chapter 6); and

- $\quad$ emphasising the need for English-medium primary teachers to receive quality PD around maximising resources, improving their reo proficiency, and developing knowledge about second language pedagogy (Chapter 6).

Throughout this study, there are numerous examples that can be drawn on to illustrate Māori language-in-education policy settings and Māori language revitalisation efforts. I intend to create tailored summaries of my research for respective stakeholders who may be interested - including teachers, whānau, resource developers, the Ministry of Education and the Māori Language Commission.

I will make the respective summaries for teachers and whānau available on the primary teachers' Facebook page (the original source for my online questionnaire respondents) for teachers to share with their peers and school communities. Another avenue for teachers will be the Ministry's new online hub for te reo Māori, Kauwhata Reo (launched on 4.9.19). In the interests of tauиtuutu, the four teacher interviewees will be given a copy of the abstract, prior to the wider dissemination of the research summaries.

Personal copies of a summary tailored to the Ministry of Education and the Māori Language Commission will be disseminated to relevant staff in those organisations. In addition, the website of the publisher of my bilingual readers (Rainbow Reading) will be used for a summary targeted at resource developers. Finally, all the summaries will feature on my website [http://alicepatrick.co.nz].

\subsection{Theoretical implications}

There are few theoretical implications as this study is focused on teachers' lived classroom experiences. As such, most of the implications are practical (see 7.3).

In my research, I attempted to contribute knowledge about the teaching of te reo Māori by non-Māori teachers in English-medium primary schools. This target group is worthy of study because most Māori students are being educated in the English-medium sector - and too many of them are not achieving their potential (as discussed earlier, in section 2.7.1, in 
the context of the Ministry's Māori education strategy Ka Hikitia). This situation is largely due to the historic failure of the NZ education system to validate Māori students' language, culture and identity - exacerbated by the demographic mismatch between most non-Māori primary teachers and many of the Māori students whom they teach.

Because this educational context is under-researched, there is an opportunity for other researchers to contribute to the discourse by undertaking culturally responsive studies associated with Māori language education, and/or teacher cognition, in English-medium primary schools. There is also scope for research that provides empirical data about the relationship between Māori students having access to te reo Māori in their early years of English-medium schooling (Years 1-6) and them achieving educational success as Māori.

(See 8.8 for specific suggestions on future research possibilities).

\subsection{Practical implications}

The biggest implication is for NZ education - especially Māori language education and Māori student achievement.

There are implications for the practice of teachers, school leaders and PD facilitators in English-medium primary school settings - as well as resource developers who work in this space. Likewise, there are implications for NZ primary school students generally, and Māori students (and whānau) specifically - in terms of recognising the benefits that ensue from learning te reo, as summarised in Chapter 4. Furthermore, there are implications for Te Mātāwai, the Māori Language Commission and the Ministryof Education, as they set about developing initiatives that will contribute to Government's goal of making Māori language universally available in schools, with one million New Zealanders speaking basic te reo by 2040 .

In the spirit of kotahitanga, these different stakeholders (discussed below) can, together, contribute to the common goals of Māori language revitalisation, Māori student success, and NZ identity.

\subsubsection{Māori Language Commission and Te Mātāwai}

In light of its mission to promote, normalise, and revitalise te reo Māori at a national level (Kia haruru a Aotearoa whānui i tō tātou reo taketake), there are implications for the Māori 
Language Commission. The teaching of Māori in schools is an area of interest for them, as evidenced in their contracting of Haemata (2019) to conduct an evaluation regarding Māori language in English-medium compulsory education. My study complements this evaluation and helps to suggest ways that the teaching and learning of Māori language can be strengthened in English-medium primary schools.

There are implications for Te Mātāwai too, in that they are positioned to work alongside whānau and communities to implement a range of initiatives, including research, to progress Māori language revitalisation.

\subsubsection{English-medium primary school teachers}

Because schools have an important role to play in arresting the decline of Māori language, there are implications for English-medium teachers in terms of providing opportunities for their students to hear and speak Māori. Schools may be the only context where NZ children experience te reo Māori.

Athough non-Māori primary school teachers are 'outsiders' like me (in terms of Māori language, culture and identity), we have a professional responsibility to contribute to the maintenance and promotion of te reo Māori, the Indigenous language of this country. This expectation is set out in the first Standard for the Teaching Profession, about the Treaty partnership and the use of te reo and tikanga Māori (Education Council, 2017). This means that we are responsible for facilitating access to te reo Māori for all students - thus contributing to the normalisation of Māori language in NZ society. My research may resonate with, and have relevance for, other teachers of Māori language in that it highlights some of the barriers faced when attempting to fulfil the aforementioned expectation.

Furthermore, as noted in my literature review, there is a relationship between Māori students being supported to learn te reo at school and their subsequent educational achievement. With a disproportionate number of Māori students in New Zealand's education system being classified as 'priority learners' (i.e. students who have not historically experienced success in the system), and in the absence of readily available Māori language PD, English-medium teachers may find they need to invest personal time in building their Māori language capacity, in order to add value to those priority learners (and others). This has implications for teacher workload. My research draws attention to the busy classroom lives of primary school teachers - where there is little time and energy 
for self-generated PD. Hence my recommendation for Ministry funding to upskill Englishmedium primary teachers in Māori language and tikanga, as well as resource familiarisation and second language acquisition knowledge.

\subsubsection{English-medium primary school students}

As well as the teachers, there are implications for students in English-medium primary schools - as principal stakeholders in the learning of te reo Māori. The Ministry’s Māori language curriculum guidelines (Ministry of Education, 2009, p. 13) state that “... all New Zealand students can benefit from learning te reo Māori." My interviews with the four case study teachers indicated that te reo Māori was indeed beneficial to students in terms of New Zealand's national identity - and as a conduit for learning about Māori values and culture. Moreover, these teachers believed that the provision of te reo Māori in their classrooms was particularly beneficial for Māori students - in terms of the validation of Māori language, culture and identity, and the achievement of educational success as Māori.

\subsubsection{English-medium primary school leaders}

My research highlights practical implications for English-medium primary school leaders, in that they need to support teachers to embed Māori language. For example, the teachers in my study expressed a need for more time in their busy classroom lives to devote to te reo Māori. The lack of 'top-down' support can have an adverse effect on teachers' sustained investment in teaching Māori, as discussed by some of my research participants. There are different ways that leaders can show their support for te reo and address the factors that impact on the teaching thereof. These include:

- $\quad$ prioritisation of Māori language in the school, to show its value and raise its status and visibility (as stated by Roberta in this study);

- provision of adequate resourcing, to facilitate quality teaching and learning of te reo (see Haemata, 2019);

- affirmation of teachers' Māori language efforts in the classroom (as discussed by Jamie in this study);

- inclusion of te reo as a cultural competency in performance appraisal, to ensure accountability (as set out in Tãtaiako, 2011); and

- provision of 'whole school' PD, to facilitate meaningful shift (and progression) across the school (as recommended by Timperley et al., 2007). 
A 'whole school' approach would see the leadership team participating in Māori language PD alongside the teachers (and members of the school community too, where practicable). Such an approach to the teaching and learning of te reo Māori me ōna tikanga in Englishmedium schools was recommended in research by NZCER (2017). Moreover, the generic benefits of a 'whole school' approach were outlined in the Ministry's BES research (AltonLee, 2003); namely, more consistency amongst teachers and leaders in terms of teaching practices, more coherence across school policies, and more collaboration and reflection by teachers.

This approach would require deeper engagement across all levels of the school, with the expectation of change and the demonstrable transfer of new Māori language learning to the classroom. Hence the Ministry's initiative called Investing in Educational Success (IES), to promote collaborative responses to NZ's main educational challenge; namely, the achievement gap between our high performing students and those at the other end of the scale, too many of whom are Māori (Cabinet Minute SOC Min (14) 10/3). The IES initiative enables teachers to work together (within and across schools), learning from each other and making use of each others' respective knowledge, skills and experience. The premise of this approach is that school-wide shifts are more likely to occur through concerted, collective action.

Such an approach would provide an opportunity for individual teachers like Ainsley, Delta, Jordan and Jamie who are delivering te reo Māori (at the micro-level of the classroom) to come together as a group (at the meso-level of the school), thus putting them in a stronger position to implement the Ministry's Māori language policy intent (at the macro-level of government) in terms of contributing to Māori language revitalisation (Barr and Seals, 2018). Moreover, there would be opportunities for ako, in that everyone would have a contribution to make. For example, novice teachers or newcomers (tēina) such as Nate, Lexi, Laurel, Shari, Maria and Bex would be assisted by more experienced teachers (tuākana) like Jamie and Delta. Conversely, the tuakana:teina relationship could be flipped on its head in instances where relative 'newbees' to teaching had more proficiency and confidence in te reo than their experienced peers.

\subsubsection{Whānau}

The importance of having whānau support to promote children's acquisition of Māori language and culture is emphasised by Hunia (2016). Her findings show that a child's 
choice of productive language is influenced by their language environment (i.e. the language used by their whānau, and the wider community).

As already indicated, my findings have implications for whānau in that they now have a lever to exert when communicating an expectation to English-medium primary schools that teachers will indeed include Māori language in the classroom curriculum, and use quality Māori language materials in the process - thus supporting the inter-generational efforts of whānau (which is one of UNESCO's indicators of language vitality).

Using the findings of my research, whānau are in a stronger position to communicate their expectations to the school around: teachers' correct pronunciation of Māori (especially their child's name); the availability of Māori readers (or a copy thereof) to be sent home and shared with whānau as part of the literacy programme (as suggested by Core, 2018); and input into the school's Māori language programme (as occurred in Ainsley's school, where parents were the driver for the teachers' Māori language PD with an external facilitator).

\subsubsection{Ministry of Education}

My study has implications for the Ministry in terms of honouring its Māori Language in Education Strategy, Tau Mai Te Reo (2013), which ensures that Māori language is prioritised in all educational settings, including English-medium primary schools - with funds set aside for resources. In exploring what constitutes quality Māori language resources, my research goes some way to determining the types of teaching and learning materials that teachers want and value. Such resources would help teachers to embed the Ministry's Māori language curriculum guidelines, Te Aho Arataki Marau, and supplementary resources. This brings practical implications for the Ministry in terms of providing funds for:

- the development of quality Māori language materials in English-medium schools - as adjudged by the teacher participants in this study, including real-life contexts, user-friendliness, and the inclusion of tikanga; and

- the creation of PD opportunities to support the teaching of te reo Māori in English-medium primary classes - specifically PD around pronunciation, proficiency, use of materials, and second language acquisition. 
Such expenditure would enhance teachers' contribution to wider Māori language revitalisation efforts, honouring the fact that Māori language is a taonga to be valued and protected.

In addition to the provision of funding, there is a need for the Ministry to support the efforts of those parents who want to better recognise the value of te reo Māori me ōna tikanga in the NZ education system - and Aotearoa whānui ${ }^{181}$. However, at the same time, the Ministry must manage other parents who are negative about the teaching and learning of te reo Māori. It falls upon the Ministry (and schools) to facilitate an appreciation of the language amongst those dissenting voices and convince them of the benefits. This can be an uphill battle, as reported by Gordon (2015). Her research reveals a progressive shift, over the past 20 or more years, where many non-Māori parents bypass the local school in favour of a high decile school where there are fewer Māori students on the roll. Gordon highlights the implications for racial segmentation in Aotearoa NZ.

As an example, the principal of Pomare School in Wellington, Katrina Day, has spoken out in the media about the stress associated with a falling school roll. Her school has nine classrooms - but only 60 students (predominantly Māori and Pasifika). She attributes this situation to 'white flight' and parents' misunderstanding of the decile system - such that they believe a decile 10 school is better than a decile 1 school in terms of a quality education (Boyack, 2018).

This viewpoint is evident in a media comment about school zoning ${ }^{182}$, by the president of the PPTA (Post Primary Teachers Association), Jack Boyle. Like Gordon (above), Boyle believes that parents' choice of schools has implications for social division and equity. There is agreement too from Damon Salesa, Associate Professor of Pacific Studies at Auckland University. He believes that some parents are determining the quality of a school by the number of Māori and Pacific students on the roll (Duff, 2015). That is, race is a factor in their decision-making.

Researchers like Gordon and Salesa express concerns about the growing school segregation, and the implications for the NZ ideal of having a society that promotes tolerance and understanding.

\footnotetext{
${ }^{181} \mathrm{NZ}$-wide

${ }^{182}$ A geographical enrolment scheme created to limit a school's roll and prevent overcrowding
} 
The 'white flight' phenomenon has implications for the teaching and learning of te reo Māori. Because high decile schools are larger and better-resourced, they are in an ideal position to invest in Māori language materials for their students and teachers. Conversely the smaller, poorer, lower decile schools are likely to struggle to provide quality reo Māori programmes. This situation is undesirable in that most Māori students are being educated in low decile schools that may not be in a position financially to provide extensive opportunities to validate those students' language, culture and identity. This has implications for Māori student achievement, as discussed in my research, where all but three of the 40 questionnaire respondents saw a relationship between the provision of te reo in the classroom and educational success for Māori students.

\subsubsection{Pre-service and in-service teacher educators}

There are implications for pre-service teacher educators in terms of needing to acknowledge that, in learning Māori, teacher trainees will likely be influenced by their own experiences learning te reo or another second language - as was the case with Ainsley's learning of French, Jordan's study of Korean, and Delta's exposure to Italian.

There are also implications for pre-service teacher educators in terms of enhancing the delivery of their service, to ensure that teacher trainees are:

- familiar with the Ministry's Māori language curriculum guidelines and associated materials, so that they can plan and implement an engaging and pedagogically sound Māori language programme - like Ainsley, who is becoming increasingly familiar with these materials; and

- $\quad$ equipped with basic Māori language knowledge (beyond individual words and commands), so that they can use the language meaningfully which is Jordan's goal with his students.

There are implications for in-service teacher educators too, in that most classroom teachers need help to improve their pronunciation, upskill their proficiency, maximise available resources, and become familiar with second language acquisition theory. Regarding these aspects, my research found that teacher proficiency was low, which was subsequently confirmed in the NMSSA project (Ministry of Education, 2018). Moreover, among my teacher respondents there was very little awareness (or use) of relevant Ministry resources. 
However, 30 of the 40 questionnaire respondents believed it would be useful to have knowledge of second language acquisition, to underpin their practice.

\subsubsection{Resource developers}

My research has implications for resource developers in that it contributes to an evidence base that creates a platform for adopting a more strategic approach to the development (and evaluation) of Māori language materials for English-medium primary schools - guided by the top three quality criteria adjudged by the 40 teachers in my study who completed the questionnaire; namely: real-life contexts, user-friendliness, and the inclusion of tikanga. Such a strategic approach would allow the Ministry and resource developers to better identify what types of materials were needed, at which class levels, covering what content - keeping in mind that the needs of English-medium teachers and students are different to those in the Māori-medium sector, for whom developers have been producing resources for many years ${ }^{183}$.

\subsection{Recommendations}

In view of the aforementioned implications, there are recommendations for: researchers; Te Mātāwai and the Māori Language Commission; primary school teachers and leaders in English-medium settings; whānau; the Ministry of Education; teacher educators; and resource developers.

\subsubsection{Researchers}

Researchers could consider instigating further studies that contribute to the knowledge base around Māori language learning in English-medium primary schools. (See Chapter 8 for suggestions around future research possibilities - with associated rationale).

\subsubsection{Māori Language Commission and Te Mātāwai}

The Māori Language Commission has a new role in supporting national and societal change. The Commission is leading the coordination of agencies (including the Ministry of

\footnotetext{
${ }^{183}$ See the Ministry's resource catalogue Down the Back of the Chair https://www.nchenz.org.nz/down-theback-of-the-chair/
} 
Education) that are implementing the Crown's Māori language strategy (Maihi Karauna). This strategy has three audacious goals; namely that, by 2040:

- $85 \%$ of New Zealanders will value te reo Māori as a key part of national identity;

- one million New Zealanders will be able to speak te reo about (at least) basic things; and

- 150,000 Māori aged 15 and over will be using Māori as much as English.

These goals are relevant to the education sector in that one of the Commission's target groups to help achieve the goals is young people up to 24 years old - because they are the future of te reo Māori. To that end, the Commission could consider following up my research on a wider scale, to adjudge the potential for English-medium primary teachers and students to be change agents contributing to Māori language revitalisation.

Te Mātāwai, with its focus on homes and communities, kia ūkaipō anō te reo, is well-placed to initiate research that looks at the engagement of whānau in home:school partnerships because of the positive influence that whānau can assert on students' motivation to learn te reo Māori. As such, there is potential to increase English-medium primary school students' Māori language ability.

\subsubsection{English-medium primary school teachers}

Primary school teachers in English-medium settings could consider familiarising themselves with the range of benefits for students learning Māori (as outlined in my study), to provide an evidential base that legitimises (to dissenting parents) the teaching of the language in their classrooms.

In addition, the teachers could be encouraged to increase their knowledge of the Ministry resources referred to in this study (i.e. the Māori language curriculum guidelines and support materials), as a way of implementing a more engaging Māori language programme. Moreover, they could consider finding ways to upskill their own Māori language proficiency beyond basic formulaic language and vocabulary, in order to expose students to rich Māori language input. Also worthy of consideration would be equipping themselves with theoretical knowledge about the teaching and learning of second languages, to ensure their Māori language programmes are pedagogically sound. 


\subsubsection{English-medium primary school leaders}

Primary school leaders in English-medium settings could consider creating the requisite conditions in their schools to facilitate the effective teaching and learning of Māori language, by addressing some of the influencing factors/ barriers raised in my study (e.g lack of resources, PD, time and support) - to show the school's demonstrable commitment to the Māori language.

\subsubsection{Whānau}

Whānau could consider communicating their aspirations more strongly to schools, in terms of the provision of Māori language resources and the desired Māori language outcomes for their primary school-aged children in English-medium settings. This would contribute to a genuine partnership between home and school, which would benefit student learning.

\subsubsection{Ministry of Education}

The Ministry of Education could consider enhancing its communications with the Englishmedium sector, to ensure there is information about existing and new materials. Moreover, regular engagement would help the Ministry to keep abreast of teachers' Māori language resource needs and gather feedback on the success (or not) of new resources. This would mean that teachers are better supported in responding to Ministry of Education expectations around Māori language teaching. The Ministry could also scope the possibility of creating a mechanism for students (and whānau if practicable) to provide feedback on the effectiveness of Māori language resources in English-medium primary schools and make suggestions on what is needed. This would enable the Ministry and its resource developers to adjudge whether existing resources are engaging for students and fit for purpose.

The Ministry could also consider providing more PD opportunities (covering reo and tikanga, second language acquisition theory, and resource familiarisation), to help Englishmedium primary teachers implement effective Māori language programmes. This would reduce teachers' anxieties and increase their confidence in relation to Māori language teaching. Another recommendation to the Ministry would be to create video clips that show English-medium primary teachers how Māori language resources can be used in the classroom. Such practical hands-on support would be a useful mechanism for those teachers who are not fortunate enough to receive Māori language PD (which is, in reality, most teachers). 
It would also be advantageous if the Ministry developed more support materials for teachers (e.g. showing them how to adapt and simplify content in instructional readers). Its commissioned research (Ministry of Education, 2017, p. 31) found that $96 \%$ of resources in English-medium were produced for students (not teachers). Support materials for teachers would provide a range of ideas for making their Māori language programmes more engaging.

English-medium primary teachers would benefit from the Ministry creating a social media/ online community (cf. Facebook page for primary teachers) to introduce new Māori language resources and relevant research, so that they can maintain currency. It would also be beneficial to teachers and students if the Ministry revived quality, out-of-print Māori language readers (suitable for English-medium settings) and converted them into digital form (notwithstanding intellectual property clearance issues). This would extend the limited range of resources currently available to English-medium students; and it would obviate the need for funding to cover the printing and publication of new resources.

The Ministry could consider strategically developing Māori language resources that align with the different learning areas taught in English-medium primary schools. This would mean that teachers, who are already time-poor, could integrate Māori language into other areas of the curriculum (as in CLIL, discussed in Chapter 6). Also recommended to the Ministry is the development of a Māori language progression framework (curriculum levels 1-2) for Year 1-8 students in English-medium settings, to avoid the same limited content being repeated year after year, and to better equip students for the transition to Māori language learning at secondary school.

The Ministry's creation of Māori language resources specifically for Year 5-6 students in English-medium settings is also recommended - because of that gap having been identified in research by the Ministry of Education (2017). This would ensure an appropriate interest level for students aged 9-11, many of whom would find the early Māori language resources too 'babyish' in appearance and content. Furthermore, the Ministry's development of more group-oriented Māori language learning resources, to encourage tuakana:teina practices in task-based learning, would bring mutual gains - with the teina benefitting from the skills and knowledge imparted by the tuakana; and, conversely, the tuakana benefitting from having to take responsibility for someone else's learning. 
It is also recommended that the Ministry develops a strategic plan for the creation of Māori language resources to support te reo Māori in English-medium primary schools. This would lead to a more even distribution of resources across the different class levels and ages, as opposed to a glut of resources for new entrants (for example).

\subsubsection{Pre-service and in-service educators}

Pre-service educators could consider adopting a strength-based approach by focussing more on upskilling teacher trainees' Māori language proficiency, and less on the deficit thinking associated with Māori student underachievement. This would mean that beginning teachers would be better prepared to embrace the teaching of Māori language, hands-on and with confidence. Furthermore, it is recommended that pre-service educators equip teacher trainees with the necessary theoretical knowledge required to teach Māori as a second language (e.g. task-based teaching). This would mean that, in teaching Māori as a subject, teachers' classroom practice would be pedagogically sound - with the theory informing their practice.

In-service educators could consider providing PD to teachers where they learn how to maximise Māori language resources so that they are suitable for use in English-medium primary schools. They could be shown how to adapt, and simplify, the readers to accommodate the needs of students by, for example: reducing the length of the sentences, replacing low frequency words with more common items, using repetition, and embedding some English in the Māori text i.e. translanguaging (so that students can straddle te reo Māori and te reo Pākehā).

Such hands-on PD would go a long way to alleviate teachers' anxieties, and build their confidence, by having simple practical ideas that are suitable for transferring to the classroom - without too much preparation. In-service educators should also extend teachers' Māori language proficiency beyond the basics, to avoid the limited repertoire being repeated each year in most English-medium primary classrooms. This would provide students with more stimulating and cognitively challenging Māori language content.

\subsubsection{Resource developers}

Resource developers could consider facilitating focus group discussions with Englishmedium primary school teachers and students (and whānau if appropriate), to discern resource needs and content areas of interest. This would help to create resources that align 
with the needs of the teacher as well as the students. Also recommended is that resource developers create a mechanism for the evaluation of Māori language resources in terms of their successful use (or not) in English-medium primary schools. This type of evaluation is needed, so that developers can adjudge whether their resources are fit for purpose - and, if not, why not, so that the same mistakes are not repeated.

\subsection{Chapter review}

This chapter outlined the contribution that my research makes to the literature - and to the practices of principal stakeholders associated with Māori language teaching and learning in English-medium primary schools. Theoretical and practical implications were discussed, and recommendations made accordingly.

In summary, the theoretical implications focussed on the mismatch (demographically) between English-medium primary teachers and many of the Māori students whom they teach - and the resultant differential achievement due to Māori students not having their language, culture and identity validated. Hence the recommendation for future associated research.

The practical implications focused on the practices of the principal stakeholders (e.g. teachers, school leaders, whānau and PD facilitators in English-medium settings) - as well as resource developers and researchers working in this space. There are also implications for NZ primary school students generally, and Māori students specifically - in terms of the benefits that ensue from learning te reo. Furthermore, there are implications for the Ministry of Education, Te Mātāwai and the Māori Language Commission in relation to initiatives that will contribute to government's goals of making Māori language universally available in schools and having one million New Zealanders speaking basic te reo by 2040 .

The recommendations focus on how respective stakeholders can become change agents through their actions, if they are genuinely committed to improving the teaching and learning of te reo Māori in English-medium primary schools.

In the next chapter, I draw conclusions based on a synthesis of the findings relevant to the beliefs and practices of the four case study teachers. The challenges and limitations of the research are acknowledged - and specific suggestions are made about future research possibilities. 


\section{CONCLUSIONS | HE KUPU WHAKATEPE}

Ko tōku nui, tōku wehi, tōku whakatiketike, tōku reo.

My language is my greatness, my inspiration, that which I hold precious.

(Waitangi Tribunal, 1986, p. 1)

This concluding chapter re-states my position as a non-Māori researcher exploring a Māori kaupapa. It also re-visits the background and aim of the study, with its associated research questions, then synthesises the findings in relation to the four case study teachers. These findings are derived from an analysis of the three different data sources (online questionnaire, classroom observations, teacher interviews), with alignment to each research question. The challenges and limitations of the study are acknowledged - and suggestions are made about worthwhile research possibilities in the future.

\subsection{Background}

Te reo Māori, the Indigenous language of Aotearoa NZ, became an endangered minority language due to the dominance of the English language since European settlement. Some argue that it is still in a perilous state - even though it is now an official language recognised as a taonga under the Treaty of Waitangi, and there have been a range of attempts at revitalisation (by Māori, the community, wider society and government). Others claim that the narrative around te reo Māori dying, or being in crisis, may in fact conspire against Māori language revitalisation efforts.

\subsection{Locating myself as a researcher}

Like myself, the participant teachers were non-Māori i.e. not owners of te reo Māori - but rather facilitators trying to provide English-medium primary school students with access to the language, in order to meet Ministry expectations, as stated in the national curriculum. Despite having no proprietary rights, we recognise that, as educatiors and as part of the majority culture, we have a professional obligation to normalise the use of te reo in Englishmedium primary school classrooms. In doing so, we acknowledge that it is important to maintain an attitude of whakaiti - as a way of supporting Māori-led initiatives to increase the use of te reo Māori and strengthen our national identity. 


\subsection{Research aim}

Teacher cognition research has investigated the relationship between teacher beliefs and pedagogical practices. However, few studies have looked at this association in the context of the beliefs and practices of NZ primary school teachers in English-medium settings, who are endeavouring to fulfil the expectation in the New Zealand Curriculum to provide opportunities for all students to learn te reo Māori.

My intention was to explore this area and contribute to research about Māori language teaching and learning in English-medium primary schools (Years 1-6), where the delivery of te reo is variable. My study sought to address the gap in the literature by canvassing the beliefs of 40 non-Māori teachers working in these settings (through an online questionnaire), then focussing on four of them (through observations and interviews) - to explore: the relationship between their beliefs and practices; their views on Māori language resources; and the different factors that can influence the teaching of te reo Māori in English-medium primary schools.

The research is important in terms of:

- $\quad$ contributing to the literature on Māori language education;

- $\quad$ highlighting the relationship between Māori students' access to te reo Māori and their overall achievement;

- $\quad$ providing the Ministry (and resource developers) with an evidence base for a strategic approach to the development of Māori language materials for English-medium primary schools;

- $\quad$ raising, or legitimising, whānau expectations around Māori language teaching and learning in English-medium primary schools; and

- drawing attention to the support that non-Māori primary school teachers in English-medium settings need, as they try to incorporate te reo Māori into their busy classroom curriculum.

\subsection{Research questions}

There were four research questions:

1. What do non-Māori teachers working in English-medium primary schools believe about Māori language teaching and learning? 
2. How are their beliefs enacted (or not) in the classroom i.e. consistency (or not) between stated beliefs and actual practice?

3. What are some of the factors that can influence teachers' attempts to teach te reo Māori?

4. What are the teachers' views about Māori language teaching and learning resources in English-medium primary schools - specifically:

a) existing Ministry resources;

b) future Māori language resource needs; and

c) the characteristics of quality Māori language resources.

As already stated, these aspects were explored using three data sources: an online questionnaire, observations and interviews.

\subsection{Synthesis of findings}

This section synthesises the findings in respect of the four case study teachers, with specific attention given to the consistencies and differences across the four - and the factors that can enable or inhibit the teaching of Māori language. There is also a summary of the four teachers' views on Māori language resources.

\subsubsection{Beliefs of four case study teachers - consistencies and differences}

In their questionnaire responses, the four case study teachers expressed a number of consistent beliefs. They emphasised the importance of incorporating Māori language and tikanga into NZ classrooms - and making the learning fun by including games, activities and songs. They also deemed it important for teachers to model correct Māori language pronunciation and to draw on students' backgrounds/cultural experiences to explain Māori words and concepts. The four teachers recognised the value of providing opportunities for their students to use Māori (individually, in pairs and in groups) - and exposing them to a range of Māori language materials, with adaptations if necessary. Knowledge about the theory of second language acquisition was also regarded as important. Furthermore, the teachers shared the belief that there was a relationship between teachers using Māori language and the positive effect on Māori student achievement (which was verified in their subsequent 1:1 interviews).

Despite the aforementioned consistencies, there were some differences across the four teachers' belief statements. Three teachers self-reported as having 'basic' 
proficiency in te reo, while one believed their proficiency was only 'limited'. Their low proficiency is likely to have influenced their beliefs about their ability to be flexible and agile when teaching Māori, in that two of the teachers believed they were lacking this ability, and two were unsure. Moreover, in terms of being comfortable teaching Māori, only one of the four teachers was 'somewhat comfortable', while another was 'somewhat uncomfortable'; and two maintained a neutral stance being 'neither comfortable nor uncomfortable'. Only one of them believed they were intrinsically motivated to include te reo in their teaching. The other three were unsure. All except one believed there were external factors, over which they had no control, that influenced their teaching of te reo. The other disagreed.

Additionally, three of the four case study teachers said they needed quality reo Māori resources, while one was unsure. Similarly, three of them believed it was important to deliberately include Māori language when planning their classroom curriculum, but one was unsure. In delivering the Māori language component of the curriculum, three of the teachers agreed that the focus should be on students' listening and speaking skills. However, one remained unsure. Three of the teachers were favourably disposed to the proposition of compulsory Māori in primary schools, while one of them was unsure. Interestingly, only two of the four case study teachers believed that having some basic Māori knowledge for the classroom was important; and two were unsure.

\subsubsection{Classroom practices of four case study teachers - consistencies and differences}

My observations of the four teachers' classroom practices revealed some consistencies. For example, their teaching of Māori was enjoyable for the students, even though the teachers' level of Māori language output was basic (congruent with the selfreporting of their proficiency in the questionnaire). Consequently, there was more emphasis on single words than phrases and sentences; and more attention was given to the meaning of words than their actual use. The four teachers used translanguaging as a strategy for vocabulary learning, by embedding Māori words (mainly nouns) into English sentences. Their pronunciation was good, which ensured appropriate modelling for students, but their use of te reo in the classroom was more planned than spontaneous. 
Moreover, it was largely formulaic (e.g. for classroom management, praise, or greetings). This suggested they were unable to use te reo Māori in a flexible and agile way. Indeed, there were several missed opportunities, where teachers could have used te reo or capitalised on Māori students' prior knowledge. Furthermore, there were only a few Māori language resources being used to support their reo Māori programmes.

As well as the above consistencies, there were differences across the four teachers' respective practices, in that two of the teachers (Ainsley and Delta) took risks to go beyond their natural comfort zone in te reo. This required them to extend their own level of Māori language output, to benefit their students. These two teachers communicated to students a positive attitude about the value of learning te reo Māori. They showcased Māori language on their classroom walls, to enhance its status, and they integrated Māori across a range of curriculum areas. Moreover, they selected appropriate Māori language resources (albeit a few only) that aligned with their teaching contexts; and they facilitated practice opportunities for their students.

\subsubsection{Congruence between beliefs and practices}

The relationship between beliefs and practice is complex. However, in my observations of each of the four teachers, it was evident that some of their shared beliefs (as stated in the questionnaire) were congruent with their classroom practice. For example, they modelled good pronunciation and ensured that the learning of te reo was fun for students. Moreover, they incorporated some aspects of tikanga e.g. tuakana: teina and ako (important for reciprocal teaching and learning); and 'pepeha' (important for place-based inquiry).

However, while the four teachers may have had genuine beliefs about propositions related to the teaching and learning of Māori language in English-medium primary classrooms, their practices were not necessarily congruent. For example, all four teachers stated the belief that group work was valuable for students. However, in practice, they generally reverted to whole class instruction - presumably because it was easier than facilitating Māori language learning in groups. (That would have required more reo proficiency, more planning and logistics, and more monitoring of progress and on-task behaviour). 
Another mismatch between the four case study teachers' stated beliefs and their actual practice was the lack of Māori language resources being used to support their reo Māori programmes. Even though they had each expressed the belief that it was important to expose students to a range of Māori language materials, this was evident (albeit minimally) in only two classrooms.

Furthermore, despite their belief that it was important to draw on students' prior knowledge/experiences, the four teachers did not always maximise potential opportunities to tap into Māori students' cultural capital.

\subsubsection{Factors influencing the teaching of Māori}

Teaching is a difficult and multi-faceted job - and the complex relationship between beliefs and practice is influenced by different factors that can enable or inhibit teaching and learning. The following factors were evident in my study:

- affective factors (e.g. teachers' previous personal experiences, both positive and negative; beliefs; lack of confidence /poor self-efficacy);

- $\quad$ cultural factors (e.g. teachers' lack of knowledge about Māori culture; absence of proprietary rights/ownership);

- linguistic factors (e.g. teachers' limited reo proficiency; lack of knowledge around second language acquisition);

- instructional factors (e.g. availability, or not, of quality reo Māori materials and associated PD);

- $\quad$ physical factors (e.g. time constraints in a crowded curriculum);

- $\quad$ social factors (e.g. parental expectations/objections; support, or not, from principal, senior leadership, colleagues and school whānau); and

- $\quad$ institutional factors (e.g. expectations in Ka Hikitia and Tãtaiako; and performance appraisal).

Teachers could be better supported by having quality user-friendly Māori language resources suitable for English-medium primary school settings. Furthermore, they need PD to become familiar with those resources, upskill their Māori language proficiency, increase their knowledge about second language acquisition, and enhance their understanding of tikanga. Additionally, they need more time within the busy classroom curriculum to 
accommodate te reo Māori teaching and learning. They also need more encouragement and support from school leaders and whānau.

\subsubsection{Teachers' views on Māori language resources}

The lack of quality Māori language resources can impact on a teacher's practice, even if they have good intentions and believe it is important to teach te reo. My study found that existing Ministry resources (depicted visually in the teacher questionnaire on Facebook, as a stimulus) were generally unknown - and therefore under-utilised. The exception was the Ministry's multimedia resource He Reo Tupu, which (unlike the other resources referred to in my questionnaire) was used by each of the four case study participants - either 'half the time', 'most of the time' or 'always'. In contrast, they 'never' used the Ministry's Māori language readers nor the First Class DVD that is associated with 'hands-on' PD around second language acquisition. Furthermore, the Māori language curriculum guidelines, Te Aho Arataki Marau, were only used 'sometimes' - or, in one case, 'never'.

Among the 40 questionnaire respondents, the top three criteria for a quality reo Māori resource were: real-life contexts, user-friendliness, and inclusion of tikanga. Two of these aspects were also ranked as the top three criteria by the four case study teachers - namely, real-life contexts and user-friendliness. Notably missing for the case study teachers, however, was the inclusion of tikanga. Instead, their next criteria of quality were English translations/glossaries and audio support (ranked equally).

In terms of future Māori language resource development, the 40 questionnaire respondents wanted:

- Māori language games/multimedia;

- Resources that help teachers to use te reo Māori in the classroom; and

- Resources that provide Māori pronunciation support.

The four case study teachers were more specific in their requests, advocating for the development of:

- Big bilingual books (for shared reading experiences and dual literacy); and

- Resources about their local area. 


\subsection{Limitations}

Although administered rigorously and conscientiously, the research has limitations. For example, my experience working in the sector is bound to have impacted on the data collected, and the subsequent analysis, in terms of teachers perhaps saying what they thought I wanted to hear.

There are also limitations around participant self-selection, where some bias is possible as in the recruitment of the online questionnaire respondents. The nature of my topic may have meant that it was mainly teachers favourably disposed to the teaching of te reo Māori who agreed to participate in the questionnaire on Facebook. Hence the positivity of their responses. That is, because they deemed it to be a worthwhile topic, and believed that their views mattered, they were prepared to invest their time in responding to the questionnaire. However, I am mindful that they were not representative of the entire population of nonMāori teachers in English-medium primary schools. The degree of generalisabilty is therefore negligible.

Similarly, the four teachers who were observed and interviewed were not necessarily representative of their colleagues. They were selected because they were known to me and because of their physical location in Wellington (for reasons of practicability), working in different parts of the region, at schools with different deciles, and at different year levels. The latter criterion was slightly compromised when, for health reasons, one of the five teachers who initially agreed to the observations and interviews had to withdraw from the study at the last minute. (She was going to be absent from school for nearly two terms). This meant a gap in my coverage of all year levels (as she was the only teacher of Year 34 students). It also meant a gap in terms of my intention to observe and interview teachers with varying degrees of experience (as she was relatively new to the profession i.e. 3-5 years' experience). Moreover, the withdrawal of her school created another gap, in that it had the lowest percentage of Māori students; namely, 7\%, in contrast to the other four case study teachers' schools where the Māori roll ranged from 12\% - 43\%.

There are also limitations associated with the self-reporting in the online questionnaire. For example, the teacher participants may have provided socially desirable or politically correct responses, having deduced that the teaching and learning of te reo Māori was valued by me, as the researcher. They may have described what should happen ideally, as opposed to 
what actually happens in their teaching - in an attempt to show themselves in a favourable light. This is a normal human tendency.

Likewise, the teachers may have over-inflated their Māori language ability, to impress or to increase their mana in my eyes, thus maintaining their 'halo' (Mackey and Gass, 2015). Conversely, some may have under-reported their ability, to avoid being perceived as whakahīhī (i.e. showing off) - as portrayed in the Māori proverb about humility, where the kūmara does not boast about its sweetness: Kāore te kūmara e kōrero ana mō tōna ake reka. I acknowledge therefore that the teachers' stated beliefs may not have genuinely represented what they truly believed. That is, their beliefs may have been articulations of what they thought others (like me) expected them to believe.

In the questionnaire, my opting for a scale with three clear points of distinction (Yes /No/ Unsure) may be perceived as a limitation, seeing that 4-11 points are recommended in research (McKelvie, 1978; Nunnally, 1978). However, as already explained in 3.8.1.4, this was because I wanted to ease respondent burden - by making it simple and quick for busy classroom teachers to respond to. The three points were adequate for my purpose. More points would have taken longer for teachers to process and discriminate. Furthermore, research by Converse and Presser (1986) and Schuman and Presser (1996) reveals no appreciable effect on overall results when a greater number of points are used on a scale. Notwithstanding, I accept that having four points, with no neutral middle alternative, would have avoided possible 'fence-sitting' - forcing participants to lean one way or the other, thus minimising ambiguity in the data.

Although my pre-existing professional relationship with the four teachers whom I observed and interviewed could be perceived by some as a limitation, I prefer to view it as an advantage, in that my physical presence during classroom observations was less intrusive than would have been the case if I had been a stranger. Having already established rapport with the teachers in the past, they felt comfortable in the follow-up interviews too.

The scope of this research (i.e. teacher perspectives only) presents a limitation too. It would be worthwhile if future research explored the perspectives of students, whānau and resource developers - to determine the extent of convergence and divergence across their respective beliefs about the teaching and learning of Māori language in English-medium primary schools. 
One final limitation is the fact that, for each of the four case study teacher participants, there were four hours of observations, which may seem light. However, this was practicable in terms of the time teachers were being asked to devote to this research. Nevertheless, it is acknowledged that a longer period devoted to observations would have enhanced reliability and validity.

\subsection{Challenges}

The literature review presented a challenge in terms of there being a dearth of literature (especially from a Māori perspective) about the teaching of Māori language in Englishmedium primary schools, and the development of associated resources.

Also challenging was the fact that, during my study, there were important changes in the policy environment. Firstly, a new coalition government was elected in 2017 - a government that was more favourably disposed to the prioritisation of Māori language education in students' formative years. Hence its vision that, by 2025, the basics of the language will be integrated into all early childhood, primary, and intermediate school education. Furthermore, the appointment of this new government brought the abolishment of the previous government's policy of National Standards, which assessed primary school students' achievement in the curriculum.

During the same period, new Standards for the Teaching Profession were also developed (Education Council, 2017), describing the expectations of effective teaching practice in Aotearoa NZ. The first standard (p. 18) is particularly relevant for my research as it relates to teachers' ability to "...practise and develop the use of te reo and tikanga Māori."

Another important policy change during my study was the creation of government's Māori Language Strategy (i.e. Maihi Karauna) in 2018 - complementary to the strategy for Māori iwi and communities, to be overseen by Te Mātāwai (i.e. Maihi Māori). The Crown strategy makes government accountable for national-level issues associated with te reo Māori (including the teaching thereof, at the meso-level of the school) and Māori language planning at a macro-level (including the public sector). Furthermore, at the time of writing up my $\mathrm{PhD}$, another iteration of the Ministry's Māori education strategy, Ka Hikitia, was imminent (and in fact overdue). 
In addition to challenges associated with the literature review and a changing policy environment, there were challenges in recruiting four non-Māori primary teachers in English-medium schools who were:

- $\quad$ willing to be observed in their normal classroom programmes, then interviewed;

- $\quad$ supported by their principals to participate, in the interests of Māori language research;

- $\quad$ teaching different-aged students (Years 1-6);

- $\quad$ representative of the primary school teaching demographic (hence the inclusion of one man); and

- $\quad$ working in schools that:

- $\quad$ covered three different geographic regions within Wellington;

- $\quad$ accommodated a range of deciles (1-10);

- $\quad$ varied in school roll size (210-373); and

- $\quad$ comprised different percentages of Māori students $(12 \%-43 \%)$.

Losing one of the original five case study participant teachers (due to illness) at the $11^{\text {th }}$ hour was particularly challenging, in that it created gaps in my sampling strategy (as discussed above, under Limitations). However, because of time constraints, and after discussions with my primary supervisor, the decision was made to proceed with four case study participants (instead of five) - selected from the 40 teachers who responded to the initial online questionnaire.

The busy nature of teachers' lives, and school life in general, presented challenges in terms of finding suitable times in teachers' diaries for me to conduct the observations and interviews. These arrangements had to be altered sometimes to accommodate teacher absences and changes to the planned teaching programme.

The most challenging aspect for me was the design of the Qualtrics survey and the use of the software data analysis package NVivo. Both were completely new to me. The former was useful for creating my online questionnaire, then analysing the quantitative responses. The latter helped me to code and analyse the qualitative data. However, it is entirely feasible that the data collection and analysis process could have been more refined if I had been more experienced with the NVivo package. 
Finally, I found it personally challenging (as a researcher) to sustain my trusted relationship with the four case study participants in affirming their efforts, while at the same time being aware of the need to maintain professional distance for the analysis.

\subsection{Future research}

The new learning that emerged from my research could be enhanced in the future by doing a nationwide survey of English-medium primary teachers, using the same/similar belief statements from my framework, as a model, to see if the beliefs of my 40 non-Māori teacher respondents (about Māori language teaching in Years 1-6) are representative of primary school teachers.

In addition, it would be useful to capture these teachers' views on: compulsory Māori language in English-medium primary schools; the conditions that would need to be put in place if indeed Māori language became compulsory in their settings; and the most common factors that impede the teaching and learning of Māori in English-medium primary schools, with recommendations on how to overcome.

It would also be useful to examine the reo Māori proficiency levels of teachers in English-medium primary schools - to determine the extent of their ability to deliver levels 1-2 of the Ministry’s Māori language curriculum guidelines.

Qualitative research could be conducted to collect whānau voice about their Māori language aspirations for their tamariki/mokopuna, and their views on the language being compulsory in English-medium schools.

Research focussing on student voice would be insightful, in terms of their views on:

- why English-medium primary students should (or should not) learn Māori e.g. motivation and perceived benefits (or not);

- what Māori language content should be covered in Years 1- 8, prior to transitioning to Māori classes at secondary school; and

- the pros and cons of compulsory Māori language in English-medium primary schools.

Additionally, it would be helpful to facilitate focus group research with Englishmedium primary school teachers and Māori language resource developers (together) 
presenting their views on what resources are needed (in terms of content and media types), and what can practicably be developed (keeping in mind the desirable characteristics that emerged from my study regarding quality Māori language resources).

A worthwhile (and overdue) piece of research would be a systematic evaluation of Māori language resources, to create an evidence base about the success (or not) of different types of resources in English-medium primary schools - with a view to informing future resource development.

Another area in need of evaluation is that of PD programmes specifically targeted at the teaching and learning of te reo in English-medium primary schools - with a focus on their quality, availability, content, uptake and outcomes.

Following on from the target group in my study, it would be useful to examine the transition years from Year 6 to Year 7/8, then to secondary school - focussing on the learning of Māori in Year 7-10 English-medium classes, as this is a focus of Ministry policy in terms of learning languages prior to NCEA in Years 11-13.

A replication of my study would be worthwhile, gathering participant-relevant perspectives from a larger and more diverse group of participants; for example:

i. A mix of Māori and non-Māori teachers in English-medium primary schools outside the Wellington region (so that the findings can be applied more widely); and/or

ii. 'Māori only' teachers in English-medium primary schools across Aotearoa NZ (to enable a comparison with my findings, which are specific to non-Māori teachers).

Finally, it may be worthwhile considering a replication of this study among other Indigenous language communities.

\subsection{Chapter review}

In this chapter, I re-stated the research aim, the research questions, and my position as a non-Māori researcher - before providing a synthesis of the findings associated with the 
four case study teachers. I acknowledged the challenges and limitations of the research and suggested future research possibilities. I now finish with my final word.

\subsection{Final word: He korero tāpiri}

Tōku reo, tōku ohooho. My language is my awakening

Te reo Māori is the Indigenous language of Aotearoa NZ - unique to this country, and a taonga under the Treaty of Waitangi. It provides a window to another world, another perspective, another set of values. By teaching Māori in English-medium settings, nonMāori primary school teachers are demonstrating their respect for Māori culture and Māori people.

Moreover, the learning of te reo Māori benefits all students - linguistically, cognitively, socially, culturally, in the future workforce, and as a marker of national identity. There are particular benefits too for Māori students. Having their language, culture and identity validated provides a platform for overall achievement at school - which is of national importance, in light of historical differential achievement due to failures of the education system. The provision of quality Māori language programmes in English-medium primary schools, during Māori students' formative years, would contribute to the vision outlined in the Ministry’s Māori Education Strategy, Ka Hikitia; namely, Māori students achieving and enjoying success as Māori.

The kaupapa of the study is close to my heart. I am personally invested - having two Māori sons and six mokopuna, and having been a reo Māori teacher and adviser in schools. I would like to think that, in the near future, my mokopuna and their contemporaries (Māori and non-Māori) will have access to an effective, incrementally progressive Māori language programme in English-medium primary schools, unlike current and previous generations exposed to a limited and repetitive repertoire.

For this to happen, we need to address teacher capability and resource development. Teachers need help, in the form of PD, to upskill their reo proficiency and familiarise themselves with theoretical knowledge associated with second language acquisition. They also need quality Māori language resources (specifically written for an English-medium audience in primary school settings) that reflect real-life contexts, incorporate aspects of tikanga, are user-friendly, provide audio support, and include English translations/glossaries. 


\section{REFERENCES | NGĀ WHAKAPUAKANGA}

Agar, M. (1996). The professional stranger: An informal introduction to ethnography. San Diego, CA: Academic Press.

Allen, L. (2002). Teachers' Pedagogical Beliefs and the Standards for Foreign Language Learning. Foreign Language Annals, 35, 518-529.

Alton-Lee, A. (2003). Quality Teaching for Diverse Students in Schooling: Best Evidence Synthesis Iteration [BES]. Report from the Medium Term Strategy Policy Division. Wellington, NZ: Ministry of Education.

Antonek, J.L., McCormick, D. E., \& Donato, R. (1997). The student-teacher portfolio as autobiography: Developing a professional identity. Modern Language Journal, $81(1), 15-27$.

Austin, P. K. \& Sallabank, J. (2011). Cambridge Handbook of Endangered Languages. Cambridge, UK: Cambridge University Press.

Bakhtin, M. (1986). Speech Genres and Other Late Essays. Translated by Vern W. McGee. Austin, TX: University of Texas Press.

Barnard, R. \& Burns, A. (Eds). (2012). Researching language teacher cognition and practice: International case studies. Bristol, UK: Multilingual Matters.

Barr, S. \& Seals, C. A. (2018): He Reo for Our Future: Te Reo Māori and Teacher Identities, Attitudes, and Micro-Policies in Mainstream NZ Schools, Journal of Language, Identity \& Education, 17(6), 434-447.

Basturkmen, H. (2012). Review of Research into the Correspondence between Language Teachers' Stated Beliefs and Practices. System, 40, 282-295.

Bauer, W. (2008). Is the Health of Te Reo Māori Improving? Te Reo, 51, 33-73.

Beach, S. A. (1994). Teachers' theories and classroom practice: Beliefs, knowledge, or context? Reading Psychology, 15(3), 189-96.

Beijaard, D., Meijer, P.C., \& Verloop, N. (2004). Reconsidering research on teachers' professional identity. Teaching and Teacher Education 20, 107-128.

Bennett, J. M., Bennett, M. J., \& Allen W. (2003). Developing intercultural competence in the language classroom. In D. L. Lange \& R. M. Paige (Eds.), Culture as the Core: Perspectives on culture in second language learning (pp. 237-270).

Greenwich, CT: Information Age Publishing. 
Benton, R. A. (1981). The flight of the Amokura. Oceanic Languages and Formal Education in the South Pacific. Wellington, NZ: NZCER/NZ Council for Educational Research.

Benton, R. A. (1983). The NZCER Māori Language Survey. Wellington, NZ: NZCER. Benton, R. A. (1985). The Māori Language, 1985 and beyond. Wellington, NZ: NZCER. Benton, R. A. (1991). The Māori language: Dying or reviving? Honolulu: East West Centre. Reprinted by NZCER 1997.

Benton, R. A. (1995). Towards a Languages Policy for NZ Education. NZ Annual Review of Education, 4, 161-173.

Benton, R. A. (2001). Whose language? Ownership and Control of Te Reo Māori in the Third Millennium. NZ Sociology, 16(1):35-54.

Bialystok, E. (2011). Reshaping the Mind: The Benefits of Bilingualism, Canadian Journal of Experimental Psychology, 65, 4: 229-235.

Bialystok, E. \& Majumder S. (1998). The relationship between bilingualism and the development of cognitive processes in problem-solving. Applied Psycholinguist, 19, 69-85.

Biddle, D. (2017, April 30). "Decile-one kids go to top of class". Stuff. Retrieved from https://www.stuff.co.nz/national/91778370/the-kids-that-were-never-meant-to-passkura-kaupapa-kids-top-ncea-exams

Biggs, B. G. (1968). The Māori Language Past and Present. In E. Schwimmer (Ed.), The Māori People in the Nineteen-Sixties, (pp. 65-84). Auckland, NZ: Blackwood and Janet Paul.

Bishop, A. R. (1997). Interviewing as collaborative storying. Education Research and Perspectives, 24(1), 28-47.

Bishop, R. (1996). Collaborative research stories: Whakawhanaungatanga. Palmerston North, NZ: Dunmore Press.

Bishop, R. \& Barr, H. (1999). NZ Country Report. In UNESCO Asia-Pacific Centre of Educational Innovation for Development (ACEID) and UNESCO. Teacher Education for Peace and International Understanding, (pp. 188-203). Tokyo: National Institute for Educational Policy Research (NIER).

Bishop, R. \& Berryman, M. (2009). The Te Kotahitanga Effective Teaching Profile. Set 2, NZCER.

Bishop, R. \& Glynn, T. (1999). Researching in Māori contexts: An interpretation of participatory consciousness. Journal of Intercultural Studies, 20(2), 167-182. 
Borg, S. (1998). Teachers' pedagogical systems and grammar teaching: A qualitative study. TESOL Quarterly, 32(1), 9-38.

Borg, S. (2003). Teacher cognition in language teaching: A review of research on what language teachers think, know, believe, and do. Language Teaching, 36(2), 81-109.

Borg, S. (2006). Teacher cognition and language education: Research and practice. London, UK: Continuum.

Bourdieu, P. (1977b). Outline of a Theory of Practice. Cambridge: Cambridge University Press.

Bourdieu, P. (1986). The forms of capital. In J. Richardson (Ed.), Handbook of Theory and Research for the Sociology of Education (pp. 240-258). New York: Greenwood.

Boyack, N. (2018. May 25). "No one keeping stats on stressed primary school principals". Stuff. Retrieved from https://www.stuff.co.nz/national/education/ $\underline{103521203 / \text { No-one-keeping-stats-on-stressed-primary-school-principals }}$

Boyce, M. (1995). The Role of Second Language Learners in Māori Language Maintenance and Revival - The Next Fifteen Years. Paper presented at the Hui Taumata, December 1995, Wellington.

Braun, V. \& Clarke, V. (2006). Using thematic analysis in psychology. Qualitative Research in Psychology, 3(2), 77-101.

Breen, M. P., Hird, B., Milton, M., Oliver, R., \& Thwaite, A. (2001). Making sense of language teaching: teachers' principles and classroom practices. Applied Linguistics, 22(4), 470-501.

Bright, N., \& Wylie, C. (2017). Ākonga Māori in English-medium primary and intermediate schools. Findings from the NZCER national survey of primary and intermediate schools 2016. Wellington: NZCER.

Bright, N., Broughton, D., \& Hutchings, J. (2017). Ka Whānau mai te Reo. In Set 1, 2017. Wellington, NZ: NZCER.

Brookhart, S. M. \& Freeman, D. J. (1992). Characteristics of entering teacher candidates. Review of Educational Research, 62, 37-60.

Brown, J. D. (2009). Open-response items in questionnaires. In J. Heigham \& R. A. Croker (Eds.), Qualitative Research in Applied Linguistics, (pp. 200-219). New York: Palgrave Macmillan.

Brown, P. \& Levinson, S. (1987). Politeness: Some Universals in Language Usage. Cambridge: Cambridge University Press. 
Bucholtz, M. \& Hall, K. (2005). Identity and Interaction: A sociocultural linguistic approach. Discourse Studies, 7(4-5), 585-614.

Burgess, J. \& Etherington, S. (2002). Focus on grammatical form: explicit or implicit? System, 30, 433-458.

Burns, A. (1996). Starting all over again: From teaching adults to teaching beginners. In D. Freeman \& J. C. Richards (Eds.), Teacher Learning in Language Teaching (pp. 154-77). Cambridge: Cambridge University Press.

Byram, M. (1997). Teaching and assessing intercultural communicative competence. Clevedon: Multilingual Matters.

Byram, M. \& Parmenter, L. (2012). The Common European Framework of Reference: The globalisation of language education policy. Bristol: Multilingual Matters.

Cabinet Minute SEQ (01) 111. Māori Language Resourcing in Schools: Effectiveness Audit Report. NZ Parliament, 2001.

Cabinet Minute SOC Min (14) 10/3. Investing in educational success. Design and implementation. NZ Parliament, 2014.

Canagarajah, S. (2011). Codemeshing in Academic Writing: Identifying Teachable Strategies of Translanguaging. The Modern Language Journal, 95(3), 401-417.

Canh, L. V. (2012). A theory-practice divide: EFL teachers' and students' beliefs about grammar instruction. English Australia Journal 27(2), 34-49.

Cenoz, J. (2013). The influence of bilingualism on third language acquisition: Focus on multilingualism. Language Teaching, 46(1), 71-86.

Cenoz, J., Genesee, F., \& Gorter, D. (2014). Critical Analysis of CLIL: Taking Stock and Looking Forward. Applied Linguistics, 35(3), 243-262.

Chomsky, N. (1965). Aspects of the Theory of Syntax. Cambridge, MA: MIT Press.

Christensen, I. (2001). Ko te whare whakamana: Māori language revitalisation. Unpublished PhD Thesis. Palmerston North: Massey University.

Christian, H., McNeilly, H., \& Jones, K. (2018). "Crowded schools ordered to enforce zones to make space for local kids". Stuff. Retrieved from https://www.stuff.co.nz/ national/education/102322013/school-zoning-under-fire-as-zones-increasealongside-enrolments.

Clark, C. M. \& Peterson, P. L. (1986). Teachers' thought processes. In M. C. Wittrock (Ed.), Handbook of Research on Teaching (3rd edition, pp. 255-296). New York: MacMillan. 
Clemente, M., Andrade, A. I., \& Martins, F. (2012). Learning to read the world, learning to look at the linguistic landscape: A primary school study. In C. Helot, M. Barni, R. Janssens, \& C. Bagna (Eds.), Linguistic landscapes, multilingualism, and social change (pp. 267-285). Frankfurt, Germany: Peter Lang.

Cohen, L., Manion, L., \& Morrison, K. (2000). Research Methods in Education (5th Edition). London: Routledge Falmer.

Converse, J. M., \& Presser, S. (1986). Survey Questions: Handcrafting the Standardized Questionnaire. Beverly Hills, CA: Sage.

Conway, C. \& Richards, H. (2014). Intercultural language learners: Are you providing opportunities for your students to reflect? NZALT Polyglot 39, 23-25.

CORE Education (2017). Taking Stock of Māori-medium Educational Resources:

Priorities, gaps and futures? Wellington, NZ: CORE Education.

CORE Education (2018). Te Reo Māori Resources in English-medium. Wellington, NZ: CORE Education.

Coyle, D. (2007). Content and Language Integrated Learning: Towards a Connected Research Agenda for CLIL Pedagogies. International Journal of Bilingual Education and Bilingualism, 10(5), 543-562.

Crabbe, D. (2005). The essence of learning second languages in the NZ school context. Paper prepared for the Ministry of Education's NZ Curriculum Marautanga Project.

Crawford, J. (1995). Endangered Native American languages: What is to be done, and Why? Bilingual Research Journal, 19(1), 17-38.

Crombie, W., Johnson, D., \& Kahukura Te Kanawa, H. (2001). Māori Syllabus and Curriculum Documents: A Critical Analysis Part 1: Tihe Mauri Ora He Puna Kōrero: Journal of Māori and Pacific Development, 2(2), 2-16.

Crookes, G. \& Arakaki, L. (1999). Teaching idea sources and work conditions in an ESL program. TESOL Journal, 8(1), 15-19.

Crystal, D. (2003). A Dictionary of Linguistics and Phonetics, 5th Edition, Maldon, MA: Blackwell Publishing.

Cummins, J. (2005). A proposal for action: Strategies for recognizing heritage language competence as a learning resource within the mainstream classroom. The Modern Language Journal, 89(4), 585-592.

Cunningham, I. (1999). The Wisdom of Strategic Learning. Aldershot, UK: Gower. 
Dagenais, D., Moore, D., Sabatier, C., Lamarre, P., \& Armand, F. (2009). Linguistic landscape and language awareness. In E. Shohamy \& D. Gorter (Eds.), Linguistic landscape: Expanding the scenery (pp. 253-269). New York, NY: Routledge.

Daly, N. (2007). Kūkupa, Koro, and Kai: The use of Māori vocabulary items in NZ English Children's Picture Books. NZ English Journal 21, 20-33.

Davies, L. \& Nicholl, K. (1993). Màori in education: A statistical profile of the position of Māori across the NZ education system. Wellington, NZ: Learning Media, Ministry of Education.

Denscombe, M. (2002). Ground Rules for Good Research. A Ten-Point Guide for Social Researchers. Buckingham: Open University Press.

Dörnyei, Z. \& Taguchi, T. (2010). Questionnaires in second language research: Construction, administration, and processing. New York: Routledge.

Duff, M. (2015, June 5). “White flight: Why middle-class parents are snubbing local schools". Stuff. Retrieved from https://www.stuff.co.nz/national/education/69025550/

Duff, P. (2008). Case study research in applied linguistics. New York, NY: Lawrence Erlbaum/Taylor and Francis.

Durie, M. (1994). Whaiora: Māori Health Development. Auckland: Oxford University Press.

Durie, M. (1995). Te Hoe Nuku Roa framework: A Māori identity measure. Journal of the Polynesion Society, 104, 4.

Durie, M. (2001). A framework for considering Māori educational advancement. Palmerston North: Massey University.

Durie, M. (2003). Ngā Kāhui Pou: Launching Māori futures. Wellington: Huia Publishers.

East, M., Shackleford, N., \& Spence, G. (2007). Promoting a multilingual future for Aotearoa/NZ. Journal of Asian Pacific Communication, 17, 1.

East, M. \& Scott, A. (2011). Assessing the foreign language proficiency of high school students in NZ: From the traditional to the innovative. Language Assessment Quarterly, 8(2), 179-189.

Education Council (2017). Our code, our standards. Wellington, NZ. Retrieved from https://www.educationcouncil.org.nz/content/our-code-our-standards.

Education Review Office/ERO (1994). Annual Report. Wellington. House of Representatives. 
Education Review Office/ERO (2007). Review of Curriculum Materials to Support the Teaching and Learning of Te Reo Māori. Wellington, NZ: ERO.

Education Review Office/ERO (2010). Success for Māori Students: Schools' Progress. Wellington, NZ: ERO.

Education Review Office/ERO (2011). Directions for learning: The NZ Curriculum principles, and teaching as inquiry. Wellington, NZ: ERO.

Elley, W. (1991). Acquiring literacy in a second language: the effect of book-based programmes. Language Learning. 41(3):375-411.

Ellis, R. (2002). Teaching Learners to Communicate: A Task-Based Approach. Rikkyo Journal of Intercultural Communication Studies, 1(4), 95-110.

Ellis, R. (2005a). Principles of Instructed Second Language Acquisition. Asian EFL Journal, 7(3):1-16. Time Taylor International, Busan, Korea.

Ellis, R. (2005b). Instructed second language acquisition: A literature review. NZ: Ministry of Education.

Everson, C. M. \& Green, J. L. (1986). Observation as inquiry and method. In M. C. Wittrock (Ed.), Handbook of research on teaching (3rd edn, pp. 162-213). New York: Macmillan.

Fairhall, U. \& Shuker, W. (1994). Report to Te Puni Kōkiri on Māori mathematics curriculum materials. Wellington: Ministry of Māori development.

Fanselow, J. F. (1988). “Let's see”: Contrasting conversations about teaching. TESOL Quarterly 22 (1), 113-30.

Fishman, J. (Ed.) (2001). From theory to practice (and vice versa): Review, reconsideration and reiteration. In Can threatened languages be saved? (pp. 451483). Clevedon: Multilingual Matters.

Fiske, E. B. \& Ladd, H. F. (2000). When schools compete: A cautionary tale. Washington, D.C.: Brookings Institution Press.

Fontana, A. \& Frey, J. (1994). Interviewing. In N. Denzin \& Y. Lincoln (Eds.), Handbook of qualitative research (pp. 361-376). Thousand Oaks, CA: Sage.

Freeman, D. (1992). Language teacher education, emerging discourse, and change in classroom practice. In J. Flowerdew, M. Brock, \& S. Hsia (Eds.), Perspectives on language teacher education (pp. 1-21). Hong Kong: City Polytechnic of Hong Kong.

Freeman, D. (1993). Renaming experience/reconstructing practice: developing new understandings of teaching. Teaching and teacher education, 9(5/6), 485-497. 
Gatbonton, E. (1999). Investigating experienced ESL teachers' pedagogical knowledge. The Modern Language Journal, 83, 35-50.

Gee, J. P. (2000). Identity as an analytic lens for research in education. Review of Research in Education, 25, 99-125.

Geertz, C. (1973). The Interpretation of Cultures, New York, NY: Basic Books.

Good, T. \& Brophy, J. (1987). Looking in classrooms (4th ed.). New York: Harper \& Row.

Gordon, L. (2015). 'Rich' and 'poor' schools revisited. NZ Journal of Educational Studies, 50, 1.

Gorter, D., Marten, H. F., \& Van Mensel, L. (Eds.) (2012). Minority languages in the linguistic landscape. Basingstoke, UK: Palgrave-Macmillan.

Gray, E. (2018, November 9). "High Court judge asks if interpreter needed following lawyer's comments in te reo". Stuff. Retrieved from https://www.stuff.co.nz/national/108484718/high-court-judge-asks-if-interpreterneeded-following-lawyers-comments-in-te-reo

Grin, F. \& Villaincourt, F. (1998). Language revitalisation policy: An analytical survey www.treasury.govt.nz/publications/research-policy/wp/1998/98-06/twp98-06.Pdf (Retrieved 4 December, 2016).

Haemata Ltd (2019). Evaluation of te reo Māori in English-medium Compulsory Education. Wellington: Te Taura Whiri i te Reo Māori (Māori Language Commission).

Hansard (9 November 2017) 725 NZPD Retrieved from https://www.parliament.nz/en/pb/hansard-debates/rhr/document/HansS_20171109 059850000/henare-peeni-rurawhe-adrian

Hansard (13 September 2018a) 732 NZPD Retrieved from https://www.parliament.nz/en/pb/hansard-debates/rhr/combined/HansD_20180913 $\underline{20180913}$

Hansard (12 September 2018b) 732 NZPD Retrieved from https://www.parliament.nz/en/pb/hansard-debates/rhr/combined/HansD_20180912 $\underline{20180912}$

Hansard (13 September 2018c) 732 NZPD Retrieved from https://www.parliament.nz/en/pb/hansard-debates/rhr/document/HansS_20180913 052350000/8-question-no-8-m\%C4\%81ori-development 
Hanson, D. J. (1980). Relationship between Methods and Findings in Attitude-Behaviour Research. Psychology 17, 11-13.

Harlow, R. (2003). Issues in Māori Language Planning and Revitalisation. He Puna Kōrero: Journal of Māori and Pacific Development, 4(1), 32.

Harrison, K. D. (2007). When Languages Die. The Extinction of the World's Languages and the Erosion of Human Knowledge. New York: Oxford University Press.

Harvey, S. (2013). Revisiting the idea of a national languages policy for NZ: How relevant are the issues today? The TESOLANZ Journal, 21, 1-13.

Hattie, J. (2002). Schools Like Mine: Cluster Analysis of NZ Schools. (Technical Report 14). Auckland, NZ: University of Auckland, Project asTTle.

Heller, M. (1995). Language choice, social institutions, and symbolic domination. Language in Society, 24(3), 373-405.

Higgins, R., \& P. Rewi, 2014. ZePA - Right-shifting: Reorientation Towards Normalisation. In Rawinia Higgins, Poia Rewi \& Vincent Olsen-Reeder (eds), The Value of the Māori Language: Te Hua o te reo Māori. Wellington: Huia, pp.7-32.

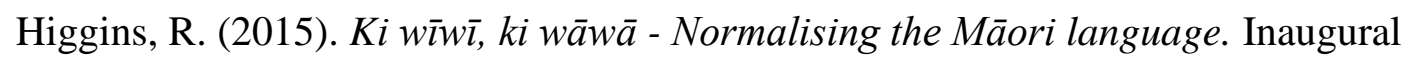
lecture, 7 July, 2015. Wellington: Victoria University of Wellington.

Hinton, L. (2001). Language revitalization: An overview. In L. Hinton \& K. Hale (Eds.), The green book of language revitalization in practice (pp. 3-18). California: Academic Press.

Hirsch, W. (1990). A report on issues and factors relating to Māori achievement in the education system. Auckland: Ministry of Education.

Hita, Q. (2005). Q's course in Māori. Harper Collins Publishers, NZ.

Hohepa, M. \& Smith, L. (1996). He Arotakenga Pukapuka: An evaluation of Māorimedium learning materials. Auckland: Te Pou Taki Kōrero. Auckland Uniservices Ltd.

Holliday, A. (1994). The House of TESEP and the communicative approach: The special needs of state English language education. ELT Journal, 48(1), 3-11.

Holmes, J. (1997). Keeping tabs on language shift in NZ: Some methodological considerations. Journal of multilingual and multicultural development, 18, 1.

Holstein, J. A. \& Gubrium, J. F. (1997). Active interviewing. In D. Silverman (Ed.), Qualitative research: Theory, method and practice (pp. 113-129). Thousand Oaks, CA: Sage. 
Holt-Reynolds, D. (1992). Personal history-based beliefs as relevant prior knowledge in coursework. American Educational Research Journal, 29, 325-49.

Hornberger, N. H. \& Wang, S. C. (2008). Who are our heritage language learners? Identity and biliteracy in heritage language education in the United States. In D. Brinton, O. Kagan, \& S. Bauckus (Eds.), Heritage language education: A new field emerging (pp. 3-35). New York, NY: Routledge.

Hunia, T. M. (2016). He kōpara e kō nei i te ata / Māori language socialisation and acquisition by two bilingual children: A case-study approach. Unpublished $\mathrm{PhD}$ Thesis. Wellington: University of Victoria, Wellington.

Irwin, K. (2017). What works with Māori? Presentation at Te Ritorito hui. June 15, 2017, Te Puni Kōkiri. https://www.youtube.com/watch?v=GmpougMiLT8. (Retrieved 14 December 2018).

Irwin, K. (1994). Māori Research Methods and Practices. Sites 28, 25-43.

Iwai, T., Kondo, K., Limm, S. J. D., Ray, E. G., Shimizu, H., \& Brown, J. D. (1999). Japanese Language Needs Analysis 1998-1999 (NFLRC NetWork 13). Honolulu: University of Hawaii, Second Language Teaching and Curriculum Centre.

Jackman, M. (2013). Te reo tamariki: Children talk about learning Māori. Unpublished BEd (Hons) Thesis. Auckland: The University of Auckland.

Jackson, M. (2013). Keynote presentation, He Manawa Whenua, He Manawa Whenua Indigenous Research Conference, Hamilton, NZ, 30 June-3 July, 2013. Retrieved from https://www.youtube.com/watch?v=lajTGQN8aAU

Johnson, K. (2003). Designing language teaching tasks. Basingstoke: Palgrave Macmillan.

Johnson, K. E. (1992a). Learning to teach: Instructional actions and decisions of preservice ESL teachers. TESOL Quarterly, 26, 507-35.

Johnson, K. E. (1992b). The relationship between teachers' beliefs and practices during literacy instruction for non-native speakers of English. Journal of Reading Behaviour, 24(1), 83-108.

Johnson, K. E. (1994). The emerging beliefs and instructional practices of pre-service English second language teachers. Teaching and Teacher Education, 10, 439-52.

Johnson, K. E. (2006). The sociocultural turn and its challenges for second language teacher education. Tesol Quarterly, 40, 235-257.

Johnson, R. B. \& Christensen, L. B. (2012). Educational research methods: Quantitative, qualitative, and mixed approaches (4th edition). Los Angeles, CA: Sage. 
Jones, M. (2016). Research Briefing. Welsh-medium education and Welsh as a subject. National Assembly for Wales, Research Service.

Kaa, W. \& Kaa, Te O. (1996). Apirana Turupa Ngata: ana tuhinga i te reo Māori. Wellington, NZ: Victoria University Press.

Ka'ai-Mahuta, R. (2011). The Impact of Colonisation on Te Reo Māori: A Critical Review of the State Education System. Te Kaharoa, 4(1), 195-225.

Kagan, D. M. (1990). Ways of evaluating teacher cognition: Inferences concerning the Goldilocks principle. Review of Educational Research, 60, 409-69.

Kagan, D. M. (1992). Implications of research on teacher belief. Educational Psychologist, 27, 65-90.

Kana, F. \& Tamatea, K. (2006). Sharing, listening, learning and developing understandings of Kaupapa Māori research by engaging with two Māori communities involved in education. Waikato Journal of Education, 12, 9-20. Retrieved from https://researchcommons.waikato.ac.nz

Kaplan, R. B. (1993). NZ Languages Policy: Making the Patient More Comfortable. Working Papers in Language Education, 1, 3-14.

Kennedy, J. (2016). Exploring opportunities for developing intercultural competence through intercultural communicative language teaching (ICLT): A case study in a Chinese as a foreign language classroom in a NZ high school. Unpublished Master's Thesis. Wellington, NZ: Victoria University of Wellington.

Kinzer, C. K. (1988). Instructional frameworks and instructional choices: Comparisons between pre- service and in-service teachers. Journal of Reading Behaviour, 20, 357-77.

Kohli, R. \& Solórzano, D. (2012). Teachers, please learn our names! Racial Microaggressions and the K-12 Classroom. Race, Ethnicity and Education. 15(4), 1-22.

Konopak, B. C. \& Williams, N. L. (1994). Elementary teachers' beliefs and decisions about vocabulary learning and instruction. Yearbook of the National Reading Conference, 43, 485-95.

Kopua, D. (2018, March 9). "In narrative therapy, Māori creation stories are being used to heal". Stuff. Retrieved from https://www.stuff.co.nz/national/102115864/innarrative-therapy-mori-creation-stories-are-being-used-to-heal

Kramsch, C. (1993). Context and culture in language teaching. Oxford: Oxford University Press. 
Kramsch, C. (2009). Third culture and language education. In V. Cook \& L. Wei (Eds.), Contemporary applied linguistics (pp. 233-254). London: Continuum.

Krashen, S. D. \& Terrell, T. D. (1983). The natural approach: Language acquisition the classroom. Hayward, CA: Alemany Press.

Krauss, M. (1992). The world's languages in crisis. Language, 68(1), 4-10.

Kvale, S. (1996). InterViews: An Introduction to Qualitative Research Interviewing. Thousand Oaks: Sage.

Landry, R. \& Bourhis, R, (1997). Linguistic Landscape and Ethnolinguistic Vitality: An Empirical Study. Journal of Language and Social Psychology. 16 (1): 23-49.

Lauchlan, F., Parisi, M., \& Fadda, R. (2012). Bilingualism in Sardinia and Scotland: Exploring the cognitive benefits of speaking a 'minority' language. International Journal of Bilingualism, 17(1), 43-56.

Lewis, M. P. \& Simons, G. F. (2009). Assessing Endangerment: Expanding Fishman's GIDS, Revue Roumaine de linguistique, 55, 1-30.

Lewis, J. (2015, July 25). ““White flight' blights Tomorrow’s Schools”. Otago Daily Times. Retrieved from https://www.odt.co.nz/news/dunedin/white-flight-blightstomorrows-schools

Liddicoat, A. J. (2007). Models of national government language-in-education policy for indigenous minority language groups. 2007 Conference of the Australian Linguistic Society. September 26-28, Adelaide.

Liddicoat, A. J. (2013). Language-in-education policies: The discursive construction of intercultural relationships. Bristol: Multilingual Matters.

Liddicoat, A. J. \& Taylor-Leech, K. (2014). Micro language planning for multilingual education: agency in local contexts. Current Issues in Language Planning, 15(3), 237-244.

Lightbown, P. \& Spada, N. (2013). How languages are learned. 4th Edition. Oxford University Press.

Lo Bianco, J. (2017). “Talk it up: A national languages policy”. Presentation to Royal Society of NZ, Wellington. 21 August, 2017.

Lortie, D. (1975). Schoolteacher: A Sociological Study. Chicago: University of Chicago Press.

Macalister, J. (1999). Trends in NZ: Some observations on the presence of Māori words in the lexicon. NZ English Journal, 13, 38-4. 
Macalister, J. (2006). The Māori presence in the NZ English Lexicon, 1850-2000:

Evidence from a corpus-based study. English World-Wide, 27(1), 1-24.

Mackey, A., \& Gass, S. M. (Eds.) (2012). Research methods in second language acquisition: a practical guide. Chichester: Wiley Blackwell.

Mackey, A., \& Gass, S.M. (Eds.) (2015). Second Language Research: Methodology and Design ( $2^{\text {nd }}$ ed). London: Routledge

Mangubhai, F., Marland, P., Dashwood, A., \& Son, J.B. (2004). Teaching a foreign language: One teacher's practical theory. Teaching and Teacher Education, 20, 291-311.

Māori Language Act 2016. Retrieved from https://www.youtube.com/watch?v=k85lsfS9rwk\&feature=youtu.be

Māori Language Commission (2017). Te Ahu o te Reo Overview Report. Wellington: NZCER.

Māori Language Commission, Mission Statement. Retrieved from http://www.tetaurawhiri.govt.nz/about-us/what-is-the-maori-languagecommission/vision-mission-and-outcomes/

Māori Language Commission (2017). Te Tauaki Whakamaunga Atu. Statement of Intent 2017/18-2020/21. Retrieved from http://www.tetaurawhiri.govt.nz/aboutus/corporate/statement-of-intent/.

Marsh, D. (1994). Bilingual Education \& Content and Language Integrated Learning. International Association for Cross-cultural Communication, Language Teaching in the Member States of the European Union (Lingua), Paris: University of Sorbonne.

Mataira, K. (1980). The Effectiveness of the Silent Way Method in the Teaching of Mãori as a Second Language. Unpublished MA thesis, Hamilton: University of Waikato.

Matika, C., Houkamau, C., \& Sibley, C. (2016). Demographic factors associated with support for Te Reo Māori: Analysis of Data from the NZ Attitudes and Values Study. Auckland: University of Auckland.

Maxwell, J. (2018, 17 December). "It's high time we ended segregation in our school system”. Dominion Post. Retrieved from https://www.stuff.co.nz/national/education/109364047/its-high-time-we-endedsegregation-in-our-school-system

May, S. (2008). Bilingual/immersion education: What the research tells us. In J. Cummins \& N. Hornberger (Eds.), Bilingual education: The Encyclopedia of Language and Education. (2nd edn, pp. 19-34). New York: Springer. 
May, S., Hill, R., \& Tiakiwai, S. (2004). Bilingual/immersion Education: Indicators of good practices. Wellington, NZ: Ministry of Education.

McComish, J. (2004). Literature survey on second language learning and teaching as it relates to te reo Māori as a subject in schools. Retrieved from Te Kete Ipurangi website, 1 December 2016: http://tereoMāori.tki.org.nz/Media/Files/LiteratureSurvey-on-Second-Language-Learning-and-Teaching-as-it-Relates-to-Te-ReoMāori-as-a-Subject-in-Schools

McKelvie, S.J. (1978). Graphic rating scales: How many categories? British Journal of Psychology, 69, 185-202.

McKenzie, T. (2014). The challenges and opportunities of using mobile devices to attain Māori language proficiency. Unpublished PhD Thesis. Wellington, NZ: Victoria University of Wellington.

McKinley, S., Christensen, I. S., Black, T. E., \& Richardson, P. (1996). Toi te Kupu: A framework for Māori language resource materials. He Pukenga Kōrero 2(1):26-33. Palmerston North: Massey University, School of Māori Studies.

Mead, L. (1996). Ngā aho o te kākahu mātauranga: The multiple layers of struggle by Māori in Education. Unpublished PhD thesis. Auckland: University of Auckland. Meijer, P. C., Verloop, N., \& Beijaard, D. (1999). Exploring language teachers' practical knowledge about teaching reading comprehension. Teaching and Teacher Education, 15, 59-84.

Meijer, P. C., Verloop, N., \& Beijaard, D. (2001). Similarities and differences in teachers' practical knowledge about teaching reading comprehension. Journal of Educational Research, 94, 171-84.

Menard-Warwick, J. (2009). Gendered identities and immigrant language learning. Clevedon: Multilingual Matters.

Menard-Warwick, J. (2005). Both a fiction and an existential fact: Theorizing identity in second language acquisition and literacy studies. Linguistics and Education, 16, $253-74$.

Mikaere, A. (2004). Are we all New Zealanders now? A Māori response to the Pākehā quest for indigeneity. Bruce Jesson Memorial Lecture. 31 October, 2004. www.converge.org.nz/pma/iwi-am04.pdf

Miles, M. B. \& Huberman, A. M. (1994). Qualitative data analysis: An expanded source book. Thousand Oaks, CA: Sage. 
Ministry of Education (n.d.) Assessment Online. Retrieved from http://assessment.tki.org.nz/Using-evidence-for-learning/Gatheringevidence/Topics/Formative-and-summative-assessment

Ministry of Education. (2006). Kiwi Kidsongs Waiata 15. Wellington, NZ: Learning Media.

Ministry of Education. (2007). Te Mana Kōrero. Retrieved from https://temangoroa.tki.org.nz/Video-stories/TMK-Culture-counts-1

Ministry of Education. (2007a). Ka Hikitia - Managing for Success: The Māori Education Strategy 2008-2012. Wellington, NZ: Ministry of Education.

Ministry of Education. (2007b). The NZ Curriculum for English-medium teaching and learning in Years 1 to 13. Wellington, NZ: Ministry of Education.

Ministry of Education. (2007c). Ka Mau te Wehi! Wellington, NZ: Huia Publishers.

Ministry of Education. (2008). Hei Waiata Hei Whakakoakoa. Wellington, NZ: Learning Media.

Ministry of Education. (2009). Te Aho Arataki Marau mō te Ako i Te Reo Māori - Kura Auraki. Wellington, NZ: Learning Media.

Ministry of Education. (2010). First Class: Effective Languages Learning Levels 1\&2. Wellington, NZ: Ministry of Education.

Ministry of Education (2011). Tātaiako: Cultural Competencies for Teachers of Māori Learners. Wellington, NZ: Ministry of Education.

Ministry of Education. (2011). He Reo Tuри He Reo Ora. Wellington, NZ: Ministry of Education.

Ministry of Education. (2013). Tau Mai te Reo: The Māori language in education strategy 2013-2017. Wellington, NZ: Ministry of Education.

Ministry of Education. (2013). Ka Hikitia-Accelerating Success 2013-2017. Wellington, NZ: Ministry of Education.

Ministry of Education. (2017). Te Pana i te Kāta me Tōna Wìra Kotahi [Pushing the onewheeled cart]. Wellington, NZ: Huia Publishers.

Ministry of Education. (2018). Learning Languages 2016 - Key Findings. NMSSA Report 12. Wellington, NZ: Educational Assessment Research Unit (University of Otago)/NZCER.

Ministry of Education (2018). Māori Language in Education. Education Counts. Retrieved from https://www.educationcounts.govt.nz/statistics/schooling/studentnumbers $/ 6040$ 
Ministry of Justice. (2013). NZ Bill of Rights Act 1990. Retrieved from http://www.legislation.govt.nz/act/public/1990/0109/latest/whole.html

Mockler, N. (2011). Beyond 'what works': Understanding teacher identity as a practical and political tool. Teachers and Teaching: Theory and Practice, 17(5), 517-528.

Moon, P. (2013). Turning Points: Events that Changed the Course of NZ History. Auckland, NZ: New Holland.

Munby, H. (1982). The place of teachers' beliefs in research on teacher thinking and decision-making, and an alternative methodology. Instructional Science, 11, 201225 .

Munby, H. (1984). A qualitative approach to the study of a teacher's beliefs. Journal of Research in Science Teaching, 21, 27-38.

Murrow, K., Hammond, K., Kalafatelis, E., Fryer, K., \& Edwards, H. (2006). Te reo Māori in the Mainstream Professional Development (PD) Pilot Programmes for Primary School Teachers - An Evaluation. Wellington: Research NZ and Aatea Consultants Ltd.

Nation, K. (2014). Lexical learning and lexical processing in children with developmental language impairments. Philosophical Transactions of the Royal Society B: Biological Sciences, 369(1634), 1-10.

Newton, J., Yates, E., Shearn, S., \& Nowitzki, W. (2010). Intercultural communicative language teaching: Implications for effective teaching and learning. Report to the Ministry of Education. Retrieved from http://www.educationcounts.govt.nz/publications/curriculum/76637/introduction

Norrby, C. \& Hajek, J. (2011). Language Policy in Practice: What happens When Swedish IKEA and H\&M Take 'You' On? In C. Norrby \& J. Hajek (Eds.), Uniformity and Diversity in Language Policy (pp. 242-258). Bristol: Multilingual Matters.

Norton, B. (2013). Identity and language learning: Extending the conversation. 2nd Edition. Bristol: Multilingual Matters.

Norton, B. \& Toohey, K. (2001). Changing perspectives on good language learners. TESOL Quarterly 35(2), 307-322.

Norton-Peirce, B. (1995). Social identity, investment, and language learning. TESOL Quarterly, 29(1), 9-31.

Numrich, C. (1996). On becoming a language teacher: Insights from diary studies. TESOL Quarterly, 30, 131-151. 
Nunnally, J. C. (1978). Psychometric theory (2 ${ }^{\text {nd }}$ ed.). New York: McGraw-Hill.

NZCER (2011). Kei Tua o Te Pae Hui proceedings. NZCER Press, Wellington, NZ.

NZCER (2017). Ka Whānau mai te Reo. Set 1. NZCER Press, Wellington, NZ.

NZEI (2018). 2018 NZEI Policy Working Document.Retrieved from

https://www.nzei.org.nz/UploadedFiles/Policy/Policy_Document_for_Annual_Meet ing_2018and_website_20180607.pdf

NZ House of Parliament. Māori Language Act, 2016. Retrieved from https://www.youtube.com/watch?v=k85lsfS9rwk\&feature=youtu.be

NZ Human Rights Commission (2010). Retrieved from https://www.hrc.co.nz/files/6214/2388/0532/HRNZ_10_Summary.html

NZ Human Rights Commission (2012). A Fair Go for All? Rite Tahi Tātou Katoa? Addressing Structural Discrimination in Public Services (Discussion paper, July 2012).

NZ School Trustees Association and Office of the Children's Commissioner (2018).

Education Matters to Me: Key insights. Retrieved from www.occ.org.nz

NZ Treasury (2012). Treasury's Advice on Lifting Student Achievement in NZ: Evidence Brief. Wellington: NZ Treasury.

OECD (2009). Creating Effective Teaching and Learning Environments: First Results from TALIS. Paris: OECD Publishing.

OECD (2010). Education at a Glance 2010: OECD Indicators. Paris: OECD Publishing. OECD (2013). Education Policy Outlook: NZ 2013. OECD Publishing, Paris.

Office of the Auditor General. (2013). Education for Māori: Implementing Ka HikitiaManaging for Success. Wellington: Parliamentary Paper.

Olsen-Reeder, V. 2018. Down the Back of the Chair: Books no one can read. Retrieved 1 November 2019, from: https://www.thesapling.co.nz/single-post/2018/12/12/Downthe-Back-of-the-Chair-Books-No-One-CanRead.

Oranje, J. (2013). Teaching culture in language classes at NZ secondary schools: Use of cultural portfolio projects as an intercultural communicative activity. Paper presented at ALANZ Conference. 27 - 29 November, 2013. Wellington, NZ.

Oranje, J. (2016). Intercultural Communicative Language Teaching: Enhancing awareness and practice through cultural portfolio projects. Unpublished $\mathrm{PhD}$ Thesis. Otago University.

Pajares, M. F. (1992). Teachers' beliefs and educational research: Cleaning up a messy construct. Review of Educational Research 62, 307-332. 
Palmer, P. J. (1998). The courage to teach. San Francisco: Jossey Bass.

Parahi, C. (2018, September 10). "Why the Government could face legal challenges over te reo Māori”. Stuff. Retrieved from https://www.stuff.co.nz/national/106895500/ why-the-government-could-face-legal-challenges-over-te-reo-maori

Parr, J., Aikman, M., Irving, E., \& Glasswell, K. (2004). An evaluation of the use and integration of ready-made commercial literacy packages into classroom programmes. Report prepared for NZ Ministry of Education. Auckland: Auckland Uniservices Limited.

Patara, L. (2012). Integrating culturally responsive teaching and learning pedagogy in line with Ka Hikitia. Set 2/4. Wellington: NZCER.

Peal, E. \& Lambert, W. (1962). The relation of bilingualism to intelligence. Psychological. Monographs 76, 1-23.

Penetito, W. (2009). Place-Based Education. Catering for Curriculum, Culture and Community. NZ Annual Review of Education 18, 5-29.

Penetito, W. (2010). What's Māori about Mãori education? Wellington: Victoria University Press.

Pennington, M. C. (1992). Reflecting on teaching and learning: A developmental focus for the second language classroom. In J. Flowerdew, M. Brock, \& S. Hsia (Eds.), Perspectives on second language teacher education (pp. 47-65). Hong Kong: City University of Hong Kong.

Pennington, M. C. (1999). Rules to break and rules to play by: Implications of different conceptions of teaching for language teacher development. In H. Trappes-Lomax \& I. McGrath (Eds.), Theory in language teacher education (pp. 99-108). London: Longman.

Pere, R. (1994). Ako: Concepts and Learning in the Māori Tradition. Wellington: Te Kōhanga Reo Trust.

Phipps, S. \& Borg, S. (2009). Exploring tensions between teachers' grammar teaching beliefs and practices. System, 37(3), 380-390.

Pihama, L. E., Tipene, J., \& Skipper, H. (2014). Ngā Hua a Tāne Rore. The Benefits of Kapa Haka. Wellington: Ministry for Culture and Heritage.

Pihama, L. (2010). Kaupapa Māori Theory: Transforming Theory in Aotearoa. He Pukenga Kōrero. Raumati (Summer), 9(2), 5-14.

Pine, R. (2018). Teacher trainees' attitudes and motivations towards learning te reo Māori. MAI Journal, Volume 7, Issue 2. 
Poulson, L., Avramidis, E., Fox, R., Medwell, J., \& Wray, D. (2010). The theoretical beliefs of effective teachers of literacy in primary schools: An exploratory study of orientations to reading and writing. Research Papers in Education, 16, 271-92.

Prowse, P. (2011). How writers write: Testimony from authors. In B. Tomlinson (ed), Materials Development in Language Teaching (2nd edn., pp. 151-174). Cambridge: Cambridge University Press.

Radio NZ (2016). "Tamsin Hanly Taking NZ history into Schools". Retrieved from https://www.radionz.co.nz/national/programmes/sunday/audio/201797377/tamsinhanly-taking-nz-history-into-schools

Radio NZ (2017). “Don Brash: Ragging on Te Reo”. Retrieved from https://www.rnz.co.nz/national/programmes/saturday/audio/2018623927/don-brashragging-on-te-reo

Ramirez, E. (2017). The intercultural dimension in language classrooms in Aotearoa NZ: A contrastive study across languages and teachers' level of proficiency. Unpublished PhD thesis. Auckland: University of Auckland.

Ratima, M. \& May, S. (2011). A Review of Indigenous Second Language Acquisition: Factors leading to proficiency in te reo Māori (the Māori language). Mai Review 1, $1-21$.

Renwick, M. \& Vize, J. (1992). Windows on teacher education. Phase 3, The third year: student progress through colleges of education. Wellington, NZ: NZCER.

Rewi, T. (2014). Utilising Kaupapa Māori Approaches to Initiate Research. MAI Journal, $3(3), 242-254$.

Richards, H., Conway, C., Roskvist, A., \& Harvey, S. (2010). Intercultural language learning (ICLL): Awareness and practice of in-service language teachers on a professional development programme. NZ Studies in Applied Linguistics, 16(1), 115.

Richards, J. C. (2017). Identity in Language Teaching. LALS lecture series. Wellington, NZ: Victoria University, 15 September 2017.

Richards, J. C., Tung, P., \& Ng, P. (1992). The culture of the English language teacher: a Hong Kong example. RELC Journal, 23(1), 81-102.

Richards, K. (1999). Working towards common understandings: Collaborative interaction in staffroom stories. Text, 19, 143-174.

Richards, K. (2006). 'Being the teacher': Identity and classroom conversation. Applied Linguistics, 27(1), 51-77. 
Richardson, V. (1996). The role of attitudes and beliefs in learning to teach. In J. Sikula, T. J. Buttery, \& E. Guyton (Eds.), Handbook of Research on Teacher Education, (2nd edn., pp.102-119). New York: Simon and Schuster.

Robb, A. (2017, March 4). "Who should call the shots on reo Māori priorities?” Etangata. Retrieved from https://e-tangata.co.nz/reo/who-should-call-the-shots-onreo-maori-priorities/

Rowland, S. (2006). The enquiring university. Maidenhead, UK: Open University Press.

Royal Society of NZ (2013). Languages in Aotearoa NZ. Retrieved from http://royalsociety.org.nz/media/Languages-in-Aotearoa- New-Zealand.

Rubie, C. (1999). The effect of a Māori cultural group experience on children's selfesteem, locus of control and academic performance. Unpublished Master's thesis. Auckland: University of Auckland.

Sakulku, J. \& Alexander, J. (2011). The impostor phenomenon. International Journal of Behavioral Science, 6(1), 73-92.

Schiffman, H. (1996). Linguistic culture and language policy. Routledge, London.

Schmitt, N. (2008). Instructed second language vocabulary learning. Language Teaching Research, 12(3), 329-363.

Schulz, R. A. (1996). Focus on form in a foreign language classroom: Students' and teachers' views on error correction and the role of grammar. Foreign Language Annals, 29, 343-64.

Schulz, R. A. (2001). Cultural differences in student and teacher perceptions concerning the role of grammar teaching and corrective feedback: USA-Colombia. Modern Language Journal, 85, 244-58.

Schuman, H. \& Presser, S. (1996). Questions \& answers in attitude surveys. London: Sage Publications.

Schunk, D. H. (1991). Self-efficacy and academic motivation. Educational Psychologist, 26, 207-231.

Seals, C. A. (2017). Positive and negative identity practices in heritage language education, International Journal of Multilingualism, 15(4), 329-348.

Seals, C.A. (2018a). "He Puna Reo: Embracing New Zealand's Linguistic Diversity" - a paper presented (with others) on the panel 'Non-Western approaches to, and views on, Translanguaging in Multilingual Education', at the 22nd Sociolinguistics Symposium, University of Auckland, NZ, June 28, 2018. 
Seals, C.A. (2018b). "Translanguaging in NZ Māori and Samoan Early Childhood Education Centres"- a seminar and master class given at Monash University, Australia, July 13, 2018.

Seals, C. A. \& Olsen-Reeder, V. (2017). Te reo Māori, Samoan, and Ukrainian in New Zealand. In C. A. Seals \& S. Shah (Eds.), Heritage Language Policies around the World (pp. 221-236). London: Routledge.

Seals, C. A. \& Peyton, J. K. (2017). Heritage language education: Valuing the languages, literacies, and cultural competencies of immigrant youth. Current issues in language planning, 18(1), 87-101.

Seals, C. A. \& Shah, S. (2018). Heritage language policies around the world. Abingdon, New York: Routledge.

Sercu, L. (2005). Teaching foreign languages in an intercultural world. In L. Sercu, E.

Bandura, P. Castro, L. Davcheva, C. Laskaridou, U. Lundgren, M. Mendez García, P. Ryan, (Eds.), Foreign language teachers and intercultural competence: An international investigation (pp. 1-18). Clevedon: Multilingual Matters.

Sercu, L. (2010). Assessing intercultural competence: More questions than answers. In A. Paran \& L. Sercu (Eds.), Testing the untestable in language education (pp. 17-34). Bristol: Multilingual Matters.

Sercu, L. \& St. John, O. (2007). Teacher beliefs and their impact on teaching practice: A literature review. In M. Jiménez Raya \& L. Sercu (Eds.), Challenges in teacher development: Learner autonomy and intercultural competence (pp. 41-64). Frankfurt am Main: Peter Lang.

Shohamy, E. (2006). Language policy: Hidden agendas and new approaches. Abingdon: Routledge.

Smith, G. H. (1992). Tane-nui-a-rangi’s legacy: Propping up the sky. Kaupapa Māori as resistance and intervention. Paper presented at NZARE/AARE Joint conference, Deakin University Australia. Published in Creating space in institutional settings for Māori. Auckland: International Research Institute for Māori and Indigenous Education, University of Auckland.

Smith, G. H. (1997). The Development of Kaupapa Māori: Theory and Praxis. Department of Education. Auckland: University of Auckland.

Smith, G. H. (2003). Kaupapa Māori theory: Theorizing indigenous transformation of education and schooling. Paper presented at NZARE/AARE Joint conference, Kaupapa Māori Symposium, Auckland, December 2003. 
Smith, L.T. (2012). Decolonizing methodologies: Research and indigenous peoples. London: Zed Books.

Smyth, A. \& Holian, R. (1999). The credibility of the researcher who does research in their own organisation: The perils of participant observation. Paper presented in July, 1999, at the Association of Qualitative Research Conference: Issues of Rigour in Qualitative Research, Melbourne, Australia.

Soler, J. \& Smith, J. (2000). Literacy in NZ: Practices, politics and policy since 1900. Auckland, NZ: Longmans.

Spada, N. \& Massey, M. (1992). The role of prior pedagogical knowledge in determining the practice of novice ESL teachers. In J. Flowerdew, M. Brock \& S. Hsia (Eds.), Perspectives on Second Language Teacher Education (pp. 23-37). Hong Kong: City Polytechnic.

Spence, G. P. (2004). The practice of policy in NZ: Current issues in language planning, 5(4), 389-406.

Spolsky, B. (1989). Conditions for Language Learning. London: Oxford University Press.

Spolsky, B. (2003). Re-assessing Māori re-generation. Language in Society, 32(4), 553578.

Spolsky, B. (2007). Toward a theory of language policy. Working Papers in Educational Linguistics, 22(1), 1-14.

Statistics NZ (2001). Survey on the health of the Mãori language. Wellington: Statistics NZ.

Statistics NZ (2008). NZ official yearbook 2008. North Shore City, NZ: David Bateman Ltd.

Statistics NZ (2013). Te Kupenga. Wellington: Statistics NZ.

Statistics NZ (2014). Measuring te reo Māori speakers: A guide to different sources. Wellington: Statistics NZ

Staub, F. C. \& Stern, E. (2002). The nature of teachers' pedagogical content beliefs matters for students' achievement gains: Quasi-experimental evidence from elementary mathematics. Journal of Educational Psychology, 94(2), 344-355.

Stewart, G. (2014) Te reo Māori in classrooms. Set 3. Wellington: NZCER.

Tabachnick, B. R. \& Zeichner, K. M. (1986). Teacher beliefs and classroom behaviours: Some teacher responses to inconsistency. In M. Ben-Perez, R. Bromme and R. 
Halkes (Eds.), Advances of Research on Teacher Thinking (pp. 84-96). Lisse,

Netherlands: Swets and Zeitlinger.

Talmy, S. (2010). Qualitative interviews in applied linguistics: From research instrument to social practice. Annual Review of Applied Linguistics, 30, 128-148.

Tāmati, S. (2016). Transacquisition Pedagogy for Bilingual Education: A Study in Kura Kaupapa Māori Schools. Unpublished PhD Thesis. Auckland: University of Auckland.

Te Huia, A. (2016). Pākehā learners of Māori language responding to racism directed toward Māori. Journal of Cross-Cultural Psychology 47(5), 734-750. Sage.

Te Puni Kōkiri. (1998). Māori Language Survey. Wellington: Te Puni Kōkiri.

Te Puni Kōkiri (2001). Māori Language Resourcing in Schools: Effectiveness Audit Report. Wellington: Te Puni Kōkiri.

Te Puni Kōkiri (2003). Survey of the health of the Māori language. Wellington: Te Puni Kōkiri.

Te Puni Kōkiri. (2007). Te Tirohanga ki te Reo Māori: The Māori language survey. Wellington: Te Puni Kōkiri.

Te Puni Kōkiri. (2008). Te Oranga o te Reo Māori 2006 - The Health of the Māori Language in 2006. Wellington: Te Puni Kōkiri.

Te Puni Kōkiri. (2010). Attitudes toward the Māori language summary sheet. Retrieved from Te Puni Kōkiri website (1.12.16): https://www.tpk.govt.nz/en/a-matoumohiotanga/language/summary-sheet-of-the-2009-Māori-languageattitudes/online/3

Te Puni Kōkiri (2014). Te Rautaki Reo Māori - Māori Language Strategy. Wellington: Ministry of Māori Development.

Te Puni Kōkiri (2019). Maihi Karauna. The Crown's Strategy for Māori Language Revitalisation 2019-2023. Wellington: Te Puni Kōkiri.

Te Puni Kōkiri \& Te Taura Whiri (2003). Te Rautaki Reo Māori. The Māori Language Strategy. Wellington: Ministry of Māori Development.

Timperley, H., Wilson, A., Barrar, H., \& Fung, I. (2007). Teacher Professional Learning and Development: Best Evidence Synthesis Iteration (BES). Wellington: Ministry of Education.

Tomlinson, B. (Ed.) (2003). Developing materials for language teaching. London: Continuum Press. 
Tomlinson. B. (2011). Materials Development in Second Language Acquisition. Cambridge: Cambridge University Press.

Treffers-Daller, J., Hofweber, J., \& Marinis, T. (2018). Code-switching, translanguaging and cognitive control. Paper presentation at ECSPM Symposium: Paradigm Shift in Language Education for the Development of multiliterate and plurilingual agencies. Darmstadt, 26-27 September 2018.

Tremblay, M. A. (1957). The key informant technique: A non-ethnographic application. American Anthropologist, 59, 699-701.

Tsui, A. B. M. (2003). Understanding expertise in teaching: Case studies of ESL teachers. Cambridge: Cambridge University Press.

UNESCO. (2003b). Language vitality and endangerment. Available online at: www.unesco/org/culture/ich/doc/src/00120-EN.Pdf (last accessed 20 February 2015).

United Nations. (2008). United Nations Declaration on the Rights of Indigenous People. (United Nations).

van den Branden, K. (2009). Diffusion and implementation of innovations. In M. H. Long \& C. J. Doughty (Eds.), The Handbook of Language Teaching. Oxford: WileyBlackwell. doi: 10.1002/9781444315783.ch35.

van Lier, L. (1988). The Classroom and the Language Learner. New York: Longman. Vásquez, C. \& Reppen, R. (2007) 'Transforming Practice: Changing Patterns of Participation in Post- observation Meetings', Language Awareness, 16(3), 153-172. Vergauwe, J., Wille, B., Feys, M., de Fruyt, F., \& Anseel, F. (2015). Fear of Being Exposed: The Trait-Relatedness of the Impostor Phenomenon and its Relevance in the Work Context. Journal of Business and Psychology. 30(3), 565-581.

Waitangi Tribunal (1986). Report of The Waitangi Tribunal on the te reo Mãori Claim (WAI 11). Wellington, NZ: Department of Justice.

Waitangi Tribunal (2011). Ko Aotearoa tēnei: A report into claims concerning NZ law and policy affecting Māori culture and identity. Waitangi Tribunal report (WAI 262), Wellington, NZ: Department of Justice.

Waite, J. (1992). Aoteareo: Speaking for Ourselves. Wellington: Learning Media.

Walters, L. (2017, September 15). "Māori Party says Labour's te reo plan lacks vision, courage, aspiration”. Stuff. Retrieved from https://www.stuff.co.nz/national/politics/96887608/mori-party-says-labours-te-reoplan-lacks-vision-courage-aspiration 
Walters, L. (2018, January 18). “Academic says te reo 'on life support', Bill English says it's not up to govt to save 'someone else's language'”. Stuff. Retrieved from https://www.stuff.co.nz/national/politics/100631948/academic-says-te-reo-on-lifesupport-bill-english-says-its-not-up-to-govt-to-save-someone-elses-language

Wenger, E. (1998). Communities of practice: Learning, meaning, and identity. 17th edn. New York: Cambridge University Press.

Westwood, P., Knight, B. A., \& Redden, E. (1997). Assessing teachers' beliefs about literacy acquisition: The development of the Teachers' Beliefs About Literacy Questionnaire (TBALQ). Journal of Research in Reading, 20, 224-35.

Whitinui, P. (2007). The Indigenous factor: Exploring kapa haka as a culturally responsive learning environment in mainstream secondary schools. Auckland: University of Auckland.

Whyte, W. F. (1984). Learning from the Field. Beverly Hill, California: Sage.

Williams, C. (2002). Extending Bilingualism in the Education System. Education and Lifelong Learning Committee. 6(2), 111-125.

Williams, K. (2019, April 16). “Government launches $\$ 12.2 \mathrm{~m}$ programme to bolster te reo Māori in classrooms”. Stuff. Retrieved from https://www.stuff.co.nz/national/education/112035496/government-launches-122mprogramme-to-bolster-te-reo-mori-in-classrooms

Willis, D. \& Willis, J. (2007). Doing task-based teaching. Oxford: Oxford University Press.

Wilson, E. K., Konopak, B. C., and Readence, J. E. (1992). Examining content area and reading beliefs, decisions and instruction: A case study of an English teacher. Yearbook of the National Reading Conference, 40, 475-82.

Winitana, C. (2011). My language, my inspiration - The struggle continues. Wellington: Huia Publishers.

Woods, D. (1996). Teacher Cognition in Language Teaching. Cambridge: Cambridge University Press. 


\section{APPENDICES}

\section{Appendix 1: Glossary}

ako - a concept that describes the notion of reciprocity in a teaching and learning relationship (incl the teacher as a learner)

Aotearoa - Māori name for New Zealand

ātaahua - beautiful

English-medium education - students being taught through the medium of English

ESL - English second language

hapori - community/communities

hapū - sub-tribe/s

harakeke - flax

hauora - wellbeing

he kanohi kitea - someone who is visible at Māori gatherings/events

he taonga tuku iho - treasures handed down

hinengaro - mind

hongi - pressing of noses as a form of greeting

Hui Taumata - Māori summit conference

ICLT - intercultural communicative language teaching

intercultural competence - the ability to interact and communicate across cultural boundaries iwi - people; tribe/s comprising sub-tribes (hapū)

Kāhui Ako - Communities of Learning (groups of people with similar beliefs/attitudes/opinions working together and sharing expertise, to help solve common problems in their practice)

kai - food

kaiako - teacher/s

kaikaranga - caller

kaikōrero - speaker

kaimoana - seafood

kaitiaki - guardian/s

kaitiakitanga - guardianship/stewardship

kanikani - dance

kanohi ki te kanohi - face-to-face

karaka - clock

karakia - prayer

karanga - call of welcome onto marae

kaumātua - elder/s 
kaupapa - topic/s

kaupapa Māori - knowledge, skills, attitudes and values of Māori society

kete - kit, basket

Kiwis - New Zealanders

koha - gift/ donation

Kōhanga Reo - Māori language pre-school 'nest/s'

kōrero - talk

koro - grandfather

kotahitanga - coming together for a common purpose in unity e.g. committed to the goal of promoting Māori language in schools

Kotemana - Scottish person

kōwhaiwhai - painted rafter patterns

kura - (Māori-medium) school/s

kura kaupapa - Māori-medium primary school/s

language acquisition - the process by which we acquire the capacity to understand and produce

language, to communicate in meaningful ways

language proficiency - knowing how to use a language

macron - a mark $($ ) over a vowel to indicate a long sound

macronisation - the placing of macrons to indicate long vowel sounds

mainstream - English-medium

Māmā - Mum

mana - status, pride, honour, prestige

manaakitanga - responsibility to take care of others, generosity

mana motuhake - self-determination and control over one's own destiny

mana tangata - accrued status; empowerment of people (e.g. participants 'taking risks' teaching te reo Māori)

mana whenua - authority and power over tribal land - occupied inter-generationally and imbued with the tribe's history and legends

manuhiri - visitor/s

mānuka - type of tree

Māori-medium education - students being taught all (or some) subjects in Māori

Māoritanga - Māori culture, practices and beliefs; Māoriness

marae - space in front of a Māori meeting house, used for social or ceremonial gatherings

Matariki - Māori New year

mātauranga Māori - Māori knowledge

maunga - mountain/s, hill/s

metalinguistic awareness - ability to think about, analyse, and discuss language 
mihi - to greet/greeting

minority language - a language used by a group that is subordinate in terms of their power relationship with the dominant group

mokopuna - grandchild(ren)

novice teacher - a teacher with less than 6 years' experience

Pākehā - people of European descent

pepa - paper

pepeha - proverbial saying that contextualises a person in terms of the land

PD - professional development

PLD - professional learning and development

pono - honest/true

pōwhiri - formal welcome on marae

Puna Reo - Māori early childhood centres, run by registered teachers

rākau - stick game, accompanied by waiata

rangatahi - youth

rangatiratanga - self-determination e.g. respecting people's opinions, recognising that everyone has a contribution to make

rauemi - resources

ringawera - workers

rongoā - medicine

School Certificate - a secondary school qualification (now obsolete)

semiotic - relating to the study of signs and symbols

sociolinguistics - the study of: i). the effect of society on how a language is used (e.g. expectations, cultural norms, context); and ii). vice versa, the effects of language use on society subtractive bilingualism - where people lose their first language during the process of learning a second language e.g. first language speakers of Māori learning English

taha Māori - Māori perspective

tamariki - children

tamariki /mokopuna - children/grandchildren

tangata whenua - local people/hosts; Indigenous people (of the land)

tangi/tangihanga - funeral $/ \mathrm{s}$

taonga - treasure

tauutuutu - reciprocity

TBLT - task-based teaching and learning

te ao Māori - the Māori world

(Te) Ataarangi - a method of learning Māori language using cuisenaire rods te iwi Māori - Māori people 
Te Kōhanga Reo National Trust - organisation with oversight of Māori language pre-school 'nests', and the use of Māori language therein

Te Māngai Pāho - the Māori Broadcasting Funding Agency

Te Paipera Tapu -The Holy Bible

Te Puni Kōkiri (TPK) - the Ministry of Māori Development

te reo - the language

te reo Māori - the Māori language

te reo Māori me ōna tikanga - Māori language and culture

te reo me ngā tikanga Māori - Māori language and customs

te reo rangatira o Aotearoa - the chiefly language of $\mathrm{NZ}$

te reo rangatira o tēnei whenua - the chiefly language of this land

Te Taura Whiri i te reo Māori - the Māori Language Commission

te tuakiritanga - identity

te uri o māia - inherent capability

tika - correct/right

tikanga - culture, custom/s (derived from tika meaning 'right')

tinana - body

tino rangatiratanga - autonomy/self-determination

tīpuna - ancestors

tî rākau - stick game, accompanied by waiata

tuakana:teina - lit. older sibling: younger sibling (same gender); a buddy system; or peer teaching tūpuna - ancestors

tūrangawaewae - a place/sense of belonging

tutū - mischievous, disobedient

waiata - song/s

waiata tawhito - old songs

wairua - spiritual aspect

waka - boat/canoe

wānanga - discuss/ion (e.g. cross-participant talks to stimulate ideas/enhance understanding) $O R$ a place of higher learning

wero - challenge

whaea - mother, auntie, or a figure who is like a mother /aunt

whaikōrero - speech making

whāinga ako - learning objective

whakahīhī - arrogant

whakaiti - humility

whakamā - ashamed, embarrassed 
whakapapa - genealogy

whakataukī - proverb/s

whakawhanaungatanga - relationship building, relating well to others

whānau - family/families

whānau/hapori/hapū/iwi - families, communities, sub-tribes, tribes

whānau hui - family gathering/s

whanaungatanga - relationship/s (usually based on kinship ties, but not exclusively so)

whāngai - 'adopted' child (lit 'to feed')

whānui - wide

whare - house

wharekura - Māori-medium secondary school/s

wharenui - meeting house

whāriki - mat 


\section{Appendix 2: Information sheet for practising teachers}

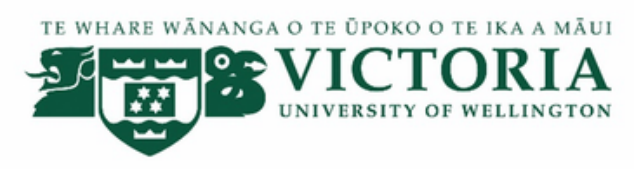

Exploring the beliefs and practices of non-Māori primary school teachers - to inform the development of materials that can support the teaching and learning of Māori language in Englishmedium classrooms

\section{INFORMATION SHEET FOR PARTICIPANT TEACHERS}

Tènā koe, ngā mihi nui ki a koe i runga i tēnei tino kaupapa - arā, ko te reo Māori kei roto i ngā kura auraki.

Ngā mate o tēnā iwi, o tēnā iwi, ka mihia, ka tangihia.

Thank you for your interest in this research. Please read the information below before deciding whether or not to take part. If you decide to participate, thank you. If you decide not to take part, I appreciate your having considered my tono.

Who am I? What is the aim of the study?

He uri nō Koterana tēenei e mihi nei. He Mãori āku tamariki, nō Ngāti Awa. Aku taura here ki te kaupapa o te reo Māori ko rātou ko aku mokopuna. Ko Alice Patrick tōku ingoa (http://alicepatrick.co.nz).

I am currently undertaking research for a $\mathrm{PhD}$ at Victoria University of Wellington - looking at the beliefs and practices of Year 1-6 non-Māori teachers in regard to Māori language teaching and learning, with a specific focus on reo Māori materials for the English-medium primary classroom.

The broad aim of the study is to help strengthen Māori language teaching and learning in Englishmedium primary schools.

The research has been approved by the Victoria University of Wellington Human Ethics Committee [approval number]. 


\section{How can you help?}

I'd like to invite you to participate in this research - to share your views on the teaching and learning of Māori language generally, and reo Māori materials specifically.

If you agree to participate, you will be asked to complete a consent form - as a record of your agreement.

The research comprises three aspects. Firstly, there is an online questionnaire (approximately 30 minutes) - to be completed by obliging, non-Māori primary teachers on the primary teachers' Facebook page. This phase of the research starts in October 2016.

Following this, I will conduct observations (one hour daily, for 4-5 days per teacher) in the classrooms of 5 of the questionnaire respondents (for approximately an hour each day, spread over a week, at times convenient to kaiako). My aim is to observe the teaching and learning of Māori generally - and more specifically the use of reo Māori materials (by both teachers and students). These observations will (with teachers' permission) be audio-recorded (and subsequently transcribed) - by having each teacher 'miked up'.

To complete the data collection process, I will do follow-up interviews (approximately 1 hour) with the 5 teachers who agreed to the classroom observations. These interviews will be semi-structured, at a time and place that's convenient to the kaiako. With their permission, the interviews will be audiorecorded so that they can be transcribed later. (I will ensure that each interviewee has an opportunity, after the event, to verify that their views have been represented accurately).

To summarise the research process, non-Māori primary teachers will be invited, through the primary teachers' Facebook page, to complete an online questionnaire. Thereafter, in the interests of manageability, and minimal intrusion, only 5 of the questionnaire respondents will be asked to participate in audio-recorded classroom observations and follow-up interviews.

\section{What will happen to the information you give?}

Any information you provide will be treated confidentially. I will not use your real name in the $\mathrm{PhD}$ dissertation, nor in any subsequent presentations or reports. Indeed, I will not include any information that could identify you. I will protect your identity (and the identity of your school) through the use of a pseudonym (which you can nominate), and the removal of any identifying details.

Any printed information that is collected will be stored in a locked cupboard at my home, while any electronic data (e.g. audio recordings) will be stored on my password-protected computer. The only 
people who will have access to the data are myself, my academic supervisors (Dr Corinne Seals, and Dr Karena Kelly), and a transcriber (who will sign a confidentiality agreement). The interview transcripts, summaries and recordings will be destroyed 5 years after the research ends.

You will receive a summary of the research findings, if requested.

\section{What will the project produce?}

The information will be used in my $\mathrm{PhD}$ dissertation. The research findings may also be used in hui presentations and academic reports. As already stated, you will not be identified - nor will your students or your school.

\section{If you accept this invitation, what are your rights as a research participant?}

You do not have to accept this invitation if you don't want to.

If you do decide to participate, you have the right to:

- ask any questions about the study at any time

- nominate a pseudonym for me to use, in lieu of your real name

- access any reports on this research by emailing me to request a copy (arahia3@clear.net.nz).

If you agree to be interviewed, this will happen mid to late 2017. You can:

- refuse to answer any question, at any time

- stop the interview at any time, without giving a reason

- ask for the audio-recording device to be turned off, at any time

- read over, and comment on, the notes/transcripts from your interview

- request a copy of your individual interview recording

- withdraw from the study up until four weeks after the observation phase, without having to explain. (If you withdraw, the information you provided will be destroyed or returned to you).

I am hoping that your participation (and reflection) will be a positive experience for you, that stimulates your thinking about materials to enhance Māori language teaching and learning in primary classrooms.

\section{Ethics}

If you have questions about the ethical conduct of the research, you can contact Associate Professor Susan Corbett (susan.corbett@vuw.ac.nz; phone 04 4635480), Convenor of the Human Ethics Committee. 
If you have general questions, or problems, please contact my primary supervisor Dr Corinne Seals [corinne.seals@vuw.ac.nz; phone 04463 5608], Lecturer in Linguistics and Applied Language Studies.

In addition, feel free to contact me at any time to discuss the research or seek clarification [arahia3@clear.net.nz ; phone 0276659443 or (04) 9777948].

Ko te tūmanako ka whakaaetia, ā, ka haere tonu te kaupapa - kia puta ai ngā hua papai mō ngā tamariki kei roto i ngā kura auraki, e ako ana i te reo rangatira o tênei whenua.

Nāku iti nei

$\mathrm{Na}$

Alice Patrick 


\title{
Appendix 3: Consent form
}

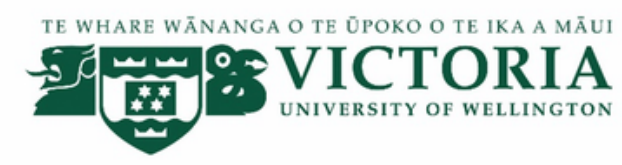

\author{
Exploring the beliefs and practices of non-Māori primary school teachers - to inform the \\ development of materials that can support the teaching and learning of Māori language in English- \\ medium classrooms
}

\section{INFORMED CONSENT}

(This consent form will be held for 5 years).

Researcher: $\quad$ Alice Patrick, LALS, Victoria University of Wellington.

\section{Please circle (or highlight) either YES or NO after each statement below, to indicate your agreement or disagreement.}

- I have read the Information Sheet and understand the nature of the study. I know that I can ask further questions at any time.

\section{YES NO}

- I agree to complete an online questionnaire (approximately 30 minutes)

YES NO

- (If requested by the researcher), I agree to the her doing audio-recorded observations (4-5 hours) of Māori language teaching and learning, and resource use, in my classroom

YES NO

- (If requested by the researcher), I agree to take part in an audio-recorded interview with her (up to one hour), after the observations - on the understanding that I can refuse to answer any questions.

YES NO

- I understand that what is audio-recorded in the interview will be transcribed (to make it easier for the researcher to analyse), but I can change my mind and veto all, or parts, of the recording.

YES NO 
I understand that:

- I can withdraw from this study up to four weeks after the observation phase, and any information that $\mathrm{I}$ have provided will be returned to me (or destroyed 5 years after the research is finished).

YES NO

- Any information I provide will be kept confidential to the researcher and her supervisors.

YES NO

- The results will be used for a $\mathrm{PhD}$ dissertation - with a summary of the results perhaps being used in academic reports and/or presented at hui.

YES NO

- My name will not be used in reports, nor will any information that would identify me, my school or my students.

YES NO

- Any printed information that is collected will be stored in a locked cupboard at the researcher's home, while any electronic data (e.g. audio- recordings) will be stored on her password-protected computer.

YES NO

I can request a summary of my interview.

YES NO

- I can request a copy of the final report.

YES NO 
Finally, in light of the aforementioned, I understand what would be required of me as a participant in this research AND I agree to participate.

YES NO

Signature of participant:

Name of participant:

Date:

Contact details (email and telephone):

NB Please return this consent form to Alice Patrick:

arahia3@clear.net.nz

$O R$

13/36 Dee St, Island Bay, Wellington 6023.

http://alicepatrick.co.nz

Kia ora mō tēnā. Thank you. 


\section{Appendix 4: Confidentiality agreement with transcriber}

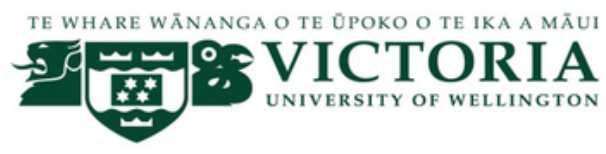

\section{Transcribing Confidentiality Agreement}

Project Title: Exploring the beliefs and practices of non-Māori primary school teachers - to inform the development of materials that can support the teaching and learning of Māori language in English-medium classrooms

Principal Investigator: Alice Patrick

$\mathrm{I}$, , agree to ensure that the audio recordings that I transcribe will remain confidential to the researcher Alice Patrick, her two PhD supervisors, and me.

I agree to take the following precautions:

1. I will ensure that no person, other than those specified above, hears the recordings.

2. I will ensure that no other person has access to my PC.

3. I will delete the files from my PC once the transcription has been completed.

4. I will not discuss any aspect of the recordings with anyone except the people specified above.

Signature of transcriber:

Date: (c) Victoria University of Wellington 


\section{Appendix 5: Online questionnaire}

\section{Intro/instructions}

This $\mathrm{PhD}$ research looks at the beliefs and practices of non-Māori primary teachers in English-medium classrooms in regard to Māori language teaching and learning. Several teachers will be invited to complete this online questionnaire. Then four of them will be asked to participate in classroom observations and follow-up interviews. The information provided will be treated confidentially.

See the attached PDF for more information.

Information sheet PDF for practising teachers 7.10.16

I agree to take part in this research. See attached PDf for more information on consent.

Pdf consent form 7.10.16

\section{Randomised Qs}

Please select YES or NO or UNSURE re the following statements:

1. I believe that my teaching of te reo Māori can be affected by external factors, over which I have no control

2. I believe that teachers should balance their own speaking of Māori with practice opportunities for students

3. I believe I have the necessary Māori language ability to depart from a planned Māori lesson and make 'on the spot' changes

4. I believe that teachers need to consciously include Māori language in their wider curriculum planning

5. I believe that primary teachers should know a bit about the theory of second language acquisition (SLA), to help them implement interactive lessons that have real- life application

6. I believe that teachers need to provide many different opportunities for students to practise Māori language

7. I believe students should participate in individual, pair, group and whole class activities when learning Māori

8. I believe the emphasis should be on listening and speaking when primary school students are learning Māori

9. I believe it's OK for teachers to use Māori words or phrases in an English sentence, if they can't say it all in Māori

10. I believe it's important to try and integrate tikanga Māori (cultural components) into my teaching 
11. I believe there is a lack of quality Māori resources, which hinders my ability to incorporate te reo Māori into my teaching

12. I believe that teachers should include games, activities and songs to make it fun to learn Māori

13. I believe that teachers should use a range of Māori language materials to build students' proficiency

14. I believe it's important to adapt Māori language materials to suit the diverse needs of my students, so that they can achieve some success learning Māori

15. I believe that teachers should draw on students' backgrounds/cultural experiences to explain Māori words and concepts e.g. pepeha

16. I believe that students learn Māori language better if there is a real life context e.g. kai; whānau

17. I believe that teachers' use of Māori language can enhance Māori student achievement

18. I believe that primary teachers should know enough Māori language to use it at a basic level in the classroom

19. I believe that teachers should try to model correct pronunciation of Māori

20. I am motivated to learn Māori to help my performance appraisal

21. I believe that learning Māori should be compulsory in NZ primary schools

22. I believe that I don't have to be a native Māori speaker to incorporate te reo into my teaching

23. I am motivated to learn Māori out of personal interest

24. I believe that primary teachers should be able to integrate Māori language across the curriculum

25. I believe that the way I include te reo Māori in my teaching is influenced by the way I was taught Māori

26. I am motivated to include Māori language in my teaching

27. I believe it's important for all NZ primary school students to learn Māori

NON-randomised Qs

28. From the list below, rank (1-3) the top 3 characteristics that determine 'quality' Māori language materials: 
Multimedia

User-friendly

Visually appealing

Audio component (as an aid to pronunciation)

Teachers' notes

Curriculum alignment

Inclusion of Māori tikanga, values, concepts

Real-life contexts (age-appropriate)

English translation (or glossary)

29. Please write down any other characteristics (not mentioned above) that are important to you when determining the 'quality' of Māori language materials:

30. How often do you use Te Aho Arataki Marau mō te Ako i Te Reo Māori - Kura Auraki Years 1-13 ie the Māori language curriculum guidelines?
Always
Most of the time
About half the time
Sometimes
Never

31. How often do you use He Reo Tupu He Reo Ora ie the multimedia resource for te reo Māori in primary schools?
Always
Most of the time
About half the time
Sometimes
Never

32. How often do you use Te Whakaipurangi Rauemi ie the online suite of materials on TKI?
Always
Most of the time
About half the time
Sometimes
Never

33. How often do you use Hei Waiata Hei Whakakoakoa ie a compilation of Māori songs?

Always

Most of the time

About half the time

Sometimes

Never

34. How often do you use Ministry- provided Māori readers?

Always

Most of the time 
About half the time

Sometimes

Never

35. How often do you use First Class i.e. a DVD about the teaching and learning of languages in NZ primary schools?

36. If there are other reo Māori resources that you use (not necessarily Ministry-provided) please specify - and add any additional comments about why you use

them:

37. What types of Māori language resources would you like to see developed in the future (for English-medium primary schools)?

38. Select the item(s) that describe(s) your previous learning of Māori language:

None

Primary school

Secondary school

University

Wānanga

Community learning

Personal learning

Ataarangi

Teacher training

In-service PD

Other (please specify):

39. Select the item that best describes your level of comfort teaching Māori:

Extremely comfortable

Somewhat comfortable

Neither comfortable nor uncomfortable

Somewhat uncomfortable

Extremely uncomfortable

40. Please select which phrase best describes your speaking ability in Māori:

LIMITED ie I can communicate in words only (not sentences)

BASIC ie I can use basic rote phrases and sentences, in highly familiar contexts

GOOD ie I can communicate meaningfully, in familiar contexts, using common words and simple grammatical structures

VERY GOOD ie I can communicate with ease, in a variety of contexts, using a wide range of vocabulary and language structures

41. Please add any additional comments about your speaking ability in Māori:

42. Select which age range you fit into: 
$18-24$

$25-34$

$35-44$

$45-54$

$55-64$

$65-74$

43. Select how many years you have been teaching:

$1-2$ years

3-5 years

6-10 years

$11-15$ years

16 years and over

44. Select the description that best reflects your role in the school:

teacher

lead teacher of Māori language

senior teacher

DP/AP

principal

other (please specify)

45. Select which level of the school you are mostly working in:

Junior school ie Y1-Y2

Middle school ie Y3-4

Senior school ie Y5-6

46. If you have any final comments about Māori language in schools, or Māori language resources, please write here:

Full Name:

School:

Region in NZ:

NGĀ MIHI NUI MŌ TĒNEI.

THANK YOU VERY MUCH INDEED. I REALLY APPRECIATE YOUR HELP. 


\section{Appendix 6: Parental permission and child consent}

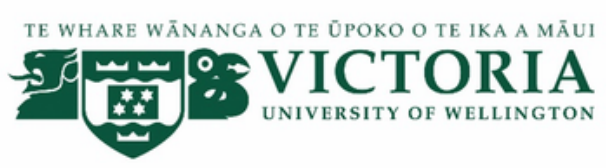

Exploring the beliefs and practices of non-Māori primary school teachers - to inform the development of materials that can support the teaching and learning of Māori language in Englishmedium classrooms

\section{PARENTAL PERMISSION}

Please tick the statement that applies:

I give permission for my child (or charge) to remain in the classroom during 4-5 hours of a researcher's observations (audio-recorded) associated with Māori language teaching.

I do not want my child (or charge) to be in the classroom while a researcher observes (and makes audio-recordings of) classroom practice around Māori language teaching.

Name of parent (or caregiver):

Date:

\section{INFORMED CONSENT - CHILDREN}

(This consent form will be held for 5 years).

Please tick the statement that applies:

I agree to the researcher recording the words that I say in class - so that she can later write about Māori language in the classroom

I do not want the researcher to write about the words that I say in class

Name:

Date:

NB Please return this parental permission slip/child consent form to the teacher or to the researcher Alice Patrick (http://alicepatrick.co.nz):

arahia3@,clear.net.nz OR 13/36 Dee St, Island Bay, Wellington 6023. 


\section{Appendix 7: Semi-structured interview}

The following kaupapa will be explored:

Motivation, obstacles and prior influences

1. What's your main motivation to teach Māori language in primary schools?

2. What things get in the way of your teaching Māori language?

3. How have your previous experiences (positive or negative) learning Māori (or indeed any other language) influenced the way you now teach te reo Māori e.g. early life, school, preservice, in-service, other?

\section{$\underline{\text { Beliefs }}$}

4. What are your beliefs about the teaching and learning of te reo Māori in primary schools?

5. What are your beliefs about the possible association between Māori students learning te reo Māori and them doing well at school?

6. What are your beliefs about the things that make a 'quality' Māori language resource?

\section{Practice}

7. Tell me about the use of Māori language resources in your classroom, generally.

8. Tell me about your specific use of Māori language resources during my classroom observations.

9. Looking at these* materials in front of you, tell me which ones you've used and why.

10. Beyond these Ministry materials, what other Māori language materials do you use - and why?

\section{$\underline{\text { Future development of Māori language materials for primary schools }}$}

11. What kinds of materials would you like to see developed in the future to promote the teaching and learning of te reo Māori in primary school classrooms?

\section{$\underline{\text { Final comments }}$}

12. Is there anything else you'd like to say?

\section{NB APPRECIATION /THANKS TO INTERVIEWEES - ESPECIALLY FOR AGREEING TO OBSERVATIONS. NB KOHA OF COMMERCIAL REO RESOURCE PACKAGES.}

\footnotetext{
*For example, reo Māori curriculum guidelines; multimedia resource He Reo Tupu; the DVD First Class about the teaching and learning of languages; the online suite of materials on TKI Te Whakaipurangi Rauemi; the waiata compilation Hei Waiata Hei Whakakoakoa; and Māori readers/journal stories.
} 


\section{Appendix 8: Permission from school}

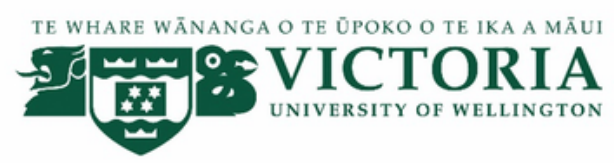

Exploring the beliefs and practices of non-Māori primary school teachers - to inform the development of materials that can support the teaching and learning of Māori language in Englishmedium classrooms

\section{SCHOOL'S PERMISSION}

Please tick the statement that applies:

We give permission for Alice Patrick to conduct some of her $\mathrm{PhD}$ research in our school - in particular, classroom observations of one teacher (one hour daily, for 4- 5 days) because of the contribution her study will make to improving Māori language teaching and learning in schools.

We do not give permission for Alice Patrick to conduct research in our school.

Name of principal/deputy principal/BOT chairperson):

Date: 
Appendix 9: Participant demographics ( $n=40$, including four men)

\begin{tabular}{|c|c|c|c|c|c|c|c|}
\hline Pseudonym & Age & $\begin{array}{l}\text { Years } \\
\text { Experience }\end{array}$ & Decile & $\begin{array}{l}\text { Class } \\
\text { level }\end{array}$ & Role & Region & $\begin{array}{l}\text { Reo } \\
\text { ability }\end{array}$ \\
\hline Summer & $55-64$ & $11-15$ & 8 & Y1-2 & Teacher & Wellington & Limited \\
\hline Sasha & $35-44$ & $6-10$ & 6 & Y5-6 & Teacher & Auckland & Basic \\
\hline Lexi & $35-44$ & $1-2$ & $1-10$ & Y3-4 & $\begin{array}{l}\text { Relief } \\
\text { teacher }\end{array}$ & Wellington & Basic \\
\hline Kerry & $25-34$ & $6-10$ & 9 & Y3-4 & $\begin{array}{l}\text { Senior } \\
\text { teacher }\end{array}$ & Auckland & Basic \\
\hline Laurel & $45-54$ & $1-2$ & 10 & Y5-6 & Teacher & Auckland & Limited \\
\hline Marg & $35-44$ & $11-15$ & 9 & Y5-6 & Teacher & $\begin{array}{l}\text { Bay of } \\
\text { Plenty }\end{array}$ & Limited \\
\hline Jane & $45-54$ & $6-10$ & 9 & Y5-6 & Teacher & Nelson & Basic \\
\hline Janet & $25-34$ & $6-10$ & 10 & Y1-2 & Teacher & Auckland & Limited \\
\hline Heather & $55-64$ & $6-10$ & 2 & Y3-4 & Teacher & Auckland & Basic \\
\hline Ellen & $45-54$ & $3-5$ & 8 & Y1-2 & Teacher & Wellington & Basic \\
\hline Jamesina & $45-54$ & $16+$ & 8 & Y1-2 & Teacher & Gisborne & Basic \\
\hline Jolene & $55-64$ & $11-15$ & 9 & Y5-6 & $\begin{array}{l}\text { Senior } \\
\text { teacher }\end{array}$ & Wellington & Basic \\
\hline Riina & $45-54$ & $6-10$ & 10 & Y1-2 & Teacher & Wellington & Limited \\
\hline Goldie & $35-44$ & $11-15$ & 7 & Y3-4 & Teacher & Christchurch & Basic \\
\hline Dee & $45-54$ & $6-10$ & 5 & Y5-6 & $\begin{array}{l}\text { Senior } \\
\text { teacher }\end{array}$ & $\begin{array}{l}\text { Bay of } \\
\text { Plenty }\end{array}$ & Limited \\
\hline Grace & $25-34$ & $11-15$ & 1 & Y3-4 & $\begin{array}{l}\text { Senior } \\
\text { teacher }\end{array}$ & Hawkes Bay & Basic \\
\hline Jessie & $45-54$ & $11-15$ & 10 & Y1-2 & Teacher & Auckland & Limited \\
\hline Gemma & $25-34$ & $6-10$ & 5 & Y1-2 & Teacher & $\begin{array}{l}\text { Bay of } \\
\text { Plenty }\end{array}$ & Limited \\
\hline Shari & $35-44$ & $1-2$ & 1 & Y1-2 & Teacher & Waikato & Basic \\
\hline Maria & $35-44$ & $1-2$ & 3 & Y1-2 & $\begin{array}{l}\text { Beginning } \\
\text { teacher }\end{array}$ & Auckland & Basic \\
\hline Sheena & $25-34$ & $6-10$ & 10 & Y5-6 & Teacher & Auckland & Basic \\
\hline Shevon & $35-44$ & $16+$ & 10 & Y5-6 & $\begin{array}{l}\text { Senior } \\
\text { teacher }\end{array}$ & Waikato & Basic \\
\hline Rikki & $25-34$ & $3-5$ & 8 & Y3-4 & $\begin{array}{l}\text { Lead } \\
\text { teacher } \\
\text { Māori }\end{array}$ & Waikato & Basic \\
\hline Hannah & $35-44$ & $16+$ & 7 & Y3-4 & Teacher & Taranaki & Basic \\
\hline Bentley & $25-34$ & $3-5$ & 8 & Y5-6 & Teacher & Northland & Good \\
\hline Nate & $35-44$ & $1-2$ & 10 & Y5-6 & Teacher & Manawatū & Limited \\
\hline Natania & $25-34$ & $3-5$ & 10 & Y3-4 & Teacher & Wellington & Basic \\
\hline Roberta & $45-54$ & $16+$ & 7 & Y3-4 & DP/AP & Wellington & Basic \\
\hline Bex & $35-44$ & $1-2$ & 8 & Y5-6 & Teacher & Wellington & Basic \\
\hline Trina & $25-34$ & $11-15$ & 7 & Y1-2 & Teacher & Waikato & Limited \\
\hline Tatiana & $35-44$ & $16+$ & 10 & Y1-2 & Teacher & Dunedin & Basic \\
\hline
\end{tabular}




\begin{tabular}{|l|l|l|l|l|l|l|l|}
\hline Chad & $35-44$ & $16+$ & 10 & Y5-6 & $\begin{array}{l}\text { Lead } \\
\text { teacher } \\
\text { Māori }\end{array}$ & Wellington & Basic \\
\hline Gwen & $35-44$ & $6-10$ & 10 & Y5-6 & Teacher & Wellington & Basic \\
\hline Catriona & $35-44$ & $11-15$ & 10 & Y1-2 & Teacher & Wellington & Basic \\
\hline Dreena & $35-44$ & $16+$ & 1 & Y1-2 & Teacher & Christchurch & Good \\
\hline Zoe & $35-44$ & $6-10$ & 1 & Y5-6 & Teacher & Waikato & Basic \\
\hline Jamie & $35-44$ & $16+$ & 1 & Y5-6 & Teacher & Wellington & Basic \\
\hline Ainsley & $25-34$ & $6-10$ & 9 & Y1-2 & $\begin{array}{l}\text { Lead } \\
\text { teacher } \\
\text { Māori }\end{array}$ & Wellington & Basic \\
\hline Jordan & $35-44$ & $6-10$ & 9 & Y5-6 & Teacher & Wellington & Basic \\
\hline Delta & $55-64$ & $16+$ & 5 & Y5-6 & Teacher & Wellington & Limited \\
\hline
\end{tabular}

\begin{tabular}{|l|l|}
\hline Age range & \\
\hline Aged 25 to 34 & $\mathrm{n}=10$ \\
\hline Aged 35 to 44 & $\mathrm{n}=18$ \\
\hline Aged 45 to 54 & $\mathrm{n}=8$ \\
\hline Aged 55 to 64 & $\mathrm{n}=4$ \\
\hline
\end{tabular}

\begin{tabular}{|l|l|}
\hline Experience & \\
\hline Under 2 years & $\mathrm{n}=6$ \\
\hline 3- 5 years & $\mathrm{n}=4$ \\
\hline 6-10 years & $\mathrm{n}=13$ \\
\hline 11-15 years & $\mathrm{n}=8$ \\
\hline Over 16 years & $\mathrm{N}=9$ \\
\hline
\end{tabular}

\begin{tabular}{|l|l|}
\hline Class level & \\
\hline Y 5-6 & $\mathrm{n}=17$ \\
\hline Y 3-4 & $\mathrm{n}=9$ \\
\hline Y 1-2 & $\mathrm{n}=14$ \\
\hline
\end{tabular}

\begin{tabular}{|l|l|}
\hline $\begin{array}{l}\text { Self-identified } \\
\text { Role }\end{array}$ & \\
\hline $\begin{array}{l}\text { Beginning } \\
\text { teacher }\end{array}$ & $\mathrm{n}=1$ \\
\hline Teacher & $\mathrm{n}=30$ \\
\hline $\begin{array}{l}\text { Lead teacher: } \\
\text { reo Māori }\end{array}$ & $\mathrm{n}=3$ \\
\hline Senior teacher & $\mathrm{n}=5$ \\
\hline DP/AP & $\mathrm{n}=1$ \\
\hline
\end{tabular}




\begin{tabular}{|l|l|}
\hline Region & \\
\hline Wellington & $\mathrm{n}=15$ \\
\hline Auckland & $\mathrm{n}=8$ \\
\hline Waikato & $\mathrm{n}=5$ \\
\hline Bay of Plenty & $\mathrm{n}=3$ \\
\hline $\begin{array}{l}\text { Hawke's } \\
\text { Bay/Gisborne }\end{array}$ & $\mathrm{n}=2$ \\
\hline Canterbury & $\mathrm{n}=2$ \\
\hline Dunedin & $\mathrm{n}=1$ \\
\hline Taranaki & $\mathrm{n}=1$ \\
\hline Northland & $\mathrm{n}=1$ \\
\hline Nelson & $\mathrm{n}=1$ \\
\hline Manawatu & $\mathrm{n}=1$ \\
\hline
\end{tabular}

\begin{tabular}{|l|l|}
\hline Levels of speaking ability in te reo & \\
\hline Limited & $\mathrm{n}=11$ \\
\hline Basic & $\mathrm{n}=27$ \\
\hline Good & $\mathrm{n}=2$ \\
\hline Very good & $\mathrm{n}=0$ \\
\hline
\end{tabular}




\section{Appendix 10: Teachers' frequency of use of different Ministry resources}

\begin{tabular}{|c|c|c|c|}
\hline \multicolumn{2}{|l|}{ Ministry resource } & Teachers' frequency of use & Notes \\
\hline $\begin{array}{l}\text { Te Aho Arataki Marau } \\
\text { mo te Akoi Te Reo Mãori } \\
\text {-Kur huras }\end{array}$ & $\begin{array}{l}\text { Te Aho Arataki Marau (i.e. Māori } \\
\text { language curriculum guidelines, year 1- } \\
\text { 13, at } 8 \text { curriculum levels). Available in } \\
\text { print and online }\end{array}$ & $\begin{array}{l}\text { Always use: } n=1 \text { (Hannah) } \\
\text { Use most of the time: } n=2 \\
\text { Use about half the time: } n=3 \\
\text { Use sometimes: } n=21 \\
\text { Never use: } n=13\end{array}$ & $\begin{array}{l}\text { It may well be that teachers do not } \\
\text { realise the valuable content therein, } \\
\text { having never explored the } \\
\text { guidelines or had any PD to unpack } \\
\text { the different sections }\end{array}$ \\
\hline$\underline{\text { http://tereoMāori.tki.org.nz/ }}$ & & & \\
\hline 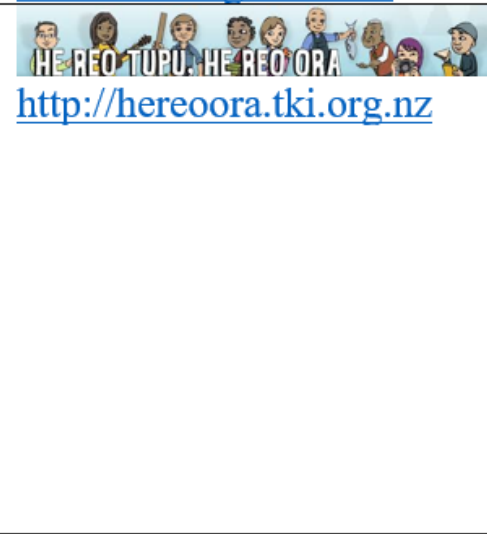 & $\begin{array}{l}\text { He Reo Tupu, He Reo Ora (i.e. multi- } \\
\text { media resource, year 1-6, aimed at } \\
\text { curriculum levels } 1-2 \text { ). Was available in } \\
\text { print and online - but now only online }\end{array}$ & $\begin{array}{l}\text { Always use: } n=1 \text { (Jordan) } \\
\text { Use most of the time: } n=10 \\
\text { Use about half the time: } n=4 \\
\text { Use sometimes: } n=15 \\
\text { Never use: } n=10\end{array}$ & $\begin{array}{l}\text { Used more frequently than Māori } \\
\text { language guidelines - more } \\
\text { practical, hands-on, with } \\
\text { multimedia aspects } \\
\text { The Ministry of Education (2017) } \\
\text { found that both primary and } \\
\text { secondary English-medium teachers } \\
\text { use this resource to guide their } \\
\text { Māori programme (even though it is } \\
\text { designed for primary) }\end{array}$ \\
\hline
\end{tabular}




\begin{tabular}{|c|c|c|}
\hline Ministry resource & Teachers' frequency of use & Notes \\
\hline $\begin{array}{ll}\text { hei Waiata Hei Whakakoakoa (i.e. } \\
\text { hultp://tereoMāori.tki.org.nz/ } \\
\text { Reo-Māori-resources/Hei- } \\
\text { Waiata }\end{array}$ & $\begin{array}{l}\text { Always use: } n=1 \text { (Dreena) } \\
\text { Use most of the time: } n=2 \\
\text { Use about half the time: } n=2 \\
\text { Use sometimes: } n=13 \\
\text { Never use: } n=22\end{array}$ & $\begin{array}{l}\text { Many of the questionnaire } \\
\text { respondents indicated they were } \\
\text { having to source waiata resources } \\
\text { online - presumably unaware of } \\
\text { this resource which remains largely } \\
\text { under-utilised }\end{array}$ \\
\hline Instructional Māori readers. Available & $\begin{array}{l}\text { Always use: } n=0 \\
\text { Use most of the time: } n=1 \\
\text { (Dreena) } \\
\text { Use about half the time: } n=4 \\
\text { Use sometimes: } n=13 \\
\text { Never use: } n=22\end{array}$ & $\begin{array}{l}\text { These readers are designed for } \\
\text { Māori-medium learners with good } \\
\text { proficiency. Consequently, they are } \\
\text { too difficult for English-medium } \\
\text { teachers and students - in terms of } \\
\text { language structures and vocabulary } \\
\text { (Ministry of Education, 2017, pp. } \\
\text { 49-58). The readers were described } \\
\text { as being "pitched too high for the } \\
\text { vast majority of learners in English- } \\
\text { medium settings". There is potential } \\
\text { for basic Māori-medium readers } \\
\text { (e.g. Ngā Kete Kōrero) to be used } \\
\text { in English-medium - with a little } \\
\text { adaptation, and with accompanying } \\
\text { PD and teachers' notes }\end{array}$ \\
\hline
\end{tabular}




\begin{tabular}{|c|c|c|}
\hline Ministry resource & Teachers' frequency of use & Notes \\
\hline $\begin{array}{cl}\begin{array}{c}\text { Te Reo Maori } \\
\text { Te Whakaipurangi }\end{array} & \begin{array}{l}\text { Te Whakaipurangi Rauemi (i.e. suite of } \\
\text { resources to support teachers). } \\
\text { Available online }\end{array} \\
\text { Rauemi - Teacher } \\
\text { Resources Collection }\end{array}$ & $\begin{array}{l}\text { Always use: } n=0 \\
\text { Use most of the time: } n=2 \\
\text { Use about half the time: } n=1 \\
\text { Use sometimes: } n=9 \\
\text { Never use: } n=28\end{array}$ & $\begin{array}{l}\text { The collection may be little-known, } \\
\text { despite its usefulness, e.g. } \\
\text { information about the teaching, } \\
\text { learning, and assessment of Māori } \\
\text { language in schools (i.e. high- } \\
\text { frequency vocab; student goal- } \\
\text { setting; second language task types } \\
\text { - with examples; grammar } \\
\text { progression; student self- } \\
\text { assessments; teacher assessments; } \\
\text { and examples of learner strategies. } \\
\text { The resources are based on current } \\
\text { second language teaching theory } \\
\text { and practice } \\
\text { Teachers can cut and paste many of } \\
\text { the materials to suit their planning. } \\
\text { The resources are designed to align } \\
\text { with the achievement objectives in } \\
\text { the Māori language curriculum } \\
\text { guidelines, Te Aho Arataki Marau } \\
\text { (2009) }\end{array}$ \\
\hline
\end{tabular}




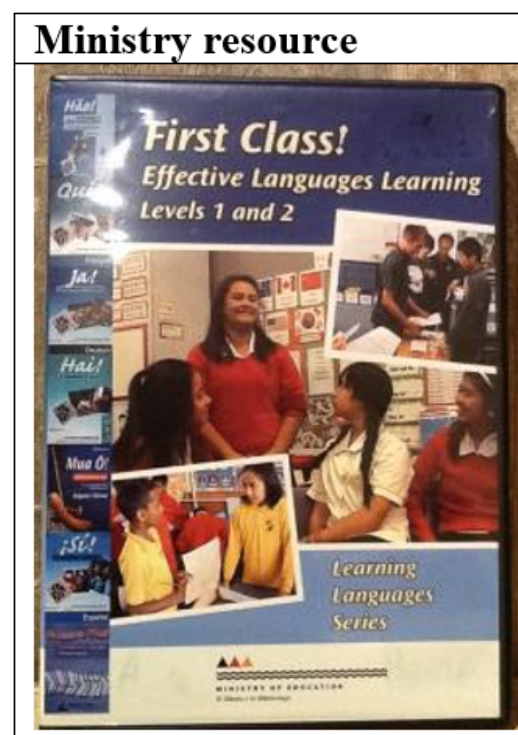

Teachers' frequency of use

First Class (i.e. video-recordings of the teaching and learning of languages in year 5-9 classes). Available on DVD
Always use: $\mathrm{n}=0$

Use most of the time: $\mathrm{n}=0$

Use about half the time: $n=0$

Use sometimes: $\mathrm{n}=2$

Never use: $\mathrm{n}=38$
Notes

This DVD aims to increase

teachers' knowledge about second

language teaching and learning,

especially in years $5-9$

It contains video recordings of students in NZ classrooms learning various languages - including te reo Māori

Its potential value is for hands-on $\mathrm{PD}$ around second language acquisition

Its lack of use is most likely due to teachers being unaware of its existence and its purpose - plus the fact that the technology is out of date. Teachers are therefore missing out on opportunities to upskill in the area of second language teaching and learning 